\title{
Federal Emergency Management Agency Mobile Housing Unit Running Gear Testing: Final Report
}

Approved for public release. Distribution is unlimited.

OAK RIDGE NATIONAL LABORATORY MANAGED BY UT-BATTELLE FOR THE US DEPARTMENT OF ENERGY
Oscar Franzese

Mary Beth Lascurain

Gary Capps

August 2019 


\title{
DOCUMENT AVAILABILITY
}

Reports produced after January 1, 1996, are generally available free via US Department of Energy (DOE) SciTech Connect.

Website www.osti.gov

Reports produced before January 1, 1996, may be purchased by members of the public from the following source:

\author{
National Technical Information Service \\ 5285 Port Royal Road \\ Springfield, VA 22161 \\ Telephone 703-605-6000 (1-800-553-6847) \\ TDD 703-487-4639 \\ Fax 703-605-6900 \\ E-mail info@ntis.gov \\ Website http://classic.ntis.gov/
}

Reports are available to DOE employees, DOE contractors, Energy Technology Data Exchange representatives, and International Nuclear Information System representatives from the following source:

Office of Scientific and Technical Information

PO Box 62

Oak Ridge, TN 37831

Telephone 865-576-8401

Fax 865-576-5728

E-mail reports@osti.gov

Website http://www.osti.gov/contact.html

This report was prepared as an account of work sponsored by an agency of the United States Government. Neither the United States Government nor any agency thereof, nor any of their employees, makes any warranty, express or implied, or assumes any legal liability or responsibility for the accuracy, completeness, or usefulness of any information, apparatus, product, or process disclosed, or represents that its use would not infringe privately owned rights. Reference herein to any specific commercial product, process, or service by trade name, trademark, manufacturer, or otherwise, does not necessarily constitute or imply its endorsement, recommendation, or favoring by the United States Government or any agency thereof. The views and opinions of authors expressed herein do not necessarily state or reflect those of the United States Government or any agency thereof. 
Energy and Transportation Science Division

\title{
FEDERAL EMERGENCY MANAGEMENT AGENCY MOBILE HOUSING UNIT
} RUNNING GEAR TESTING: FINAL REPORT

\author{
Oscar Franzese \\ Mary Beth Lascurain \\ Gary Capps
}

Date Published: August 2019

Prepared by

OAK RIDGE NATIONAL LABORATORY

Oak Ridge, TN 37831-6283

managed by

UT-BATTELLE, LLC

for the

US DEPARTMENT OF ENERGY

under contract DE-AC05-00OR22725 



\section{CONTENTS}

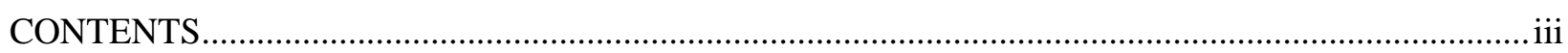

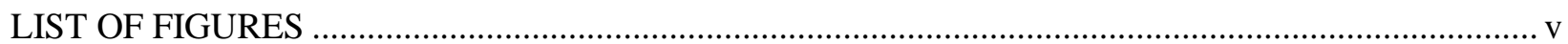

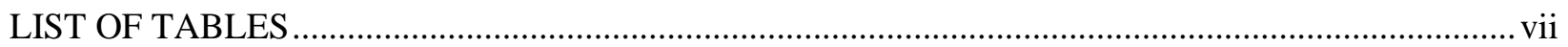

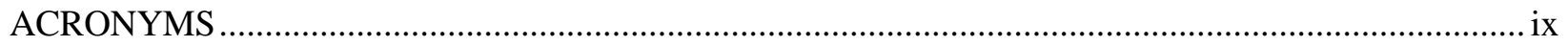

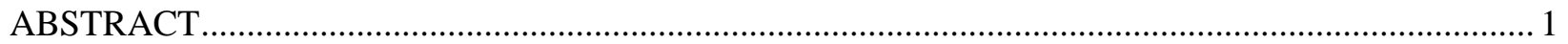

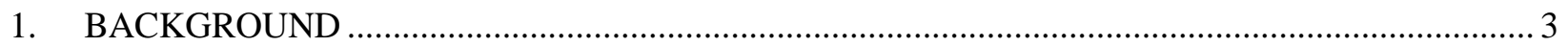

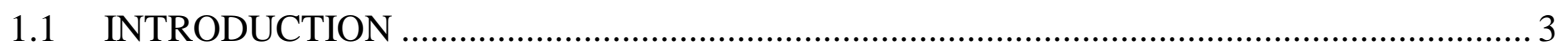

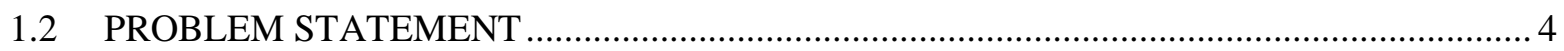

1.2.1 Issues Driving the Consideration of New MHU Running Gear .................................. 4

1.2.2 Issues Related to Vibration and Transmitted Forces in Transit .................................. 5

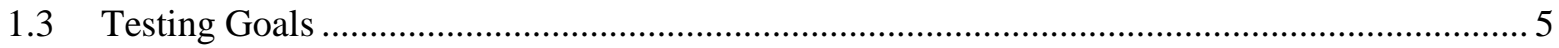

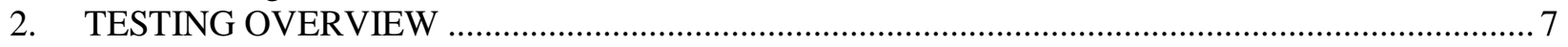

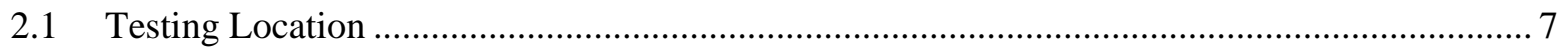

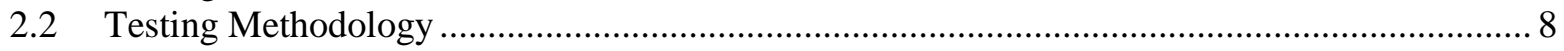

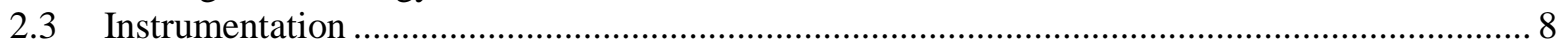

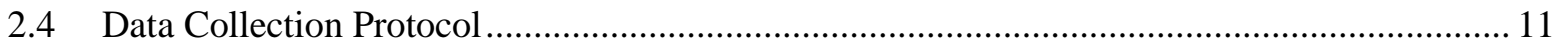

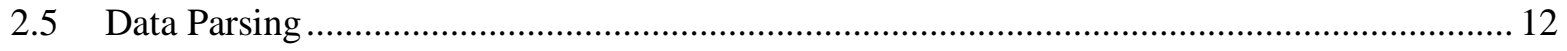

2.6 Longevity and Rough-road Testing …..................................................................... 13

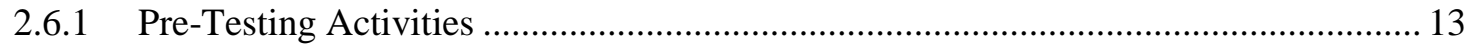

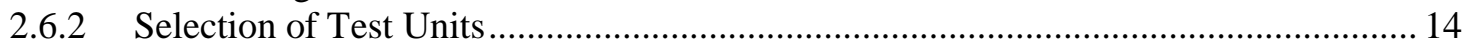

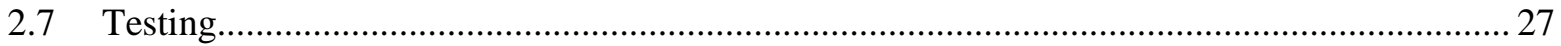

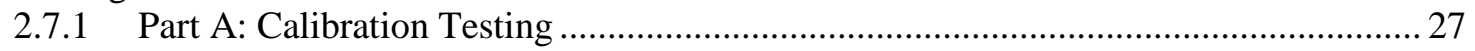

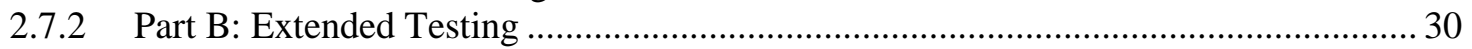

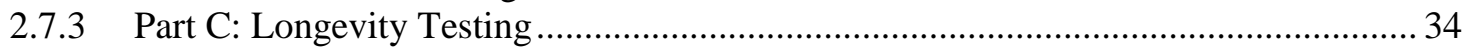

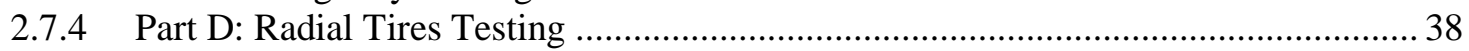

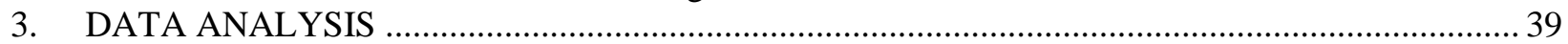

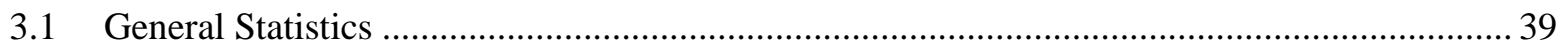

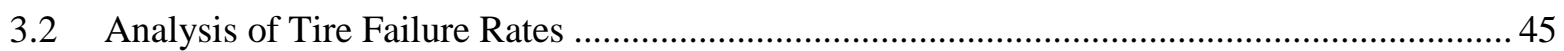

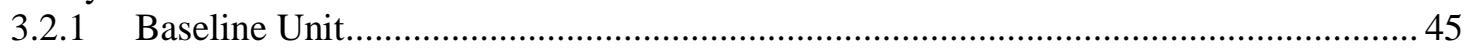

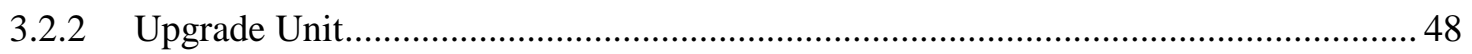

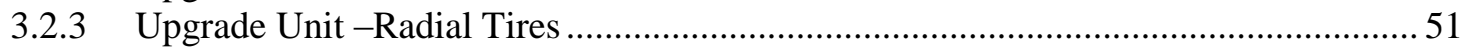

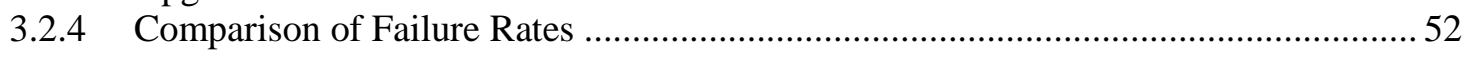

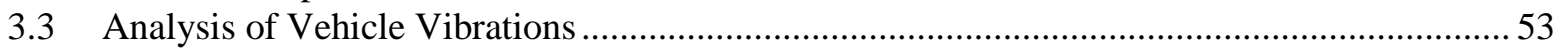

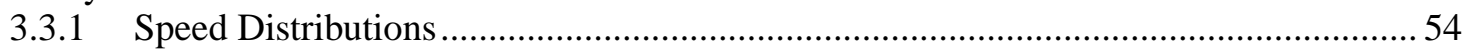

3.3.2 Effect of Suspension on Vibrations: Baseline Unit vs. Upgrade Unit .........................56

3.3.3 Effect of Suspension on Vibrations: Upgrade Unit Radial Tires vs. Regular

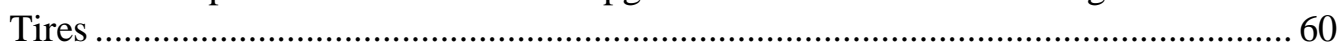

3.3.4 Effect of Suspension on Vibrations: Rough-road Test Baseline Unit vs.

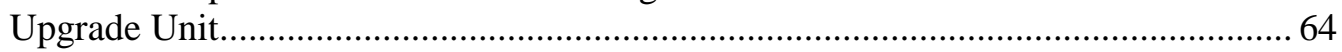

3.3.5 Effect of Suspension on Vibrations: Rough-Road Test Upgrade Unit with

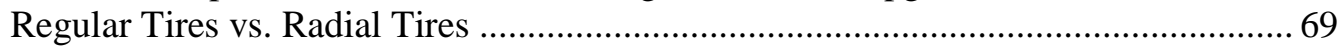

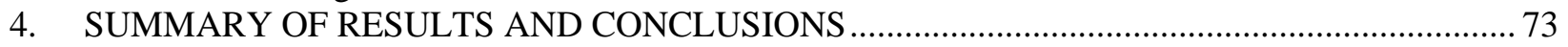

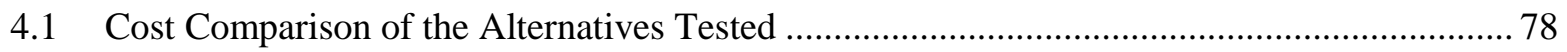

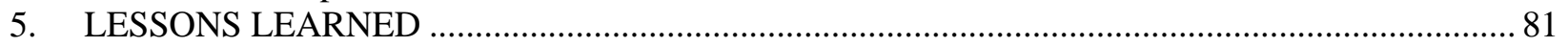

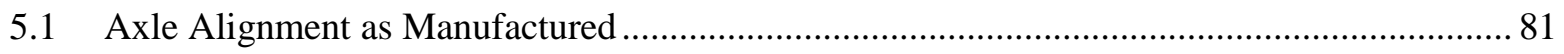

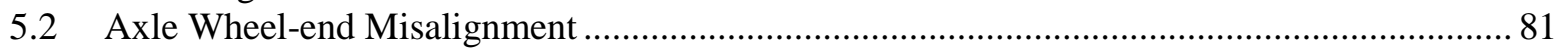

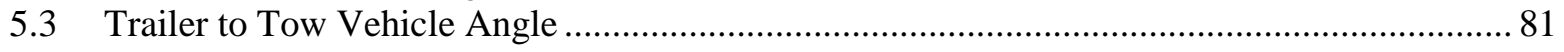




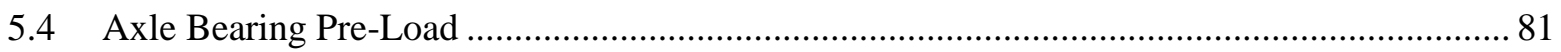

5.5 Suspension Connecting Bolts Overtightened ................................................................... 81

5.6 Stamped/Formed Equalizers Cracked Prematurely ............................................................. 82

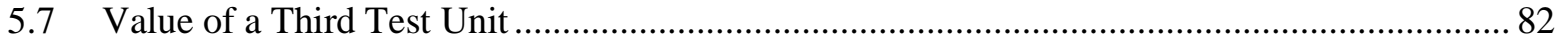

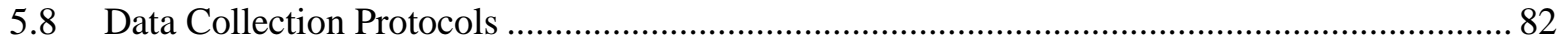

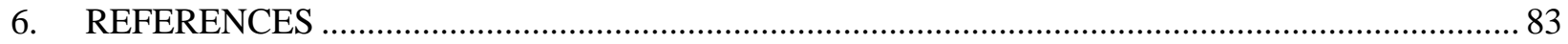

APPENDIX A. PRE-TEST ACCELEROMETER DATA EXAMINATION ……................................ A-3

APPENDIX B. UPGRADE UNIT AXLES REPLACEMENT ……................................................ B-3

APPENDIX C. ADDITIONAL STATISTICAL COMPARISONS ….............................................

APPENDIX D. BASELINE UNIT NPG INSPECTION REPORTS …..............................................

APPENDIX E. UPGRADE UNIT NPG INSPECTION REPORTS …............................................. E-3

APPENDIX F. BASELINE AND UPGRADE UNIT END-OF-TEST FEMA INSPECTION

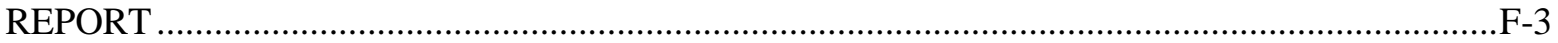




\section{LIST OF FIGURES}

Figure 1. Navistar Proving Grounds' Three-mile Oval Track - New Carlisle, IN................................... 7

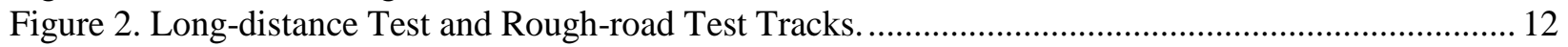

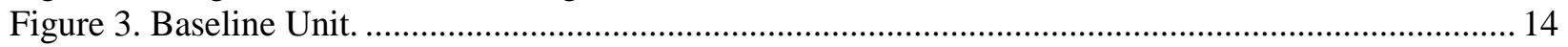

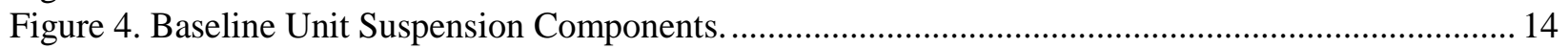

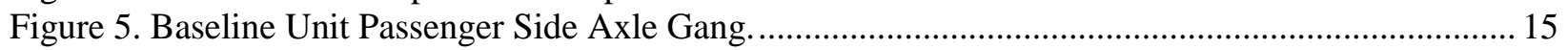

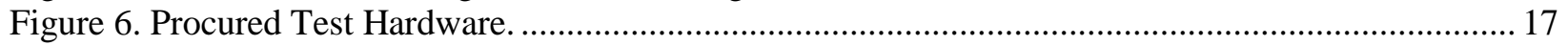

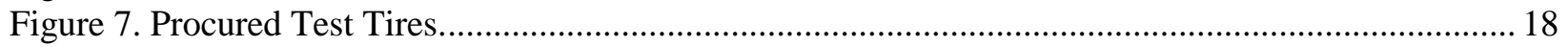

Figure 8. Procured 7,000 lb. Axles; for Use on the Upgraded Unit..................................................... 18

Figure 9. Procured 6,000 lb. Axles; for Use on the Baseline Unit......................................................... 19

Figure 10. 20,000 lbs Analog Wheel Scales (HAENI Model 101) ........................................................ 19

Figure 11. One of the Data Acquisition Systems Used during the Test. ............................................... 21

Figure 12. Tri-Axial Accelerometers Installed inside the Units. ...................................................... 21

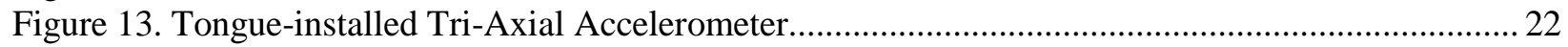

Figure 14. Four-inch Spring Hanger Compared to Existing Three-inch Spring Hanger.......................... 22

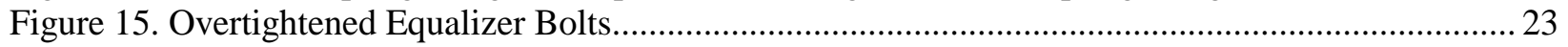

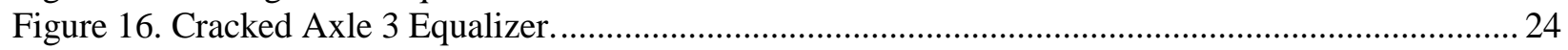

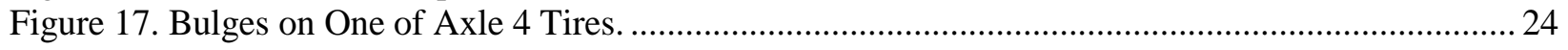

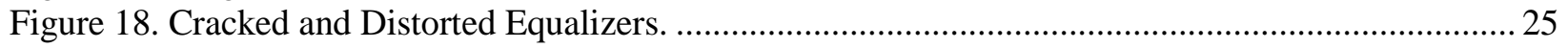

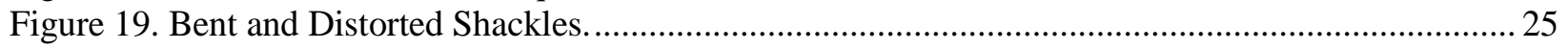

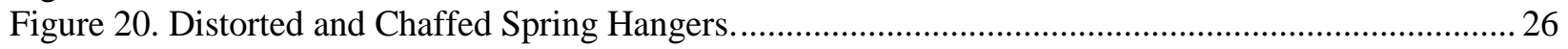

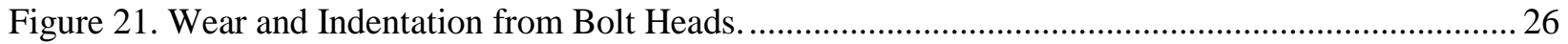

Figure 22. Distorted Spring-eye Bushings Due to Mismatch between The Diameter of The

Bushing and That of The Fastener (Smaller Diameter)............................................................ 27

Figure 23. Segment of Accelerometer Data at the Axle Group ( $x=$ Longitudinal, $y=$ Lateral, $z=$

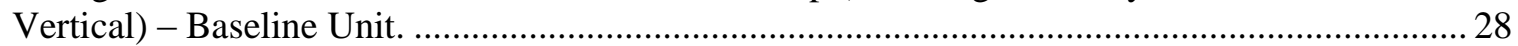

Figure 24. Segment of Accelerometer Data at the Axle Group ( $\mathrm{x}=$ Longitudinal, $\mathrm{y}=$ Lateral, $\mathrm{z}=$

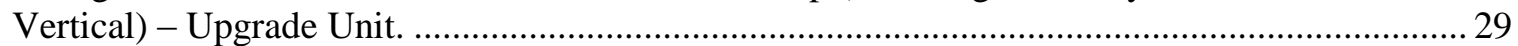

Figure 25. Frequency Distribution of Accelerometer Data at the Axle Group (3-Minute Segment)

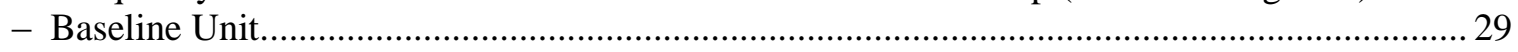

Figure 26. Frequency Distribution of Accelerometer Data at the Axle Group (3-Minute Segment)

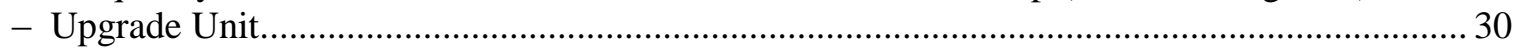

Figure 27. Segment of Baseline Unit Accelerometers Time History Data ( $\mathrm{x}=$ Longitudinal, $\mathrm{y}=$

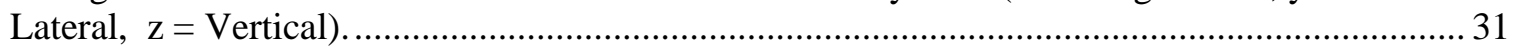

Figure 28. Baseline Unit Acceleration Distributions ( $\mathrm{x}=$ Longitudinal, $\mathrm{y}=$ Lateral, $\mathrm{z}=$ Vertical)........... 32

Figure 29. Illustration of Frequency Analysis for Part B Baseline Unit Lap 20..................................... 33

Figure 30. Upgrade Unit - GRMS for Vertical Accelerometer at Axle Group (Center)......................... 35

Figure 31. Baseline Unit - GRMS for Vertical Accelerometer at Axle Group (Center).......................... 36

Figure 32. Baseline Unit - GRMS for Vertical Accelerometer 1 at Axle Group (Center) - Short

Test with New Tires........................................................................................................ 37

Figure 33. Baseline Unit - GRMS for Vertical Accelerometer 2 at Axle Group (Center) - Short

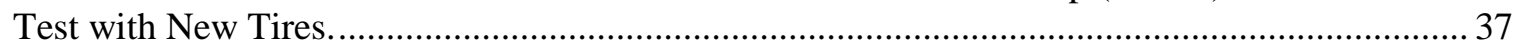

Figure 34. Part B Day 2 - Baseline and Upgrade Units GRMS for Vertical Accelerometer at Axle

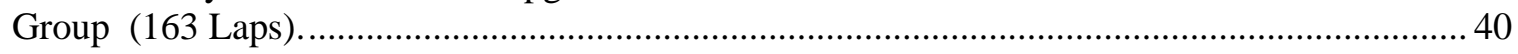

Figure 35. Part C1 (Days 1 and 2) - Baseline and Upgrade Units GRMS for Vertical Accelerometer at Axle Group (Center) 163 Laps. .................................................................. 41

Figure 36. Part C2 - Baseline and Upgrade Units GRMS for Vertical Accelerometer at Axle Group (Center) 2,411 Laps. 
Figure 37. Part D -Upgrade Units GRMS for Vertical Accelerometer at Axle Group (Center) 809 Laps with Radial Tires.

Figure 38. Baseline Unit Tire Failure Histogram (500mile Bins) and Fitted Probability Density Function.

Figure 39. Upgrade Unit Tire Failure Histogram (500mile Bins) and Fitted Probability Density Function. 51

Figure 40. Part C2 - Baseline and Upgrade Units Speed Distributions (All Laps).

Figure 41. Part C2 - Baseline and Upgrade Units Speed Distributions - Clockwise Laps.

Figure 42. Part C2 - Baseline and Upgrade Units Speed Distributions -Counter-clockwise Laps............ 55

Figure 43. Part C2 - Baseline and Upgrade Units GRMS for Vertical Accelerometer at Axle Group (Center) Selected Laps for Statistical Analysis.

Figure 44. Part C2 - Baseline and Upgrade Units GRMS for Longitudinal Accelerometer at Axle Group (Center) - Selected Laps for Statistical Analysis.

Figure 45. Part C2 - Baseline and Upgrade Units GRMS for Lateral Accelerometer at Axle Group (Center) Selected Laps for Statistical Analysis.

Figure 46. Upgrade Unit with Regular and Radial Tires GRMS for Vertical Accelerometer at Axle Group (Center) - Selected Laps for Statistical Analysis.

Figure 47. Upgrade Unit with Regular and Radial Tires GRMS for Longitudinal Accelerometer at Axle Group (Center) - Selected Laps for Statistical Analysis.

Figure 48. Upgrade Unit with Regular and Radial Tires GRMS for Lateral Accelerometer at Axle Group (Center) - Selected Laps for Statistical Analysis.

Figure 49. Baseline Unit Tire Failure Histogram (500mile Bins) and Fitted Probability Density Function.

Figure 50. Part C2 Rough-Road Test - Baseline and Upgrade Units GRMS for Vertical Accelerometer at Axle Group (Center) - Selected Laps for Statistical Analysis.

Figure 51. Part C2 Rough-Road Test - Baseline and Upgrade Units GRMS for Longitudinal Accelerometer at Axle Group (Center) - Selected Laps for Statistical Analysis.

Figure 52. Part C2 Rough-Road Test - Baseline and Upgrade Units GRMS for Lateral Accelerometer at Axle Group (Center) - Selected Laps for Statistical Analysis.

Figure 53. Part C2 Upgrade Unit Rough-Road Test - Regular and Radial Tires GRMS for Vertical Accelerometer at Axle Group (Center) - Selected Laps for Statistical Analysis.

Figure 54. Part C2 Part C2 Upgrade Unit Rough-Road Test - Regular and Radial Tires GRMS for Longitudinal Accelerometer at Axle Group (Center) - Selected Laps for Statistical Analysis.

Figure 55. Part C2 Upgrade Unit Rough-Road Test - Regular and Radial Tires GRMS for Lateral Accelerometer at Axle Group (Center) - Selected Laps for Statistical Analysis. 


\section{LIST OF TABLES}

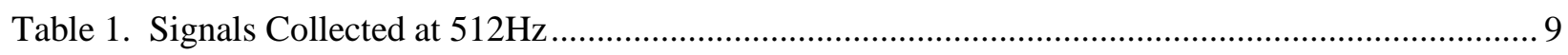

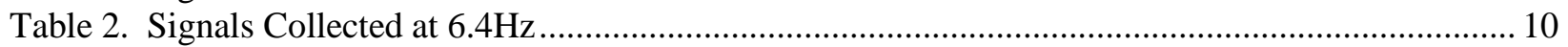

Table 3. FEMA IDs and Serial Number for the Selected Testing MHUs............................................. 14

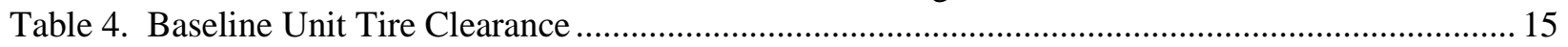

Table 5. MHU Weight Information Provided by Transportation Company ........................................... 16

Table 6. Procured Parts for Testing Vehicles ......................................................................................... 17

Table 7. Upgrade Unit Axle and Trailer Weight - Level to Floor, 19 1/2 Inches from Top of

Receiver to Concrete Floor (Not Connected to Tow Vehicle)..................................................... 20

Table 8. Upgrade Unit Axle Weights - Hitch in Nearest Locking Hole, 19 3/16 Inches from Top

of Receiver to Concrete Floor (Connected to Tow Vehicle) ........................................................ 20

Table 9. GRMS Values for Selected Part B Lap Accelerometer Data at the Axle Group ........................ 34

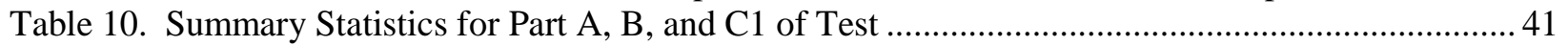

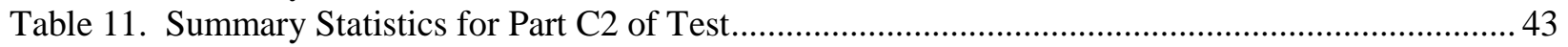

Table 12. End of Part C2 Testing: Status of Tires Remaining on the Vehicles ........................................ 43

Table 13. Summary Statistics for Part D of Test - Upgrade Unit w/Radial Tires..................................... 44

Table 14. End of Part D Testing: Status of Tires Remaining on the Upgrade Unit ................................45

Table 15. Baseline Unit Tire Failures during Part C2 ............................................................................. 46

Table 16. Tire Failure Rates per 1,000 Miles Traveled and Expected Mean Travel Distance

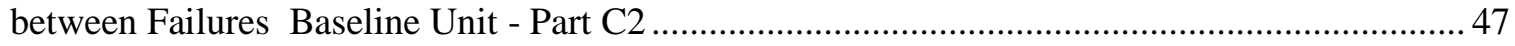

Table 17. Upgrade Unit Tire Failures during Part C2 .................................................................... 49

Table 18. Tire Failure Rates per 1,000 Miles Traveled and Expected Mean Travel Distance

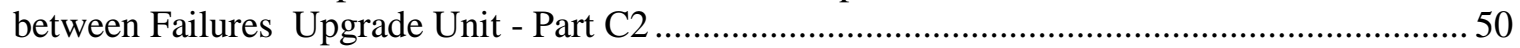

Table 19. Upgrade Unit Tire Failures during Part D (Radial Tires) .................................................... 51

Table 20. Tire Failure Rates per 1,000 Miles Traveled and Expected Mean Travel Distance

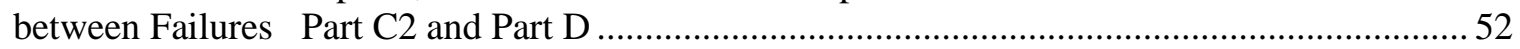

Table 21. Statistical Comparison of Tire Failures: Empirical Failure Rate vs. Observed Baseline

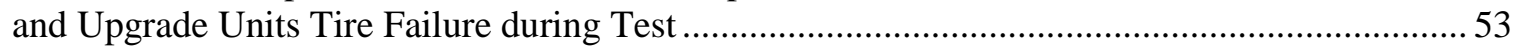

Table 22. Statistical Comparison of Tire Failures: Observed Upgrade Unit Tire Failure Rate vs.

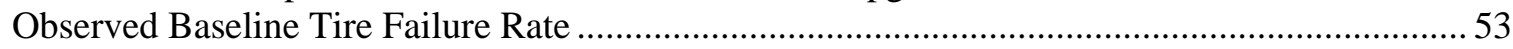

Table 23. Vehicle Speed Distribution Parameters Baseline and Upgrade Units - Part C2 All

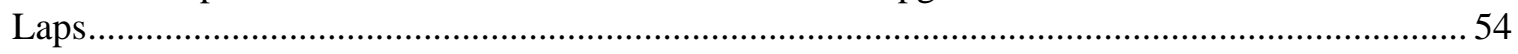

Table 24. Vehicle Speed Distribution Parameters Baseline and Upgrade Units - Selected Laps

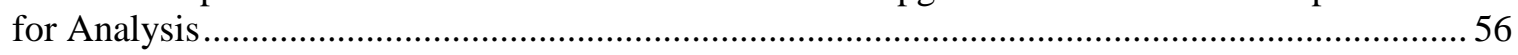

Table 25. Statistical Comparison of GRMS Measure: Baseline Unit vs. Upgrade Unit All Accelerometers - Vertical Direction............................................................................................. 57

Table 26. Statistical Comparison of GRMS Measure: Baseline Unit vs. Upgrade Unit All

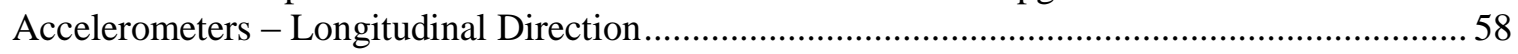

Table 27. Statistical Comparison of GRMS Measure: Baseline Unit vs. Upgrade Unit All

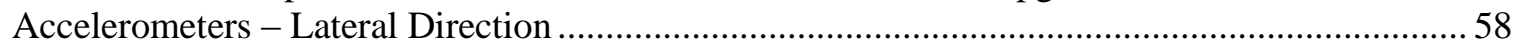

Table 28. Vehicle Speed Distribution Parameters Upgrade Unit with Radial and Regular TiresSelected Laps for Analysis.

Table 29. Statistical Comparison of GRMS Measure: Radial Tires vs. Regular Tires Upgrade Unit - All Accelerometers - Vertical Direction

Table 30. Statistical Comparison of GRMS Measure: Radial Tires vs. Regular Tires Upgrade Unit - All Accelerometers - Longitudinal Direction..

Table 31. Statistical Comparison of GRMS Measure: Radial Tires vs. Regular Tires Upgrade Unit - All Accelerometers - Lateral Direction 
Table 32. Vehicle Speed Distribution Parameters Baseline and Upgrade Units - Rough-road

Test -Laps Selected for Analysis.

Table 33. Statistical Comparison of GRMS Measure: Baseline Unit vs. Upgrade Unit Rough-

Road Test - All Accelerometers - Vertical Direction 66

Table 34. Statistical Comparison of GRMS Measure: Baseline Unit vs. Upgrade Unit Rough-

Road Test - All Accelerometers - Longitudinal Direction 66

Table 35. Statistical Comparison of GRMS Measure: Baseline Unit vs. Upgrade Unit Rough-

Road Test - All Accelerometers - Lateral Direction

Table 36. Vehicle Speed Distribution Parameters Upgrade Unit with Radial and Regular Tires -

Laps Selected for Analysis

Table 37. Statistical Comparison of GRMS Measure: Radial Tires vs. Regular Rough-Road Test

- Upgrade Unit - All Accelerometers - Vertical Direction.

Table 38. Statistical Comparison of GRMS Measure: Radial Tires vs. Regular Rough-Road Test

- Upgrade Unit - All Accelerometers - Longitudinal Direction... 70

Table 39. Statistical Comparison of GRMS Measure: Radial Tires vs. Regular Rough-Road Test

- Upgrade Unit - All Accelerometers - Lateral Direction .71

Table 40. Tire Failure Rates per 1,000 Miles Traveled and Expected Mean Travel Distance

between Failures Alternatives 0, 1, 2, and 3

Table 41. Maximum Average GRMS (and Location of Maximum GRMS Average) by

Accelerometer Type, Test Type, and Alternative .75

Table 42. Summary of Reported Damages during Part B/C1 and Part C2 - Baseline Unit ..................... 76

Table 43. Summary of Reported Damages during Part B/C1, Part C2 and Part D - Upgrade Unit......... 77

Table 44. Expected Cost for a 1,800 Mile Trip for Each Alternative Analyzed. 


\section{ACRONYMS}

$\begin{array}{ll}\text { B } & \text { Baseline Unit } \\ \text { BO } & \text { (Tire) Blowout } \\ \text { BU } & \text { Baseline Unit } \\ \text { CCW } & \text { Counter-clockwise } \\ \text { CE } & \text { (Tire) Cords Exposed } \\ \text { CW } & \text { Clockwise } \\ \text { DAS } & \text { Data Acquisition System } \\ \text { DOT } & \text { U.S. Department of Transportation } \\ \text { FEMA } & \text { Federal Emergency Management Agency } \\ \text { FFT } & \text { Fast Fourier Transform } \\ \text { FL } & \text { (Tire) Flat } \\ \text { FMCSA } & \text { Federal Motor Carrier Safety Administration } \\ \text { FTP } & \text { File Transferring Protocol } \\ \text { GPS } & \text { Global Positioning System } \\ \text { GRMS } & \text { Root-Mean-Square Acceleration } \\ \text { Hz } & \text { Hertz } \\ \text { MHU } & \text { Mobile Housing Unit } \\ \text { MOE } & \text { Measure of Effectiveness } \\ \text { MPH } & \text { Miles per Hour } \\ \text { NPG } & \text { Navistar Proving Grounds } \\ \text { N/A } & \text { Not Available } \\ \text { ORNL } & \text { Oak Ridge National Laboratory } \\ \text { RBPR } & \text { Rugged Based Performance Requirements } \\ \text { RMS } & \text { Root Mean Square Amplitude } \\ \text { RPM } & \text { Revolutions per Minute } \\ \text { SB } & \text { (Tire) Sidewall Bulge } \\ \text { TS } & \text { (Tire) Tread Separation } \\ \text { U } & \text { Upgrade Unit } \\ \text { U.S. DOE } & \text { U.S. Department of Energy } \\ \text { UU } & \text { Upgrade Unit } \\ \text { WI } & \text { (Tire) Worn Past Wear Indicator } \\ & \end{array}$





\begin{abstract}
The Federal Emergency Management Agency (FEMA) stages manufactured housing units (MHUs) at key locations to be used during disasters when other housing accommodations cannot be arranged for individuals or families. Due to the unpredictability of natural disasters and the limitations of the manufactured housing industry to produce large numbers of MHUs in very short periods of time, it is necessary for FEMA to store a large number of units for many months or years. With these long storage periods come degradation issues with frames, tires, bearing, and braking systems. These types of issues are also of interest to the U.S. Department of Transportation (DOT) Federal Motor Carrier Safety Administration (FMCSA) because regulated carriers normally transport these units and 49 CFR 393.75 Tires specifies tire loading restrictions for manufactured homes.
\end{abstract}

To compare the running gear (tires, brakes, drums, bearings, axles, springs, and spring mounting hardware) currently specified in the 2014 Rugged Based Performance Requirements (RBPR) and the newly recommended running gear specified in the upcoming revision to the RBPR, the Oak Ridge National Laboratory (ORNL) outlined a Longevity Test Plan, which focused on the assessment of component longevity (failure rates by component type).

The Test Plan also studied the forces imparted to the MHU from the running gear from interaction with the roadway for both the running gear in the 2014 RBPR and the running gear specified in the upcoming RBPR revision. Since the assessment of component longevity and failures are also issues of concern for FMCSA, both agencies collaborated to support the research presented in this report. The tests and data collection were conducted at the Navistar Proving Grounds (NPG) in New Carlisle (near South Bend), Indiana, during the May-November 2018 period.

Four alternatives for the suspension system of a typical three-bedroom MHU were considered in this test. Alternative 0 was the MHU that was selected from the FEMA staging area in Selma, Alabama. Empirical data had shown that, on average, this alternative experiences one tire failure every 150 miles (or 0.0067 tire failures per mile traveled). Before testing, Alternative 0 was equipped with similar running gear hardware, although in new condition and installed following the manufacturer's specifications. This became the Baseline Unit, or Alternative 1. Another unit, also selected from the FEMA staging area in Selma, Alabama, was equipped with better axles (i.e., axles that were rated for 7,000lbs as opposed to $6,0001 \mathrm{bs}$ for the Baseline Unit) and better tires. This became the Upgrade Unit, or Alternative 2. At the end of the Longevity Test, the Upgrade Unit was mounted with radial tires. This became Alternative 3.

Alternative 1 (Baseline Unit) had, on average, one tire failure every 251 miles (or 0.0040 tire failures per mile traveled). So, by simply following the correct manufacturer's specifications for the assembly of the transportation system, a reduction of $41 \%$ in the per mile tire failure was achieved. In the same test, Alternative 2 (Upgrade Unit) showed, on average, one tire failure every 728 miles traveled (or 0.0014 tire failure s per mile traveled). When the Upgrade Unit was mounted with radial tires in the last part of the test, no tire failures were observed for the 2,400 miles tested. That is, in the case of the radial tires (Alternative 3) the tire failure was less than one per 2,400 miles traveled (or less than 0.0004 tire failures per mile traveled).

The data collected for the Longevity Test showed that the maximum accelerations were registered in all cases at the center of the MHU in the vertical direction. The overall maximum was registered by the Baseline Unit, Alternative 1. If that value is normalized to $100 \%$, then the Upgrade Unit (Alternative 2) showed, on average, $81 \%$ at the same location, and Alternative 3 (radial-tire test) 59\%. That is, the upgraded transportation system showed a reduction of $19 \%$ and $41 \%$ in the vertical accelerations transmitted to MHU at its center when regular and radial tires, respectively, were used. 
As part of the Test Protocol, NPG conducted a visual inspection of the MHUs and transportation system at the end of each test day. ORNL reviewed all the inspection reports in an attempt to determine if there was any difference in the damage that the Baseline and Upgrade MHUs showed during the test. The Upgrade Unit always showed lower accelerations transmitted to the MHU than the Baseline Unit. In most cases, these differences were statistically significant. The FEMA inspection report, conducted by a FEMA certified inspector at the end of the tests, included a shorter list of damaged items for the Baseline Unit than for the Upgrade Unit, although similar type of damages was described for both units. This may be an indication that, although lower than those of the Baseline Unit, the accelerations transmitted by the Upgrade Unit were above the threshold at which MHU elements start to fail. 


\section{BACKGROUND}

\subsection{INTRODUCTION}

Currently the Federal Emergency Management Agency (FEMA) stages manufactured housing units (MHUs) at key locations to be used during disasters when other housing accommodations cannot be arranged for individuals or families. Due to the uncertainty of disasters and the limitations of the manufactured housing industry to produce large numbers of MHUs in very short periods of time, it is necessary for FEMA to store a large number of units for many months or years. With these long storage periods come degradation issues with frames, tires, bearing, and braking systems. Further, current practices and materials used in the manufactured housing industry were not intended to support the possible long delivery distances demanded by some disasters. Thus, tire, bearing, axle, and suspension failures become an issue in many situations. These types of issues are also of interest to the U.S. Department of Transportation (DOT) Federal Motor Carrier Safety Administration (FMCSA) because regulated carriers normally transport these units and 49 CFR 393.75 Tires specifies tire loading restrictions for manufactured homes.

The Oak Ridge National Laboratory (ORNL) outlined a Test Plan (Lascurain et al. [1]) to compare the running gear (tires, brakes, drums, bearings, axles, springs, and spring mounting hardware) currently specified in the 2014 Rugged Based Performance Requirements (RBPR) and the newly recommended running gear specified in the upcoming revision to the RBPR. The Test Plan focused on the assessment of component longevity (failure rates by component type) and the forces imparted to the MHU from the running gear from interaction with the roadway for both the running gear in the 2014 RBPR and the running gear specified in the upcoming RBPR revision. Since the assessment of component longevity and failures are also issues of concern for FMCSA, both agencies collaborated to support the research presented in this report.

The tests and data collection were conducted at the Navistar Proving Grounds (NPG) in New Carlisle (near South Bend), Indiana, during the May-November 2018 period. The testing effort was supported by FEMA, and the subsequent data analysis and the development of this report was supported by FMCSA.

This report presents a detailed analysis of the data collected at NPG. The remainder of this chapter includes a description of the problem that triggered this research, as well as the testing goals. The next chapter describes the tests conducted at NPG, including descriptions of the test facility, outfitting and instrumentation of the tested vehicles, test protocols, and preliminary analysis of the data collected. In the data analysis chapter, the data collected is summarized and analyzed using statistical methodologies. The data analysis focuses on tire and component failures as well as the transmission of accelerations to the MHUs by the corresponding suspension systems. Three alternatives with different suspension systems are compared to determine if there were any statistically significant differences in terms of suspension component failures and the level of vibrations transmitted to the MHUs. The following chapter summarizes the results and conclusions, including a cost analysis of the different alternatives tested. The final chapter of this report presents the lessons learned while conducting this research.

The report also includes five appendices. APPENDIX A and APPENDIX B present more details about the preliminary data analysis and outfitting of the test vehicles, respectively. Additional information related to the data analysis is included in APPENDIX C. APPENDIX D and APPENDIX E presents the information provided by NPG regarding the inspection of the test vehicles and MHUs at the end of each test day. The final appendix of the report, APPENDIX F, includes the damage reports for each test unit, prepared by a qualified FEMA inspector at the end of the test. 


\subsection{PROBLEM STATEMENT}

\subsubsection{Issues Driving the Consideration of New MHU Running Gear}

The currently specified FEMA MHU running gear is of mobile home type and is not intended for Interstate speeds, long delivery distances or reuse.

The axles, brakes, wheels, and tires currently used in the mobile home industry are limited by the component manufacturer to a maximum speed of $50 \mathrm{mph}$. However, it appears that FEMA MHUs are typically delivered at speeds in excess of some posted interstate speed limits (meaning speeds in excess of $55 \mathrm{mph}$ ). These components are required by the FEMA 2014 RBPR to be of new condition, not used or remanufactured. The 2014 RBPR for MHU axles does specify a distance and hours requirements but does not specify a speed requirement. The current axle offerings provided to meet the 2014 RBPR have not been tested for the specified distance or the operating hours requirement. The lack of a speed requirement in the 2014 RBPR allows the MHU industry to fit the FEMA MHUs with standard mobile home quality tires which are identified by the tire manufacturer as speed limited to $50 \mathrm{mph}$.

Anecdotally, in our discussion with MHU manufactures, movers, and FEMA, we obtained the following failure rate information for the running gear specified in the 2014 RBPR. In other cases (noted below), it was necessary to estimate test parameters regarding failure rate limits for the purposes of test planning. These working estimates are provided below:

- $\quad$ Tires

$\circ \quad$ Typical failure rate -1 tire per 150 miles (industry provided)

- Upper limit failure rate -1 tire per 100 miles (test parameter estimate)

- Wheels/Hubs/Axles

$\circ$ Typical failure rate -1 of each per 1000 miles (test parameter estimate)

○ Upper limit failure rate -1 of each per 670 miles (test parameter estimate)

With FEMA MHU deployments from their two staging areas (Chambersburg, Maryland, and Selma, Alabama) being 300 to 500 miles or more, each deployment is expected to experience tire and wheel-end failures based on the listed estimates. These running gear failures delay the delivery of the MHUs to their final deployment and can result in damage to the MHUs, both of which increase the overall deployment cost.

Additionally, the distance traveled by the MHUs from their point of manufacture to the FEMA staging areas will typically be hundreds of miles. While noticeably damaged running gear components are replaced prior to deployment to disaster areas, these delivery trips do impart wear to the tires, axle bearings, spring hangers and brakes, increasing the likelihood of running gear component failure during emergency deployments.

Ideally, an MHU should be deployable to any continental U.S. location with no running gear failure and minimal damage to the MHUs themselves from roadway vibration and transmitted forces, assuming a "start of deployment condition" with tires in serviceable condition at the proper air pressure and axle assemblies properly greased and wheel-bearings properly pre-loaded. 


\subsubsection{Issues Related to Vibration and Transmitted Forces in Transit}

The forces transmitted through the running gear as the MHU is transported over roadways are a significant cause of damage to the MHU which must ultimately be repaired at the destination. While no transport damage statistics exist for FEMA MHUs, transport damage information for MHUs sold to the public (non-FEMA units) has been provided for testing by the Institute for Building Technology and Safety. The top five issues are:

1. “Racked" Exterior Doors

2. “Racked” Interior Doors

3. Loose plumbing

4. "Racked" Windows

\section{Loose HV/AC Ducts}

It is assumed that since the building practices and materials used in construction of commercial MHUs and FEMA MHUs are similar, the same transport damage issues due to vibration and transmitted forces would be prevalent in FEMA MHUs.

Prior to the test and the analysis of the collected data presented here, it was expected that the proposed improvements to the running gear (e.g., radial tires, balanced tires, and spring equalizers), would result in lower levels of energy transmitted to the MHU while in transit. This lowered energy transmission should translate to decreased stress on the unit and consequently in less damage to the MHU. As described in the chapters that follow, the analysis of the data collected supported the first statement (it was shown to be statistically significant), but the data was inconclusive regarding the second statement.

\subsection{TESTING GOALS}

The testing that was proposed and performed at NPG sought to quantify to a limited degree the failure rates of the running gear components specified in the 2014 RBPR and the running gear components proposed in the upcoming RBPR revision. Further, it sought to measure the forces imparted to the MHU by the running gear from the roadway for both the current and proposed components. The testing and data collected also aimed at quantifying and comparing the energy transmitted to MHUs during transportation by each of the two running gear component options.

These two testing goals, monitoring the rate of failure of transportation components and determining whether there is any statistically significant difference between the two transportation alternatives regarding the transmission of energy to the MHU while in transit, are focused on comparison between two running gear options rather than an absolute understanding of dynamics of the individual options. It is important to note that it was not the goal of this testing to statistically sample or identify/contrast discrete failures of components or systems within the greater MHU beyond the running gear system. 



\section{TESTING OVERVIEW}

\subsection{TESTING LOCATION}

The MHU testing and data collection was conducted at the Navistar Proving Grounds (NPG), 2104 State Road 2, New Carlisle, IN 46552 (see Figure 1). The testing employed NPG's three-mile oval track and a subset of their durability roads.

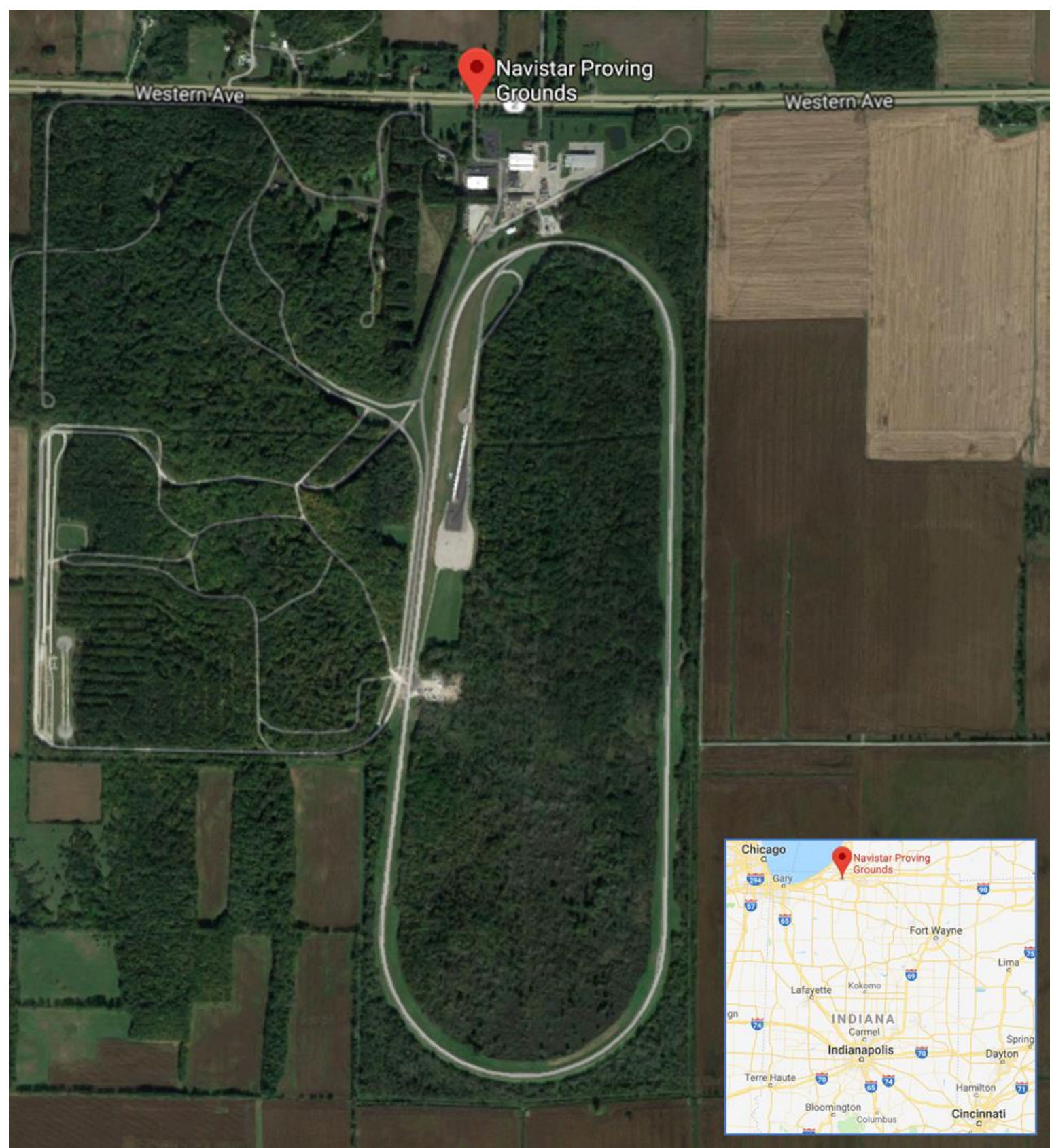

Figure 1. Navistar Proving Grounds' Three-mile Oval Track - New Carlisle, IN. 


\subsection{TESTING METHODOLOGY}

The test plan developed for this research required each unit to run for 4,800 miles, with an additional 4,800 miles if statistically significant failure rates were not obtained during the first half of the test (first 4,800 miles). The empirical/anecdotal tire-failure rate observed with similar units was one failure every 150 miles. If this failure rate were confirmed, it would be expected to observe 32 failures during the first half of the test (i.e., $32 * 150$ miles $=4,800$ miles) and 64 for the entire test (9,600 miles). Also, this distance, 9,600 miles, would, in most cases, exceed any planned deployment and recovery distance for a given MHU, thus allowing one data set to be gathered for the extreme life cycle of an MHU.

To control for exogenous variables (e.g., effect of air temperature, wind, and other external conditions), the 2014 RBPR running gear (Baseline Unit) and the proposed running gear (Upgrade Unit) were subjected to the same driving course and mileage simultaneously. Moreover, during the test, the leading and following units were interchanged such that for half of the miles tested the Baseline Unit was the leading unit and the Upgrade Unit was the following unit, and vice-versa for the other half of the miles tested. Similarly, the tractors were switched from one unit to the other such that each unit logged half of the test miles with one of the tractors and the other half of the miles with the second tractor. Also, and to control for any possible influence that the track superelevation may have on the running gear of the tested units, half of the miles were run in a clockwise direction and the other half in a counter-clockwise direction. This required the test to take place only during the time in which track usage exclusivity could be assured.

The test was divided into four parts. The first one (Part A: Calibration Testing) focused on confirming that the data collection procedures (including storage and transmission of data), as well as operation of the deployed sensors (including their mounting solution), was as expected. The second part of the test (Part B: Extended Testing) had as a main objective to test that the data collection procedures that were to be implemented in the longevity test (Part C) performed in the manner planned and if they did not, to determine and implement any corrective actions before the main data collection effort started. Part B also offered the researchers an opportunity to analyze the data collected to determine if the proposed data analysis methodology was feasible and gave the expected results. During the last part of the test (Part D: Radial Tires Testing), the Upgrade Unit was mounted with radial tires. Data was collected similarly as in Part C, but with only the Upgrade Unit to contrast the radial tires with the upgraded tires.

Parts A and B were scheduled for a total of 600 miles of data collection, Part C for 4,200 miles (with an additional 4,800 miles if required by the statistical analysis), and Part D for 2,400 miles.

\subsection{INSTRUMENTATION}

This section describes the instrumentation of the vehicles during the four test regimes that were conducted at NPG. For all the regimes, a basic instrumentation of the vehicle(s) to facilitate collection of its location (latitude and longitude), its speed, and other similar parameters was deployed. In addition to these basic sensors, NPG installed accelerometers to capture the vibration profile of the MHU trailers. While the basic information was collected at low frequency $(6.4 \mathrm{~Hz})$, the accelerometers collected information at $512 \mathrm{~Hz}$ to ensure that all the vehicle responses (suspension, tires, structure) were captured. Notice that the ratio between the high and low frequencies of data collection is an exact number, 80, which allowed for better synchronization of the data collected. That is, for every reading of the low-frequency data there were 80 readings of the high-frequency information.

For the calibration test, only one of the existing MHUs was instrumented with six set of accelerometers, with each set capturing vertical, lateral, and longitudinal vibrations. The sensors were mounted at the center of the axle gang (to directly capture the response of the transportation system), at each of the four corners of the MHU (to capture, together with the center accelerometers, the response of the MHU 
trailer), and at the trailer tongue (to capture the response of the tractor-trailer interactions). At each location, three accelerometers were mounted. One was deployed in a horizontal position in the direction of travel. This accelerometer gathered information associated to the vehicle dynamics and driving task during transportation, mainly longitudinal accelerations. A second accelerometer was placed horizontally and perpendicular to the direction of travel; this allowed to gather information associated to the geometry of the roadway during transportation, mainly lateral accelerations. The third accelerometer was mounted vertically to gather data associated to road irregularities during transportation. The following two tables present the channels of information that were gathered during the test. Table 1 shows the high-frequency data (accelerometer information) and Table 2 the low-frequency data (GPS data).

Table 1. Signals Collected at $512 \mathrm{~Hz}$

\begin{tabular}{|c|l|c|}
\hline $\begin{array}{c}\text { Channel } \\
\text { Name }\end{array}$ & \multicolumn{1}{|c|}{ Description } & Format/Units \\
\hline TimeStamp & $\begin{array}{l}\text { Time stamp provided by the data } \\
\text { acquisition system }\end{array}$ & $\begin{array}{c}\text { YYYY-MM- } \\
\text { DD } \\
\text { hh:mm:ss.ss }\end{array}$ \\
\hline HitchX & Hitch Center Longitudinal & $\mathrm{g}$ \\
\hline HitchY & Hitch Center Lateral & $\mathrm{g}$ \\
\hline HitchZ & Hitch Center Vertical & $\mathrm{g}$ \\
\hline RSFX & $\begin{array}{l}\text { Road Side Front Corner } \\
\text { Longitudinal }\end{array}$ & $\mathrm{g}$ \\
\hline RSFY & Road Side Front Corner Lateral & $\mathrm{g}$ \\
\hline RSFZ & Road Side Front Corner Vertical & $\mathrm{g}$ \\
\hline CSFX & $\begin{array}{l}\text { Curb Side Front Corner } \\
\text { Longitudinal }\end{array}$ & $\mathrm{g}$ \\
\hline CSFY & Curb Side Front Corner Lateral & $\mathrm{g}$ \\
\hline CSFZ & Curb Side Front Corner Vertical & $\mathrm{g}$ \\
\hline AxleX & Axle Group Center Longitudinal & $\mathrm{g}$ \\
\hline AxleY & Axle Group Center Lateral & $\mathrm{g}$ \\
\hline AxleZ & Axle Group Center Vertical & $\mathrm{g}$ \\
\hline RSRX & $\begin{array}{l}\text { Road Side Rear Corner } \\
\text { Longitudinal }\end{array}$ & $\mathrm{g}$ \\
\hline RSRY & Road Side Rear Corner Lateral & $\mathrm{g}$ \\
\hline RSRZ & Road Side Rear Corner Vertical & $\mathrm{g}$ \\
\hline CSRX & Curb Side Rear Corner & $\mathrm{g}$ \\
\hline Longitudinal & $\mathrm{g}$ \\
\hline CSRY & Curb Side Rear Corner Lateral & Curb Side Rear Corner Vertical \\
\hline & & \\
\hline
\end{tabular}


Table 2. Signals Collected at $6.4 \mathrm{~Hz}$

\begin{tabular}{|l|l|c|}
\hline $\begin{array}{c}\text { Channel } \\
\text { Name }\end{array}$ & \multicolumn{1}{c|}{ Description } & Format/Units \\
\hline TimeStamp & $\begin{array}{l}\text { Time stamp provided by } \\
\text { the data acquisition } \\
\text { system. }\end{array}$ & $\begin{array}{c}\text { YYYY-MM-DD } \\
\text { hh:mm:ss.ss }\end{array}$ \\
\hline Speed_mph & Vehicle Speed & mph \\
\hline Lat & Latitude & degrees \\
\hline Long & Longitude & degrees \\
\hline Month & Month & date \\
\hline Day & Day & date \\
\hline Hour & Hour & time \\
\hline Minute & Minute & time \\
\hline Second & Second & time \\
\hline
\end{tabular}

Besides the information presented in Table 2, ORNL also requested the following channels of data to be collected:

\section{- Engine RPM}

- $\quad$ Trip Distance

- Fuel Rate

- Average Fuel Economy

- Instantaneous Fuel Economy

- Total Fuel Used

- Trip Fuel

These signals are usually present in the vehicle databus. However, the data acquisition system (DAS) was not able (i.e., it required an additional board) to collect this data and therefore these channels were discarded. However, NPG did provide total fuel consumption at the end of each shift.

As described later in this report, the analysis of the data collected requires not only the synchronization of the low- and high-frequency signals for each unit, but also the synchronization of both units. The synchronization of the low-and high-frequency channels is done by the DAS automatically. Each reading of the information provided by the accelerometers is timestamped by the DAS, and once every 80 readings, one reading is made of the low-frequency data, and timestamped.

Each test unit was equipped with its own DAS, and each DAS had an internal clock that provided the timestamps described above. However, these clocks were not used to synchronize both units; rather, the GPS data and time channels were used to achieve this synchronization. Since these channels are read from the GPS satellites, an "elapsed time since midnight" can be computed and used to synchronize the units. 


\subsection{DATA COLLECTION PROTOCOL}

Because of the large number of sensors (18 accelerometers) and their high frequency of data collection $(512 \mathrm{~Hz})$, it was specified in the test plan to collect data in "bursts," rather than continuously. For example, in one eight-hour shift, each unit would collect approximately $2.2 \mathrm{~GB}$ if gathering data continuously. These generated data files would be unwieldy to store, transmit, and manipulate. The DAS can be programmed to collect data at given times (time trigger) or when a x number of miles have been traveled (distance triggered). Originally, it was specified to collect a five-minute interval of data every hour of test. Since the data analysis methodology required the comparison of Baseline and Upgrade Units information for the same segment of road collected at approximately the same time, the data collection "bursts" needed to be synchronized. Moreover, it also required the drivers to initiate the software that controlled these data collection "bursts."

This requirement proved to be difficult for the drivers to comply with because it is not a task that they perform habitually. If one driver forgot to initiate the data-collection triggering software, then the data collection for that part of the test could not be used for the analysis since it was based on the comparison of the two streams of data as explained below. Because of this, it was decided to collect data continuously, but dividing each data collection shift into two-hour segments. At the end of these segments, the data was downloaded from the DAS and transferred to a computer which was used to send the files to the ORNL researchers the following day.

At the start of a given run, and as soon as the drivers turned on the engine, the DAS started collecting information. The vehicles departed the garage area, located north of the oval (see Figure 2) and traveled south traversing a segment of road with rough pavement (rough-road test), shown in the figure with a dashed-line. NPG has a Durability Roads Area located west of the test-track entrance (see Figure 2) that initially it was going to be used for the durability testing ${ }^{1}$. However, and because of the grades, tight turn, slopes at turns, and tree obstructions, it was decided to use the NPG access road to the oval (traveling on some potholes and rumble strips on this road).

After traveling on the rough-road segment, the units continued south and entered the test track at the point indicated in Figure 2 with a thick arrow pointing right (west side of the oval). Once in the oval, they started the longevity-test run either in a clockwise or counter-clockwise direction-as specified for that particular part of the test - with one unit being the leading vehicle and the other one the follower. The direction of travel and the order of the units was changed such that half of the data collection was accomplished while traveling in a clockwise direction and the other half in a counter-clockwise direction. Similarly, half of the data collected had the Baseline Unit as the leading vehicle, and the other half the Upgrade Unit. In the same way, half of the data was collected with one of the tractors pulling the Baseline Unit and the other tractor pulling the Upgrade Unit, and vice-versa for the other half of the information collected in this test.

Once the vehicles entered the test track, they would speed up to the agreed speed of travel (approximately $60 \mathrm{mph}$ ) and collect data continuously for about two hours. At the end of the run, the vehicles exited the oval and traveled north towards the garage area, collecting another batch of rough-road data. The vehicle drivers or NPG engineers downloaded the data collected, labeled the files with name of the unit that collected it (Baseline or Upgrade) and Date and Time at which the test started. The files were stored and submitted to ORNL the next business day using the ORNL FTP (file transferring protocol) service. Once

\footnotetext{
${ }^{1}$ During the real-world deployment of the units, the vehicles sometimes must travel coarse roads which affect the tires. Also, sometimes the vehicles stop on the shoulders of highways traveling on the rumble strips which similarly affects the tires. To account for these effects, a small part of the miles collected during the test were on roads with potholes and rumble strips to try to mimic these situations. This is identified as "Rough-road Tests" in this document.
} 
ORNL received the files, they were divided into GPS $(6.4 \mathrm{~Hz})$ and Accelerometer $(512 \mathrm{~Hz})$ information files and saved to be post-processed.

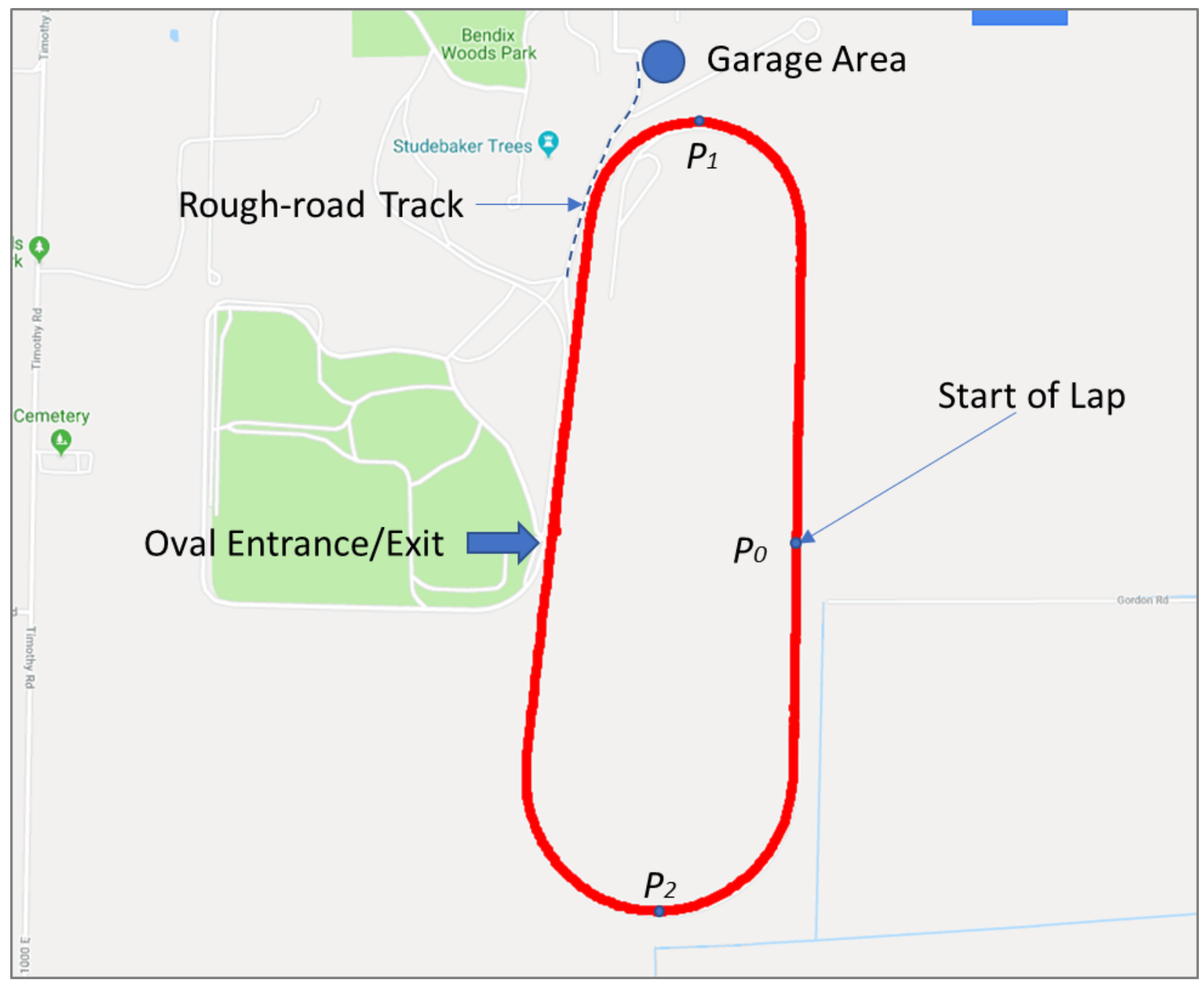

Figure 2. Long-distance Test and Rough-road Test Tracks.

\subsection{DATA PARSING}

Due to the continuous data collection approach adopted, the methodology for the data analysis initially proposed prior to the initiation of testing was changed. Rather than using five-minute data intervals collected every hour for both units, the data was divided into segments that corresponded exactly to one lap around the NPG oval. Figure 2 shows the location of the selected start-of-the-lap point, $\boldsymbol{P}_{\boldsymbol{0}}$, with latitude $=41.6588439941$ and longitude $=-86.4830551147$. The data segments were parsed using software developed by ORNL that identified when the vehicle went by the start-of-the-lap point using the information (i.e., vehicle latitude and longitude) collected using the GPS device connected to the DAS (GPS File). The software saved the DAS TimeStamp $\left(\boldsymbol{T} \boldsymbol{S}_{\boldsymbol{D G}}\right)$ corresponding to that event and also generated a UTC (Universal Time Coordinates) TimeStamp $\left(\boldsymbol{T} \boldsymbol{S}_{\boldsymbol{U G}}\right)$ using the date and time channels provided by the GPS. $\boldsymbol{T} \boldsymbol{S}_{U G}$ was also saved. The procedure continued until there was no more data for that run to be processed. 
Since for a given test unit the on-board DAS collected both the GPS and Accelerometer information simultaneously, these data files could be synchronized using the DAS TimeStamp. The ORNL software used the variable $\boldsymbol{T} \boldsymbol{S}_{\boldsymbol{D}}$ to determine where (which data record number) in the Accelerometers File had that timestamp (i.e., $\boldsymbol{T} \boldsymbol{S}_{\boldsymbol{D G}}=\boldsymbol{T} \boldsymbol{S}_{\boldsymbol{D A}}$ ). That would be the first accelerometer record for the lap under consideration. When the following lap $\boldsymbol{T} \boldsymbol{S}_{\boldsymbol{D A}}$ was identified, a new Accelerometer File record was saved for the new lap, with the previous lap finishing at the previous record. For example, if for lap $\boldsymbol{n}$ the GPS $\boldsymbol{T} \boldsymbol{S}_{D}(\boldsymbol{n})$ matched $\boldsymbol{T} \boldsymbol{S}_{\boldsymbol{D A}}$ for Accelerometer File Record $\boldsymbol{r}$, then the start of the Accelerometer Data Segment was assigned $\boldsymbol{r}$ (i.e., lap $\boldsymbol{n}$ starts at record $\boldsymbol{r}$ ). Once the Accelerometer File $\boldsymbol{T S}_{\boldsymbol{D A}}$ was matched to the GPS timestamp corresponding to the start of the next lap $\boldsymbol{T} \boldsymbol{S}_{\boldsymbol{D}}(\boldsymbol{n}+\mathbf{1})$ the Accelerometer File Record $\boldsymbol{s}$ (with $\boldsymbol{s}>\boldsymbol{r}$ ) becomes the start of the Accelerometer data segment for lap $n+1$ and $s-1$ becomes the end record for the Accelerometer data segment corresponding to lap $\boldsymbol{n}$.

The software saved all these pointers, and then computed the duration of each lap, its average speed, and its standard deviation. It also assigned a timestamp to the start of the lap, which was computed as the time elapsed from midnight using the GPS date and time channels, $\boldsymbol{T S}_{\boldsymbol{M}}$. Because these date and time channels are provided to the GPS device by the satellites from which it derives its spatial location, they are universal. That is, at any given time, any GPS device will get the same readings for these channels. Therefore, any time-elapsed-since-midnight computed using the Baseline Unit GPS, $\boldsymbol{T S}_{\boldsymbol{M B}}$, was synchronized with time-elapsed-since-midnight computed using the Upgrade Unit GPS, $\boldsymbol{T} \boldsymbol{S}_{\boldsymbol{M U}}$. That is, if two events had the same time-elapsed-since-midnight values (i.e., $\boldsymbol{T} \boldsymbol{S}_{\boldsymbol{M B}}=\boldsymbol{T} \boldsymbol{S}_{\boldsymbol{M U}}$ ), then these two events were simultaneous. This parameter permitted identifying which unit was the leader and which one was the follower during any given lap, as well as determining the headway between them. Moreover, by selecting two additional geopoints on the test track $\boldsymbol{P}_{\boldsymbol{1}}$ and $\boldsymbol{P}_{\boldsymbol{2}}$ (e.g., $\boldsymbol{P}_{\boldsymbol{1}}=$ the northmost point of the oval and $\boldsymbol{P}_{2}=$ the southmost point of the oval, see Figure 2) it is possible to determine the direction of travel using the time-elapsed-since-midnight parameter. If for a given lap, a vehicle reached $\boldsymbol{P}_{\boldsymbol{1}}$ earlier than $\boldsymbol{P}_{\boldsymbol{2}}$, then the direction of travel was counter-clockwise (clockwise if $\boldsymbol{P}_{2}$ was reached earlier than $\boldsymbol{P}_{1}$ ).

Other geopoints identified as the rough-road north and south ends and were used by the software to determine when the vehicle started and ended traveling on that road. Again, pointers to the database of collected information were generated as explained above, and the relevant data extracted for the analysis.

If during a run any damage occurred (e.g., a tire blowout) and the drivers became aware of the damage, then the damaged component was replaced, if feasible and required for the continuation of the test. If the drivers were not aware of the damage (most of the runs were conducted during the night), then when the vehicles were returned to the garage/parking area the component was replaced. In either case, a damage report was generated, and the information entered in an Excel spreadsheet by NPG personnel. Pictures were also taken of the damaged component. Both pictures and Excel spreadsheet were regularly submitted to ORNL.

\subsection{LONGEVITY AND ROUGH-ROAD TESTING}

\subsubsection{Pre-Testing Activities}

This subsection presents a description of the activities that were conducted before the testing started. These include the selection of the units to be tested, the outfitting of the hardware that was necessary for the improved-transportation unit (Upgrade Unit), as well as any changes made to current inventory MHUs (Baseline Unit). 


\subsubsection{Selection of Test Units}

Two three-bedroom units for testing at NPG were selected from the FEMA MHU Storage Facility located in Selma, Alabama. Those were six-axle Live Oak Homes units that were sequentially produced and were identified by FEMA as shown in Table 3. Figure 3 shows four views of the Baseline Unit, while Figure 4 presents details of the MHU suspension mounting hardware. Similar new stock suspension and mounting hardware were used during the longevity testing at NPG for the Baseline Unit. An improved suspension system was deployed on the Upgrade Unit before the tests as described later in this section.

Table 3. FEMA IDs and Serial Number for the Selected Testing MHUs

\begin{tabular}{|c|c|c|}
\hline Alternative & Unit ID & Unit Serial Number \\
\hline Baseline & 140152GIBB-1729BB3U-0912S & LOHGA21733042AC \\
\hline Upgrade & 140152GIBB-1729BB3U-0913S & LOHGA21733043AC \\
\hline
\end{tabular}

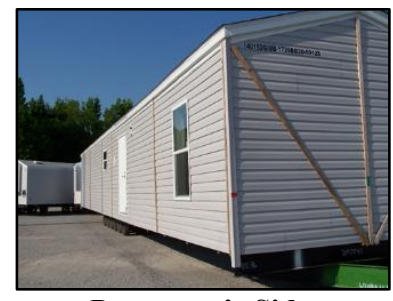

Passenger's Side

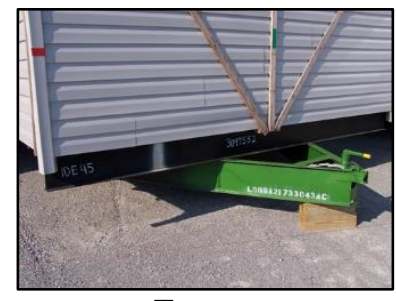

Tongue

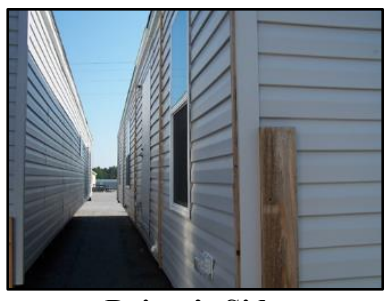

Driver's Side

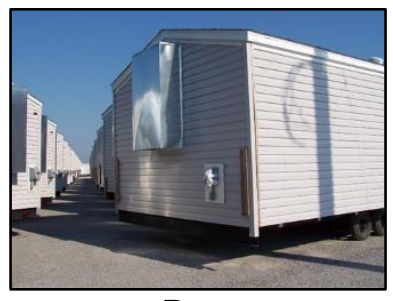

Rear

Figure 3. Baseline Unit.

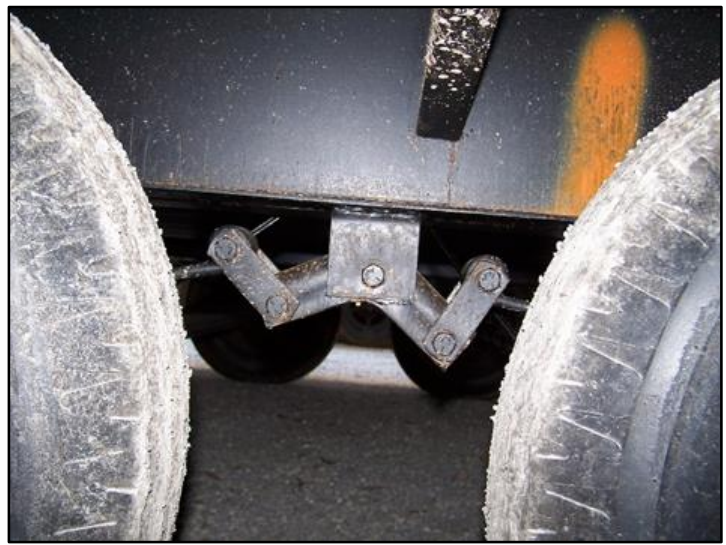

Suspension Equalizer

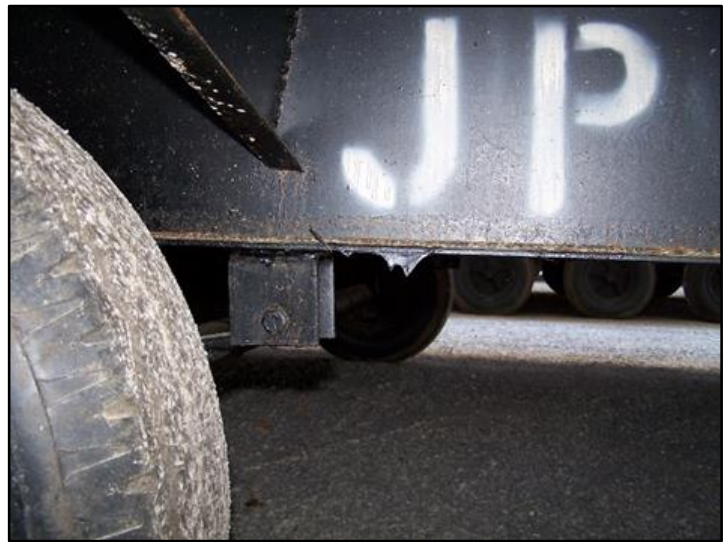

Spring Hanger

Figure 4. Baseline Unit Suspension Components.

The units were inspected by a project researcher to determine if it were possible to install the tri-axle accelerometers that would collect data during the test at the selected locations (I.e., four interior corners of the units, center of the unit, and tongue). The interior of the units did not present any obstructions for the mounting of the instruments. Also, before departing the Selma, Alabama facility, tire clearances (as currently configured with standard MHU axles and tires) were measured on the passenger side of Baseline Unit. Tire height was 26 inches with eight inches between each tire and five inches of clearance above each tire. Figure 5 shows the passenger's side axles with the rearmost axle (Axle 1) being on the left of the image and the forward-most axle (Axle 6) being on the right of the image. More clearance information for each tire to the adjacent outriggers is presented in Table 4 . 


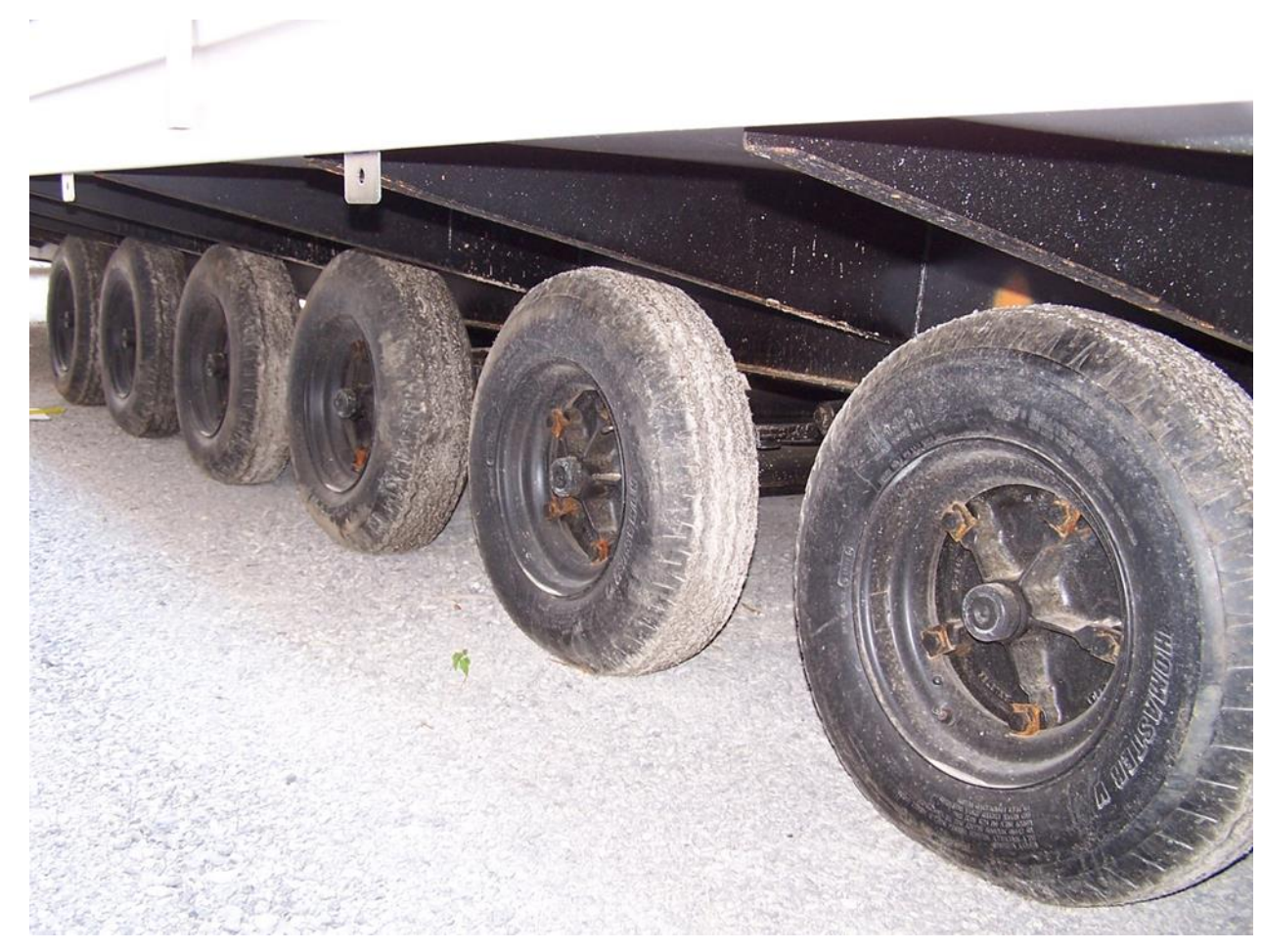

Figure 5. Baseline Unit Passenger Side Axle Gang.

Table 4. Baseline Unit Tire Clearance

\begin{tabular}{|c|r|r|}
\hline Tire & $\begin{array}{c}\text { Distance to Left } \\
\text { Outrigger [in] }\end{array}$ & $\begin{array}{c}\text { Distance to Right } \\
\text { Outrigger [in] }\end{array}$ \\
\hline Axle 1 & 2 & 7 \\
\hline Axle 2 & 6 & 8.5 \\
\hline Axle 3 & 5 & 8 \\
\hline Axle 4 & 5.5 & 9 \\
\hline Axle 5 & 4.5 & 9 \\
\hline Axle 6 & 5 & 3.5 \\
\hline
\end{tabular}

One of FEMA's regular subcontractors who provides MHU transportation services during emergency situations was selected by the agency to transport the units from Selma, Alabama, to the NPG facilities in Indiana during the week of May 14, 2018. The transportation company weighed the two units and provided the information presented in Table 5 . Notice that because the units were not individually identified, the weight information in that table is labeled as belonging to Unit A and Unit B. 
Table 5. MHU Weight Information Provided by Transportation Company

\begin{tabular}{|c|l|r|r|}
\hline \multicolumn{2}{|c|}{} & $\begin{array}{c}\text { Unit A } \\
{[\mathbf{l b s}]}\end{array}$ & $\begin{array}{c}\text { Unit B } \\
{[\mathbf{l b s}]}\end{array}$ \\
\hline \multirow{4}{*}{$\begin{array}{c}\text { Measure } \\
\text { Weights }\end{array}$} & Steer Axle & 8,760 & 8,760 \\
\cline { 2 - 4 } & Drive Axle & 17,720 & 17,740 \\
\cline { 2 - 4 } & Trailer Axles & 26,140 & 26,060 \\
\cline { 2 - 4 } & Total Combination Vehicle & 52,620 & 52,560 \\
\cline { 2 - 4 } & Tractor Only & 18,740 & 19,540 \\
\hline \multirow{3}{*}{$\begin{array}{c}\text { Calculated } \\
\text { Weights }\end{array}$} & Trailer Only & 33,880 & 33,020 \\
\cline { 2 - 4 } & Trailer Tongue & 7,740 & 6,960 \\
\cline { 2 - 4 } & Estimated Weight Per Axle & 4,357 & 4,343 \\
\hline Calculated & \% Trailer Wt. on Tongue & 22.8 & 21.1 \\
\hline
\end{tabular}

\subsubsection{Inspection, Instrumentation, and Outfitting of Test Units}

\section{Inspection}

The units arrived at test facility on May 15, 2018 and were inspected using NPG vehicle inspection form procedures. Several minor problems were identified in the interior of the units, none of them considered serious or affecting the testing. These included siding panels loose and popped out, missing roof vent, misaligned doors, and bent hinges, among others for the Baseline Unit and broken siding vertical trim, sprung windows and doors, and bent hinges, among others for the Upgrade Unit. Also, during the transportation of the units from Selma, Alabama, to New Carlisle, Indiana, the Baseline Unit experienced two tire failures (Axle 5 right and Axle 6 right). The driver did not report mileage when the failures occurred. The Upgrade Unit had no tire failures during transport.

New axles, tires, and other relevant parts were procured and made available to NPG to be used during the testing of the units. The list of procured parts, including quantities ordered, is presented Table 6Table 6 and shown in Figure 6 to Figure 9. Five of the 8-14.5 standard MHU tires received were of a different manufacture (SECURA versus HOMASTER V). Since it was not possible to determine if these five SECURA tires had the same durability as the HOMASTER $\mathrm{V}^{2}$ tires, the project researcher that was onsite for the delivery of the units instructed NPG personnel not to use these five tires in the test. Also, the 235/80R-16 radial tires were not balanced, so the on-site project researcher instructed NPG personnel to machine balance them before installation. Regarding the axles, originally it was planned to test five-axle MHUs, and the corresponding hardware was procured. However, the units that were chosen for the tests were six-axle; therefore, additional wheels, tires, and hardware were ordered to compensate for the additional axle.

\footnotetext{
2 The HOMASTER V tires that were used in the longevity testing were the same brand/model as was originally installed on the two test units from the factory.
} 
Table 6. Procured Parts for Testing Vehicles

\begin{tabular}{|c|c|}
\hline Part Description & Quantity \\
\hline $13 / 4$ Spring Hanger & 20 \\
\hline 2" Spring Hanger & 20 \\
\hline 4" Spring Hanger & 18 \\
\hline $21 \frac{1}{2}$ in Side Link & 40 \\
\hline $21 / 2$ in Side Link & 48 \\
\hline Hanger Bolts (9/16" - 18X3 1/2") & 60 \\
\hline 9/16" Nut & 60 \\
\hline Hanger Bolts (9/16" - 18X3”) & 66 \\
\hline 9/16" Nut & 66 \\
\hline Equalizer, EQ-104 (Cast) & 12 \\
\hline Braked Axle; 6,000 lb.; 95 1⁄2”"; Top Mount; Lube Option & 20 \\
\hline Braked Axle; 7,000 lb.; 95 1⁄2”; Top Mount; Lube Option & 12 \\
\hline 8-14.5 Tire and Wheel (FEMA Type) & 77 \\
\hline 240/60D 14.5 Tire; 8-6.5 Pattern Wheel & 14 \\
\hline 235/80R-16 Tire; 8-6.5 Pattern Wheel & 12 \\
\hline
\end{tabular}

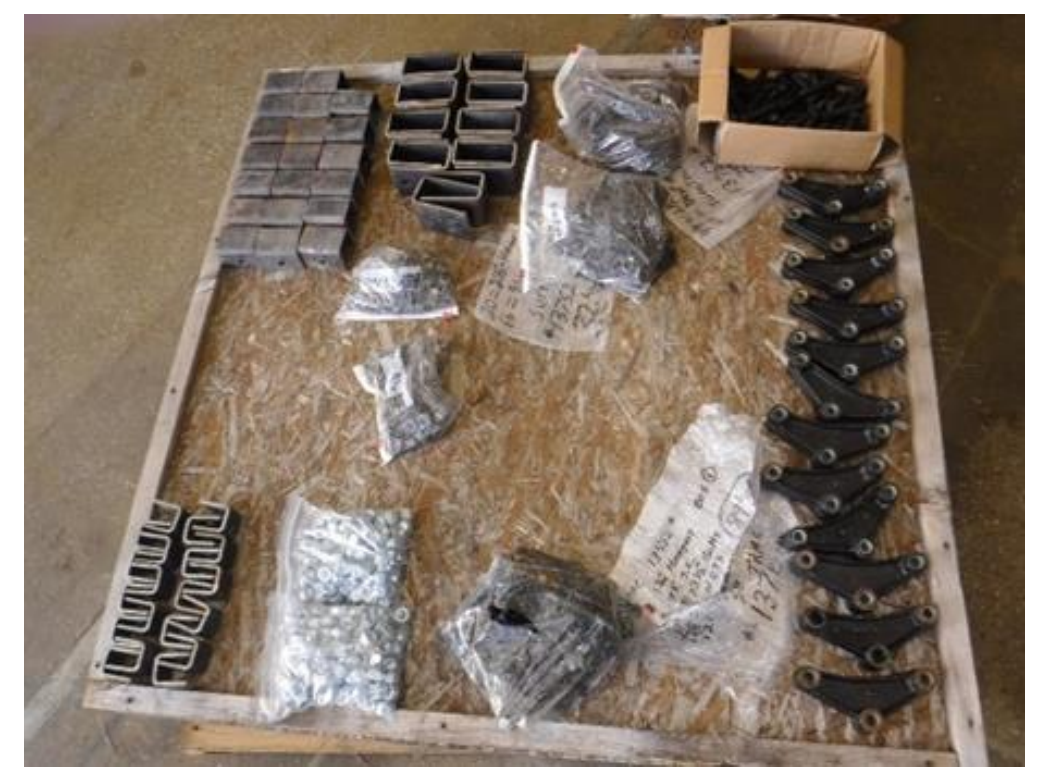

Figure 6. Procured Test Hardware. 


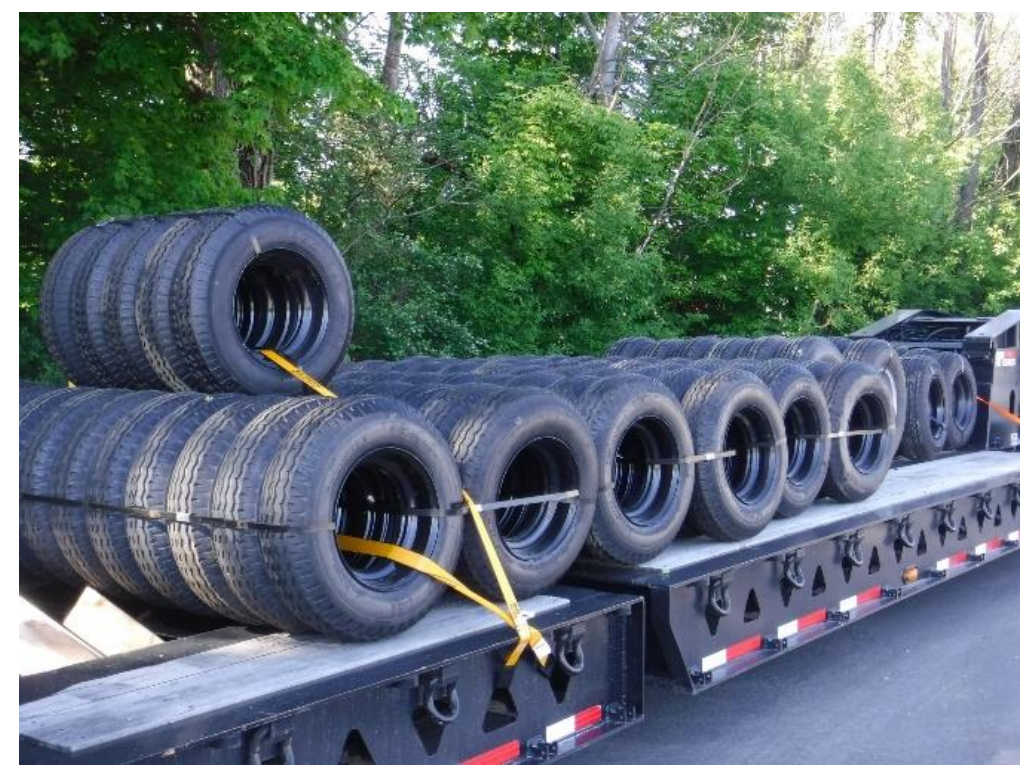

Figure 7. Procured Test Tires.

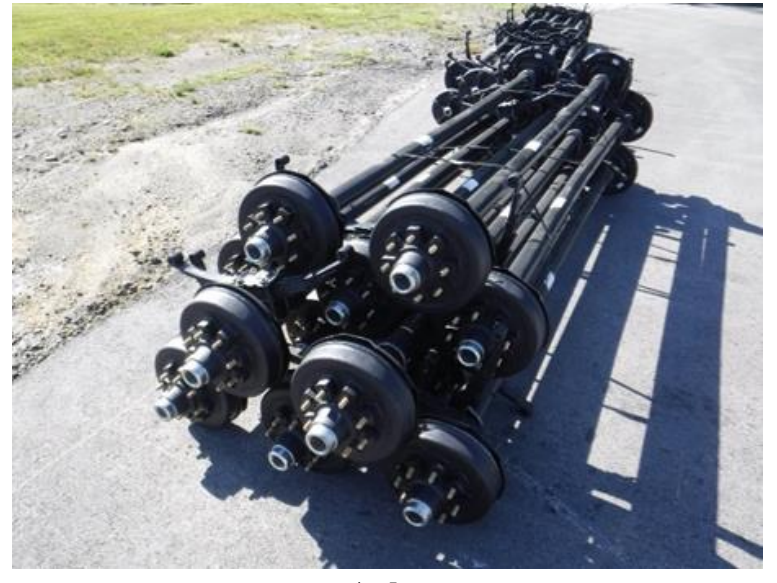

Axles

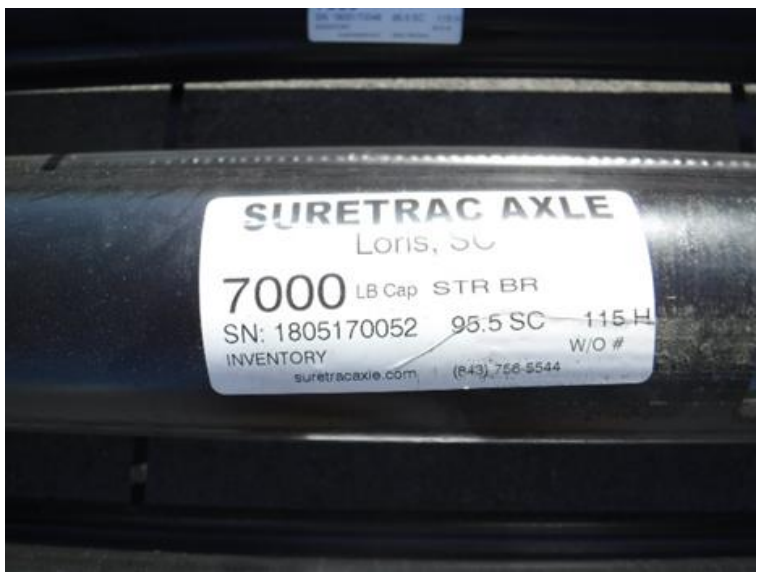

Axle Tag

Figure 8. Procured 7,000 lb. Axles; for Use on the Upgraded Unit. 


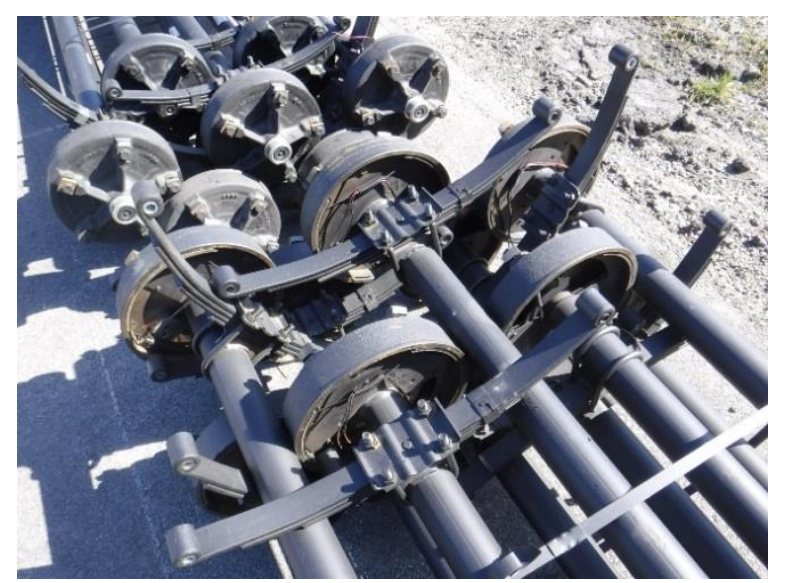

Axles

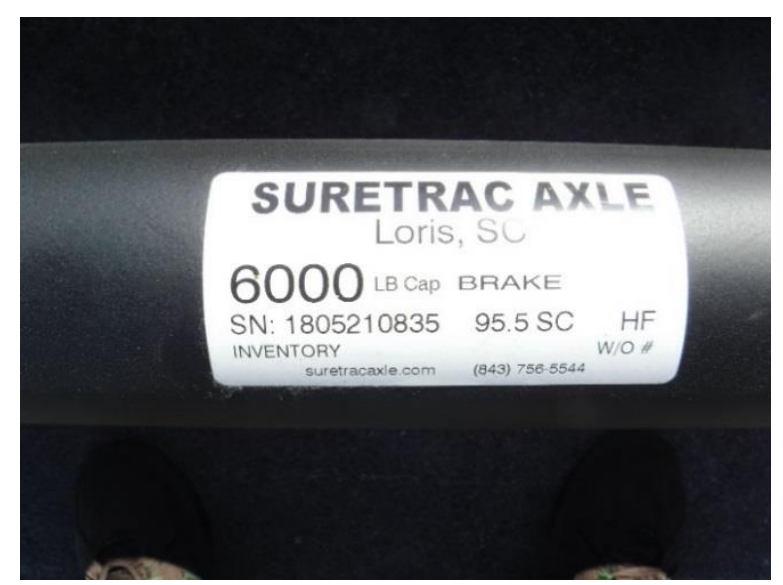

Axle Tag

Figure 9. Procured 6,000 lb. Axles; for Use on the Baseline Unit.

When the upgrade test unit arrived at NPG, and prior to any outfitting work, it was weighed using 13 analog HAENI model 101 20,000 lbs wheel scales (see Figure 10) ${ }^{3}$. The Upgrade Unit was set parallel to the shop floor with a scale under each tire and the trailer tongue. Each reading taken was verified by a second person. Table 7 shows the measured individual wheel-end weights and tongue weight as well as the calculated axle weights, axle gang weight, and total unit weight. These measurements were taken with the trailer tongue $191 / 2$ " from the floor. Table 8 shows the wheel-end weights measured with the MHU connected to the power unit. The connection changed the tongue-to-floor distance to 19 13/16" and did increase the weight to Axles 5 and 6 (the rearmost axles). This demonstrates the need to tow MHUs in the level-most position achievable to prevent overloading the rearmost or forward most axles. The center of balance achieved at the place of manufacture ( $21 \%$ tongue weight) was acceptable for the Upgrade Unit, and therefore, the position of the axles was not changed.

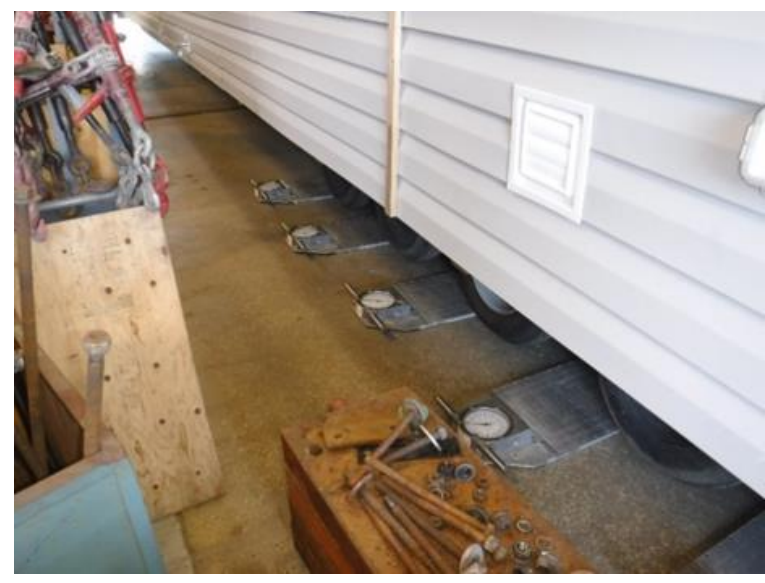

Placement of Scale Prior to Moving the Upgrade Test Unit

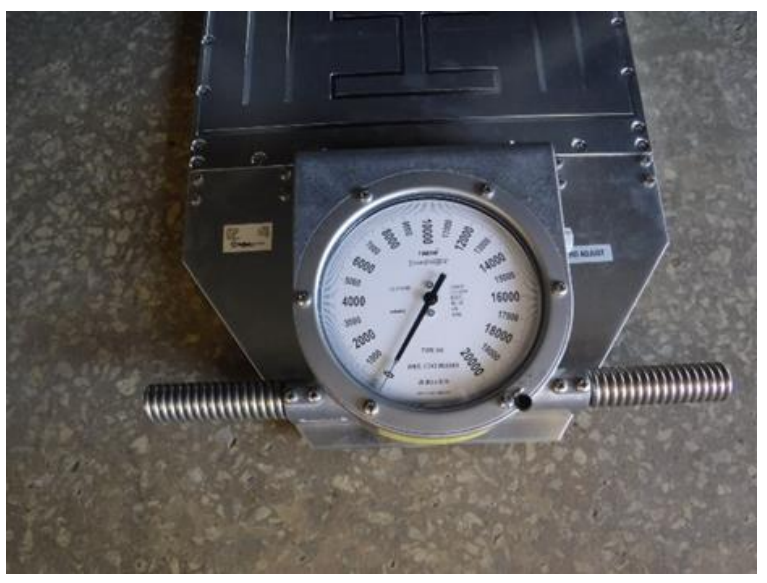

Scale Analog Dial

Figure 10. 20,000 lbs Analog Wheel Scales (HAENI Model 101).

\footnotetext{
${ }^{3}$ Some of these scales used were calibrated on 9/25/2017 and the others on 2/12/2018.
} 
Table 7. Upgrade Unit Axle and Trailer Weight - Level to Floor, 19 1/2 Inches from Top of Receiver to Concrete Floor (Not Connected to Tow Vehicle)

\begin{tabular}{|c|c|c|c|c|c|}
\hline \multirow{2}{*}{$\begin{array}{c}\text { Axle \# } \\
\text { (Front to } \\
\text { Back) }\end{array}$} & \multicolumn{2}{|c|}{ Roadside (Left) } & \multicolumn{2}{|c|}{ Curbside (Right) } & \multirow{2}{*}{$\begin{array}{c}\text { Total } \\
\text { Weight } \\
{[\text { lb] }}\end{array}$} \\
\hline & $\begin{array}{l}\text { Scale } \\
\text { ID }\end{array}$ & $\begin{array}{c}\text { Weight } \\
\text { [lb] }\end{array}$ & $\begin{array}{l}\text { Scale } \\
\text { ID }\end{array}$ & $\begin{array}{c}\text { Weight } \\
\text { [lb] }\end{array}$ & \\
\hline 1 & 25024 & 1,700 & 24505 & 2,475 & 4,175 \\
\hline 2 & 25469 & 2,000 & 25468 & 2,175 & 4,175 \\
\hline 3 & 24503 & 2,000 & 24504 & 2,250 & 4,250 \\
\hline 4 & 25467 & 1,975 & 25466 & 2,150 & 4,125 \\
\hline 5 & 24502 & 2,200 & 25025 & 2,350 & 4,550 \\
\hline 6 & 26204 & 2,625 & 26206 & 2,575 & 5,200 \\
\hline Tongue & 26198 & & & & 7,100 \\
\hline \multicolumn{5}{|c|}{ Total Axles } & 26,475 \\
\hline \multicolumn{5}{|c|}{ Total Trailer } & 33,575 \\
\hline
\end{tabular}

Table 8. Upgrade Unit Axle Weights - Hitch in Nearest Locking Hole, 19 3/16 Inches from Top of Receiver to Concrete Floor (Connected to Tow Vehicle)

\begin{tabular}{|c|c|c|c|c|c|}
\hline \multirow{2}{*}{$\begin{array}{c}\text { Axle \# } \\
\text { (Front to } \\
\text { Back) }\end{array}$} & \multicolumn{2}{|c|}{ Roadside (Left) } & \multicolumn{2}{c|}{ Curbside (Right) } & Total \\
\cline { 2 - 5 } & $\begin{array}{c}\text { Scale } \\
\text { ID }\end{array}$ & $\begin{array}{c}\text { Weight } \\
{[\mathbf{l b}]}\end{array}$ & $\begin{array}{c}\text { Scale } \\
\text { ID }\end{array}$ & $\begin{array}{c}\text { Weight } \\
{[\mathbf{l b}]}\end{array}$ & $\begin{array}{c}\text { Weight } \\
{[\mathbf{l b ]}}\end{array}$ \\
\hline 1 & 25024 & 1,600 & 24505 & 2,300 & 3,900 \\
\hline 2 & 25469 & 1,950 & 25468 & 2,100 & 4,050 \\
\hline 3 & 24503 & 1,975 & 24504 & 2,200 & 4,175 \\
\hline 4 & 25467 & 2,000 & 25466 & 2,175 & 4,175 \\
\hline 5 & 24502 & 2,225 & 25025 & 2,400 & 4,625 \\
\hline 6 & 26204 & 2,675 & 26206 & 2,750 & 5,425 \\
\hline \multicolumn{6}{|c|}{ Total Axles } \\
\hline
\end{tabular}

\section{Sensors and Data Acquisition System}

After the units were inspected at NPG, the instrumentation task started. The six tri-axis accelerometers were installed along with the data acquisition units and the interconnecting wiring, power and control wiring. All the sensors as well as the GPS devices were connected to a SoMat Data Acquisition System (see Figure 11).

The corner-based accelerometers were attached to the outermost corners of the units and were attached to the floor and two adjoining walls with epoxy. The flooring and walls were protected with tape. The sensor mounting blocks used were $1 \frac{1 / 4}{\mathrm{in}}$. by $1 \frac{1 / 4}{\mathrm{in}}$., and the distance from the outside corner of the unit to the corner of the mounting block was approximately seven inches (see Figure 12). The accelerometer placed over the axle gang was located against the door jamb of the center bathroom eight inches to the rear of the center of the axle gang and centered in the lateral direction (see Figure 12). The tongue mounted accelerometer was mounted $191 / 4$ in. from center of the mounting base to center of the hitch ball (see Figure 13). All sensors were located in the same position for both units. 


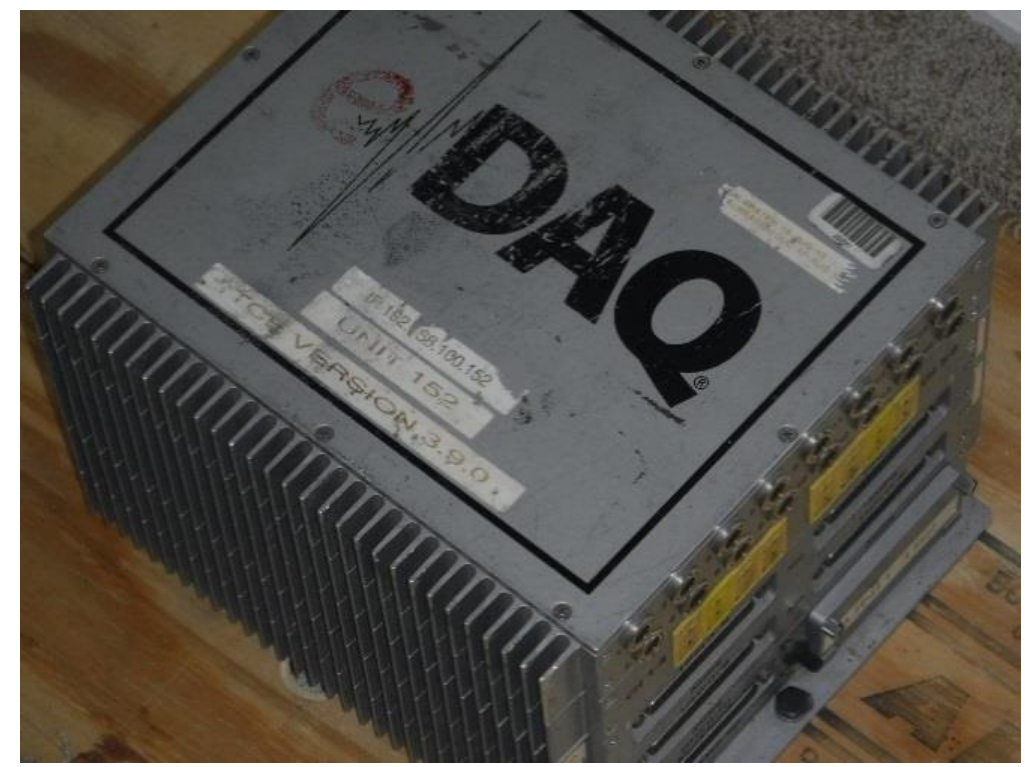

Figure 11. One of the Data Acquisition Systems Used during the Test.

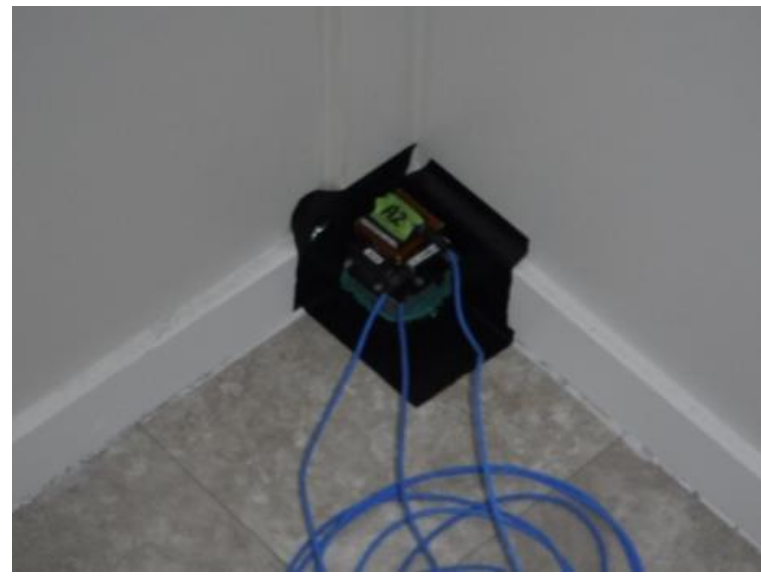

One of Four Corner-Mounted Sensors

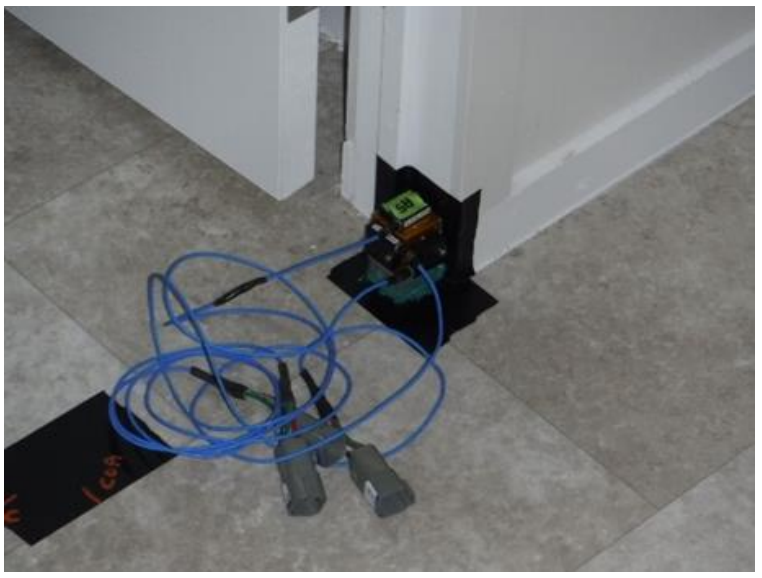

Center of Axle Gang Sensor

Figure 12. Tri-Axial Accelerometers Installed inside the Units. 


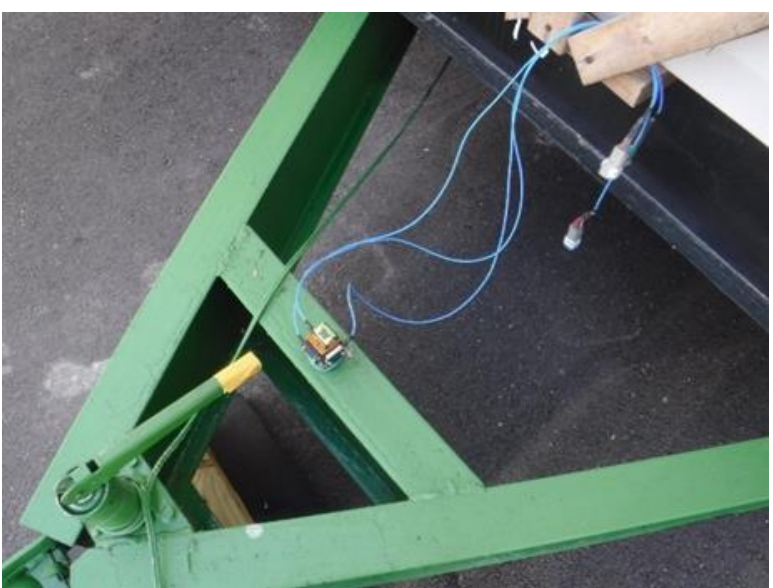

Tongue Mounted Sensor

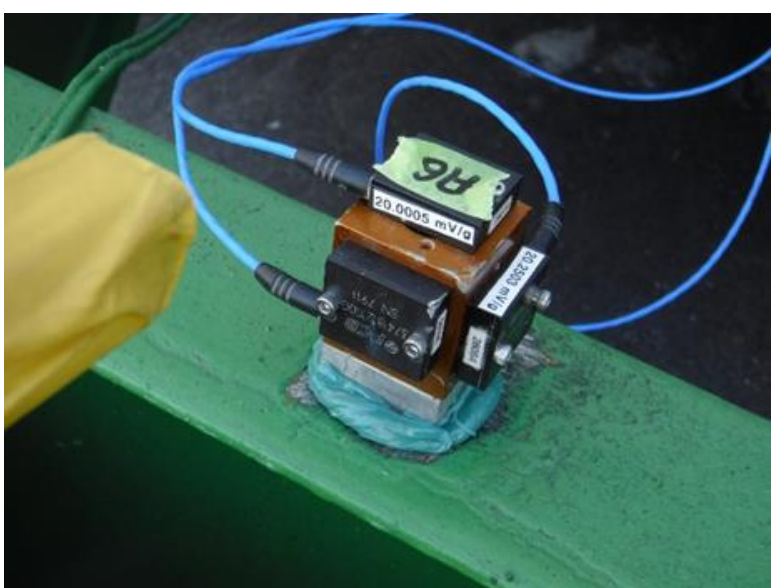

Tongue Mounted Sensor - Closer View

Figure 13. Tongue-installed Tri-Axial Accelerometer.

\section{Outfitting of Test Units}

When the units arrived at NPG, no issues were immediately identified with the outfitting of the Baseline Unit. It was determined that the new-condition, 6,000-lb axles/springs could be installed directly into the existing spring hangers. The unit employed an axle equalizer of a stamped or formed design (not the cast type that was to be used on the Upgrade Unit). It was decided to test this stamp equalizer as a part of the overall testing (i.e., to compare the longevity of stamped versus cast equalizers), and so new equalizers of this type were ordered to be installed on the Baseline Unit.

Similarly, there were no issues immediately discovered with the Upgrade Unit other than the fact that this unit was going to be outfitted at the end of the testing regiment with 235/80R-16 wheels and radial tires. These wheels and tires are larger in diameter that the 8-14.5 wheels and tires with which the MHUs are normally equipped; therefore, to accommodate the larger radial tires so they can clear the outriggers and underpinning of the unit, four-inch spring hangers were required (see Figure 14).

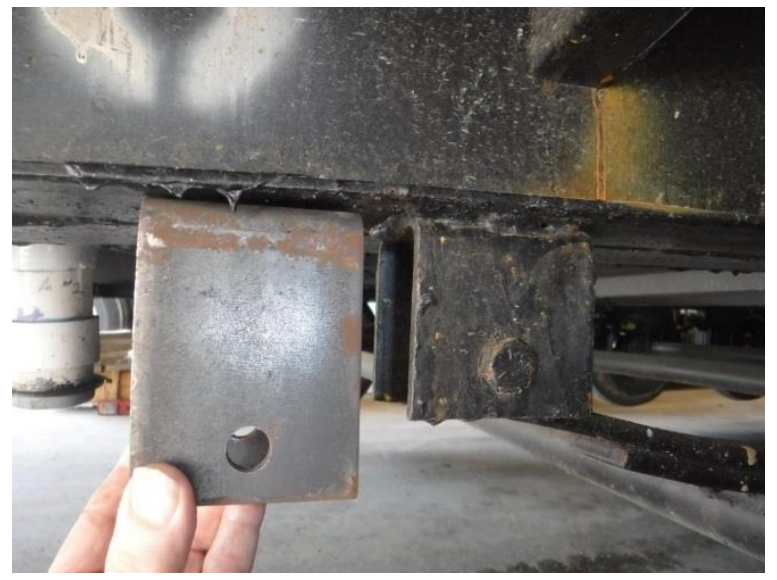

Figure 14. Four-inch Spring Hanger Compared to Existing Three-inch Spring Hanger.

Work immediately commenced on the Upgrade Unit. The list of tasks that were performed included the following: 1) tagging and removing the six existing axle/tire/spring assemblies; 2) cutting the existing two-inch spring hangers off of the main frame rails; 3) installing four-inch hangers on the frame rails in the same locations as the removed two-inch hangers; 4) installing updated equalizer, PN EQ-104; 5) 
installing the new 7,000 lbs. axles, PN 95.5SC/115" DE-6.8-6.5; 6) installing the new 240/60D14.5 tires; and 7) connecting brakes on all six axles.

As soon as the work started, it was determined that approximately half of the axles had wheel bearings that were loose, allowing the hubs and tires to move laterally. The NPG mechanics determined that this would likely lead to premature failure of the bearings. It was also observed that the bolts and nuts on all equalizers were overtightened, thus impeding the movement between equalizers and shackles and extremely limiting suspension travel. It appeared that the incorrect bolts were used, since all of them were tightened in this manner and then double-nutted (see Figure 15).

It was later determined that the double nutting was a manufacturer specification, which also required two threads to be exposed in order to achieve the correct fastener engagement. Trying to comply with these two specs simultaneously would again result in deforming (crushing) the equalizers as was done at the factory. To avoid this problem, it was recommended that the first nut be installed making sure that the components were free to move. And then the second nut would be installed, foregoing the two-thread clearance if this was not possible to achieve without overtightening the nuts.
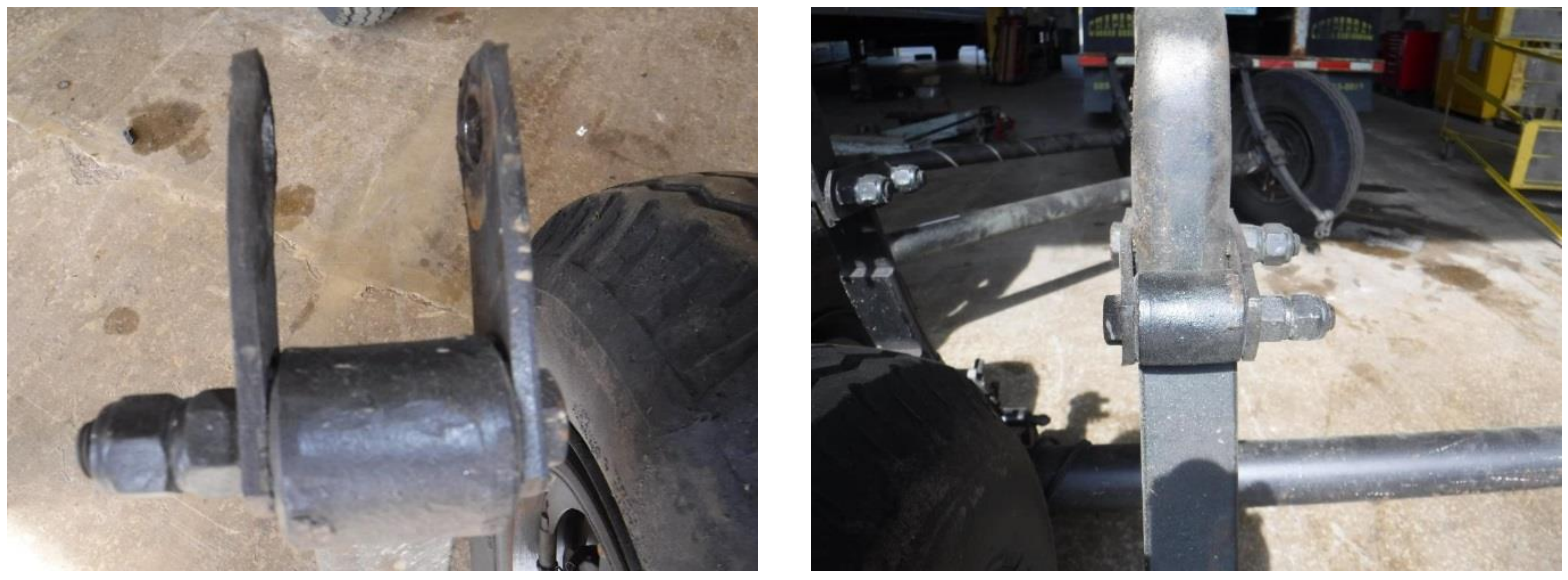

Figure 15. Overtightened Equalizer Bolts.

The mechanics found that the equalizer on Axle 3 was cracked at the apex (see Figure 16), most likely due to the overtightened nuts. Also, a tire on Axle 4 had two large bulges on the inboard side and appeared ready to fail (see Figure 17). 


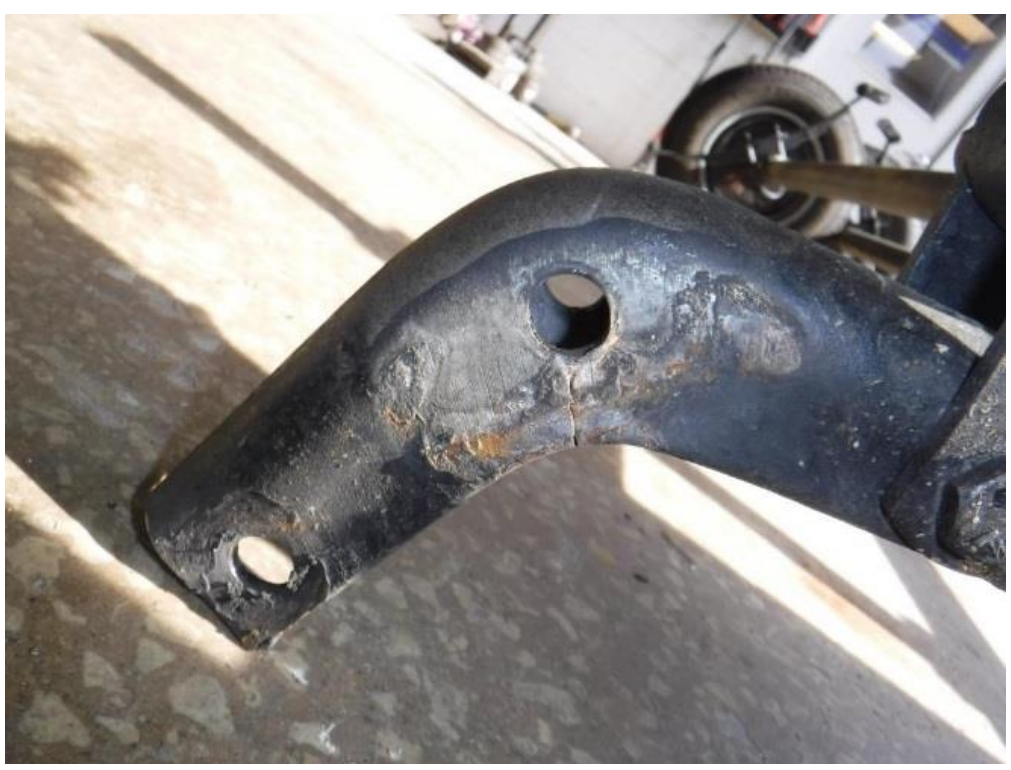

Figure 16. Cracked Axle 3 Equalizer.
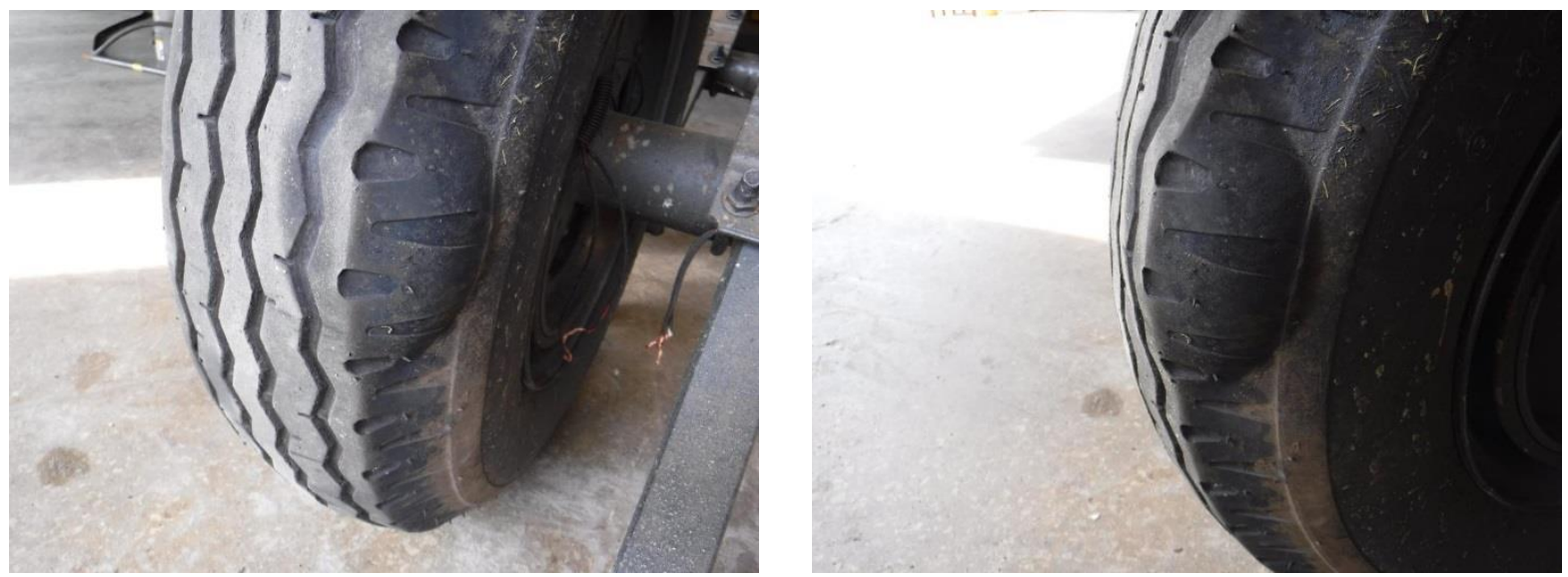

Figure 17. Bulges on One of Axle 4 Tires.

Similar issues were found during the outfitting of the Baseline Unit. As before, the suspension movement was severely limited due to overtightened fasteners. This also resulted in the equalizers' being distorted and/or cracked (Figure 18), as well as bent and distorted shackles (Figure 19). Also, the inside of all the spring hangers were distorted and abraded due to the overtightening of fasteners and the lack of proper clearance (Figure 20). The outboard flanges of the spring hangers were deformed due to wear and indentation from the bolt heads (Figure 21). There was also a mismatch between the 9/16-inch bushing and the 1/2-inch fastener that were used, resulting in the distortion of the spring-eye bushings (Figure 22). These issues were corrected before proceeding with testing. 

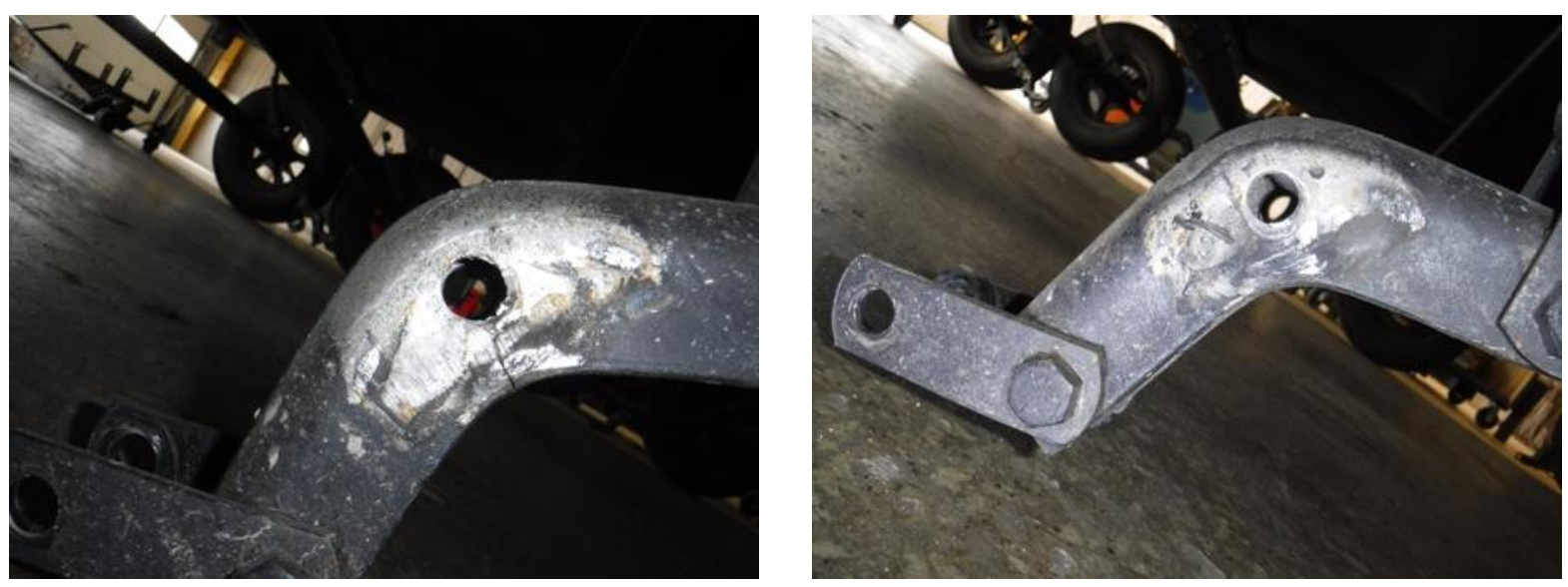

Figure 18. Cracked and Distorted Equalizers.
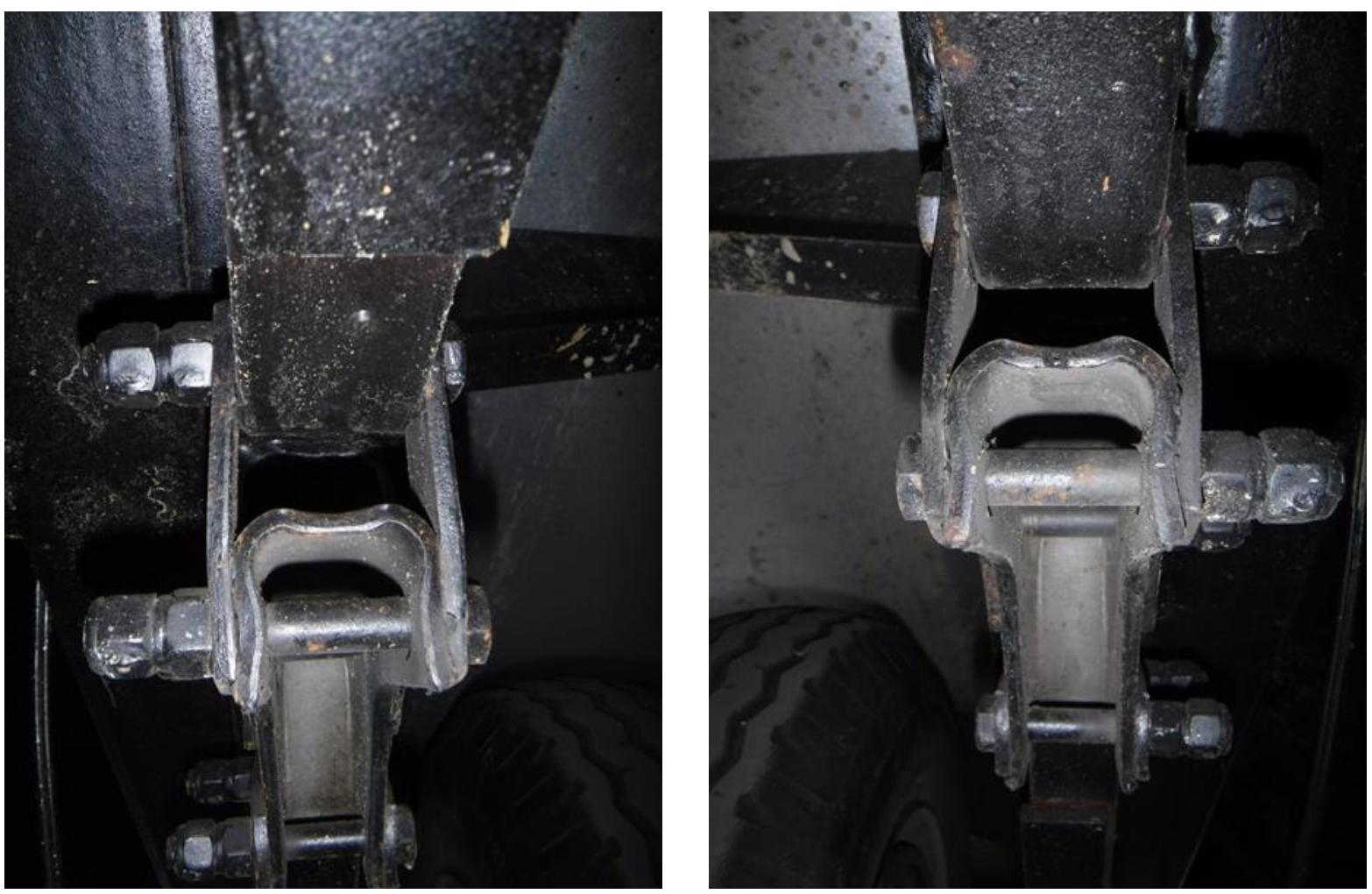

Figure 19. Bent and Distorted Shackles. 

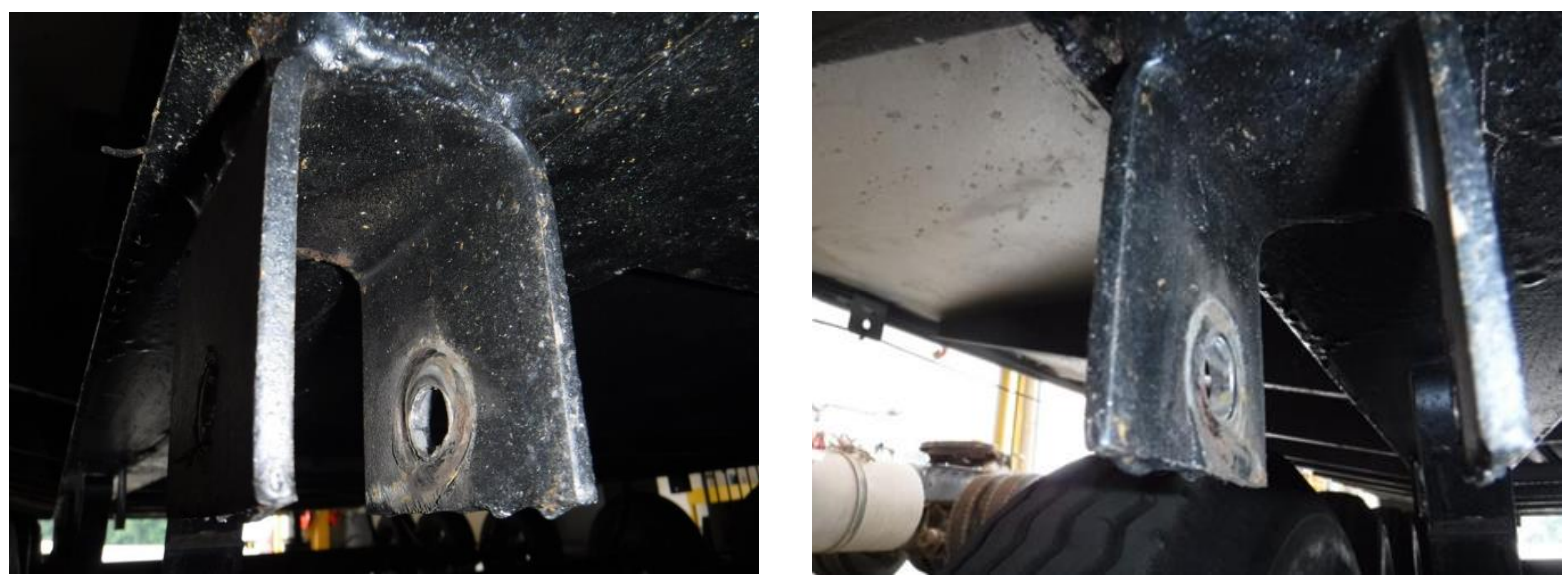

Figure 20. Distorted and Chaffed Spring Hangers.
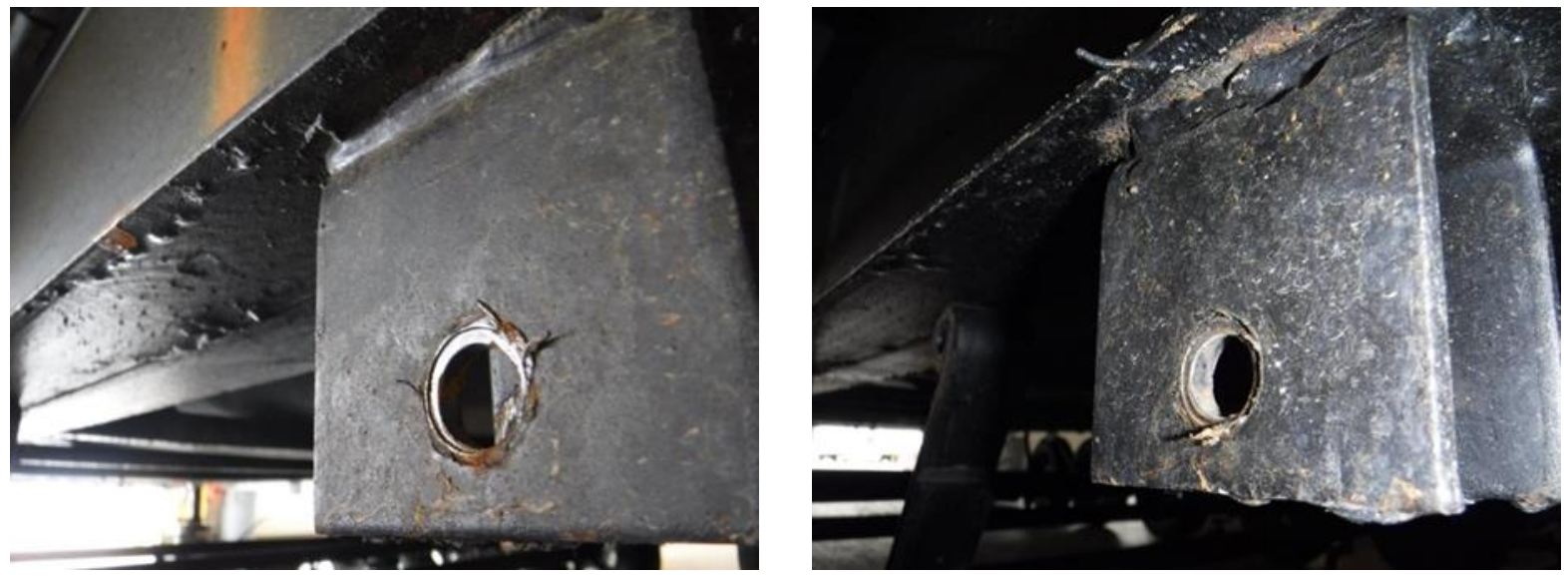

Figure 21. Wear and Indentation from Bolt Heads. 

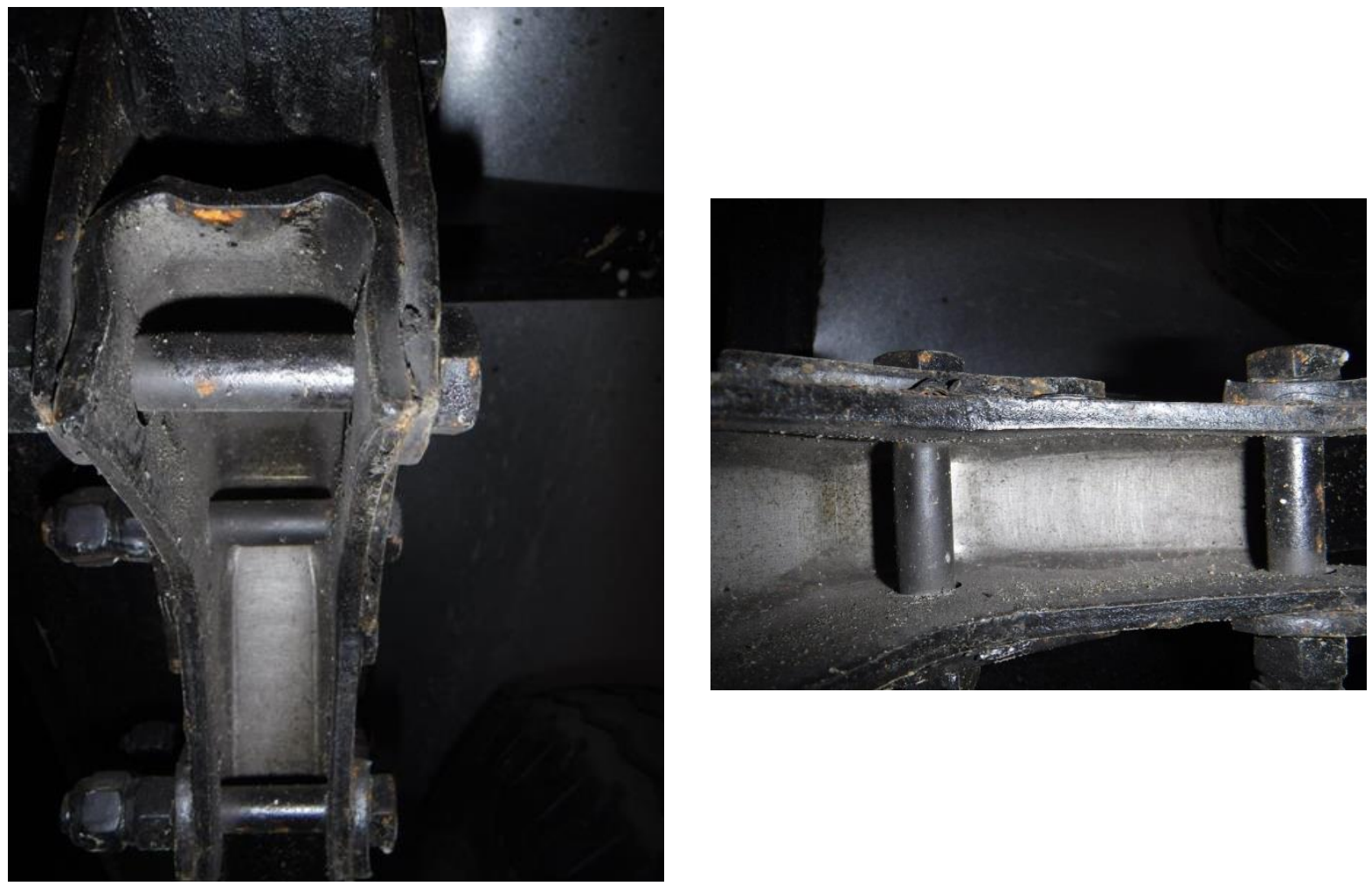

Figure 22. Distorted Spring-eye Bushings Due to Mismatch between The Diameter of The Bushing and That of The Fastener (Smaller Diameter).

\subsection{TESTING}

The new hardware was installed on both test units, with all the outfitting and vehicle instrumentation work completed by June 25, 2018. Testing started on June 27, 2018.

\subsubsection{Part A: Calibration Testing}

In Part A, 100 miles of data were collected on both the baseline and upgraded unit. The purpose of this testing was to confirm that all sensors were working, the data was received in a useable format, and the data extraction and parsing procedures developed were working correctly. Once that was confirmed, the preliminary analysis consisted mainly of data spot-checks as shown below.

\subsubsection{GPS Data}

In the full analysis task, the GPS data was used to extract and identify short single-loop time segments for frequency analysis, comparing the baseline and upgraded MHUs as explained above. For this preliminary data check, a short interval of latitude and longitude data was plotted. That plot was used to identify the coordinates of points $\boldsymbol{P}_{0}, \boldsymbol{P}_{1}$, and $\boldsymbol{P}_{2}$ (see Figure 2) as well as the start and end points of the rough-road track. 


\subsubsection{Accelerometer Data}

The accelerometer data was also examined. For this preliminary analysis, three-minute segments of data from one hour into the testing were used. This corresponds to approximately a single loop on the track for each vehicle.

Figure 23 shows data from the sensor located at the center of the baseline unit, while Figure 24 shows data from that corresponding sensor location on the upgraded unit. In each figure, the top plots show the raw sensor data during that three-minute period, and the frequency analysis for that segment is shown underneath. Consistent $\mathrm{X}$ - and $\mathrm{Y}$-axis limits are used for each set of figures to facilitate comparisons. The plots that follow (Figure 25 and Figure 26) show the frequency response for the three-minute segments broken out by individual sensor. A consistent scale was used for all of these figures to facilitate comparison. Error! Reference source not found. shows similar plots as those of Figure 23 to Figure 26, but for the other five sets of accelerometers.

No anomalies were detected in the data collected when the initial Part A analysis was conducted, and therefore it was deemed that all the sensors and data collection equipment were working according to test plan. Therefore, the tests entered its second phase (Part B: Extended Testing).
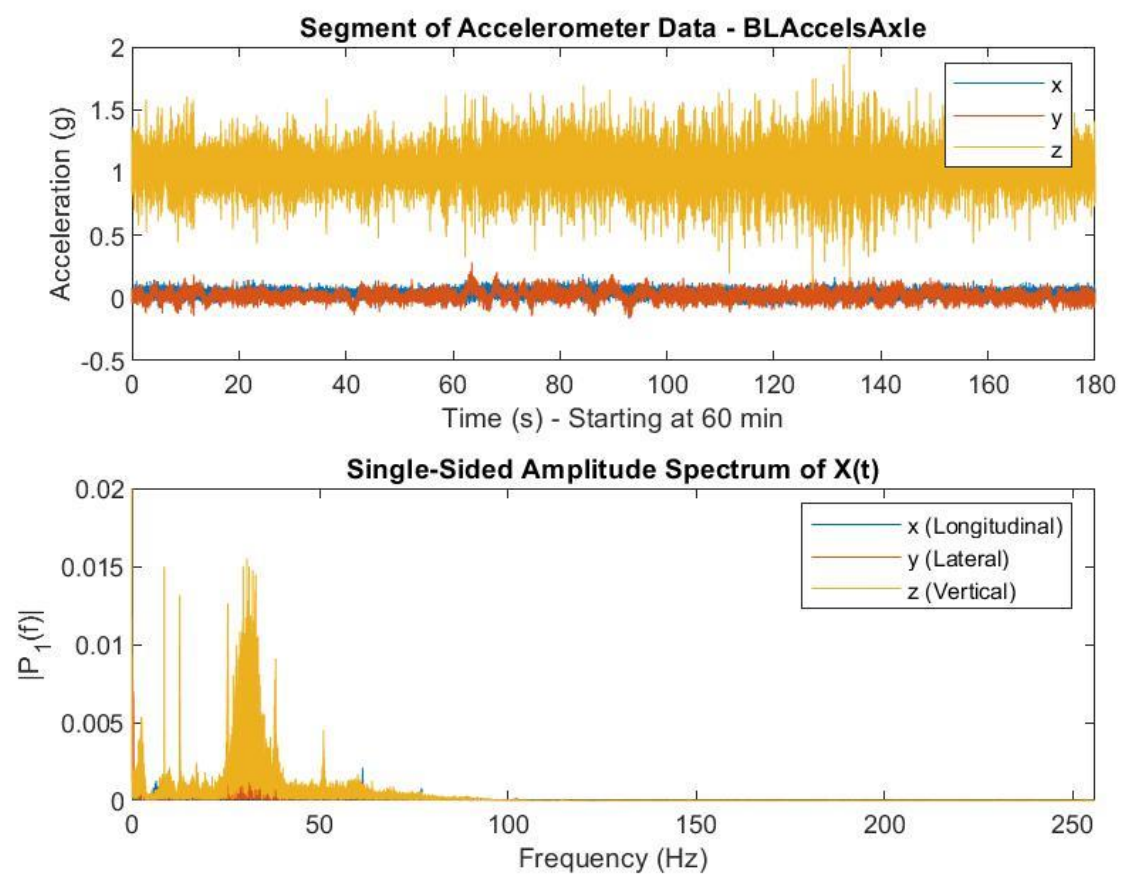

Figure 23. Segment of Accelerometer Data at the Axle Group $(x=$ Longitudinal, $y=$ Lateral, $z=$ Vertical $)-$ Baseline Unit. 

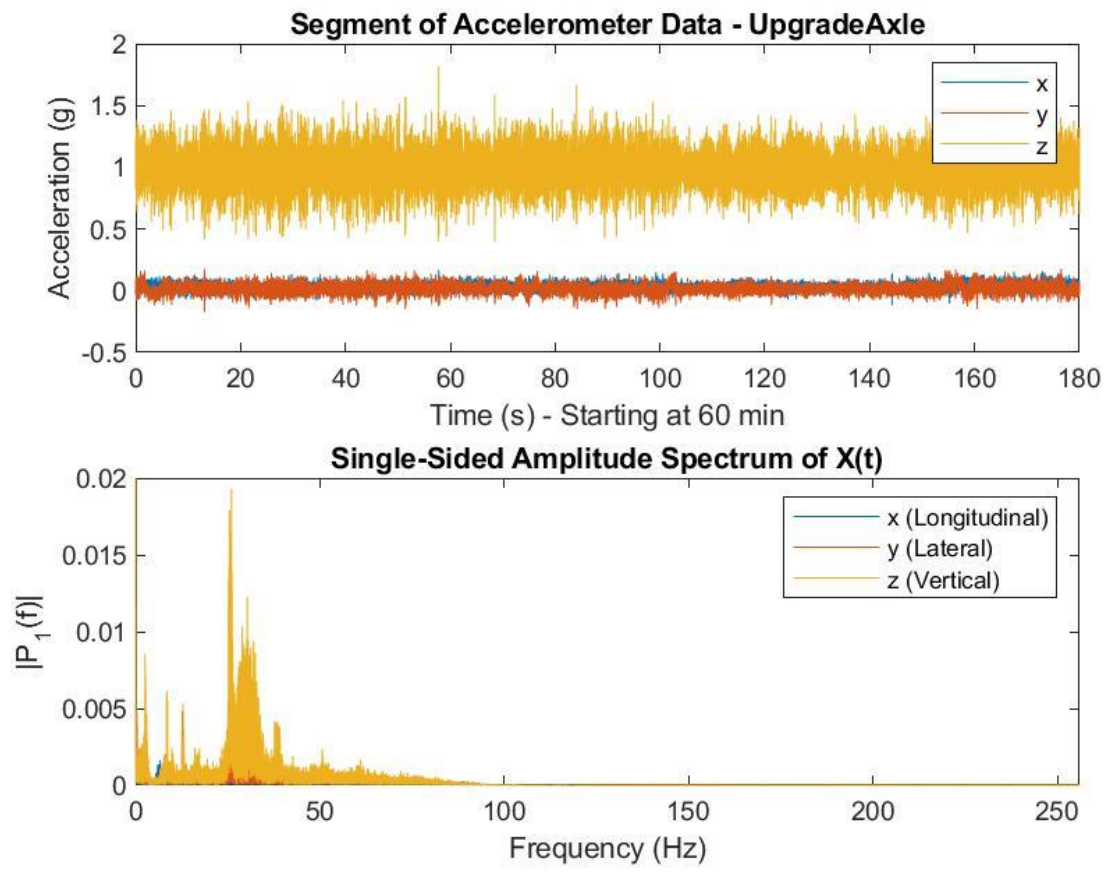

Figure 24. Segment of Accelerometer Data at the Axle Group $(x=$ Longitudinal, $y=$ Lateral, $z=$ Vertical $)-$ Upgrade Unit.
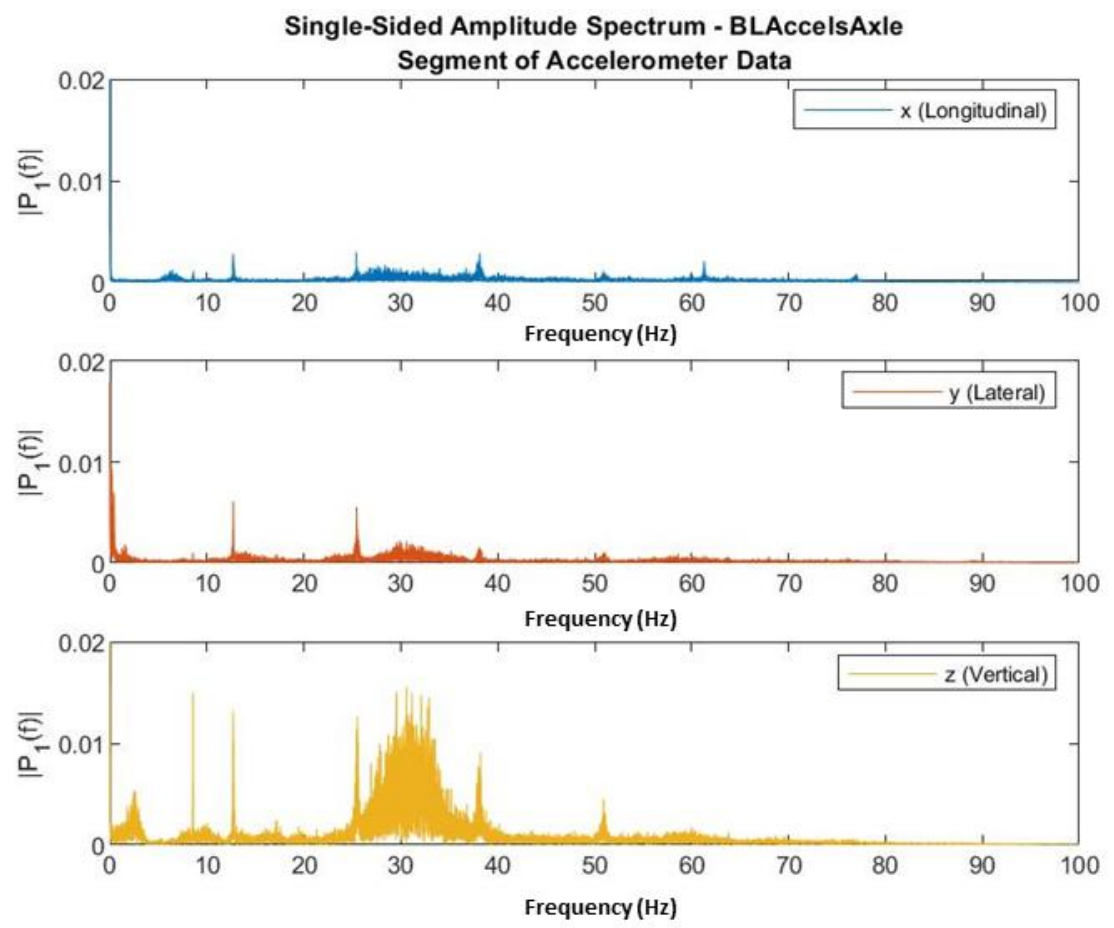

Figure 25. Frequency Distribution of Accelerometer Data at the Axle Group (3-Minute Segment) Baseline Unit. 

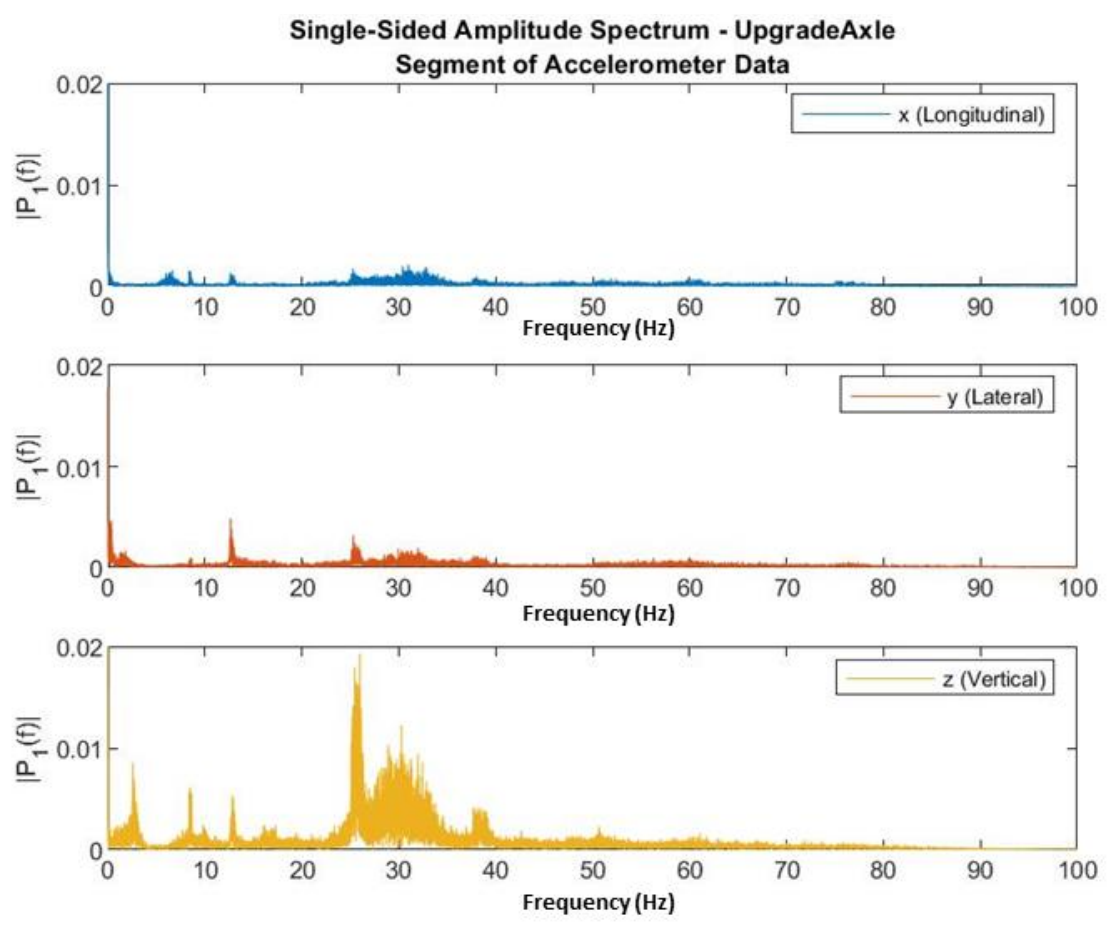

\section{Figure 26. Frequency Distribution of Accelerometer Data at the Axle Group (3-Minute Segment) - Upgrade Unit.}

\subsubsection{Part B: Extended Testing}

The main objective of the Part B test was to collect data similar to that of the main longevity test (Part C) in the manner planned for this longer test. Additionally, the Part B 500-mile test data was analyzed to confirm that the proposed data analysis methodology was feasible and provided the expected results.

\subsubsection{Basic Data Checking}

The most basic analysis tool developed to assist in evaluating the Part B data analysis was a MATLAB script to generate time histories and histograms of each file containing accelerometer data. These plots could be quickly inspected to confirm that no accelerometer data was missing and that the sensors were without offset or zeroing error. The abbreviations specified in Table 1 are used in the graphs presented below.

A sample time-history graph for one of the baseline unit data files is shown in Figure 27 below. As expected, the $\mathrm{X}$-axis and $\mathrm{Y}$-axis signals begin and end with a fairly stable value around $0 \mathrm{~g}$, which then varies as the vehicle is in motion. The $Z$-axis signals have a similar shape centered around $1 \mathrm{~g}$. Any extended-period stops (e.g., to change a tire) during the time represented in time-history graphs would also be apparent. 

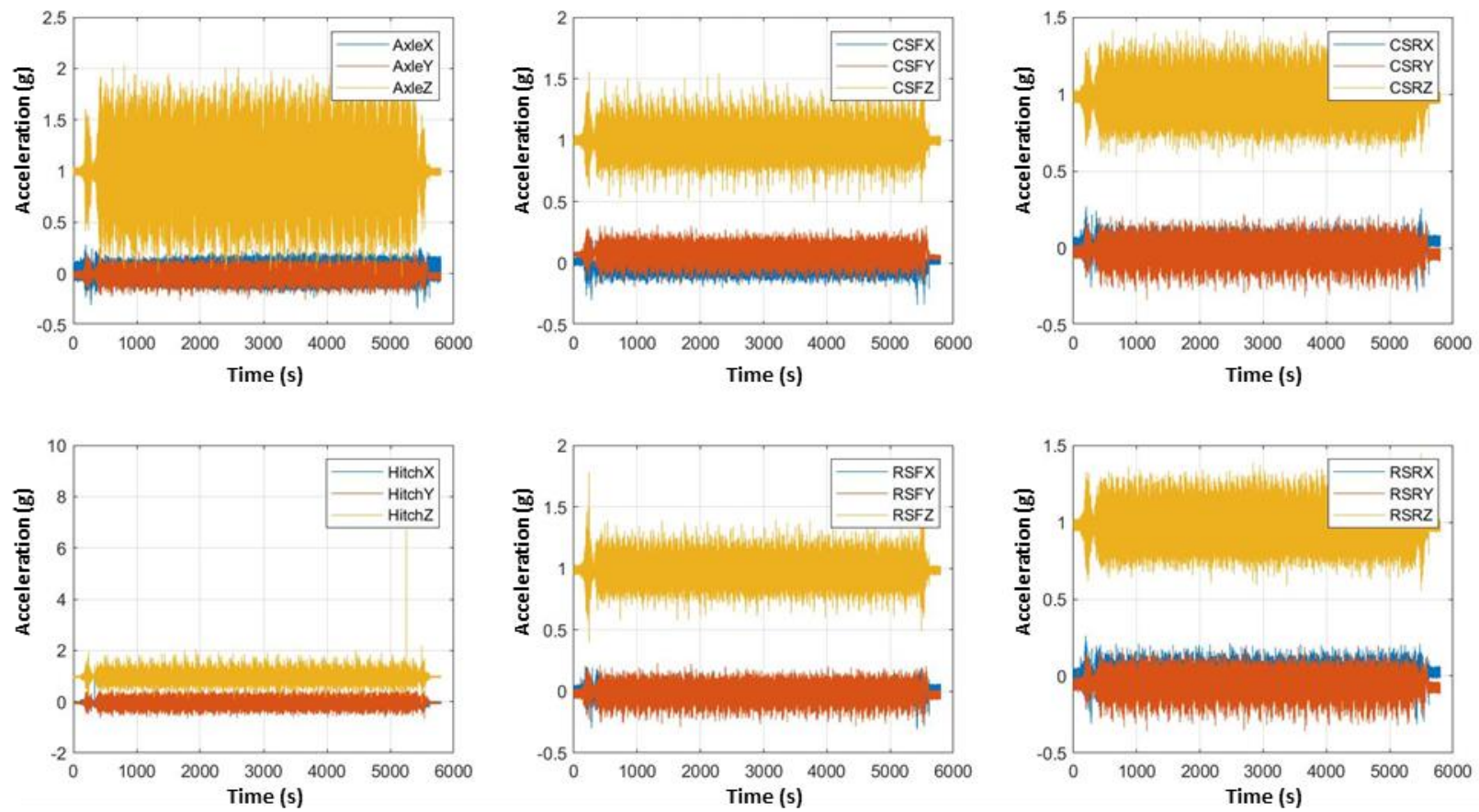

Figure 27. Segment of Baseline Unit Accelerometers Time History Data $(x=$ Longitudinal, $y=$ Lateral, $\mathbf{z}=$ Vertical).

The corresponding histograms for this sample data file are shown below in Figure 28. As mentioned above, the $\mathrm{X}$-axis (blue) and $\mathrm{Y}$-axis (red) signals should be centered at $0 \mathrm{~g}$, and the $\mathrm{Z}$-axis (yellow) signals should be centered at $1 \mathrm{~g}$. The distributions for the hitch accelerometers (lower left-hand corner) cover a wider range of accelerations than the other distributions due to the brief high-value acceleration experienced at that location (see the HitchZ value at about 5,200 seconds in the lower left plot of Figure 27 above). 

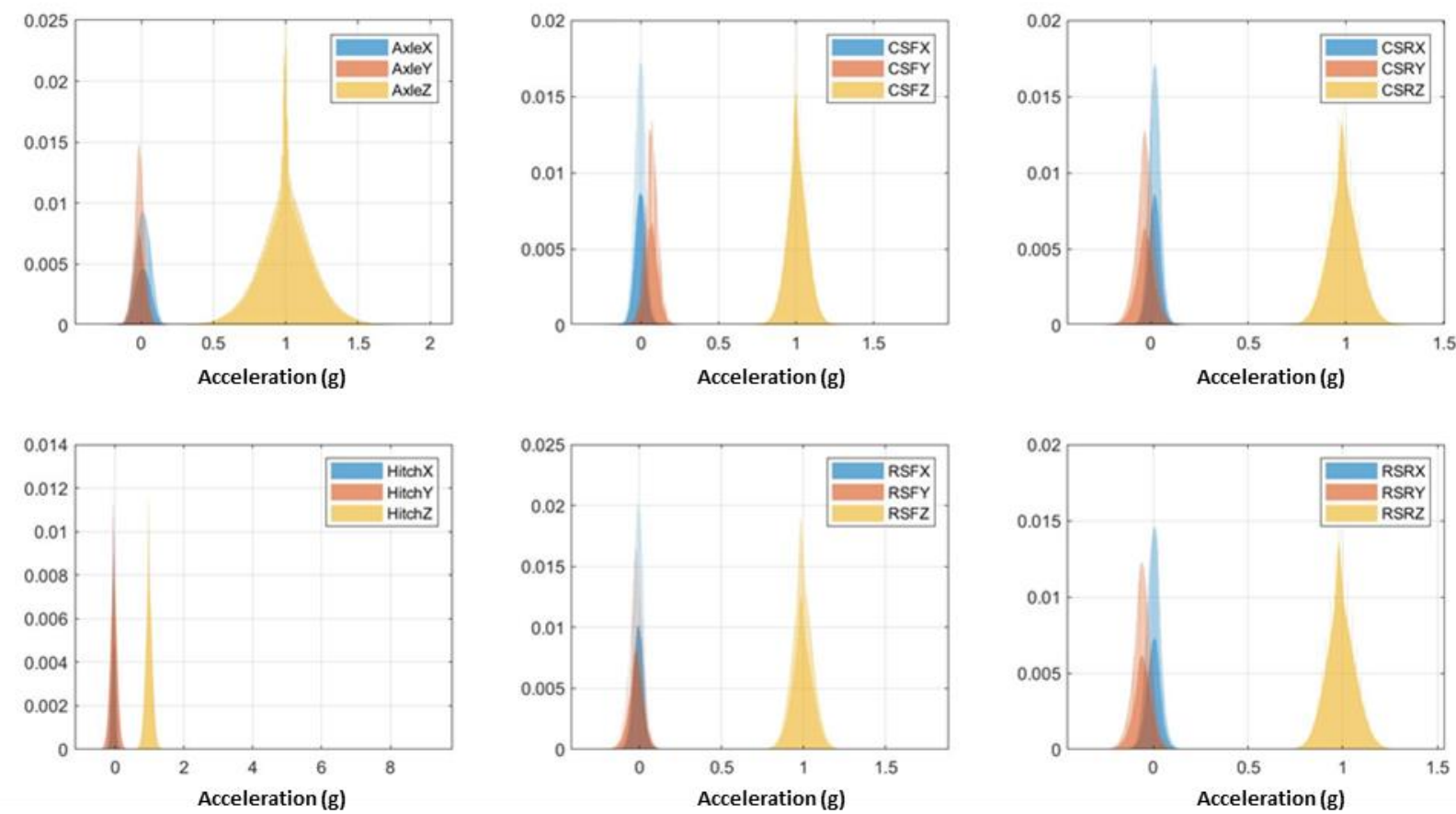

Figure 28. Baseline Unit Acceleration Distributions ( $x=$ Longitudinal, $y=$ Lateral, $\mathrm{z}=$ Vertical $)$.

These plots revealed some minor zeroing issues with a few of the Y-axis sensors (in red) at the curbside front (top center), curbside rear (upper right), and roadside rear (lower right). The other acceleration reading(s) distributions were as expected. The widest range of accelerations was observed along the $\mathrm{Z}$ axis, as expected, with the most extreme accelerations observed at the hitch. Adjustments to the sensors that needed zeroing were made before the start of the Longevity Testing phase.

Summary plots such as those shown above were also generated and inspected regularly during the Part C data collection as data was received, in order to confirm continued functionality and calibration of the accelerometers.

\subsubsection{Extraction of Data Segments Using GPS Data}

The GPS data was used to extract two categories of synchronized accelerometer data from the baseline and upgraded units. The first category of data segments was from the test track itself. Single data segments representing one lap of 60-mph travel (approximately 3 minutes each) were extracted for approximately every hour of travel in Part B. As explained above, this was later changed since it required the drivers to activate the triggering software at the start of each two-hour tests, which proved to be a test protocol difficult to follow. The new protocol called for continuously collecting data and parsing it in a post-processing task. The second category of data segments extracted (besides loop data) was for the "rough road" travel to and from the track. 


\subsubsection{Frequency Analysis}

Each segment identified for analysis from the data collected in Part B was processed to calculate a Root Mean Square Amplitude (RMS) value of the acceleration (in $\mathrm{g}$ ) for each sensor location. ${ }^{4}$ This provided a set of 18 numbers for each data segment (one for each sensor) that could be used to compare the forces experienced by the baseline unit to those of the upgraded unit. This analysis is illustrated in Figure 29. Each segment was given a unique identifier - in this case, the Part B baseline unit data is shown for lap 20, thus the label BB20. The plot in the upper-left-hand corner of Figure 29 is of the simple time history data. Below that is the Fast Fourier Transform (FFT) of this data. The FFT shows the approximate amplitude of each frequency component of the time history signal-in this case $0-256 \mathrm{~Hz}$. These values are used to determine the power represented by each of these components, shown in both decibels (upper right) and in a linear scale (lower right). For each of these 18 traces, the area under the curve is GRMS value.
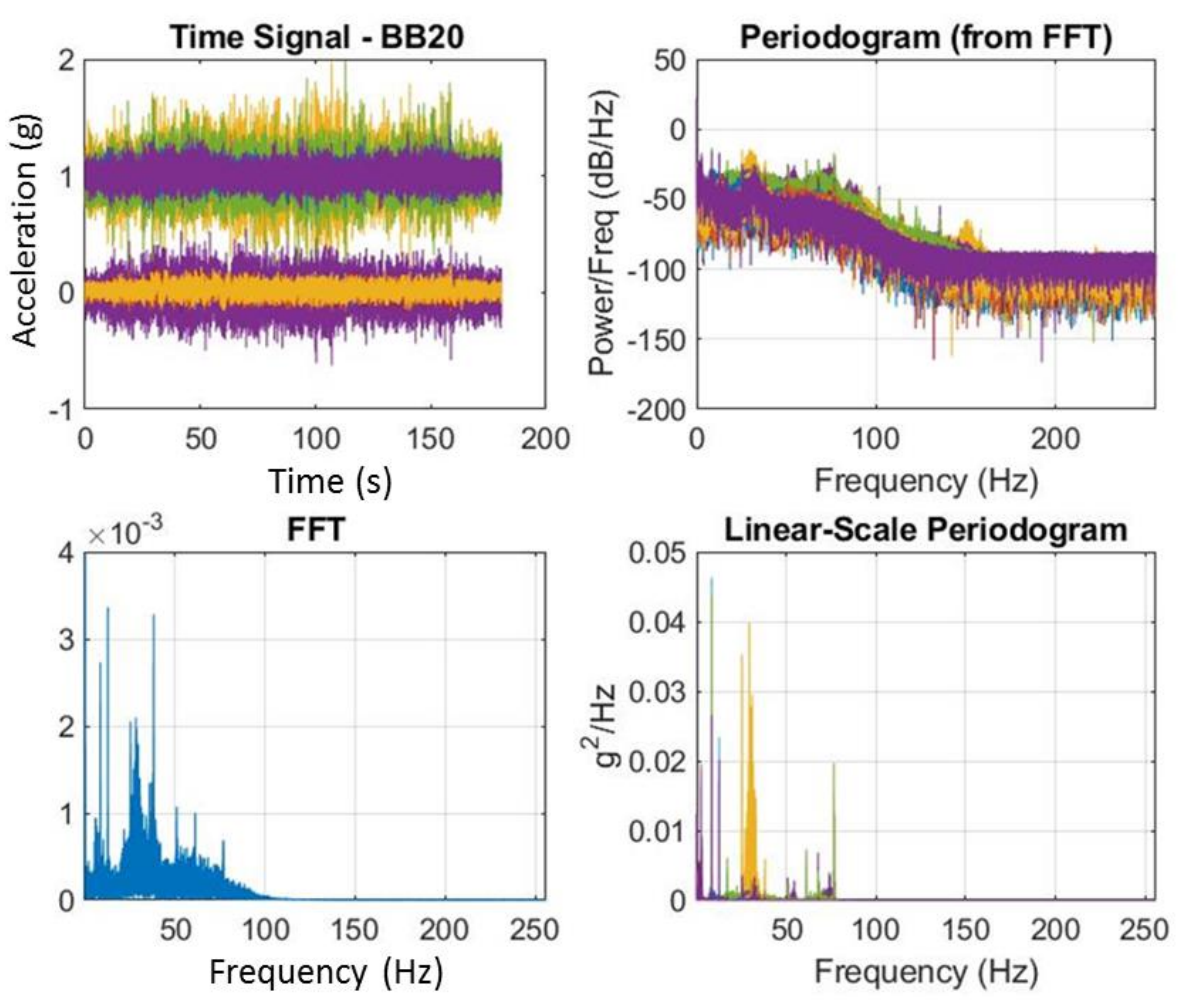

Figure 29. Illustration of Frequency Analysis for Part B Baseline Unit Lap 20.

These GRMS values are calculated for each sensor for each selected segment. In order to avoid errors introduced by zeroing problems, the calculation omits frequencies below $0.1 \mathrm{~Hz}$. A summary of these values for the $\mathrm{Z}$-axis sensors at the axle group is shown for the analyzed lap data in Table 9. The laps shown in the table were selected about every sixty miles. As described earlier, the average speed of each lap was computed and used to control for the "speed" differentials between the two units which may affect the observed vibrations and therefore the observed accelerations. That is, laps where the difference in this parameter between the baseline and upgrade units was very small were selected.

\footnotetext{
${ }^{4}$ The root mean square (RMS) value of the accelerometer signals is calculated by computing the square of the signal at every point, finding the mean (average) value of the squared magnitude, and then taking the square root of the average value. The resulting number is the what is known as the GRMS metric.
} 
Table 9. GRMS Values for Selected Part B Lap Accelerometer Data at the Axle Group

\begin{tabular}{|l|c|}
\hline \multicolumn{2}{|c|}{ Baseline Unit } \\
\hline \multicolumn{1}{|c|}{ Identifier } & Axle Z GRMS \\
\hline BB20 & 0.1642 \\
\hline BB39 & 0.1638 \\
\hline BB58 & 0.1600 \\
\hline BB77 & 0.1648 \\
\hline BB101 & 0.1849 \\
\hline BB127 & 0.1942 \\
\hline BB146 & 0.1847 \\
\hline BB161 & 0.1811 \\
\hline
\end{tabular}

\begin{tabular}{|l|c|}
\hline \multicolumn{2}{|c|}{ Upgraded Unit } \\
\hline \multicolumn{1}{|c|}{ Identifier } & Axle Z GRMS \\
\hline BU20 & 0.1692 \\
\hline BU39 & 0.1721 \\
\hline BU58 & 0.1732 \\
\hline BU77 & 0.1759 \\
\hline BU101 & 0.2006 \\
\hline BU127 & 0.1949 \\
\hline BU146 & 0.2105 \\
\hline BU161 & 0.2213 \\
\hline
\end{tabular}

In Table 9, the upgrade unit appears to experience higher accelerations than the baseline unit for equivalent data segments. Ultimately, a statistical test was performed in order to confirm or reject that this was the case (see the Analysis of Vehicle Vibrations section).

\subsubsection{Part C: Longevity Testing}

Part $\mathrm{C}$ of the testing was the main data collection effort. Data from this phase was used to statistically analyze and compare the two alternatives (i.e., current transportation system-Baseline Unit - vs. improved transportation system-Upgrade Unit) using the sensor suite refined from Part A and Part B testing and the data collection and analysis methodology refined in Part B.

Initially, Part $C$ was organized into two stages. In the first stage, the vehicles would run 4,200 miles, which together with the 600 miles already accrued in Part A and Part B would total 4,800 miles. Conditional on the failure rates observed in this first stage, a second stage of 4,800 miles could be implemented.

The data collection for Part C started in earnest on July 27, 2018. The data collection and distribution protocol used in the previous two parts was implemented in Part C as well. Similarly, the software developed for parsing the data into single laps, synchronizing these laps between the two units, and running the Fast Fourier Transform methodology that were developed for Part A and tested and debugged in Part B were used to process the data as it was received in Part C. In general, and because of the testtrack exclusivity need (due to test vehicles running clockwise during some part of the test and counterclockwise during the rest) the data was collected during evening and/or midnight shifts and uploaded next morning. Once the data was uploaded and the notification of such event received, ORNL researchers parsed and processed the data. Plots were created to visually determine that all the sensors were working as expected.

During the first two days of the Part $\mathrm{C}$ testing, the data collection protocol was changed from collecting data every hour for five minutes (burst regime) to collecting the data continuously (continuous regime). As explained above, the drivers needed to start the software that would collect data at given intervals. If that software was not started, then no data was collected. The first time this happened, it was decided to change the data collection protocol from "burst" to "continuous" data collection. The files were downloaded from the data acquisition system every time the drivers stopped for a break (usually, every two hours).

Also, during the first two days of testing it was observed that the Upgrade Unit started to have unusual tire failures, including frequent blowouts. Those happened at two specific axle ends. It was decided to stop the test and inspect more closely the unit, which resulted in determining that some of the wheel-ends were not perpendicular to axle tubes. This resulted in the tires not rolling freely and causing the failures 
observed. New axles were ordered and installed in the Upgrade Unit. More details about this issue are included in APPENDIX B.

As it was standard procedure, the data collected for both the Baseline and Upgrade units was plotted. Figure 30 and Figure 31 show the GRMS for the vertical accelerometer at Axle Group for each lap for day 1 and 2 of Part $C$ (the vertical line in the center of each chart indicates the separation between day 1 and 2). The horizontal axis in these two figures, as well as in all similar figures included in this report, shows the cumulative miles traveled by the units on the test oval. It starts at 0 and increases by 3 miles (i.e.; the length of the NPG test oval) with every lap completed. Because it does not show the actual vehicle odometer miles, it was labelled as "Pseudo-odometer."

Figure 30 shows an oscillating behavior of the vertical GRMS measure corresponding to the direction of travel (clockwise - CW - or counter-clockwise- CCW). The Baseline Unit did not show a similar behavior in day 1. However, on day 2 it looked as if the Baseline Unit had developed the same behavior as the Upgrade Unit (compare Figure 30 and Figure 31 for day 1 and day 2). This observation triggered an inspection of the Baseline Unit, focusing on the alignment of the axles. Although no problems were found, the decision was made to replace the tires (since the Upgrade Unit would also get new tires with the newly installed axles) and run a small test of 20 laps to determine whether the problem persisted.

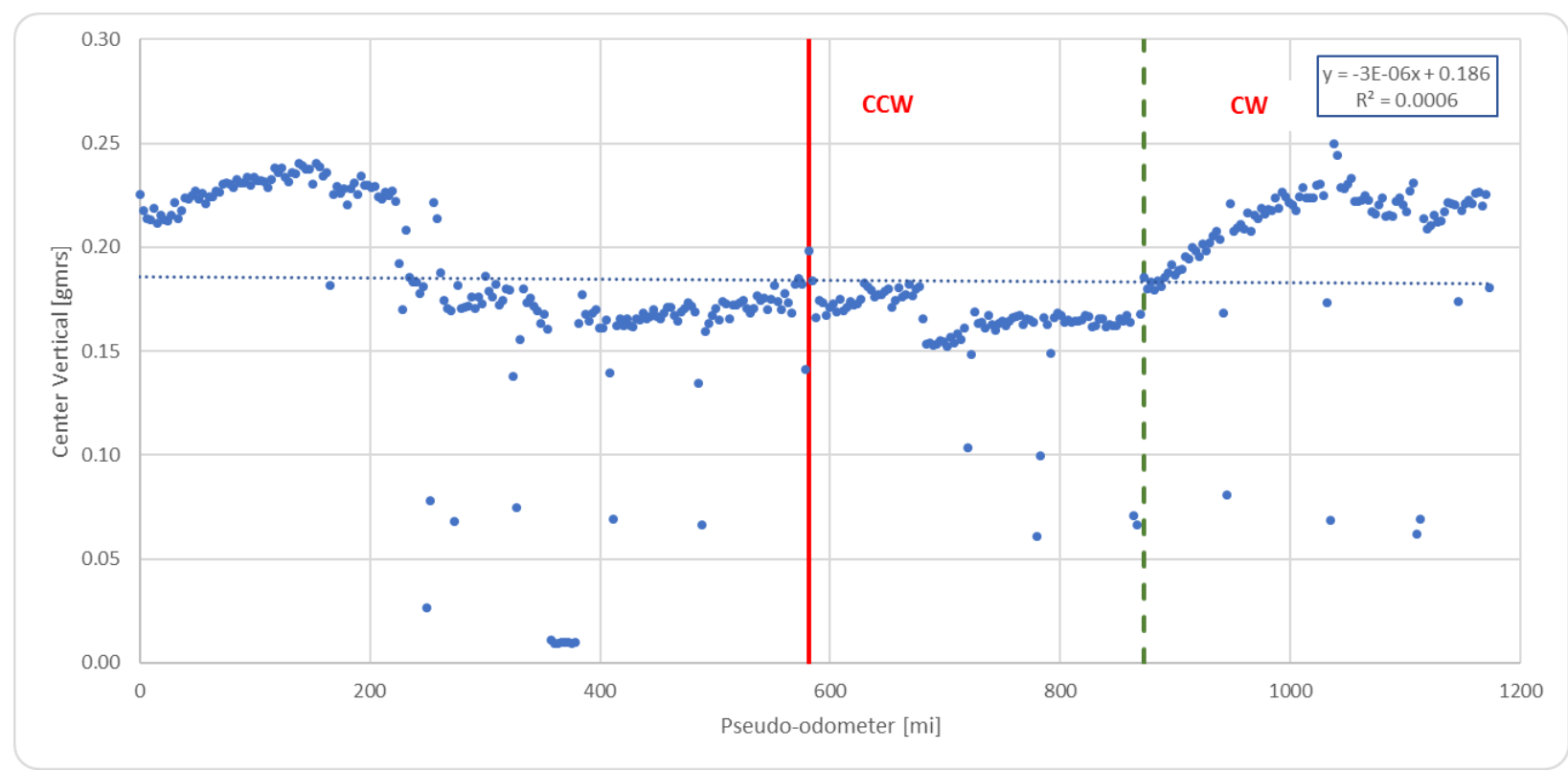

Figure 30. Upgrade Unit - GRMS for Vertical Accelerometer at Axle Group (Center). 


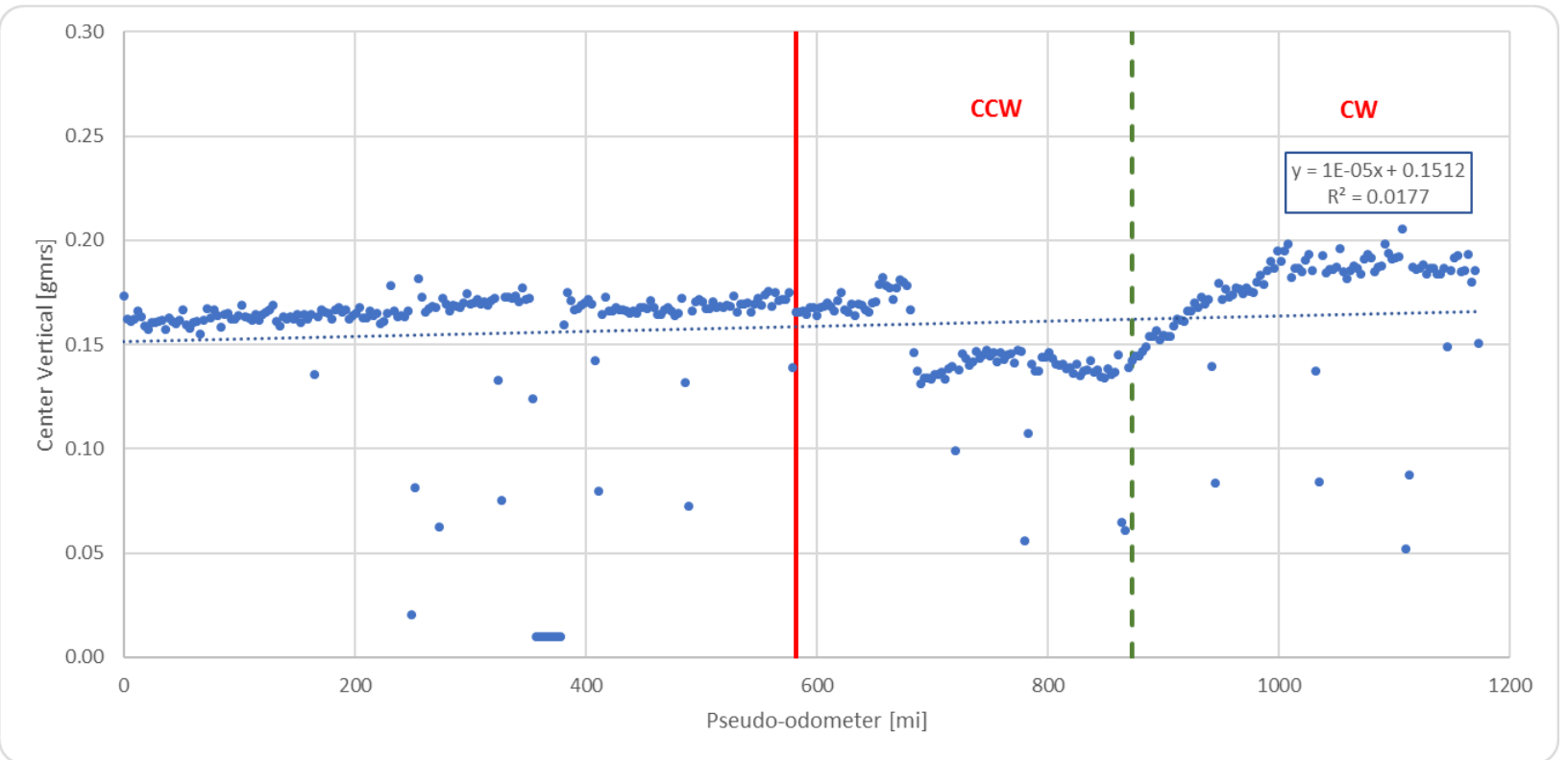

Figure 31. Baseline Unit - GRMS for Vertical Accelerometer at Axle Group (Center).

Besides replacing the Baseline Unit tires for the short test, an additional vertical accelerometer was installed at the center of the unit. This accelerometer was attached directly to the floor of the unit; the first accelerometer was also on the floor but attached to a wall. ORNL requested this installation to try to understand whether structural movements when traveling in one direction versus the other direction were causing the observed differences in the associated vertical GRMS measures.

The short 20-lap test showed only minor differences between the data collected when traveling in a CW direction and that corresponding to the $\mathrm{CCW}$ direction. In both cases, the second vertical accelerometer registered slightly higher readings than the first one. One possible explanation for this observation was that the second accelerometer, being screwed directly into the floor, was subject to flexing of the flooring materials while traveling, which could have resulted in slightly higher vibrations and thus in slightly higher readings. Since there were no other apparent differences between the first and second accelerometers (except in the magnitude of the measurements), it was decided that the latter was not necessary since it did not add any new insights. Figure 32 and Figure 33 show the results of the short test for accelerometers 1 and 2 . 


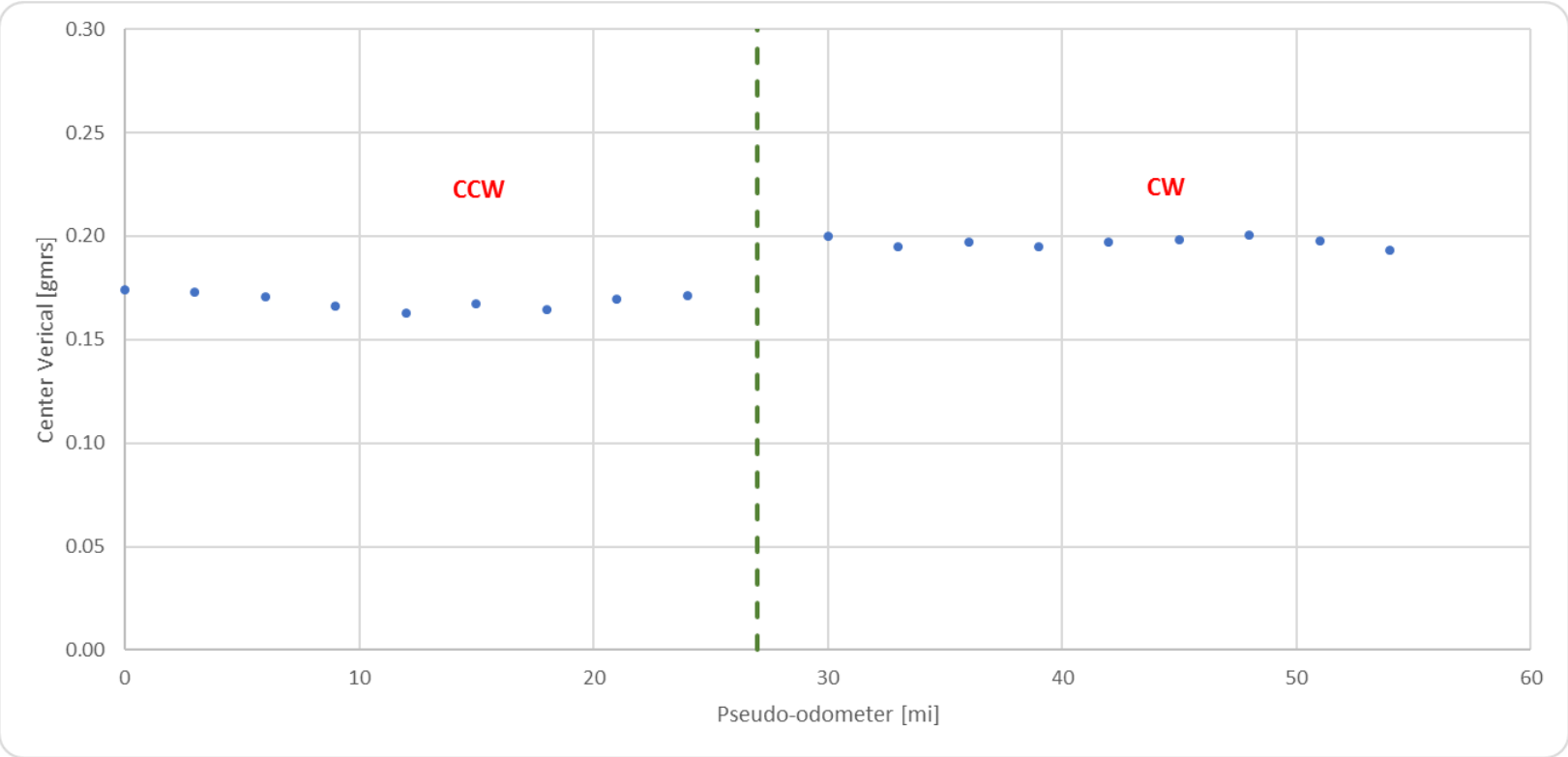

Figure 32. Baseline Unit - GRMS for Vertical Accelerometer 1 at Axle Group (Center) Short Test with New Tires.

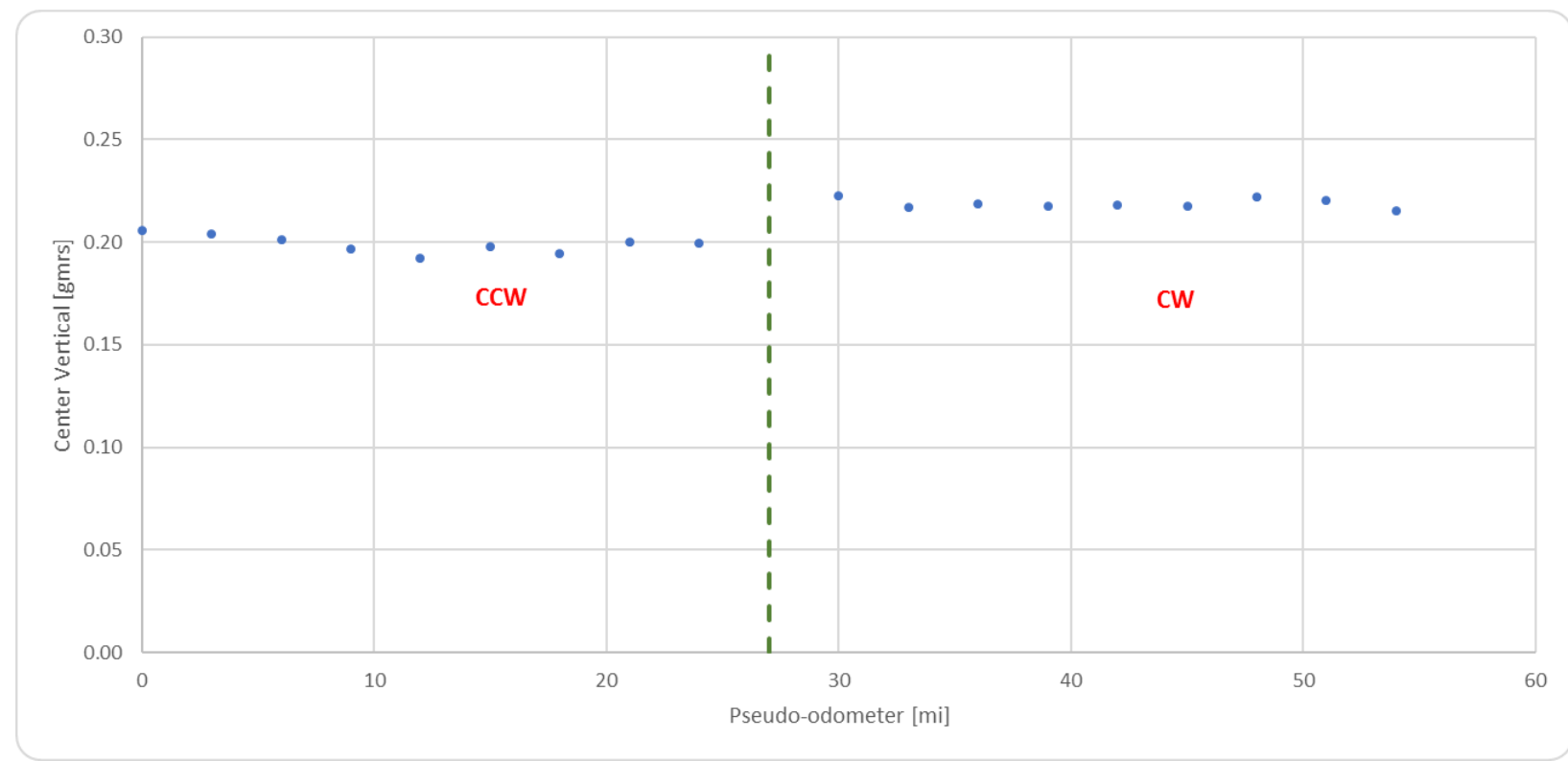

Figure 33. Baseline Unit - GRMS for Vertical Accelerometer 2 at Axle Group (Center) Short Test with New Tires.

Once the Upgrade Unit was outfitted with new axles and new tires, 20 laps were run so it was at the same level as the Baseline Unit regarding tire wear. Data from the first two days of Part $\mathrm{C}$ data collection were discarded since otherwise the comparison between the Baseline and Upgrade units would have been biased towards the former. Data collection for Part C: Longevity Testing started on day 3. Because approximately 1,200 miles of collected data had to be discarded from the analysis (in addition to the 1,200 miles collected in Part A and Part B), it was then decided that the additional 4,800 miles would be 
run, for a total of approximately 7,200 miles (7,296 miles to be precise). Part $\mathrm{C}$ was completed over 12 days.

\subsubsection{Part D: Radial Tires Testing}

The main objective of the Part D test was to collect data similar to that of the main longevity test (Part C) but only for the Upgrade Unit equipped with radial tires instead of regular tires. Part D was completed over four days and 2,448 miles of data were collected. This data was used in the analysis to compare the effect of these two types of tires on the vibrations experienced by the unit while traveling. 


\section{DATA ANALYSIS}

This section describes the data analysis procedures and results. The General Statistics subsection presents general statistics for the four stages into which the test was divided. These include a summary of the laps that were run at the test track (including test date, number of laps run, direction of travel, number of miles accrued, and were available, fuel efficiency achieved) as well a summary of tire failures (including failure date, tire location by axle and side, and type of failure).

The following subsection (Analysis of Tire Failure Rates) concentrates on the analysis of tire failures during the test, comparing the a-priori expectation of the failure rates (i.e., empirical observations made by companies that routinely transport these manufactured housing units) with the rates observed in the test. The statistical tests also compare the observed failure rates for both the Baseline Unit (where no changes were made to the transportation hardware) and the Upgrade Unit (where a new suspension system was added). Comparison of failure rates were also performed to contrast regular tires and radial tires (Upgrade Unit only).

The third part of this chapter, Analysis of Vehicle Vibrations, focuses on the effect that the proposed improvements have on the vibration of the MHUs while being transported. Data was collected using accelerometers, permitting an estimation of the energy transmitted to the MHU by the transportation system while in transit, is used to conduct statistical tests of hypothesis to determine if there were any differences in the distribution of these forces for the Baseline and Upgrade units.

\subsection{GENERAL STATISTICS}

The test was divided into four stages, as described in the previous chapter. The first stage, Part A, was run on June 27, 2018, and 34 laps were completed in the NPG oval, for a total of 104 miles. Three of these laps were selected at random to develop the data parsing software and the software to conduct the Fourier Transforms for the analysis. The data transfer to ORNL was also tested during this first phase.

Part B of the test was conducted on July 3, 2018, with 165 laps completed with a total of 503 miles traveled. Some of these laps were run during the early hours of the day, and the Baseline Unit hit a deer at one point during the testing. Minor damage was reported on the front bumper of the tractor. However, the biggest problem was that the on-board data acquisition system deployed on the Baseline Unit malfunctioned and no data was collected. This affected the vibration side of the data collection, since the methodology called for comparisons between the Baseline and the Upgrade Unit. Although this issue did not have an effect on the component failure data collection, the test was repeated on July 13, 2018, when 163 laps were completed for a total of 503 miles traveled. Of these 503 miles, 492 miles were accrued on the test oval and the remaining 11 miles by traveling back and forth from the garage area to the oval and back for each break period. (The drivers generally took a break every two hours of testing.) Figure 34 presents the GRMS values derived from the data collected by the vertical accelerometer located at axle group (center of the MHU). Notice that there are a few observations with low GRMS values; these correspond to the start lap of a testing cycle (i.e., after a break or a stop). Since the vehicles start from a slow speed and accelerate to achieve the target testing speed of $60 \mathrm{mph}$, the vibration during these types of laps was much lower. This type of behavior is present in all the graphs shown below, since they include all the test-oval laps. For the statistical analysis, these laps were filtered out.

Figure 34, as well as all the graphs presented below, also shows a linear fit of the data to give an idea of the general trend of the vibrations identified by the accelerometers. In this case, it is evident that the Upgrade Unit showed larger GRMS values than the Baseline Unit for any given lap. The reason for this 
was later on attributed to the identified "out-of-square" wheel-end to axle tubes of the Upgrade Unit as discussed in APPENDIX B, which was a manufacturing error at the axle manufacturer.

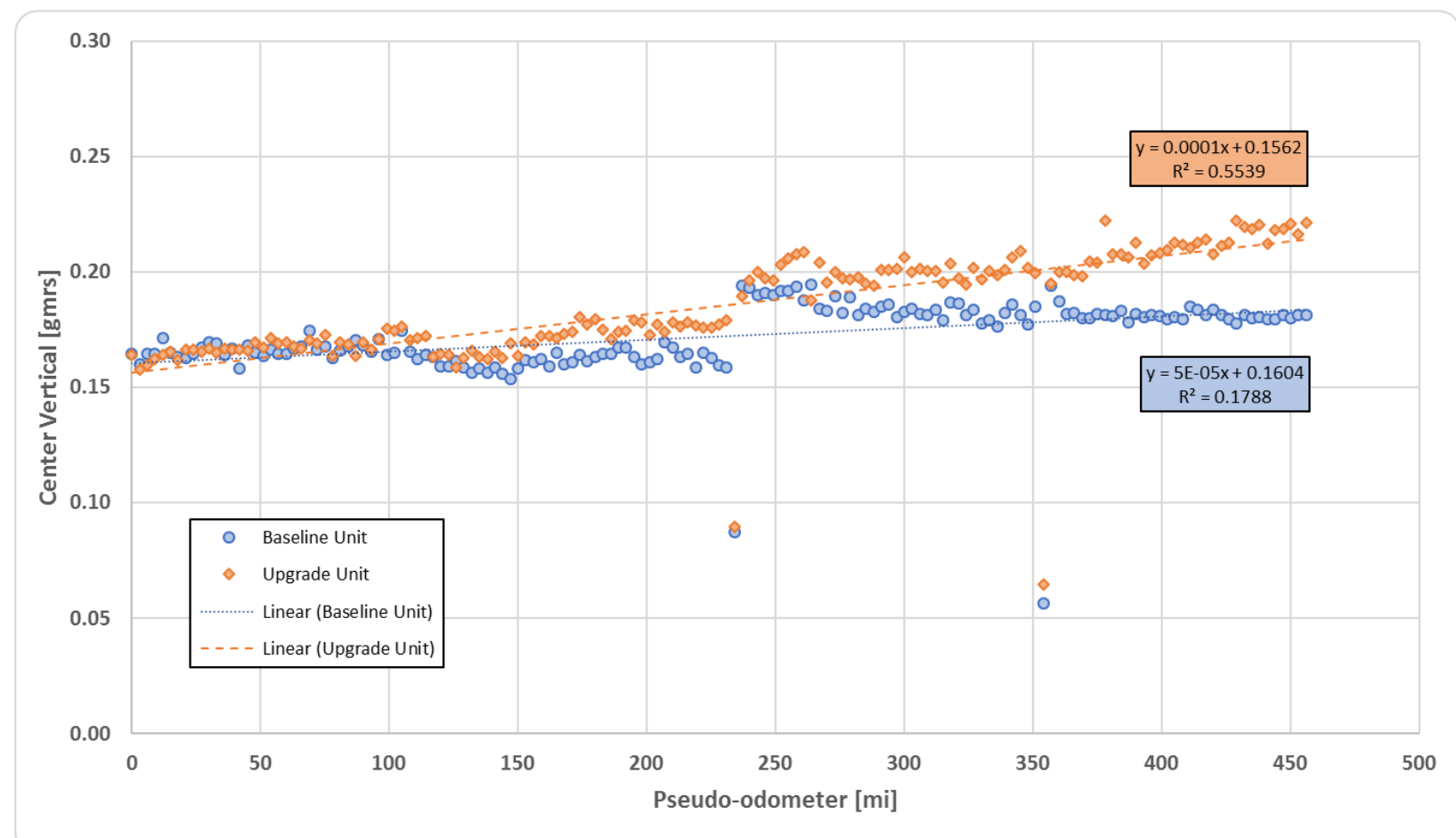

Figure 34. Part B Day 2 - Baseline and Upgrade Units GRMS for Vertical Accelerometer at Axle Group (163 Laps).

Since the data collection systems and procedures were working according to plan, Part C of the testing (i.e., the main testing regime) started on July 27, 2018. During the first day, 194 laps were run (567 miles), and on the second day of Part C, another 198 laps (599 miles) were completed. The data is presented in Figure 35. As in Part B, the Upgrade Unit showed significantly larger GRMS values for each lap compared to the Baseline Unit. Moreover, during these two days the tire failures of the Upgrade Unit started to grow disproportionately. It was then decided to stop the test and investigate whether there were any apparent reasons for the increase in tire failures. It was then discovered that some of the Upgrade Unit axle wheel-ends were "out-of-square" (see APPENDIX B for more details).

Table 10 presents summary statistics regarding number of laps, miles logged, and tire failures during Part A, B, and the first two days of Part C (Longevity Test); this initial Part C testing was labeled as Part C1. The last two columns of this table show the tire failures of the Baseline and Upgrade Units. Each tire failure event is indicated by a five-character code, where the first two places indicate the axle number (1 to 6) and the side (left or right) where the failure was observed, and the last two characters indicated the type of tire failure; a legend with a key for the last two characters is paced at the bottom of the table. During these three phases, the Baseline Unit had three tire failures (two flat tires and one tire showing a sidewall bulge) and the Upgrade Unit had nine (five blowouts, two tires with cord exposed, and two flat tires). 


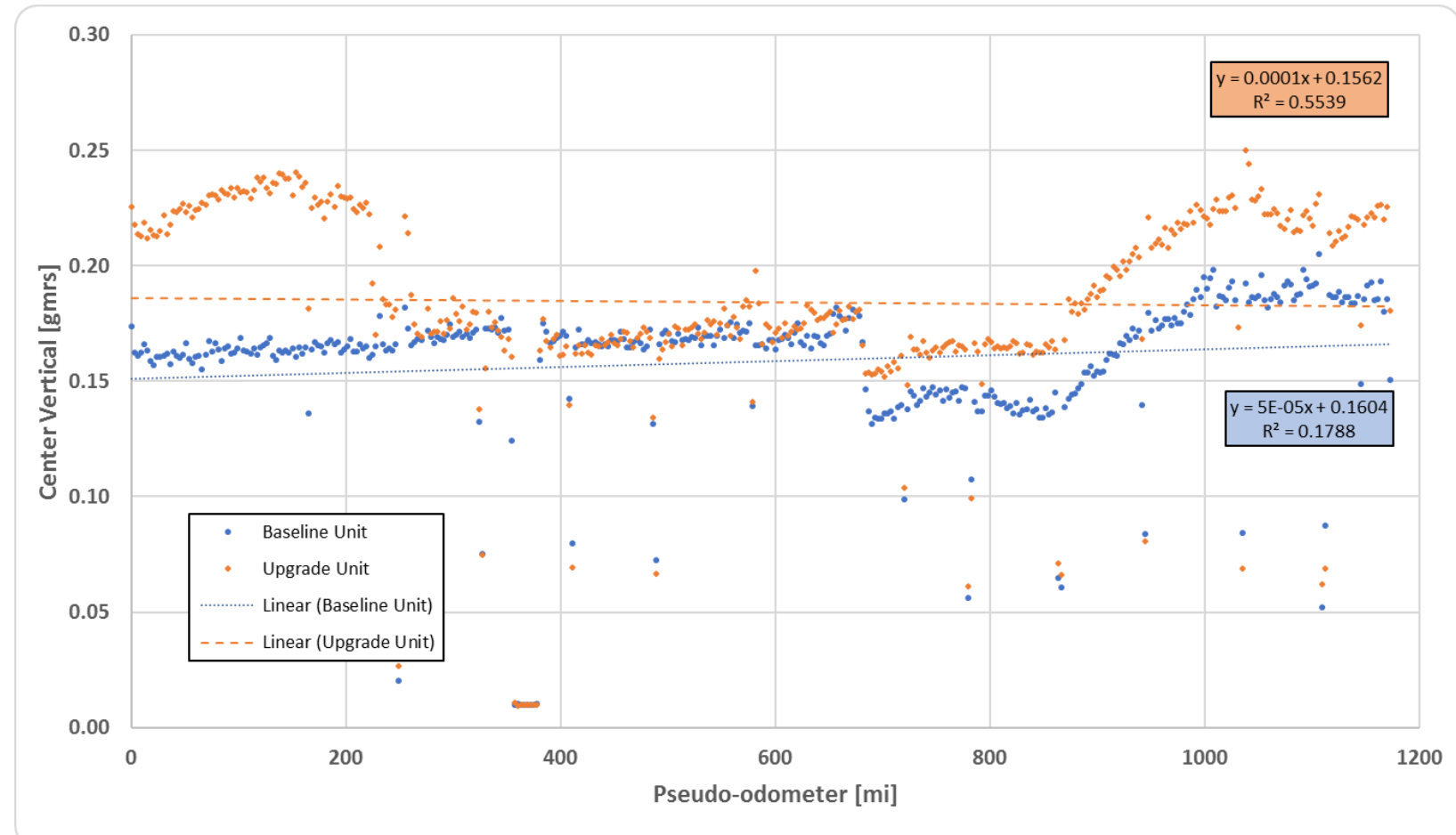

Figure 35. Part C1 (Days 1 and 2) - Baseline and Upgrade Units GRMS for Vertical Accelerometer at Axle Group (Center) 163 Laps.

Table 10. Summary Statistics for Part A, B, and C1 of Test

\begin{tabular}{|c|c|c|c|c|c|c|c|}
\hline \multirow{2}{*}{ Day } & \multicolumn{3}{|c|}{ Laps } & \multirow{2}{*}{$\begin{array}{l}\text { Total } \\
\text { Miles }\end{array}$} & \multirow{2}{*}{$\begin{array}{c}\text { Cumulative } \\
\text { Miles }\end{array}$} & \multicolumn{2}{|c|}{ Failures } \\
\hline & Total & CW & CCW & & & Baseline & Upgrade \\
\hline May $17-$ Jun 26 & N/A & N/A & N/A & & 0 & New Tires & New Tires \\
\hline A-01 $(06 / 27 / 18)$ & 34 & & 34 & 71 & 71 & None & None \\
\hline B-01 $(07 / 03 / 18)$ & 165 & 99 & 66 & 503 & 574 & None & 4R_BO \\
\hline B-02 $(07 / 13 / 18)$ & 163 & 81 & 82 & 503 & 1077 & None & 1L_CE \\
\hline C1-01 (07/27/18) & 183 & 98 & 85 & 567 & 1644 & None & 5R_BO; 5R_BO \\
\hline C1-02 $(07 / 31 / 18)$ & 193 & 99 & 94 & 599 & 2243 & $\begin{array}{l}\text { A1L_FL; A3R_FL } \\
\text { (nail); A6L_SB }\end{array}$ & $\begin{array}{l}\text { 1L_FL; 2L_FL; 4R_BO; } \\
\text { 6L_CE; 6R_BO }\end{array}$ \\
\hline C1-02' (08/29/18) & 20 & 10 & 10 & 124 & 2367 & New Tires & $\begin{array}{l}\text { New Axles and New } \\
\text { Tires }\end{array}$ \\
\hline Total & 758 & 387 & 371 & 2,367 & 2,367 & & \\
\hline
\end{tabular}

BO: Blowout; CE: Cords exposed; FL: Flat; SB: Sidewall bulge.

After new axles were ordered and installed in the Upgrade Unit and both units were equipped with new tires, the test resumed. Initially, a few laps (20) were run for both units, although not simultaneously, to determine that all the data collection equipment was working correctly, and that the replacement of the Upgrade Unit axles had fixed the observed problem (see next to last row in Table 10). Since this was the case, the longevity test restarted on September 12, 2018.

During this phase, 2,411 laps were run for a total of 7,315 miles logged. The test was run during 12 days during the period from September 12, 2018 to October 16, 2018. As specified in the test plan, 50\% of the laps were run in a clockwise direction (1,204 laps) and the rest in a counter-clockwise direction $(1,207$ laps). 
The data collected while running these 2,411 laps is presented in Figure 36, while summary statistics are shown in Table 11. As expected, (and contrary to what was observed in Parts A, B, and C1), in Part C2, the Upgrade Unit showed significantly lower GRMS values compared to the Baseline Unit for almost $100 \%$ of the laps run. At the end of the test, there was a slight degradation in the performance of the Upgrade Unit in terms of the vibrations transmitted to the MHU by the transportation system the as shown in the figure. However, the Upgrade Unit still presented lower GRMS values than the Baseline Unit, except during the next-to-last day of Part C2 test (October 15, 2018).

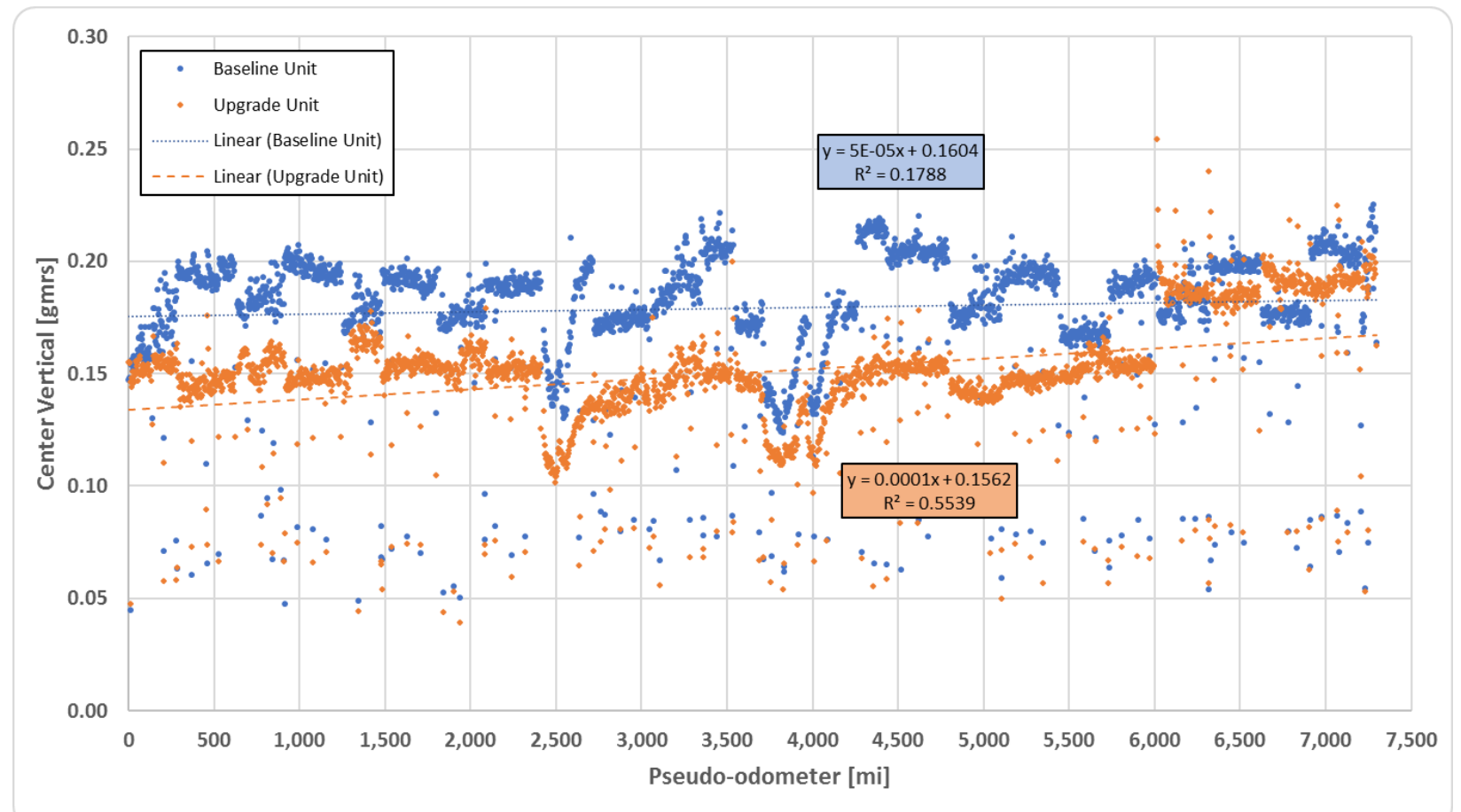

\section{Figure 36. Part C2 - Baseline and Upgrade Units GRMS for Vertical Accelerometer at Axle Group (Center) 2,411 Laps.}

During Part C2 of the test (i.e., the actual Longevity Test), the Baseline Unit showed a total of 29 tire failures (see Table 11). These included three blowouts, four flat tires, 13 tires with exposed cords, one tire showing a sidewall bulge, three tires showing tread separation, and five worn tires. The Upgrade Unit presented 10 tire failures. These included two blowouts, two tires with exposed cords, three tires with tread separation, and three worn tires. 
Table 11. Summary Statistics for Part C2 of Test

\begin{tabular}{|c|c|c|c|c|c|c|c|c|c|}
\hline \multirow[b]{2}{*}{ Day } & \multicolumn{3}{|c|}{ Laps } & \multirow{2}{*}{$\begin{array}{l}\text { Total } \\
\text { Miles }\end{array}$} & \multirow{2}{*}{$\begin{array}{c}\text { Cumulative } \\
\text { Miles }\end{array}$} & \multicolumn{2}{|c|}{ FE [mpg] } & \multicolumn{2}{|c|}{ Failures } \\
\hline & Total & CW & $\begin{array}{l}\mathbf{C C} \\
W\end{array}$ & & & Baseline & Upgrade & Baseline & Upgrade \\
\hline Part A, B, C1 & & & & & 2,367 & & & New Tires & New Tires \\
\hline $01(09 / 12 / 18)$ & 210 & 113 & 97 & 636 & 3,003 & 4.60 & 4.68 & None & 2L_BO \\
\hline $02(09 / 13 / 18)$ & 206 & 112 & 94 & 622 & 3,625 & 4.94 & 4.52 & None & None \\
\hline $03(09 / 14 / 18)$ & 181 & 106 & 75 & 554 & 4,179 & 4.54 & 5.49 & None & None \\
\hline $04(09 / 15 / 18)$ & 202 & 108 & 94 & 613 & 4,792 & 4.17 & 4.35 & 1L_CE; 1R_CE; 3R_CE; 6L_BO; 6R_FL & None \\
\hline $05(09 / 20 / 18)$ & 210 & 6 & 204 & 638 & 5,430 & 4.83 & 4.56 & 5L_BO; 6L_FL & None \\
\hline $06(09 / 21 / 18)$ & 160 & 59 & 101 & 488 & 5,918 & 4.82 & 4.52 & 5R_CE & None \\
\hline $07(09 / 25 / 18)$ & 206 & 110 & 96 & 624 & 6,542 & 4.50 & 4.55 & None & None \\
\hline $08(09 / 26 / 18)$ & 208 & 173 & 35 & 632 & 7,174 & 4.61 & 4.80 & 4L_TS; 5L_SB; 6L_CE; 6L_BO & 6L_CE \\
\hline $09(10 / 08 / 18)$ & 213 & 110 & 103 & 645 & 7,819 & 4.90 & 4.25 & None & None \\
\hline $10(10 / 09 / 18)$ & 187 & 91 & 96 & 566 & 8,385 & 4.53 & 4.42 & $\begin{array}{l}\text { 1L_CE; 1R_CE; 2L_CE; 2R_CE; 3L_TS; } \\
\text { 4R_TS; 5L_FL; 6L_CE; 6R_CE } \\
\end{array}$ & 6R_CE \\
\hline $11(10 / 15 / 18)$ & 202 & 100 & 102 & 613 & 8,998 & 4.52 & 4.47 & 5R_CE; 6L_FL; 6R_CE & None \\
\hline $12(10 / 16 / 18)$ & 226 & 116 & 110 & 651 & 9,649 & N/A & N/A & 1R_WI; 6L_WI; 6R_WI; 1L_WI ${ }^{1} ; 3 \mathrm{R} \_W I^{1}$ & $\begin{array}{l}\text { 2L_BO; } 1 \mathrm{~L}_{\text {LWI }}{ }^{1} ; 1 \mathrm{R} \_W I^{1} ; 2 \mathrm{R} \_W I^{1} ; \\
\text { 3R_TS }{ }^{1} ; 4 \mathrm{~L}_{-} \mathrm{TS}^{1} ; 5 \mathrm{~L}_{-} \mathrm{TS}^{1}\end{array}$ \\
\hline Total & 2,411 & 1,204 & 1,207 & 7,282 & 9,682 & 4.62 & 4.58 & & \\
\hline
\end{tabular}

BO: Blowout; CE: Cords exposed; FL: Flat; SB: Sidewall bulge; TS: Tread separation; WI: Worn past wear indicator.

${ }^{1}$ Condition at End of Test

Table 12. End of Part C2 Testing: Status of Tires Remaining on the Vehicles

\begin{tabular}{|c|l|l|}
\hline $\begin{array}{c}\text { Tire } \\
\text { Location }\end{array}$ & \multicolumn{1}{|c|}{ Baseline } & \multicolumn{1}{c|}{ Upgrade } \\
\hline Axle 1L & Worn past wear indicator & Worn past wear indicator \\
\hline Axle 1R & Like new & Worn past wear indicator \\
\hline Axle 2L & Worn but useable & Like new \\
\hline Axle 2R & Worn but useable & Worn past wear indicator \\
\hline Axle 3L & Worn but useable & Worn but useable \\
\hline Axle 3R & Worn past wear indicator & Tread starting to separate \\
\hline Axle 4L & Worn but useable & Tread starting to separate \\
\hline Axle 4R & Worn but useable & Worn but useable \\
\hline Axle 5L & Worn but useable & Tread starting to separate \\
\hline Axle 5R & Worn but useable & Worn but useable \\
\hline Axle 6L & Like new & Worn but useable \\
\hline Axle 6R & Like new & Worn but useable \\
\hline
\end{tabular}


For the last part of the test, the Upgrade Unit was outfitted with radial tires. The unit then completed 809 laps and logged 2,461 miles during a four-day period from October 22, 2018 through October 25, 2018. During this test, the Upgrade Unit presented no tire failures. Figure 37 presents the GRMS derived from the data collected by the vertical accelerometer located at the axle group (center of the MHU) in Part D. The figure shows a significant reduction in GRMS values (roughly 33\%) when compared to both Baseline and Upgrade regular tires (see Figure 36).

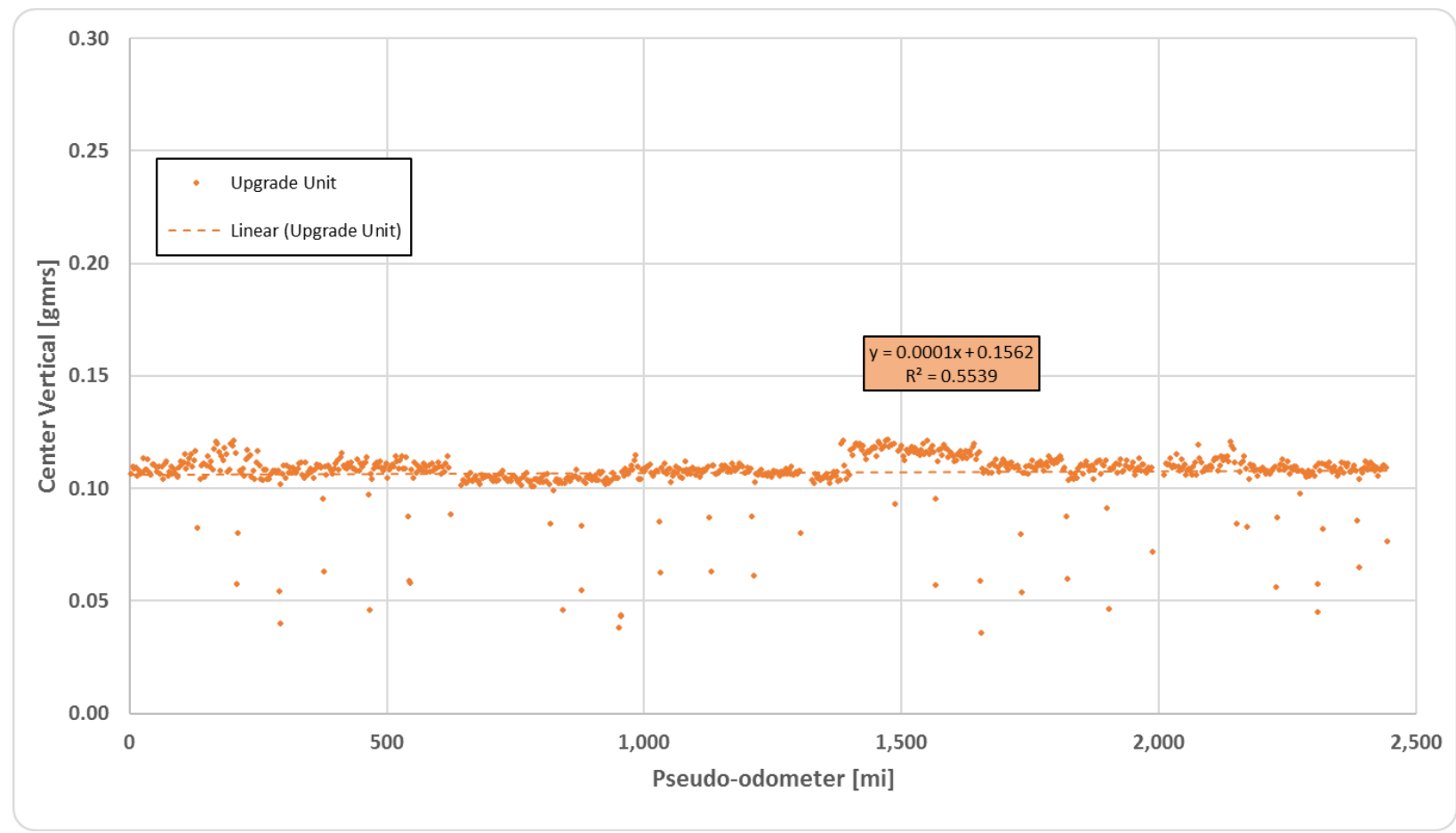

Figure 37. Part D -Upgrade Units GRMS for Vertical Accelerometer at Axle Group (Center) 809 Laps with Radial Tires.

Table 13 presents summary statistics for the four-day testing of Part D. No tire failures were observed during this part of the test. The condition of the tires at the end of the test is shown in Table 14.

Table 13. Summary Statistics for Part D of Test - Upgrade Unit w/Radial Tires

\begin{tabular}{|c|c|c|c|c|c|c|}
\hline \multirow{2}{*}{ Day } & \multicolumn{3}{|c|}{ Laps } & \multirow{2}{*}{$\begin{array}{l}\text { Total } \\
\text { Miles }\end{array}$} & \multirow{2}{*}{$\begin{array}{c}\text { Cumulative } \\
\text { Miles }\end{array}$} & \multirow{2}{*}{ Failures } \\
\hline & Total & CW & CCW & & & \\
\hline Part A, B, C & & & & & 9,715 & New Tires \\
\hline $01(10 / 22 / 18)$ & 212 & 0 & 212 & 643 & 10,358 & None \\
\hline $02(10 / 23 / 18)$ & 224 & 117 & 107 & 682 & 11,040 & None \\
\hline $03(10 / 24 / 18)$ & 225 & 112 & 113 & 684 & 11,724 & None \\
\hline $04(10 / 25 / 18)$ & 148 & 47 & 101 & 452 & 12,176 & None \\
\hline Total & 809 & 276 & 533 & 2,461 & 12,176 & \\
\hline
\end{tabular}


Table 14. End of Part D Testing: Status of Tires Remaining on the Upgrade Unit

\begin{tabular}{|c|l|}
\hline $\begin{array}{c}\text { Tire } \\
\text { Location }\end{array}$ & $\begin{array}{c}\text { Tire } \\
\text { Condition }\end{array}$ \\
\hline Axle 1L & Like new \\
\hline Axle 1R & Like new \\
\hline Axle 2L & Like new \\
\hline Axle 2R & Like new \\
\hline Axle 3L & Like new \\
\hline Axle 3R & Like new \\
\hline Axle 4L & Like new \\
\hline Axle 4R & Like new \\
\hline Axle 5L & Like new \\
\hline Axle 5R & Like new \\
\hline Axle 6L & Like new \\
\hline Axle 6R & Like new \\
\hline
\end{tabular}

The data collected showed that maximum average vertical accelerations registered was for the Baseline alternative (see Figure 36 and Figure 37). If a value of $100 \%$ is given to this alternative for this measure, then the Upgrade Unit with regular tires was at $81 \%$. When the Upgrade Unit was mounted with radial tires, this measure decreased to $59 \%$.

\subsection{ANALYSIS OF TIRE FAILURE RATES}

One important objective of the tests was to assess the tire failure rates of the MHUs. Empirical evidence gathered from past FEMA deployments of these housing units showed an average of one tire failure per 150 miles traveled. Very detailed records were kept during the test regarding the type of tire failures and the miles that the component had accrued when the failure was observed.

\subsubsection{Baseline Unit}

Table 15 presents tire failure rate information for the Baseline Unit during the longevity test. The table shows only test dates when a tire failure occurred, and the cells that are populated indicate the number of miles that that particular tire had accrued to the point of failure. The superscripts that accompany each figure provide information about the type of failure observed. For example, on September 15, 2018, the left-side tire of Axle 6 suffered a blowout. That tire had accrued 1,884 miles when this failure occurred. On that day, the right-side tire of Axle 6 also suffered a blowout after 1,947 miles of travel since installation.

When a tire failed, it was replaced with a new tire. If that tire suffered another failure, the table shows the number of miles following installation. Continuing with the previous example, the left-side tire of Axle 6 failed again on September 20, 2018. It suffered a blowout 740 miles after being installed as a new tire on September 15, 2018. 
Table 15. Baseline Unit Tire Failures during Part C2

\begin{tabular}{|c|c|c|c|c|c|c|c|c|c|c|c|}
\hline \multirow{2}{*}{$\begin{array}{c}\text { Axle \#- } \\
\text { Side }\end{array}$} & \multicolumn{5}{|c|}{ September 2018} & \multicolumn{5}{|c|}{ October 2018} & \multirow{2}{*}{$\begin{array}{l}\text { Total } \\
\text { Miles }\end{array}$} \\
\hline & 15 & 17 & 20 & 21 & 26 & 9 & 15 & 16 & 17 & 18 & \\
\hline 1-Left & & $2,458^{2}$ & & & & $2,987^{2}$ & & & & $1,837^{3}$ & 7,282 \\
\hline 1-Right & & $2,458^{2}$ & & & & $2,987^{2}$ & & & $1,745^{3}$ & $92^{5}$ & 7,282 \\
\hline 2-Left & & & & & & $5,445^{2}$ & & & & $1,837^{4}$ & 7,282 \\
\hline 2-Right & & & & & & $5,445^{2}$ & & & & $1,837^{4}$ & 7,282 \\
\hline 3-Left & & & & & & $5,445^{2}$ & & & & $1,837^{4}$ & 7,282 \\
\hline 3-Right & & $2,458^{2}$ & & & & & & & & $4,824^{3}$ & 7,282 \\
\hline 4-Left & & & & & $4,186^{2}$ & & & & & $3,096^{4}$ & 7,282 \\
\hline 4-Right & & & & & & $5,445^{2}$ & & & & $1,837^{4}$ & 7,282 \\
\hline 5-Left & & & $2,626^{1}$ & & $1,561^{2}$ & $1,259^{2}$ & & & & $1,837^{4}$ & 7,283 \\
\hline 5-Right & & & & $3,088^{2}$ & & & & $3,521^{2}$ & & $674^{4}$ & 7,283 \\
\hline 6-Left & $1,884^{1}$ & & $740^{2}$ & & \begin{tabular}{|r|}
$1,561^{2}$ \\
$116^{1}$ \\
\end{tabular} & $1,143^{2}$ & $662^{2}$ & & $1,083^{3}$ & $92^{5}$ & 7,282 \\
\hline 6-Right & $1,947^{2}$ & & & & & $3,498^{2}$ & & $1,163^{2}$ & $582^{3}$ & $92^{5}$ & 7,282 \\
\hline
\end{tabular}

${ }^{1}$ Blowout; ${ }^{2}$ Tire failure; ${ }^{3}$ Worn past indicator; ${ }^{4}$ Worn but useable; ${ }^{5}$ Like new

With the information collected, failure rates per 1,000 miles traveled were computed for each tire position of the Baseline Unit. This information is presented in Table 16. The tire failure rates were computed by dividing the number of failures by the total number of miles traveled and multiplying that by 1,000 . For example, the left-side tire of Axle 6 suffered seven failures during Part C2 of the test (Table 15). Since 7,282 miles were logged during the test, this resulted in a failure rate (of some type) of $0.961=$ $7 / 7,282 * 1,000$. That side of Axle 6 suffered four blowouts, which resulted in a failure rate per 1,000 miles traveled of $0.549=4 / 7,282 * 1,000$. Notice that when no tire failure was observed, Table 16 does not show a rate of 0.00 , but rather it is labeled as "N/A" or not available. This is because the test was not long enough to observe these failures. An upper limit for these N/A rates would be less than one tire failure per 7,282 miles traveled.

Table 16 also presents the expected mean travel distance between failures. This was computed by dividing the total number of miles traveled during Part C2 (i.e., 7,282 miles) by the number of observed failures. For example, Axle 6 left side had seven failures and therefore the expected mean travel distance between failures is 1,040 miles $=7,282$ miles $/ 7$. For blowouts, this parameter is 3,641 miles (i.e., one blowout every 3,641 miles traveled) for the Axle 6 left-side tire. 
Table 16. Tire Failure Rates per 1,000 Miles Traveled and Expected Mean Travel Distance between Failures Baseline Unit - Part C2

\begin{tabular}{|l|r|r|r|r|}
\hline \multirow{2}{*}{$\begin{array}{c}\text { Axle \#- } \\
\text { Side }\end{array}$} & \multicolumn{2}{|c|}{$\begin{array}{c}\text { Failure Rates } \\
\text { per 1,000 Miles }\end{array}$} & \multicolumn{2}{c|}{$\begin{array}{c}\text { Mean Travel Distance } \\
\text { between Failures [miles] }\end{array}$} \\
\cline { 2 - 5 } & $\begin{array}{c}\text { Any } \\
\text { Failure }\end{array}$ & \multicolumn{1}{c|}{ Blowouts } & $\begin{array}{c}\text { Any } \\
\text { Failure }\end{array}$ & \multicolumn{1}{c|}{ Blowouts } \\
\hline 1-Left & 0.412 & N/A & 2,427 & N/A \\
\hline 1-Right & 0.412 & N/A & 2,427 & N/A \\
\hline 2-Left & 0.137 & N/A & 7,282 & N/A \\
\hline 2-Right & 0.137 & N/A & 7,282 & N/A \\
\hline 3-Left & 0.137 & N/A & 7,282 & N/A \\
\hline 3-Right & 0.275 & N/A & 3,641 & N/A \\
\hline 4-Left & 0.137 & N/A & 7,282 & N/A \\
\hline 4-Right & 0.137 & N/A & 7,282 & N/A \\
\hline 5-Left & 0.412 & 0.137 & 2,428 & 7,282 \\
\hline 5-Right & 0.275 & N/A & 3,642 & N/A \\
\hline 6-Left & 0.961 & 0.275 & 1,040 & 3,641 \\
\hline 6-Right & 0.549 & N/A & 1,821 & 7,282 \\
\hline Trailer & 3.982 & 0.412 & 251 & 2,427 \\
\hline N/A:Not Av & & & & \\
\hline
\end{tabular}

N/A: Not Available

Table 16 shows that the overall expected mean travel distance between failures is 251 miles. This can be compared to the reported empirical failure rate of one every 150 miles traveled, showing an improvement of $67 \%$ by just installing the axles and corresponding hardware correctly. That is, once the correct size of bolts were used (as it was the case when NPG installed new axles on the Baseline Unit for the test) and the correct torque force applied to tighten these bolts, a considerable improvement was achieved at no cost (i.e., the same hardware and tires of any similar MHU were used for the tested Baseline Unit). Under the tested conditions, and with the observed failure rates, for a 1,800-mile trip seven tire failures are expected to occur. A similar MHU without the correct installation of the transportation hardware would be expected to show 12 tire failures over this same trip. The additional five tire failures would not only increase the transportation cost (since five additional stops would be required to replace these failed tires with new ones), but would also lengthen the delivery time of the unit.

Since information regarding the life of the tires that failed was collected during the test (i.e., the distance traveled by that tire from its new status until it failed) it is possible to build a probability density function that shows how the number of component failures are distributed over distance traveled. The distribution shown in Figure 38 was built with the data presented in Table 15 using 500-mile bins for the histogram. The probability density function (shown as a continuous line in the figure) is the curve that results as the bin size approaches zero, and this density function has been normalized so that its area is equal to 1 (i.e., $100 \%$ ). In other words, the histogram shows the number of failures per bin, while the probability density function is scaled to show the probability of failure per distance traveled. Using that curve, for the 1,800mile trip used in the example above, it is expected that $40 \%$ of the tires would fail before 1,800 miles, and therefore $60 \%$ are expected to last at least 1,800 miles. 


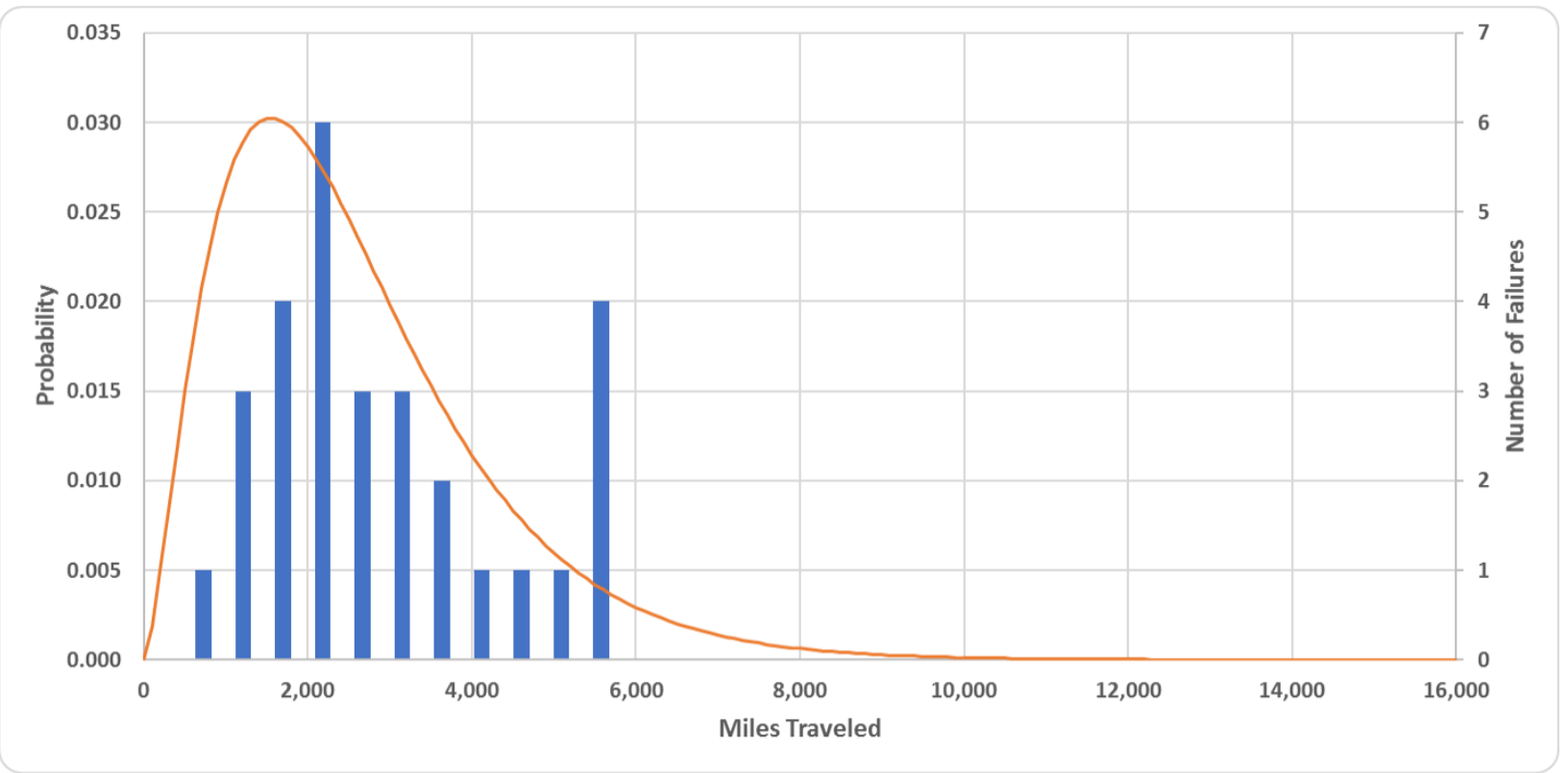

Figure 38. Baseline Unit Tire Failure Histogram (500mile Bins) and Fitted Probability Density Function.

\subsubsection{Upgrade Unit}

Upgrade Unit tire-failure information collected during the longevity test is presented in Table 17. Just from a simple visual comparison of this table to Table 15, it is evident that the Upgrade Unit presented much lower number of tires failures than the Baseline Unit. While the latter had 29 tire failures during the 7,282 test miles of Part C2, the former only had ten failures. The number of blowouts, however, were close when comparing these two units (two for the Upgrade Unit and three for the Baseline Unit). Notice that both Upgrade Unit blowouts occurred to the left tire of Axle 2 (September 12 and October 18, 2018). As discussed earlier in this report, at the end of Part B and beginning of Part C of the test, it was discovered that the axle-wheel ends mounted on the Upgrade Unit were defective (i.e., were not squared) and were replaced by new axles. During Part A/B/C1, the Upgrade Unit with defective axles suffered five blowouts out of nine tire failures (see Table 10). That is, with defective axles, $56 \%$ of the observed tire failures for this unit were blowouts. In Part C2 of the test, this rate was reduced to $20 \%$ (two out of ten). Given that both of them occurred at the same tire position, this may be an indication that Axle 2 may have been slightly defective. Two other failures that were observed during the test for this unit were exposure of cords for Axle 6 left tire with a tire life of 4,808 miles, and Axle 6 right tire with a tire life of 5,445 miles (see Table 11 and Table 17). The remaining six tire failures were observed at the end of the tests when the tires were inspected. Those were three tires presenting tread separation and another three tires that were worn past the indicator. 
Table 17. Upgrade Unit Tire Failures during Part C2

\begin{tabular}{|l|c|c|r|r|r|}
\hline \multirow{2}{*}{$\begin{array}{l}\text { Axle \#- } \\
\text { Side }\end{array}$} & \multicolumn{2}{|c|}{ September 2018 } & \multicolumn{2}{c|}{ October 2018 } & \multicolumn{1}{c|}{ Total } \\
\cline { 2 - 4 } 1-Left & $\mathbf{1 2}$ & $\mathbf{2 7}$ & $\mathbf{9}$ & $\mathbf{1 8}$ & \multicolumn{1}{c}{ Miles } \\
\hline 1-Right & & & & $7,282^{3}$ & 7,282 \\
\hline \multirow{2}{*}{ 2-Left } & \multirow{2}{*}{$75^{1}$} & & & $7,282^{3}$ & 7,282 \\
\hline 2-Right & & & & $7,137^{1}$ & 7,282 \\
\hline 3-Left & & & & $70^{5}$ & \\
\hline 3-Right & & & & $7,282^{3}$ & 7,282 \\
\hline 4-Left & & & & $7,282^{2}$ & 7,282 \\
\hline 4-Right & & & & $7,282^{2}$ & 7,282 \\
\hline 5-Left & & & & $7,282^{4}$ & 7,282 \\
\hline 5-Right & & & & $7,282^{4}$ & 7,282 \\
\hline 6-Left & & $4,808^{2}$ & & $2,474^{4}$ & 7,282 \\
\hline 6-Right & & & $5,445^{2}$ & $1,837^{4}$ & 7,282 \\
\hline
\end{tabular}

Table 18 presents the failure rates per 1,000 miles traveled for each tire position of the Upgrade Unit computed with information collected in Part C2. Tire failure rates were smaller for this unit than for the Baseline Unit (compare the first column of Table 18 and Table 16). Moreover, while all the tire positions of the Baseline Unit experienced at least one tire failure during Part C2, Axle 3 left, Axle 4 right and Axle 5 right did not show any failure and after 7,282 miles, they were worn but useable. At any tire position, the tire failure rate for the Upgrade Unit was smaller or equal to that of the Baseline Unit. The exception was Axle 2 left which, as discussed previously, may have been defective. The overall tire failure rate per 1,000 miles traveled was 1.37. The table also shows the observed blowout rate per 1,000 miles traveled (third column). Notice that when no tire failure was observed, the table does not show a rate of 0.00 , but rather "N/A" or not available.

The expected mean travel distance between failures is also presented in Table 18. This was computed by dividing the total number of miles traveled during Part C2 (i.e., 7,282 miles) by the number of observed failures. The overall mean travel distance between failures was 728 miles $=7,282$ miles $/ 10$. For blowouts, this parameter is 3,641 miles (i.e., one blowout every 3,641 miles traveled) for the Upgrade Unit. 
Table 18. Tire Failure Rates per 1,000 Miles Traveled and Expected Mean Travel Distance between Failures Upgrade Unit - Part C2

\begin{tabular}{|l|r|r|r|r|}
\hline \multirow{2}{*}{$\begin{array}{c}\text { Axle \#- } \\
\text { Side }\end{array}$} & \multicolumn{2}{|c|}{$\begin{array}{c}\text { Failure Rates } \\
\text { per 1,000 Miles }\end{array}$} & \multicolumn{2}{c|}{$\begin{array}{c}\text { Mean Travel Distance } \\
\text { between Failures [miles] }\end{array}$} \\
\cline { 2 - 5 } & $\begin{array}{c}\text { Any } \\
\text { Failure }\end{array}$ & \multicolumn{1}{c|}{ Blowouts } & $\begin{array}{c}\text { Any } \\
\text { Failure }\end{array}$ & \multicolumn{1}{c|}{ Blowouts } \\
\hline 1-Left & 0.137 & N/A & 7,282 & N/A \\
\hline 1-Right & 0.137 & N/A & 7,282 & N/A \\
\hline 2-Left & 0.275 & 0.275 & 3,641 & 3,641 \\
\hline 2-Right & 0.137 & N/A & 7,282 & N/A \\
\hline 3-Left & N/A & N/A & N/A & N/A \\
\hline 3-Right & 0.137 & N/A & 7,282 & N/A \\
\hline 4-Left & 0.137 & N/A & 7,282 & N/A \\
\hline 4-Right & N/A & N/A & N/A & N/A \\
\hline 5-Left & 0.137 & N/A & 7,282 & N/A \\
\hline 5-Right & N/A & N/A & N/A & N/A \\
\hline 6-Left & 0.137 & N/A & 7,282 & N/A \\
\hline 6-Right & 0.137 & N/A & 7,282 & N/A \\
\hline Trailer & 1.373 & 0.275 & 728 & 3,641 \\
\hline
\end{tabular}

N/A: Not Available

The overall expected mean travel distance between failures of 728 miles can be compared to the reported empirical failure of one every 150 miles traveled, showing an improvement of $385 \%$. This was achieved by the new suspension system. (Compare this improvement to the $67 \%$ improvement shown by the Baseline Unit by just installing the axles and corresponding hardware correctly.) Although this improvement has a cost attached to it (i.e., the cost of the new suspension system and better tires), it could achieve significant savings in travel time by reducing the total delays associated with tire failures to $1 / 3$ of the delays expected by the Baseline Unit, and about 20\% of those of any MHU where the transportation system had not been installed correctly.

For example, under the tested conditions, and with the observed failure rates, for a 1,800-mile trip about two tire failures are expected to occur. A similar MHU without the correct installation of the transportation hardware would be expected to show 12 tire failures for that same trip. Not only would the additional ten tire failures increase the transportation cost (since ten additional stops would be required to replace these failed tires with new ones), but also the delivery time of the unit would be much longer. As in the case of the Baseline Unit, a probability density function that shows how the number of component failures are distributed over distance traveled was built using information regarding the life of the tires that failed. This distribution, shown in Figure 39, was built with the data presented in Table 17 using 500-mile bins for the histogram. It is presented here for completeness, but since so few tire failures were observed for the Upgrade Unit during the test, this probability distribution has much more uncertainty than the one built for the Baseline Unit (see Figure 38). The probability density function (shown as a continuous line in the figure) is the curve that results as the bin size approaches zero, and it has been normalized so that its area is equal to 1 . In other words, the histogram shows the number of failures per bin, while the probability density function is scaled to show the probability of failure per distance traveled. Using the probability density function (shown as a continuous line in the Figure 39), for the 1,800-mile trip used in the example above, it is expected that $1.1 \%$ of the tires would fail before 1,800 miles, and therefore $98.9 \%$ are expected to last at least 1,800 miles. 


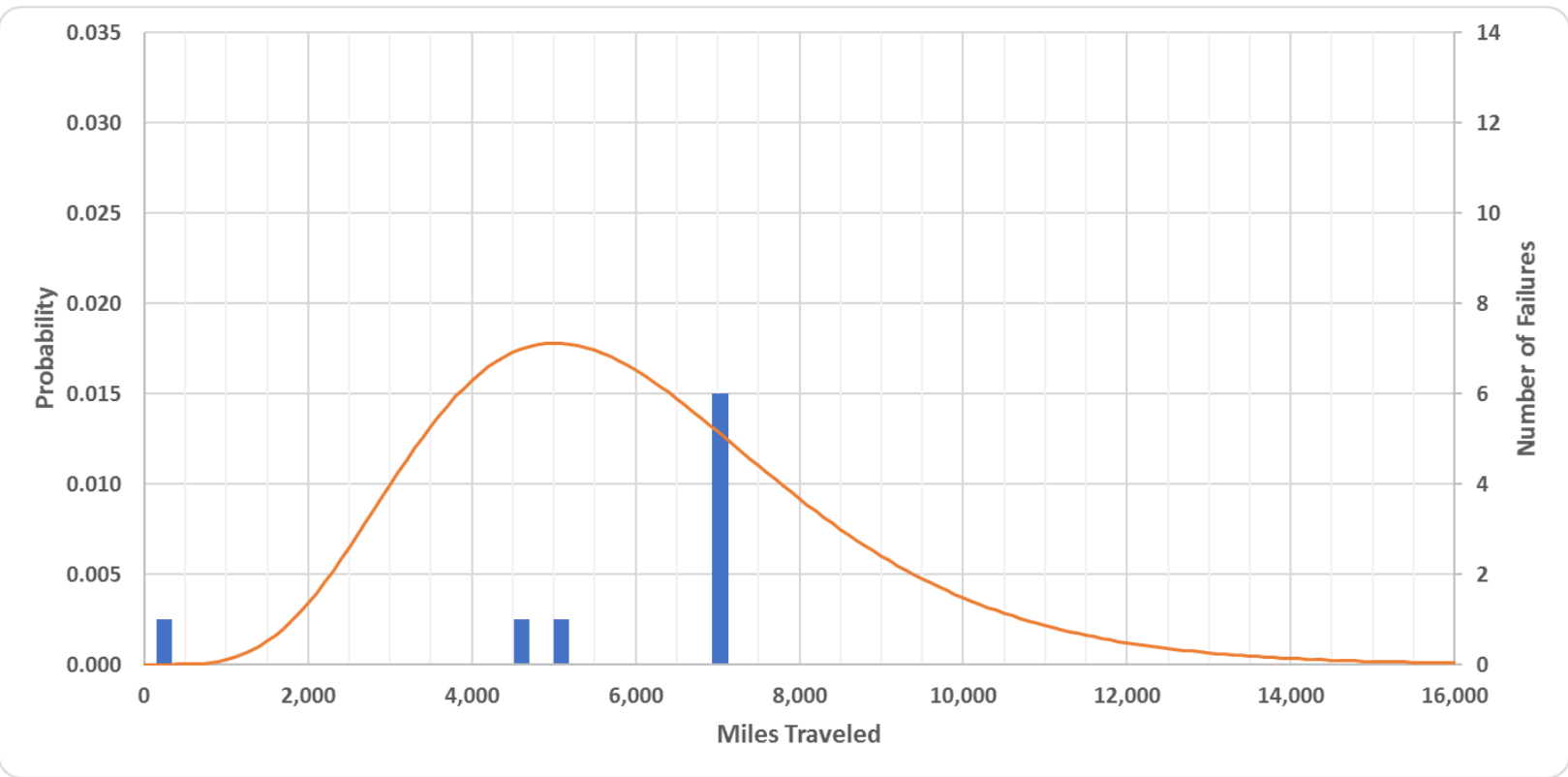

Figure 39. Upgrade Unit Tire Failure Histogram (500mile Bins) and Fitted Probability Density Function.

\subsubsection{Upgrade Unit -Radial Tires}

After the conclusion of the Longevity Test, the Upgrade Unit was outfitted with radial tires and another 2,400 miles of data were collected. During this part of the test, the Upgrade Unit did not present any tire failures and all the tires were still in a "like new" state at the end of the test (see Table 19). With this type of tires and suspension, in a 1,800-mile trip, it is expected that no tire failures would be observed, which would result in a significant improvement in travel time.

Table 19. Upgrade Unit Tire Failures during Part D (Radial Tires)

\begin{tabular}{|l|r|r|}
\hline Axle \#-Side & $\begin{array}{c}\text { October 26, } \\
\text { 2018 }\end{array}$ & \multicolumn{1}{c|}{ Total Miles } \\
\hline 1-Left & $2,400^{1}$ & 2,400 \\
\hline 1-Right & $2,400^{1}$ & 2,400 \\
\hline 2-Left & $2,400^{1}$ & 2,400 \\
\hline 2-Right & $2,400^{1}$ & 2,400 \\
\hline 3-Left & $2,400^{1}$ & 2,400 \\
\hline 3-Right & $2,400^{1}$ & 2,400 \\
\hline 4-Left & $2,400^{1}$ & 2,400 \\
\hline 4-Right & $2,400^{1}$ & 2,400 \\
\hline 5-Left & $2,400^{1}$ & 2,400 \\
\hline 5-Right & $2,400^{1}$ & 2,400 \\
\hline 6-Left & $2,400^{1}$ & 2,400 \\
\hline 6-Right & $2,400^{1}$ & 2,400 \\
\hline 1Like new & & \\
\hline
\end{tabular}

A summary of the results is presented in Table 20 below for each of the three cases considered (i.e., Baseline Unit, Upgrade Unit with regular tires, and Upgrade Unit with radial tires). 
Table 20. Tire Failure Rates per 1,000 Miles Traveled and Expected Mean Travel Distance between Failures Part C2 and Part D

\begin{tabular}{|c|c|c|c|c|}
\hline \multirow{2}{*}{ Alternative } & \multicolumn{2}{|c|}{$\begin{array}{l}\text { Failure Rates } \\
\text { per 1,000 Miles }\end{array}$} & \multicolumn{2}{|c|}{$\begin{array}{c}\text { Mean Travel Distance } \\
\text { between Failures [miles] }\end{array}$} \\
\hline & $\begin{array}{l}\text { Any } \\
\text { Failure }\end{array}$ & Blowouts & $\begin{array}{l}\text { Any } \\
\text { Failure }\end{array}$ & Blowouts \\
\hline Baseline Unit & 3.982 & 0.412 & 251 & 2,427 \\
\hline Upgrade Unit w/Regular Tires & 1.373 & 0.275 & 728 & 3,641 \\
\hline Upgrade Unit w/Radial Tires & $<0.417$ & $<0.417$ & $>2,400$ & $>2,400$ \\
\hline Empirical Data (As Estimated by & 6.667 & N/A & 150 & N/A \\
\hline
\end{tabular}

\subsubsection{Comparison of Failure Rates}

With the data collected in the four stages of the test, it is possible to statistically compare the Baseline and Upgrade Units observed tire failure rates against empirical rates (as estimated by carriers). As mentioned above, the empirical tire failure rate was one failure every 150 miles traveled, or 0.0067 tire failures per mile traveled. This failure rate can be statistically compared to the observed failure rates for the Baseline and Upgrade units during each part of the test.

The information presented in Table 21 is from Part A/B/C1, Part C2, and Part D of the test for both Baseline and Upgrade units. Consider, for example, the 29 tire failures observed for the Baseline Unit during Part C2 of the test. Given the 7,282 miles traveled, these 29 failures resulted in 0.0040 tire failures per mile traveled, or about $2 / 3$ of the empirical tire failure rate.

In order to determine whether or not this reduction in the tire failure rate was statistically significant, a test of hypothesis was conducted (Devore [2]). The null hypothesis was that tire failure rate for the Baseline Unit was the same as the empirical rate (i.e., $p=0.0067$ ). This was tested against the alternative hypothesis that the Baseline Unit failure rate was smaller than the empirical rate (i.e., $p<0.0067$ ). When the statistical test was conducted, it was possible to reject the null hypothesis in favor of the alternative hypothesis with $99.8 \%$ confidence, strongly suggesting that the Baseline Unit tire failure rate observed in Part C2 of the test was smaller than the empirical tire failure rate (see Table 21). In every case, except for the Upgrade Unit during the first part of the test, it was possible to reject the null hypothesis in favor of the alternative hypothesis with more than $99 \%$ confidence. For the Upgrade Unit in Part A/B/C1, it was also possible to reject the null hypothesis, but with a lower confidence level (97.5\%). 
Table 21. Statistical Comparison of Tire Failures: Empirical Failure Rate vs. Observed Baseline and Upgrade Units Tire Failure during Test

\begin{tabular}{|l|r|r|r|r|r|r|}
\hline \multirow{2}{*}{} & \multicolumn{2}{|c|}{ Part A/B/C1 } & \multicolumn{2}{c|}{ Part C2 } & \multicolumn{2}{c|}{$\begin{array}{c}\text { Part D } \\
\text { (Radial Tires) }\end{array}$} \\
\cline { 2 - 7 } & \multicolumn{1}{|c|}{ BU } & \multicolumn{1}{c|}{ UU } & \multicolumn{1}{c|}{ BU } & \multicolumn{1}{c|}{ UU } & \multicolumn{1}{c|}{ BU } & \multicolumn{1}{c|}{ UU } \\
\hline Length of Test [miles] & 2,367 & 2,367 & 7,282 & 7,282 & N/A & 2,400 \\
\hline $\begin{array}{l}\text { Expected \# of Failures } \\
\text { (Empirical Data) }\end{array}$ & 16 & 16 & 49 & 49 & N/A & 16 \\
\hline Observed \# of Failures (Test Data) & 3 & 8 & 29 & 10 & N/A & 0 \\
\hline Expected Probability of Failure & \multicolumn{7}{|c|}{0.0067} \\
\hline Observed Probability of Failure & 0.0013 & 0.0034 & 0.0040 & 0.0014 & N/A & 0.0000 \\
\hline$Z$ & -3.2280 & -1.9651 & -2.8148 & -5.5509 & N/A & -3.9101 \\
\hline Reject Ho with Confidence Level $=$ & $99.9 \%$ & $97.5 \%$ & $99.8 \%$ & $99.9+\%$ & N/A & $99.9+\%$ \\
\hline
\end{tabular}

\subsubsection{Comparison of Upgrade Unit Failures against Baseline Unit Failures (Part C2)}

Table 21 also shows that the per mile tire failure rate observed in Part C2 was smaller for the Upgrade Unit than for the Baseline Unit (i.e., 0.0014 and 0.0040, respectively). As in the previous case, it is possible to test whether or not this reduction in the tire failure rate was statistically significant. Again, a test of hypothesis was performed where the null hypothesis was that tire failure rate for the Upgrade Unit was the same as the one for the Baseline Unit (i.e., $p=0.0040$ ). This was tested against the alternative hypothesis that the Upgrade Unit failure rate was smaller than the Baseline Unit failure rate (i.e., $\mathrm{p}<$ 0.0040).

The result of the test of hypothesis is presented in Table 22. The statistical test shows that it is possible to reject the null hypothesis in favor of the alternative hypothesis with $99.9 \%$ confidence, strongly suggesting that the Upgrade Unit tire failure rate observed in Part C2 of the test was smaller than the Baseline Unit tire failure rate.

Table 22. Statistical Comparison of Tire Failures: Observed Upgrade Unit Tire Failure Rate vs. Observed Baseline Tire Failure Rate

\begin{tabular}{|l|r|}
\hline & Upgrade \\
\hline Length of Test [miles] & 7,282 \\
\hline Observed \# of Failures (Upgrade Unit Data) & 10 \\
\hline Expected Probability of Failure & 0.0040 \\
\hline Observed Probability of Failure & 0.0014 \\
\hline $\mathbf{z}$ & -3.5353 \\
\hline Reject Ho with Confidence Level = & $99.9 \%$ \\
\hline
\end{tabular}

\subsection{ANALYSIS OF VEHICLE VIBRATIONS}

During past deployments, FEMA had observed that the MHUs arrived at their destination damaged (e.g., door frames out of square, wall cracks, disconnected pipes, and other damages). ORNL proposed to conduct a statistical analysis of the vibration data collected during the test to determine if there was any statistically significant difference between the vibrations transmitted by the Baseline Unit suspension/tire system to MHU and those transmitted by the Upgrade Unit. The rationale for this test was that if it was 
possible to prove that the improved transportation system (Upgrade Unit) transmitted lower amplitude vibrations to the MHU, it would be expected to show less severe damage at the end of the deployment trip. Here it is necessary to clarify that this may or may not be the case. Less severe vibrations would be expected to result in less severe damage, but it is unknown at which vibration levels this damage occurs. Therefore, even if the Upgrade Unit is shown to transmit statistically significant lower accelerations to the MHU, it is not possible to conclude that the damage will be less severe, since both the Baseline and Upgrade units could be transmitting vibrations that are above the damage-occurring threshold. On the other hand, if the Upgrade Unit (improved transportation system) is proven, through the tests conducted here, not to transmit lower accelerations (i.e., forces) to the MHU than the Baseline Unit (current transportation system), then avoidance of vibration-related damage would not be sufficient cause to justify a more costly transportation system.

\subsubsection{Speed Distributions}

The vibration information was collected by six tri-axial accelerometers, five of them located inside the MHU and the sixth on the hitch. The data was collected and processed, and the corresponding measure of effectiveness (MOE) was computed as described in previous sections of this report. For each lap, one data value which summarized the forces transmitted by the transportation system to the MHU was computed for both the Baseline and Upgrade units and served as one observation for the statistical analysis.

Vibration amplitudes, and in consequence forces transmitted, are directly correlated to the speed of the vehicle. As the speed increases, these forces due to vibration increase. Therefore, it was very important to select the laps that would be used in the statistical comparison to minimize the difference of speeds between the Baseline and Upgrade units. That is, the average speed difference between the Baseline and Upgrade units for any given pair of laps considered for the analysis should be as close to 0 (zero) as possible.

In Part C2 of the test, 2,240 laps were logged at the NPG three-mile test track. Of these, 1,123 laps were traveled in a clockwise direction and 1,117 in a counter-clockwise direction. Table 23 presents some statistics regarding the average vehicle speeds for this part of the test. In general, both vehicles traveled at the same speed (about $60 \mathrm{mph}$ ), because that was the protocol established for the test. The table, however, shows that there were some differences in travel speed between the two tested units (see the values of the standard deviations presented in the table). These differences can be seen in a graphical form by comparing the histograms shown in Figure 40, Figure 41, and Figure 42.

For the statistical analyses presented in this section and in Error! Reference source not found., the observations were selected considering the difference of the average lap speed between the two units. Summary speed statistics for the laps selected for the analysis are presented at the beginning of each subsection below.

Table 23. Vehicle Speed Distribution Parameters Baseline and Upgrade Units - Part C2 All Laps

\begin{tabular}{|l|r|r|r|r|r|r|}
\hline \multirow{2}{*}{ Statistics } & \multicolumn{3}{|c|}{ Baseline Unit } & \multicolumn{3}{|c|}{ Upgrade Unit } \\
\cline { 2 - 7 } & All Laps & \multicolumn{1}{|c|}{ CW } & CCW & All Laps & \multicolumn{1}{c|}{ CW } & \multicolumn{1}{c|}{ CCW } \\
\hline Obs. & 2,240 & 1,123 & 1,117 & 2,240 & 1,123 & 1,117 \\
\hline Min. [mph] & 54.1 & 54.1 & 55.7 & 54.6 & 54.6 & 55.2 \\
\hline Max. [mph] & 62.6 & 62.1 & 62.6 & 63.5 & 63.5 & 61.7 \\
\hline Mean [mph] & 60.1 & 60.2 & 60.0 & 60.1 & 60.2 & 59.9 \\
\hline Std. Dev. & 0.706 & 0.710 & 0.688 & 0.740 & 0.703 & 0.763 \\
\hline
\end{tabular}



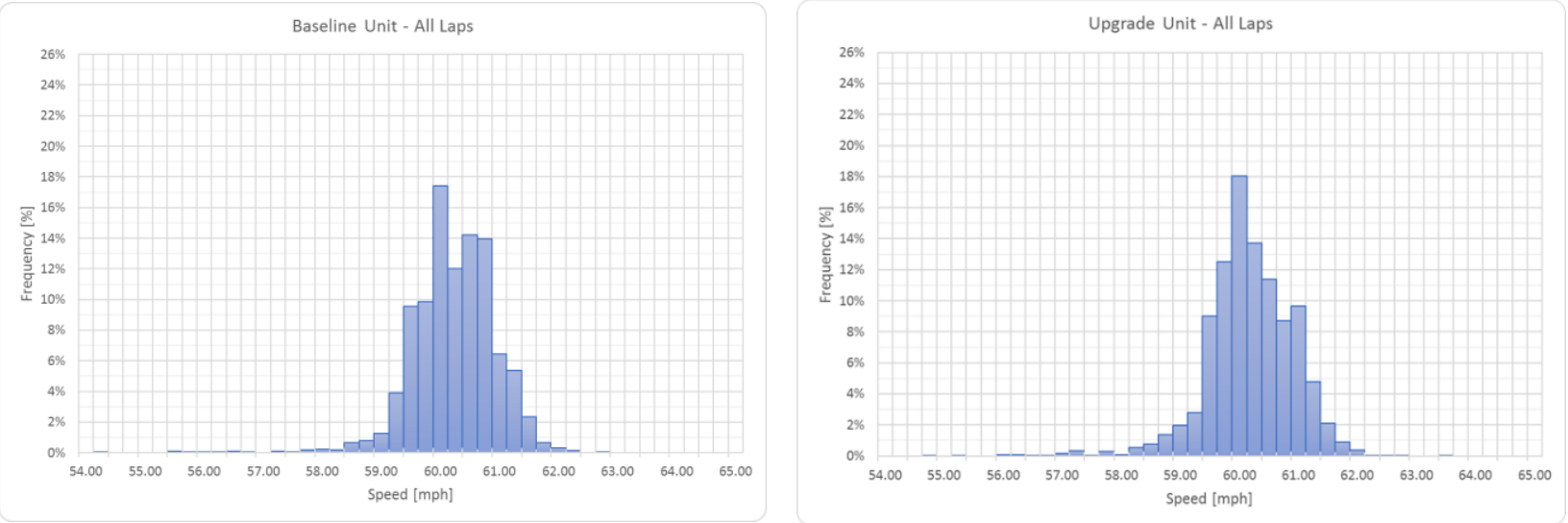

Figure 40. Part C2 - Baseline and Upgrade Units Speed Distributions (All Laps).
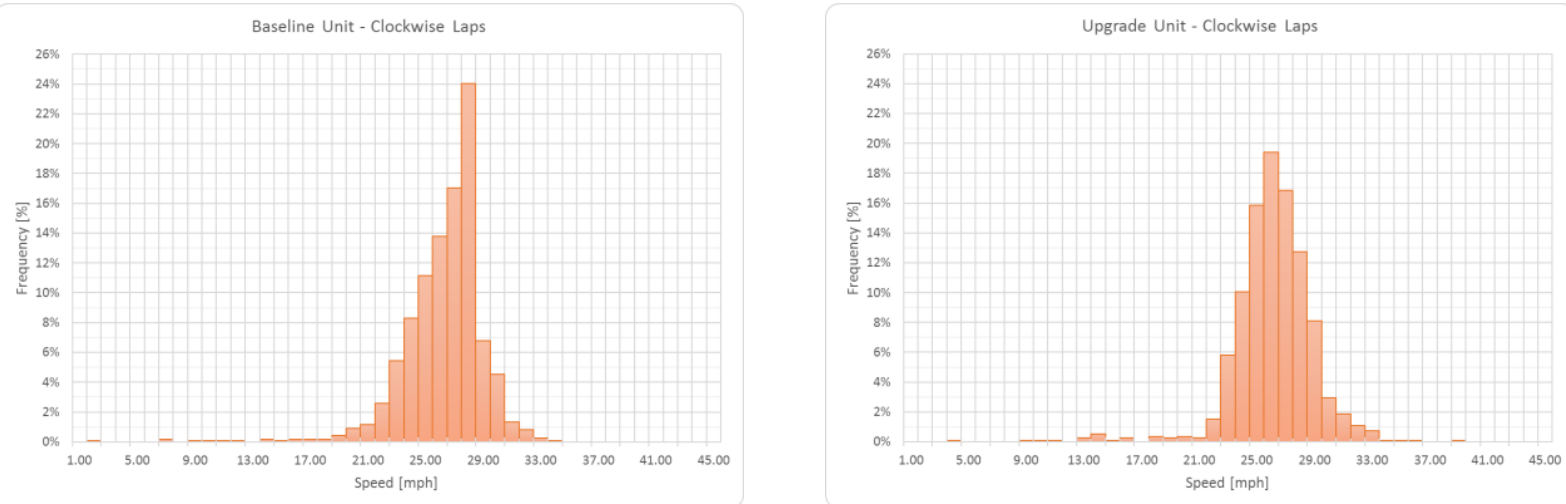

Figure 41. Part C2 - Baseline and Upgrade Units Speed Distributions - Clockwise Laps.
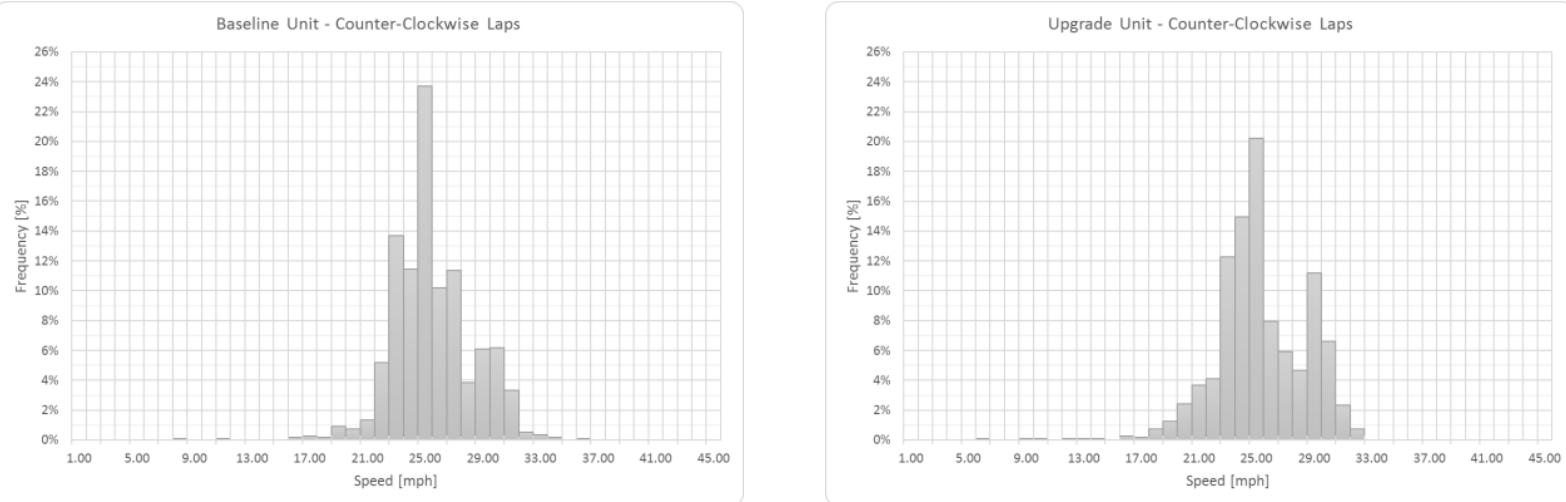

Figure 42. Part C2 - Baseline and Upgrade Units Speed Distributions -Counter-clockwise Laps. 


\subsubsection{Effect of Suspension on Vibrations: Baseline Unit vs. Upgrade Unit}

This subsection presents a statistical comparison of the effect that suspensions of the Baseline and Upgrade units have on the vibrations transmitted to the respective MHUs. The statistical analysis consists of a test of hypothesis were the null hypothesis states that the mean of the distribution of the accelerations transmitted by the suspension (captured by the GRMS value as described earlier in this report) is the same for both the Baseline and Upgrade units. That is, the suspension system has no influence on the accelerations transmitted to the respective MHUs. This is statistically tested against the alternative hypothesis stating that the mean of the distribution of the accelerations transmitted by the Upgrade Unit is smaller than that of the Baseline Unit.

As explained above, the speed at which the vehicle is traveling has a significant influence on the vibrations and therefore accelerations transmitted by the suspension system to MHU. To control for this effect, only laps in which the difference between the lap average speed between the Baseline and Upgrade units was below a certain threshold were selected. This threshold was set as low as possible while still providing enough observations to allow for a statistically significant determination of the hypothesis tested.

For the overall test, a difference in average speed of $0.05 \mathrm{mph}$ was used. That is, any lap where the difference in the average speed between the Baseline and Upgrade units was within $+/-0.05 \mathrm{mph}$ was included in the analysis. Table 24 presents summary speed statistics for the 202 laps selected for the statistical analysis. Notice that for the 202 laps selected, the average of the speed distribution is slightly larger for the Upgrade Unit than for the Baseline Unit, which puts the former at a slight disadvantage with respect to the latter.

Table 24. Vehicle Speed Distribution Parameters Baseline and Upgrade Units - Selected Laps for Analysis

\begin{tabular}{|l|r|r|r|r|r|r|}
\hline \multirow{2}{*}{ Statistics } & \multicolumn{3}{|c|}{ Baseline Unit } & \multicolumn{3}{c|}{ Upgrade Unit } \\
\cline { 2 - 7 } & All Laps & $\begin{array}{c}\text { CW } \\
\text { Laps }\end{array}$ & $\begin{array}{c}\text { CCW } \\
\text { Laps }\end{array}$ & All Laps & $\begin{array}{c}\text { CW } \\
\text { Laps }\end{array}$ & $\begin{array}{c}\text { CCW } \\
\text { Laps }\end{array}$ \\
\hline Obs. & 202 & 84 & 118 & 202 & 84 & 118 \\
\hline Min. [mph] & 59.0 & 59.1 & 59.0 & 59.1 & 59.1 & 59.1 \\
\hline Max. [mph] & 61.4 & 61.3 & 61.4 & 61.4 & 61.3 & 61.4 \\
\hline Mean [mph] & 60.1 & 60.3 & 60.0 & 60.2 & 60.3 & 60.0 \\
\hline Std. Dev. & 0.52 & 0.43 & 0.55 & 0.52 & 0.42 & 0.56 \\
\hline
\end{tabular}

The results of the statistical tests are presented in Table 25, Table 26, and Table 27, for the three directions for which the accelerometers collected data (i.e., vertical, longitudinal, and lateral, respectively). The tables present the results for each one of the six accelerometers deployed in each unit. The one labeled "Center" was located at the center of each MHU as described above, and is the one of most interest for the analysis since it always presented the highest values of the vertical GRMS measure (see Table 25), thus indicating that this was the location that experienced the largest vertical accelerations. The data used in the analysis for this accelerometer is presented in graphical form in Figure 43, while Figure 44 and Figure 45 present the data for the center accelerometer in the longitudinal and lateral direction, respectively.

Each table presents statistics (i.e., minimum observed value, maximum, mean, and standard deviation) of the distributions of the GRMS measure for tested unit and each accelerometer location within that unit. For the test of hypothesis, the delta mean of the distributions and standard deviation were used to compute the level of confidence at which the null hypothesis could be rejected in favor of the alternative 
hypothesis. For any given accelerometer location, the delta mean was computed by subtracting the mean of the Baseline distribution of the GRMS measure from that of the Upgrade Unit. In each case, except for the front-right vertical accelerations and the hitch longitudinal accelerations, the delta mean was negative, indicating that the Baseline Unit transmitted (on average) higher accelerations than the Upgrade Unit. For the two cases (front-right vertical accelerations and the hitch longitudinal accelerations) and for any other cases in the following subsections where the delta mean has a different sign (positive) from what would be expected (negative), the delta mean is shown in italics.

The last row of the tables always includes the confidence level at which the null hypothesis could be rejected in favor of the alternative hypothesis. For the vertical direction (Table 25), it was always possible to reject the null hypothesis with $99.9+\%$ confidence (almost certainty), strongly indicating that except for the front right location, the suspension system of the Upgrade Unit always transmitted lower vertical accelerations than the suspension system of the Baseline Unit.

In the case of the longitudinal accelerations (accelerations in the direction of travel), it was possible to reject the null hypothesis with $99.9+\%$ confidence for the front right, center, and rear left locations (see Table 26). For the front left and rear right, although on average the Upgrade Unit transmitted lower accelerations than the Baseline Unit, it was not possible to reject the null hypothesis at a reasonable level of confidence (i.e., >=95\%). For these cases, the confidence level is shown in italics in the tables below. For the lateral direction, it was always possible to reject the null hypothesis in favor of the alternative hypothesis with $99.9+\%$ confidence. This strongly indicated that the Upgrade Unit transmitted lower lateral accelerations than the Baseline Unit

Table 25. Statistical Comparison of GRMS Measure: Baseline Unit vs. Upgrade Unit All Accelerometers - Vertical Direction

\begin{tabular}{|c|c|c|c|c|c|c|c|c|c|c|c|c|}
\hline \multirow{2}{*}{ Statistics } & \multicolumn{2}{|c|}{ Front Left } & \multicolumn{2}{|c|}{ Hitch } & \multicolumn{2}{|c|}{ Front Right } & \multicolumn{2}{|c|}{ Center } & \multicolumn{2}{|c|}{ Rear Left } & \multicolumn{2}{|c|}{ Rear Right } \\
\hline & B & $\mathbf{U}$ & B & $\mathbf{U}$ & B & $\mathbf{U}$ & B & $\mathbf{U}$ & B & $\mathbf{U}$ & B & $\mathbf{U}$ \\
\hline Obs. & 202 & 202 & 202 & 202 & 202 & 202 & 202 & 202 & 202 & 202 & 202 & 202 \\
\hline Min. & 0.05 & 0.05 & 0.09 & 0.09 & 0.06 & 0.06 & 0.13 & 0.10 & 0.07 & 0.06 & 0.07 & 0.06 \\
\hline Max. & 0.06 & 0.06 & 0.18 & 0.12 & 0.07 & 0.07 & 0.21 & 0.20 & 0.08 & 0.08 & 0.08 & 0.08 \\
\hline Mean & 0.06 & 0.06 & 0.10 & 0.10 & 0.06 & 0.07 & 0.18 & 0.15 & 0.07 & 0.07 & 0.08 & 0.07 \\
\hline Std. Dev. & 0.00 & 0.00 & 0.00 & 0.00 & 0.00 & 0.00 & 0.01 & 0.01 & 0.00 & 0.00 & 0.00 & 0.00 \\
\hline Delta Mean & \multicolumn{2}{|c|}{-0.001} & \multicolumn{2}{|c|}{-0.002} & \multicolumn{2}{|c|}{0.002} & \multicolumn{2}{|c|}{-0.036} & \multicolumn{2}{|c|}{-0.001} & \multicolumn{2}{|c|}{-0.007} \\
\hline Std. Dev. Diff. & \multicolumn{2}{|c|}{0.000} & \multicolumn{2}{|c|}{0.001} & \multicolumn{2}{|c|}{0.000} & \multicolumn{2}{|c|}{0.001} & \multicolumn{2}{|c|}{0.000} & \multicolumn{2}{|c|}{0.000} \\
\hline $\mathbf{Z}$ & \multicolumn{2}{|c|}{-5.582} & \multicolumn{2}{|c|}{-2.338} & \multicolumn{2}{|c|}{6.808} & \multicolumn{2}{|c|}{-24.564} & \multicolumn{2}{|c|}{-5.504} & \multicolumn{2}{|c|}{-27.317} \\
\hline P-value & \multicolumn{2}{|c|}{$1.2 \mathrm{E}-08$} & \multicolumn{2}{|c|}{0.010} & \multicolumn{2}{|c|}{1.000} & \multicolumn{2}{|c|}{0.000} & \multicolumn{2}{|c|}{$1.9 \mathrm{E}-08$} & \multicolumn{2}{|c|}{0.000} \\
\hline $\begin{array}{l}\text { Reject Ho at } \\
\text { confidence } \\
\text { level }\end{array}$ & \multicolumn{2}{|c|}{$99.9+\%$} & \multicolumn{2}{|c|}{$99.0 \%$} & \multicolumn{2}{|c|}{$\begin{array}{c}\text { Cannot } \\
\text { Reject Ho }\end{array}$} & \multicolumn{2}{|c|}{$99.9+\%$} & \multicolumn{2}{|c|}{$99.9+\%$} & \multicolumn{2}{|c|}{$99.9+\%$} \\
\hline
\end{tabular}


Table 26. Statistical Comparison of GRMS Measure: Baseline Unit vs. Upgrade Unit All Accelerometers - Longitudinal Direction

\begin{tabular}{|c|c|c|c|c|c|c|c|c|c|c|c|c|}
\hline \multirow{2}{*}{ Statistics } & \multicolumn{2}{|c|}{ Front Left } & \multicolumn{2}{|c|}{ Hitch } & \multicolumn{2}{|c|}{ Front Right } & \multicolumn{2}{|c|}{ Center } & \multicolumn{2}{|c|}{ Rear Left } & \multicolumn{2}{|c|}{ Rear Right } \\
\hline & B & $\mathbf{U}$ & B & $\mathbf{U}$ & B & $\mathbf{U}$ & B & $\mathbf{U}$ & B & $\mathbf{U}$ & B & $\mathbf{U}$ \\
\hline Obs. & 202 & 202 & 202 & 202 & 202 & 202 & 202 & 202 & 202 & 202 & 202 & 202 \\
\hline Min. & 0.02 & 0.02 & 0.05 & 0.06 & 0.03 & 0.02 & 0.02 & 0.02 & 0.03 & 0.03 & 0.02 & 0.02 \\
\hline Max. & 0.03 & 0.03 & 0.06 & 0.07 & 0.03 & 0.03 & 0.05 & 0.03 & 0.04 & 0.04 & 0.03 & 0.03 \\
\hline Mean & 0.03 & 0.03 & 0.05 & 0.06 & 0.03 & 0.03 & 0.03 & 0.02 & 0.04 & 0.03 & 0.03 & 0.03 \\
\hline Std. Dev. & 0.00 & 0.00 & 0.00 & 0.00 & 0.00 & 0.00 & 0.00 & 0.00 & 0.00 & 0.00 & 0.00 & 0.00 \\
\hline Delta Mean & \multicolumn{2}{|c|}{0.000} & \multicolumn{2}{|c|}{0.010} & \multicolumn{2}{|c|}{-0.002} & \multicolumn{2}{|c|}{-0.004} & \multicolumn{2}{|c|}{-0.004} & \multicolumn{2}{|c|}{0.000} \\
\hline Std. Dev. Diff. & \multicolumn{2}{|c|}{0.000} & \multicolumn{2}{|c|}{0.000} & \multicolumn{2}{|c|}{0.000} & \multicolumn{2}{|c|}{0.001} & \multicolumn{2}{|c|}{0.000} & \multicolumn{2}{|c|}{0.000} \\
\hline $\mathbf{Z}$ & \multicolumn{2}{|c|}{0.276} & \multicolumn{2}{|c|}{26.965} & \multicolumn{2}{|c|}{-9.707} & \multicolumn{2}{|c|}{-7.018} & \multicolumn{2}{|c|}{-11.616} & \multicolumn{2}{|c|}{-0.812} \\
\hline P-value & \multicolumn{2}{|c|}{0.609} & \multicolumn{2}{|c|}{1.000} & \multicolumn{2}{|c|}{0.000} & \multicolumn{2}{|c|}{$1.1 \mathrm{E}-12$} & \multicolumn{2}{|c|}{0.000} & \multicolumn{2}{|c|}{0.208} \\
\hline $\begin{array}{l}\text { Reject Ho at } \\
\text { confidence } \\
\text { level }\end{array}$ & \multicolumn{2}{|c|}{$<85.0 \%$} & \multicolumn{2}{|c|}{$\begin{array}{c}\text { Cannot } \\
\text { Reject Ho }\end{array}$} & \multicolumn{2}{|c|}{$99.9+\%$} & \multicolumn{2}{|c|}{$99.9+\%$} & \multicolumn{2}{|c|}{$99.9+\%$} & \multicolumn{2}{|c|}{$<85.0 \%$} \\
\hline
\end{tabular}

Table 27. Statistical Comparison of GRMS Measure: Baseline Unit vs. Upgrade Unit All Accelerometers - Lateral Direction

\begin{tabular}{|c|c|c|c|c|c|c|c|c|c|c|c|c|}
\hline \multirow{2}{*}{ Statistics } & \multicolumn{2}{|c|}{ Front Left } & \multicolumn{2}{|c|}{ Hitch } & \multicolumn{2}{|c|}{ Front Right } & \multicolumn{2}{|c|}{ Center } & \multicolumn{2}{|c|}{ Rear Left } & \multicolumn{2}{|c|}{ Rear Right } \\
\hline & B & $\mathbf{U}$ & B & $\mathbf{U}$ & B & $\mathbf{U}$ & B & $\mathbf{U}$ & B & $\mathbf{U}$ & B & $\mathbf{U}$ \\
\hline Obs. & 202 & 202 & 202 & 202 & 202 & 202 & 202 & 202 & 171 & 171 & 202 & 202 \\
\hline Min. & 0.03 & 0.03 & 0.09 & 0.09 & 0.03 & 0.03 & 0.03 & 0.02 & 0.04 & 0.03 & 0.04 & 0.03 \\
\hline Max. & 0.04 & 0.04 & 0.11 & 0.12 & 0.04 & 0.04 & 0.04 & 0.04 & 0.05 & 0.05 & 0.05 & 0.04 \\
\hline Mean & 0.04 & 0.04 & 0.10 & 0.10 & 0.04 & 0.04 & 0.03 & 0.03 & 0.04 & 0.04 & 0.04 & 0.04 \\
\hline Std. Dev. & 0.00 & 0.00 & 0.00 & 0.00 & 0.00 & 0.00 & 0.00 & 0.00 & 0.00 & 0.00 & 0.00 & 0.00 \\
\hline Delta Mean & \multicolumn{2}{|c|}{-0.001} & \multicolumn{2}{|c|}{-0.002} & \multicolumn{2}{|c|}{-0.001} & \multicolumn{2}{|c|}{-0.003} & \multicolumn{2}{|c|}{-0.002} & \multicolumn{2}{|c|}{-0.004} \\
\hline Std. Dev. Diff. & \multicolumn{2}{|c|}{0.000} & \multicolumn{2}{|c|}{0.001} & \multicolumn{2}{|c|}{0.000} & \multicolumn{2}{|c|}{0.000} & \multicolumn{2}{|c|}{0.000} & \multicolumn{2}{|c|}{0.000} \\
\hline $\mathbf{Z}$ & \multicolumn{2}{|c|}{-7.300} & \multicolumn{2}{|c|}{-2.987} & \multicolumn{2}{|c|}{-6.626} & \multicolumn{2}{|c|}{-13.277} & \multicolumn{2}{|c|}{-7.257} & \multicolumn{2}{|c|}{-14.922} \\
\hline P-value & \multicolumn{2}{|c|}{$1.4 \mathrm{E}-13$} & \multicolumn{2}{|c|}{0.001} & \multicolumn{2}{|c|}{$1.7 \mathrm{E}-11$} & \multicolumn{2}{|c|}{0.000} & \multicolumn{2}{|c|}{$2.0 \mathrm{E}-13$} & \multicolumn{2}{|c|}{0.000} \\
\hline $\begin{array}{l}\text { Reject Ho at } \\
\text { confidence } \\
\text { level }\end{array}$ & \multicolumn{2}{|c|}{$99.9+\%$} & \multicolumn{2}{|c|}{$99.9 \%$} & \multicolumn{2}{|c|}{$99.9+\%$} & \multicolumn{2}{|c|}{$99.9+\%$} & \multicolumn{2}{|c|}{$99.9+\%$} & \multicolumn{2}{|c|}{$99.9+\%$} \\
\hline
\end{tabular}




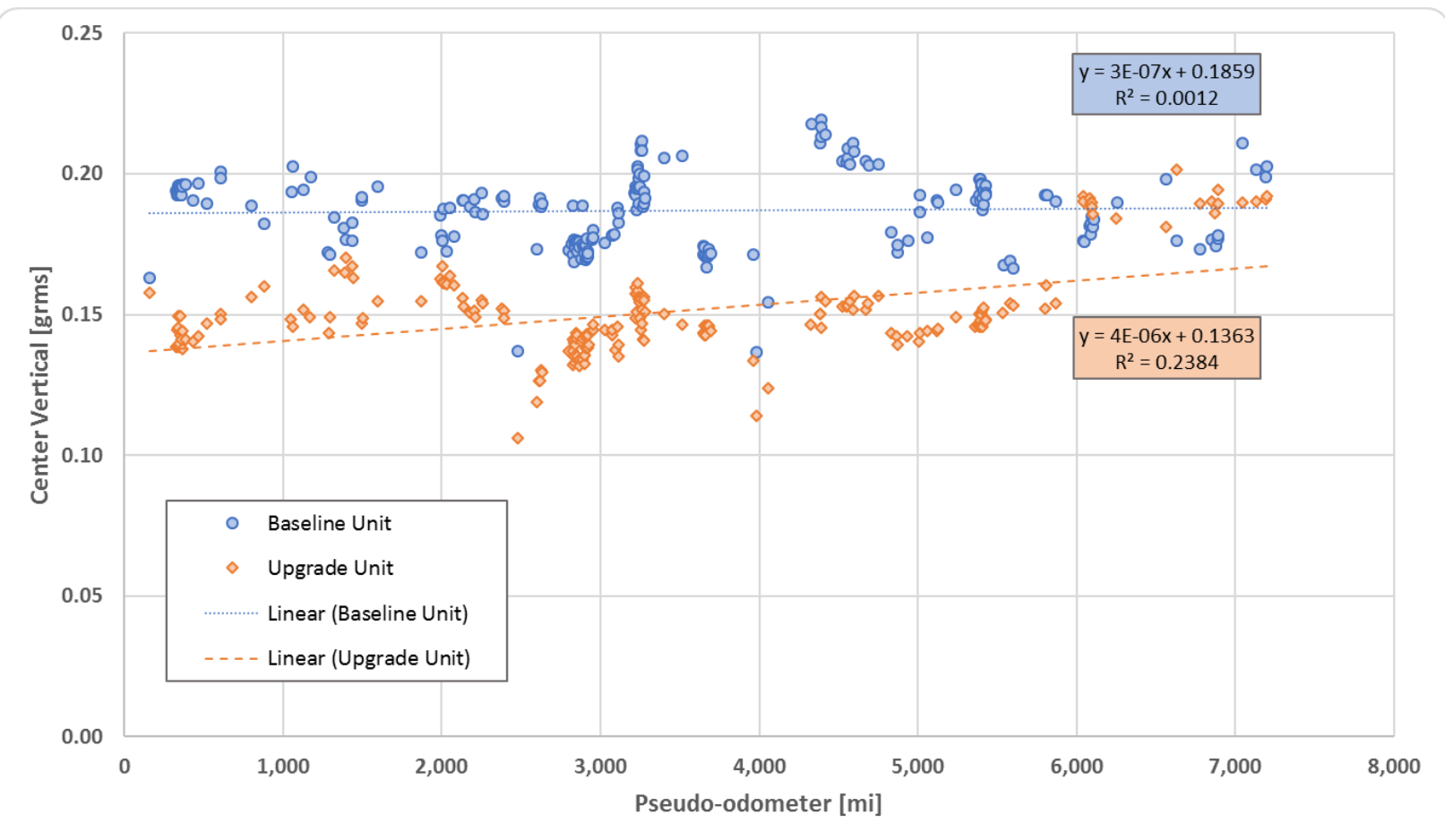

Figure 43. Part C2 - Baseline and Upgrade Units GRMS for Vertical Accelerometer at Axle Group (Center) Selected Laps for Statistical Analysis.

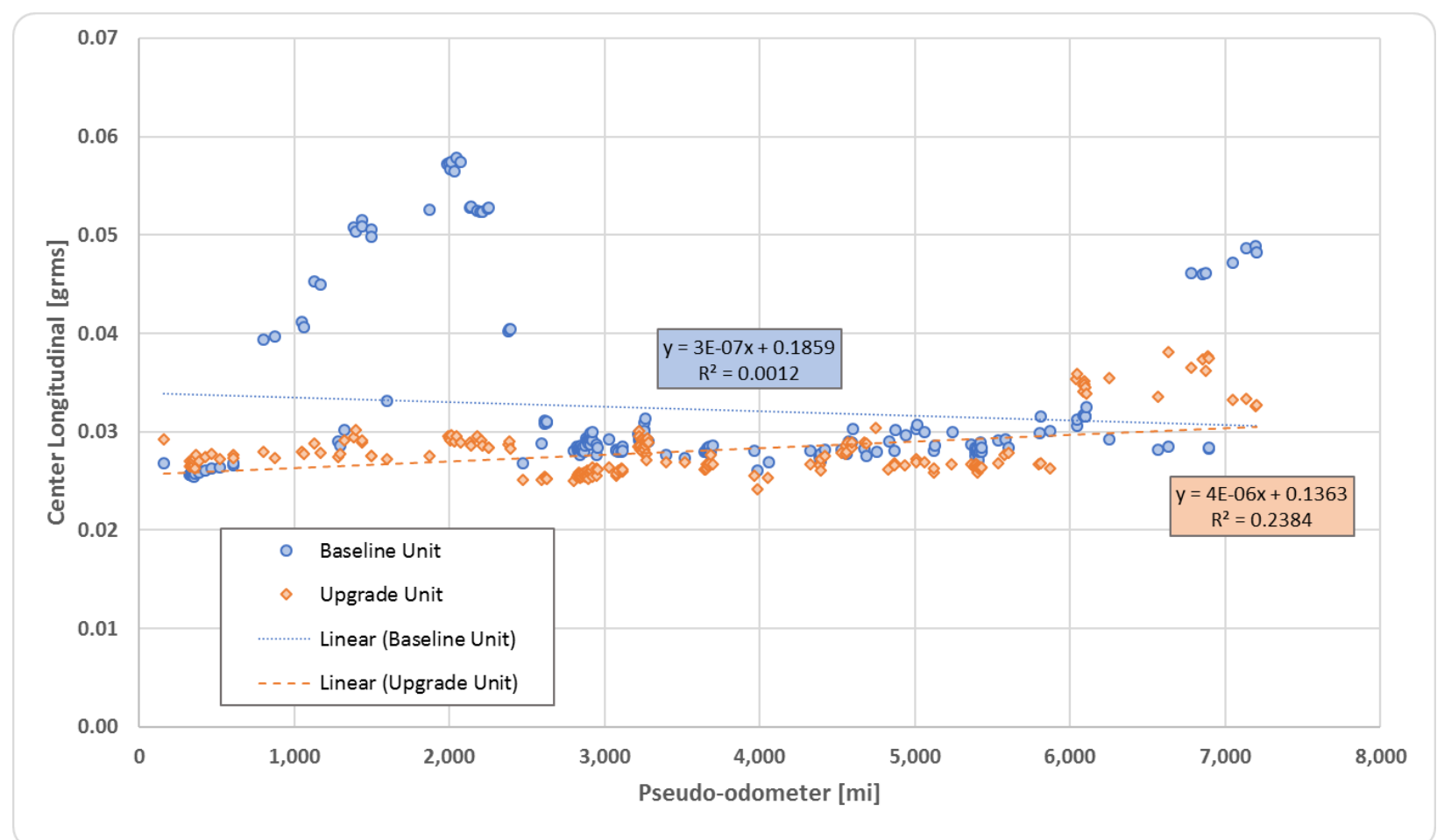

Figure 44. Part C2 - Baseline and Upgrade Units GRMS for Longitudinal Accelerometer at Axle Group (Center) - Selected Laps for Statistical Analysis. 


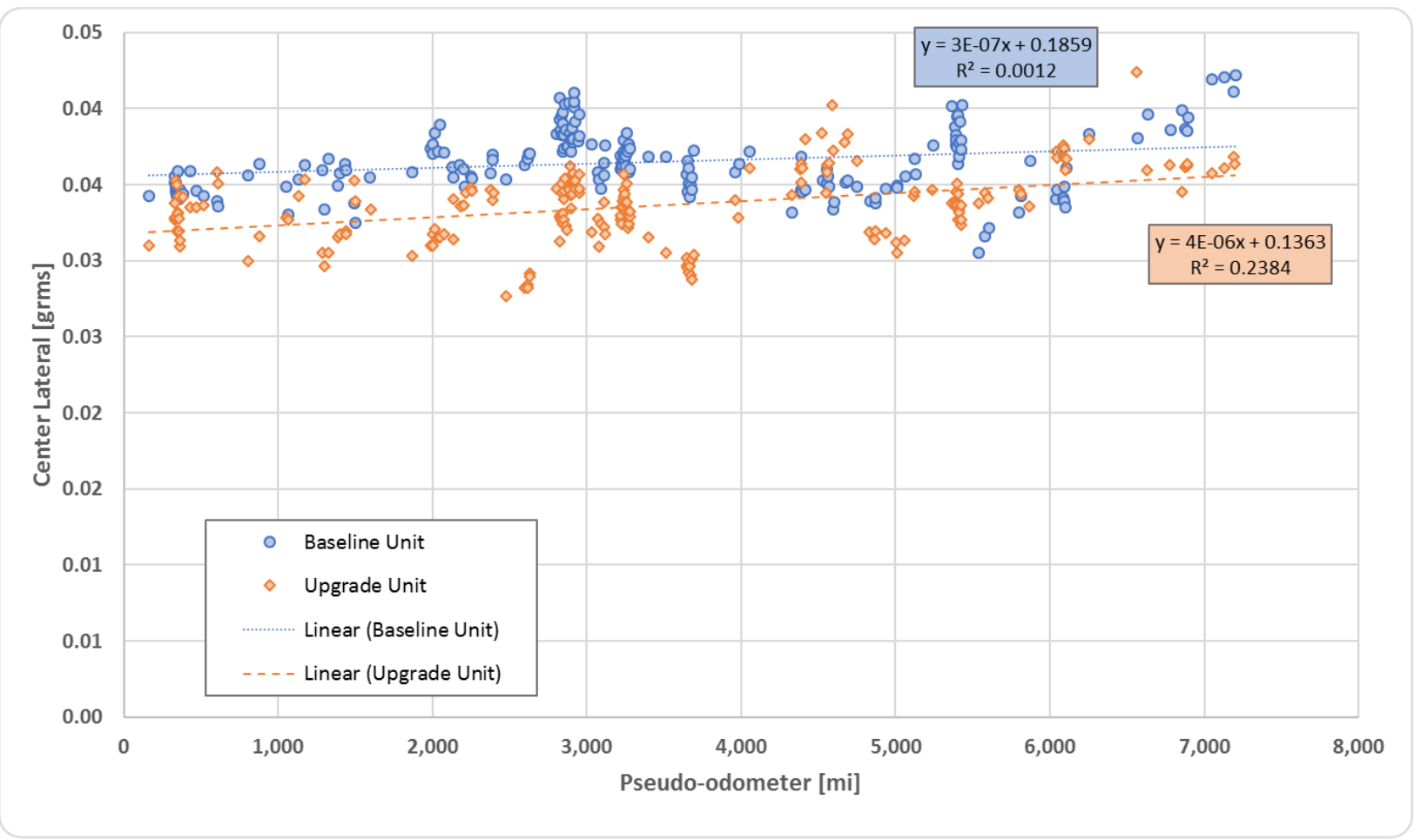

Figure 45. Part C2 - Baseline and Upgrade Units GRMS for Lateral Accelerometer at Axle Group (Center) Selected Laps for Statistical Analysis.

The data for the statistical analysis was further divided into clockwise and counter-clockwise laps. This was done to check whether the direction of travel had any effect on the results obtained when all laps (i.e., any direction of travel) were considered. The results of the statistical tests are presented in APPENDIX C. The results for both the clockwise and counter-clockwise lap clusters are similar to those presented above, showing that the Upgrade Unit transmitted lower accelerations to the MHU that the Baseline Unit. For the center accelerometer it was always possible to reject the null hypothesis in favor of the alternative hypothesis with $99.9+\%$ confidence. This was true for both clockwise and counter-clockwise direction of travel and for the vertical, longitudinal, and lateral accelerations.

APPENDIX C also presents a statistical analysis comparing the direction of travel (clockwise and counter-clockwise) for each unit tested. In general, there was no difference between one direction of travel and the other, for both units. However, for the acceleration at the center of each MHU and considering the lateral accelerations, the counter-clockwise direction showed lower accelerations for the Upgrade Unit than the clockwise direction of travel (null hypothesis rejected with 99.9+\% confidence). The reverse was true for the Baseline Unit.

\subsubsection{Effect of Suspension on Vibrations: Upgrade Unit Radial Tires vs. Regular Tires}

Data was collected for the Upgrade Unit with both regular and radial tires. A statistical analysis was conducted to compare the accelerations transmitted to the MHU by these two types of tires. As described above, the first step in the analysis methodology was to select laps where the average speed of one alternative (e.g., regular tires) and the other (radial tires) was less than a certain threshold. In this case, since the laps were not simultaneous, only laps with a certain speed range (e.g., 60.15 to $60.30 \mathrm{mph}$ ) were selected. Moreover, for fairness in the comparison and since the radial-tire test was run for just 2,400 miles, only observations for the first 2,400 miles of the regular tire test were considered for the analysis. 
Summary statistics for the selected laps are presented in Table 28. As shown in that table, the mean of the speed distributions was the same, independent of the tire type or the direction of travel.

Table 28. Vehicle Speed Distribution Parameters

Upgrade Unit with Radial and Regular Tires-Selected Laps for Analysis

\begin{tabular}{|l|r|r|r|r|r|r|}
\hline \multirow{2}{*}{ Statistics } & \multicolumn{3}{|c|}{ Radial Tires } & \multicolumn{3}{c|}{ Regular Tires } \\
\cline { 2 - 7 } & All Laps & $\begin{array}{c}\text { CW } \\
\text { Laps }\end{array}$ & $\begin{array}{c}\text { CCW } \\
\text { Laps }\end{array}$ & All Laps & $\begin{array}{c}\text { CW } \\
\text { Laps }\end{array}$ & $\begin{array}{c}\text { CCW } \\
\text { Laps }\end{array}$ \\
\hline Obs. & 105 & 37 & 68 & 99 & 61 & 38 \\
\hline Min. [mph] & 60.2 & 60.2 & 60.2 & 60.2 & 60.2 & 60.2 \\
\hline Max. [mph] & 60.3 & 60.3 & 60.3 & 60.3 & 60.3 & 60.3 \\
\hline Mean [mph] & 60.2 & 60.2 & 60.2 & 60.2 & 60.2 & 60.2 \\
\hline Std. Dev. & 0.04 & 0.03 & 0.04 & 0.03 & 0.03 & 0.04 \\
\hline
\end{tabular}

The statistical analysis with the results of the tests of hypothesis are presented in Table 29, Table 30, and Table 31. Figure 46, Figure 47, and Figure 48 show the data used for the statistical tests for the three axes of the accelerometer located at the center of the Upgrade Unit MHU for the regular and radial tire cases. For the vertical accelerations at the center of the MHU (see Table 29), the radial tires transmitted a lower level of accelerations than the regular tires. In that case it was possible to reject the null hypothesis that both types of tires transmitted, on average, the same level of accelerations in favor of the alternative hypothesis that the accelerations were lower in the case of the radial tires than for the regular tires with a confidence level of $99.9+\%$. The same was true for the front left and rear left locations. For the other locations, there was no statistically significant difference between the two types of tires.

For the longitudinal and lateral accelerations (Table 30 and Table 31), the radial tires transmitted, on average, statistically significant lower accelerations for any of the six acceleration locations. In every case, it was possible to reject the null hypothesis in favor of the alternative hypothesis with $99.9+\%$ confidence level, except for the Center accelerometer for the longitudinal direction in which it was not possible to reject the null hypothesis (see Table 30).

Table 29. Statistical Comparison of GRMS Measure: Radial Tires vs. Regular Tires Upgrade Unit - All Accelerometers - Vertical Direction

\begin{tabular}{|c|c|c|c|c|c|c|c|c|c|c|c|c|}
\hline \multirow{2}{*}{ Statistics } & \multicolumn{2}{|c|}{ Front Left } & \multicolumn{2}{|c|}{ Hitch } & \multicolumn{2}{|c|}{ Front Right } & \multicolumn{2}{|c|}{ Center } & \multicolumn{2}{|c|}{ Rear Left } & \multicolumn{2}{|c|}{ Rear Right } \\
\hline & Radial & Reg. & Radial & Reg. & Radial & Reg. & Radial & Reg. & Radial & Reg. & Radial & Reg. \\
\hline Obs. & 105 & 99 & 105 & 99 & 105 & 99 & 105 & 99 & 105 & 99 & 105 & 99 \\
\hline Min. & 0.05 & 0.06 & 0.09 & 0.09 & 0.06 & 0.06 & 0.10 & 0.14 & 0.03 & 0.07 & 0.06 & 0.07 \\
\hline Max. & 0.06 & 0.07 & 0.17 & 0.12 & 0.07 & 0.07 & 0.12 & 0.16 & 0.08 & 0.08 & 0.07 & 0.07 \\
\hline Mean & 0.06 & 0.06 & 0.10 & 0.10 & 0.07 & 0.07 & 0.11 & 0.15 & 0.07 & 0.07 & 0.07 & 0.07 \\
\hline Std. Dev. & 0.00 & 0.00 & 0.00 & 0.00 & 0.00 & 0.00 & 0.00 & 0.00 & 0.01 & 0.00 & 0.00 & 0.00 \\
\hline Delta Mean & \multicolumn{2}{|r|}{-0.003} & \multicolumn{2}{|r|}{0.000} & \multicolumn{2}{|r|}{0.002} & \multicolumn{2}{|r|}{-0.042} & \multicolumn{2}{|r|}{-0.006} & \multicolumn{2}{|r|}{0.000} \\
\hline Std. Dev. Diff. & \multicolumn{2}{|r|}{0.000} & \multicolumn{2}{|r|}{0.001} & \multicolumn{2}{|r|}{0.000} & \multicolumn{2}{|r|}{0.001} & \multicolumn{2}{|r|}{0.002} & \multicolumn{2}{|r|}{0.000} \\
\hline $\mathbf{Z}$ & \multicolumn{2}{|c|}{-11.656} & \multicolumn{2}{|r|}{-0.198} & \multicolumn{2}{|r|}{5.019} & \multicolumn{2}{|c|}{-63.449} & \multicolumn{2}{|r|}{-3.279} & \multicolumn{2}{|r|}{0.527} \\
\hline P-value & \multicolumn{2}{|c|}{0.000} & \multicolumn{2}{|r|}{0.421} & & 0.999 & \multicolumn{2}{|r|}{0.000} & \multicolumn{2}{|r|}{0.001} & \multicolumn{2}{|r|}{0.701} \\
\hline $\begin{array}{l}\text { Reject Ho at } \\
\text { confidence } \\
\text { level }\end{array}$ & \multicolumn{2}{|c|}{$99.9+\%$} & \multicolumn{2}{|r|}{$<60 \%$} & \multicolumn{2}{|c|}{$\begin{array}{c}\text { Cannot } \\
\text { Reject Ho }\end{array}$} & \multicolumn{2}{|c|}{$99.9+\%$} & \multicolumn{2}{|r|}{$99.9 \%$} & \multicolumn{2}{|r|}{$<60 \%$} \\
\hline
\end{tabular}


Table 30. Statistical Comparison of GRMS Measure: Radial Tires vs. Regular Tires Upgrade Unit - All Accelerometers - Longitudinal Direction

\begin{tabular}{|c|c|c|c|c|c|c|c|c|c|c|c|c|}
\hline \multirow{2}{*}{ Statistics } & \multicolumn{2}{|c|}{ Front Left } & \multicolumn{2}{|c|}{ Hitch } & \multicolumn{2}{|c|}{ Front Right } & \multicolumn{2}{|c|}{ Center } & \multicolumn{2}{|c|}{ Rear Left } & \multicolumn{2}{|c|}{ Rear Right } \\
\hline & Radial & Reg. & Radial & Reg. & Radial & Reg. & Radial & Reg. & Radial & Reg. & Radial & Reg. \\
\hline Obs. & 105 & 99 & 105 & 99 & 105 & 99 & 105 & 99 & 105 & 99 & 105 & 99 \\
\hline Min. & 0.02 & 0.02 & 0.05 & 0.06 & 0.02 & 0.02 & 0.02 & 0.02 & 0.03 & 0.03 & 0.02 & 0.02 \\
\hline Max. & 0.03 & 0.03 & 0.07 & 0.07 & 0.03 & 0.03 & 0.03 & 0.03 & 0.03 & 0.04 & 0.03 & 0.03 \\
\hline Mean & 0.02 & 0.03 & 0.06 & 0.06 & 0.02 & 0.03 & 0.02 & 0.02 & 0.03 & 0.03 & 0.02 & 0.03 \\
\hline Std. Dev. & 0.00 & 0.00 & 0.00 & 0.00 & 0.00 & 0.00 & 0.00 & 0.00 & 0.00 & 0.00 & 0.00 & 0.00 \\
\hline Delta Mean & \multicolumn{2}{|c|}{-0.001} & \multicolumn{2}{|c|}{-0.002} & \multicolumn{2}{|c|}{-0.003} & \multicolumn{2}{|c|}{0.000} & \multicolumn{2}{|c|}{-0.003} & \multicolumn{2}{|c|}{-0.002} \\
\hline Std. Dev. Diff. & \multicolumn{2}{|c|}{0.000} & \multicolumn{2}{|c|}{0.000} & \multicolumn{2}{|c|}{0.000} & \multicolumn{2}{|c|}{0.000} & \multicolumn{2}{|c|}{0.000} & \multicolumn{2}{|c|}{0.000} \\
\hline $\mathbf{Z}$ & \multicolumn{2}{|c|}{-8.619} & \multicolumn{2}{|c|}{-5.323} & \multicolumn{2}{|c|}{-15.898} & \multicolumn{2}{|c|}{2.114} & \multicolumn{2}{|c|}{-19.241} & \multicolumn{2}{|c|}{-12.610} \\
\hline P-value & \multicolumn{2}{|c|}{0.000} & \multicolumn{2}{|c|}{$5.1 \mathrm{E}-08$} & \multicolumn{2}{|c|}{0.000} & \multicolumn{2}{|c|}{0.983} & \multicolumn{2}{|c|}{0.000} & \multicolumn{2}{|c|}{0.000} \\
\hline $\begin{array}{l}\text { Reject Ho at } \\
\text { confidence } \\
\text { level }\end{array}$ & \multicolumn{2}{|c|}{$99.9+\%$} & \multicolumn{2}{|c|}{$99.9+\%$} & \multicolumn{2}{|c|}{$99.9+\%$} & \multicolumn{2}{|c|}{$\begin{array}{c}\text { Cannot } \\
\text { Reject Ho }\end{array}$} & \multicolumn{2}{|c|}{$99.9+\%$} & \multicolumn{2}{|c|}{$99.9+\%$} \\
\hline
\end{tabular}

Table 31. Statistical Comparison of GRMS Measure: Radial Tires vs. Regular Tires Upgrade Unit - All Accelerometers - Lateral Direction

\begin{tabular}{|c|c|c|c|c|c|c|c|c|c|c|c|c|}
\hline \multirow{2}{*}{ Statistics } & \multicolumn{2}{|c|}{ Front Left } & \multicolumn{2}{|c|}{ Hitch } & \multicolumn{2}{|c|}{ Front Right } & \multicolumn{2}{|c|}{ Center } & \multicolumn{2}{|c|}{ Rear Left } & \multicolumn{2}{|c|}{ Rear Right } \\
\hline & Radial & Reg. & Radial & Reg. & Radial & Reg. & Radial & Reg. & Radial & Reg. & Radial & Reg. \\
\hline Obs. & 105 & 99 & 105 & 99 & 105 & 99 & 105 & 99 & 105 & 99 & 105 & 99 \\
\hline Min. & 0.03 & 0.03 & 0.08 & 0.09 & 0.03 & 0.03 & 0.02 & 0.02 & 0.03 & 0.03 & 0.03 & 0.03 \\
\hline Max. & 0.04 & 0.04 & 0.11 & 0.11 & 0.04 & 0.04 & 0.03 & 0.03 & 0.04 & 0.04 & 0.04 & 0.04 \\
\hline Mean & 0.03 & 0.04 & 0.09 & 0.10 & 0.03 & 0.04 & 0.03 & 0.03 & 0.03 & 0.04 & 0.03 & 0.04 \\
\hline Std. Dev. & 0.00 & 0.00 & 0.00 & 0.00 & 0.00 & 0.00 & 0.00 & 0.00 & 0.00 & 0.00 & 0.00 & 0.00 \\
\hline Delta Mean & \multicolumn{2}{|c|}{-0.002} & \multicolumn{2}{|c|}{-0.006} & \multicolumn{2}{|c|}{-0.002} & \multicolumn{2}{|c|}{-0.001} & \multicolumn{2}{|c|}{-0.003} & \multicolumn{2}{|c|}{-0.003} \\
\hline Std. Dev. Diff. & \multicolumn{2}{|c|}{0.000} & \multicolumn{2}{|c|}{0.001} & \multicolumn{2}{|c|}{0.000} & \multicolumn{2}{|c|}{0.000} & \multicolumn{2}{|c|}{0.000} & \multicolumn{2}{|c|}{0.000} \\
\hline $\mathbf{Z}$ & \multicolumn{2}{|c|}{-8.191} & \multicolumn{2}{|c|}{-8.379} & \multicolumn{2}{|c|}{-9.011} & \multicolumn{2}{|c|}{-3.368} & \multicolumn{2}{|c|}{-8.554} & \multicolumn{2}{|c|}{-8.919} \\
\hline P-value & \multicolumn{2}{|c|}{0.000} & \multicolumn{2}{|c|}{0.000} & \multicolumn{2}{|c|}{0.000} & \multicolumn{2}{|c|}{0.000} & \multicolumn{2}{|c|}{0.000} & \multicolumn{2}{|c|}{0.000} \\
\hline $\begin{array}{l}\text { Reject Ho at } \\
\text { confidence } \\
\text { level }\end{array}$ & \multicolumn{2}{|c|}{$99.9+\%$} & \multicolumn{2}{|c|}{$99.9+\%$} & \multicolumn{2}{|c|}{$99.9+\%$} & \multicolumn{2}{|c|}{$99.9+\%$} & \multicolumn{2}{|c|}{$99.9+\%$} & \multicolumn{2}{|c|}{$99.9+\%$} \\
\hline
\end{tabular}




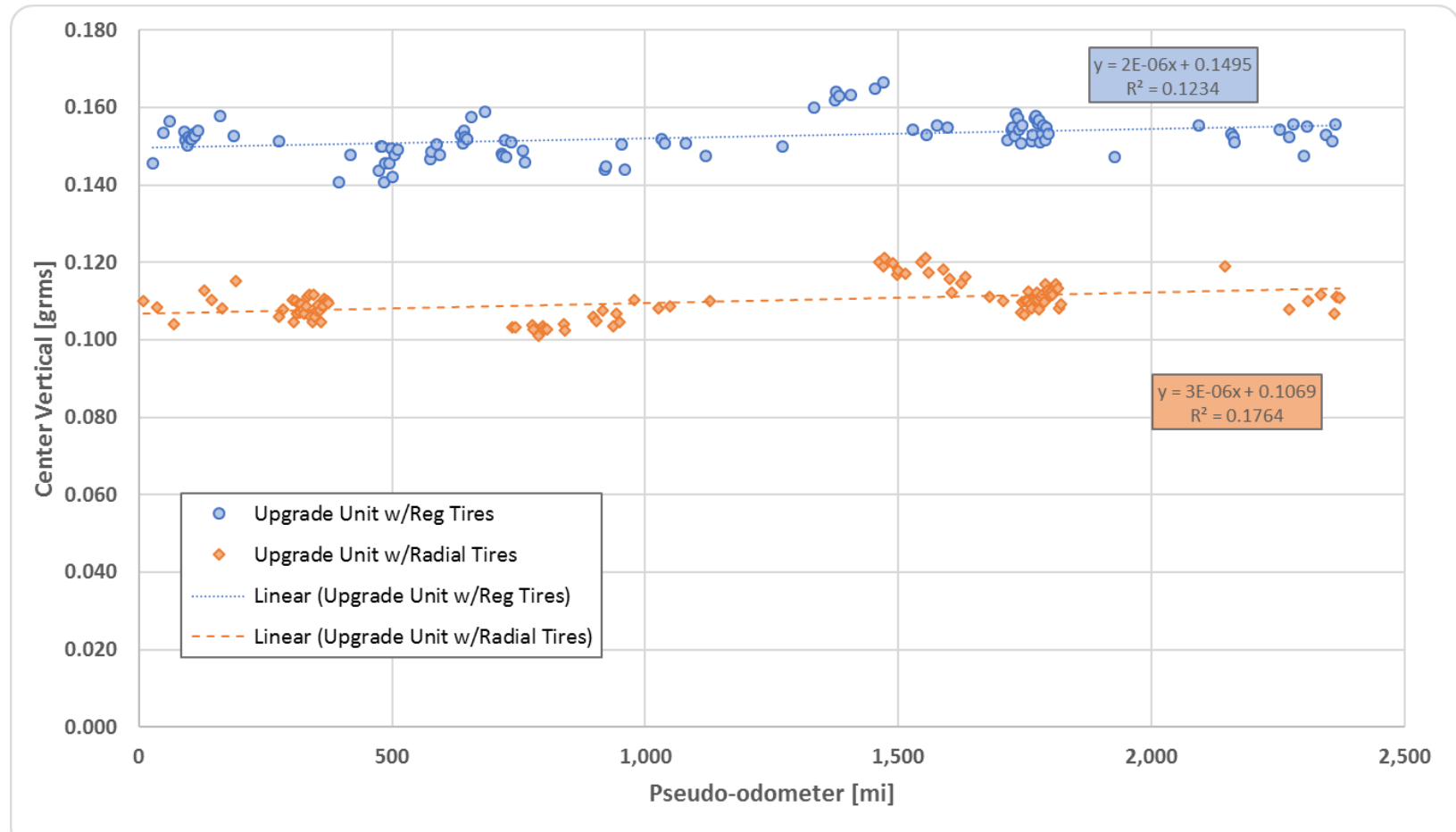

Figure 46. Upgrade Unit with Regular and Radial Tires GRMS for Vertical Accelerometer at Axle Group (Center) - Selected Laps for Statistical Analysis.

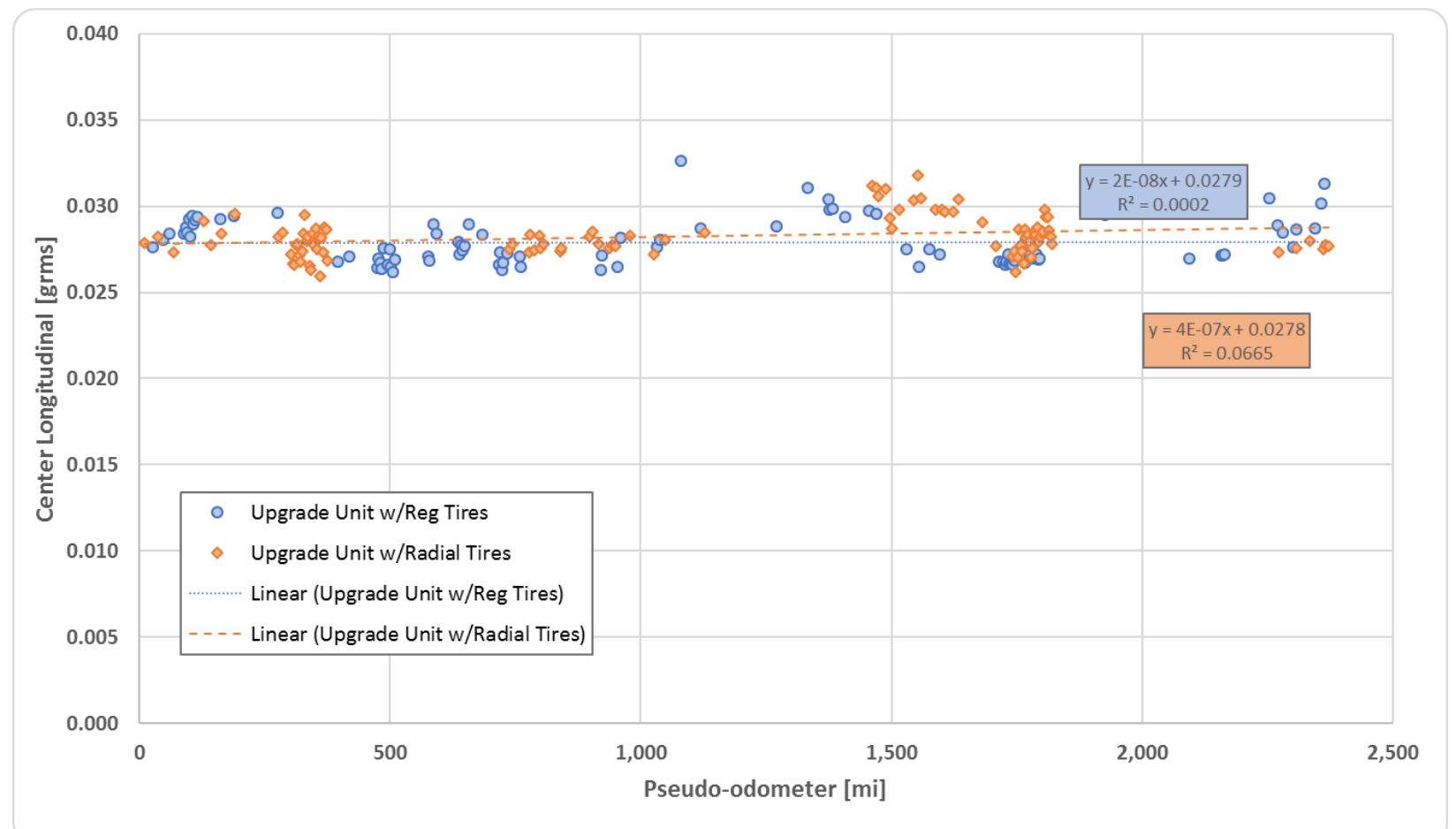

Figure 47. Upgrade Unit with Regular and Radial Tires GRMS for Longitudinal Accelerometer at Axle Group (Center) - Selected Laps for Statistical Analysis. 


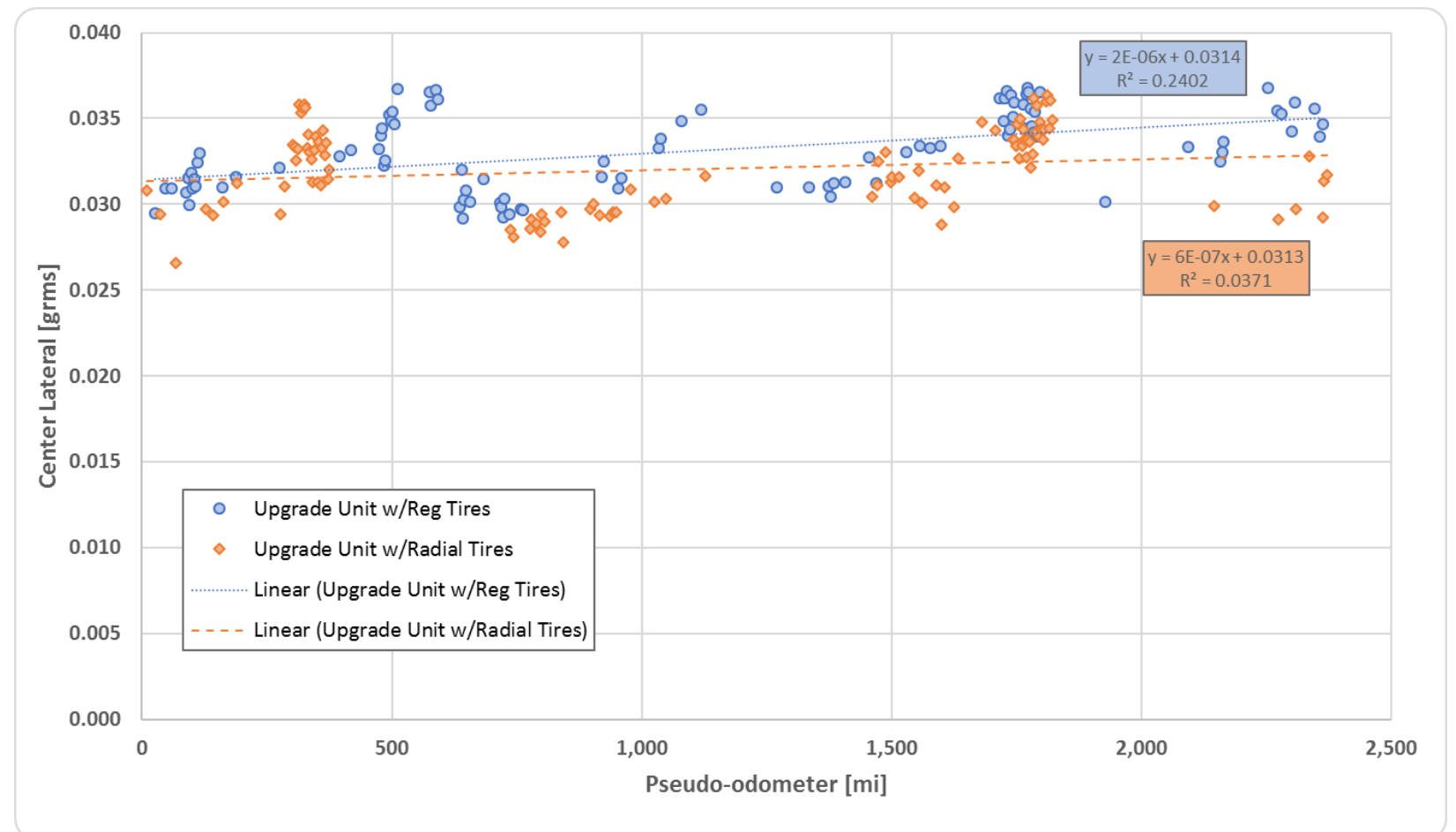

Figure 48. Upgrade Unit with Regular and Radial Tires GRMS for Lateral Accelerometer at Axle Group (Center) - Selected Laps for Statistical Analysis.

A comparison of radial and regular tires clustered by the direction of travel is presented in Error!

Reference source not found.. For the clockwise laps, the radial tires showed, on average, statistically significant lower vertical accelerations than the regular tires for the accelerometer located at the center of the MHU. This was also the case when the counter-clockwise laps were analyzed. However, in general, there was no statistically significant difference for the longitudinal and lateral accelerations at this accelerometer location for either the clockwise or counter-clockwise direction of travel. The exception was the lateral acceleration for the clockwise laps where the radial tires showed statistically significant lower accelerations.

\subsubsection{Effect of Suspension on Vibrations: Rough-road Test Baseline Unit vs. Upgrade Unit}

Every time the units went from the NPG garage to the test track and vice versa, data was collected on secondary roads in an effort to mimic the "rough-road" conditions that the MHUs encounter when they are deployed. A similar methodology and statistical tests to that described before was used in this case. Table 32 presents statistics regarding the average rough-road segment speed for both the Baseline and Upgrade units. Nineteen observations were selected with the criterion of minimal difference in average speed of the vehicles while traveling on the rough-road segment. The drivers were instructed to travel at a speed of about $20 \mathrm{mph}$, but this speed was not always maintained. 
Table 32. Vehicle Speed Distribution Parameters

Baseline and Upgrade Units - Rough-road Test - Laps Selected for Analysis

\begin{tabular}{|l|r|r|}
\hline Statistics & Baseline Unit & Upgrade Unit \\
\hline Obs. & 19 & 19 \\
\hline Min. & 18.446 & 18.432 \\
\hline Max. & 21.818 & 21.906 \\
\hline Mean & 20.512 & 20.579 \\
\hline Std. Dev. & 1.082 & 1.097 \\
\hline
\end{tabular}

A graphical representation of the speed of each vehicle for each observation used in the analysis is presented in Figure 49. As previously mentioned, ORNL instructed NPG to try to keep the same speed for the two vehicles for each part of the test (longevity and rough-road tests). While it was easier to achieve this "same-speed" objective while testing at the NPG oval test-track, the speed of the vehicles for the rough-road test was more difficult to homogenize. To counter this, ORNL selected for the analysis only segments where the average speeds for the Baseline and Upgrade units were similar. Nevertheless, even when ORNL tried to minimize the speed differences between the two vehicles through selection of data segments for comparison, in 13 runs the speed of the Upgrade Unit was higher that the speed of the Baseline Unit. This put the former at slight disadvantage with respect to the latter for the statistical comparison, since higher speeds generate higher levels of vibration.

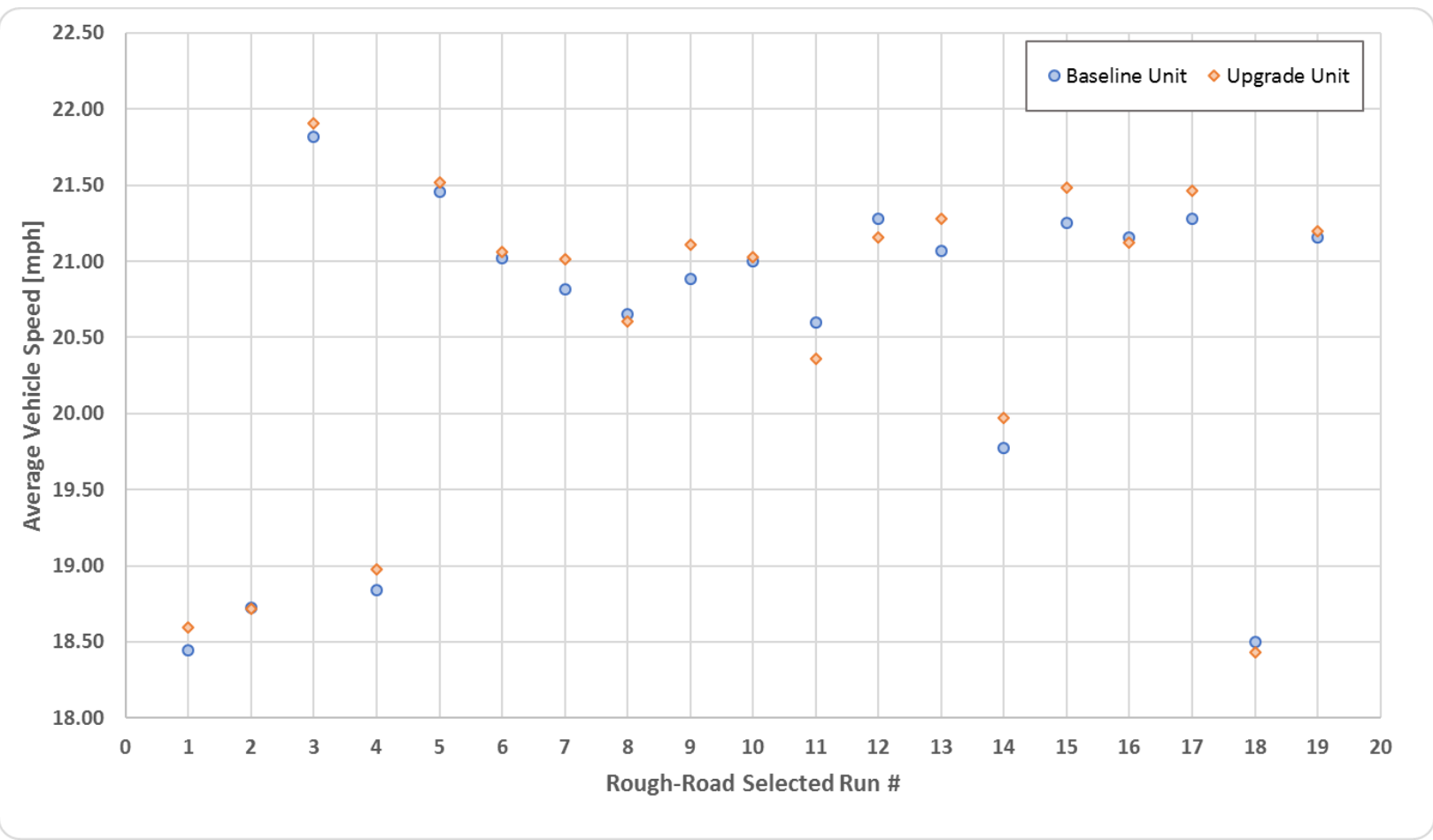

Figure 49. Baseline Unit Tire Failure Histogram (500mile Bins) and Fitted Probability Density Function.

As in the previous subsections, a test of hypothesis was performed to determine if any differences between the tested units existed in the transmission of accelerations during travel to the MHU. In this case, because of the small number of observations, a t-test was used to determine the confidence level at which the null hypothesis (i.e., no difference in average accelerations transmitted by the suspensions of the two units to the MHU) could be rejected in favor of the alternative hypothesis (i.e., the Upgrade Unit, on average, transmitted lower accelerations to the MHU than the Baseline Unit). 
The statistics and results of these tests are presented in Table 33, Table 34, and Table 35 for the vertical, longitudinal, and lateral accelerometers at each one of the six locations where they were deployed.

Except for the accelerometer at the center of the MHU, it was not possible to reject the null hypothesis, thus concluding that there was no difference between the Baseline and Upgrade units for the accelerations transmitted at the Front Left, Hitch, Front Right, Rear Left, and Rear Right locations of the MHU. At the center of the MHU, however, it was possible to reject the null hypothesis with at least $97.6 \%$ confidence, strongly suggesting that Upgrade Unit transmitted, on average, lower accelerations at this position when traveling on rough roads than the Baseline Unit. Figure 50, Figure 51, and Figure 52 present in a graphical form the data that was used for the statistical analysis corresponding to the accelerometer located at the center of the MHU.

Table 33. Statistical Comparison of GRMS Measure: Baseline Unit vs. Upgrade Unit Rough-Road Test - All Accelerometers - Vertical Direction

\begin{tabular}{|c|c|c|c|c|c|c|c|c|c|c|c|c|}
\hline \multirow{2}{*}{ Statistics } & \multicolumn{2}{|c|}{ Front Left } & \multicolumn{2}{|c|}{ Hitch } & \multicolumn{2}{|c|}{ Front Right } & \multicolumn{2}{|c|}{ Center } & \multicolumn{2}{|c|}{ Rear Left } & \multicolumn{2}{|c|}{ Rear Right } \\
\hline & B & $\mathbf{U}$ & B & $\mathbf{U}$ & B & $\mathbf{U}$ & B & $\mathbf{U}$ & B & $\mathbf{U}$ & B & $\mathbf{U}$ \\
\hline Obs. & 19 & 19 & 19 & 19 & 19 & 19 & 19 & 19 & 19 & 19 & 19 & 19 \\
\hline Min. & 0.04 & 0.04 & 0.06 & 0.05 & 0.04 & 0.04 & 0.06 & 0.06 & 0.04 & 0.04 & 0.04 & 0.04 \\
\hline Max. & 0.05 & 0.06 & 0.07 & 0.07 & 0.06 & 0.06 & 0.09 & 0.08 & 0.06 & 0.06 & 0.05 & 0.05 \\
\hline Mean & 0.05 & 0.05 & 0.06 & 0.06 & 0.05 & 0.05 & 0.08 & 0.07 & 0.05 & 0.05 & 0.05 & 0.04 \\
\hline Std. Dev. & 0.00 & 0.00 & 0.00 & 0.00 & 0.00 & 0.00 & 0.00 & 0.00 & 0.00 & 0.00 & 0.00 & 0.00 \\
\hline Delta Mean & \multicolumn{2}{|c|}{0.001} & \multicolumn{2}{|c|}{0.000} & \multicolumn{2}{|c|}{0.002} & \multicolumn{2}{|c|}{-0.011} & \multicolumn{2}{|c|}{0.002} & \multicolumn{2}{|c|}{-0.001} \\
\hline Std. Dev. Diff. & \multicolumn{2}{|c|}{0.001} & \multicolumn{2}{|c|}{0.001} & \multicolumn{2}{|c|}{0.001} & \multicolumn{2}{|c|}{0.002} & \multicolumn{2}{|c|}{0.001} & \multicolumn{2}{|c|}{0.001} \\
\hline $\mathbf{t}$ & \multicolumn{2}{|c|}{0.949} & \multicolumn{2}{|c|}{0.301} & \multicolumn{2}{|c|}{1.450} & \multicolumn{2}{|c|}{-5.476} & \multicolumn{2}{|c|}{1.204} & \multicolumn{2}{|c|}{-0.769} \\
\hline P-value & \multicolumn{2}{|c|}{0.251} & \multicolumn{2}{|c|}{0.382} & \multicolumn{2}{|c|}{0.139} & \multicolumn{2}{|c|}{$5.4 \mathrm{E}-06$} & \multicolumn{2}{|c|}{0.191} & \multicolumn{2}{|c|}{0.293} \\
\hline $\begin{array}{l}\text { Reject Ho at } \\
\text { confidence } \\
\text { level }\end{array}$ & \multicolumn{2}{|c|}{$\begin{array}{c}\text { Cannot } \\
\text { Reject Ho }\end{array}$} & \multicolumn{2}{|c|}{$\begin{array}{c}\text { Cannot } \\
\text { Reject Ho }\end{array}$} & \multicolumn{2}{|c|}{$\begin{array}{c}\text { Cannot } \\
\text { Reject Ho }\end{array}$} & \multicolumn{2}{|c|}{$99.9+\%$} & \multicolumn{2}{|c|}{$\begin{array}{c}\text { Cannot } \\
\text { Reject Ho }\end{array}$} & \multicolumn{2}{|c|}{$<85.0 \%$} \\
\hline
\end{tabular}

Table 34. Statistical Comparison of GRMS Measure: Baseline Unit vs. Upgrade Unit Rough-Road Test - All Accelerometers - Longitudinal Direction

\begin{tabular}{|c|c|c|c|c|c|c|c|c|c|c|c|c|}
\hline \multirow{2}{*}{ Statistics } & \multicolumn{2}{|c|}{ Front Left } & \multicolumn{2}{|c|}{ Hitch } & \multicolumn{2}{|c|}{ Front Right } & \multicolumn{2}{|c|}{ Center } & \multicolumn{2}{|c|}{ Rear Left } & \multicolumn{2}{|c|}{ Rear Right } \\
\hline & B & $\mathbf{U}$ & B & $\mathbf{U}$ & B & $\mathbf{U}$ & B & $\mathbf{U}$ & B & $\mathbf{U}$ & B & $\mathbf{U}$ \\
\hline Obs. & 19 & 19 & 19 & 19 & 19 & 19 & 19 & 19 & 19 & 19 & 19 & 19 \\
\hline Min. & 0.02 & 0.02 & 0.03 & 0.03 & 0.02 & 0.02 & 0.01 & 0.02 & 0.02 & 0.02 & 0.02 & 0.02 \\
\hline Max. & 0.03 & 0.02 & 0.04 & 0.04 & 0.03 & 0.03 & 0.05 & 0.02 & 0.03 & 0.03 & 0.03 & 0.02 \\
\hline Mean & 0.02 & 0.02 & 0.03 & 0.04 & 0.02 & 0.02 & 0.03 & 0.02 & 0.02 & 0.03 & 0.02 & 0.02 \\
\hline Std. Dev. & 0.00 & 0.00 & 0.00 & 0.00 & 0.00 & 0.00 & 0.01 & 0.00 & 0.00 & 0.00 & 0.00 & 0.00 \\
\hline Delta Mean & \multicolumn{2}{|c|}{0.001} & \multicolumn{2}{|c|}{0.006} & \multicolumn{2}{|c|}{0.001} & \multicolumn{2}{|c|}{-0.008} & \multicolumn{2}{|c|}{0.001} & \multicolumn{2}{|c|}{0.002} \\
\hline Std. Dev. Diff. & \multicolumn{2}{|c|}{0.001} & \multicolumn{2}{|c|}{0.001} & \multicolumn{2}{|c|}{0.001} & \multicolumn{2}{|c|}{0.003} & \multicolumn{2}{|c|}{0.001} & \multicolumn{2}{|c|}{0.001} \\
\hline $\mathbf{t}$ & \multicolumn{2}{|c|}{2.444} & \multicolumn{2}{|c|}{5.868} & \multicolumn{2}{|c|}{1.319} & \multicolumn{2}{|c|}{-2.918} & \multicolumn{2}{|c|}{1.238} & \multicolumn{2}{|c|}{2.733} \\
\hline P-value & \multicolumn{2}{|c|}{0.023} & \multicolumn{2}{|c|}{$1.6 \mathrm{E}-06$} & \multicolumn{2}{|c|}{0.166} & \multicolumn{2}{|c|}{0.008} & \multicolumn{2}{|c|}{0.183} & \multicolumn{2}{|c|}{0.012} \\
\hline $\begin{array}{l}\text { Reject Ho at } \\
\text { confidence } \\
\text { level }\end{array}$ & \multicolumn{2}{|c|}{$\begin{array}{c}\text { Cannot } \\
\text { Reject Ho }\end{array}$} & \multicolumn{2}{|c|}{$\begin{array}{c}\text { Cannot } \\
\text { Reject Ho }\end{array}$} & \multicolumn{2}{|c|}{$\begin{array}{c}\text { Cannot } \\
\text { Reject Ho }\end{array}$} & \multicolumn{2}{|c|}{$99.2 \%$} & \multicolumn{2}{|c|}{$\begin{array}{c}\text { Cannot } \\
\text { Reject Ho }\end{array}$} & \multicolumn{2}{|c|}{$\begin{array}{c}\text { Cannot } \\
\text { Reject Ho }\end{array}$} \\
\hline
\end{tabular}


Table 35. Statistical Comparison of GRMS Measure: Baseline Unit vs. Upgrade Unit Rough-Road Test - All Accelerometers - Lateral Direction

\begin{tabular}{|c|c|c|c|c|c|c|c|c|c|c|c|c|}
\hline \multirow{2}{*}{ Statistics } & \multicolumn{2}{|c|}{ Front Left } & \multicolumn{2}{|c|}{ Hitch } & \multicolumn{2}{|c|}{ Front Right } & \multicolumn{2}{|c|}{ Center } & \multicolumn{2}{|c|}{ Rear Left } & \multicolumn{2}{|c|}{ Rear Right } \\
\hline & B & $\mathbf{U}$ & B & $\mathbf{U}$ & B & $\mathbf{U}$ & B & $\mathbf{U}$ & B & $\mathbf{U}$ & B & $\mathbf{U}$ \\
\hline Obs. & 19 & 19 & 19 & 19 & 19 & 19 & 19 & 19 & 19 & 19 & 19 & 19 \\
\hline Min. & 0.03 & 0.02 & 0.06 & 0.05 & 0.02 & 0.02 & 0.02 & 0.02 & 0.02 & 0.02 & 0.02 & 0.02 \\
\hline Max. & 0.03 & 0.03 & 0.07 & 0.07 & 0.03 & 0.03 & 0.02 & 0.02 & 0.03 & 0.03 & 0.03 & 0.03 \\
\hline Mean & 0.03 & 0.03 & 0.06 & 0.06 & 0.03 & 0.03 & 0.02 & 0.02 & 0.03 & 0.03 & 0.03 & 0.03 \\
\hline Std. Dev. & 0.00 & 0.00 & 0.00 & 0.00 & 0.00 & 0.00 & 0.00 & 0.00 & 0.00 & 0.00 & 0.00 & 0.00 \\
\hline Delta Mean & \multicolumn{2}{|c|}{-0.001} & \multicolumn{2}{|c|}{0.001} & \multicolumn{2}{|c|}{0.000} & \multicolumn{2}{|c|}{-0.001} & \multicolumn{2}{|c|}{0.001} & \multicolumn{2}{|c|}{-0.001} \\
\hline Std. Dev. Diff. & \multicolumn{2}{|c|}{0.001} & \multicolumn{2}{|c|}{0.001} & \multicolumn{2}{|c|}{0.001} & \multicolumn{2}{|c|}{0.001} & \multicolumn{2}{|c|}{0.001} & \multicolumn{2}{|c|}{0.001} \\
\hline t & \multicolumn{2}{|c|}{-1.168} & \multicolumn{2}{|c|}{0.851} & \multicolumn{2}{|c|}{-0.557} & \multicolumn{2}{|c|}{-2.421} & \multicolumn{2}{|c|}{1.119} & \multicolumn{2}{|c|}{-1.600} \\
\hline P-value & \multicolumn{2}{|c|}{0.199} & \multicolumn{2}{|c|}{0.274} & \multicolumn{2}{|c|}{0.338} & \multicolumn{2}{|c|}{0.024} & \multicolumn{2}{|c|}{0.214} & \multicolumn{2}{|c|}{0.111} \\
\hline $\begin{array}{l}\text { Reject Ho at } \\
\text { confidence } \\
\text { level }\end{array}$ & \multicolumn{2}{|c|}{$<85.0 \%$} & \multicolumn{2}{|c|}{$\begin{array}{c}\text { Cannot } \\
\text { Reject Ho }\end{array}$} & \multicolumn{2}{|c|}{$\begin{array}{c}\text { Cannot } \\
\text { Reject Ho }\end{array}$} & \multicolumn{2}{|c|}{$97.6 \%$} & \multicolumn{2}{|c|}{$\begin{array}{c}\text { Cannot } \\
\text { Reject Ho }\end{array}$} & \multicolumn{2}{|c|}{$88.9 \%$} \\
\hline
\end{tabular}

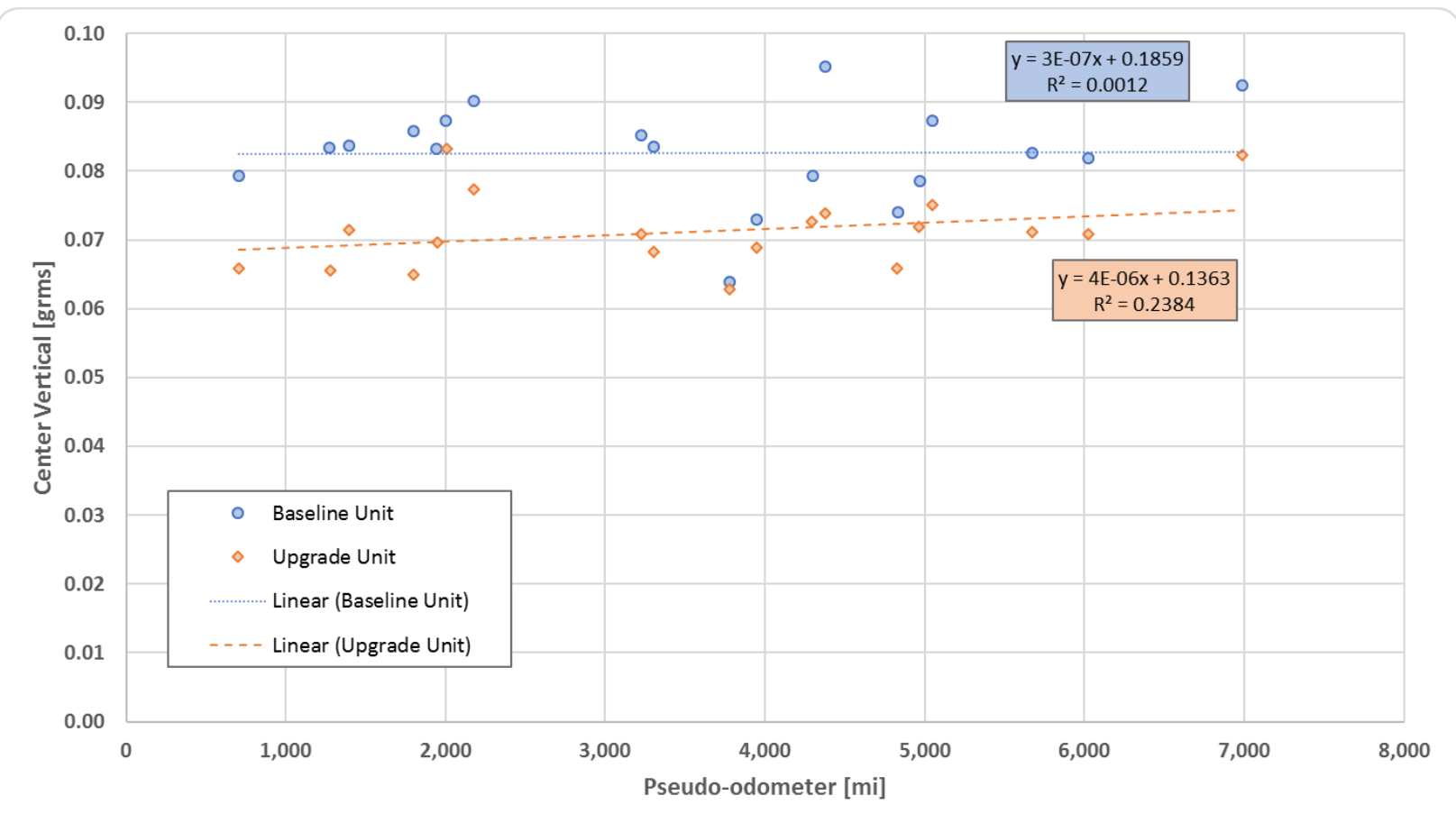

Figure 50. Part C2 Rough-Road Test - Baseline and Upgrade Units GRMS for Vertical Accelerometer at Axle Group (Center) - Selected Laps for Statistical Analysis. 


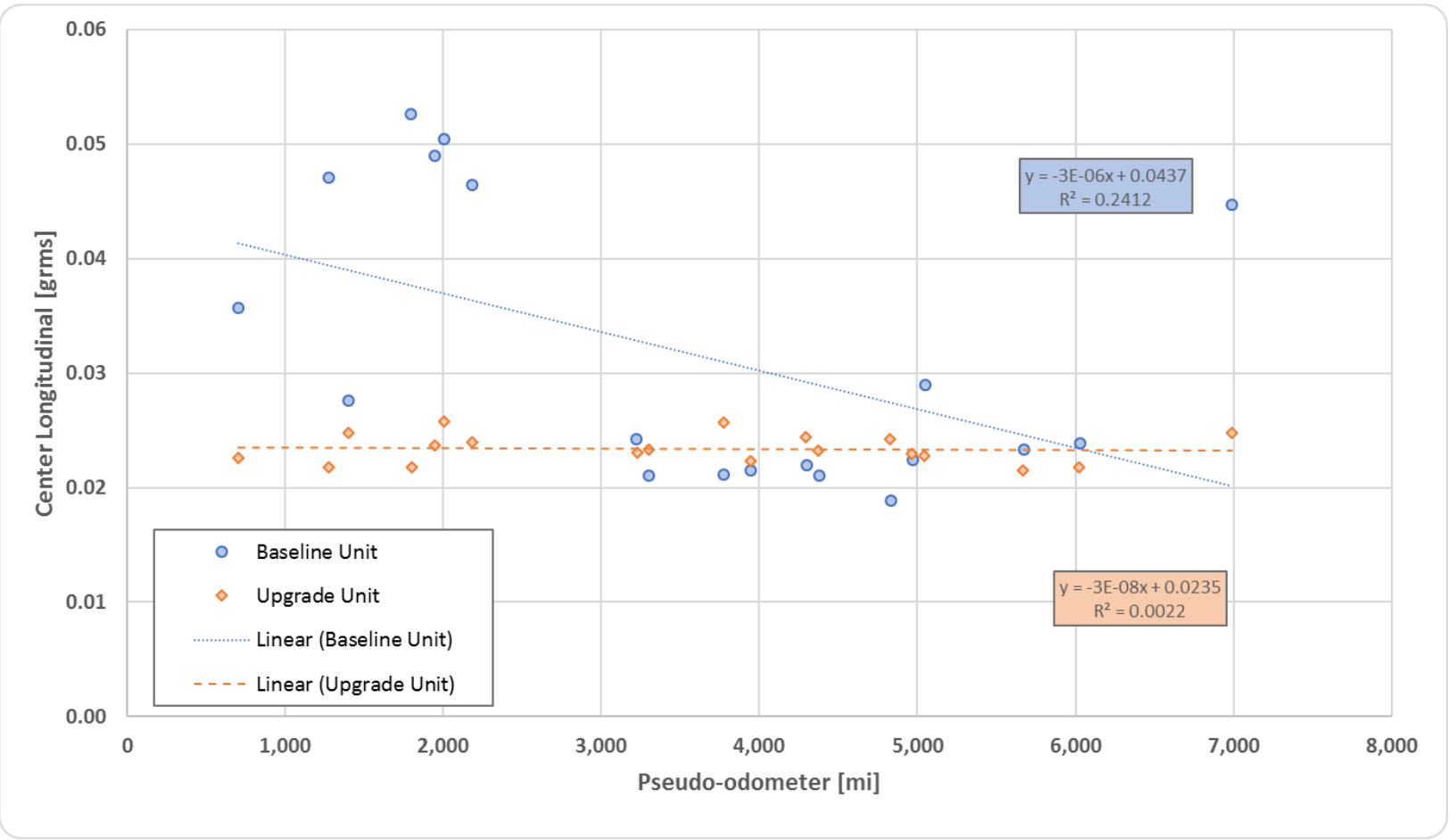

Figure 51. Part C2 Rough-Road Test - Baseline and Upgrade Units GRMS for Longitudinal Accelerometer at Axle Group (Center) - Selected Laps for Statistical Analysis.

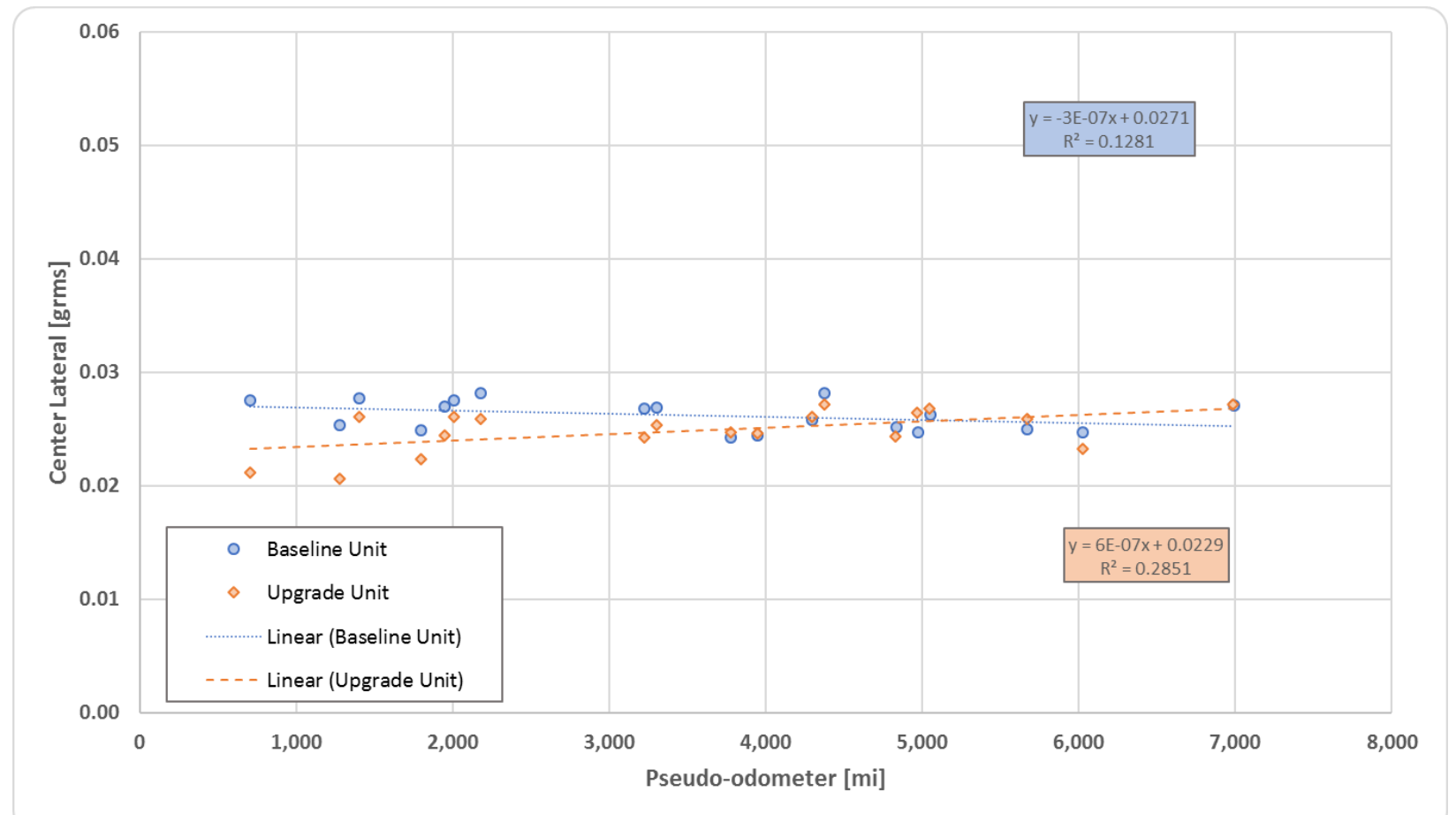

Figure 52. Part C2 Rough-Road Test - Baseline and Upgrade Units GRMS for Lateral Accelerometer at Axle Group (Center) - Selected Laps for Statistical Analysis. 


\subsubsection{Effect of Suspension on Vibrations: Rough-Road Test Upgrade Unit with Regular Tires vs. Radial Tires}

A statistical test was also performed to compare the effect of radial tires in the transmission of accelerations to the MHU during travel on rough roads. For fairness in the comparison and since the radial-tire test was run for just 2,400 miles, only observations for the first 2,400 miles of the regular tire test were considered for the analysis. Those were selected at random with the only condition that the average speed on the rough-road segment was around $21 \mathrm{mph}$ (on average) for both regular and radial tire observations. Statistics regarding the average rough-road segment speed for the Upgrade unit mounted with both radial and regular tires are presented in Table 36.

Table 36. Vehicle Speed Distribution Parameters Upgrade Unit with Radial and Regular Tires - Laps Selected for Analysis

\begin{tabular}{|l|r|r|}
\hline Statistics & Radial Tires & Regular Tires \\
\hline Obs. & 20 & 13 \\
\hline Min. & 20.195 & 20.072 \\
\hline Max. & 21.812 & 21.906 \\
\hline Mean & 20.796 & 20.978 \\
\hline Std. Dev. & 0.489 & 0.539 \\
\hline
\end{tabular}

The results of the statistical tests are presented in Table 37, Table 38, and Table 39 for the vertical, longitudinal, and lateral accelerometers, respectively. The tables also show some statistics about the distribution of accelerations (captured by the variable GRMS) at each one of the six locations where the accelerometers were deployed.

For the vertical accelerations (Table 37) it was possible to reject the null hypothesis with at least $98.5 \%$ confidence (hitch, and 99.9+\% confidence everywhere else), strongly suggesting that radial tires transmitted, on average, lower vertical accelerations at any position when traveling on rough roads than regular tires. The same conclusion was reached for the longitudinal direction, although the rejection confidence was lower (i.e., only $89.7 \%$ confidence for the Center accelerometer). For lateral accelerations (except for the rear-left and rear-right positions), there was no statistically significant difference between the radial and regular tires. Figure 53, Figure 54, and Figure 55 present in a graphical form the data that was used for the statistical analysis corresponding to the accelerometer located at the center of the MHU. 
Table 37. Statistical Comparison of GRMS Measure: Radial Tires vs. Regular Rough-Road Test - Upgrade Unit - All Accelerometers - Vertical Direction

\begin{tabular}{|c|c|c|c|c|c|c|c|c|c|c|c|c|}
\hline \multirow{2}{*}{ Statistics } & \multicolumn{2}{|c|}{ Front Left } & \multicolumn{2}{|c|}{ Hitch } & \multicolumn{2}{|c|}{ Front Right } & \multicolumn{2}{|c|}{ Center } & \multicolumn{2}{|c|}{ Rear Left } & \multicolumn{2}{|c|}{ Rear Right } \\
\hline & Radial & Reg. & Radial & Reg. & Radial & Reg. & Radial & Reg. & Radial & Reg. & Radial & Reg. \\
\hline Obs. & 20 & 13 & 20 & 13 & 20 & 13 & 20 & 13 & 20 & 13 & 20 & 13 \\
\hline Min. & 0.04 & 0.05 & 0.05 & 0.06 & 0.04 & 0.05 & 0.05 & 0.06 & 0.05 & 0.05 & 0.04 & 0.04 \\
\hline Max. & 0.06 & 0.06 & 0.07 & 0.07 & 0.06 & 0.06 & 0.06 & 0.08 & 0.06 & 0.06 & 0.04 & 0.05 \\
\hline Mean & 0.04 & 0.05 & 0.06 & 0.06 & 0.05 & 0.05 & 0.05 & 0.07 & 0.05 & 0.05 & 0.04 & 0.05 \\
\hline Std. Dev. & 0.00 & 0.00 & 0.00 & 0.00 & 0.00 & 0.00 & 0.00 & 0.00 & 0.00 & 0.00 & 0.00 & 0.00 \\
\hline Delta Mean & \multicolumn{2}{|c|}{-0.007} & \multicolumn{2}{|c|}{-0.004} & \multicolumn{2}{|c|}{-0.006} & \multicolumn{2}{|c|}{-0.016} & \multicolumn{2}{|c|}{-0.005} & \multicolumn{2}{|c|}{-0.005} \\
\hline Std. Dev. Diff. & \multicolumn{2}{|c|}{0.001} & \multicolumn{2}{|c|}{0.002} & \multicolumn{2}{|c|}{0.001} & \multicolumn{2}{|c|}{0.002} & \multicolumn{2}{|c|}{0.001} & \multicolumn{2}{|c|}{0.001} \\
\hline $\mathbf{t}$ & \multicolumn{2}{|c|}{-4.846} & \multicolumn{2}{|c|}{-2.657} & \multicolumn{2}{|c|}{-4.600} & \multicolumn{2}{|c|}{-7.688} & \multicolumn{2}{|c|}{-4.090} & \multicolumn{2}{|c|}{-7.294} \\
\hline P-value & \multicolumn{2}{|c|}{$4.8 \mathrm{E}-05$} & \multicolumn{2}{|c|}{0.015} & \multicolumn{2}{|c|}{$9.6 \mathrm{E}-05$} & \multicolumn{2}{|c|}{$1.5 \mathrm{E}-08$} & \multicolumn{2}{|c|}{0.000} & \multicolumn{2}{|c|}{$4.5 \mathrm{E}-08$} \\
\hline $\begin{array}{l}\text { Reject Ho at } \\
\text { confidence } \\
\text { level }\end{array}$ & \multicolumn{2}{|c|}{$99.9+\%$} & \multicolumn{2}{|c|}{$98.5 \%$} & \multicolumn{2}{|c|}{$99.9+\%$} & \multicolumn{2}{|c|}{$99.9+\%$} & \multicolumn{2}{|c|}{$99.9+\%$} & \multicolumn{2}{|c|}{$99.9+\%$} \\
\hline
\end{tabular}

Table 38. Statistical Comparison of GRMS Measure: Radial Tires vs. Regular Rough-Road Test - Upgrade Unit - All Accelerometers - Longitudinal Direction

\begin{tabular}{|c|c|c|c|c|c|c|c|c|c|c|c|c|}
\hline \multirow{2}{*}{ Statistics } & \multicolumn{2}{|c|}{ Front Left } & \multicolumn{2}{|c|}{ Hitch } & \multicolumn{2}{|c|}{ Front Right } & \multicolumn{2}{|c|}{ Center } & \multicolumn{2}{|c|}{ Rear Left } & \multicolumn{2}{|c|}{ Rear Right } \\
\hline & Radial & Reg. & Radial & Reg. & Radial & Reg. & Radial & Reg. & Radial & Reg. & Radial & Reg. \\
\hline Obs. & 20 & 13 & 20 & 13 & 20 & 13 & 20 & 13 & 20 & 13 & 20 & 13 \\
\hline Min. & 0.02 & 0.02 & 0.03 & 0.03 & 0.02 & 0.02 & 0.01 & 0.02 & 0.02 & 0.02 & 0.02 & 0.02 \\
\hline Max. & 0.02 & 0.03 & 0.04 & 0.04 & 0.03 & 0.03 & 0.02 & 0.02 & 0.03 & 0.03 & 0.03 & 0.03 \\
\hline Mean & 0.02 & 0.02 & 0.03 & 0.04 & 0.02 & 0.02 & 0.02 & 0.02 & 0.02 & 0.03 & 0.02 & 0.02 \\
\hline Std. Dev. & 0.00 & 0.00 & 0.00 & 0.00 & 0.00 & 0.00 & 0.00 & 0.00 & 0.00 & 0.00 & 0.00 & 0.00 \\
\hline Delta Mean & \multicolumn{2}{|c|}{-0.002} & \multicolumn{2}{|c|}{-0.003} & \multicolumn{2}{|c|}{-0.002} & \multicolumn{2}{|c|}{-0.001} & \multicolumn{2}{|c|}{-0.003} & \multicolumn{2}{|c|}{-0.002} \\
\hline Std. Dev. Diff. & \multicolumn{2}{|c|}{0.001} & \multicolumn{2}{|c|}{0.001} & \multicolumn{2}{|c|}{0.001} & \multicolumn{2}{|c|}{0.001} & \multicolumn{2}{|c|}{0.001} & \multicolumn{2}{|c|}{0.001} \\
\hline $\mathbf{t}$ & \multicolumn{2}{|c|}{-2.715} & \multicolumn{2}{|c|}{-2.362} & \multicolumn{2}{|c|}{-2.820} & \multicolumn{2}{|c|}{-1.648} & \multicolumn{2}{|c|}{-3.658} & \multicolumn{2}{|c|}{-2.313} \\
\hline P-value & \multicolumn{2}{|c|}{0.013} & \multicolumn{2}{|c|}{0.028} & \multicolumn{2}{|c|}{0.010} & \multicolumn{2}{|c|}{0.103} & \multicolumn{2}{|c|}{0.001} & \multicolumn{2}{|c|}{0.031} \\
\hline $\begin{array}{l}\text { Reject Ho at } \\
\text { confidence } \\
\text { level }\end{array}$ & \multicolumn{2}{|c|}{$98.7 \%$} & \multicolumn{2}{|c|}{$97.2 \%$} & \multicolumn{2}{|c|}{$99.0 \%$} & \multicolumn{2}{|c|}{$89.7 \%$} & \multicolumn{2}{|c|}{$99.9 \%$} & \multicolumn{2}{|c|}{$96.9 \%$} \\
\hline
\end{tabular}


Table 39. Statistical Comparison of GRMS Measure: Radial Tires vs. Regular Rough-Road Test - Upgrade Unit - All Accelerometers - Lateral Direction

\begin{tabular}{|c|c|c|c|c|c|c|c|c|c|c|c|c|}
\hline \multirow{2}{*}{ Statistics } & \multicolumn{2}{|c|}{ Front Left } & \multicolumn{2}{|c|}{ Hitch } & \multicolumn{2}{|c|}{ Front Right } & \multicolumn{2}{|c|}{ Center } & \multicolumn{2}{|c|}{ Rear Left } & \multicolumn{2}{|c|}{ Rear Right } \\
\hline & Radial & Reg. & Radial & Reg. & Radial & Reg. & Radial & Reg. & Radial & Reg. & Radial & Reg. \\
\hline Obs. & 20 & 13 & 20 & 13 & 20 & 13 & 20 & 13 & 20 & 13 & 20 & 13 \\
\hline Min. & 0.02 & 0.02 & 0.05 & 0.05 & 0.02 & 0.02 & 0.02 & 0.02 & 0.02 & 0.02 & 0.02 & 0.02 \\
\hline Max. & 0.03 & 0.03 & 0.07 & 0.07 & 0.03 & 0.03 & 0.02 & 0.02 & 0.03 & 0.03 & 0.03 & 0.03 \\
\hline Mean & 0.03 & 0.03 & 0.06 & 0.06 & 0.03 & 0.03 & 0.02 & 0.02 & 0.02 & 0.03 & 0.02 & 0.03 \\
\hline Std. Dev. & 0.00 & 0.00 & 0.00 & 0.00 & 0.00 & 0.00 & 0.00 & 0.00 & 0.00 & 0.00 & 0.00 & 0.00 \\
\hline Delta Mean & \multicolumn{2}{|c|}{-0.001} & \multicolumn{2}{|c|}{-0.002} & \multicolumn{2}{|c|}{-0.001} & \multicolumn{2}{|c|}{0.000} & \multicolumn{2}{|c|}{-0.002} & \multicolumn{2}{|c|}{-0.002} \\
\hline Std. Dev. Diff. & \multicolumn{2}{|c|}{0.001} & \multicolumn{2}{|c|}{0.002} & \multicolumn{2}{|c|}{0.001} & \multicolumn{2}{|c|}{0.001} & \multicolumn{2}{|c|}{0.001} & \multicolumn{2}{|c|}{0.001} \\
\hline $\mathbf{t}$ & \multicolumn{2}{|c|}{-0.970} & \multicolumn{2}{|c|}{-1.036} & \multicolumn{2}{|c|}{-1.063} & \multicolumn{2}{|c|}{0.151} & \multicolumn{2}{|c|}{-3.007} & \multicolumn{2}{|c|}{-2.731} \\
\hline P-value & \multicolumn{2}{|c|}{0.245} & \multicolumn{2}{|c|}{0.230} & \multicolumn{2}{|c|}{0.223} & \multicolumn{2}{|c|}{0.391} & \multicolumn{2}{|c|}{0.007} & \multicolumn{2}{|c|}{0.013} \\
\hline $\begin{array}{l}\text { Reject Ho at } \\
\text { confidence } \\
\text { level }\end{array}$ & \multicolumn{2}{|c|}{$<85.0 \%$} & \multicolumn{2}{|c|}{$<85.0 \%$} & \multicolumn{2}{|c|}{$<85.0 \%$} & \multicolumn{2}{|c|}{$\begin{array}{c}\text { Cannot } \\
\text { Reject Ho }\end{array}$} & \multicolumn{2}{|c|}{$99.3 \%$} & \multicolumn{2}{|c|}{$98.7 \%$} \\
\hline
\end{tabular}

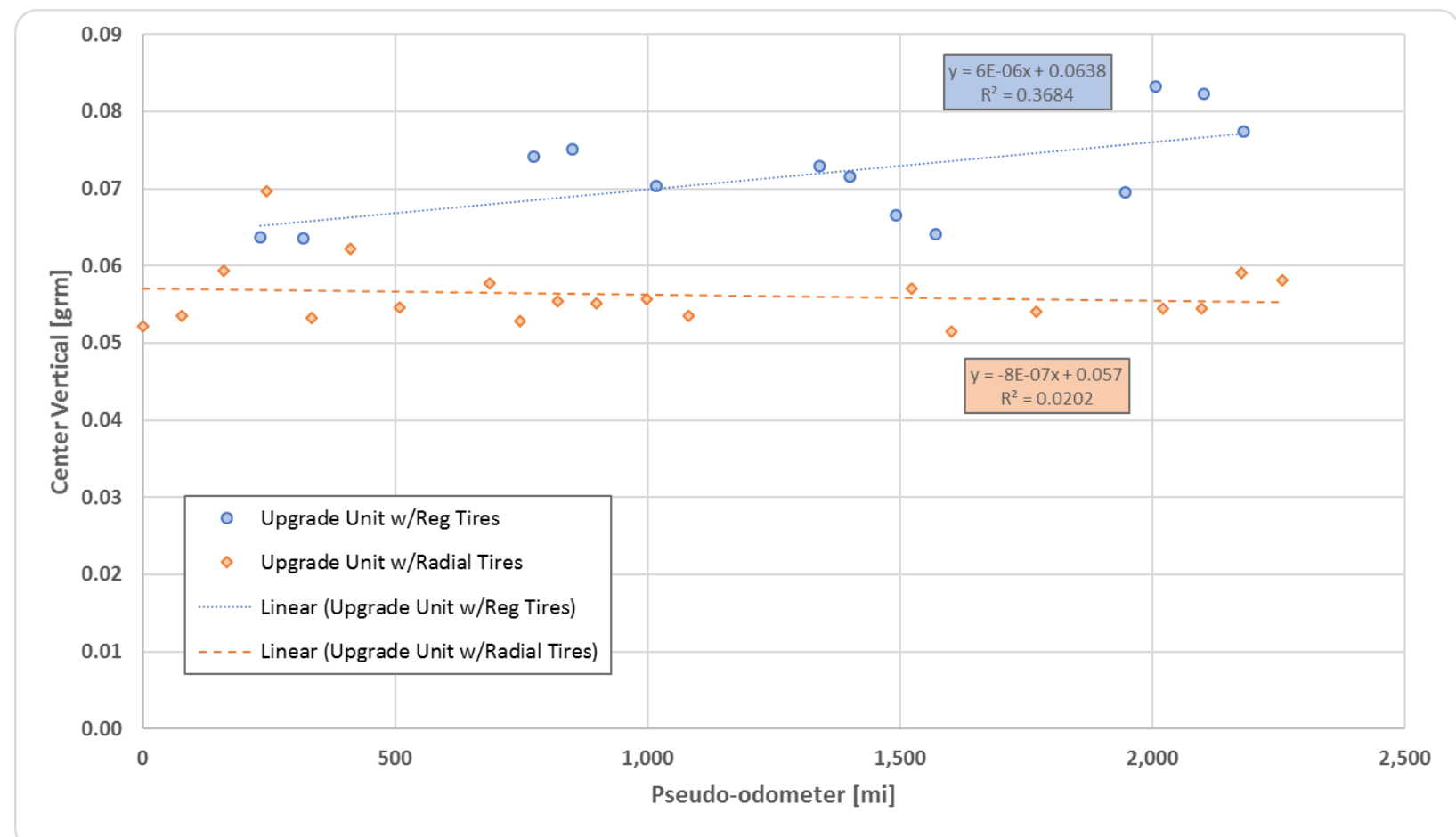

Figure 53. Part C2 Upgrade Unit Rough-Road Test - Regular and Radial Tires GRMS for Vertical Accelerometer at Axle Group (Center) - Selected Laps for Statistical Analysis. 


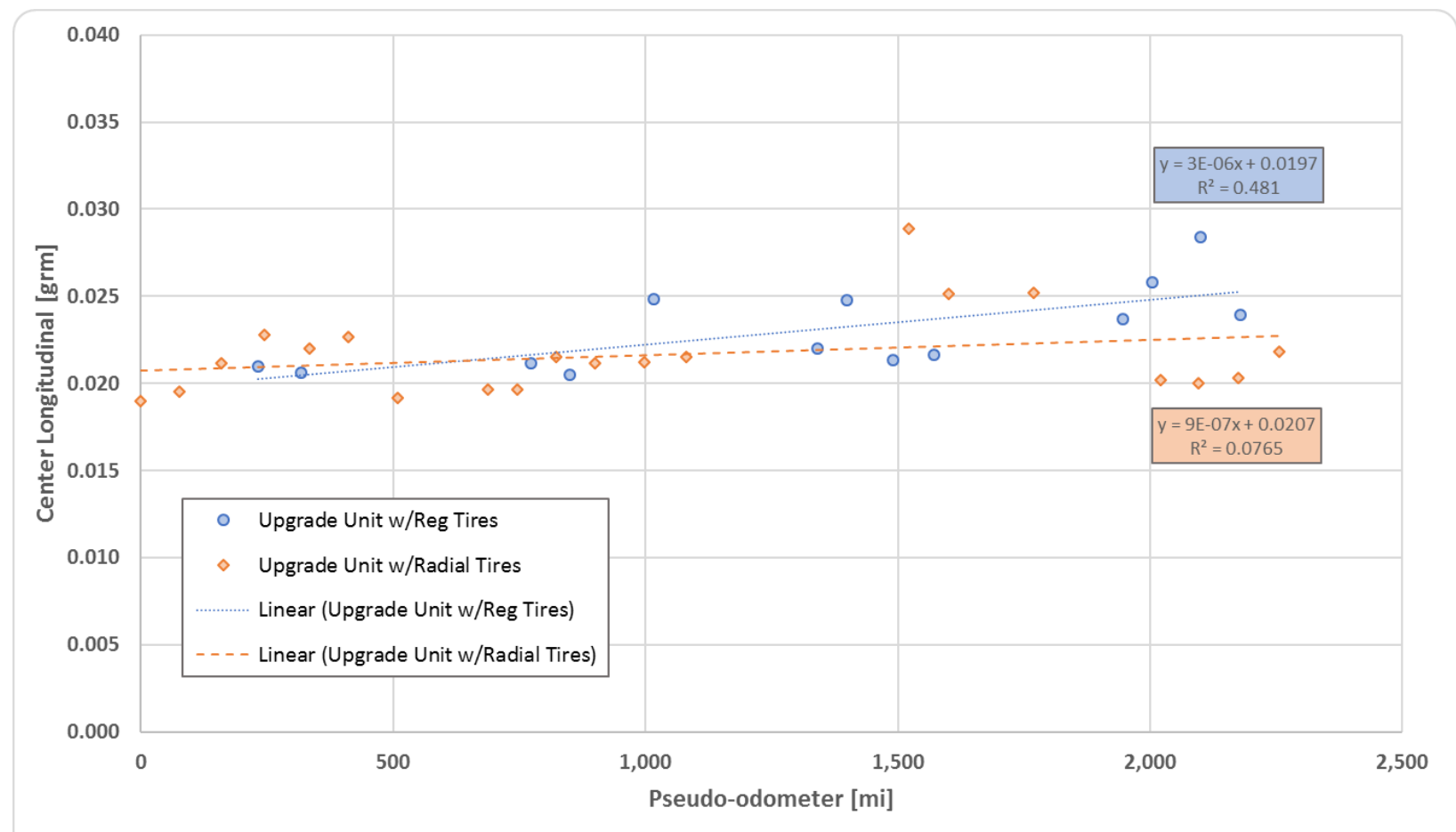

Figure 54. Part C2 Part C2 Upgrade Unit Rough-Road Test - Regular and Radial Tires GRMS for Longitudinal Accelerometer at Axle Group (Center) - Selected Laps for Statistical Analysis.

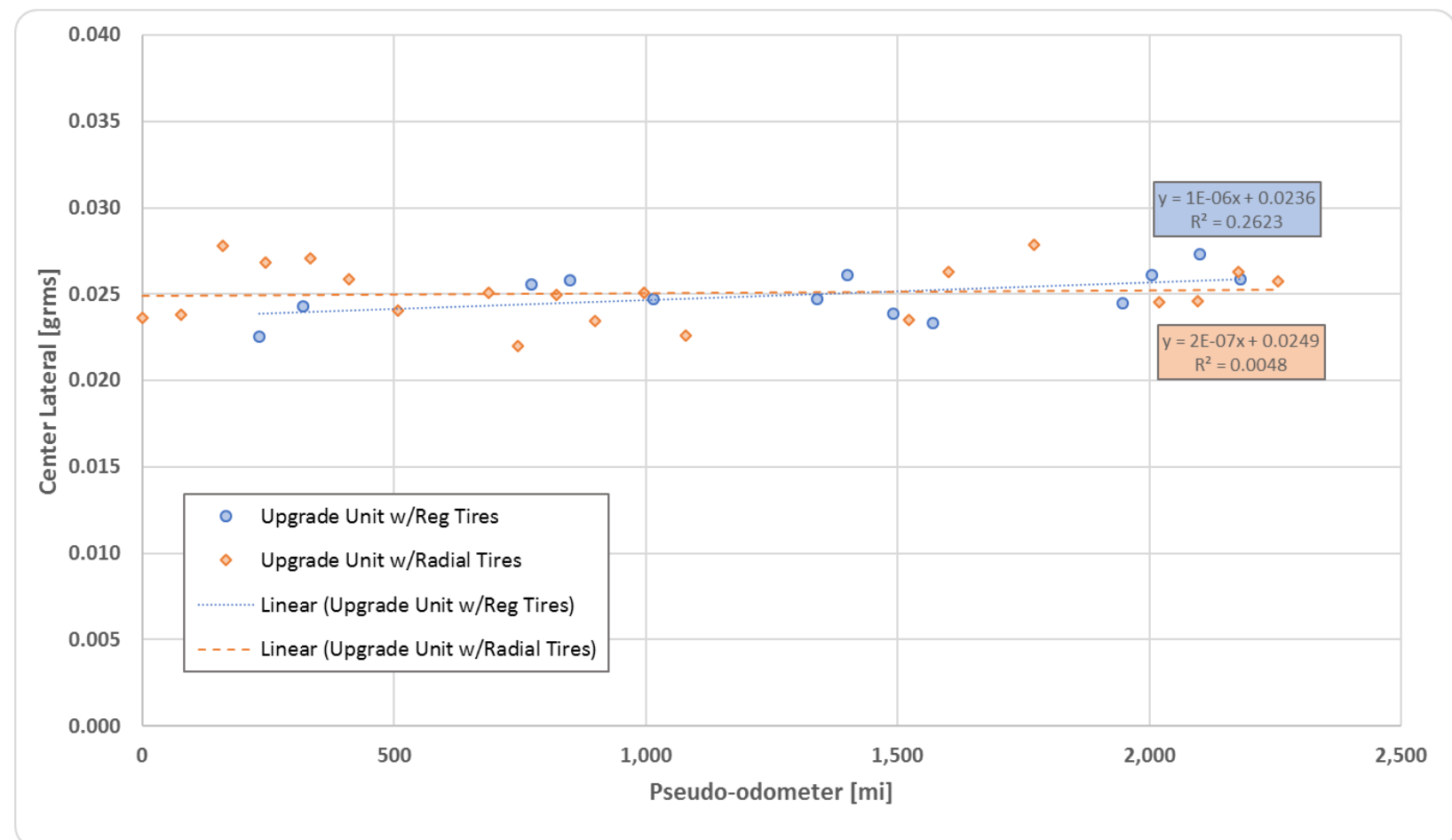

Figure 55. Part C2 Upgrade Unit Rough-Road Test - Regular and Radial Tires GRMS for Lateral Accelerometer at Axle Group (Center) - Selected Laps for Statistical Analysis. 


\section{SUMMARY OF RESULTS AND CONCLUSIONS}

Four alternatives for the suspension system of a typical three-bedroom MHU were considered in this test. Alternative 0 was the MHU that was selected from the staging area in Selma, Alabama. Empirical data has shown that, on average, this Alternative 0 experiences one tire failure every 150 miles (or 0.0067 tire failures per mile traveled). When the two test units arrived at NPG, they were equipped with new axles and tires. One of these two test units was equipped with similar hardware, although in new condition, to that of Alternative 0. This became the Baseline Unit, or Alternative 1. The installation of this new hardware was performed following the correct manufacturer specifications regarding bolt sizes and torque force needed to tighten these bolts. The cost of the axles was $\$ 175^{5}$ each and each tire cost $\$ 65$ each. Thus, the difference in cost between Alternative 0 and Alternative 1 was $\$ 0$, since both use the same equipment for the transportation system.

The second MHU was equipped with better axles (i.e., axles that were rated for 7,000lbs as opposed to $6,000 \mathrm{lbs}$ for the Baseline Unit) and better tires. This became the Upgrade Unit, or Alternative 2. The cost of this new and better equipment cost $\$ 295$ for each axle and $\$ 119$ for each tire. This was a difference of $\$ 1,368(=6 * \$ 295+12 * \$ 119-6 * \$ 175-12 * \$ 65)$, with the installation cost being the same for both alternatives.

At the end of the Longevity Test, the Upgrade Unit was mounted with radial tires, which cost $\$ 165$ each. This became Alternative 3, and the difference in cost with respect to Alternative 0 (or 1) was $\$ 1,920$ (= $6 * \$ 295+12 * \$ 165-6 * \$ 175-12 * \$ 65)$.

A summary of the tire-failure results of the test conducted at NPG is presented in Table 40 below for each of the four alternatives considered in this section.

Table 40. Tire Failure Rates per 1,000 Miles Traveled and Expected Mean Travel Distance between Failures Alternatives 0, 1, 2, and 3

\begin{tabular}{|c|c|c|c|c|}
\hline \multirow{2}{*}{ Alternative } & \multicolumn{2}{|c|}{$\begin{array}{l}\text { Failure Rates } \\
\text { per 1,000 Miles }\end{array}$} & \multicolumn{2}{|c|}{$\begin{array}{l}\text { Mean Travel Distance } \\
\text { between Failures [miles] }\end{array}$} \\
\hline & $\begin{array}{l}\text { Any } \\
\text { Failure }\end{array}$ & Blowouts & $\begin{array}{l}\text { Any } \\
\text { Failure }\end{array}$ & Blowouts \\
\hline $\begin{array}{l}\text { Alt 0: MHU Selected from the Staging Area in } \\
\text { Selma, AL }\end{array}$ & 6.667 & N/A & 150 & N/A \\
\hline Alt 1: Baseline Unit & 3.982 & 0.412 & 251 & 2,427 \\
\hline Alt 2: Upgrade Unit w/Regular Tires & 1.373 & 0.275 & 728 & 3,641 \\
\hline Alt 3: Upgrade Unit w/Radial Tires & $<0.417$ & $<0.417$ & $>2,400$ & $>2,400$ \\
\hline
\end{tabular}

Table 40 shows that Alternative 1 (Baseline Unit) had, on average, one tire failure every 251 miles (or 0.0040 tire failures per mile traveled). So, by simply following the correct manufacturer specifications for the assembly of the transportation system, a reduction of $41 \%$ in the per mile tire failure was achieved. In the same test, Alternative 2 (Upgrade Unit) showed, on average, one tire failure every 728 miles traveled (or 0.0014 tire failure s per mile traveled). This was a reduction of $79 \%$ in tire failures per mile traveled when compared to Alternative 0, and a reduction of $66 \%$ when compared to Alternative 1 (Baseline Unit). When the Upgrade Unit was mounted with radial tires in the last part of the test, no tire failures were observed for the 2,400 miles tested. That is, in the case of the radial tires (Alternative 3 ) the

\footnotetext{
${ }^{5}$ It should be noted that this and the other component costs presented here were for small quantity purchases. Cost could be lower if components were purchase in large quantities as would be the case in MHU manufacturing.
} 
tire failure was less than one per 2,400 miles traveled (or less than 0.0004 tire failures per mile traveled). This was an improvement of at least $94 \%$ when compared to Alternative $0,90 \%$ when compared to Alternative 1 (Baseline Unit), and 70\% when compared to Alternative 2 (Upgrade Unit with regular tires). In all cases the differences in tire failures rates were statistically significant at the $99.8 \%$ confidence level or higher.

Data was also collected to determine the effect that the suspension of Alternative 1, 2, and 3 had in transmitting vibrations (accelerations) to the MHU while traveling. Two different types of tests were conducted to imitate regular conditions during the deployment of these mobile homes. In one test, the vehicles traveled on a roadway similar to an Interstate highway (NPG Test Track) at $60 \mathrm{mph}$ (similar to highway speed at which these vehicles would be traveling during deployment). For the second test, data was collected while the vehicles traveled on short segments of roadways that resembled traveling on highway shoulder strips (to change a tire, for example) or rough roads (e.g., when approaching the trip destination). The speed for this second test was set at about $20 \mathrm{mph}$.

Extensive data was collected using six tri-axial accelerometers located at the four corners of the MHU and at its center (all of them attached to the interior floor and/or interior walls of the unit), and one accelerometer located at the hitch. These accelerometers registered and captured the vibrations transmitted by the suspension system to the MHUs for the three alternatives tested. The vibration data was then processed and used to conduct statistical analyses comparing the accelerations transmitted by the Baseline and Upgrade Unit (with regular and with radial tires) to the MHU. The objective of this analysis was to determine if there were statistically significant reductions in the accelerations transmitted to the MHUs in the upgraded (axles and tires) transportation system compared to the current deployed transportation system.

The data collected for the Longevity Test and Rough-Road Test showed that the maximum accelerations were registered in all cases at the center of the MHU in the vertical direction. The overall maximum (GRMS average $=0.187$, see Table 25$)$ was registered by the Baseline Unit (center location, vertical direction) during the Longevity Tests (Part C2). If that value is normalized to $100 \%$, then the Upgrade Unit showed, on average, $81 \%$ at the same location for Part C2 (Longevity Test) and 59\% for Part D (radial-tire test). ${ }^{6}$ That is, the upgraded transportation system showed a reduction of $19 \%$ and $41 \%$ in the vertical accelerations transmitted to MHU at its center when regular and radial tires, respectively, were used. All the other average GMRSs at the other locations where the accelerometers were placed were lower than 59\%, ranging from 57\% (vertical direction at the hitch location for the Upgrade Unit with radial tires) to $14 \%$ (longitudinal direction at the rear-right location for the Upgrade Unit with radial tires). When the rough-road test averages were considered, the maximum were again registered in the vertical direction at the center of the units. Compared to the normalized $100 \%$, the Baseline Unit had $44 \%$ and the Upgrade Unit 38\% (regular tires) and 29\% (radial tires).

Table 41 shows the maximum average GRMS values observed during Part C2 and Part D of the longevity and rough-road tests. For each alternative and test type, the table shows these maximum values for each one of the three accelerometer directions in which the data was collected, as well as the location where these maximum averages occurred. The latter is indicated in the table with a letter $\mathrm{H}$, for hitch, or $\mathrm{C}$, for Center, since these where the two locations with the highest observed GRMSs. As pointed out before, the maximum was observed at the vertical accelerometer located at the center of the Baseline Unit (it is shown in boldface in the table below).

\footnotetext{
${ }^{6}$ In Part B and Part C1, before it was determined that the Upgrade Unit had some defective axles, its average GRMS was registered at 0.184 or about $99 \%$ of the maximum GRMS average (Baseline Unit, Part C2)
} 
Table 41. Maximum Average GRMS (and Location of Maximum GRMS Average) by Accelerometer Type, Test Type, and Alternative

\begin{tabular}{|l|c|c|c|c|c|c|}
\hline \multirow{2}{*}{ Accelerometer Type } & \multicolumn{3}{|c|}{ Longevity Test } & \multicolumn{3}{c|}{ Rough-Road Test } \\
\cline { 2 - 5 } & Baseline & \multicolumn{2}{|c|}{ Upgrade Unit } & Baseline & \multicolumn{2}{|c|}{ Upgrade Unit } \\
\cline { 3 - 4 } \cline { 6 - 7 } & Unit & Reg & Radial & Unit & Reg & Radial \\
\hline Longitudinal & $0.058(\mathrm{H})$ & $0.065(\mathrm{H})$ & $0.065(\mathrm{H})$ & $0.037(\mathrm{H})$ & $0.041(\mathrm{H})$ & $0.063(\mathrm{H})$ \\
\hline Lateral Direction & $0.105(\mathrm{H})$ & $0.098(\mathrm{H})$ & $0.098(\mathrm{H})$ & $0.066(\mathrm{H})$ & $0.064(\mathrm{H})$ & $0.037(\mathrm{H})$ \\
\hline Vertical Direction & $\mathbf{0 . 1 8 7}(\mathrm{C})$ & $0.143(\mathrm{H})$ & $0.110(\mathrm{C})$ & $0.083(\mathrm{C})$ & $0.067(\mathrm{C})$ & $0.063(\mathrm{H})$ \\
\hline
\end{tabular}

(H): Hitch; (C): Center

When the Baseline Unit was compared to the Upgrade Unit for the acceleration data collected in Part C2, the following results were observed. For the vertical direction accelerations, it was always possible to reject the null hypothesis with $99.9+\%$ (except for the front right location), strongly indicating that the suspension system of the Upgrade Unit always transmitted lower vertical accelerations than the suspension system of the Baseline Unit. For the longitudinal direction accelerations (accelerations in the direction of travel) it was possible to reject the null hypothesis with $99.9+\%$ confidence for the front right, center, and rear left locations. For the front left and rear right, although the Upgrade Unit transmitted lower accelerations than the Baseline Unit on average, it was not possible to reject the null hypothesis at a reasonable level of confidence (i.e., $>=95 \%$ ). For the lateral direction accelerations, it was always possible to reject the null hypothesis in favor of the alternative hypothesis with $99.9+\%$ confidence. Therefore, out of the 18 tests of hypothesis performed, it was possible to reject the null hypothesis with a high confidence level in 14 cases. This strongly indicated that the Upgrade Unit transmitted lower accelerations than the Baseline Unit to the respective MHUs.

When the Upgrade Unit with regular tires was compared to the Upgrade Unit with radial tires, it was found that for the vertical accelerations at the center of the MHU, the radial tires transmitted a lower level of accelerations than the regular tires, with $99.9 \%$ confidence level. The same was true for the front left and rear left locations. For the other locations, there was no statistically significant difference between the two types of tires. For the longitudinal and lateral accelerations, the radial tires transmitted, on average, statistically significant lower accelerations for any of the acceleration locations, except for the Center position of the longitudinal accelerometer. In every case, except for the Center accelerometer, it was possible to reject the null hypothesis in favor of the alternative hypothesis with $99.9+\%$ confidence level. Therefore, out of the 18 tests of hypothesis performed, it was possible to reject the null hypothesis with a high confidence level in 14 cases. This strongly indicated that the Upgrade Unit equipped with radial tires transmitted lower accelerations than the Upgrade Unit mounted with regular tires to the MHU.

For the rough-road tests, it was not possible to reject the null hypothesis; thus, it cannot be concluded that there was any difference between the Baseline and Upgrade units. The exception was the accelerometer at the center of the MHU. For this location, it was possible to reject the null hypothesis with at least 97.6\% confidence, strongly suggesting that when traveling on rough roads, the Upgrade Unit transmitted, on average, lower accelerations at this location than the Baseline Unit. When comparing regular and radial tires on rough-roads, it was possible to reject the null hypothesis the vertical accelerations with at least $98.5 \%$ confidence (hitch, and $99.9+\%$ confidence anywhere else). This strongly suggests that radial tires transmitted, on average, lower vertical accelerations at any of the six position when traveling on rough roads than regular tires. The same conclusion was reached for the longitudinal direction, although the rejection confidence was lower. For lateral accelerations, in general, there were not statistically significant difference between the radial and regular tires.

In summary, the radial tires transmitted lower acceleration levels to the MHU than the regular tires, thus making the Upgrade Unit with radial tires (i.e., Alternative 3) the best performing option for both regular- 
and rough-road tests. As explained earlier in this report, a lower level of accelerations transmitted may result in less damage to the MHU while traveling. While it is generally accepted that less severe vibrations would be expected to result in less severe damage, it is unknown at which vibration levels and frequencies this damage occurs. In consequence, even if the Upgrade Unit is shown to transmit statistically significant lower accelerations to the MHU, it is not possible to conclude that the damage will be less severe, since both the Baseline and Upgrade units could be transmitting vibrations that are above the damage-occurring threshold.

In an attempt to determine if there was any difference in the damage that the Baseline and Upgrade MHUs showed during the test, ORNL reviewed all the inspection reports that were generated by NPG. As part of the Test Protocol, ORNL required NPG to conduct a visual inspection of the MHUs and transportation system at the end of each test day. A form was provided to NPG with a list of different components to be checked by the drivers at the end of any test day. The forms also provided room for the drivers to annotate and explain in more detail any damaged observed. All these inspection forms are included in APPENDIX D for the Baseline Unit (data collected during Part B, C1, and C2 of the test) and APPENDIX E for the Upgrade Unit (data collected during Part B, C1, C2, and D of the test). Each appendix also presents a table with the type and number of identified elements that were observed to be damaged for each test day. A summary of these tables, focusing only on the MHUs, is presented below (see Table 42 and Table 43). At the end of Part C2 testing, a qualified FEMA inspector provided a damage report for each one of the two MHU units. That report is included in APPENDIX F.

Table 42. Summary of Reported Damages during Part B/C1 and Part C2 - Baseline Unit

\begin{tabular}{|l|r|r|}
\hline BASELINE MHU COMPONENT & Part B/C1 & Part C2 \\
\hline FLOOR SYSTEMS & $\mathbf{0}$ & $\mathbf{4}$ \\
\hline Damage, separations, loosening of lags from chassis to floor & 0 & 2 \\
\hline $\begin{array}{l}\text { Buckled floor, damaged decking/floor coverings, opening of joints, loose for popped } \\
\text { feathers }\end{array}$ & 0 & 0 \\
\hline Damage to bottom board, patches, loose fasteners & 0 & 2 \\
\hline EXTERIOR, INTERIOR, MARRIAGE WALLS & $\mathbf{5}$ & $\mathbf{1 6}$ \\
\hline Interior wall panels - buckled, cracked, bowed, separations, fasteners popped or loose & 1 & 5 \\
\hline Separation of walls at floor, ceiling, column supports, window and door openings & 0 & 2 \\
\hline $\begin{array}{l}\text { Exterior siding and trim - buckled, cracked, bowed, separations, fasteners popped or } \\
\text { loose }\end{array}$ & 2 & 3 \\
\hline Windows and doors - damaged, buckled, bowed, or parts missing & 1 & 1 \\
\hline Windows and doors - operate properly & 1 & 0 \\
\hline Damage to caulking and sealants & 0 & 5 \\
\hline ROOF, CEILINGS & $\mathbf{2}$ & $\mathbf{1}$ \\
\hline Roofing - buckled, cracked, bowed, splits, openings, loose or popped fasteners & 0 & 1 \\
\hline Damage to roof penetrations - vents, roof jacks, skylights, caulking and sealants & 2 & 0 \\
\hline Damage to eaves, overhangs, transitions & 0 & 0 \\
\hline Ceilings - buckled, cracked, bowed, sagging, separations, loose or popped fasteners & 0 & 0 \\
\hline PLUMBING & $\mathbf{0}$ & $\mathbf{0}$ \\
\hline Damage to fixtures, piping, fittings, connections and supports & 0 & 0 \\
\hline
\end{tabular}


Table 43. Summary of Reported Damages during Part B/C1, Part C2 and Part D - Upgrade Unit

\begin{tabular}{|c|c|c|c|}
\hline UPGRADE MHU COMPONENT & Part B/C1 & Part C2 & Part D \\
\hline FLOOR SYSTEMS & 1 & $\mathbf{0}$ & $\mathbf{0}$ \\
\hline Damage, separations, loosening of lags from chassis to floor & 1 & 0 & 0 \\
\hline $\begin{array}{l}\text { Buckled floor, damaged decking/floor coverings, opening of joints, loose } \\
\text { for popped feathers }\end{array}$ & 0 & 0 & 0 \\
\hline Damage to bottom board, patches, loose fasteners & 0 & 0 & 0 \\
\hline EXTERIOR, INTERIOR, MARRIAGE WALLS & 11 & 19 & 2 \\
\hline $\begin{array}{l}\text { Interior wall panels - buckled, cracked, bowed, separations, fasteners } \\
\text { popped or loose }\end{array}$ & 7 & 5 & 0 \\
\hline $\begin{array}{l}\text { Separation of walls at floor, ceiling, column supports, window and door } \\
\text { openings }\end{array}$ & 0 & 3 & 0 \\
\hline $\begin{array}{l}\text { Exterior siding and trim - buckled, cracked, bowed, separations, } \\
\text { fasteners popped or loose }\end{array}$ & 2 & 6 & 2 \\
\hline Windows and doors - damaged, buckled, bowed, or parts missing & 2 & 2 & 0 \\
\hline Windows and doors - operate properly & 0 & 0 & 0 \\
\hline Damage to caulking and sealants & 0 & 3 & 0 \\
\hline ROOF, CEILINGS & $\mathbf{0}$ & 5 & 2 \\
\hline $\begin{array}{l}\text { Roofing - buckled, cracked, bowed, splits, openings, loose or popped } \\
\text { fasteners }\end{array}$ & 0 & 2 & 1 \\
\hline $\begin{array}{l}\text { Damage to roof penetrations - vents, roof jacks, skylights, caulking and } \\
\text { sealants }\end{array}$ & 0 & 2 & 1 \\
\hline Damage to eaves, overhangs, transitions & 0 & 0 & 0 \\
\hline $\begin{array}{l}\text { Ceilings - buckled, cracked, bowed, sagging, separations, loose or } \\
\text { popped fasteners }\end{array}$ & 0 & 1 & 0 \\
\hline PLUMBING & $\mathbf{0}$ & $\mathbf{0}$ & $\mathbf{0}$ \\
\hline Damage to fixtures, piping, fittings, connections and supports & 0 & 0 & 0 \\
\hline
\end{tabular}

As expected, the Upgrade Unit showed a larger number of MHU elements damaged during Part B and C1 of the tests than the Baseline Unit (12 vs 7 elements damaged, respectively). This is very likely the result of the Upgrade Unit's defective axles. In fact, as shown in Figure 34 and Figure 35, the accelerations transmitted to MHU by the defective Upgrade suspension system were larger than those transmitted to its MHU by the Baseline Unit.

In Part C2, however, the Upgrade Unit always showed lower accelerations transmitted to the MHU than the Baseline Unit. In most cases (i.e., accelerometer locations and direction), these differences were statistically significant. Nevertheless, the Upgrade Unit accumulated more MHU damage than the Baseline Unit in Part C2 (24 vs 21). The FEMA inspection report included a shorter list of items for the Baseline Unit than for the Upgrade Unit, although similar type of damages was described for both units.

This may be an indication that, although lower than those of the Baseline Unit, the accelerations transmitted by the Upgrade Unit were above the threshold at which MHU elements start to fail. The most likely explanation, however, is that because of the defective axles, the elements of the Upgrade MHU were weakened during Part B and Part C1, and were more prone to failure in Part C2, even under lower accelerations. Regardless of the explanation above, the results obtained by visual examination of the MHUs involved this testing suggest that the damages to the MHU(s) were not reduced by the improved suspension system. 


\subsection{COST COMPARISON OF THE ALTERNATIVES TESTED}

All the information gathered in this project, including the tire failure rates, accelerations transmitted to the MHU by different suspension systems, the observed damage to the different elements of the two MHUs, and the cost of the hardware used for the different alternatives can be combined to determine the cost of Alternatives 1, 2, and 3 relative to Alternative $0^{7}$.

Some of the benefits included in the analysis below are captured as reduced costs. For example, a suspension system with a lower tire failure rate will reduce the transportation cost by requiring a lower number of tires to be replaced in order to arrive at its destination. Other benefits are harder to quantify. For example, a unit with a better suspension system will arrive at the destination faster than one with a suspension system that requires more stops along the way to repair or replace different elements of that system. There is no doubt that getting the units as quickly as possible to the destination has a value to FEMA and, more importantly, to the population that needs to be sheltered. But what is the value of this benefit? In the analysis below, it is assumed to be $\$ 10 /$ hour saved in the transportation time, although there is no empirical data available to set it at that level. Still other benefits are much more difficult to capture and are not included in the analysis at all. For example, the value of the reduced congestion resulting from the mobile home not needing to stop as often on the highway shoulder to fix a tire. Or the reduction in property damage and even lives saved by reducing the failure rates of the transportation system resulting in a lower number of tires or wheel assemblies "flying off" the trailer and crashing with other vehicles traveling on the highway.

Table 44 presents the expected cost for each of the four alternatives described at the beginning of this chapter. Note that the costs presented in this table are rough estimates contingent on the assumptions described below. They are presented here to provide a comparison of the upfront and operational costs of the alternatives studied. To perform this comparison, a 1,800-mile trip from the staging area to the deployment area was considered.

Assuming a speed of $60 \mathrm{mph}$, the expected travel time for a 1,800-mile trip would 30 hours. Based on the information collected in the tests performed at NPG, the expected of tire failures for a trip of this length was computed and is presented in the second row of Table 44. With this information and assuming 30 minutes to replace a tire, the table presents in row 3 the delay that each alternative would incur due to tire failures during the trip. The total time of the trip is then presented in the next row.

Alternative 1, the Baseline Unit tested, did not require any new hardware, so its cost differential with respect to a similar unit parked at Selma, Alabama is $\$ 0$. Alternatives 2 and 3 required different type of axles and tires. The differential cost of this hardware is presented in row 5 of Table 44 . Notice that these costs would decrease if the hardware is ordered in quantities larger than what is was used in the test.

The additional cost of the driver is based on the additional time that would be required for each alternative to replace the failed tires. This assumes a cost of $\$ 30 / \mathrm{hr}$. for the driver and 30 minutes to replace a tire. The cost of a new tire of the type used by each alternative was discussed earlier in this chapter.

While the tire replacement is taking place, in general, the vehicle will be idling, and therefore there will be an additional fuel cost. The fuel consumed while idling was assumed to be $0.61 \mathrm{gal} / \mathrm{hr}$., an estimate derived from past studies conducted by ORNL (Capps et al. [3]). The cost of a gallon of diesel was $\$ 3.079$ (as of March 11, 2019), an estimate obtained from the U.S. DOE Energy Information Administration website (https://www.eia.gov/petroleum/gasdiesel/).

\footnotetext{
${ }^{7}$ Alternative 0 was the MHU that was selected from the staging area in Selma, Alabama; Alternative 1: Baseline Unit; Alternative 2: Upgrade Unit with regular tires; Alternative 3: Upgrade Unit with radial tires
} 
Finally, as discussed earlier in this chapter, it was assumed that there would be a certain cost associated with not delivering the unit on time to the deployment site. This cost was assumed to be $\$ 10.00 / \mathrm{hr}$. of delay. This figure is very likely wrong, but it was not possible for the researchers to obtain a good estimate. However, the table could be easily updated in this figure is refined. What are not included in the table are the other societal costs that may be caused by the tire failures (e.g., increase in congestion). Those are very difficult to estimate.

Once all the costs described here are taken into account, the least expensive alternative to operate is Alternative 1, which was the tested Baseline Unit with the suspension installed correctly. The total savings for that alternative compared to a similar unit with incorrect hardware (i.e., a similar unit parked at Selma, Alabama) is $42 \%$. Alternative 2 and 3 cost about $60 \%$ and $86 \%$ more than Alternative 0. The last two rows of Table 44 show the maximum average vertical accelerations registered by each alternative during the test; $100 \%$ is given to Alternative 1, which showed the highest average vertical accelerations. Alternative 2 (Upgrade Unit with regular tires) was at $81 \%$ and $86 \%$ of that maximum value for the regular and rough-road tests, while Alternative 3 (Upgrade Unit with radial tires) was at 59\% and $67 \%$, respectively. While these two alternatives showed lower levels of accelerations transmitted to MHU while traveling, both the Baseline and Upgrade units' MHUs showed similar level of damages at the end of the test.

Based on these findings, the recommendation is to use the Baseline Alternative, with the suspension system installed following the correct specifications regarding bolt sizes and torque force needed to tighten these bolts.

Table 44. Expected Cost for a 1,800 Mile Trip for Each Alternative Analyzed

\begin{tabular}{|l|r|r|r|r|}
\hline & Alternative 0 & Alternative 1 & Alternative 2 & Alternative 3 \\
\cline { 2 - 5 } & $\begin{array}{c}\text { Baseline Unit } \\
\text { As Is }\end{array}$ & $\begin{array}{c}\text { Baseline Unit } \\
\text { Tested }\end{array}$ & $\begin{array}{c}\text { Upgrade Unit } \\
\text { Regular Tires }\end{array}$ & $\begin{array}{c}\text { Upgrade Unit } \\
\text { Radial Tires }\end{array}$ \\
\hline $\begin{array}{l}\text { Expected Travel Time } \\
\text { No Tire Failures [hr.] }\end{array}$ & 30 & 30 & 30 & 30 \\
\hline Expected \# Tire Failures & 12 & 7 & 2 & 0 \\
\hline Delay Time [hr.] & 6.00 & 3.59 & 1.24 & 0.00 \\
\hline Total Trip Time [hr.] & 36.00 & 33.50 & 31.00 & 30.00 \\
\hline Delta Upfront Cost & $\$ 0.00$ & $\$ 0.00$ & $\$ 1,368.00$ & $\$ 1,920.00$ \\
\hline Cost of Tire Replacement & $\$ 780.00$ & $\$ 455.00$ & $\$ 238.00$ & $\$ 0.00$ \\
\hline Additional Driver Cost & $\$ 180.00$ & $\$ 105.00$ & $\$ 30.00$ & $\$ 0.00$ \\
\hline Additional Cost of Fuel & $\$ 11.21$ & $\$ 6.54$ & $\$ 1.87$ & $\$ 0.00$ \\
\hline Additional Cost of Delays & $\$ 60.00$ & $\$ 35.00$ & $\$ 10.00$ & $\$ 0.00$ \\
\hline Total Trip Cost & $\$ 1,031.21$ & $\$ 601.54$ & $\$ 1,647.87$ & $\$ 1,920.00$ \\
\hline \% Saved w/respect to Alt 0 & $0.00 \%$ & $41.67 \%$ & $-59.80 \%$ & $-86.19 \%$ \\
\hline $\begin{array}{l}\text { Vertical Accelerations } \\
\text { (Regular Road) }\end{array}$ & N/A & $100 \%$ & $81 \%$ & $59 \%$ \\
\hline $\begin{array}{l}\text { Vertical Accelerations } \\
\text { (Rough Road) }\end{array}$ & N/A & $100 \%$ & $86 \%$ & $67 \%$ \\
\hline
\end{tabular}





\section{LESSONS LEARNED}

As with any novel large-scale testing effort, basic assumptions in several cases proved to be incorrect. Additionally, unforeseen circumstances arise that negatively affect the planned parameters and variables within the testing regiment.

This section of the report seeks to tabulate and quantify, if possible, these issues and to specify a resolution or methodology to account for them in future testing.

\subsection{AXLE ALIGNMENT AS MANUFACTURED}

The MHUs as delivered had issues with axle alignment (axles not being perpendicular with the frame rails). This caused the axles to be at an angular difference relative to each other in relation to the MHU's two main frame rails which are the attachment point for the axles. This created a situation in which tires would scrub due to their rotational axis being mis-aligned with the other tires on the MHU. This axle misalignment was caused by the axle spring hangers being welded at non-symmetrical distances along the frame rails. This issue was corrected by NPG before the start of testing. Each axle's spring hangers were welded to within 1/16 inch relative to the left and right mounting points along the frame rails. While we did not have a third unit to test (one in which the axle alignment was not corrected), this "native" axle misalignment could be the cause of the high rate of premature tire failure called out in the Problem Statement of this report and referenced in the analysis as empirical failure rates.

\subsection{AXLE WHEEL-END MISALIGNMENT}

The initial lot of upgraded axles had issues with some axles having their wheel spindles welded on at angles greater than 90 degrees. This was not that was noticeable to the naked eye, but this issue caused the high rate of tire failures in the upgraded unit at the beginning of the Part $\mathrm{C}$ testing. Once the problem was identified, the axle manufacturer was notified, and replacement axles were provided and installed.

\subsection{TRAILER TO TOW VEHICLE ANGLE}

While not an issue during out testing, the angle relative the tow vehicle, in which the MHU is towed can cause a non-homogeneous distribution of MHU weight across the axle gang. If the front of the MHU is above level, weight is shifted to the rearmost axles. If the front of the trailer is below level weight is shifted to the forward most axles. Depending on the initial weight of the MHU and the degree of the "out of level" condition, rearward or forward axles could be overloaded. This is shown to some degree in Table 7 and Table 8.

\subsection{AXLE BEARING PRE-LOAD}

During the inspection process by NPG, it was discovered that the some of the axle's wheel-end bearing preloads were not properly set. Clearly, this would have affected the life of these bearings. NPG set the preload of all axle bearing prior to testing.

\subsection{SUSPENSION CONNECTING BOLTS OVERTIGHTENED}

During the installation of the "as new condition" axles on both the baseline and upgraded axles, NPG determined that the suspension mounting bolts on the units as received had been tightened to the point of suspension components yielding. Additionally, 1/2-inch diameter bolts had been used even though the 
suspension components were designed to receive 9/16- inch bolts. NPG installed the new axles with 9/16-inch bolts and tightened the mounting bolt nuts just to the point of contacting the suspension shackles and then used double nuts to secure the bolts for testing. This issue is described in more detail in the Outfitting of the Test Units section of this report.

\subsection{STAMPED/FORMED EQUALIZERS CRACKED PREMATURELY}

Upon removal of the "as arrived" suspension hardware, NPG noted that some of the stamped/formed equalizers had cracked at the frame hanger mounting hole. It was not clear why this would have happened with such low mileage on the MHUs (factory to Selma, Alabama, and Selma, Alabama, to the NPG facility). It was suggested that these failures may have resulted from a poor design of the stamped/formed equalizer, poor manufacture process or inferior materials, or the over-tightening of the mounting bolts. It was determined to reinstall the stamped/formed equalizer onto the baseline unit and test their longevity as compared to the cast type equalizer to be installed on the upgraded unit.

A portion of the tires ordered for the baseline unit, while of this same size, were from a different manufacturer than the majority of the lot. This would not be an issue in normal operations, if the quality of the two manufactures were the same, however for a test of this nature, it introduced a new variable that would not be quantifiable. It was therefore decided not to use these tires. For future testing, it should be noted that all supplied parts should be of the same type, series, and manufacture.

\subsection{VALUE OF A THIRD TEST UNIT}

It would have been good to have tested a third MHU that could have represented the "as delivered condition" to understand how poorly it would have performed as compared to the baseline unit which had it axles aligned to 1/16" along the frame longerons and did not have the suspension mounting bolts overtightened. It is assumed that this unit would have had tire and wheel-end failures in similar quantities as called out in the Problem Statement section of this report.

\subsection{DATA COLLECTION PROTOCOLS}

Because of the large number of sensors (18 accelerometers) and their high frequency of data collection $(512 \mathrm{~Hz})$, it was first specified in the test plan to collect data in "bursts" of five-minute interval of data every hour of test rather than continuously. Since the data analysis methodology required the comparison of Baseline and Upgrade Units information for the same segment of road collected at approximately the same time, the data collection "bursts" needed to be synchronized. Moreover, it also required the drivers to initiate the software that controlled these data collection "bursts." This requirement proved to be difficult to comply for the drivers because it was not a task that they perform habitually. If one driver forgot to initiate the data-collection triggering software, then the data collection for that part of the test could not be used for the analysis since it was based on the comparison of the two streams of data. After two occasions in which data was not collected because the burst data-collection software was not initiated, the data collection protocol was changed to one of continuous data collection (which would be triggered when the tractor engine started without driver intervention) and more frequent uploads of the data collected. 


\section{REFERENCES}

[1] Lascurain, M.B., Capps, G., and O. Franzese. Federal Emergency Management Agency Mobile Housing Unit Running Gear Testing Overview, Draft Report, Oak Ridge National Laboratory, Oak Ridge, TN, 2008.

[2] Devore, J. Probability and Statistics for Engineering and the Sciences. Eighth Edition, 2012.

[3] Capps, G., O. Franzese, H. Knee, M. Lascurain, and P. Otaduy. Class-8 Heavy Truck Duty Cycle Project Final Report. ORNL/TM-2008/122, Oak Ridge National Laboratory, Oak Ridge, TN, 2008. 

APPENDIX A. PRE-TEST ACCELEROMETER DATA EXAMINATION 



\section{APPENDIX A. PRE-TEST ACCELEROMETER DATA EXAMINATION}

This Appendix shows plots of accelerometer data collected and analyzed prior to the official test to certify that the accelerometers were collecting data correctly and that the proposed methodology for the statistical analysis of vibrations could be applied as proposed. The figures in this appendix were generated using the data collected by the accelerometers located at the front-left, hitch, front-right, rearleft, and rear-right MHU locations. In each one of Figure A-1 to Figure A5, the top plots show the raw sensor data during that three-minute period, and the frequency analysis for that segment is shown underneath. The plots that follow (Figure A-6 to Figure A-10) show the frequency response for the threeminute segments broken out by individual sensor. A consistent scale was used for all of these figures.
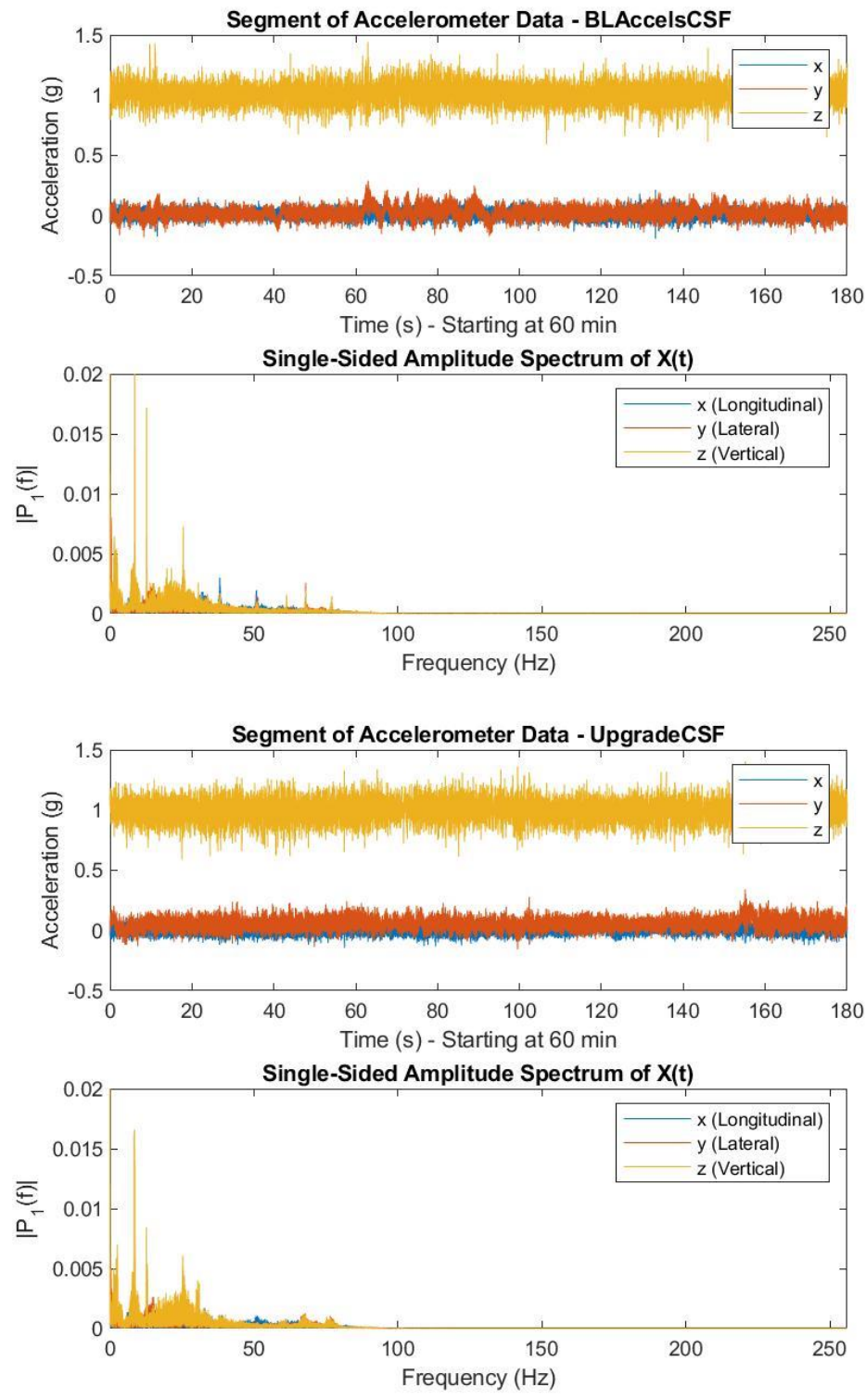

Figure A- 1. Segment of Accelerometer Data at the Curb Side Front Corner $(\mathrm{x}=$ Longitudinal, $\mathbf{y}=$ Lateral, $\mathrm{z}=$ Vertical $)$. 

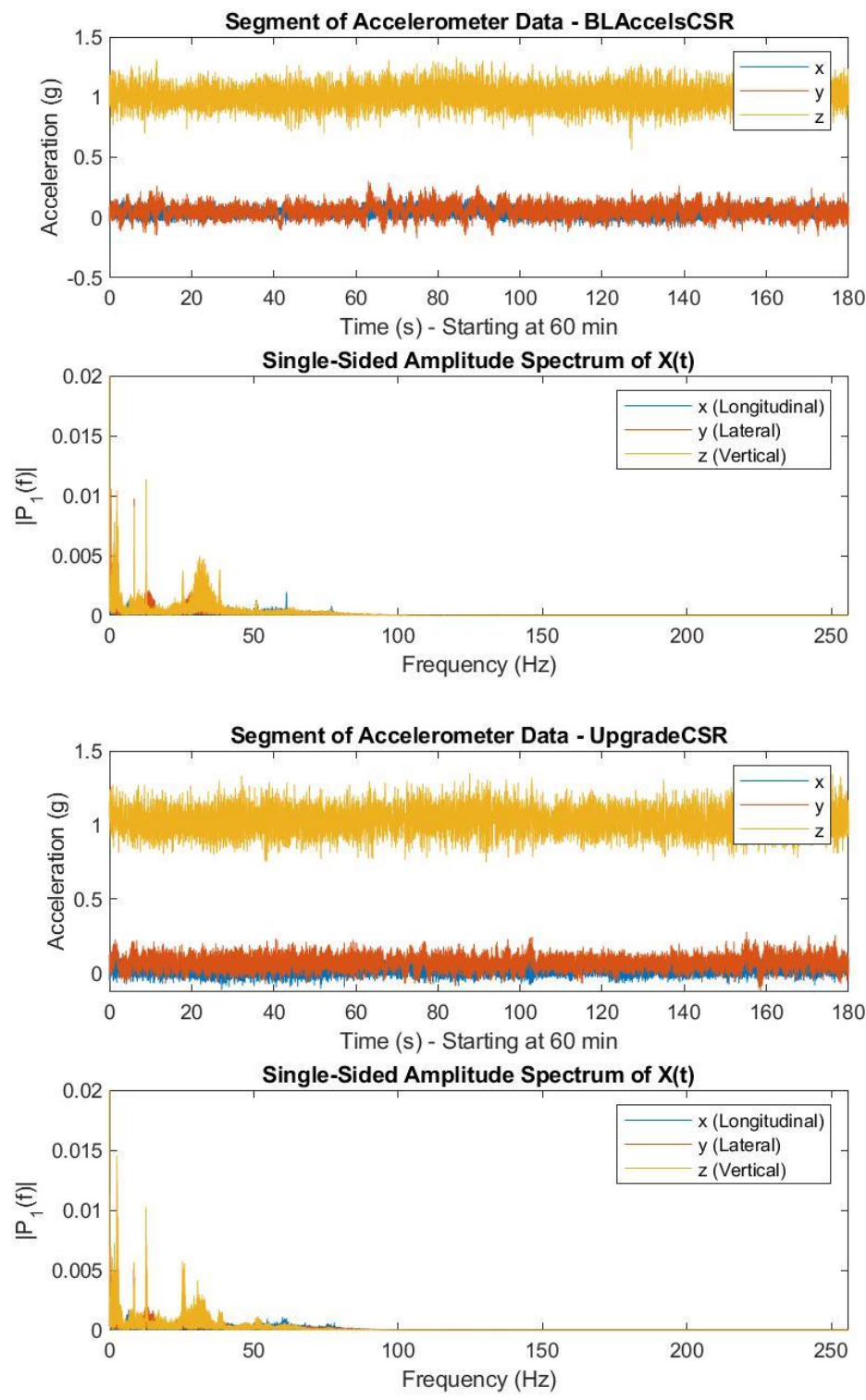

Figure A- 2. Segment of Accelerometer Data at the Curb Side Rear Corner $(\mathrm{x}=$ Longitudinal, $\mathbf{y}=$ Lateral, $\mathrm{z}=$ Vertical $)$. 

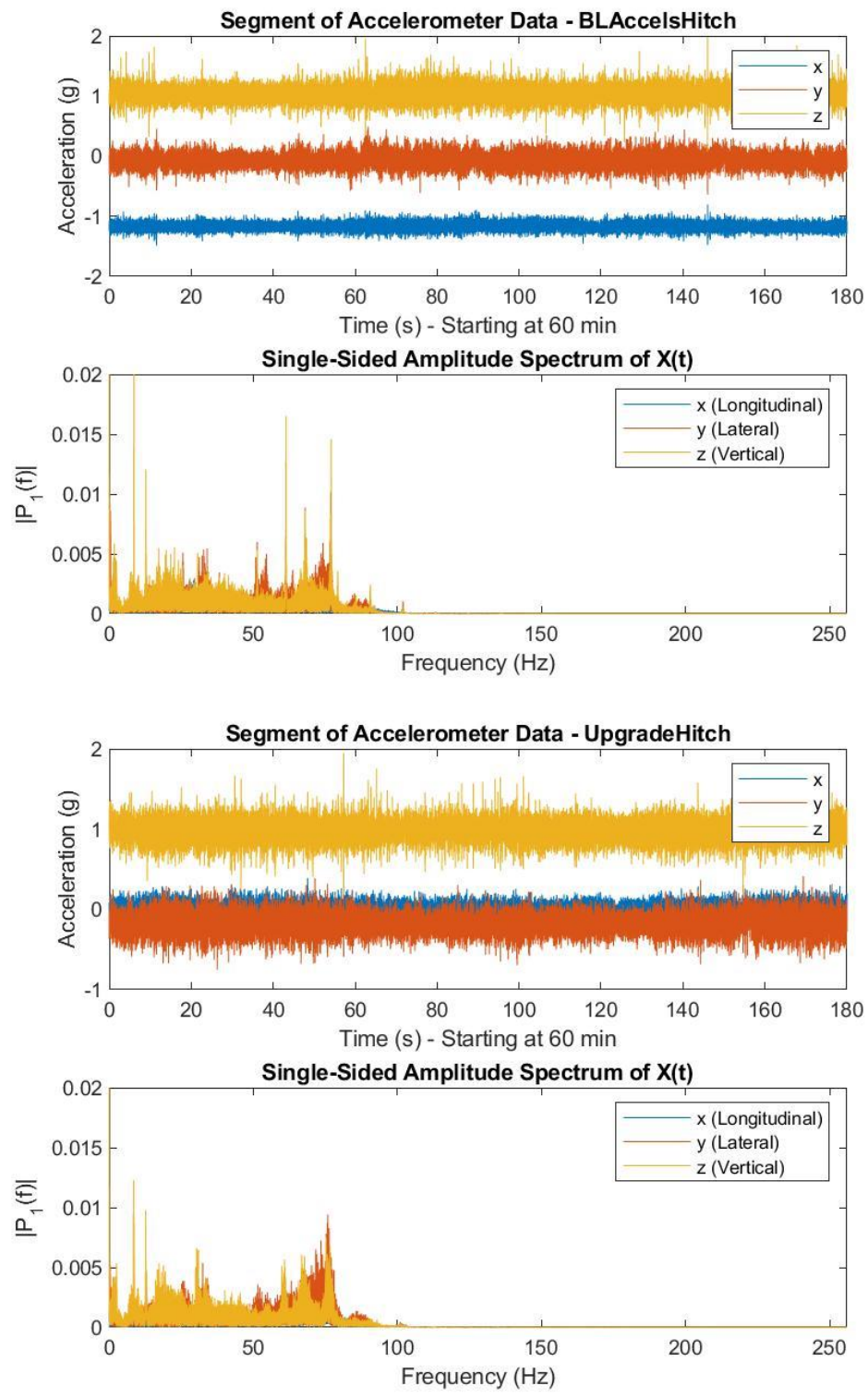

Figure A- 3. Segment of Accelerometer Data at the Hitch Center $(\mathrm{x}=$ Longitudinal, $\mathbf{y}=$ Lateral, $\mathrm{z}=$ Vertical $)$. 

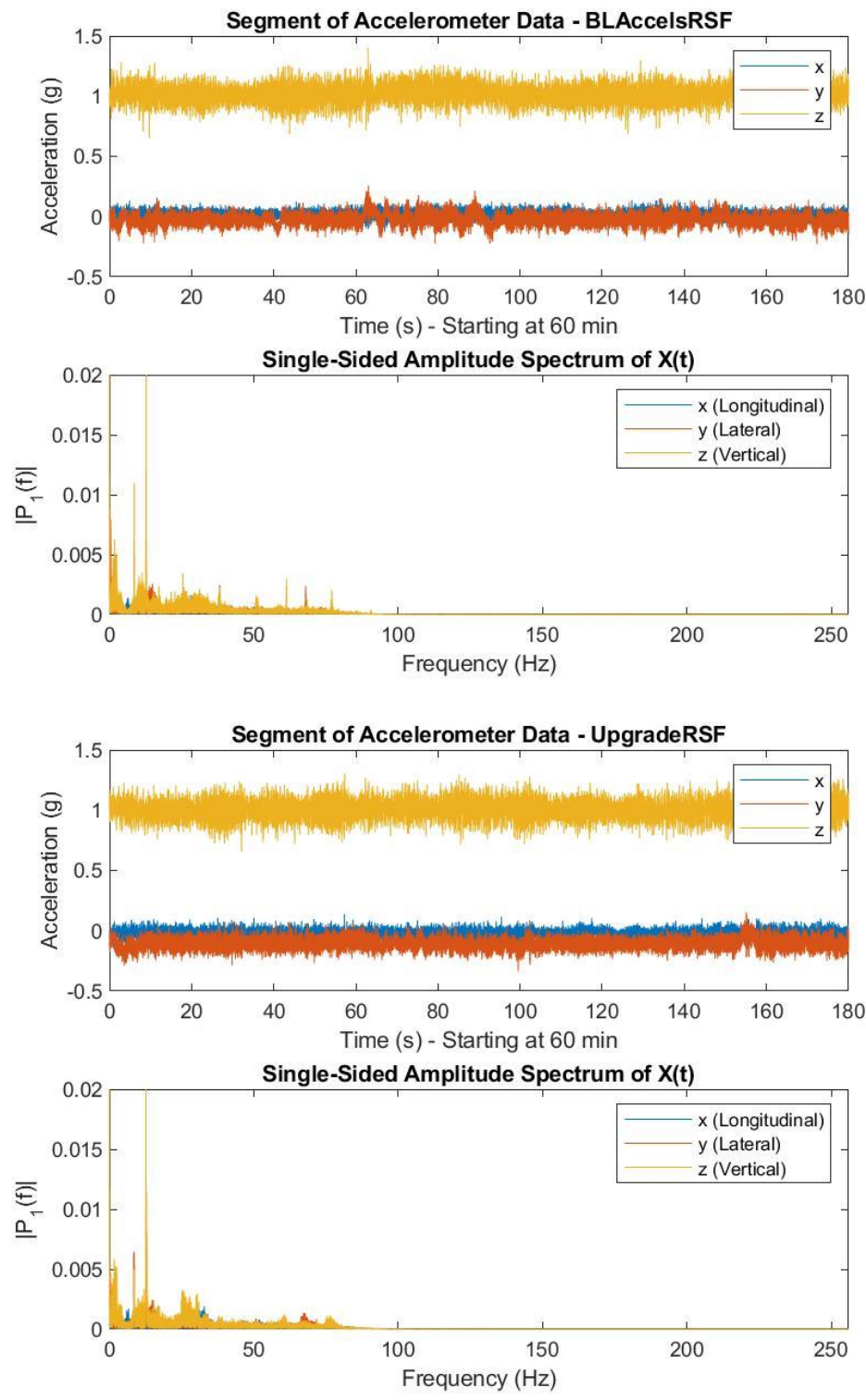

Figure A- 4. Segment of Accelerometer Data at the Road Side Front Corner ( $x=$ Longitudinal, $y=$ Lateral, $\mathrm{z}=$ Vertical $)$. 

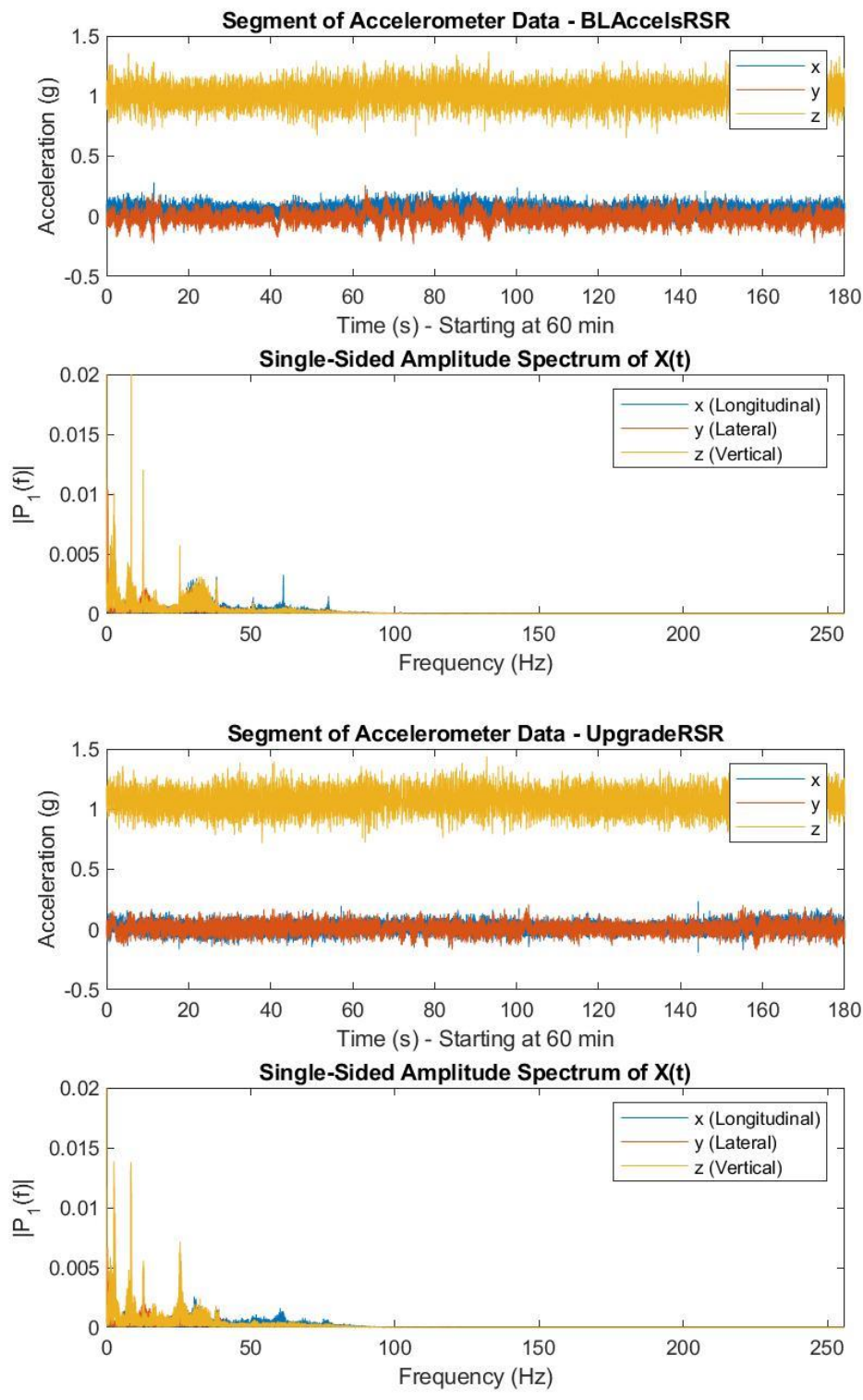

Figure A- 5. Segment of Accelerometer Data at the Road Side Rear Corner $(\mathrm{x}=$ Longitudinal, $\mathbf{y}=$ Lateral, $\mathrm{z}=$ Vertical $)$. 
The following plots show the frequency response for the three-minute segments broken out by individual sensor. A consistent scale was used for all of these figures.
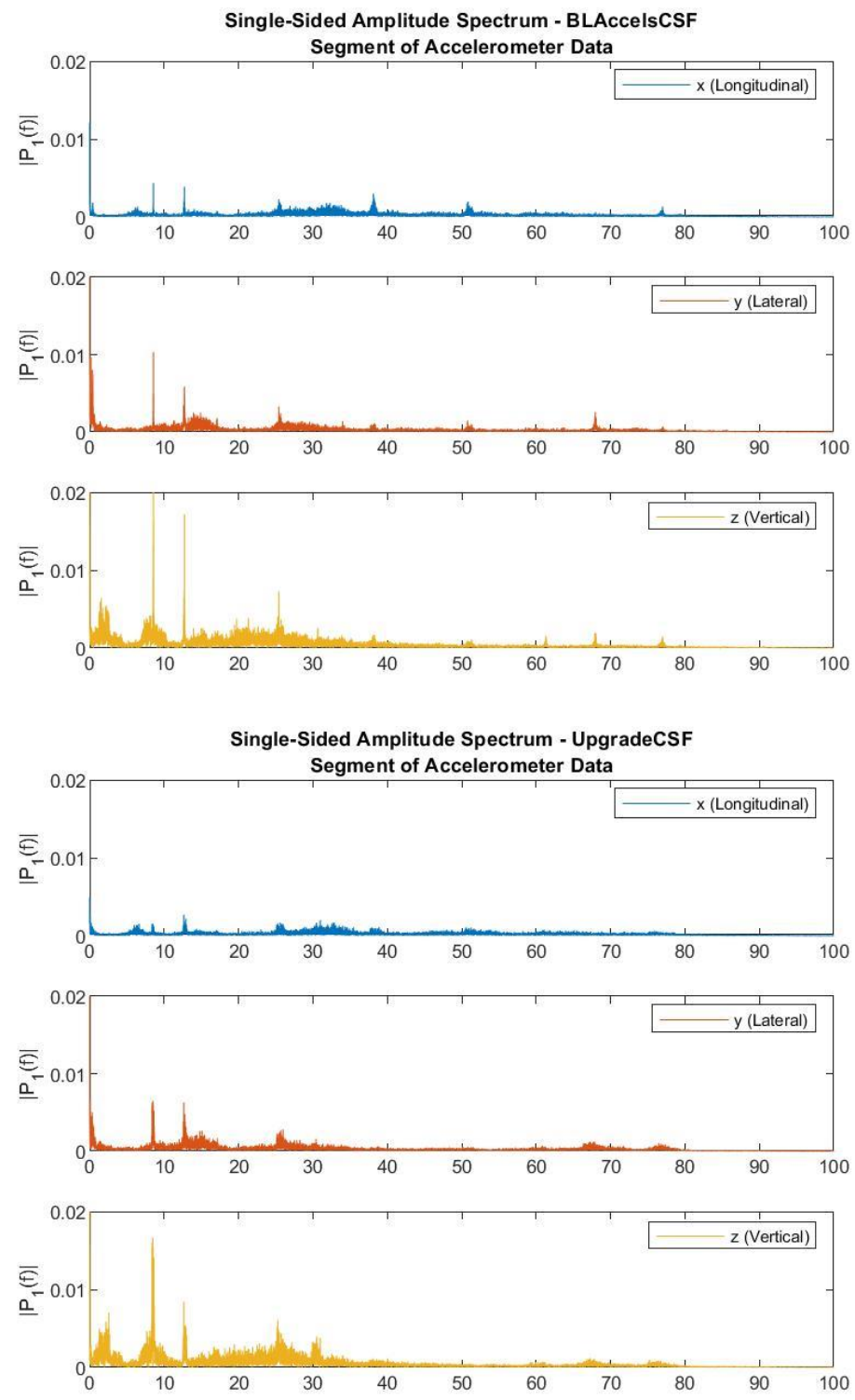

Figure A- 6. Frequency Distribution of Accelerometer Data at the Curb Side Front Corner (3-Minute Segment). 

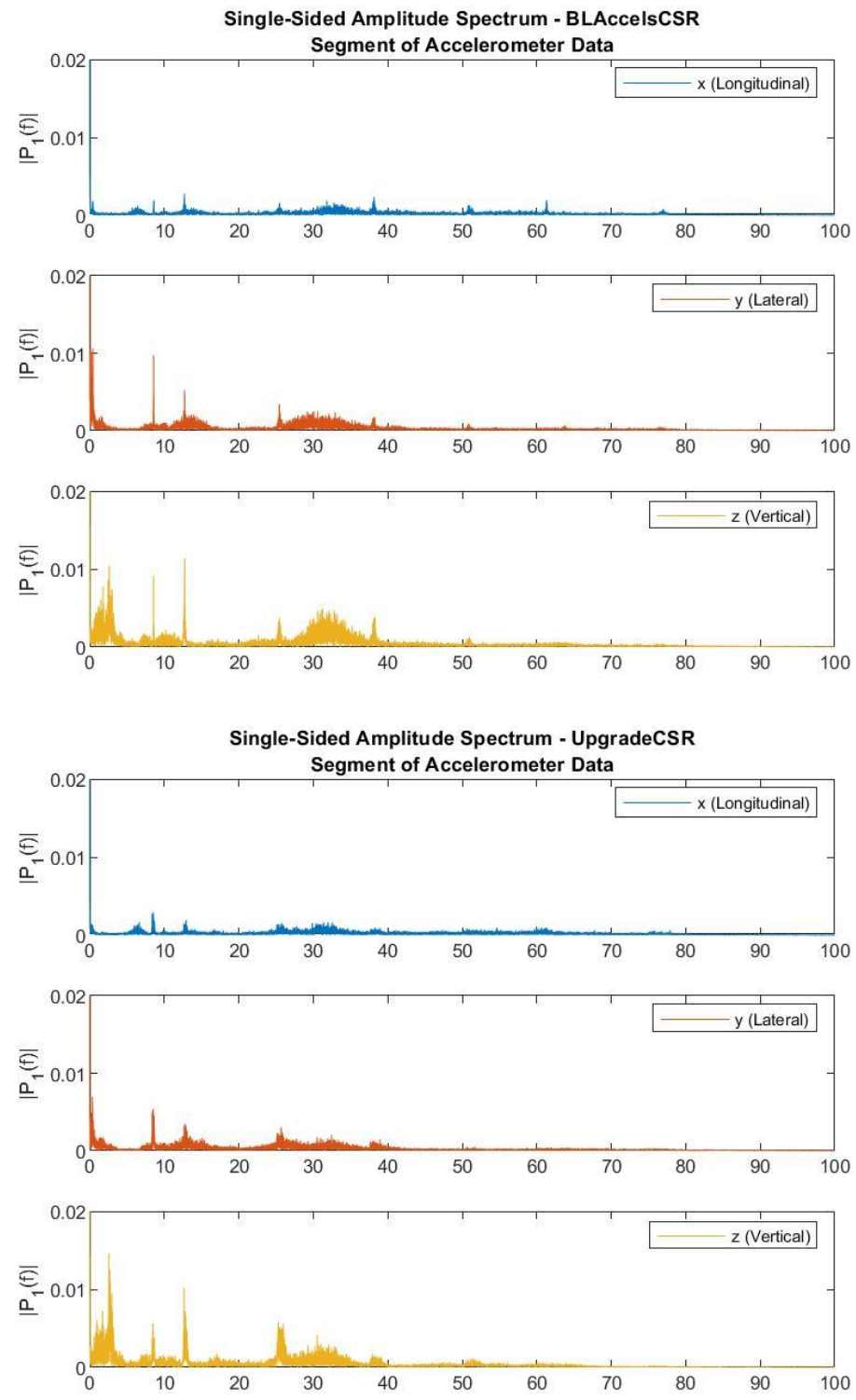

Figure A- 7. Frequency Distribution of Accelerometer Data at the Curb Side Rear Corner (3-Minute Segment). 

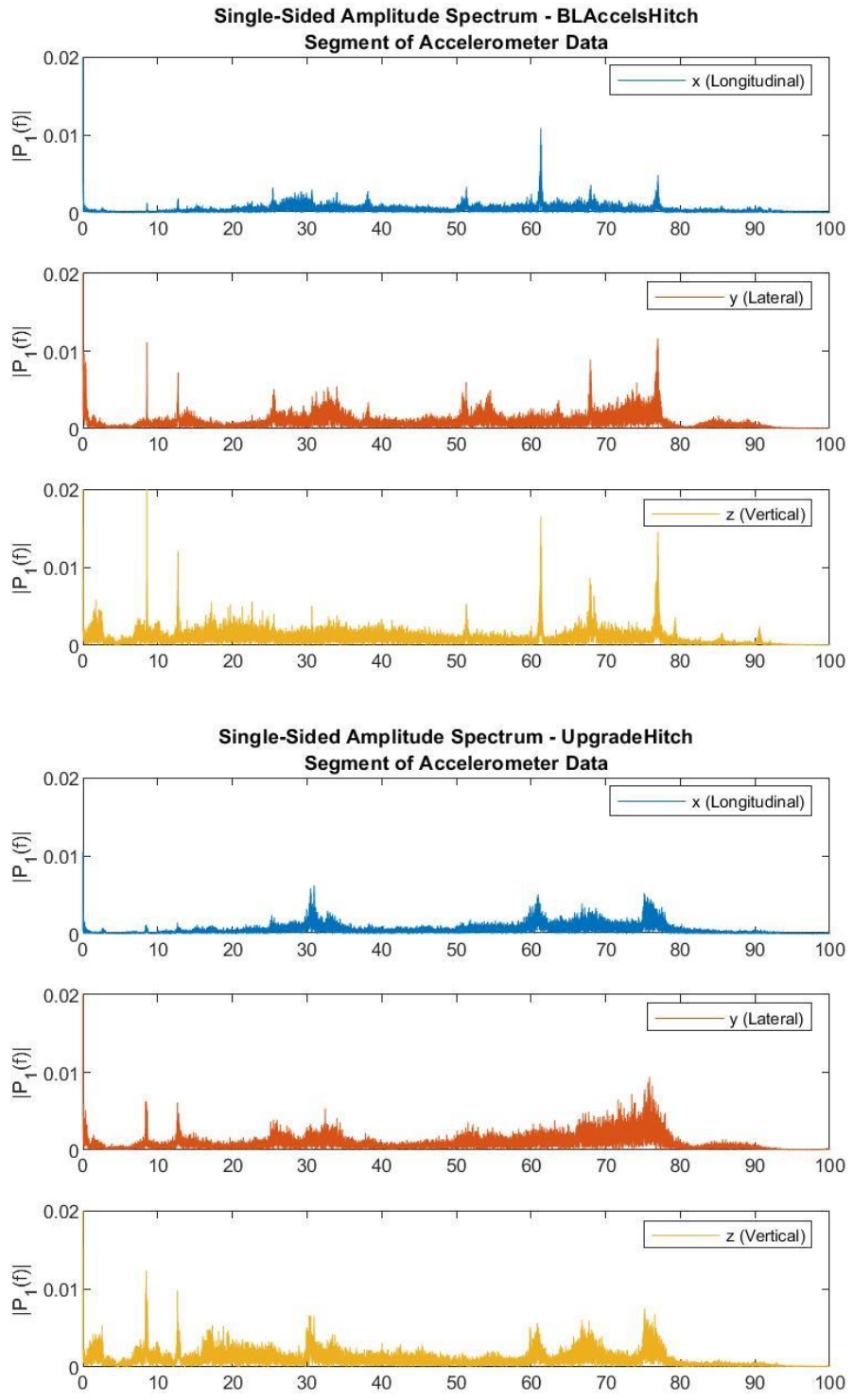

Figure A- 8. Frequency Distribution of Accelerometer Data at the Hitch Center (3-Minute Segment). 

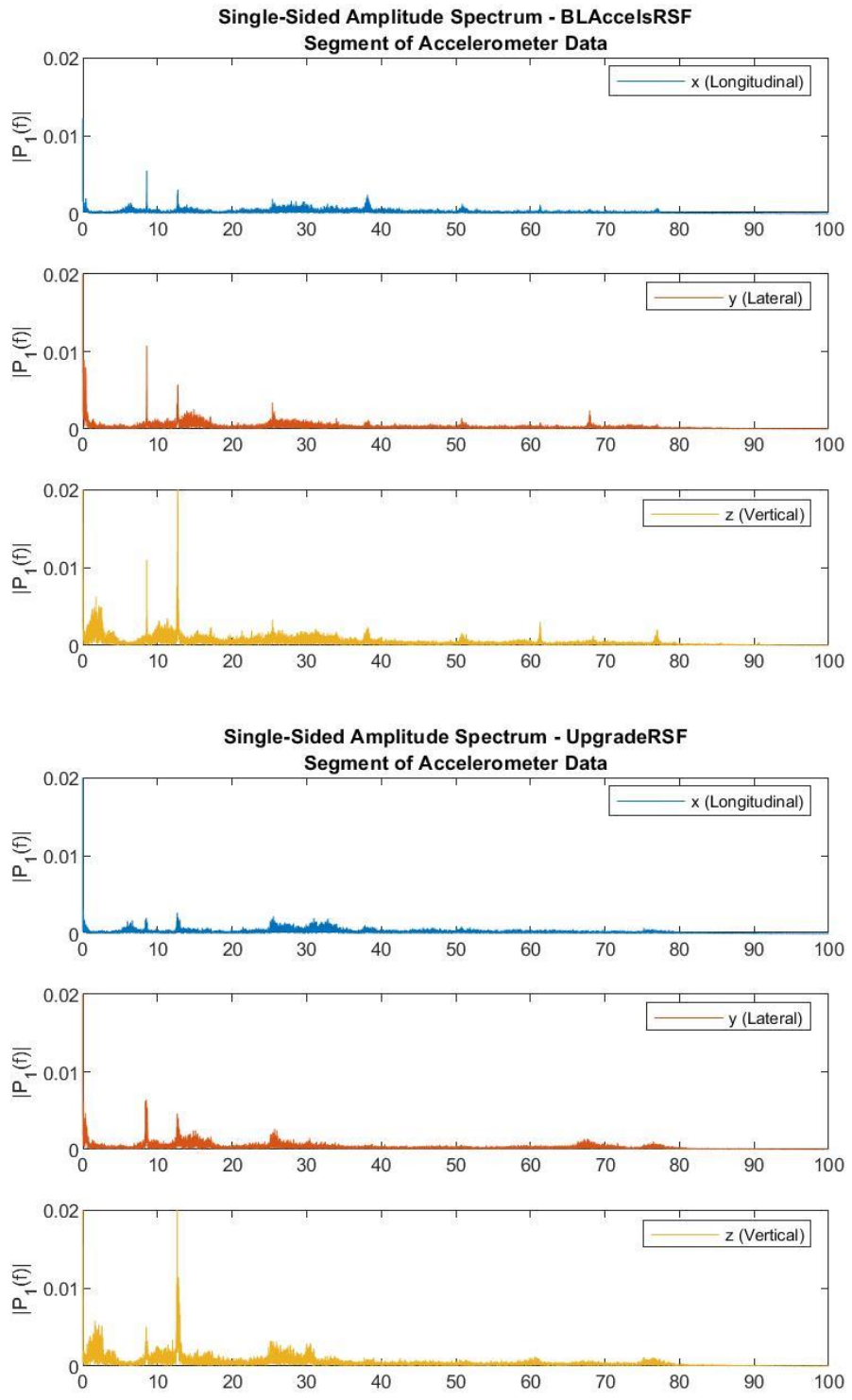

Figure A- 9. Frequency Distribution of Accelerometer Data at the Road Side Front Corner (3-Minute Segment). 

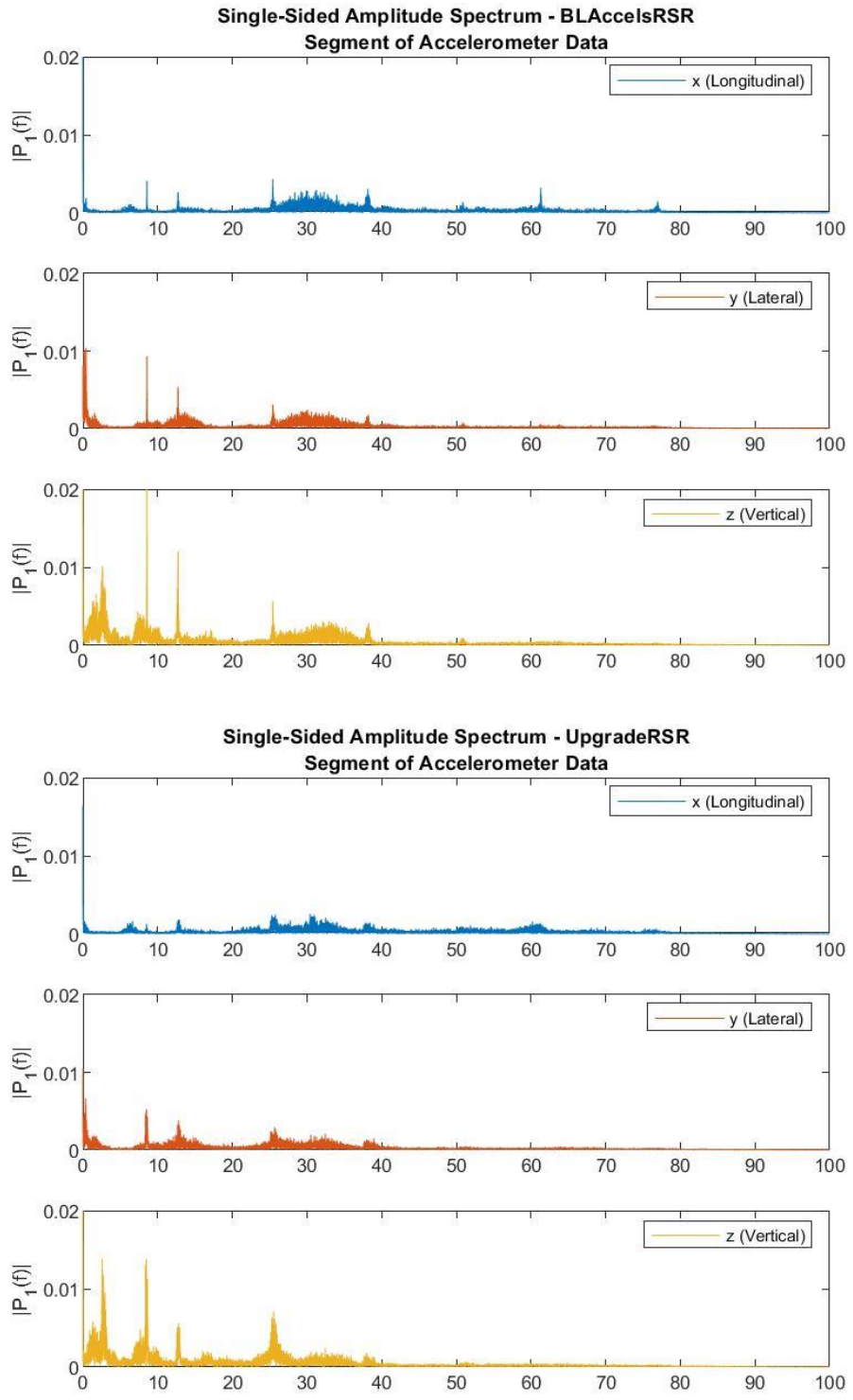

Figure A- 10. Segment of Accelerometer Data at the Road Side Rear Corner ( $x=$ Longitudinal, $y=$ Lateral, $\mathrm{z}=$ Vertical $)$. 
APPENDIX B. UPGRADE UNIT AXLES REPLACEMENT 



\section{APPENDIX B. UPGRADE UNIT AXLES REPLACEMENT}

During the first two days of Part C testing, it was observed that Upgrade Unit tire failures started to increase disproportionately. Moreover, these tire failures were not randomly distributed, but happened on particular axles (Axles 4, 5, and 6) and were more predominant on a particular side of these axles (right side). More information related to these tire failures are presented in Table B- 1 .

Table B- 1. Upgrade Unit Tire Failures by Position and Mileage

\begin{tabular}{|c|c|r|r|r|l|}
\hline Date & Axle & $\begin{array}{c}\text { Truck } \\
\text { Odometer }\end{array}$ & $\begin{array}{c}\text { Component } \\
\text { Test Miles }\end{array}$ & $\begin{array}{c}\text { Vehicle } \\
\text { Test Miles }\end{array}$ & Failure \\
\hline $07 / 04 / 2018$ & 4-R & 78,381 & 571 & 571 & Blowout \\
\hline $07 / 17 / 2018$ & 1-L & 78,921 & 1,100 & 1,100 & Cords \\
\hline $07 / 27 / 2018$ & 5-R & 79,161 & 1,351 & 1,351 & Blowout \\
\hline $07 / 27 / 2018$ & 4-R & 79,182 & 801 & 1,372 & Blowout \\
\hline $07 / 30 / 2018$ & 6-R & 79,287 & 1,477 & 1,477 & Blowout \\
\hline $08 / 01 / 2018$ & 6-L & 79,489 & 1,677 & 1,677 & Severe \\
\hline $08 / 01 / 2018$ & 4-R & 80,090 & 906 & 2,278 & Blowout \\
\hline $08 / 01 / 2018$ & 4-L & 80,090 & 2,278 & 2,278 & Severe \\
\hline $08 / 01 / 2018$ & 5-L & 80,090 & 2,278 & 2,278 & Severe \\
\hline $08 / 01 / 2018$ & 5-R & 80,090 & 927 & 2,278 & Severe \\
\hline
\end{tabular}

As part of the unit outfitting before testing, NPG had installed new four-inch spring hangers, which were welded to accommodate the Suretrac 7,000 lbs axles and the larger diameter Hometraxx tires (a description of the assembly procedure of the Suretrac 7,000 is included at the end of this Appendix). During the outfitting of the unit, it was noted that the original spring hangers were not welded squarely onto the unit frame and also that the original installed axles were not perpendicular to the unit frame. The NPG shop reinstalled the spring hangers centering them on the frame rails and welding them perpendicular to the rails. They also made sure that each set of hangers were perpendicular to the rails to allow for proper axle alignment. The Suretrac 7,000-lbs axles and the Hometraxx tires and wheel assemblies were then installed. The vehicle was weighed, and it was determined that the location of the newly installed hangers and axles maintained the previously obtained weight distribution to the axle gang and the towing power unit, with no axle-overload condition observed. Also, during testing, the pressure of the tires was checked at the start of each testing shift and set at $115 \mathrm{psi}$ (as per the sidewall max load/pressure indication).

At that point, it was decided to stop the testing and investigate this situation. NPG was instructed to check if the axle mounting brackets were indeed perpendicular to the unit's frame, check if any of these axles had rotated within its mounting solution, and to check if the axles had moved side-to-side in their mounting solution (i.e., if a given axle was allowing the wheel end to be outside the plane of the other axles).

NPG conducted an inspection of the Upgrade Unit as instructed by the researchers working in this project. First, the unit was weighed on a level surface, with trailer connected to tractor in the normal towing configuration. The measured axle weights are presented in Table B- 2. 
Table B- 2. Upgrade Unit Axle Weights - Unit Connected to Tow Vehicle in Testing Configuration

\begin{tabular}{|c|c|c|r|}
\hline \multirow{2}{*}{$\begin{array}{c}\text { Axle \# } \\
\text { Front to } \\
\text { Back) }\end{array}$} & $\begin{array}{c}\text { Roadside } \\
\text { (Left) }\end{array}$ & $\begin{array}{c}\text { Curbside } \\
\text { (Right) }\end{array}$ & Total \\
\hline 1 & 2,375 & 2,450 & 4,825 \\
\hline 2 & 2,000 & 2,225 & 4,225 \\
\hline 3 & 2,100 & 2,200 & 4,300 \\
\hline 4 & 2,075 & 2,250 & 4,325 \\
\hline 5 & 1,950 & 2,250 & 4,200 \\
\hline 6 & 2,300 & 2,625 & 4,925 \\
\hline \multicolumn{3}{|c|}{ Total Axles } & $\mathbf{2 6 , 8 0 0}$ \\
\hline
\end{tabular}

When NPG examined the Upgrade Unit suspension and tires, they found several misalignment issues. First, they stretched a string along the tires on the left side. With the string touching the sidewall on front and rear tires (forward of the rim and rearward of the rim), there were no gaps between string and sidewall on any other tires (see Figure B-1). This was an indication that all the tires were square with each other.

Then, they stretched the string along the right side in the same manner and found that the tires all appear to be tipped outward on the front side. The string touched the sidewall on the front or leading edge of the tires, but there was as much as a $3 / 4$ " gap (Axle 4) between string and sidewall on the rear or trailing edge of the tires. These measurements are presented in Table B- 3 .

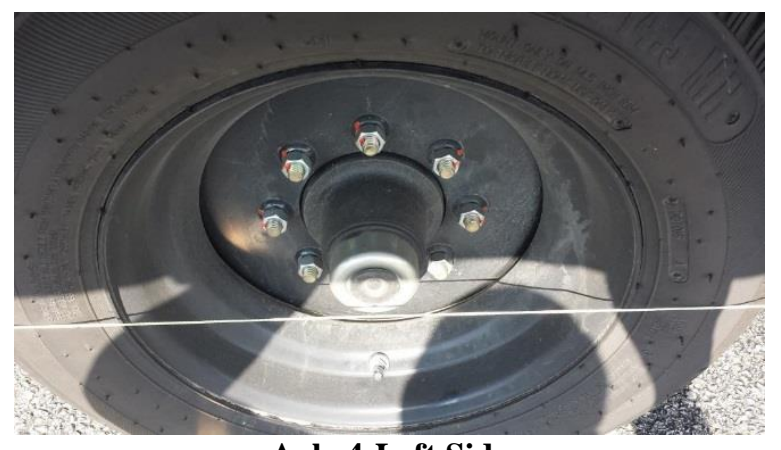

Axle 4-Left Side

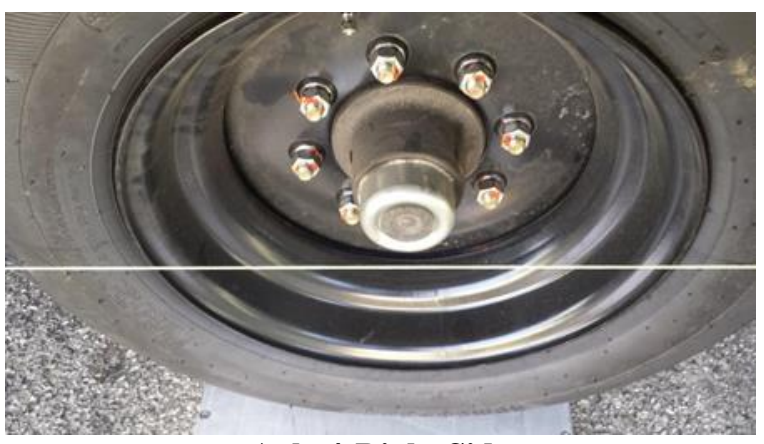

Axle 4-Right Side

Figure B- 1. Upgrade Unit Aligned (Left Side) and Misaligned (Right Side) Wheels. 
Table B- 3. Upgrade Unit - Distance from Sidewall to String

\begin{tabular}{|c|r|r|r|}
\hline Axle \# & $\begin{array}{c}\text { Left-Side } \\
\text { [in] }\end{array}$ & $\begin{array}{c}\text { Rim } \\
\text { Location }\end{array}$ & $\begin{array}{c}\text { Right Side } \\
\text { [in] }\end{array}$ \\
\hline \multirow{2}{*}{1} & 0.00 & Front & 0.00 \\
\cline { 2 - 4 } & 0.00 & Rear & 0.25 \\
\hline \multirow{2}{*}{2} & 0.00 & Front & 0.00 \\
\cline { 2 - 4 } & 0.00 & Rear & 0.50 \\
\hline \multirow{2}{*}{3} & 0.00 & Front & 0.25 \\
\cline { 2 - 4 } & 0.00 & Rear & 0.50 \\
\hline \multirow{2}{*}{4} & 0.00 & Front & 0.00 \\
\cline { 2 - 4 } & 0.00 & Rear & 0.75 \\
\hline \multirow{2}{*}{5} & 0.00 & Front & 0.00 \\
\cline { 2 - 4 } & 0.00 & Rear & 0.50 \\
\hline \multirow{2}{*}{6} & 0.00 & Front & 0.00 \\
\cline { 2 - 4 } & 0.00 & Rear & 0.50 \\
\hline
\end{tabular}

If NPG had encountered the same condition on both sides of the trailer, but on opposite sides of the tire, misalignment of the hangers by equal amounts would be suspected. However, since they saw this condition only on the right side, they hypothesized that the axles were bent. To determine if this was the case, NPG used a straight-edge on the remaining new Upgrade Unit axles in stock. With a framing square tight against the backing plate, the left side backing plate of each axle measured appears to be perpendicular to the axle. With the square against the right-side packing plates, they are out of square by as much as 1-1/2" at the center of the axles. This is shown in Figure B- 2.

The same procedure was then used on the installed axles with the same results. Figure B- 3 clearly shows that on the right side of axle 4 the packing plate and the axle itself are out-of-square. This was again confirmed once the axles were dismounted (see Figure B-4).

Twelve of the 7,000-lbs axles that were purchased from Suretrac were deemed defective and new replacement axles were requested from that company. Additional tires were also ordered at that time. With the mounting bolts, equalizers, and other hardware at hand, and the replacement axles and tires, it was decided to reestablish the Upgrade Unit running gear to "as new" condition for restart of testing. It was also decided to replace the equalizers, shackles, and mounting bolts with new ones (but leave the current welded spring hangers in place) before the test was restarted. The rationale for this decision was to eliminate any possible increased wear on those components that might have been caused by the misaligned wheel-ends on the improperly manufactured axles. 


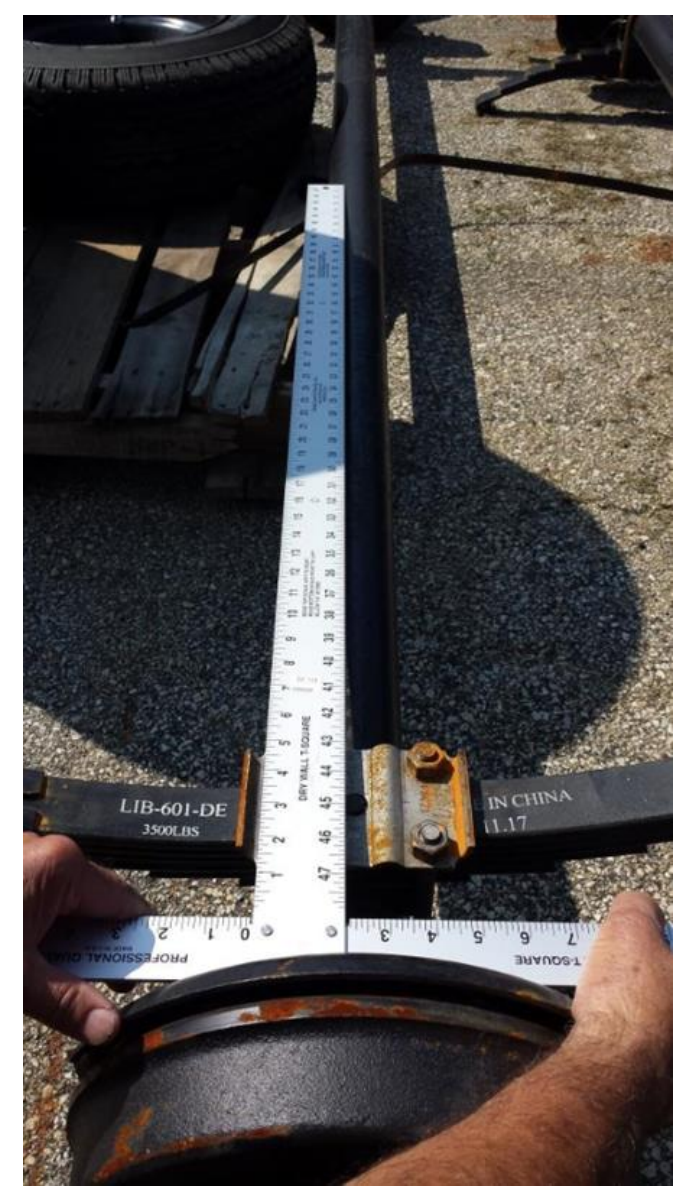

Left Side

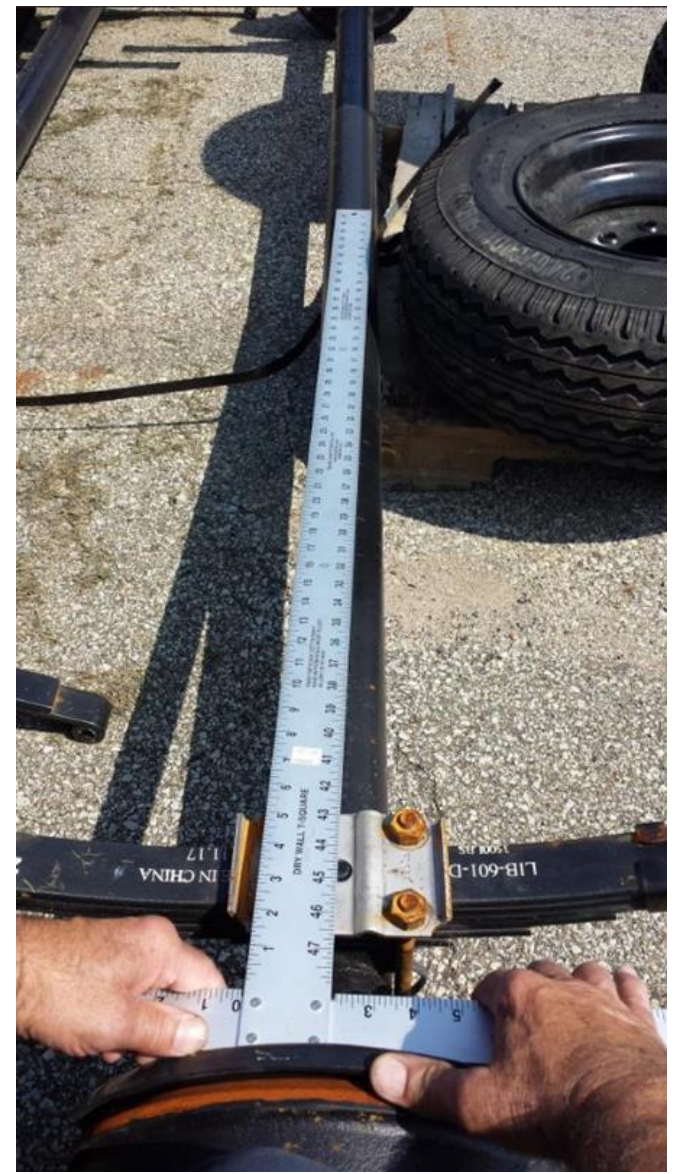

Right Side

Figure B- 2. Spare-Axle Left Side and Right Side.

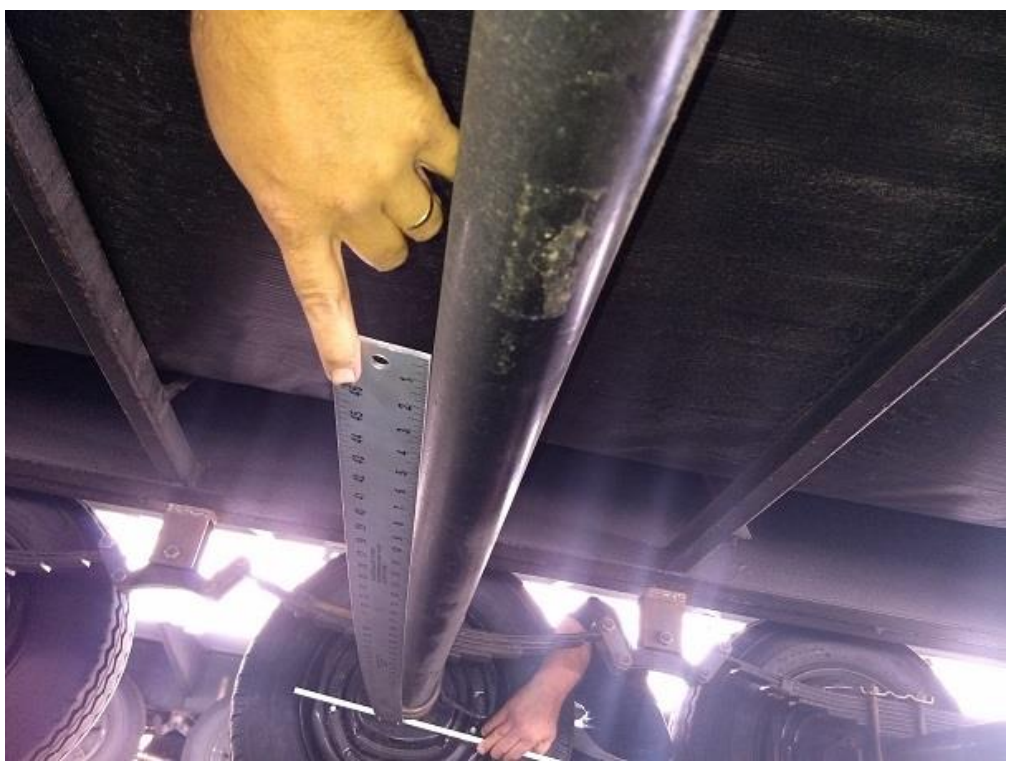

Figure B- 3. Upgrade Unit Axle 4 Out-of-Square Packing Plate/Axle. 


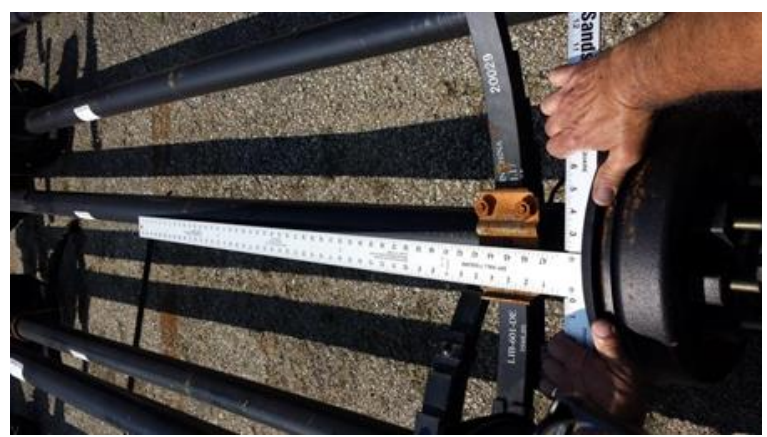

Axle 4-Left Side

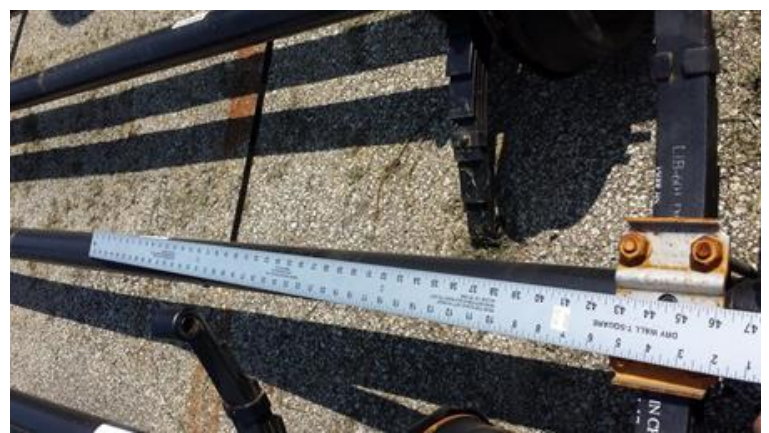

Axle 4-Right Side

Figure B- 4. Upgrade Unit Perpendicular (Left Side) and Out-of-Square (Right Side) Packing Plates/Axles.

Once all the replacement components arrived at the test site, NPG checked that the new axles were squared. Since that was the case (see Figure B- 5) NPG proceeded to install new upgrade axles on the Upgrade Unit, replacing everything except the hangers.
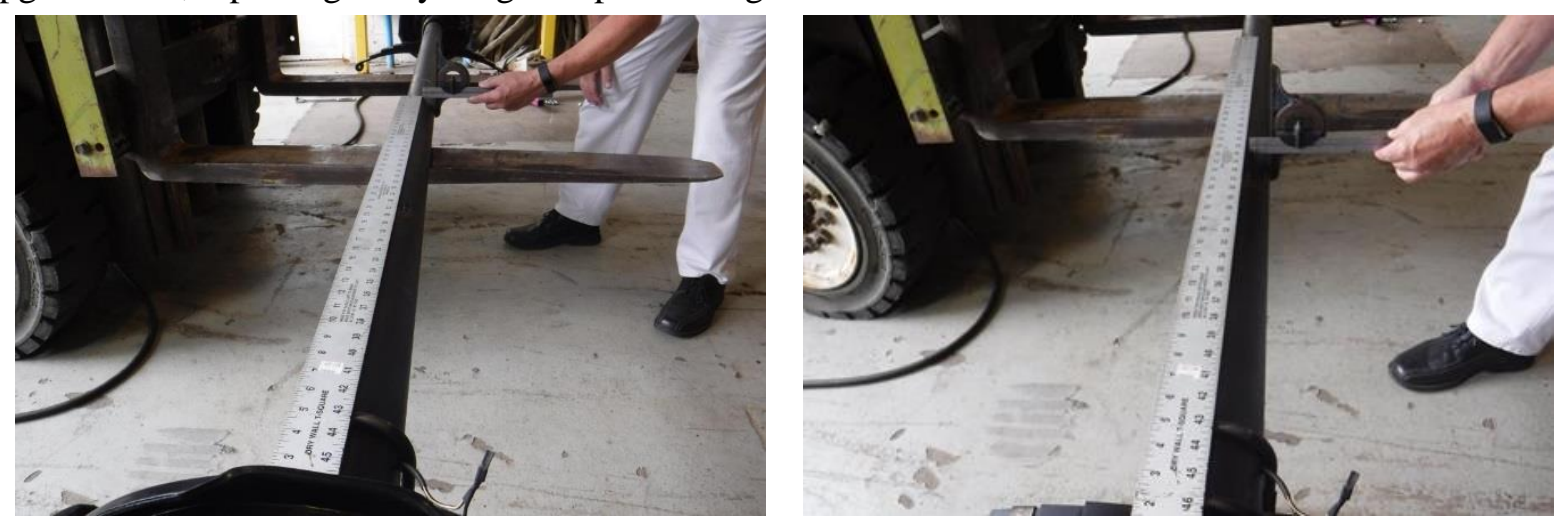

Figure B- 5. Upgrade Unit Perpendicular (Left Side) and Out-of-Square (Right Side) Packing Plates/Axles.

The Baseline Unit was also inspected, and NPG found no obvious issues or defects. Table B- 44 presents the measurements made using the string method and the T-square method discussed above. Note: since there no axle backing plates for the Baseline Unit, the T-square was positioned against the tires. When inspected, NPG found that all spring hanger fasteners were tight as required, and that there were no issues with the hangers. 
Table B- 4. Baseline Unit- String and T-Square Measurements of Axles and Wheels

\begin{tabular}{|c|c|c|c|c|c|}
\hline \multirow{2}{*}{ Axle \# } & \multicolumn{3}{|c|}{ String Measurements } & \multicolumn{2}{|c|}{ T-Square Measurement } \\
\hline & Left-Side [in] & Rim Location & Right Side [in] & Left-Side & Right Side \\
\hline \multirow{2}{*}{1} & 0.00 & Front & 0.00 & \multirow{2}{*}{ Square } & \multirow{2}{*}{ Square } \\
\hline & 0.00 & Rear & 0.25 & & \\
\hline \multirow{2}{*}{2} & 0.25 & Front & 0.00 & \multirow{2}{*}{ Square } & \multirow{2}{*}{ Square } \\
\hline & 0.00 & Rear & 0.03 & & \\
\hline \multirow{2}{*}{3} & 0.06 & Front & 0.06 & \multirow{2}{*}{ Square } & \multirow{2}{*}{ Square } \\
\hline & 0.00 & Rear & 0.06 & & \\
\hline \multirow{2}{*}{4} & 0.13 & Front & 0.00 & \multirow{2}{*}{ Square } & \multirow{2}{*}{ Square } \\
\hline & 0.00 & Rear & 0.03 & & \\
\hline \multirow{2}{*}{5} & 0.00 & Front & 0.06 & \multirow{2}{*}{ Square } & \multirow{2}{*}{ Square } \\
\hline & 0.00 & Rear & 0.00 & & \\
\hline \multirow{2}{*}{6} & 0.06 & Front & 0.00 & \multirow{2}{*}{ Square } & \multirow{2}{*}{ Square } \\
\hline & 0.00 & Rear & 0.00 & & \\
\hline
\end{tabular}

There were some minor damages to the shingles of the Upgrade Unit when it was backed out of the garage after the suspension work was finished. Repairs were made before the tests restarted.

\section{Assembly Procedure for Suretrac 7K Axles / Suspension.}

\begin{tabular}{|c|l|}
\hline Step & \multicolumn{1}{c|}{ Description of Procedure } \\
\hline 1 & Install hanger brackets onto the frame using weld procedure supplied by Live Oak Homes. \\
\hline 2 & Insert cast equalizer into all hanger brackets, omitting the forwardmost and rearmost hanger locations. \\
\hline 3 & Install Suretrac-supplied 9/16" x 3" serrated bolt into hanger to secure equalizer. \\
\hline 4 & Tap hanger bolt into place using a hammer. \\
\hline 5 & $\begin{array}{l}\text { Install Suretrac-supplied 9/16" lock nut onto hanger bolt. Tighten nut to continue to pull hanger bolt into } \\
\text { place until seated. Use a wrench on the bolt head to keep it from rotating within the hanger. }\end{array}$ \\
\hline 6 & Back up the lock nut 1/2 turn to allow clearance for parts to rotate freely. \\
\hline 7 & Install shackle plates onto the spring eyes using Suretrac-supplied 9/16" x 3" serrated bolt. \\
\hline 8 & Tap shackle bolts into place using a hammer. \\
\hline 9 & $\begin{array}{l}\text { Install Suretrac-supplied 9/16" lock nut onto shackle bolts. Tighten nut to continue to pull hanger bolt } \\
\text { into place. Use a wrench on the bolt head to keep it from rotating within the hanger. }\end{array}$ \\
\hline 10 & Back up the lock nut 1/2 turn to allow clearance for parts to rotate freely. \\
\hline 11 & $\begin{array}{l}\text { Line up axle and spring assembly within the frame-mounted hanger brackets. Loosen axle U-bolts if } \\
\text { necessary, to align springs with equalizers. }\end{array}$ \\
\hline 12 & Install Suretrac-supplied 9/16" x 3" serrated bolt into shackle to secure spring to equalizer. \\
\hline 13 & $\begin{array}{l}\text { Install Suretrac-supplied 9/16" lock nut onto shackle bolts. Tighten nut to continue to pull hanger bolt } \\
\text { into place. Use a wrench on the bolt head to keep it from rotating within the hanger. }\end{array}$ \\
\hline 14 & Torque axle U-bolts to 60 lb-ft. \\
\hline
\end{tabular}




\section{APPENDIX C. ADDITIONAL STATISTICAL COMPARISONS}





\section{APPENDIX C. ADDITIONAL STATISTICAL COMPARISONS}

This Appendix presents additional statistical tests that were conducted on the data collected. Those statistical tests were performed to corroborate the tests described in the main body of this report. Tables with statistical parameters describing the distributions that were used in the test of hypothesis are included for each case considered and for each accelerometer direction. In all cases the null hypothesis states that there is no difference between the means of the thro distributions considered (e.g., Baseline Unit GRMS vs Upgrade Unit GRMS for laps conducted in a clockwise direction, Table C-1). This is tested against the alternative hypothesis that the Upgrade Unit performs better. Figures are also included showing the data that was used in the analysis of the GRMS statistic for the vertical accelerometer located at the center of the MHU. In all cases, this accelerometer was the one that recorded the highest accelerations of any of the positions and directions.

Effect of Suspension on Vibrations: Baseline Unit vs. Upgrade Unit-Clockwise-direction Laps

Table C- 1. Statistical Comparison of GRMS Measure: Baseline Unit vs. Upgrade Unit Clockwise-direction Laps - All Accelerometers -Vertical Direction

\begin{tabular}{|c|c|c|c|c|c|c|c|c|c|c|c|c|}
\hline \multirow{2}{*}{ Statistics } & \multicolumn{2}{|c|}{ Front Left } & \multicolumn{2}{|c|}{ Hitch } & \multicolumn{2}{|c|}{ Front Right } & \multicolumn{2}{|c|}{ Center } & \multicolumn{2}{|c|}{ Rear Left } & \multicolumn{2}{|c|}{ Rear Right } \\
\hline & B & $\mathbf{U}$ & B & $\mathbf{U}$ & B & $\mathbf{U}$ & B & $\mathbf{U}$ & B & $\mathbf{U}$ & B & $\mathbf{U}$ \\
\hline Obs. & 84 & 84 & 84 & 84 & 84 & 84 & 84 & 84 & 84 & 84 & 84 & 84 \\
\hline Min. & 0.05 & 0.05 & 0.09 & 0.09 & 0.06 & 0.06 & 0.13 & 0.11 & 0.07 & 0.07 & 0.07 & 0.06 \\
\hline Max. & 0.06 & 0.06 & 0.11 & 0.11 & 0.07 & 0.07 & 0.21 & 0.19 & 0.08 & 0.08 & 0.08 & 0.08 \\
\hline Mean & 0.06 & 0.06 & 0.10 & 0.10 & 0.06 & 0.07 & 0.19 & 0.15 & 0.07 & 0.07 & 0.08 & 0.07 \\
\hline Std. Dev. & 0.00 & 0.00 & 0.00 & 0.00 & 0.00 & 0.00 & 0.01 & 0.01 & 0.00 & 0.00 & 0.00 & 0.00 \\
\hline Delta Mean & \multicolumn{2}{|c|}{-0.002} & \multicolumn{2}{|c|}{-0.003} & \multicolumn{2}{|c|}{0.001} & \multicolumn{2}{|c|}{-0.046} & \multicolumn{2}{|c|}{0.000} & \multicolumn{2}{|c|}{-0.007} \\
\hline Std. Dev. Diff. & \multicolumn{2}{|c|}{0.000} & \multicolumn{2}{|c|}{0.001} & \multicolumn{2}{|c|}{0.000} & \multicolumn{2}{|c|}{0.002} & \multicolumn{2}{|c|}{0.000} & \multicolumn{2}{|c|}{0.000} \\
\hline $\mathbf{Z}$ & \multicolumn{2}{|c|}{-5.753} & \multicolumn{2}{|c|}{-3.890} & \multicolumn{2}{|c|}{3.455} & \multicolumn{2}{|c|}{-25.362} & \multicolumn{2}{|c|}{-0.718} & \multicolumn{2}{|c|}{-18.983} \\
\hline P-value & \multicolumn{2}{|c|}{ 4.4E-09 } & \multicolumn{2}{|c|}{$5.0 \mathrm{E}-05$} & \multicolumn{2}{|c|}{0.999} & \multicolumn{2}{|c|}{0.000} & \multicolumn{2}{|c|}{0.237} & \multicolumn{2}{|c|}{0.000} \\
\hline $\begin{array}{l}\text { Reject Ho at } \\
\text { confidence } \\
\text { level }\end{array}$ & \multicolumn{2}{|c|}{$99.9+\%$} & \multicolumn{2}{|c|}{$99.9+\%$} & \multicolumn{2}{|c|}{$\begin{array}{c}\text { Cannot } \\
\text { Reject Ho }\end{array}$} & \multicolumn{2}{|c|}{$99.9+\%$} & \multicolumn{2}{|c|}{$<85.0 \%$} & \multicolumn{2}{|c|}{$99.9+\%$} \\
\hline
\end{tabular}


Table C- 2. Statistical Comparison of GRMS Measure: Baseline Unit vs. Upgrade Unit Clockwise-direction Laps - All Accelerometers - Longitudinal Direction

\begin{tabular}{|c|c|c|c|c|c|c|c|c|c|c|c|c|}
\hline \multirow{2}{*}{ Statistics } & \multicolumn{2}{|c|}{ Front Left } & \multicolumn{2}{|c|}{ Hitch } & \multicolumn{2}{|c|}{ Front Right } & \multicolumn{2}{|c|}{ Center } & \multicolumn{2}{|c|}{ Rear Left } & \multicolumn{2}{|c|}{ Rear Right } \\
\hline & B & $\mathbf{U}$ & B & $\mathbf{U}$ & B & $\mathbf{U}$ & B & $\mathbf{U}$ & B & $\mathbf{U}$ & B & $\mathbf{U}$ \\
\hline Obs. & 84 & 84 & 84 & 84 & 84 & 84 & 84 & 84 & 84 & 84 & 84 & 84 \\
\hline Min. & 0.02 & 0.02 & 0.05 & 0.06 & 0.03 & 0.02 & 0.02 & 0.02 & 0.03 & 0.03 & 0.02 & 0.02 \\
\hline Max. & 0.03 & 0.03 & 0.06 & 0.07 & 0.03 & 0.03 & 0.05 & 0.03 & 0.04 & 0.04 & 0.03 & 0.03 \\
\hline Mean & 0.02 & 0.03 & 0.05 & 0.06 & 0.03 & 0.03 & 0.03 & 0.02 & 0.03 & 0.03 & 0.03 & 0.03 \\
\hline Std. Dev. & 0.00 & 0.00 & 0.00 & 0.00 & 0.00 & 0.00 & 0.00 & 0.00 & 0.00 & 0.00 & 0.00 & 0.00 \\
\hline Delta Mean & \multicolumn{2}{|c|}{0.001} & \multicolumn{2}{|c|}{0.009} & \multicolumn{2}{|c|}{-0.002} & \multicolumn{2}{|c|}{-0.005} & \multicolumn{2}{|c|}{0.000} & \multicolumn{2}{|c|}{0.000} \\
\hline Std. Dev. Diff. & \multicolumn{2}{|c|}{0.000} & \multicolumn{2}{|c|}{0.000} & \multicolumn{2}{|c|}{0.000} & \multicolumn{2}{|c|}{0.001} & \multicolumn{2}{|c|}{0.000} & \multicolumn{2}{|c|}{0.000} \\
\hline $\mathbf{Z}$ & \multicolumn{2}{|c|}{4.311} & \multicolumn{2}{|c|}{26.130} & \multicolumn{2}{|c|}{-7.571} & \multicolumn{2}{|c|}{-4.767} & \multicolumn{2}{|c|}{-0.882} & \multicolumn{2}{|c|}{-1.652} \\
\hline P-value & \multicolumn{2}{|c|}{0.999} & \multicolumn{2}{|c|}{0.999} & \multicolumn{2}{|c|}{$1.9 \mathrm{E}-14$} & \multicolumn{2}{|c|}{$9.3 \mathrm{E}-07$} & \multicolumn{2}{|c|}{0.189} & \multicolumn{2}{|c|}{0.049} \\
\hline $\begin{array}{l}\text { Reject Ho at } \\
\text { confidence } \\
\text { level }\end{array}$ & \multicolumn{2}{|c|}{$\begin{array}{c}\text { Cannot } \\
\text { Reject Ho }\end{array}$} & \multicolumn{2}{|c|}{$\begin{array}{c}\text { Cannot } \\
\text { Reject Ho }\end{array}$} & \multicolumn{2}{|c|}{$99.9+\%$} & \multicolumn{2}{|c|}{$99.9+\%$} & \multicolumn{2}{|c|}{$<85.0 \%$} & \multicolumn{2}{|c|}{$95.1 \%$} \\
\hline
\end{tabular}

Table C- 3. Statistical Comparison of GRMS Measure: Baseline Unit vs. Upgrade Unit Clockwise-direction Laps - All Accelerometers - Lateral Direction

\begin{tabular}{|c|c|c|c|c|c|c|c|c|c|c|c|c|}
\hline \multirow{2}{*}{ Statistics } & \multicolumn{2}{|c|}{ Front Left } & \multicolumn{2}{|c|}{ Hitch } & \multicolumn{2}{|c|}{ Front Right } & \multicolumn{2}{|c|}{ Center } & \multicolumn{2}{|c|}{ Rear Left } & \multicolumn{2}{|c|}{ Rear Right } \\
\hline & B & $\mathbf{U}$ & B & $\mathbf{U}$ & B & $\mathbf{U}$ & B & $\mathbf{U}$ & B & $\mathbf{U}$ & B & $\mathbf{U}$ \\
\hline Obs. & 84 & 84 & 84 & 84 & 84 & 84 & 84 & 84 & 84 & 84 & 84 & 84 \\
\hline Min. & 0.03 & 0.03 & 0.09 & 0.09 & 0.03 & 0.03 & 0.03 & 0.03 & 0.04 & 0.03 & 0.04 & 0.03 \\
\hline Max. & 0.04 & 0.04 & 0.11 & 0.11 & 0.04 & 0.04 & 0.04 & 0.04 & 0.05 & 0.05 & 0.05 & 0.04 \\
\hline Mean & 0.04 & 0.03 & 0.10 & 0.10 & 0.04 & 0.03 & 0.03 & 0.03 & 0.04 & 0.04 & 0.04 & 0.04 \\
\hline Std. Dev. & 0.00 & 0.00 & 0.00 & 0.00 & 0.00 & 0.00 & 0.00 & 0.00 & 0.00 & 0.00 & 0.00 & 0.00 \\
\hline Delta Mean & \multicolumn{2}{|c|}{-0.002} & \multicolumn{2}{|c|}{0.001} & \multicolumn{2}{|c|}{-0.002} & \multicolumn{2}{|c|}{-0.002} & \multicolumn{2}{|c|}{-0.002} & \multicolumn{2}{|c|}{-0.004} \\
\hline Std. Dev. Diff. & \multicolumn{2}{|c|}{0.000} & \multicolumn{2}{|c|}{0.001} & \multicolumn{2}{|c|}{0.000} & \multicolumn{2}{|c|}{0.000} & \multicolumn{2}{|c|}{0.000} & \multicolumn{2}{|c|}{0.000} \\
\hline $\mathbf{Z}$ & \multicolumn{2}{|c|}{-5.489} & \multicolumn{2}{|c|}{1.328} & \multicolumn{2}{|c|}{-5.560} & \multicolumn{2}{|c|}{-5.048} & \multicolumn{2}{|c|}{-6.583} & \multicolumn{2}{|c|}{-10.673} \\
\hline P-value & \multicolumn{2}{|c|}{$2.0 \mathrm{E}-08$} & \multicolumn{2}{|c|}{0.908} & \multicolumn{2}{|c|}{$1.3 \mathrm{E}-08$} & \multicolumn{2}{|c|}{ 2.2E-07 } & \multicolumn{2}{|c|}{ 2.3E-11 } & \multicolumn{2}{|c|}{0.000} \\
\hline $\begin{array}{l}\text { Reject Ho at } \\
\text { confidence } \\
\text { level }\end{array}$ & \multicolumn{2}{|c|}{$99.9+\%$} & \multicolumn{2}{|c|}{$\begin{array}{c}\text { Cannot } \\
\text { Reject Ho }\end{array}$} & \multicolumn{2}{|c|}{$99.9+\%$} & \multicolumn{2}{|c|}{$99.9+\%$} & \multicolumn{2}{|c|}{$99.9+\%$} & \multicolumn{2}{|c|}{$99.9+\%$} \\
\hline
\end{tabular}




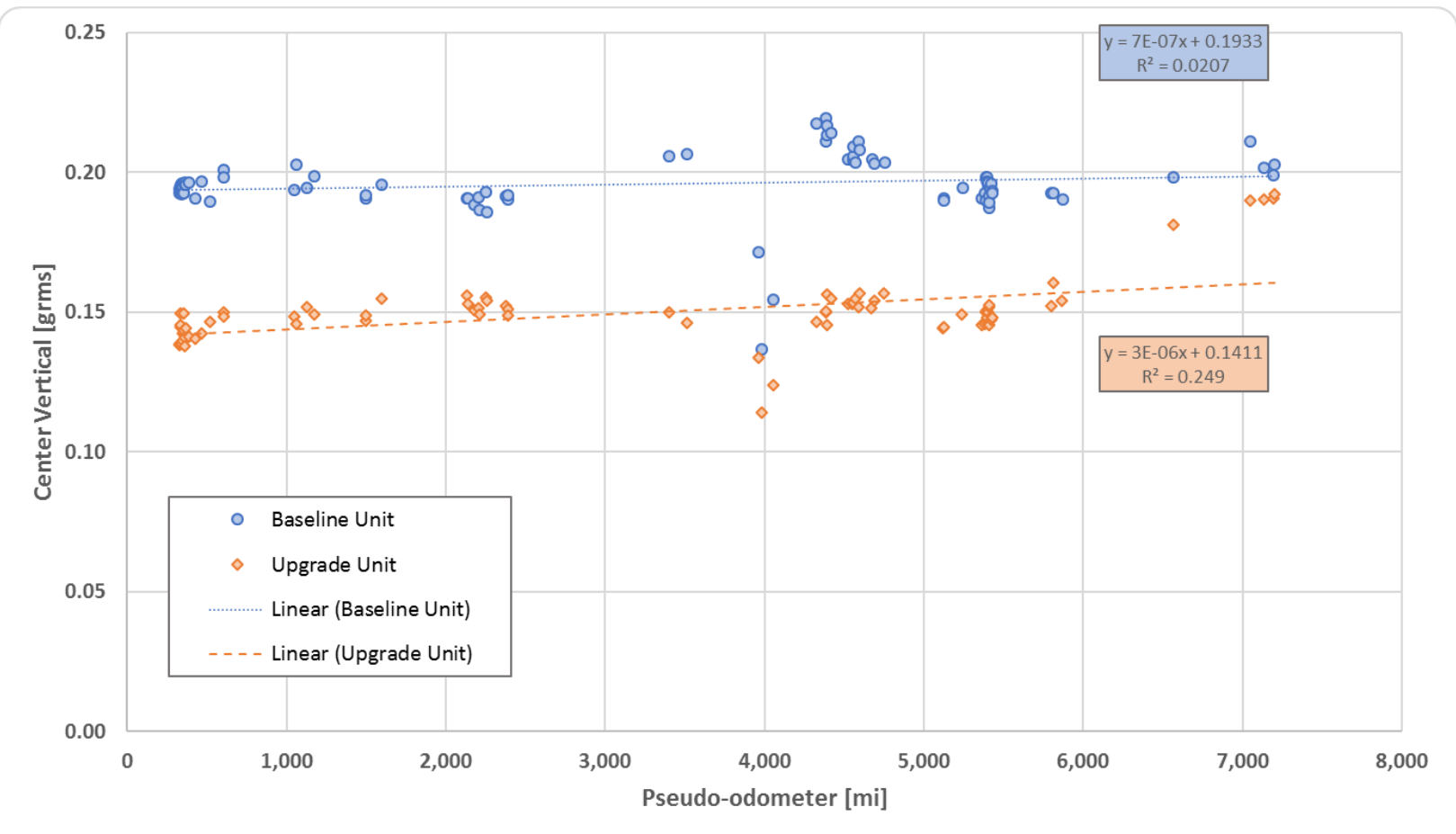

Figure C- 1 Part C2 - Baseline and Upgrade Units GRMS for Vertical Accelerometer at Axle Group (Center) Selected Clockwise Laps for Statistical Analysis.

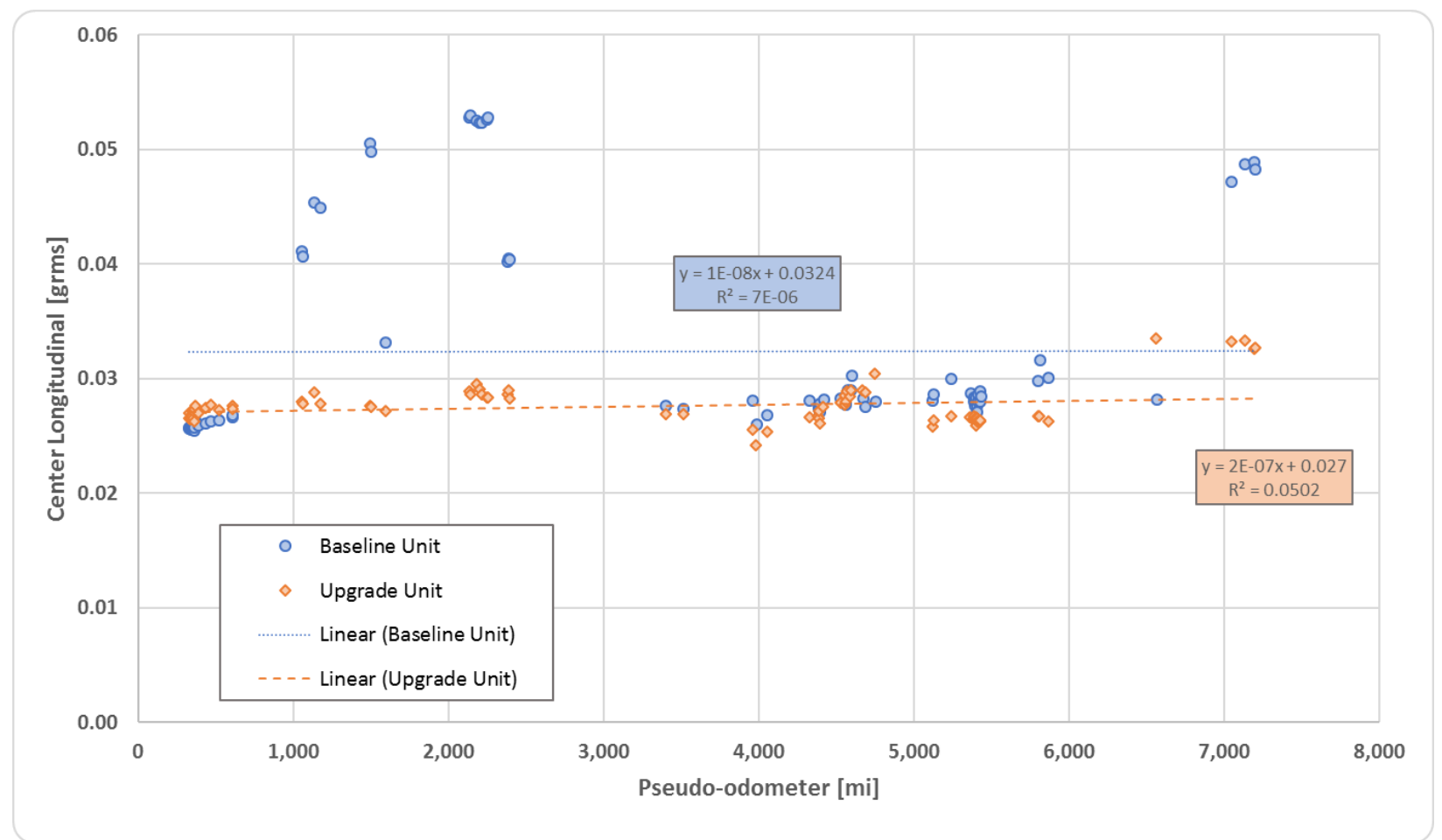

Figure C- 2 Part C2 - Baseline and Upgrade Units GRMS for Longitudinal Accelerometer at Axle Group (Center) - Selected Clockwise Laps for Statistical Analysis. 


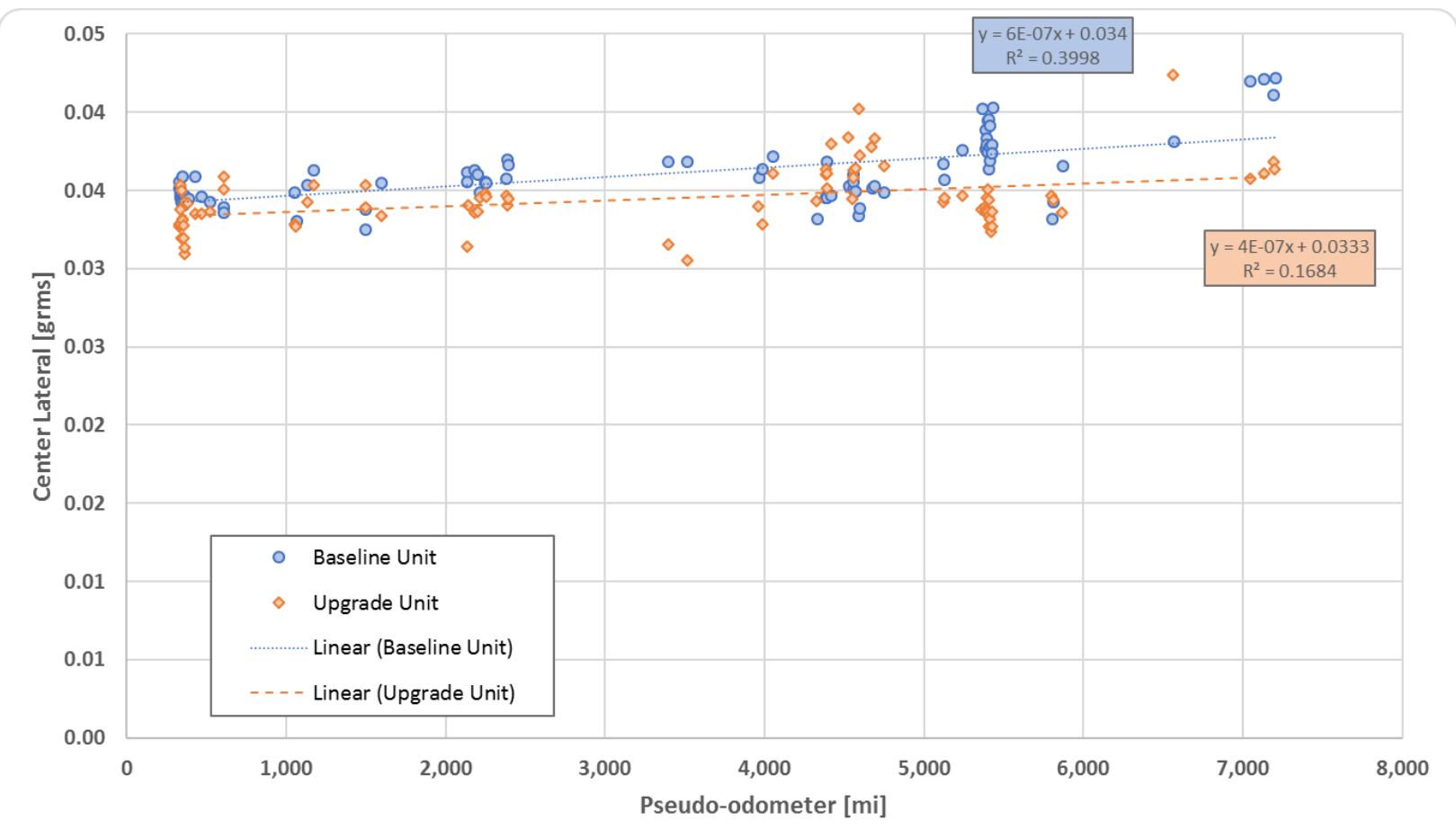

Figure C- 3 Part C2 - Baseline and Upgrade Units GRMS for Lateral Accelerometer at Axle Group (Center) Selected Clockwise Laps for Statistical Analysis.

Effect of Suspension on Vibrations: Baseline Unit vs. Upgrade Unit-Counter-clockwise Direction Laps

Table C- 4. Statistical Comparison of GRMS Measure: Baseline Unit vs. Upgrade Unit Counter-clockwise Direction Laps - All Accelerometers -Vertical Direction

\begin{tabular}{|c|c|c|c|c|c|c|c|c|c|c|c|c|}
\hline \multirow{2}{*}{ Statistics } & \multicolumn{2}{|c|}{ Front Left } & \multicolumn{2}{|c|}{ Hitch } & \multicolumn{2}{|c|}{ Front Right } & \multicolumn{2}{|c|}{ Center } & \multicolumn{2}{|c|}{ Rear Left } & \multicolumn{2}{|c|}{ Rear Right } \\
\hline & B & $\mathbf{U}$ & B & $\mathbf{U}$ & B & $\mathbf{U}$ & B & $\mathbf{U}$ & B & $\mathbf{U}$ & B & $\mathbf{U}$ \\
\hline Obs. & 118 & 118 & 118 & 118 & 118 & 118 & 118 & 118 & 118 & 118 & 118 & 118 \\
\hline Min. & 0.05 & 0.05 & 0.09 & 0.09 & 0.06 & 0.06 & 0.13 & 0.10 & 0.07 & 0.06 & 0.07 & 0.06 \\
\hline Max. & 0.06 & 0.06 & 0.18 & 0.12 & 0.07 & 0.07 & 0.21 & 0.20 & 0.08 & 0.08 & 0.08 & 0.08 \\
\hline Mean & 0.06 & 0.06 & 0.10 & 0.10 & 0.06 & 0.06 & 0.18 & 0.15 & 0.07 & 0.07 & 0.08 & 0.07 \\
\hline Std. Dev. & 0.00 & 0.00 & 0.00 & 0.00 & 0.00 & 0.00 & 0.01 & 0.01 & 0.00 & 0.00 & 0.00 & 0.00 \\
\hline Delta Mean & \multicolumn{2}{|c|}{-0.001} & \multicolumn{2}{|c|}{-0.001} & \multicolumn{2}{|c|}{0.002} & \multicolumn{2}{|c|}{-0.029} & \multicolumn{2}{|c|}{-0.002} & \multicolumn{2}{|c|}{-0.008} \\
\hline Std. Dev. Diff. & \multicolumn{2}{|c|}{0.000} & \multicolumn{2}{|c|}{0.001} & \multicolumn{2}{|c|}{0.000} & \multicolumn{2}{|c|}{0.002} & \multicolumn{2}{|c|}{0.000} & \multicolumn{2}{|c|}{0.000} \\
\hline $\mathbf{Z}$ & \multicolumn{2}{|c|}{-2.982} & \multicolumn{2}{|c|}{-0.629} & \multicolumn{2}{|c|}{6.110} & \multicolumn{2}{|c|}{-14.862} & \multicolumn{2}{|c|}{-6.461} & \multicolumn{2}{|c|}{-20.566} \\
\hline P-value & \multicolumn{2}{|c|}{0.001} & \multicolumn{2}{|c|}{0.265} & \multicolumn{2}{|c|}{0.999} & \multicolumn{2}{|c|}{0.000} & \multicolumn{2}{|c|}{0.000} & \multicolumn{2}{|c|}{0.000} \\
\hline $\begin{array}{l}\text { Reject Ho at } \\
\text { confidence } \\
\text { level }\end{array}$ & \multicolumn{2}{|c|}{$99.9 \%$} & \multicolumn{2}{|c|}{$<85.0 \%$} & \multicolumn{2}{|c|}{$\begin{array}{c}\text { Cannot } \\
\text { Reject Ho }\end{array}$} & \multicolumn{2}{|c|}{$99.9+\%$} & \multicolumn{2}{|c|}{$99.9+\%$} & \multicolumn{2}{|c|}{$99.9+\%$} \\
\hline
\end{tabular}


Table C- 5. Statistical Comparison of GRMS Measure: Baseline Unit vs. Upgrade Unit Counter-clockwise Direction Laps - All Accelerometers - Longitudinal Direction

\begin{tabular}{|c|c|c|c|c|c|c|c|c|c|c|c|c|}
\hline \multirow{2}{*}{ Statistics } & \multicolumn{2}{|c|}{ Front Left } & \multicolumn{2}{|c|}{ Hitch } & \multicolumn{2}{|c|}{ Front Right } & \multicolumn{2}{|c|}{ Center } & \multicolumn{2}{|c|}{ Rear Left } & \multicolumn{2}{|c|}{ Rear Right } \\
\hline & B & $\mathbf{U}$ & B & $\mathbf{U}$ & B & $\mathbf{U}$ & B & $\mathbf{U}$ & B & $\mathbf{U}$ & B & $\mathbf{U}$ \\
\hline Obs. & 118 & 118 & 118 & 118 & 118 & 118 & 118 & 118 & 118 & 118 & 118 & 118 \\
\hline Min. & 0.02 & 0.02 & 0.05 & 0.06 & 0.03 & 0.02 & 0.02 & 0.02 & 0.03 & 0.03 & 0.02 & 0.02 \\
\hline Max. & 0.03 & 0.03 & 0.06 & 0.07 & 0.03 & 0.03 & 0.05 & 0.03 & 0.04 & 0.04 & 0.03 & 0.03 \\
\hline Mean & 0.03 & 0.03 & 0.05 & 0.07 & 0.03 & 0.03 & 0.03 & 0.02 & 0.04 & 0.03 & 0.03 & 0.03 \\
\hline Std. Dev. & 0.00 & 0.00 & 0.00 & 0.00 & 0.00 & 0.00 & 0.00 & 0.00 & 0.00 & 0.00 & 0.00 & 0.00 \\
\hline Delta Mean & \multicolumn{2}{|c|}{-0.001} & \multicolumn{2}{|c|}{0.010} & \multicolumn{2}{|c|}{-0.002} & \multicolumn{2}{|c|}{-0.004} & \multicolumn{2}{|c|}{-0.006} & \multicolumn{2}{|c|}{0.000} \\
\hline Std. Dev. Diff. & \multicolumn{2}{|c|}{0.000} & \multicolumn{2}{|c|}{0.001} & \multicolumn{2}{|c|}{0.000} & \multicolumn{2}{|c|}{0.001} & \multicolumn{2}{|c|}{0.000} & \multicolumn{2}{|c|}{0.000} \\
\hline $\mathbf{Z}$ & \multicolumn{2}{|c|}{-2.150} & \multicolumn{2}{|c|}{20.397} & \multicolumn{2}{|c|}{-7.011} & \multicolumn{2}{|c|}{-5.135} & \multicolumn{2}{|c|}{-17.538} & \multicolumn{2}{|c|}{0.063} \\
\hline P-value & \multicolumn{2}{|c|}{0.016} & \multicolumn{2}{|c|}{0.999} & \multicolumn{2}{|c|}{0.000} & \multicolumn{2}{|c|}{0.000} & \multicolumn{2}{|c|}{0.000} & \multicolumn{2}{|c|}{0.525} \\
\hline $\begin{array}{l}\text { Reject Ho at } \\
\text { confidence } \\
\text { level }\end{array}$ & \multicolumn{2}{|c|}{$98.4 \%$} & \multicolumn{2}{|c|}{$\begin{array}{c}\text { Cannot } \\
\text { Reject Ho }\end{array}$} & \multicolumn{2}{|c|}{$99.9+\%$} & \multicolumn{2}{|c|}{$99.9+\%$} & \multicolumn{2}{|c|}{$99.9+\%$} & \multicolumn{2}{|c|}{$\begin{array}{c}\text { Cannot } \\
\text { Reject Ho }\end{array}$} \\
\hline
\end{tabular}

Table C- 6. Statistical Comparison of GRMS Measure: Baseline Unit vs. Upgrade Unit Counter-clockwise Direction Laps - All Accelerometers - Lateral Direction

\begin{tabular}{|c|c|c|c|c|c|c|c|c|c|c|c|c|}
\hline \multirow{2}{*}{ Statistics } & \multicolumn{2}{|c|}{ Front Left } & \multicolumn{2}{|c|}{ Hitch } & \multicolumn{2}{|c|}{ Front Right } & \multicolumn{2}{|c|}{ Center } & \multicolumn{2}{|c|}{ Rear Left } & \multicolumn{2}{|c|}{ Rear Right } \\
\hline & B & $\mathbf{U}$ & B & $\mathbf{U}$ & B & $\mathbf{U}$ & B & $\mathbf{U}$ & B & $\mathbf{U}$ & B & $\mathbf{U}$ \\
\hline Obs. & 118 & 118 & 118 & 118 & 118 & 118 & 118 & 118 & 87 & 87 & 118 & 118 \\
\hline Min. & 0.03 & 0.03 & 0.09 & 0.09 & 0.03 & 0.03 & 0.03 & 0.02 & 0.04 & 0.03 & 0.04 & 0.03 \\
\hline Max. & 0.04 & 0.04 & 0.11 & 0.12 & 0.04 & 0.04 & 0.04 & 0.03 & 0.04 & 0.04 & 0.05 & 0.04 \\
\hline Mean & 0.04 & 0.04 & 0.10 & 0.10 & 0.04 & 0.04 & 0.03 & 0.03 & 0.04 & 0.04 & 0.04 & 0.04 \\
\hline Std. Dev. & 0.00 & 0.00 & 0.00 & 0.00 & 0.00 & 0.00 & 0.00 & 0.00 & 0.00 & 0.00 & 0.00 & 0.00 \\
\hline Delta Mean & \multicolumn{2}{|c|}{-0.001} & \multicolumn{2}{|c|}{-0.004} & \multicolumn{2}{|c|}{-0.001} & \multicolumn{2}{|c|}{-0.004} & \multicolumn{2}{|c|}{-0.002} & \multicolumn{2}{|c|}{-0.004} \\
\hline Std. Dev. Diff. & \multicolumn{2}{|c|}{0.000} & \multicolumn{2}{|c|}{0.001} & \multicolumn{2}{|c|}{0.000} & \multicolumn{2}{|c|}{0.000} & \multicolumn{2}{|c|}{0.000} & \multicolumn{2}{|c|}{0.000} \\
\hline $\mathbf{Z}$ & \multicolumn{2}{|c|}{-4.898} & \multicolumn{2}{|c|}{-4.604} & \multicolumn{2}{|c|}{-4.047} & \multicolumn{2}{|c|}{-13.522} & \multicolumn{2}{|c|}{-4.610} & \multicolumn{2}{|c|}{-10.859} \\
\hline P-value & \multicolumn{2}{|c|}{0.000} & \multicolumn{2}{|c|}{$2.1 \mathrm{E}-06$} & \multicolumn{2}{|c|}{ 2.6E-05 } & \multicolumn{2}{|c|}{0.000} & \multicolumn{2}{|c|}{$2.0 \mathrm{E}-06$} & \multicolumn{2}{|c|}{0.000} \\
\hline $\begin{array}{l}\text { Reject Ho at } \\
\text { confidence } \\
\text { level }\end{array}$ & \multicolumn{2}{|c|}{$99.9+\%$} & \multicolumn{2}{|c|}{$99.9+\%$} & \multicolumn{2}{|c|}{$99.9+\%$} & \multicolumn{2}{|c|}{$99.9+\%$} & \multicolumn{2}{|c|}{$99.9+\%$} & \multicolumn{2}{|c|}{$99.9+\%$} \\
\hline
\end{tabular}




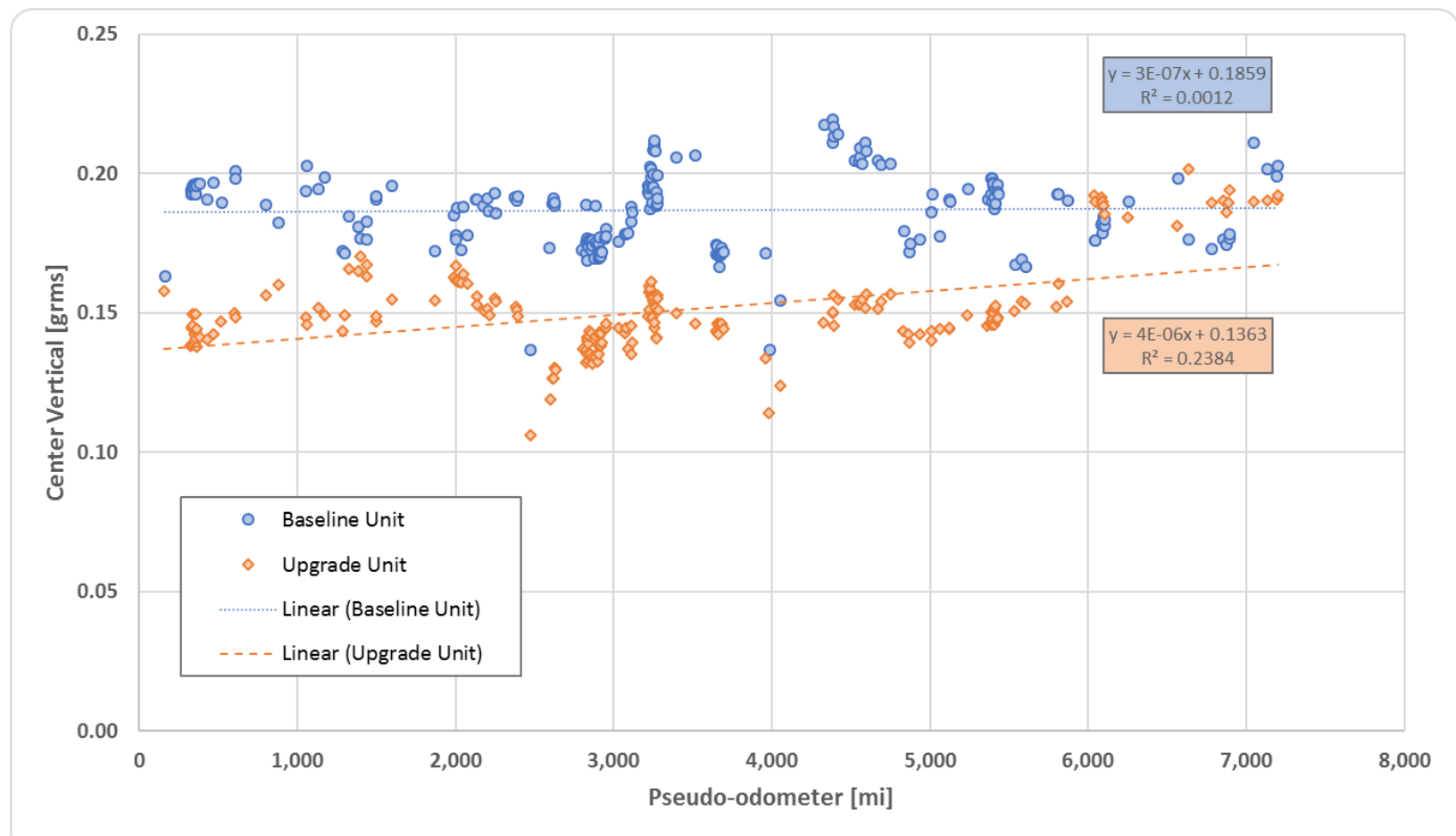

Figure C- 4 Part C2 - Baseline and Upgrade Units GRMS for Vertical Accelerometer at Axle Group (Center) Selected Counter-clockwise Laps for Statistical Analysis.

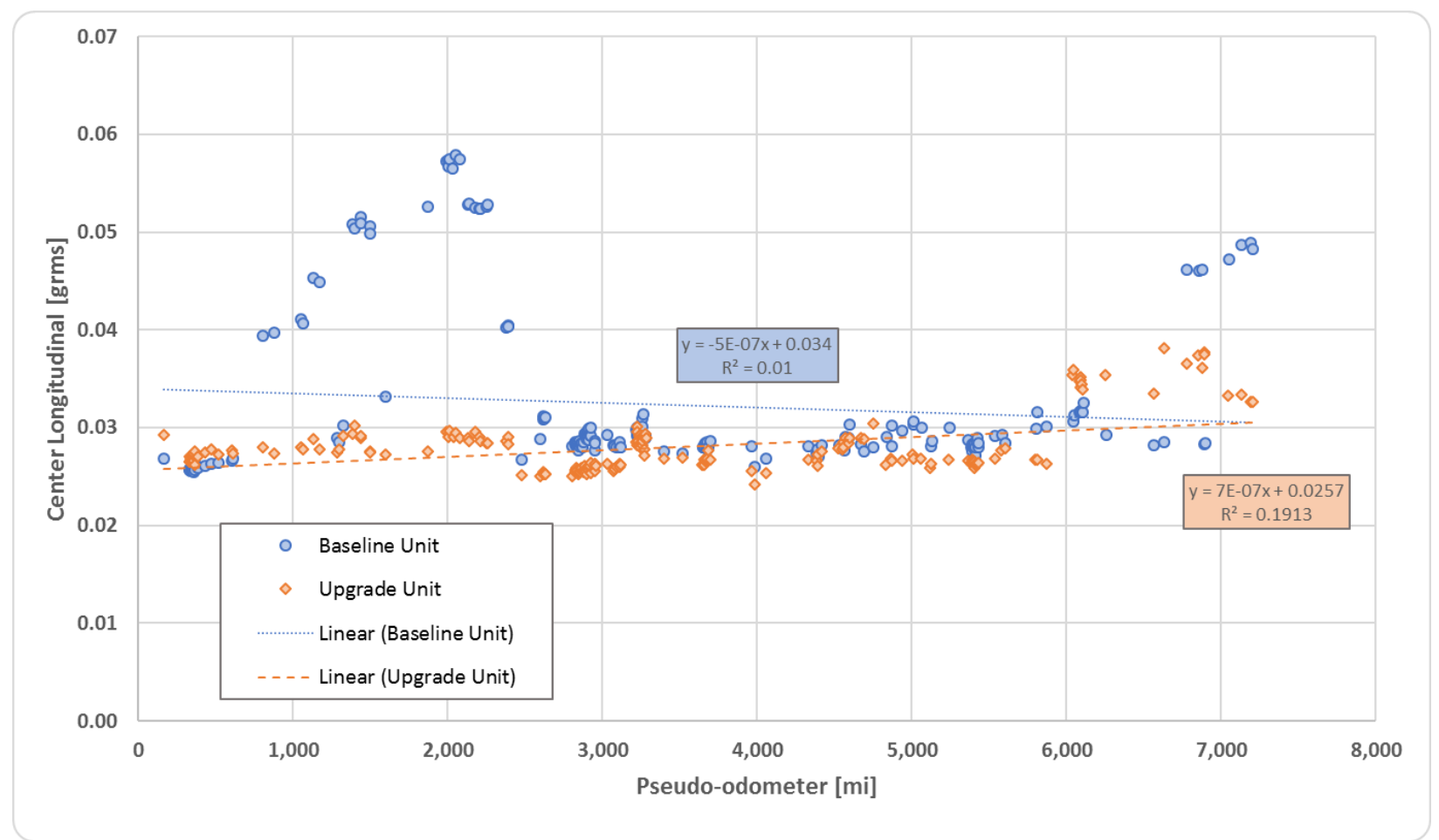

Figure C- 5 Part C2 - Baseline and Upgrade Units GRMS for Longitudinal Accelerometer at Axle Group (Center) - Selected Counter-clockwise Laps for Statistical Analysis. 


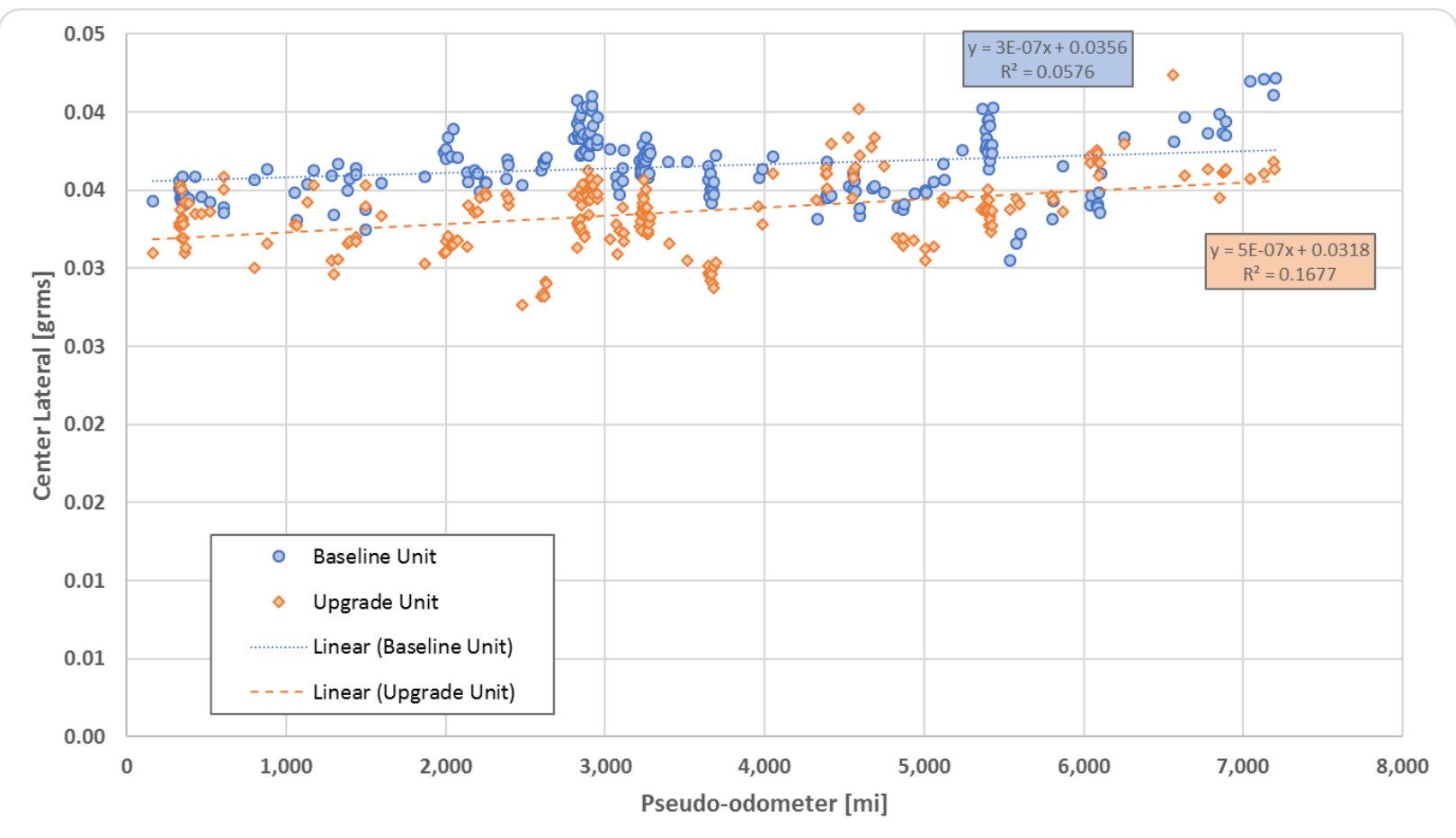

Figure C- 6 Part C2 - Baseline and Upgrade Units GRMS for Lateral Accelerometer at Axle Group (Center) Selected Counter-clockwise Laps for Statistical Analysis.

Effect of Suspension on Vibrations: Clockwise vs. Counter-clockwise Laps-Baseline Unit

Table C- 7. Statistical Comparison of GRMS Measure: Clockwise vs. Counter-clockwise Laps Baseline Unit - All Accelerometers - Vertical Direction

\begin{tabular}{|c|c|c|c|c|c|c|c|c|c|c|c|c|}
\hline \multirow[b]{2}{*}{ Statistics } & \multicolumn{2}{|c|}{ Front Left } & \multicolumn{2}{|c|}{ Hitch } & \multicolumn{2}{|c|}{ Front Right } & \multicolumn{2}{|c|}{ Center } & \multicolumn{2}{|c|}{ Rear Left } & \multicolumn{2}{|c|}{ Rear Right } \\
\hline & $\begin{array}{c}\mathrm{B} \\
\mathrm{CW} \\
\end{array}$ & $\begin{array}{c}\mathrm{B} \\
\mathrm{CCW}\end{array}$ & $\begin{array}{c}\text { B } \\
\text { CW }\end{array}$ & $\begin{array}{c}\text { B } \\
\text { CCW }\end{array}$ & $\begin{array}{c}\mathrm{B} \\
\mathrm{CW} \\
\end{array}$ & $\begin{array}{c}\mathrm{B} \\
\mathrm{CCW}\end{array}$ & $\begin{array}{c}B \\
C W\end{array}$ & $\begin{array}{c}\mathrm{B} \\
\mathrm{CCW}\end{array}$ & $\begin{array}{c}\mathrm{B} \\
\mathrm{CW} \\
\end{array}$ & $\begin{array}{c}B \\
\mathrm{CCW}\end{array}$ & $\begin{array}{c}\mathrm{B} \\
\mathrm{CW} \\
\end{array}$ & $\begin{array}{c}\mathrm{B} \\
\mathrm{CCW}\end{array}$ \\
\hline Obs. & 84 & 118 & 84 & 118 & 84 & 118 & 84 & 118 & 84 & 118 & 84 & 118 \\
\hline Min. & 0.05 & 0.05 & 0.09 & 0.09 & 0.06 & 0.06 & 0.13 & 0.13 & 0.07 & 0.07 & 0.07 & 0.07 \\
\hline Max. & 0.06 & 0.06 & 0.11 & 0.18 & 0.07 & 0.07 & 0.21 & 0.21 & 0.08 & 0.08 & 0.08 & 0.08 \\
\hline Mean & 0.06 & 0.06 & 0.10 & 0.10 & 0.06 & 0.06 & 0.19 & 0.18 & 0.07 & 0.07 & 0.08 & 0.08 \\
\hline Std. Dev. & 0.00 & 0.00 & 0.00 & 0.00 & 0.00 & 0.00 & 0.01 & 0.01 & 0.00 & 0.00 & 0.00 & 0.00 \\
\hline Delta Mean & \multicolumn{2}{|c|}{0.001} & \multicolumn{2}{|c|}{0.003} & \multicolumn{2}{|c|}{-0.002} & \multicolumn{2}{|c|}{-0.015} & \multicolumn{2}{|c|}{0.000} & \multicolumn{2}{|c|}{0.000} \\
\hline Std. Dev. Diff. & \multicolumn{2}{|c|}{0.000} & \multicolumn{2}{|c|}{0.001} & \multicolumn{2}{|c|}{0.000} & \multicolumn{2}{|c|}{0.002} & \multicolumn{2}{|c|}{0.000} & \multicolumn{2}{|c|}{0.000} \\
\hline $\mathbf{Z}$ & \multicolumn{2}{|c|}{1.999} & \multicolumn{2}{|c|}{3.682} & \multicolumn{2}{|c|}{-5.526} & \multicolumn{2}{|c|}{-9.657} & \multicolumn{2}{|c|}{0.240} & \multicolumn{2}{|c|}{-1.281} \\
\hline P-value & \multicolumn{2}{|c|}{0.977} & \multicolumn{2}{|c|}{0.999} & \multicolumn{2}{|c|}{$1.6 \mathrm{E}-08$} & \multicolumn{2}{|c|}{0.000} & \multicolumn{2}{|c|}{0.595} & \multicolumn{2}{|c|}{0.100} \\
\hline $\begin{array}{l}\text { Reject Ho at } \\
\text { confidence } \\
\text { level }\end{array}$ & \multicolumn{2}{|c|}{$\begin{array}{c}\text { Cannot } \\
\text { Reject Ho }\end{array}$} & \multicolumn{2}{|c|}{$\begin{array}{c}\text { Cannot } \\
\text { Reject Ho }\end{array}$} & \multicolumn{2}{|c|}{$99.9+\%$} & \multicolumn{2}{|c|}{$99.9+\%$} & \multicolumn{2}{|c|}{$\begin{array}{c}\text { Cannot } \\
\text { Reject Ho }\end{array}$} & \multicolumn{2}{|c|}{$90.0 \%$} \\
\hline
\end{tabular}


Table C- 8. Statistical Comparison of GRMS Measure: Clockwise vs. Counter-clockwise Laps Baseline Unit - All Accelerometers - Longitudinal Direction

\begin{tabular}{|c|c|c|c|c|c|c|c|c|c|c|c|c|}
\hline \multirow[b]{2}{*}{ Statistics } & \multicolumn{2}{|c|}{ Front Left } & \multicolumn{2}{|c|}{ Hitch } & \multicolumn{2}{|c|}{ Front Right } & \multicolumn{2}{|c|}{ Center } & \multicolumn{2}{|c|}{ Rear Left } & \multicolumn{2}{|c|}{ Rear Right } \\
\hline & $\begin{array}{c}\mathrm{B} \\
\mathrm{CW}\end{array}$ & $\begin{array}{c}\text { B } \\
\mathrm{CCW}\end{array}$ & $\begin{array}{c}\text { B } \\
\mathrm{CW}\end{array}$ & $\begin{array}{c}\text { B } \\
\mathrm{CCW}\end{array}$ & $\begin{array}{c}B \\
C W\end{array}$ & $\begin{array}{c}\text { B } \\
\mathrm{CCW}\end{array}$ & $\begin{array}{c}\text { B } \\
\mathrm{CW}\end{array}$ & $\begin{array}{c}\text { B } \\
\mathbf{C C W}\end{array}$ & $\begin{array}{c}\mathrm{B} \\
\mathrm{CW}\end{array}$ & $\begin{array}{c}\mathrm{B} \\
\mathrm{CCW}\end{array}$ & $\begin{array}{c}\text { B } \\
\text { CW }\end{array}$ & $\begin{array}{c}\text { B } \\
\text { CCW }\end{array}$ \\
\hline Obs. & 84 & 118 & 84 & 118 & 84 & 118 & 84 & 118 & 84 & 118 & 84 & 118 \\
\hline Min. & 0.02 & 0.02 & 0.05 & 0.05 & 0.03 & 0.03 & 0.02 & 0.02 & 0.03 & 0.03 & 0.02 & 0.02 \\
\hline Max. & 0.03 & 0.03 & 0.06 & 0.06 & 0.03 & 0.03 & 0.05 & 0.05 & 0.04 & 0.04 & 0.03 & 0.03 \\
\hline Mean & 0.02 & 0.03 & 0.05 & 0.05 & 0.03 & 0.03 & 0.03 & 0.03 & 0.03 & 0.04 & 0.03 & 0.03 \\
\hline Std. Dev. & 0.00 & 0.00 & 0.00 & 0.00 & 0.00 & 0.00 & 0.00 & 0.00 & 0.00 & 0.00 & 0.00 & 0.00 \\
\hline Delta Mean & \multicolumn{2}{|c|}{0.002} & \multicolumn{2}{|c|}{0.002} & \multicolumn{2}{|c|}{0.001} & \multicolumn{2}{|c|}{0.000} & \multicolumn{2}{|c|}{0.005} & \multicolumn{2}{|c|}{0.000} \\
\hline Std. Dev. Diff. & \multicolumn{2}{|c|}{0.000} & \multicolumn{2}{|c|}{0.000} & \multicolumn{2}{|c|}{0.000} & \multicolumn{2}{|c|}{0.001} & \multicolumn{2}{|c|}{0.000} & \multicolumn{2}{|c|}{0.000} \\
\hline $\mathbf{Z}$ & \multicolumn{2}{|c|}{11.256} & \multicolumn{2}{|c|}{5.556} & \multicolumn{2}{|c|}{3.575} & \multicolumn{2}{|c|}{-0.024} & \multicolumn{2}{|c|}{19.636} & \multicolumn{2}{|c|}{-0.315} \\
\hline P-value & \multicolumn{2}{|c|}{0.999} & \multicolumn{2}{|c|}{0.999} & \multicolumn{2}{|c|}{0.999} & \multicolumn{2}{|c|}{0.490} & \multicolumn{2}{|c|}{0.999} & \multicolumn{2}{|c|}{0.377} \\
\hline $\begin{array}{l}\text { Reject Ho at } \\
\text { confidence } \\
\text { level }\end{array}$ & \multicolumn{2}{|c|}{$\begin{array}{c}\text { Cannot } \\
\text { Reject Ho }\end{array}$} & \multicolumn{2}{|c|}{$\begin{array}{c}\text { Cannot } \\
\text { Reject Ho }\end{array}$} & \multicolumn{2}{|c|}{$\begin{array}{c}\text { Cannot } \\
\text { Reject Ho }\end{array}$} & \multicolumn{2}{|c|}{$<85.0 \%$} & \multicolumn{2}{|c|}{$\begin{array}{c}\text { Cannot } \\
\text { Reject Ho }\end{array}$} & \multicolumn{2}{|c|}{$<85.0 \%$} \\
\hline
\end{tabular}

Table C- 9. Statistical Comparison of GRMS Measure: Clockwise vs. Counter-clockwise Laps Baseline Unit - All Accelerometers - Lateral Direction

\begin{tabular}{|c|c|c|c|c|c|c|c|c|c|c|c|c|}
\hline \multirow[b]{2}{*}{ Statistics } & \multicolumn{2}{|c|}{ Front Left } & \multicolumn{2}{|c|}{ Hitch } & \multicolumn{2}{|c|}{ Front Right } & \multicolumn{2}{|c|}{ Center } & \multicolumn{2}{|c|}{ Rear Left } & \multicolumn{2}{|c|}{ Rear Right } \\
\hline & $\begin{array}{c}\mathrm{B} \\
\mathrm{CW}\end{array}$ & $\begin{array}{c}\mathrm{B} \\
\mathrm{CCW}\end{array}$ & $\begin{array}{c}\mathrm{B} \\
\mathrm{CW}\end{array}$ & $\begin{array}{c}\mathrm{B} \\
\mathrm{CCW}\end{array}$ & $\begin{array}{c}\text { B } \\
\text { CW }\end{array}$ & $\begin{array}{c}\text { B } \\
\mathrm{CCW}\end{array}$ & $\begin{array}{c}\mathrm{B} \\
\mathrm{CW}\end{array}$ & $\begin{array}{c}\mathrm{B} \\
\mathrm{CCW}\end{array}$ & $\begin{array}{c}\mathrm{B} \\
\mathrm{CW}\end{array}$ & $\begin{array}{c}\mathrm{B} \\
\mathrm{CCW}\end{array}$ & $\begin{array}{c}\mathrm{B} \\
\mathrm{CW}\end{array}$ & $\begin{array}{c}\mathrm{B} \\
\mathrm{CCW}\end{array}$ \\
\hline Obs. & 84 & 118 & 84 & 118 & 84 & 118 & 84 & 118 & 84 & 87 & 84 & 118 \\
\hline Min. & 0.03 & 0.03 & 0.09 & 0.09 & 0.03 & 0.03 & 0.03 & 0.03 & 0.04 & 0.04 & 0.04 & 0.04 \\
\hline Max. & 0.04 & 0.04 & 0.11 & 0.11 & 0.04 & 0.04 & 0.04 & 0.04 & 0.05 & 0.04 & 0.05 & 0.05 \\
\hline Mean & 0.04 & 0.04 & 0.10 & 0.10 & 0.04 & 0.04 & 0.03 & 0.03 & 0.04 & 0.04 & 0.04 & 0.04 \\
\hline Std. Dev. & 0.00 & 0.00 & 0.00 & 0.00 & 0.00 & 0.00 & 0.00 & 0.00 & 0.00 & 0.00 & 0.00 & 0.00 \\
\hline Delta Mean & \multicolumn{2}{|c|}{0.000} & \multicolumn{2}{|c|}{0.006} & \multicolumn{2}{|c|}{0.000} & \multicolumn{2}{|c|}{0.001} & \multicolumn{2}{|c|}{-0.002} & \multicolumn{2}{|c|}{-0.001} \\
\hline Std. Dev. Diff. & \multicolumn{2}{|c|}{0.000} & \multicolumn{2}{|c|}{0.001} & \multicolumn{2}{|c|}{0.000} & \multicolumn{2}{|c|}{0.000} & \multicolumn{2}{|c|}{0.000} & \multicolumn{2}{|c|}{0.000} \\
\hline $\mathbf{Z}$ & \multicolumn{2}{|c|}{-0.475} & \multicolumn{2}{|c|}{7.512} & \multicolumn{2}{|c|}{-0.219} & \multicolumn{2}{|c|}{2.538} & \multicolumn{2}{|c|}{-7.948} & \multicolumn{2}{|c|}{-3.448} \\
\hline P-value & \multicolumn{2}{|c|}{0.318} & \multicolumn{2}{|c|}{0.999} & \multicolumn{2}{|c|}{0.413} & \multicolumn{2}{|c|}{0.994} & \multicolumn{2}{|c|}{0.000} & \multicolumn{2}{|c|}{0.000} \\
\hline $\begin{array}{l}\text { Reject Ho at } \\
\text { confidence } \\
\text { level }\end{array}$ & \multicolumn{2}{|c|}{$<85.0 \%$} & \multicolumn{2}{|c|}{$\begin{array}{c}\text { Cannot } \\
\text { Reject Ho }\end{array}$} & \multicolumn{2}{|c|}{$<85.0 \%$} & \multicolumn{2}{|c|}{$\begin{array}{c}\text { Cannot } \\
\text { Reject Ho }\end{array}$} & \multicolumn{2}{|c|}{$99.9+\%$} & \multicolumn{2}{|c|}{$99.9+\%$} \\
\hline
\end{tabular}




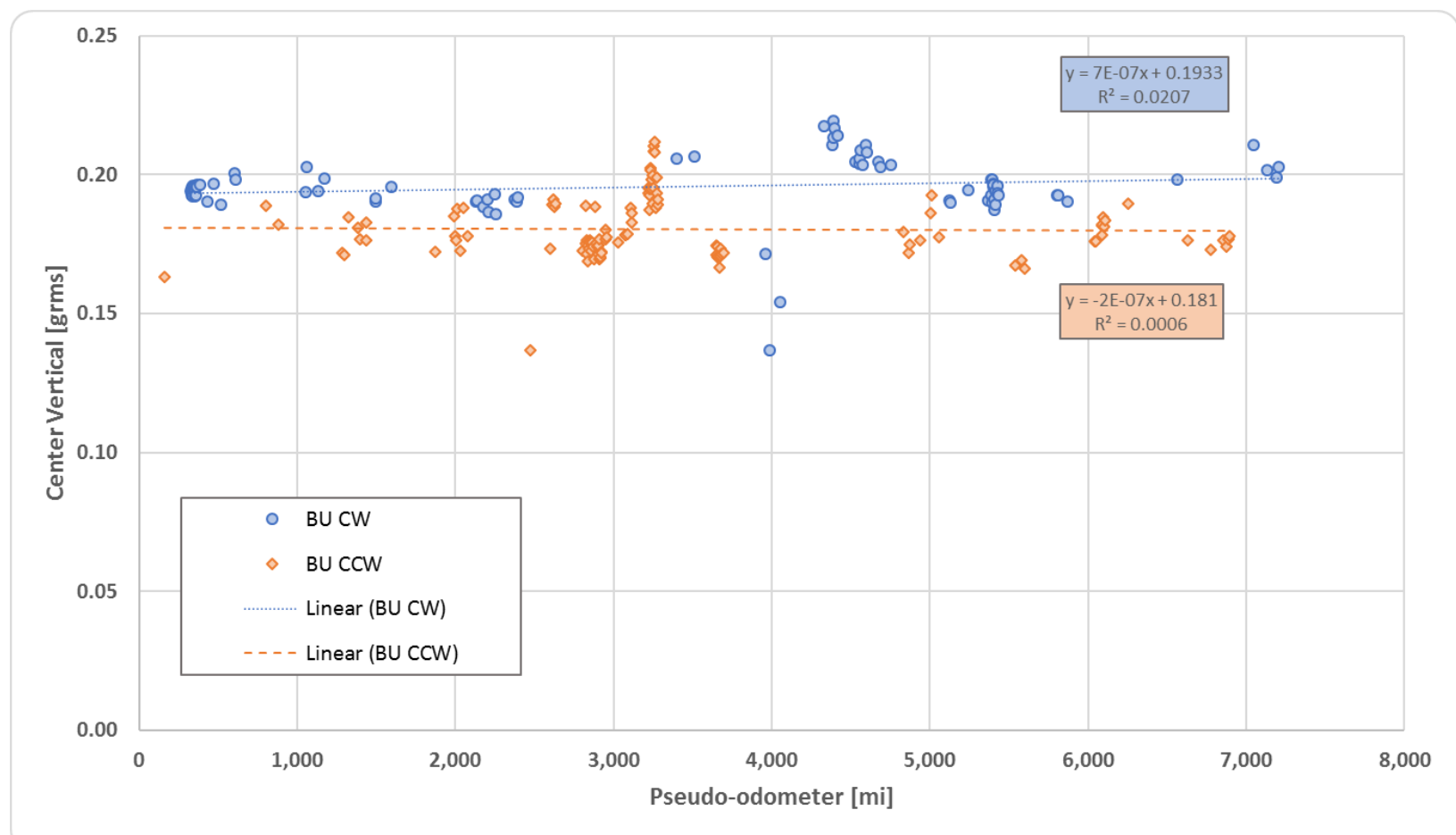

Figure C- 7 Part C2 - Baseline Unit GRMS for Vertical Accelerometer at Axle Group (Center) Selected Clockwise vs. Counter-clockwise Laps for Statistical Analysis.

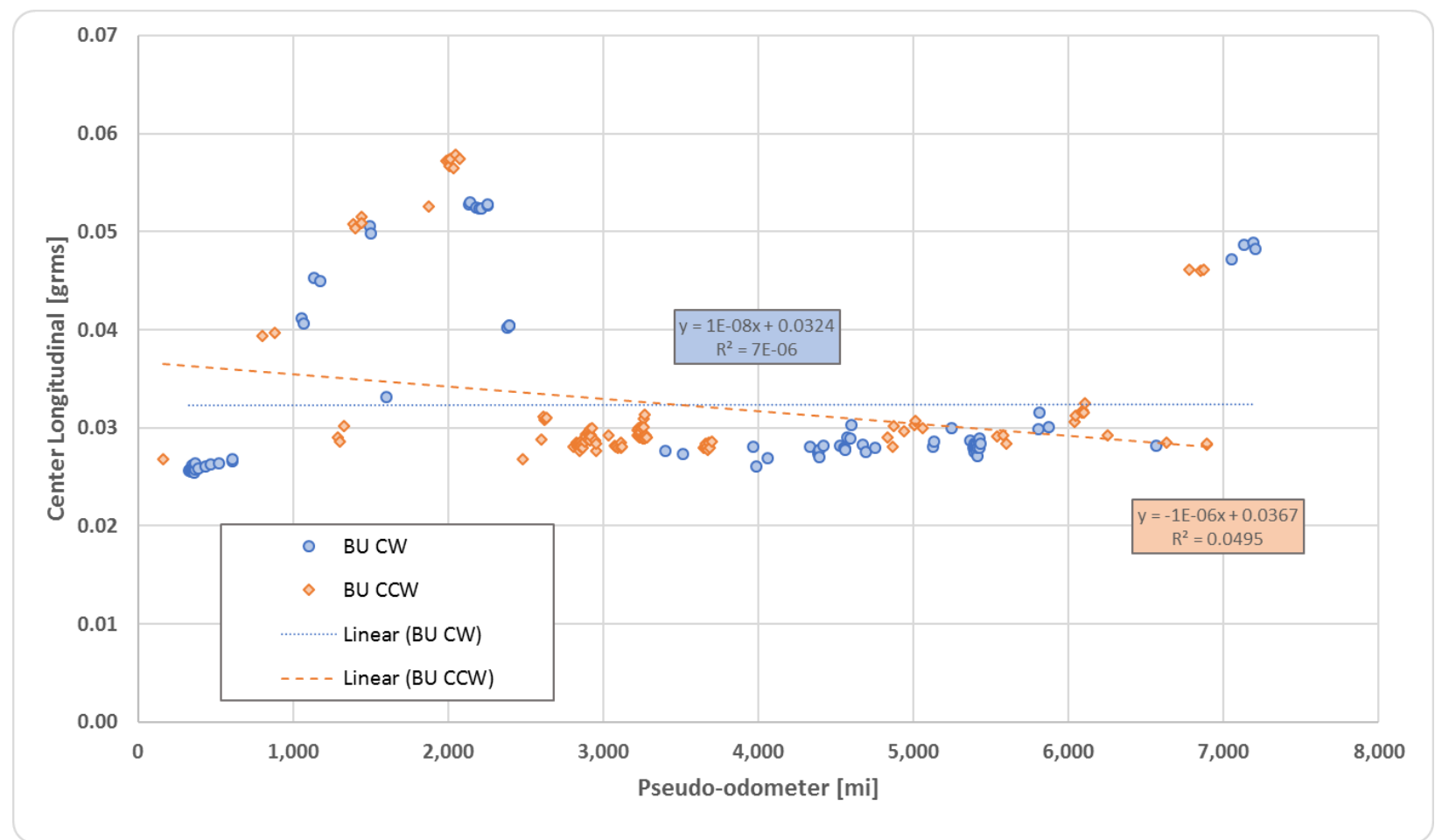

Figure C- 8 Part C2 - Baseline Unit GRMS for Longitudinal Accelerometer at Axle Group (Center) Selected Clockwise vs. Counter-clockwise Laps for Statistical Analysis. 


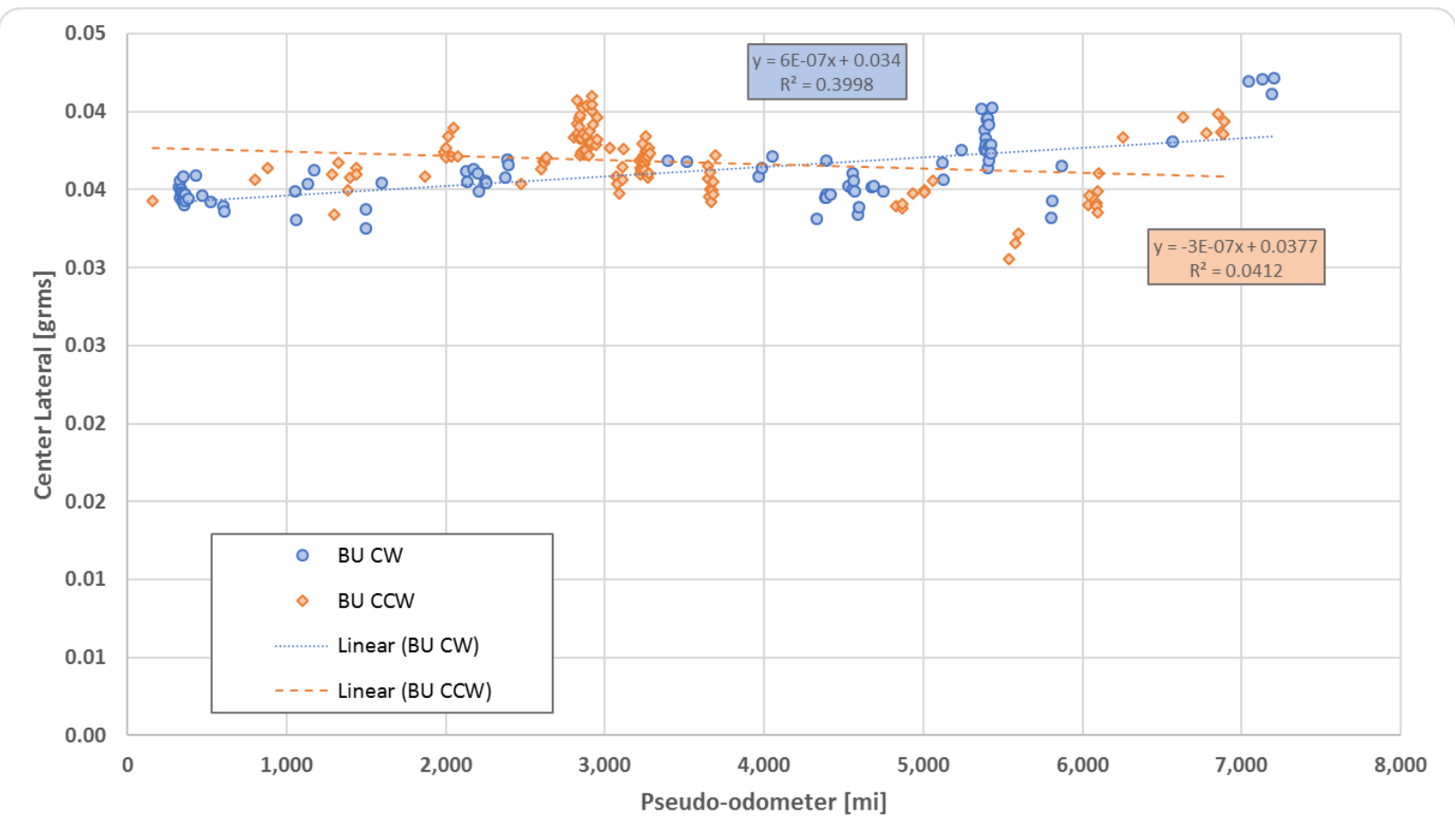

Figure C- 9 Part C2 - Baseline Unit GRMS for Lateral Accelerometer at Axle Group (Center) Selected Clockwise vs. Counter-clockwise Laps for Statistical Analysis.

Effect of Suspension on Vibrations: Clockwise vs. Counter-clockwise Laps-Upgrade Unit

Table C- 10. Statistical Comparison of GRMS Measure: Clockwise vs. Counter-clockwise Laps Upgrade Unit - All Accelerometers - Vertical Direction

\begin{tabular}{|c|c|c|c|c|c|c|c|c|c|c|c|c|}
\hline \multirow[b]{2}{*}{ Statistics } & \multicolumn{2}{|c|}{ Front Left } & \multicolumn{2}{|c|}{ Hitch } & \multicolumn{2}{|c|}{ Front Right } & \multicolumn{2}{|c|}{ Center } & \multicolumn{2}{|c|}{ Rear Left } & \multicolumn{2}{|c|}{ Rear Right } \\
\hline & $\begin{array}{c}\mathrm{U} \\
\mathrm{CW}\end{array}$ & $\begin{array}{c}\mathrm{U} \\
\mathbf{C C W}\end{array}$ & $\begin{array}{c}\mathrm{U} \\
\mathbf{C W}\end{array}$ & $\begin{array}{c}\mathbf{U} \\
\mathbf{C C W}\end{array}$ & $\begin{array}{c}\mathrm{U} \\
\mathbf{C W}\end{array}$ & $\begin{array}{c}\mathrm{U} \\
\mathbf{C C W}\end{array}$ & $\begin{array}{c}\mathrm{U} \\
\mathbf{C W}\end{array}$ & $\begin{array}{c}\mathrm{U} \\
\mathrm{CCW}\end{array}$ & $\begin{array}{c}\mathrm{U} \\
\mathbf{C W}\end{array}$ & $\begin{array}{c}\mathrm{U} \\
\mathbf{C C W}\end{array}$ & $\begin{array}{c}\mathrm{U} \\
\mathrm{CW}\end{array}$ & $\begin{array}{c}\mathrm{U} \\
\mathrm{CCW}\end{array}$ \\
\hline Obs. & 84 & 118 & 84 & 118 & 84 & 118 & 84 & 118 & 84 & 118 & 84 & 118 \\
\hline Min. & 0.05 & 0.05 & 0.09 & 0.09 & 0.06 & 0.06 & 0.11 & 0.10 & 0.07 & 0.06 & 0.06 & 0.06 \\
\hline Max. & 0.06 & 0.06 & 0.11 & 0.12 & 0.07 & 0.07 & 0.19 & 0.20 & 0.08 & 0.08 & 0.08 & 0.08 \\
\hline Mean & 0.06 & 0.06 & 0.10 & 0.10 & 0.07 & 0.06 & 0.15 & 0.15 & 0.07 & 0.07 & 0.07 & 0.07 \\
\hline Std. Dev. & 0.00 & 0.00 & 0.00 & \begin{tabular}{|l|}
0.00 \\
\end{tabular} & 0.00 & 0.00 & 0.01 & 0.01 & 0.00 & 0.00 & 0.00 & 0.00 \\
\hline Delta Mean & \multicolumn{2}{|c|}{0.001} & \multicolumn{2}{|c|}{0.006} & \multicolumn{2}{|c|}{-0.001} & \multicolumn{2}{|c|}{0.001} & \multicolumn{2}{|c|}{-0.002} & \multicolumn{2}{|c|}{-0.001} \\
\hline Std. Dev. Diff. & \multicolumn{2}{|c|}{0.000} & \multicolumn{2}{|c|}{0.001} & \multicolumn{2}{|c|}{0.000} & \multicolumn{2}{|c|}{0.002} & \multicolumn{2}{|c|}{0.000} & \multicolumn{2}{|c|}{0.000} \\
\hline $\mathbf{Z}$ & \multicolumn{2}{|c|}{4.273} & \multicolumn{2}{|c|}{7.093} & \multicolumn{2}{|c|}{-1.604} & \multicolumn{2}{|c|}{0.621} & \multicolumn{2}{|c|}{-5.105} & \multicolumn{2}{|c|}{-3.146} \\
\hline P-value & \multicolumn{2}{|c|}{0.999} & \multicolumn{2}{|c|}{0.999} & \multicolumn{2}{|c|}{0.054} & \multicolumn{2}{|c|}{0.733} & \multicolumn{2}{|c|}{$1.7 \mathrm{E}-07$} & \multicolumn{2}{|c|}{0.001} \\
\hline $\begin{array}{l}\text { Reject Ho at } \\
\text { confidence } \\
\text { level }\end{array}$ & \multicolumn{2}{|c|}{$\begin{array}{c}\text { Cannot } \\
\text { Reject Ho }\end{array}$} & \multicolumn{2}{|c|}{$\begin{array}{c}\text { Cannot } \\
\text { Reject Ho }\end{array}$} & \multicolumn{2}{|c|}{$94.6 \%$} & \multicolumn{2}{|c|}{$\begin{array}{c}\text { Cannot } \\
\text { Reject Ho }\end{array}$} & \multicolumn{2}{|c|}{$99.9+\%$} & \multicolumn{2}{|c|}{$99.9 \%$} \\
\hline
\end{tabular}


Table C- 11. Statistical Comparison of GRMS Measure: Clockwise vs. Counter-clockwise Laps Upgrade Unit - All Accelerometers - Longitudinal Direction

\begin{tabular}{|c|c|c|c|c|c|c|c|c|c|c|c|c|}
\hline \multirow[b]{2}{*}{ Statistics } & \multicolumn{2}{|c|}{ Front Left } & \multicolumn{2}{|c|}{ Hitch } & \multicolumn{2}{|c|}{ Front Right } & \multicolumn{2}{|c|}{ Center } & \multicolumn{2}{|c|}{ Rear Left } & \multicolumn{2}{|c|}{ Rear Right } \\
\hline & $\begin{array}{c}\mathbf{U} \\
\mathbf{C W}\end{array}$ & $\begin{array}{c}\mathrm{U} \\
\mathrm{CCW}\end{array}$ & $\begin{array}{c}\mathbf{U} \\
\mathbf{C W}\end{array}$ & $\begin{array}{c}\mathrm{U} \\
\mathrm{CCW}\end{array}$ & $\begin{array}{c}\mathbf{U} \\
\mathbf{C W}\end{array}$ & $\begin{array}{c}\mathrm{U} \\
\mathrm{CCW}\end{array}$ & $\begin{array}{c}\mathbf{U} \\
\mathbf{C W}\end{array}$ & $\begin{array}{c}\mathrm{U} \\
\mathrm{CCW}\end{array}$ & $\begin{array}{c}\mathbf{U} \\
\mathbf{C W}\end{array}$ & $\begin{array}{c}\mathrm{U} \\
\mathbf{C C W}\end{array}$ & $\begin{array}{c}\mathbf{U} \\
\mathbf{C W}\end{array}$ & $\begin{array}{c}\mathrm{U} \\
\mathrm{CCW}\end{array}$ \\
\hline Obs. & 84 & 118 & 84 & 118 & 84 & 118 & 84 & 118 & 84 & 118 & 84 & 118 \\
\hline Min. & 0.027 & 0.027 & 0.063 & 0.063 & 0.027 & 0.027 & 0.024 & 0.025 & 0.033 & 0.033 & 0.026 & 0.026 \\
\hline Max. & 0.035 & 0.037 & 0.071 & 0.079 & 0.036 & 0.039 & 0.034 & 0.038 & 0.044 & 0.046 & 0.036 & 0.039 \\
\hline Mean & 0.030 & 0.030 & 0.066 & 0.070 & 0.030 & 0.030 & 0.028 & 0.028 & 0.036 & 0.036 & 0.030 & 0.030 \\
\hline Std. Dev. & 0.001 & 0.002 & 0.002 & 0.004 & 0.002 & 0.003 & 0.002 & 0.003 & 0.002 & 0.003 & 0.002 & 0.003 \\
\hline Delta Mean & \multicolumn{2}{|c|}{0.000} & \multicolumn{2}{|c|}{0.004} & \multicolumn{2}{|c|}{0.000} & \multicolumn{2}{|c|}{0.001} & \multicolumn{2}{|c|}{0.000} & \multicolumn{2}{|c|}{0.000} \\
\hline Std. Dev. Diff. & \multicolumn{2}{|c|}{0.000} & \multicolumn{2}{|c|}{0.000} & \multicolumn{2}{|c|}{0.000} & \multicolumn{2}{|c|}{0.000} & \multicolumn{2}{|c|}{0.000} & \multicolumn{2}{|c|}{0.000} \\
\hline $\mathbf{Z}$ & \multicolumn{2}{|c|}{1.119} & \multicolumn{2}{|c|}{8.908} & \multicolumn{2}{|c|}{0.606} & \multicolumn{2}{|c|}{1.590} & \multicolumn{2}{|c|}{-0.364} & \multicolumn{2}{|c|}{1.114} \\
\hline P-value & \multicolumn{2}{|c|}{0.868} & \multicolumn{2}{|c|}{0.999} & \multicolumn{2}{|c|}{0.727} & \multicolumn{2}{|c|}{0.944} & \multicolumn{2}{|c|}{0.358} & \multicolumn{2}{|c|}{0.867} \\
\hline $\begin{array}{l}\text { Reject Ho at } \\
\text { confidence } \\
\text { level }\end{array}$ & \multicolumn{2}{|c|}{$\begin{array}{c}\text { Cannot Reject } \\
\text { Ho }\end{array}$} & \multicolumn{2}{|c|}{$\begin{array}{c}\text { Cannot Reject } \\
\text { Ho }\end{array}$} & \multicolumn{2}{|c|}{$\begin{array}{c}\text { Cannot Reject } \\
\text { Ho }\end{array}$} & \multicolumn{2}{|c|}{$\begin{array}{c}\text { Cannot Reject } \\
\text { Ho }\end{array}$} & \multicolumn{2}{|c|}{$<85.0 \%$} & \multicolumn{2}{|c|}{$\begin{array}{c}\text { Cannot Reject } \\
\text { Ho }\end{array}$} \\
\hline
\end{tabular}

Table C- 12. Statistical Comparison of GRMS Measure: Clockwise vs. Counter-clockwise Laps Upgrade Unit - All Accelerometers - Lateral Direction

\begin{tabular}{|c|c|c|c|c|c|c|c|c|c|c|c|c|}
\hline \multirow[b]{2}{*}{ Statistics } & \multicolumn{2}{|c|}{ Front Left } & \multicolumn{2}{|c|}{ Hitch } & \multicolumn{2}{|c|}{ Front Right } & \multicolumn{2}{|c|}{ Center } & \multicolumn{2}{|c|}{ Rear Left } & \multicolumn{2}{|c|}{ Rear Right } \\
\hline & $\begin{array}{c}\mathbf{U} \\
\mathbf{C W}\end{array}$ & $\begin{array}{c}\mathrm{U} \\
\mathrm{CCW}\end{array}$ & $\begin{array}{c}\mathbf{U} \\
\mathbf{C W}\end{array}$ & $\begin{array}{c}\mathrm{U} \\
\mathbf{C C W}\end{array}$ & $\begin{array}{c}\mathbf{U} \\
\mathbf{C W}\end{array}$ & $\begin{array}{c}\mathrm{U} \\
\mathrm{CCW}\end{array}$ & $\begin{array}{c}\mathbf{U} \\
\mathbf{C W}\end{array}$ & $\begin{array}{c}\mathrm{U} \\
\mathrm{CCW}\end{array}$ & $\begin{array}{c}\mathbf{U} \\
\mathbf{C W}\end{array}$ & $\begin{array}{c}\mathrm{U} \\
\mathrm{CCW}\end{array}$ & $\begin{array}{c}\mathbf{U} \\
\mathbf{C W}\end{array}$ & $\begin{array}{c}\mathrm{U} \\
\mathrm{CCW}\end{array}$ \\
\hline Obs. & 84 & 118 & 84 & 118 & 84 & 118 & 84 & 118 & 84 & 118 & 84 & 118 \\
\hline Min. & 0.03 & 0.03 & 0.09 & 0.09 & 0.03 & 0.03 & 0.03 & 0.02 & 0.03 & 0.03 & 0.03 & 0.03 \\
\hline Max. & 0.04 & 0.04 & 0.11 & 0.12 & 0.04 & 0.04 & 0.04 & 0.03 & 0.05 & 0.04 & 0.04 & 0.04 \\
\hline Mean & 0.03 & 0.04 & 0.10 & 0.10 & 0.03 & 0.04 & 0.03 & 0.03 & 0.04 & 0.04 & 0.04 & 0.04 \\
\hline Std. Dev. & 0.00 & 0.00 & 0.00 & 0.00 & 0.00 & 0.00 & 0.00 & 0.00 & 0.00 & 0.00 & 0.00 & 0.00 \\
\hline Delta Mean & \multicolumn{2}{|c|}{0.000} & \multicolumn{2}{|c|}{0.001} & \multicolumn{2}{|c|}{0.001} & \multicolumn{2}{|c|}{-0.002} & \multicolumn{2}{|c|}{-0.001} & \multicolumn{2}{|c|}{-0.001} \\
\hline Std. Dev. Diff. & \multicolumn{2}{|c|}{0.000} & \multicolumn{2}{|c|}{0.001} & \multicolumn{2}{|c|}{0.000} & \multicolumn{2}{|c|}{0.000} & \multicolumn{2}{|c|}{0.000} & \multicolumn{2}{|c|}{0.000} \\
\hline $\mathbf{Z}$ & \multicolumn{2}{|c|}{1.087} & \multicolumn{2}{|c|}{1.388} & \multicolumn{2}{|c|}{1.791} & \multicolumn{2}{|c|}{-4.946} & \multicolumn{2}{|c|}{-2.855} & \multicolumn{2}{|c|}{-1.956} \\
\hline P-value & \multicolumn{2}{|c|}{0.862} & \multicolumn{2}{|c|}{0.917} & \multicolumn{2}{|c|}{0.963} & \multicolumn{2}{|c|}{$3.8 \mathrm{E}-07$} & \multicolumn{2}{|c|}{0.002} & \multicolumn{2}{|c|}{0.025} \\
\hline $\begin{array}{l}\text { Reject Ho at } \\
\text { confidence } \\
\text { level }\end{array}$ & \multicolumn{2}{|c|}{$\begin{array}{c}\text { Cannot } \\
\text { Reject Ho }\end{array}$} & \multicolumn{2}{|c|}{$\begin{array}{c}\text { Cannot } \\
\text { Reject Ho }\end{array}$} & \multicolumn{2}{|c|}{$\begin{array}{c}\text { Cannot } \\
\text { Reject Ho }\end{array}$} & \multicolumn{2}{|c|}{$99.9+\%$} & \multicolumn{2}{|c|}{$99.8 \%$} & \multicolumn{2}{|c|}{$97.5 \%$} \\
\hline
\end{tabular}




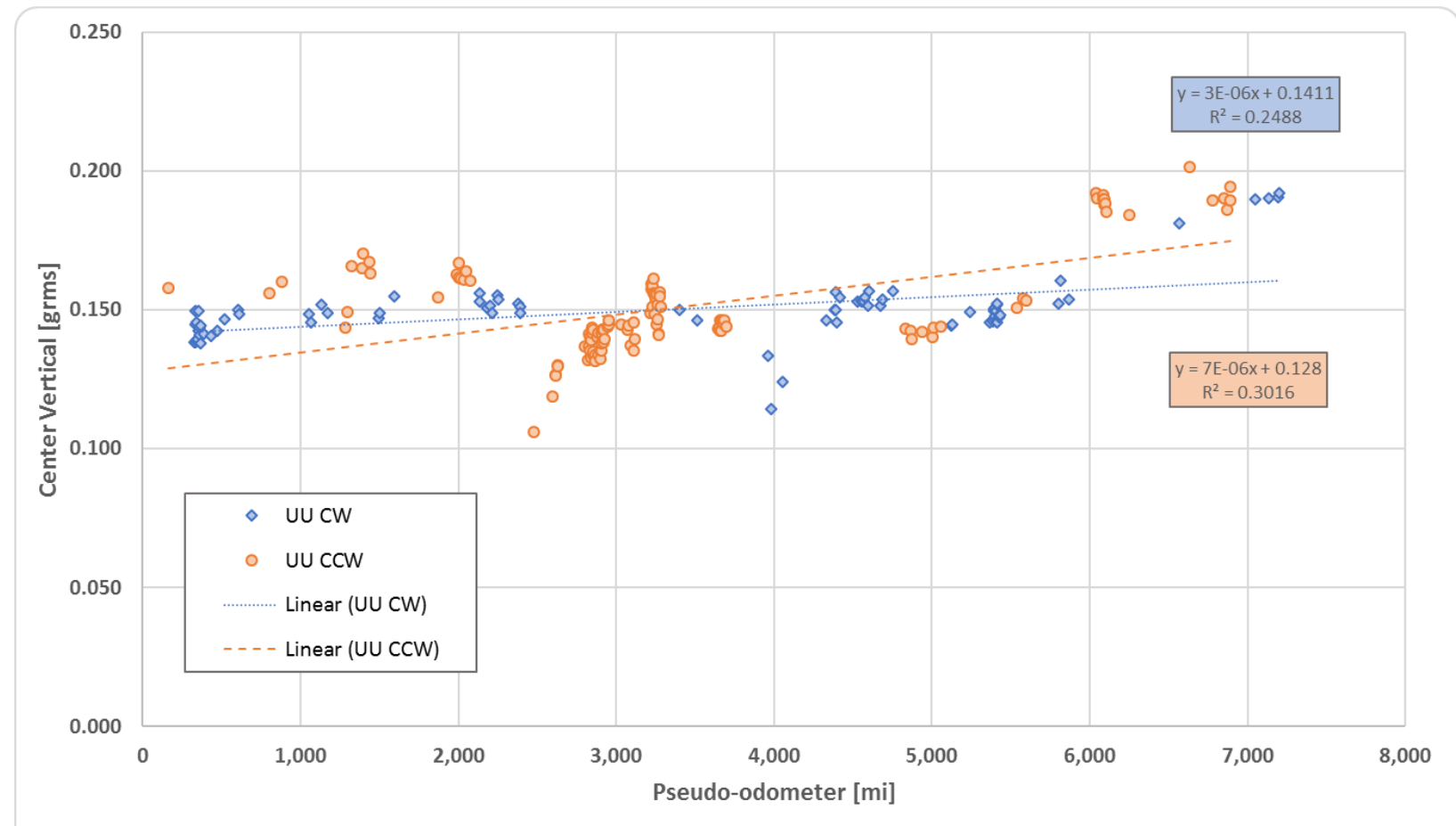

Figure C- 10 Part C2 - Upgrade Unit GRMS for Vertical Accelerometer at Axle Group (Center) Selected Clockwise vs. Counter-clockwise Laps for Statistical Analysis.

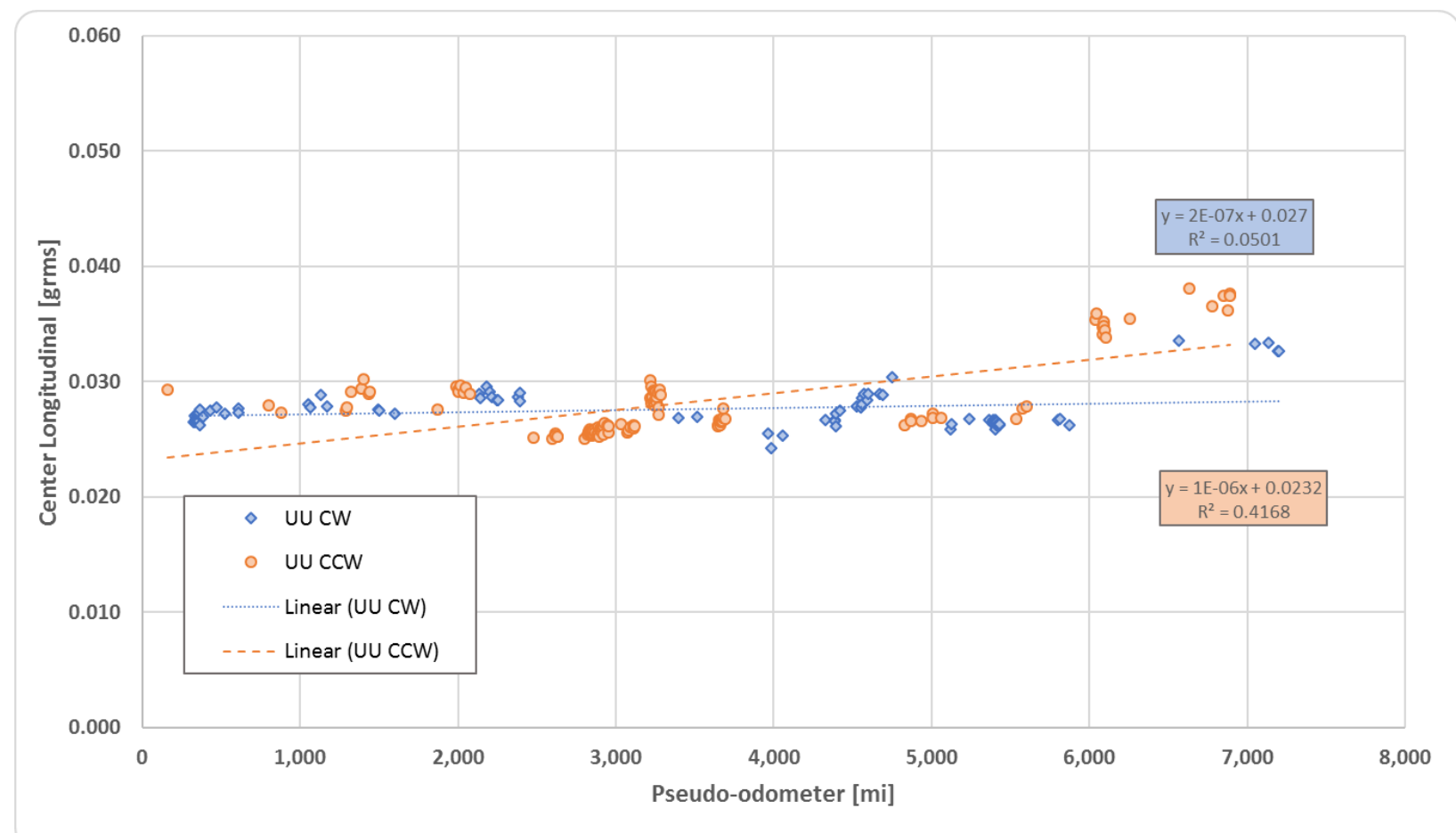

Figure C- 11 Part C2 - Upgrade Unit GRMS for Longitudinal Accelerometer at Axle Group (Center) Selected Clockwise vs. Counter-clockwise Laps for Statistical Analysis. 


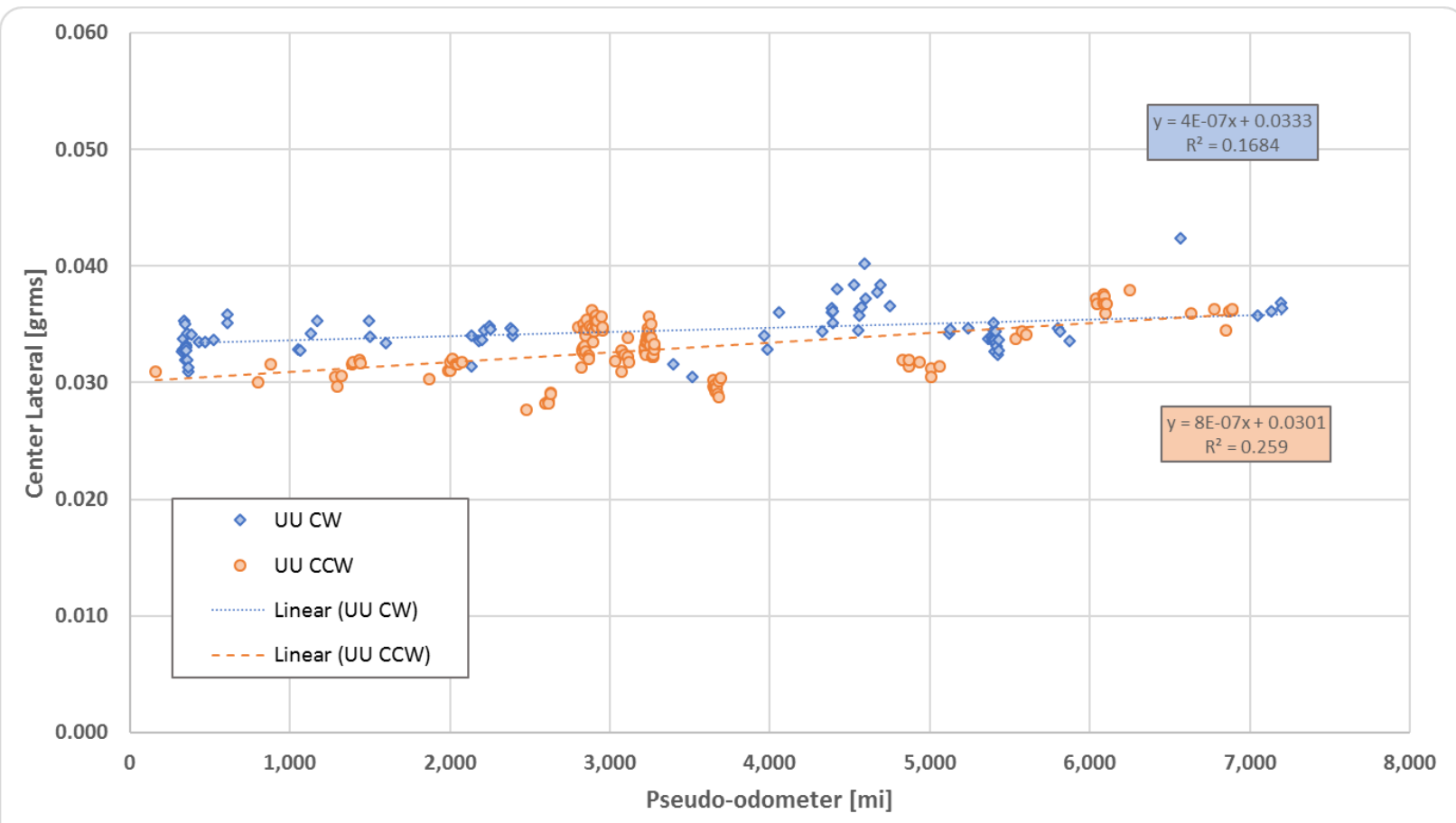

Figure C- 12 Part C2 - Upgrade Unit GRMS for Lateral Accelerometer at Axle Group (Center) Selected Clockwise vs. Counter-clockwise Laps for Statistical Analysis.

Effect of Suspension on Vibrations: Radial Tires vs. Regular Tires - Clockwise Laps - Upgrade Unit

Table C- 13. Statistical Comparison of GRMS Measure: Radial Tires vs. Regular Tires Upgrade Unit - Clockwise Laps - All Accelerometers - Vertical Direction

\begin{tabular}{|c|c|c|c|c|c|c|c|c|c|c|c|c|}
\hline \multirow{2}{*}{ Statistics } & \multicolumn{2}{|c|}{ Front Left } & \multicolumn{2}{|c|}{ Hitch } & \multicolumn{2}{|c|}{ Front Right } & \multicolumn{2}{|c|}{ Center } & \multicolumn{2}{|c|}{ Rear Left } & \multicolumn{2}{|c|}{ Rear Right } \\
\hline & Radial & Reg. & Radial & Reg. & Radial & Reg. & Radial & Reg. & Radial & Reg. & Radial & Reg. \\
\hline Obs. & 37 & 61 & 37 & 61 & 37 & 61 & 37 & 61 & 37 & 61 & 37 & 61 \\
\hline Min. & 0.05 & 0.06 & 0.10 & 0.09 & 0.07 & 0.06 & 0.10 & 0.14 & 0.03 & 0.07 & 0.06 & 0.07 \\
\hline Max. & 0.06 & 0.06 & 0.10 & 0.11 & 0.07 & 0.07 & 0.11 & 0.15 & 0.08 & 0.08 & 0.07 & 0.07 \\
\hline Mean & 0.06 & 0.06 & 0.10 & 0.10 & 0.07 & 0.07 & 0.11 & 0.15 & 0.07 & 0.07 & 0.07 & 0.07 \\
\hline Std. Dev. & 0.00 & 0.00 & 0.00 & 0.00 & 0.00 & 0.00 & 0.00 & 0.00 & 0.01 & 0.00 & 0.00 & 0.00 \\
\hline Delta Mean & \multicolumn{2}{|c|}{-0.003} & \multicolumn{2}{|c|}{0.000} & \multicolumn{2}{|c|}{0.003} & \multicolumn{2}{|c|}{-0.041} & \multicolumn{2}{|c|}{-0.002} & \multicolumn{2}{|c|}{0.000} \\
\hline Std. Dev. Diff. & \multicolumn{2}{|c|}{0.000} & \multicolumn{2}{|c|}{0.000} & \multicolumn{2}{|c|}{0.000} & \multicolumn{2}{|c|}{0.001} & \multicolumn{2}{|c|}{0.002} & \multicolumn{2}{|c|}{0.000} \\
\hline $\mathbf{Z}$ & \multicolumn{2}{|c|}{-11.625} & \multicolumn{2}{|c|}{0.463} & \multicolumn{2}{|c|}{6.022} & \multicolumn{2}{|c|}{-63.464} & \multicolumn{2}{|c|}{-0.641} & \multicolumn{2}{|c|}{1.226} \\
\hline P-value & \multicolumn{2}{|c|}{0.000} & \multicolumn{2}{|c|}{0.678} & \multicolumn{2}{|c|}{0.999} & \multicolumn{2}{|c|}{0.000} & \multicolumn{2}{|c|}{0.261} & \multicolumn{2}{|c|}{0.890} \\
\hline $\begin{array}{l}\text { Reject Ho at } \\
\text { confidence } \\
\text { level }\end{array}$ & \multicolumn{2}{|c|}{$99.9+\%$} & \multicolumn{2}{|c|}{$\begin{array}{c}\text { Cannot } \\
\text { Reject Ho }\end{array}$} & \multicolumn{2}{|c|}{$\begin{array}{c}\text { Cannot } \\
\text { Reject Ho }\end{array}$} & \multicolumn{2}{|c|}{$99.9+\%$} & \multicolumn{2}{|c|}{$<85.0 \%$} & \multicolumn{2}{|c|}{$\begin{array}{c}\text { Cannot } \\
\text { Reject Ho }\end{array}$} \\
\hline
\end{tabular}


Table C- 14. Statistical Comparison of GRMS Measure: Radial Tires vs. Regular Tires Upgrade Unit - Clockwise Laps - All Accelerometers - Longitudinal Direction

\begin{tabular}{|c|c|c|c|c|c|c|c|c|c|c|c|c|}
\hline \multirow{2}{*}{ Statistics } & \multicolumn{2}{|c|}{ Front Left } & \multicolumn{2}{|c|}{ Hitch } & \multicolumn{2}{|c|}{ Front Right } & \multicolumn{2}{|c|}{ Center } & \multicolumn{2}{|c|}{ Rear Left } & \multicolumn{2}{|c|}{ Rear Right } \\
\hline & Radial & Reg. & Radial & Reg. & Radial & Reg. & Radial & Reg. & Radial & Reg. & Radial & Reg. \\
\hline Obs. & 37 & 61 & 37 & 61 & 37 & 61 & 37 & 61 & 37 & 61 & 37 & 61 \\
\hline Min. & 0.02 & 0.02 & 0.05 & 0.06 & 0.02 & 0.02 & 0.02 & 0.02 & 0.03 & 0.03 & 0.02 & 0.02 \\
\hline Max. & 0.03 & 0.03 & 0.06 & 0.06 & 0.03 & 0.03 & 0.03 & 0.03 & 0.03 & 0.04 & 0.02 & 0.03 \\
\hline Mean & 0.02 & 0.03 & 0.06 & 0.06 & 0.02 & 0.03 & 0.02 & 0.02 & 0.03 & 0.03 & 0.02 & 0.02 \\
\hline Std. Dev. & 0.00 & 0.00 & 0.00 & 0.00 & 0.00 & 0.00 & 0.00 & 0.00 & 0.00 & 0.00 & 0.00 & 0.00 \\
\hline Delta Mean & \multicolumn{2}{|c|}{-0.001} & \multicolumn{2}{|c|}{-0.003} & \multicolumn{2}{|c|}{-0.002} & \multicolumn{2}{|c|}{0.001} & \multicolumn{2}{|c|}{-0.003} & \multicolumn{2}{|c|}{-0.002} \\
\hline Std. Dev. Diff. & \multicolumn{2}{|c|}{0.000} & \multicolumn{2}{|c|}{0.000} & \multicolumn{2}{|c|}{0.000} & \multicolumn{2}{|c|}{0.000} & \multicolumn{2}{|c|}{0.000} & \multicolumn{2}{|c|}{0.000} \\
\hline $\mathbf{Z}$ & \multicolumn{2}{|c|}{-7.446} & \multicolumn{2}{|c|}{-7.321} & \multicolumn{2}{|c|}{-12.219} & \multicolumn{2}{|c|}{2.698} & \multicolumn{2}{|c|}{-15.801} & \multicolumn{2}{|c|}{-7.219} \\
\hline P-value & \multicolumn{2}{|c|}{$4.8 \mathrm{E}-14$} & \multicolumn{2}{|c|}{$1.2 \mathrm{E}-13$} & \multicolumn{2}{|c|}{0.000} & \multicolumn{2}{|c|}{0.997} & \multicolumn{2}{|c|}{0.000} & \multicolumn{2}{|c|}{$2.6 \mathrm{E}-13$} \\
\hline $\begin{array}{l}\text { Reject Ho at } \\
\text { confidence } \\
\text { level }\end{array}$ & \multicolumn{2}{|c|}{$99.9+\%$} & \multicolumn{2}{|c|}{$99.9+\%$} & \multicolumn{2}{|c|}{$99.9+\%$} & \multicolumn{2}{|c|}{$\begin{array}{c}\text { Cannot } \\
\text { Reject Ho }\end{array}$} & \multicolumn{2}{|c|}{$99.9+\%$} & \multicolumn{2}{|c|}{$99.9+\%$} \\
\hline
\end{tabular}

Table C- 15. Statistical Comparison of GRMS Measure: Radial Tires vs. Regular Tires Upgrade Unit - Clockwise Laps - All Accelerometers - Lateral Direction

\begin{tabular}{|c|c|c|c|c|c|c|c|c|c|c|c|c|}
\hline \multirow{2}{*}{ Statistics } & \multicolumn{2}{|c|}{ Front Left } & \multicolumn{2}{|c|}{ Hitch } & \multicolumn{2}{|c|}{ Front Right } & \multicolumn{2}{|c|}{ Center } & \multicolumn{2}{|c|}{ Rear Left } & \multicolumn{2}{|c|}{ Rear Right } \\
\hline & Radial & Reg. & Radial & Reg. & Radial & Reg. & Radial & Reg. & Radial & Reg. & Radial & Reg. \\
\hline Obs. & 37 & 61 & 37 & 61 & 37 & 61 & 37 & 61 & 37 & 61 & 37 & 61 \\
\hline Min. & 0.03 & 0.03 & 0.08 & 0.09 & 0.03 & 0.03 & 0.02 & 0.03 & 0.03 & 0.03 & 0.03 & 0.03 \\
\hline Max. & 0.04 & 0.04 & 0.09 & 0.10 & 0.04 & 0.04 & 0.03 & 0.03 & 0.04 & 0.04 & 0.04 & 0.04 \\
\hline Mean & 0.03 & 0.04 & 0.09 & 0.10 & 0.03 & 0.04 & 0.03 & 0.03 & 0.04 & 0.04 & 0.03 & 0.04 \\
\hline Std. Dev. & 0.00 & 0.00 & 0.00 & 0.00 & 0.00 & 0.00 & 0.00 & 0.00 & 0.00 & 0.00 & 0.00 & 0.00 \\
\hline Delta Mean & \multicolumn{2}{|c|}{-0.002} & \multicolumn{2}{|c|}{-0.007} & \multicolumn{2}{|c|}{-0.002} & \multicolumn{2}{|c|}{-0.001} & \multicolumn{2}{|c|}{-0.004} & \multicolumn{2}{|c|}{-0.004} \\
\hline Std. Dev. Diff. & \multicolumn{2}{|c|}{0.000} & \multicolumn{2}{|c|}{0.000} & \multicolumn{2}{|c|}{0.000} & \multicolumn{2}{|c|}{0.000} & \multicolumn{2}{|c|}{0.000} & \multicolumn{2}{|c|}{0.000} \\
\hline $\mathbf{Z}$ & \multicolumn{2}{|c|}{-6.040} & \multicolumn{2}{|c|}{-14.215} & \multicolumn{2}{|c|}{-6.531} & \multicolumn{2}{|c|}{-2.948} & \multicolumn{2}{|c|}{-8.338} & \multicolumn{2}{|c|}{-8.312} \\
\hline P-value & \multicolumn{2}{|c|}{$7.7 \mathrm{E}-10$} & \multicolumn{2}{|c|}{0.000} & \multicolumn{2}{|c|}{$3.3 \mathrm{E}-11$} & \multicolumn{2}{|c|}{0.002} & \multicolumn{2}{|c|}{0.000} & \multicolumn{2}{|c|}{0.000} \\
\hline $\begin{array}{l}\text { Reject Ho at } \\
\text { confidence } \\
\text { level }\end{array}$ & \multicolumn{2}{|c|}{$99.9+\%$} & \multicolumn{2}{|c|}{$99.9+\%$} & \multicolumn{2}{|c|}{$99.9+\%$} & \multicolumn{2}{|c|}{$99.8 \%$} & \multicolumn{2}{|c|}{$99.9+\%$} & \multicolumn{2}{|c|}{$99.9+\%$} \\
\hline
\end{tabular}




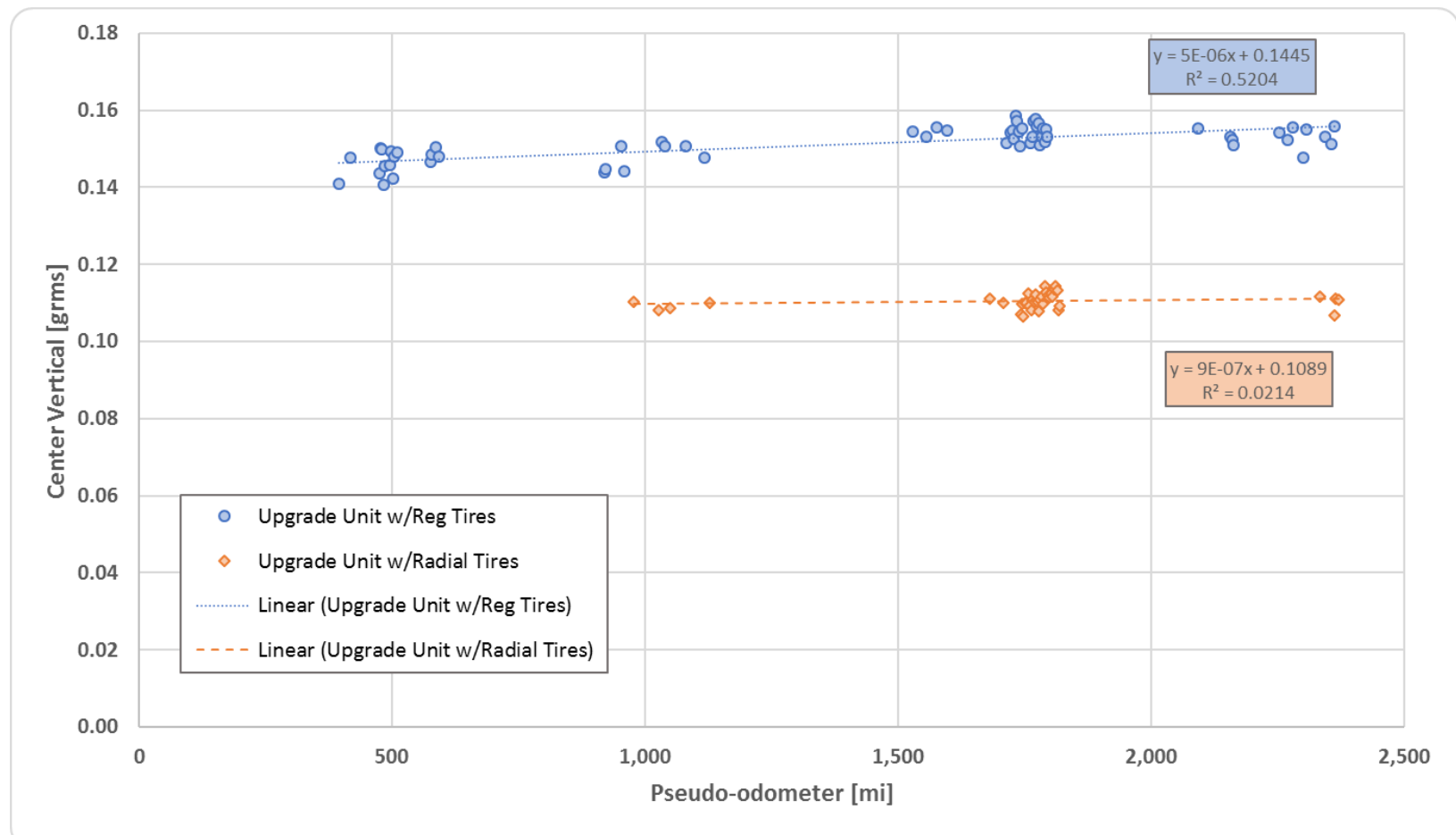

Figure C- 13 Part C2 - Upgrade Unit GRMS for Vertical Accelerometer at Axle Group (Center) Radial Tires vs. Regular Tires - Selected Clockwise Laps for Statistical Analysis.

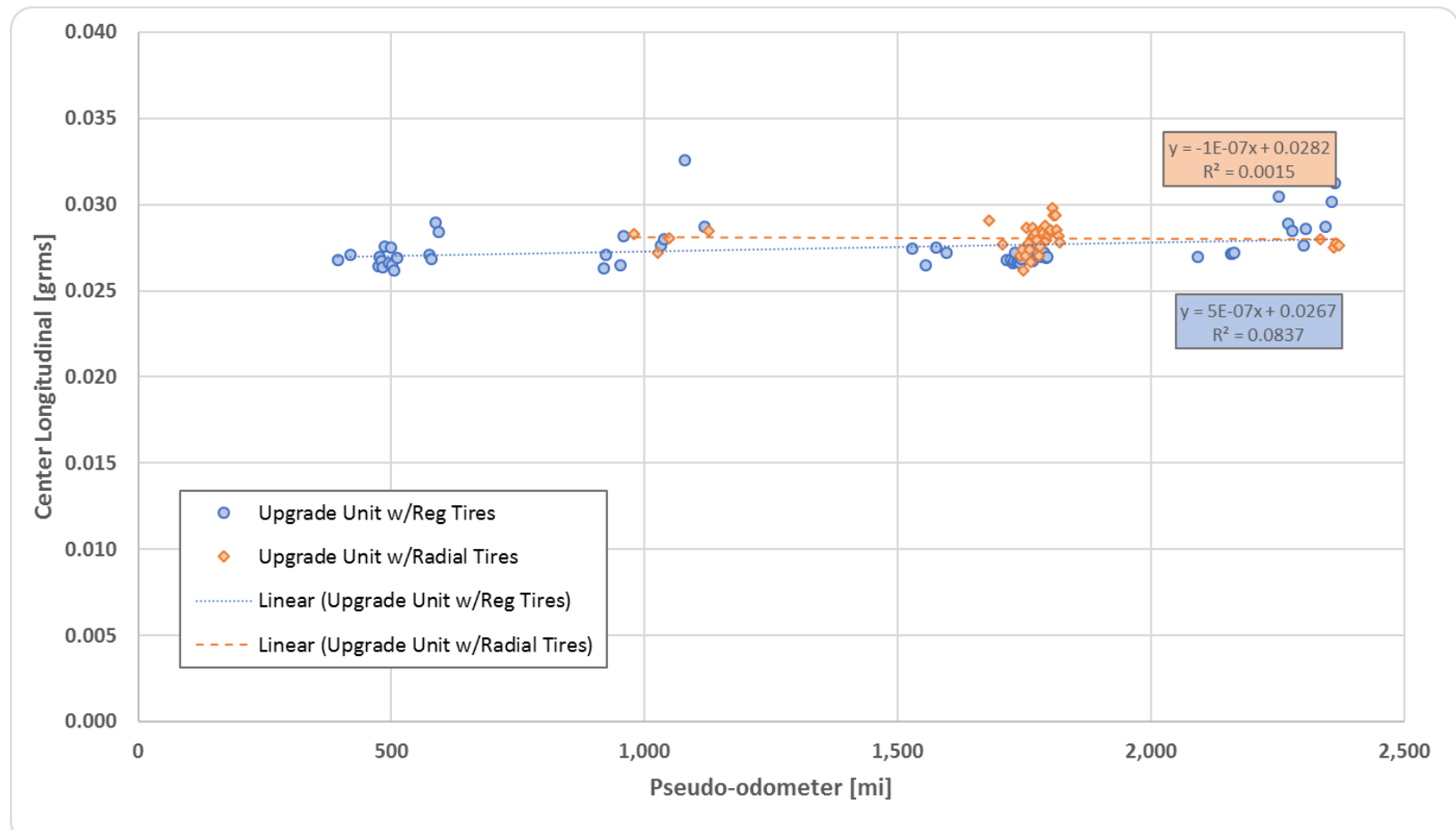

Figure C- 14 Part C2 - Upgrade Unit GRMS for Longitudinal Accelerometer at Axle Group (Center) Radial Tires vs. Regular Tires - Selected Clockwise Laps for Statistical Analysis. 


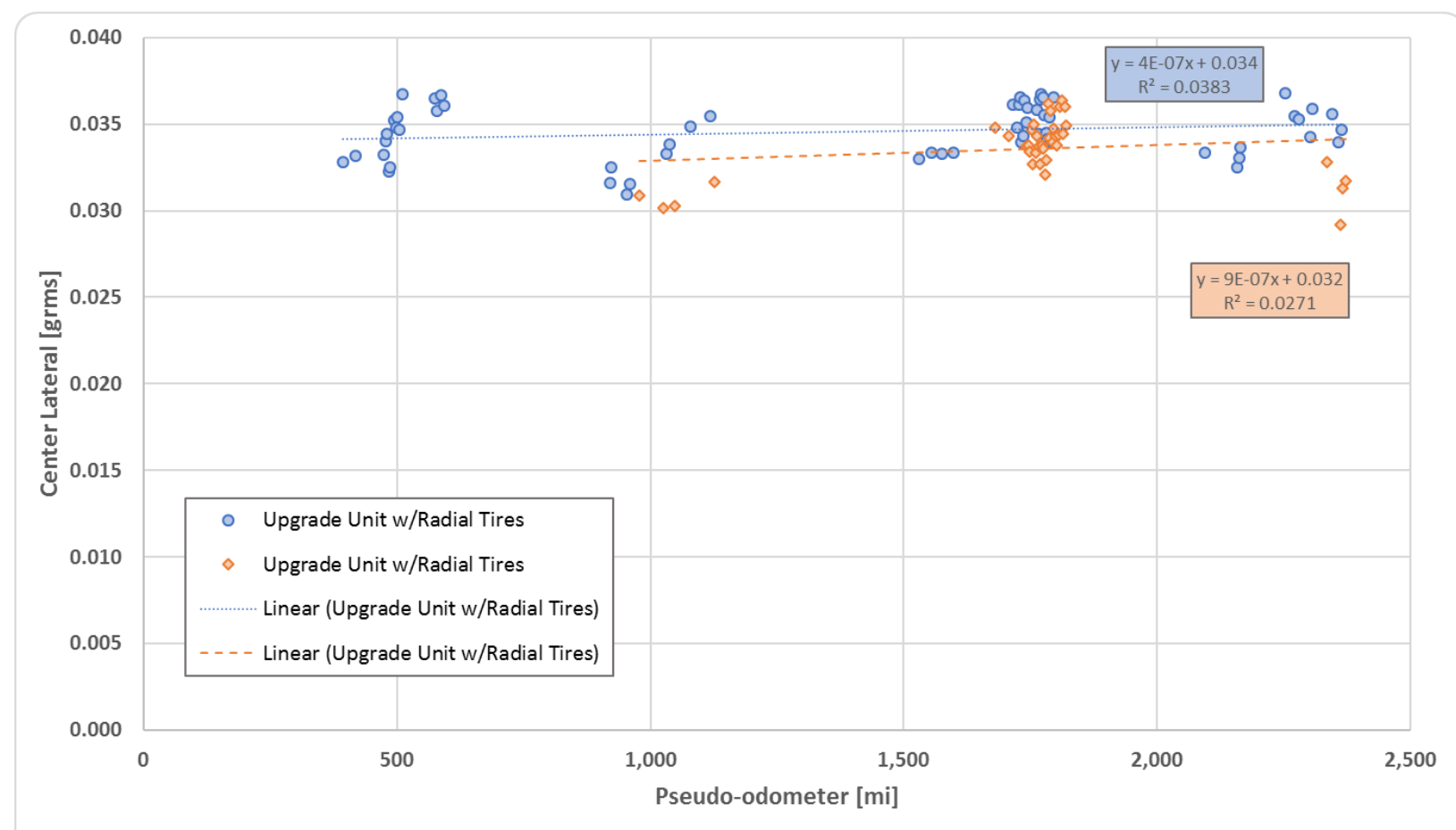

Figure C- 15 Part C2 - Upgrade Unit GRMS for Lateral Accelerometer at Axle Group (Center) Radial Tires vs. Regular Tires - Selected Clockwise Laps for Statistical Analysis.

Effect of Suspension on Vibrations: Radial Tires vs. Regular Tires - Counter-clockwise Laps Upgrade Unit

Table C- 16. Statistical Comparison of GRMS Measure: Radial Tires vs. Regular Tires Upgrade Unit - Counter-clockwise Laps - All Accelerometers - Vertical Direction

\begin{tabular}{|c|c|c|c|c|c|c|c|c|c|c|c|c|}
\hline \multirow{2}{*}{ Statistics } & \multicolumn{2}{|c|}{ Front Left } & \multicolumn{2}{|c|}{ Hitch } & \multicolumn{2}{|c|}{ Front Right } & \multicolumn{2}{|c|}{ Center } & \multicolumn{2}{|c|}{ Rear Left } & \multicolumn{2}{|c|}{ Rear Right } \\
\hline & Radial & Reg. & Radial & Reg. & Radial & Reg. & Radial & Reg. & Radial & Reg. & Radial & Reg. \\
\hline Obs. & 68 & 38 & 68 & 38 & 68 & 38 & 68 & 38 & 68 & 38 & 68 & 38 \\
\hline Min. & 0.057 & 0.061 & 0.098 & 0.100 & 0.069 & 0.067 & 0.101 & 0.146 & 0.033 & 0.074 & 0.069 & 0.070 \\
\hline Max. & 0.067 & 0.070 & 0.177 & 0.122 & 0.079 & 0.077 & 0.121 & 0.166 & 0.083 & 0.080 & 0.079 & 0.077 \\
\hline Mean & 0.061 & 0.065 & 0.107 & 0.110 & 0.073 & 0.072 & 0.110 & 0.154 & 0.069 & 0.077 & 0.073 & 0.073 \\
\hline Std. Dev. & 0.002 & 0.002 & 0.010 & 0.006 & 0.003 & 0.002 & 0.005 & 0.006 & 0.019 & 0.001 & 0.002 & 0.001 \\
\hline Delta Mean & \multicolumn{2}{|c|}{-0.004} & \multicolumn{2}{|c|}{-0.003} & \multicolumn{2}{|c|}{0.001} & \multicolumn{2}{|c|}{-0.044} & \multicolumn{2}{|c|}{-0.008} & \multicolumn{2}{|c|}{0.000} \\
\hline Std. Dev. Diff. & \multicolumn{2}{|c|}{0.000} & \multicolumn{2}{|c|}{0.002} & \multicolumn{2}{|c|}{0.001} & \multicolumn{2}{|c|}{0.001} & \multicolumn{2}{|c|}{0.002} & \multicolumn{2}{|c|}{0.000} \\
\hline $\mathbf{Z}$ & \multicolumn{2}{|c|}{-8.889} & \multicolumn{2}{|c|}{-1.706} & \multicolumn{2}{|c|}{1.969} & \multicolumn{2}{|c|}{-39.784} & \multicolumn{2}{|c|}{-3.401} & \multicolumn{2}{|c|}{-0.429} \\
\hline P-value & \multicolumn{2}{|c|}{0.000} & \multicolumn{2}{|c|}{0.044} & \multicolumn{2}{|c|}{0.976} & \multicolumn{2}{|c|}{0.000} & \multicolumn{2}{|c|}{0.000} & \multicolumn{2}{|c|}{0.334} \\
\hline $\begin{array}{l}\text { Reject Ho at } \\
\text { confidence level }\end{array}$ & \multicolumn{2}{|c|}{$99.9+\%$} & \multicolumn{2}{|c|}{$95.6 \%$} & \multicolumn{2}{|c|}{$\begin{array}{c}\text { Cannot Reject } \\
\text { Ho }\end{array}$} & \multicolumn{2}{|c|}{$99.9+\%$} & \multicolumn{2}{|c|}{$99.9+\%$} & \multicolumn{2}{|c|}{$<85.0 \%$} \\
\hline
\end{tabular}


Table C- 17. Statistical Comparison of GRMS Measure: Radial Tires vs. Regular Tires Upgrade Unit - Counter-clockwise Laps - All Accelerometers - Longitudinal Direction

\begin{tabular}{|c|c|c|c|c|c|c|c|c|c|c|c|c|}
\hline \multirow{2}{*}{ Statistics } & \multicolumn{2}{|c|}{ Front Left } & \multicolumn{2}{|c|}{ Hitch } & \multicolumn{2}{|c|}{ Front Right } & \multicolumn{2}{|c|}{ Center } & \multicolumn{2}{|c|}{ Rear Left } & \multicolumn{2}{|c|}{ Rear Right } \\
\hline & Radial & Reg. & Radial & Reg. & Radial & Reg. & Radial & Reg. & Radial & Reg. & Radial & Reg. \\
\hline Obs. & 68 & 38 & 68 & 38 & 68 & 38 & 68 & 38 & 68 & 38 & 68 & 38 \\
\hline Min. & 0.028 & 0.029 & 0.061 & 0.064 & 0.027 & 0.029 & 0.026 & 0.026 & 0.030 & 0.033 & 0.025 & 0.028 \\
\hline Max. & 0.032 & 0.033 & 0.074 & 0.076 & 0.031 & 0.034 & 0.032 & 0.031 & 0.035 & 0.038 & 0.030 & 0.033 \\
\hline Mean & 0.029 & 0.031 & 0.066 & 0.070 & 0.028 & 0.032 & 0.028 & 0.029 & 0.032 & 0.035 & 0.027 & 0.030 \\
\hline Std. Dev. & 0.001 & 0.001 & 0.003 & 0.003 & 0.001 & 0.001 & 0.001 & 0.001 & 0.001 & 0.001 & 0.001 & 0.001 \\
\hline Delta Mean & \multicolumn{2}{|c|}{-0.001} & \multicolumn{2}{|c|}{-0.004} & \multicolumn{2}{|c|}{-0.004} & \multicolumn{2}{|c|}{0.000} & \multicolumn{2}{|c|}{-0.003} & \multicolumn{2}{|c|}{-0.003} \\
\hline Std. Dev. Diff. & \multicolumn{2}{|c|}{0.000} & \multicolumn{2}{|c|}{0.001} & \multicolumn{2}{|c|}{0.000} & \multicolumn{2}{|c|}{0.000} & \multicolumn{2}{|c|}{0.000} & \multicolumn{2}{|c|}{0.000} \\
\hline $\mathbf{Z}$ & \multicolumn{2}{|c|}{-6.323} & \multicolumn{2}{|c|}{-6.477} & \multicolumn{2}{|c|}{-12.893} & \multicolumn{2}{|c|}{-0.620} & \multicolumn{2}{|c|}{-13.158} & \multicolumn{2}{|c|}{-11.192} \\
\hline P-value & \multicolumn{2}{|c|}{$1.3 \mathrm{E}-10$} & \multicolumn{2}{|c|}{$4.7 \mathrm{E}-11$} & \multicolumn{2}{|c|}{0.000} & \multicolumn{2}{|c|}{0.268} & \multicolumn{2}{|c|}{0.000} & \multicolumn{2}{|c|}{0.000} \\
\hline $\begin{array}{l}\text { Reject Ho at } \\
\text { confidence level }\end{array}$ & \multicolumn{2}{|c|}{$99.9+\%$} & \multicolumn{2}{|c|}{$99.9+\%$} & \multicolumn{2}{|c|}{$99.9+\%$} & \multicolumn{2}{|c|}{$<85.0 \%$} & \multicolumn{2}{|c|}{$99.9+\%$} & \multicolumn{2}{|c|}{$99.9+\%$} \\
\hline
\end{tabular}

Table C- 18. Statistical Comparison of GRMS Measure: Radial Tires vs. Regular Tires Upgrade Unit - Counter-clockwise Laps - All Accelerometers - Lateral Direction

\begin{tabular}{|c|c|c|c|c|c|c|c|c|c|c|c|c|}
\hline \multirow{2}{*}{ Statistics } & \multicolumn{2}{|c|}{\begin{tabular}{|l|} 
Front Left \\
\end{tabular}} & \multicolumn{2}{|c|}{ Hitch } & \multicolumn{2}{|c|}{ Front Right } & \multicolumn{2}{|c|}{ Center } & \multicolumn{2}{|c|}{ Rear Left } & \multicolumn{2}{|c|}{ Rear Right } \\
\hline & Radial & Reg. & Radial & Reg. & Radial & Reg. & Radial & Reg. & Radial & Reg. & Radial & Reg. \\
\hline Obs. & 68 & 38 & 68 & 38 & 68 & 38 & 68 & 38 & 68 & 38 & 68 & 38 \\
\hline Min. & 0.03 & 0.03 & 0.08 & 0.09 & 0.03 & 0.03 & 0.02 & 0.02 & 0.03 & 0.03 & 0.03 & 0.03 \\
\hline Max. & 0.04 & 0.04 & 0.11 & 0.11 & 0.04 & 0.04 & 0.03 & 0.03 & 0.04 & 0.04 & 0.04 & 0.04 \\
\hline Mean & 0.03 & 0.03 & 0.09 & 0.10 & 0.03 & 0.03 & 0.03 & 0.03 & 0.03 & 0.03 & 0.03 & 0.03 \\
\hline Std. Dev. & 0.00 & 0.00 & 0.00 & 0.00 & 0.00 & 0.00 & 0.00 & 0.00 & 0.00 & 0.00 & 0.00 & 0.00 \\
\hline Delta Mean & \multicolumn{2}{|r|}{-0.001} & \multicolumn{2}{|r|}{-0.006} & \multicolumn{2}{|r|}{-0.002} & \multicolumn{2}{|r|}{0.000} & \multicolumn{2}{|r|}{-0.001} & \multicolumn{2}{|r|}{-0.001} \\
\hline Std. Dev. Diff. & \multicolumn{2}{|r|}{0.000} & \multicolumn{2}{|r|}{0.001} & \multicolumn{2}{|r|}{0.000} & \multicolumn{2}{|r|}{0.000} & \multicolumn{2}{|r|}{0.000} & \multicolumn{2}{|r|}{0.000} \\
\hline $\mathbf{Z}$ & \multicolumn{2}{|r|}{-4.259} & \multicolumn{2}{|c|}{-5.795} & \multicolumn{2}{|r|}{-4.951} & \multicolumn{2}{|r|}{1.382} & \multicolumn{2}{|r|}{-3.125} & \multicolumn{2}{|r|}{-3.606} \\
\hline P-value & \multicolumn{2}{|c|}{$1.0 \mathrm{E}-05$} & \multicolumn{2}{|c|}{$3.4 \mathrm{E}-09$} & \multicolumn{2}{|c|}{$3.7 \mathrm{E}-07$} & \multicolumn{2}{|r|}{0.917} & \multicolumn{2}{|r|}{0.001} & \multicolumn{2}{|r|}{0.000} \\
\hline $\begin{array}{l}\text { Reject Ho at } \\
\text { confidence }\end{array}$ & \multicolumn{2}{|c|}{$99.9+\%$} & \multicolumn{2}{|c|}{$99.9+\%$} & \multicolumn{2}{|c|}{$99.9+\%$} & \multicolumn{2}{|c|}{$\begin{array}{c}\text { Cannot } \\
\text { Reject Ho }\end{array}$} & \multicolumn{2}{|r|}{$99.9 \%$} & \multicolumn{2}{|c|}{$99.9+\%$} \\
\hline
\end{tabular}




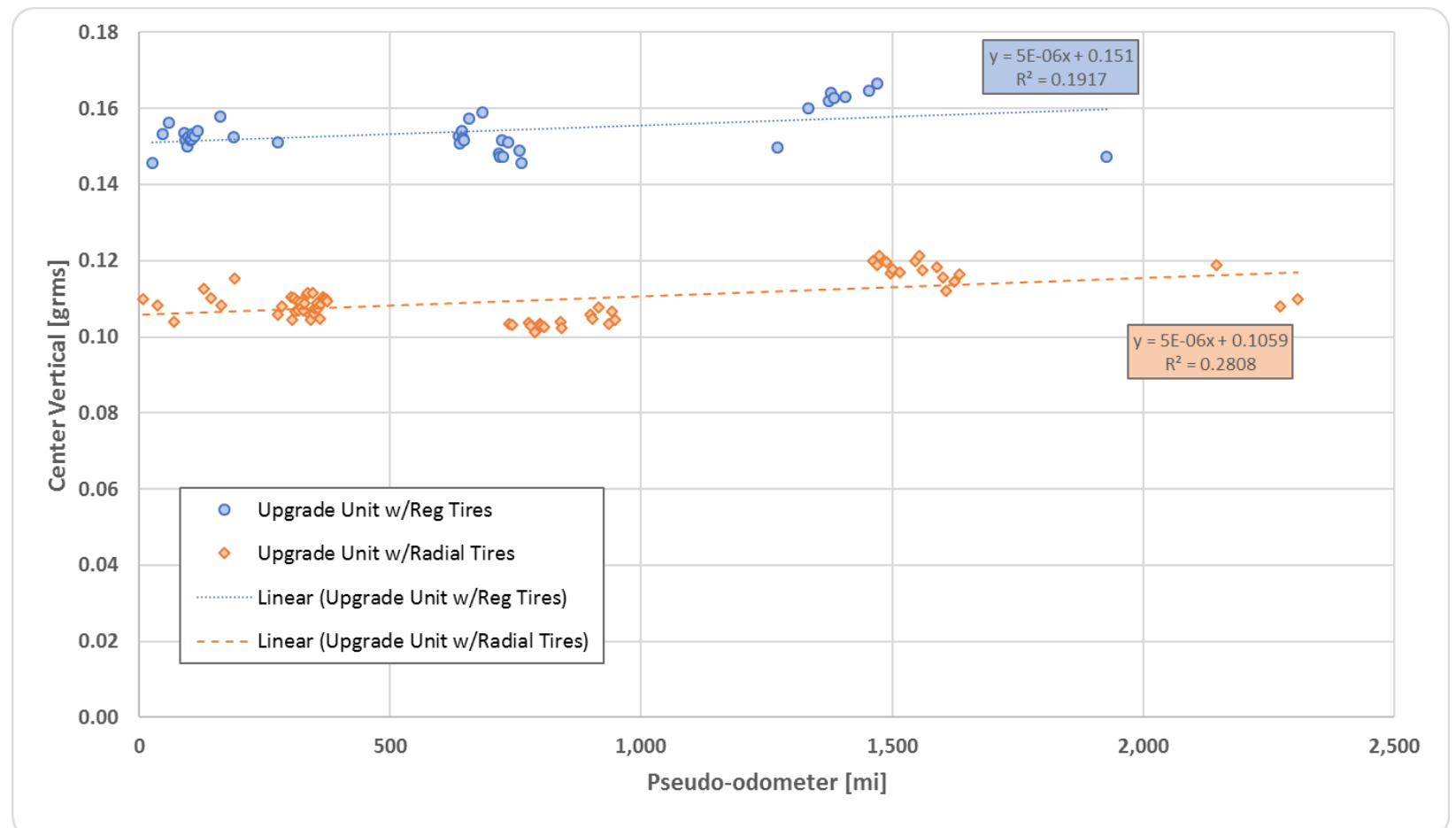

Figure C- 16 Part C2 - Upgrade Unit GRMS for Vertical Accelerometer at Axle Group (Center)

Radial Tires vs. Regular Tires - Selected Counter-clockwise Laps for Statistical Analysis.

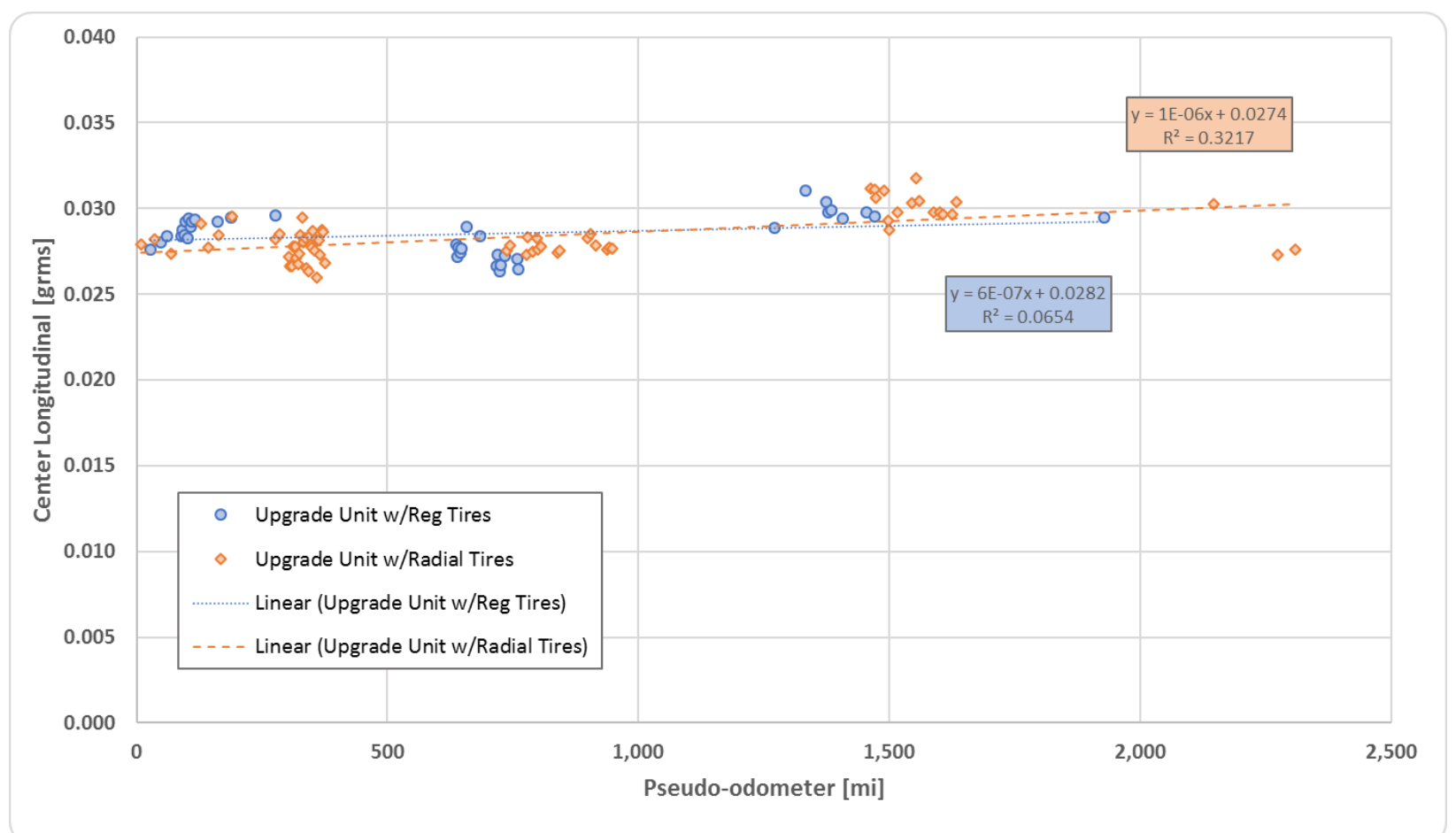

Figure C- 17 Part C2 - Upgrade Unit GRMS for Longitudinal Accelerometer at Axle Group (Center) Radial Tires vs. Regular Tires - Selected Counter-clockwise Laps for Statistical Analysis. 


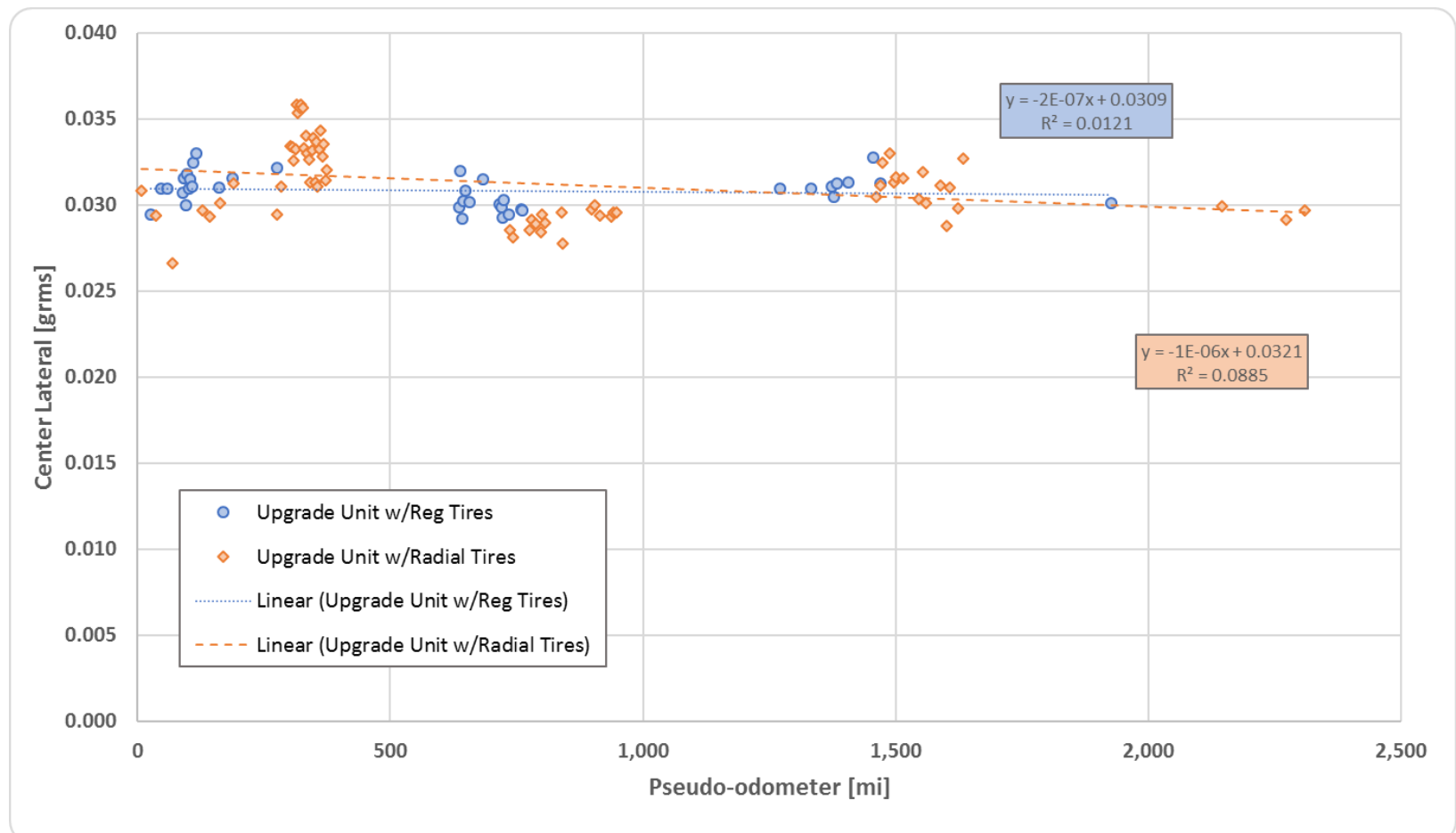

Figure C- 18 Part C2 - Upgrade Unit GRMS for Lateral Accelerometer at Axle Group (Center) Radial Tires vs. Regular Tires - Selected Counter-clockwise Laps for Statistical Analysis. 

APPENDIX D. BASELINE UNIT NPG INSPECTION REPORTS 



\section{APPENDIX D. BASELINE UNIT NPG INSPECTION REPORTS}

This Appendix presents the Baseline Unit inspections forms that were completed by the NPG test drivers at the end of each testing day during Part B, C1, and C2. Two different types of reports are included: 1) MHU Longevity Testing - Recurring Inspection, 2) MHU Longevity Testing - Record of Damage. The table below shows a summary of the results of the recurring inspections for each day of tasting. The numbers in the body of the table indicate the number of instances that the identified damage type was registered by the driver filling out the report. 
Table D- 1. Summary of Reported Damages during Part B, C1, and Part C2 - Baseline Unit.

\begin{tabular}{|c|c|c|c|c|c|c|c|c|c|c|c|c|c|}
\hline & \multicolumn{2}{|c|}{ Part B } & \multicolumn{2}{|c|}{$\begin{array}{c}\text { Part } \\
\text { C1 }\end{array}$} & \multicolumn{9}{|c|}{ Part C2 } \\
\hline & 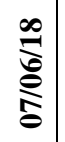 & $\underset{\stackrel{S}{S}}{\stackrel{\infty}{S}}$ & 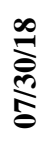 & $\stackrel{\infty}{\stackrel{\infty}{\rho}}$ & 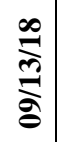 & $\frac{\stackrel{\infty}{\partial}}{\stackrel{\partial}{g}}$ & $\frac{\infty}{\stackrel{\infty}{\partial}}$ & $\frac{\infty}{\stackrel{\infty}{S}}$ & 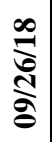 & $\underset{\stackrel{\infty}{N}}{\stackrel{\infty}{N}}$ & $\stackrel{\infty}{\stackrel{\infty}{\varrho}}$ & 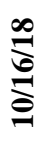 & $\stackrel{\infty}{\stackrel{\infty}{\sigma}}$ \\
\hline CHASSIS & $\mathbf{0}$ & $\mathbf{0}$ & 1 & 1 & $\mathbf{0}$ & $\mathbf{0}$ & 1 & 2 & 1 & 1 & 4 & 2 & 3 \\
\hline Main beams - buckled, bent, twists & & & & & & & & & & & & & 1 \\
\hline Outriggers - buckled, bent, twists & & & & & & & & 1 & & & & & \\
\hline \multicolumn{14}{|l|}{ Cross members - buckled, bent, twists } \\
\hline \multicolumn{14}{|l|}{ Hitch/coupler damage } \\
\hline Axle, spring, spring hanger, wheel damage & & & 1 & 1 & & & 1 & 1 & 1 & 1 & 4 & 2 & 1 \\
\hline Welds/connections - cracks, breaks, damage & & & & & & & & & & & & & 1 \\
\hline \multicolumn{14}{|l|}{ Damage to exposed gas, waterlines, drain-lines or supports } \\
\hline FLOOR SYSTEMS & 0 & ( & $\mathbf{0}$ & $\mathbf{0}$ & $\mathbf{0}$ & 0 & $\mathbf{0}$ & 2 & ( & 2 & $\mathbf{0}$ & $\mathbf{0}$ & $\mathbf{0}$ \\
\hline Damage, separations, loosening of lags from chassis to floor & & & & & & & & 1 & & 1 & & & \\
\hline \multicolumn{14}{|l|}{ Buckled floor, damaged decking/floor coverings, opening of joints, loose for popped feathers } \\
\hline Damage to bottom board, patches, loose fasteners & & & & & & & & 1 & & 1 & & & \\
\hline EXTERIOR/INTERIOR/MARRIAGE WALLS & 3 & $\mathbf{0}$ & 1 & 1 & 4 & 0 & 2 & $\mathbf{0}$ & 8 & $\mathbf{0}$ & $\mathbf{0}$ & 1 & 1 \\
\hline Interior wall panels - buckled, cracked, bowed, separations, fasteners popped or loose & & & 1 & & 2 & & 1 & & 2 & & & & \\
\hline Separation of walls at floor, ceiling, column supports, window and door openings & & & & & & & & & 2 & & & & \\
\hline Exterior siding and trim - buckled, cracked, bowed, separations, fasteners popped or loose & 1 & & & 1 & & & & & 2 & & & & 1 \\
\hline Windows and doors - damaged, buckled, bowed, or parts missing & 1 & & & & & & & & & & & 1 & \\
\hline Windows and doors - operate properly & 1 & & & & & & & & & & & & \\
\hline Damage to caulking and sealants & & & & & 2 & & 1 & & 2 & & & & \\
\hline ROOF/CEILINGS & 2 & $\mathbf{0}$ & $\mathbf{0}$ & $\mathbf{0}$ & 1 & $\mathbf{0}$ & $\mathbf{0}$ & $\mathbf{0}$ & $\mathbf{0}$ & $\mathbf{0}$ & $\mathbf{0}$ & $\mathbf{0}$ & $\mathbf{0}$ \\
\hline Roofing - buckled, cracked, bowed, splits, openings, loose or popped fasteners & & & & & 1 & & & & & & & & \\
\hline Damage to roof penetrations - vents, roof jacks, skylights, caulking and sealants & 2 & & & & & & & & & & & & \\
\hline \multicolumn{14}{|l|}{ Damage to eaves, overhangs, transitions } \\
\hline \multicolumn{14}{|l|}{ Ceilings - buckled, cracked, bowed, sagging, separations, loose or popped fasteners } \\
\hline PLUMBING & (0) & $\mathbf{0}$ & $\mathbf{0}$ & $\mathbf{0}$ & (0) & $\mathbf{0}$ & $\mathbf{0}$ & O & $\mathbf{0}$ & 0 & $\mathbf{0}$ & $\mathbf{0}$ & $\mathbf{0}$ \\
\hline \multicolumn{14}{|l|}{ Damage to fixtures, piping, fittings, connections and supports } \\
\hline MODIFIED COMPONENTS FOR TESTING & $\mathbf{0}$ & $\mathbf{0}$ & 2 & 4 & $\mathbf{0}$ & 5 & 3 & 3 & 8 & 10 & 9 & 2 & 4 \\
\hline Axles and suspension & & & 1 & 1 & & 1 & 3 & 1 & 1 & 1 & 2 & & 1 \\
\hline Wheels and tires & & & 1 & 3 & & 4 & & 2 & 7 & 9 & 7 & 2 & 3 \\
\hline
\end{tabular}




\section{Attachment 3: MHU Longevity Testing - Recurring Inspection}

MHU

Baseline

Q-Upgraded
Mileage of Power Unit: 82996

Miles into testing (multiple of 500): 600

\section{A. CHASSIS}

1. Main beams - buckled, bent, twists

2. Outriggers - buckled, bent, twists

3. Cross members - buckled, bent, twists

4. Hitch/coupler damage

5. Axle, spring, spring hanger, wheel damage

6. Welds/connections - cracks, breaks, damage

7. Damage to exposed gas, waterlines, drain-lines or supports

\section{B. FLOOR SYSTEMS}

1. Damage, separations, loosening of lags from chassis to floor

2 Buckled floor, damaged decking/floor coverings, opening of joints loose for popped feathers

3. Damage to bottom board, patches, loose fasteners

\section{EXTERIOR/INTERIOR/MARRIAGE WALLS}

1. Interior wall panels - buckled, cracked, bowed, separations, fasteners popped or loose

2. Separation of walls at floor, ceilıng, column supports, window and door openıngs

3. Exterior siding and trim - buckled, cracked, bowed, separations, fasteners popped or loose

4. Windows and doors - damaged, buckled, bowed, or parts missing

5. Windows and doors - operate properly

6. Damage to caulking and sealants

\section{ROOF/CEILINGS}

1 Roofing buckled, cracked, bowed, splits, openings, loose or popped fasteners

2 Damage to roof penetratıons vents, roof jacks, skylights, caulkıng and sealants

3 Damage to eaves, overhangs, transitions

4. Ceilings - buckled, cracked, bowed, sagging, separat ons, loose or popped fasteners

\section{E. PLUMBING}

Damage to fixtures, piping, fittings, connectıons and suppo $s$

\section{E. MODIFIED COMPONENTS FOR TESTING}

1 Axles and suspension

2 Whee and tir

Damaged?

Yes No
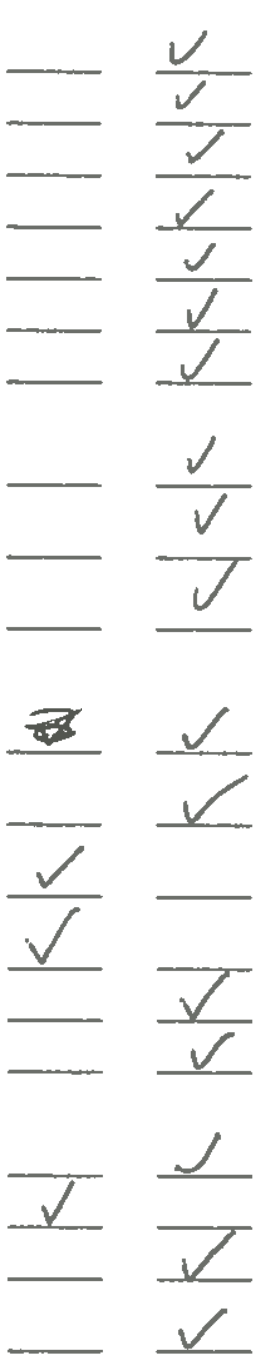
Attachment 3, Continued

MHU Longevity Testing - Recurring Inspection, p.2

Mileage of Power Unit: 82996

Testing miles (multiple of 500): 608

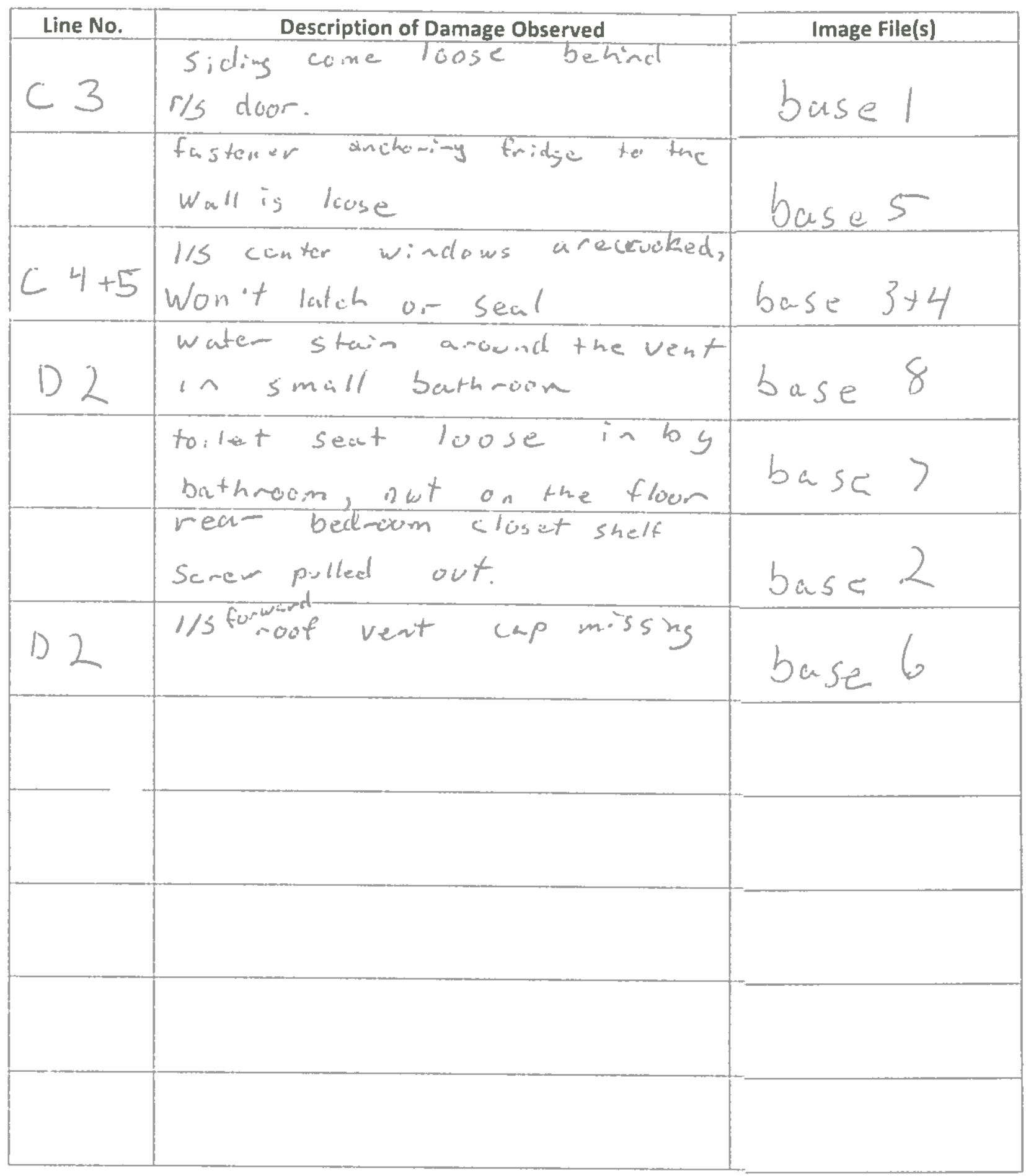

D-6 


\section{Attachment 3: MHU Longevity Testing - Recurring Inspection}

MHU

Baseline
Mileage of Power Unit: 83499

Miles into testing (multiple of 500 ): 1100

\section{A. CHASSIS}

Damaged?

1. Main beams - buckled, bent, twists

2. Outriggers - buckled, bent, twists

3. Cross members - buckled, bent, twists

4. Hitch/coupler damage

5. Axle, spring, spring hanger, wheel damage

6. Welds/connections - cracks, breaks, damage

7. Damage to exposed gas, waterlines, drain-lines or supports

B. FLOOR SYSTEMS

1. Damage, separations, loosening of lags from chassis to floor

2. Buckled floor, damaged decking/floor coverings, opening of joints, loose for popped feathers

3. Damage to bottom board, patches, loose fasteners

C. EXTERIOR/INTERIOR/MARRIAGE WALLS

1. Interior wall panels - buckled, cracked, bowed, separations, fasteners popped or loose

2. Separation of walls at floor, ceiling, column supports, window and door openings

3. Exterior siding and trim - buckled, cracked, bowed, separations, fasteners popped or loose

4. Windows and doors - damaged, buckled, bowed, or parts missing

5. Windows and doors - operate properly

6. Damage to caulking and sealants

D. ROOF/CEILINGS

1. Roofing - buckled, cracked, bowed, splits, openings, loose or popped fasteners

2. Damage to roof penetrations - vents, roof jacks, skylights, caulking and sealants

3. Damage to eaves, overhangs, transitions

4. Ceilings - buckled, cracked, bowed, sagging, separations, loose or popped fasteners

E. PLUMBING

Damage to fixtures, piping, fittings, connections and supports

E. MODIFIED COMPONENTS FOR TESTING

1. Axles and suspension

2. Wheels and tires

Yes

No
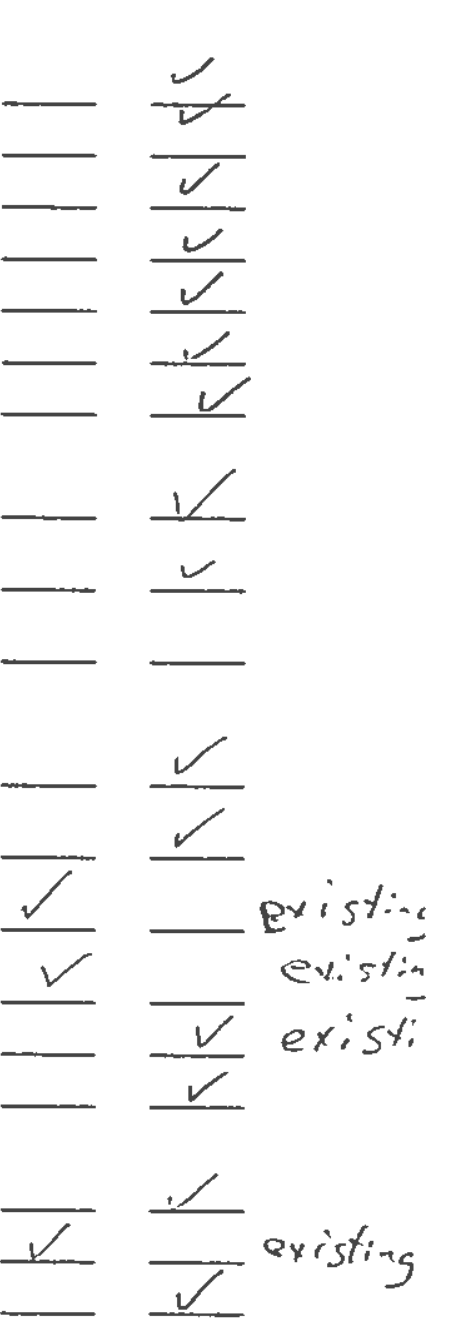
Attachment 3, Continued

MHU Longevity Testing - Recurring Inspection, p.2

MHU

Q Baseline

$\square$ Upgraded
Mileage of Power Unit: 83499

Testing miles (multiple of 500): $1 / 00$

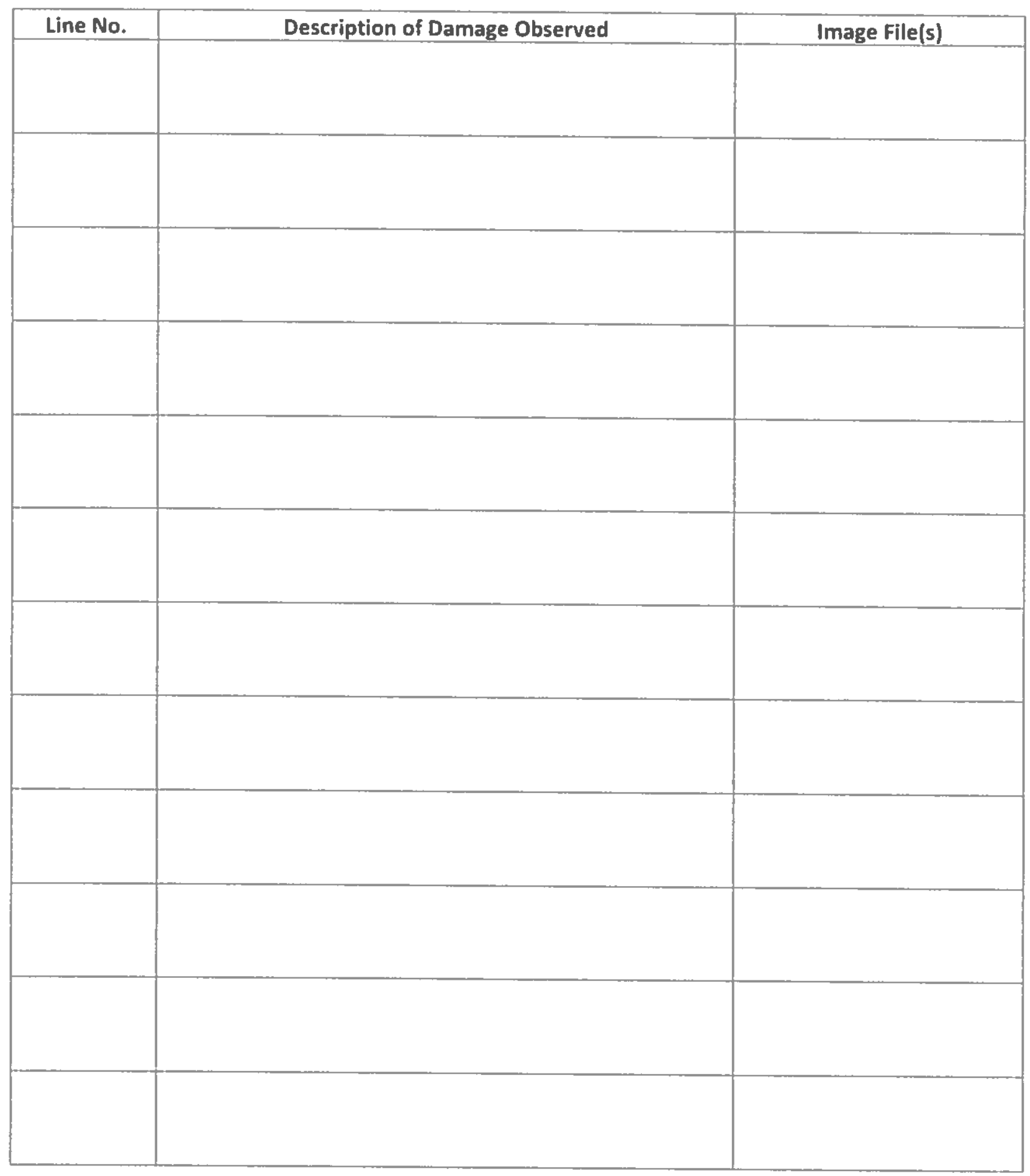




\section{Attachment 3: MHU Longevity Testing Recurring Inspection}

MHU

Baseline

Upgraded
Mileage of Power Unit 840

Miles into testing (multıple of 500) $/ 677$

\section{A. CHASSIS}

Damaged?

Yes

No

1 Main beams buckled, bent twists

2. Outriggers - buckled, bent, twists

3. Cross members - buckled, bent, twists

4 Hitch/coupler damage

5. Axle spring, spring hanger wheel damage

6 Welds/connections cracks, breaks damage

7. Damage to exposed gas, waterlines, drain-lines or supports

B. FLOOR SYSTEMS

1 Damage, separations, loosening of lags from chassis to floor

2. Bu kled floor, damaged decking/floor coverings, open'ng o joints, loose or popped feathers

3. Damage to bottom board, patches, loose fasteners

C. EXTERIOR/INTERIOR/MARRIAGE WALLS

1. Interior wall panels - buckled, cracked, bowed, separations, fasteners popped or loose

2. Separation of walls at floor, ceiling, column supports, window and door openıngs

3. Exterior siding and trim - buckled, cracked, bowed, separations, fasteners popped or loose

4. Windows and doors - damaged, buckled, bowed, or parts missing

5. Windows and doors - operate properly

6. Damage to caulking and sealants

D. ROOF/CEILINGS

1. Roofing - buckled, cracked, bowed, splits, openings, loose or popped fasteners

2. Damage to roof penetrations - vents, roof jacks, skylights, caulking and sealants

3. Damage to eaves, overhangs, transitions

4. Ceilings - buckled, cracked, bowed, sagging, separations, loose or popped fasteners

E. PLUMBING

Damage to fixtures, piping, fittings, connections and supports

E. MODIFIED COMPONENTS FOR TESTING

1. Axles and suspension

2 Wheels and tires

D-9 


$$
7-30-18
$$

Attachment 3, Continued

MHU Longevity Testing - Recurring Inspection, p.2

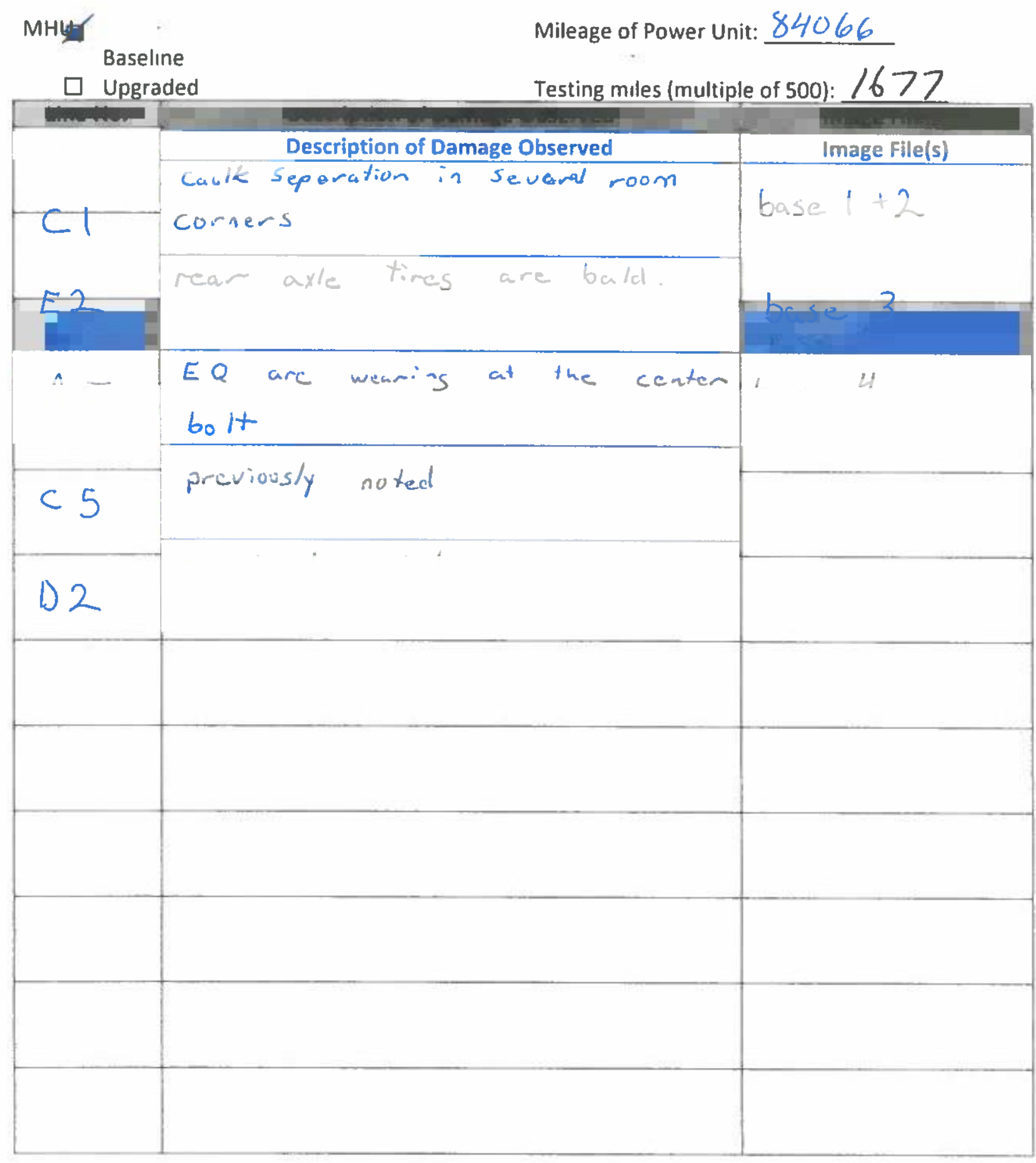


Attachment 3, Continued

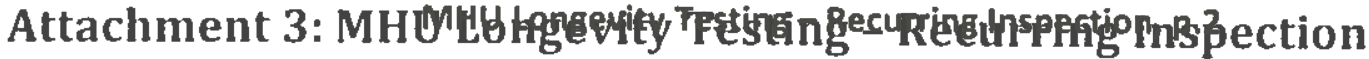

MHU

Baseline

Opgradeg

Mileage of power Unit: 894665

Tresting miles (multiple of 500 )

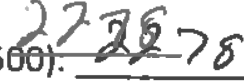

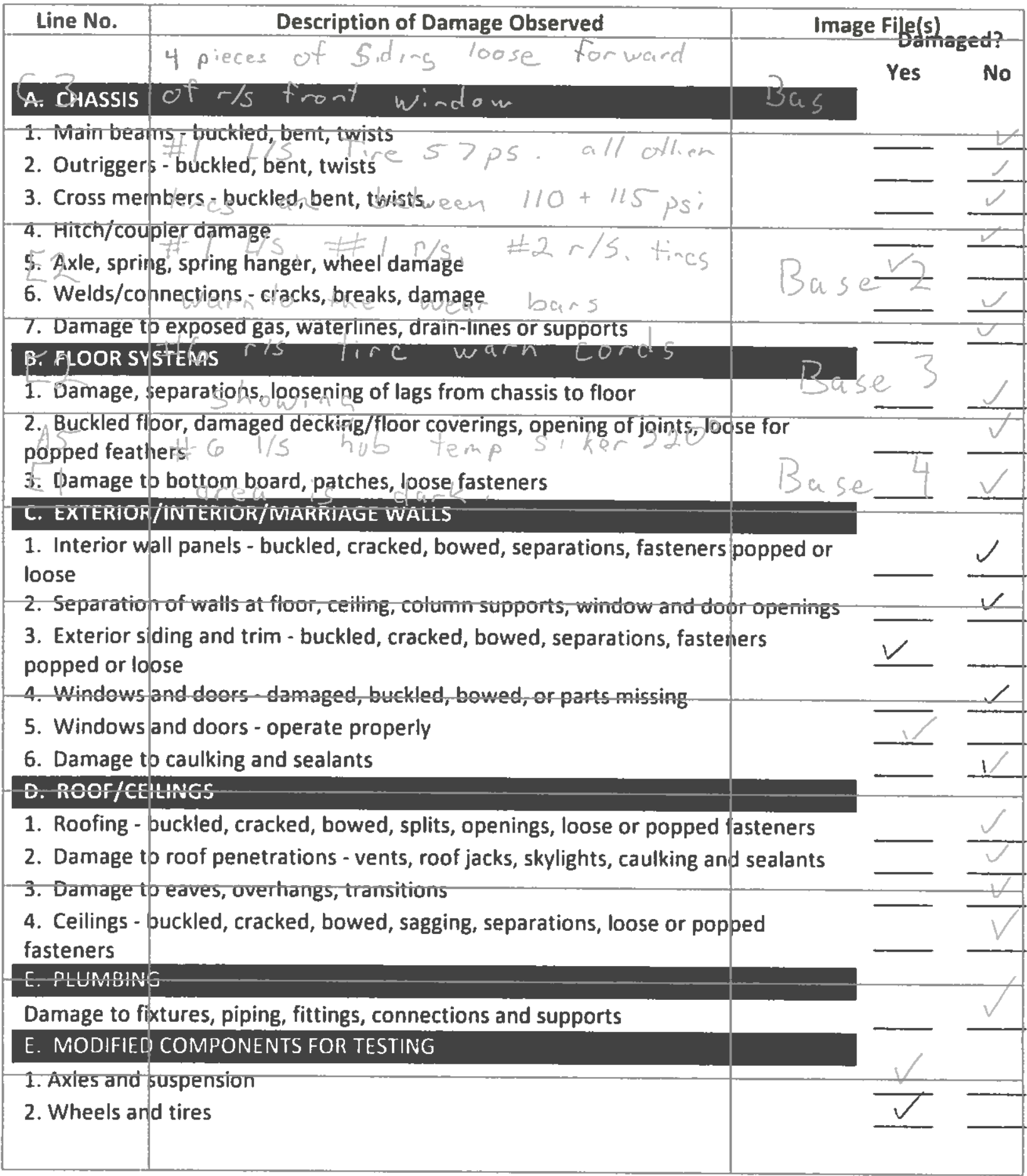




\section{$9-13-18$}

\section{Attachment 3: MHU Longevity Testing - Recurring Inspection}

\author{
MHU \\ B Baseline \\ Upgraded
}

Mileage of Power Unit: 85429

Miles into testing (multiple of 500):

Damaged?

\section{A. CHASSIS}

1. Main beams - buckled, bent, twists

2. Outriggers - buckled, bent, twists

3. Cross members - buckled, bent, twists

4. Hitch/coupler damage

5. Axle, spring, spring hanger, wheel damage

6. Welds/connections - cracks, breaks, damage

7. Damage to exposed gas, waterlines, drain-lines or supports

\section{B. FLOOR SYSTEMS}

1. Damage, separations, loosening of lags from chassis to floor

2. Buckled floor, damaged decking/floor coverings, opening of joints, loose for popped feathers

3. Damage to bottom board, patches, loose fasteners

C. EXTERIOR/INTERIOR/MARRIAGE WALLS

1. Interior wall panels - buckled, cracked, bowed, separations, fasteners popped or loose

2. Separation of walls at floor, ceiling, column supports, window and door openings

3. Exterior siding and trim - buckled, cracked, bowed, separations, fasteners popped or loose

4. Windows and doors - damaged, buckled, bowed, or parts missing

5. Windows and doors - operate properly

6. Damage to caulking and sealants

D. ROOF/CEILINGS

1. Roofing - buckled, cracked, bowed, splits, openings, loose or popped fasteners

2. Damage to roof penetrations - vents, roof jacks, skylights, caulking and sealants

3. Damage to eaves, overhangs, transitions

4. Ceilings - buckled, cracked, bowed, sagging, separations, loose or popped fasteners

\section{E. PLUMBING}

Damage to fixtures, piping, fittings, connections and supports

E. MODIFIED COMPONENTS FOR TESTING

1. Axles and suspension

2. Wheels and tires

\section{Yes}

No
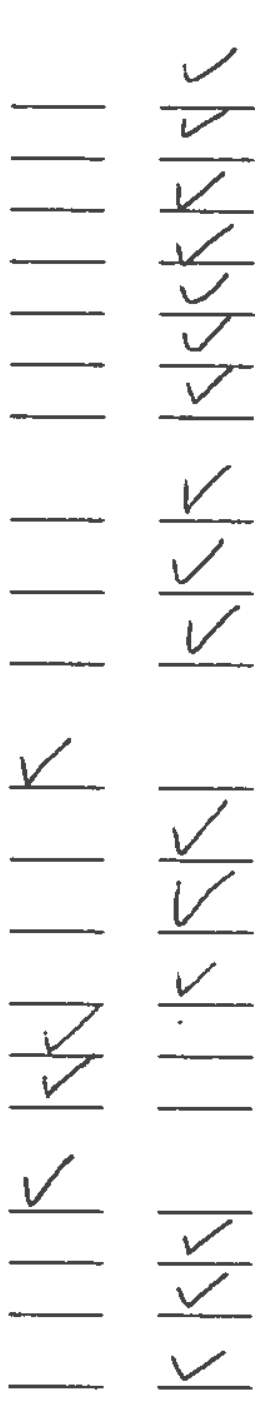
Attachment 3, Continued

$$
9-13-18
$$

MHU Longevity Testing - Recurring Inspection, p.2

MHO

Baseline

Upgraded
Mileage of Power Unit: $85-424$

Testing miles (multiple of 500):

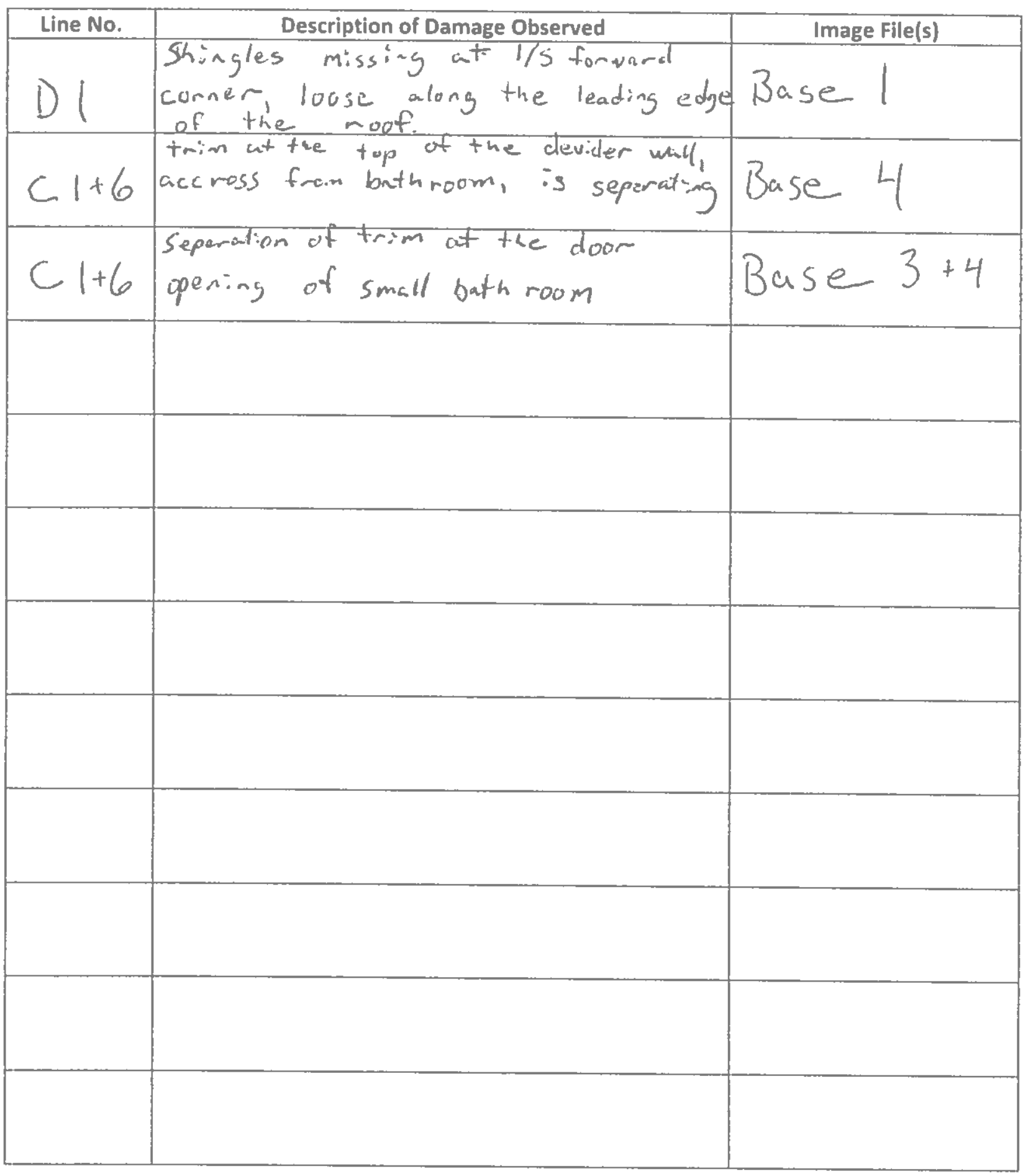

23

D-13 


\section{Attachment 3: MHU Longevity Testing-Recurring Inspection $9-14-18$}

MHU

Baseline
$\square$ Upgraded
Mileage of Power Unit: $8605-1$

Miles into testing (multiple of 500):

\section{A. CHASSIS}

1. Main beams - buckled, bent, twists

2. Outriggers - buckled, bent, twists

3. Cross members buckled, bent, twists

4. Hitch/coupler damage

5. Axle, spring, spring hanger, wheel damage

6. Welds/connections cracks, breaks, damage

7. Damage to exposed gas, waterlınes, drain-lines or supports

\section{B. FLOOR SYSTEMS}

1. Damage, separations, loosening of lags from chassis to floor

2 Buckled floor, damaged decking/floor coverings, opening of joints, loose for popped feathers

3. Damage to bottom board, patches, loose fasteners

C. EXTERIOR/INTERIOR/MARRIAGE WALLS

1. Interior wall panels - buckled, cracked, bowed, separations, fasteners popped or loose

2. Separation of walls at floor, ceiling, column supports, window and door openings

3. Exterior siding and trim - buckled, cracked, bowed, separations, fasteners popped or loose

4. Windows and doors - damaged, buckled, bowed, or parts missing

5. Windows and doors - operate properly

6. Damage to caulking and sealants

D. ROOF/CEILINGS

1. Roofing - buckled, cracked, bowed, splits, openings, loose or popped fasteners

2. Damage to roof penetrations - vents, roof jacks, skylights, caulking and sealants

3. Damage to eaves, overhangs, transitions

4. Ceilings - buckled, cracked, bowed, sagging, separations, loose or popped fasteners

\section{E. PLUMBING}

Damage to fixtures, piping, fittings, connections and supports

E. MODIFIED COMPONENTS FOR TESTING

1 Axles and suspension

2 Wheels and tires

Damaged?

Yes No
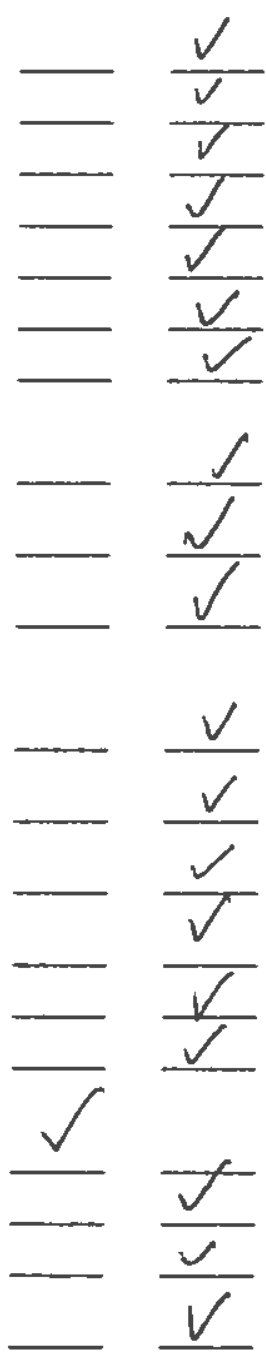
Attachment 3, Continued

$$
9-14-18
$$

MHU Longevity Testing - Recurring Inspection, p.2

MHO

baseline

Upgraded
Mileage of Power Unit: 86051

Testing miles (multiple of 500):

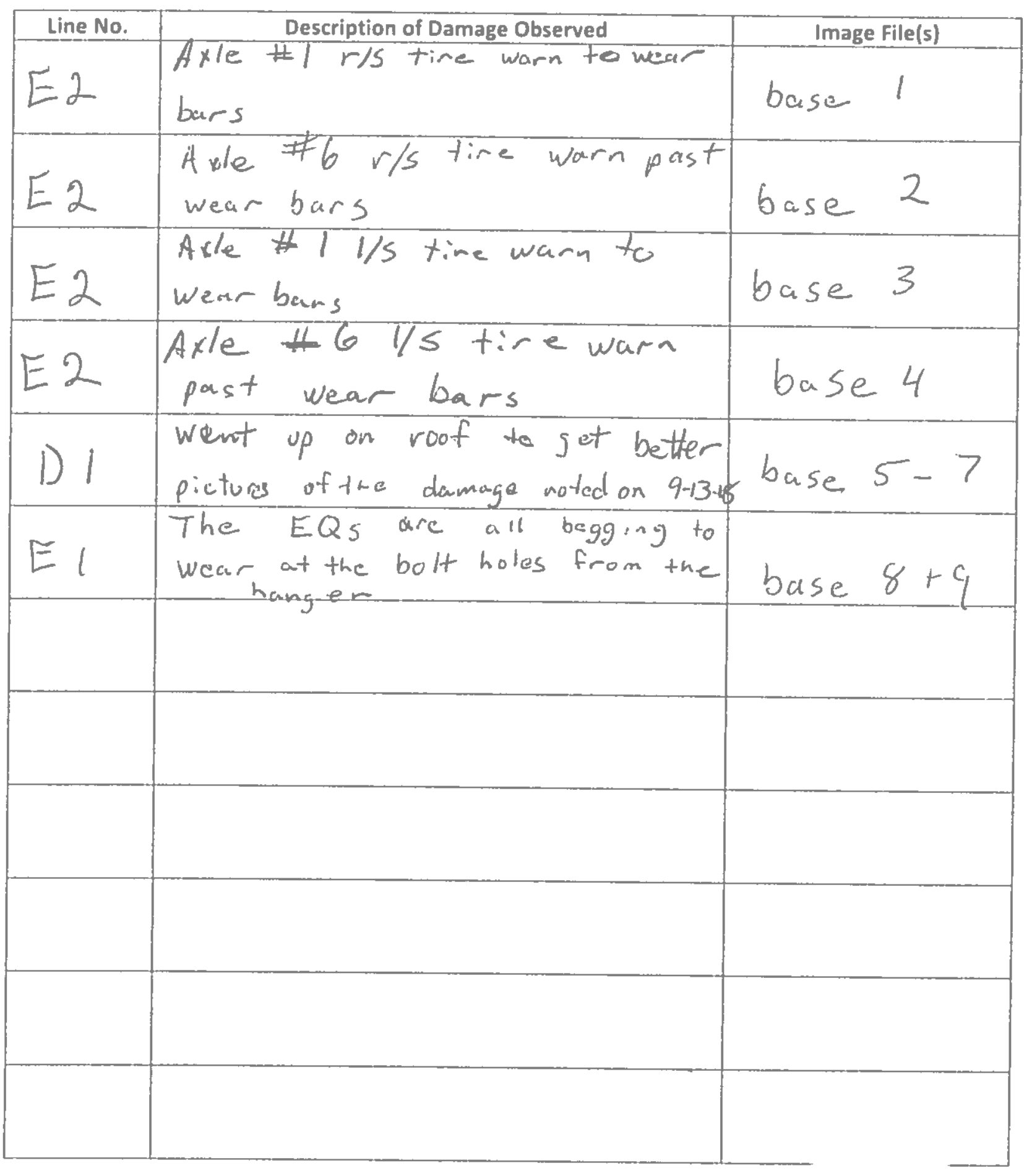

23

D-15 


\section{Attachment 3: MHU Longevity Testing - Recurring Inspection}

MHU

$\square$ Baseline

$\square$ Upgraded
Mileage of Power Unit: 86605

Miles into testing (multiple of 500):
Damaged?

Yes No

A. CHASSIS

1. Main beams - buckled, bent, twists

2. Outriggers - buckled, bent, twists

3. Cross members - buckled, bent, twists

4. Hitch/coupler damage

5. Axle, spring, spring hanger, wheel damage

6. Welds/connections - cracks, breaks, damage

7. Damage to exposed gas, waterlines, drain-lines or supports

\section{B. FLOOR SYSTEMS}

1. Damage, separations, loosening of lags from chassis to floor

2 Buckled floor, damaged decking/floor coverings, opening of joints, loose for popped feathers

3 Damage to bottom board, patches, oose fasteners

\section{EXTERIOR/INTERIOR/MARRIAGE WALLS}

1 Interior wa pane s buckled, cracked, bowed, separations, fasteners poppe or loose

2 Separation of walls at floor ceilıng column supports, w ndow and door openıngs

3 xterıor sıdıng and trım buckled cracked, bowed, separations, fasteners popped or loose

. Windows and doors damaged buckled, bowed, or parts $m$ ssing

5. Windows and doors - operate properly

6. Damage to caulking and sealants

D. ROOF/CEILINGS

1. Roofing buckled, cracked, bowed, splits, openings, loose or popped fasteners

2. Damage to roof penetrations - vents, roof jacks, skylights, caulking and sealants

3 Damage to eaves, overhangs, transitions

4. Ceilings - buckled, cracked, bowed, sagging, separatıons, loose or popped fasteners

E. PLUMBING

Damage to fixtures, piping, fittings, connections and supports

E. MODIFIED COMPONENTS FOR TESTING

1. Axles and suspension

2. Wheels and tires

If "Yes" column is checked for any item, please take one or more pictures and detall on reverse.
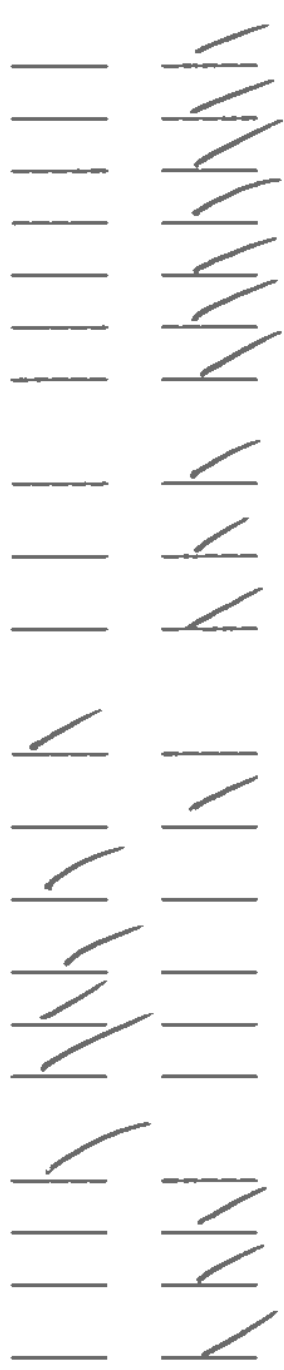

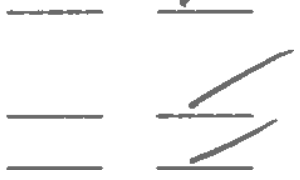




\section{Attachment 3: MHU Longevity Testing - Recurring Inspection

MHU

$\otimes$ Baseline
$\square$ Upgraded
Mileage of Power Unit: 83219

Miles into testing (multiple of 500):

\section{A. CHASSIS}

1 Main beams buckled, bent, twists

2. Outriggers - buckled, bent, twists

3. Cross members - buckled, bent, twists

4 Hitch/coupler damage

5 Axle, spring, spring hanger, wheel damage

6. Welds/connections - cracks, breaks, damage

7. Damage to exposed gas, waterlines, drain-lines or supports

\section{FLOOR SYSTEMS}

1. Damage, separations, loosening of lags from chassis to floor

2 Buckled floor, damaged deckıng/floor coverings, openıng of joints, loose for popped feathers

3. Damage to bottom board, patches, loose fasteners

\section{EXTERIOR/INTERIOR/MARRIAGE WALLS}

1. Interior wall panels - buckled, cracked, bowed, separations, fasteners popped or loose

2. Separation of walls at floor, ceiling, column supports, window and door openings

3. Exterior siding and trim - buckled, cracked, bowed, separations, fasteners popped or loose

4. Windows and doors - damaged, buckled, bowed, or parts missing

5. Windows and doors - operate properly

6. Damage to caulking and sealants

\section{ROOF/CEILINGS}

1. Roofing - buckled, cracked, bowed, splits, openings, loose or popped fasteners

2. Damage to roof penetrations vents, roof jacks, skylights, caulking and sealants

3. Damage to eaves, overhangs, transitions

4. Ceilings - buckled, cracked, bowed, sagging, separations, loose or popped fasteners

E. PLUMBING

Damage to fixtures, piping, fittings, connections and supports

E. MODIFIED COMPONENTS FOR TESTING

1. Axles and suspension

2 Wheels and tires

Damaged?

Yes No
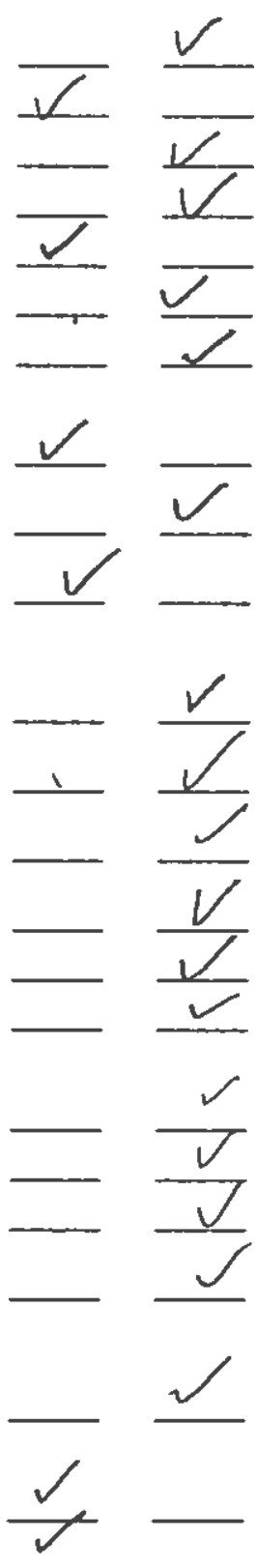
Attachment 3, Continued

MHU Longevity Testing - Recurring Inspection, p.2 $9-21-18$

MU

Q- Baseline

Upgraded
Mileage of Power Unit: 832,9

Testing miles (multiple of 500):

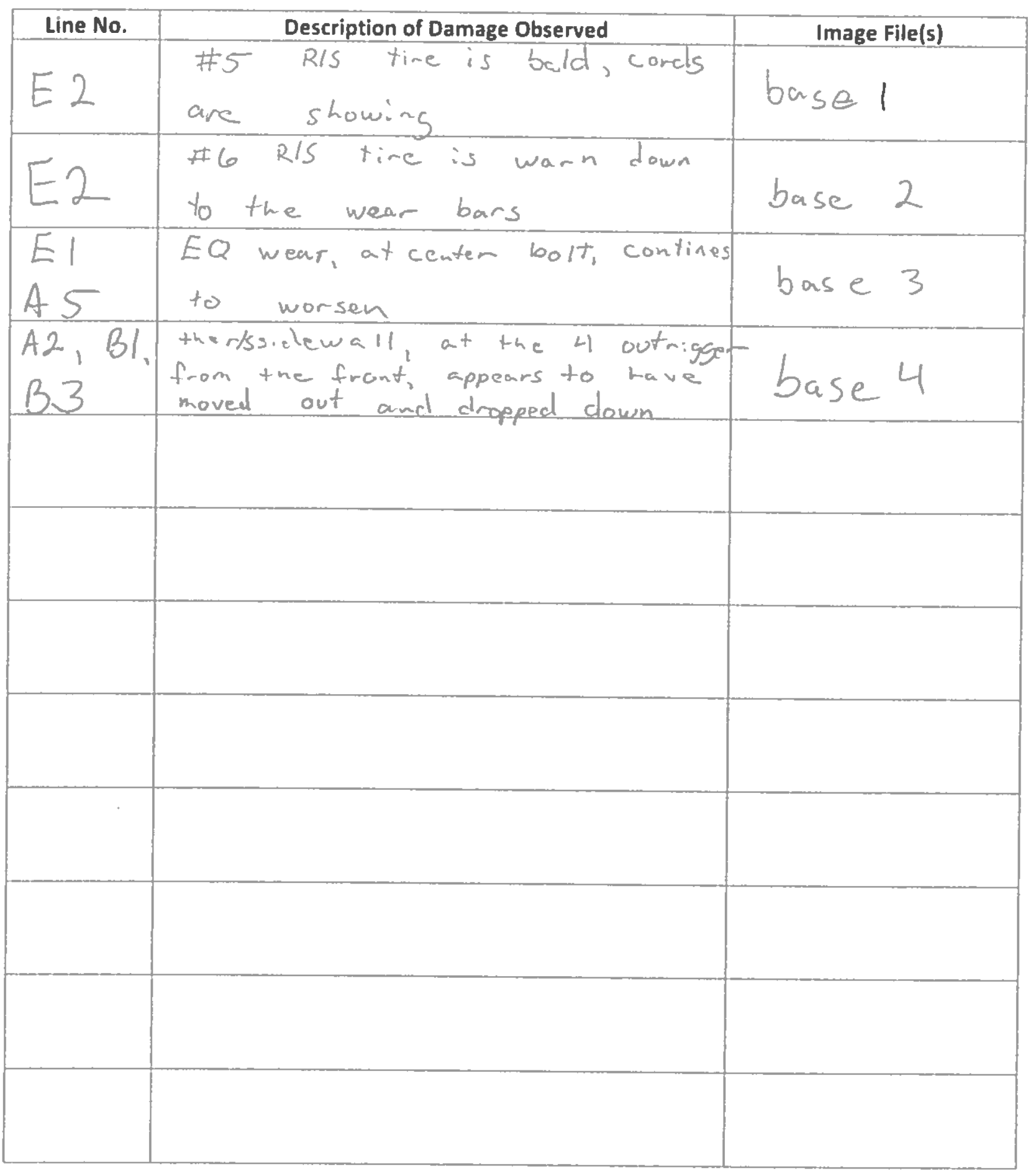

23

D-18 


\section{Attachment 3: MHU Longevity Testing - Recurring Inspection}

$\mathrm{MHU}$

Baseline

Upgraded
Mileage of Power Unit: 84331

Miles into testing (multiple of 500):

\section{A. CHASSIS}

1 Main beams buckled, bent, twists

2 Outriggers buckled, bent, twists

3. Cross members - buckled, bent, twists

4. Hitch/coupler damage

5. Axle, spring, spring hanger, wheel damage

6. Welds/connections - cracks, breaks, damage

7. Damage to exposed gas, waterlines, drain-lines or supports

B. FLOOR SYSTEMS

1. Damage, separations, loosening of lags from chassis to floor

2. Buckled floor, damaged decking/floor coverings, opening of joints, loose for popped feathers

3. Damage to bottom board, patches, loose fasteners

C. EXTERIOR/INTERIOR/MARRIAGE WALLS

1. Interior wall panels - buckled, cracked, bowed, separations, fasteners popped or loose

2. Separation of walls at floor, ceiling, column supports, window and door openings

3. Exterior siding and trim - buckled, cracked, bowed, separations, fasteners popped or loose

4. Windows and doors - damaged, buckled, bowed, or parts missing

5. Windows and doors - operate properly

6. Damage to caulking and sealants

D. ROOF/CEILINGS

1. Roofing - buckled, cracked, bowed, splits, openings, loose or popped fasteners

2 Damage to roof penetrations - vents, roof jacks, skylights, caulking and sealants

3. Damage to eaves, overhangs, transitions

4. Cellıngs - buckled, cracked, bowed, sagging, separations, loose or popped fasteners

E. PLUMBING

Damage to fixtures, piping, fittings, connections and supports

E. MODIFIED COMPONENTS FOR TESTING

1 Axles and suspension

2 Wheels and tires 
Attachment 3, Continued

MHU Longevity Testing - Recurring Inspection, p.2 $9-26-18$

MHO

Baseline

Upgraded
Mileage of Power Unit: 84331

Testing miles (multiple of 500):

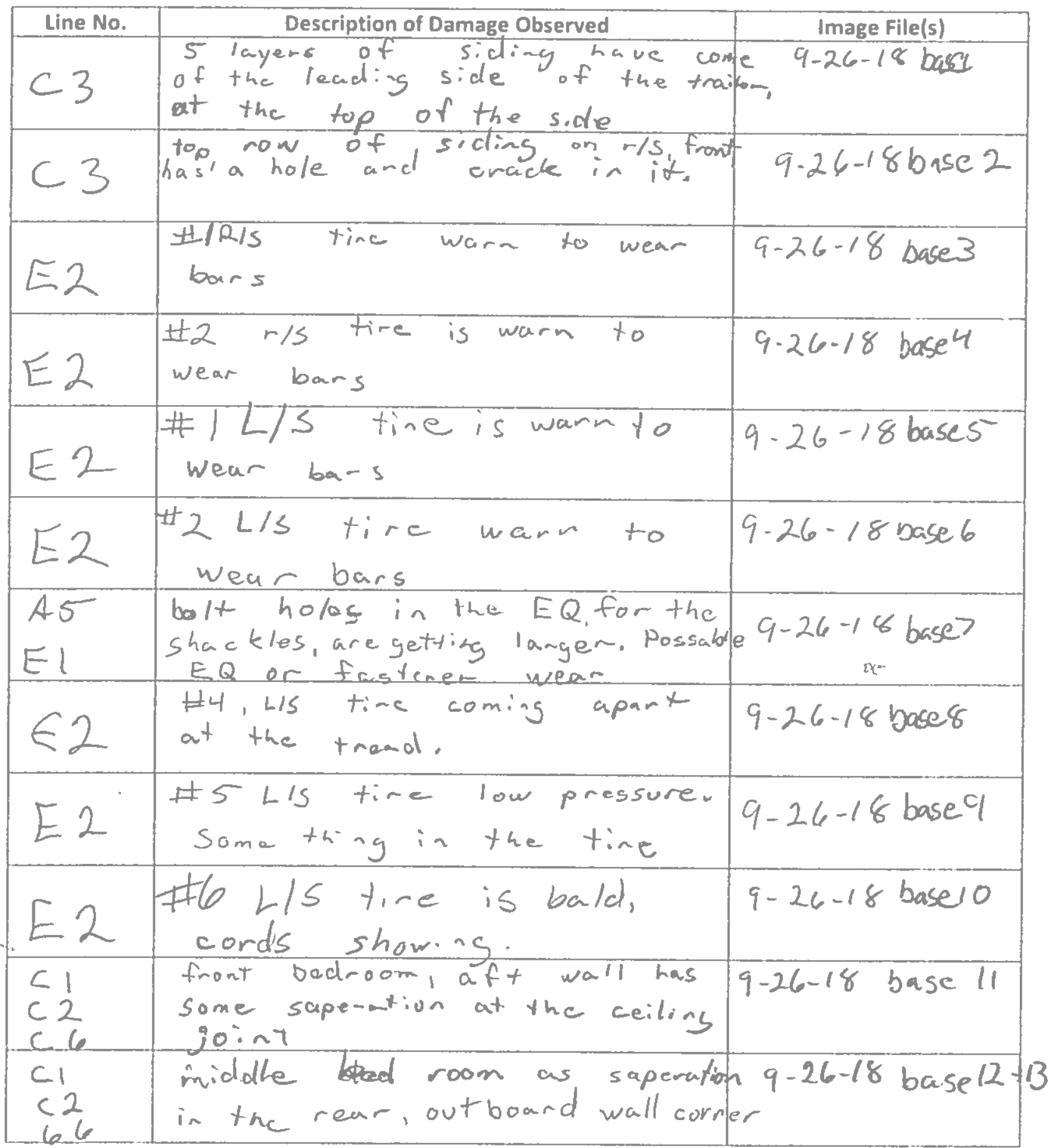

23

D-20 


\section{Attachment 3: MHU Longevity Testing - Recurring Inspection $9-27-18$}

$\mathrm{MHU}$

D. Baseline

Upgraded
Mileage of Power Unit: $849 / 63$

Miles into testing (multiple of 500):

A. CHASSIS

1 Main beams buckled, bent, twists

2. Outriggers - buckled, bent, twists

3. Cross members buckled, bent, twists

4. Hitch/coupler damage

5. Axle, spring, spring hanger, wheel damage

6. Welds/connections - cracks, breaks, damage

7. Damage to exposed gas, waterlınes, drain-lines or supports

B. FLOOR SYSTEMS

1. Damage, separations, loosening of lags from chassis to floor

2. Buckled floor, damaged decking/floor coverings, opening of joints, loose for popped feathers

3. Damage to bottom board, patches, loose fasteners

C. EXTERIOR/INTERIOR/MARRIAGE WALLS

1. Interior wall panels - buckled, cracked, bowed, separations, fasteners popped or loose

2. Separation of walls at floor, ceiling, column supports, window and door openings

3. Exterior siding and trim - buckled, cracked, bowed, separations, fasteners popped or loose

4. Windows and doors - damaged, buckled, bowed, or parts missing

5. Windows and doors - operate properly

6. Damage to caulking and sealants

\section{ROOF/CEILINGS}

1. Roofing - buckled, cracked, bowed, splits, openings, loose or popped fasteners

2. Damage to roof penetrations - vents, roof jacks, skylights, caulking and sealants

3. Damage to eaves, overhangs, transitions

4. Ceilings - buckled, cracked, bowed, sagging, separations, loose or popped fasteners

E. PLUMBING

Damage to fixtures, piping, fittings, connections and supports

E. MODIFIED COMPONENTS FOR TESTING

1. Axles and suspension

2 Wheels and tires 
Attachment 3, Continued

MHU Longevity Testing - Recurring Inspection, p.2

$9-2>-1 \ll$

MHU

Baseline

Mifeage of Power Unit: $849 / 63$

$\square$ Upgraded

Testing miles (multiple of 500):

\begin{tabular}{|c|c|c|}
\hline Line No. & Description of Damage Observed & Image File(s) \\
\hline$B 1_{>}$ & 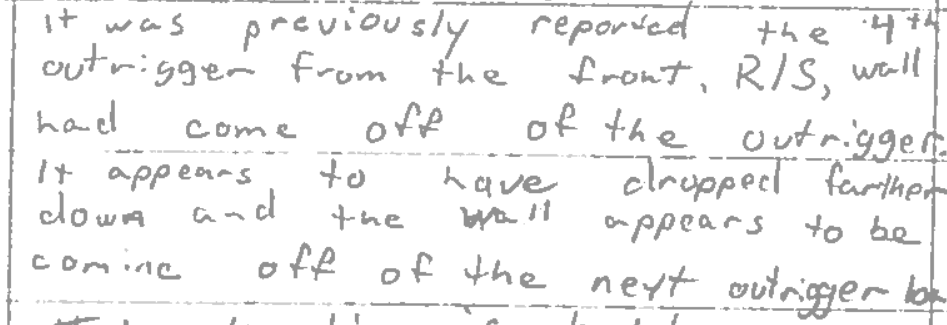 & $9-27-18$ ba be $1+$ \\
\hline & FI r/s tine is bald & $9-27-18$ base 3 \\
\hline & $\$ 2 \mathrm{r} / \mathrm{s}$ tine is baid & $9-27-18$ base 4 \\
\hline & $\begin{array}{l}\text { \#4 r/s tine is warn down } \\
\text { to wear burs }\end{array}$ & $9 \cdot 27-18$ base 5 \\
\hline & $\begin{array}{l}\text { \#s r/s tircis warn down } \\
\text { to wear bars }\end{array}$ & $9-27-18$ base 6 \\
\hline & $\begin{array}{l}H 6 \mathrm{r} / \mathrm{s} \text { tire is warn down } \\
\text { to wear burs }\end{array}$ & $9-27-18$ base 7 \\
\hline El & $\begin{array}{l}\text { the spri-ss are sagging ard } \\
\text { the sprims eys are contacti-g } \\
\text { the frame flange at the EQ }\end{array}$ & 9.27 .18 base 8 \\
\hline$E$ & $\begin{array}{l}\text { +3 L/S tinc is warr clown } \\
\text { to the wiar bears }\end{array}$ & $7 \cdot 27-18$ base 9 \\
\hline & $\begin{array}{l} \pm 245 \text { tire is warn down } \\
\text { to wear bar }\end{array}$ & $9-2>-18$ base 10 \\
\hline & $\begin{array}{l}+1: L / S+i r e \text { is warn clown } \\
\text { to wer- bur }\end{array}$ & $9.27-18$ base 11 \\
\hline & 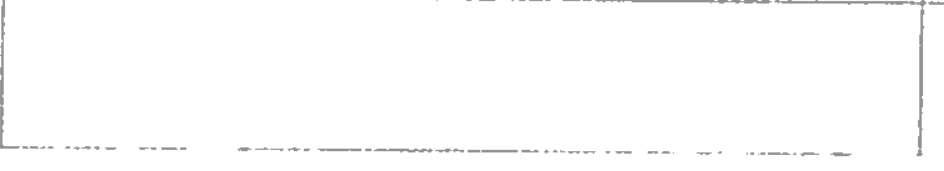 & \\
\hline
\end{tabular}




\section{Attuchment 3: MHU Longevity Testing Recurring Inspection}

\author{
MHU \\ Baseline \\ - Upgraded
}

Mileage of Power Unit: 85608

Miles into testing (multiple of 500):

\section{A. CHASSIS}

Damaged?

1 Main beams buckled, bent, twists

2 Outriggers buckled, bent, twists

3 Cross members buckled bent, twists

4 Hitch/coupler damage

5. Axle spring, spring hanger, wheel damage

6 Welds/connections cracks, breaks, damage

7 Damage to exposed gas, waterlınes, drain-lınes or supports

B. FLOOR SYSTEMS

1 Damage, separations, loosening of lags from chassis to floor

2 Buckled floor, damaged decking/floor coverings, openıng of joints, loose for popped feathers

3. Damage to bottom board, patches, loose fasteners

\section{EXTERIOR/INTERIOR/MARRIAGE WALLS}

1. Interior wall panels - buckled, cracked, bowed, separations, fasteners popped or loose

2. Separation of walls at floor, ceiling, column supports, window and door openings

3. Exterior siding and trim - buckled, cracked, bowed, separations, fasteners popped or loose

4. Windows and doors - damaged, buckled, bowed, or parts missing

5. Windows and doors - operate properly

6. Damage to caulking and sealants

D. ROOF/CEILINGS

1. Roofing - buckled, cracked, bowed, splits, openings, loose or popped fasteners

2. Damage to roof penetrations - vents, roof jacks, skylights, caulking and sealants

3. Damage to eaves, overhangs, transitions

4. Ceilings - buckled, cracked, bowed, sagging, separations, loose or popped fasteners

\section{E. PLUMBING}

Damage to fixtures, piping, fittings, connections and supports

\section{E. MODIFIED COMPONENTS FOR TESTING}

1. Axles and suspension

2 Wheels and tires

Yes No
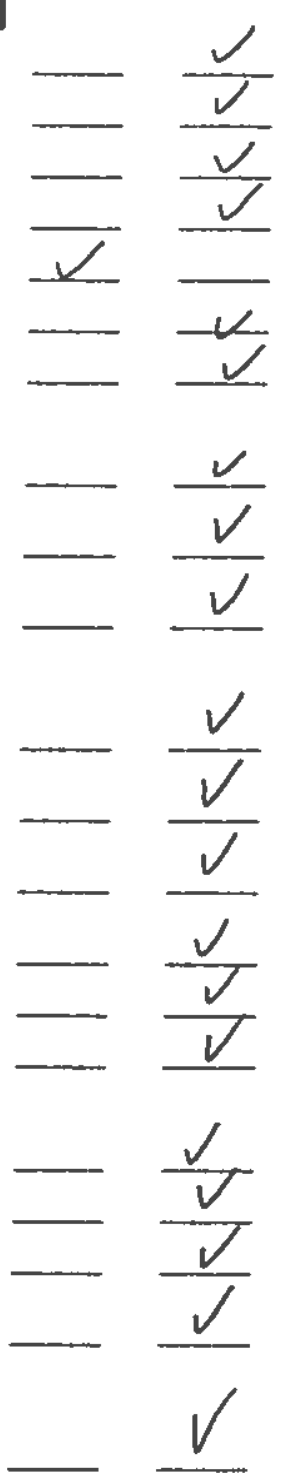
Attachment 3, Continued MHU Longevity Testing - Recurring Inspection, p.

MHU

$\checkmark$ Baseline

$\square$ Upgraded
Mileage of Power Unit: $85-608$

Testing miles (multiple of 500):

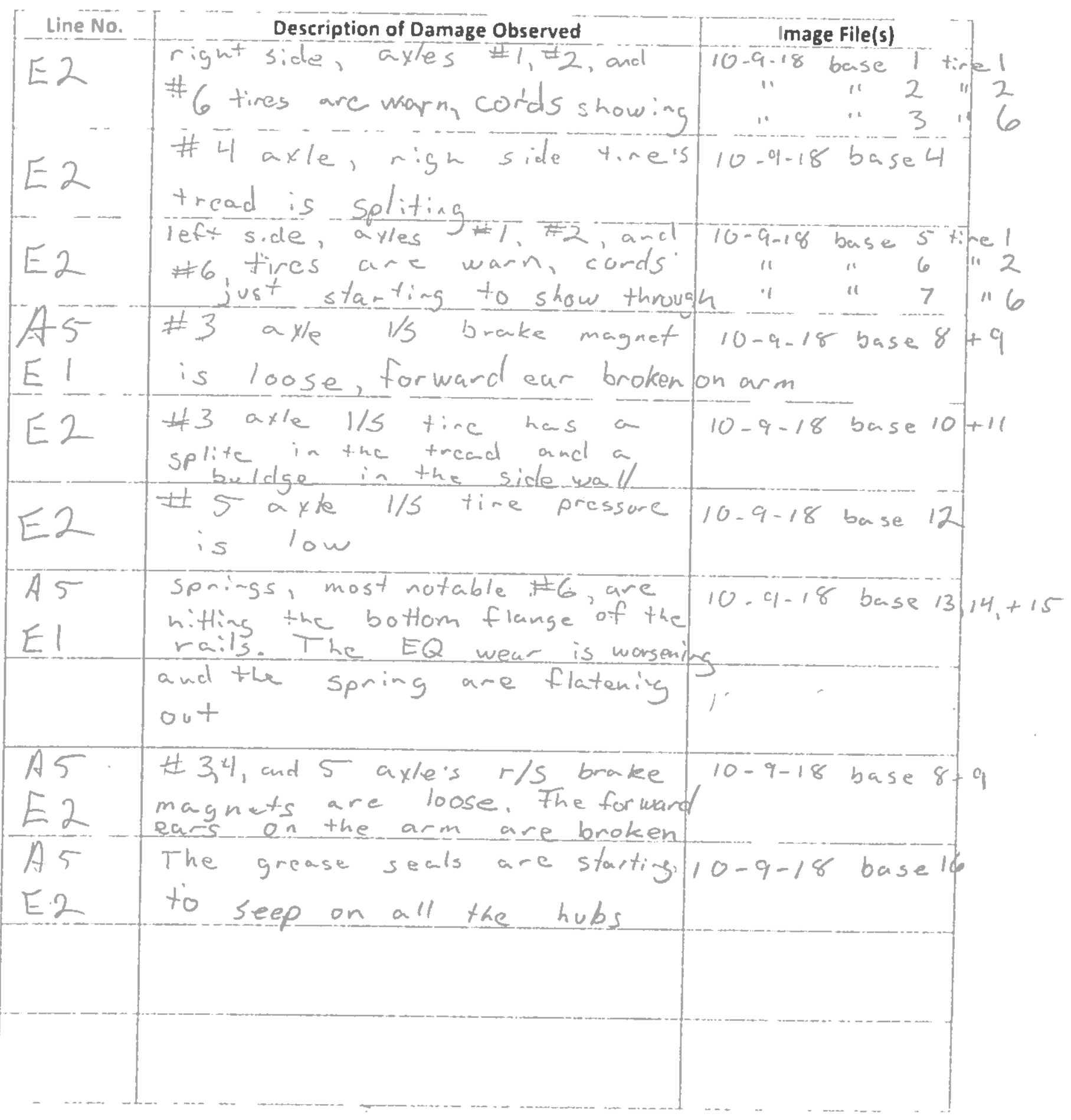




\section{Attachment 3: MHU Longevity Testing Recurring Inspection}

MHU

Wr Baseline

$\square$ Upgraded
Mileage of Power Unit: $861 \geq 4$

Miles into testing (multiple of 500):

\section{A. CHASSIS}

Damaged?

Yes

No

1 Main beams buckled, bent twists

2 Outriggers buckled bent, twists

3 Cross members buckled, bent, twists

4 Hitch/coupler damage

5. Axle spring, spring hanger, wheel damage

6 Welds/connections cracks, breaks, damage

7 Damage to exposed gas, waterlınes, drain-lines or supports

\section{B. FLOOR SYSTEMS}

1 Damage, separations, loosening of lags from chassis to floor

2 Buckled floor, damaged decking/floor coverings, openıng of jounts, loose for popped feathers

3. Damage to bottom board, patches, loose fasteners

C. EXTERIOR/INTERIOR/MARRIAGE WALLS

1. Interior wall panels - buckled, cracked, bowed, separations, fasteners popped or loose

2. Separation of walls at floor, ceiling, column supports, window and door openings

3. Exterior siding and trim - buckled, cracked, bowed, separations, fasteners popped or loose

4. Windows and doors - damaged, buckled, bowed, or parts missing

5. Windows and doors - operate properly

6. Damage to caulking and sealants

\section{ROOF/CEILINGS}

1. Roofing - buckled, cracked, bowed, splits, openings, loose or popped fasteners

2. Damage to roof penetrations - vents, roof jacks, skylights, caulking and sealants

3. Damage to eaves, overhangs, transitions

4. Ceilings - buckled, cracked, bowed, sagging, separations, loose or popped fasteners

\section{E. PLUMBING}

Damage to fixtures, piping, fittings, connections and supports

\section{E. MODIFIED COMPONENTS FOR TESTING}

1. Axles and suspension

2 Wheels and tires 
Attachment 3, Continued

MHU Longevity Testing - Recurring Inspection, p.2

$\mathrm{MHU}$

$\square$ Baseline

Upgraded
Mileage of Power Unit: $861>4$

Testing miles (multiple of 500)

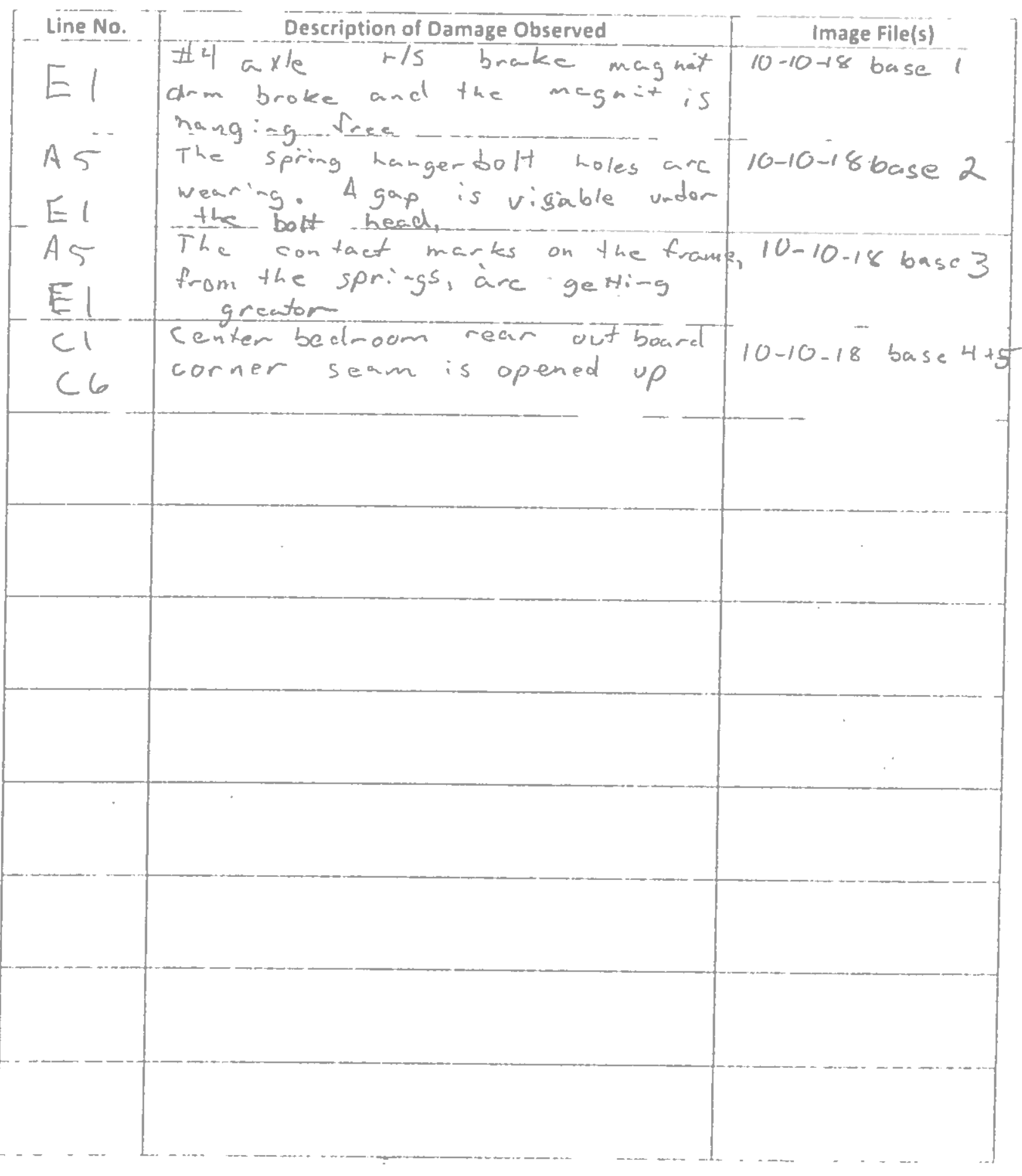




\section{Altachment 3: MHU Longevity Testing Recurring Inspection $10-16-18$}

MHU

$\square$ Baseline

Upgraded
Mileage of Power Unit: $9 / 420$

Miles into testing (multiple of 500):

\section{A. CHASSIS}

1 Main beams buckled, bent, twists

2 Outriggers buckled, bent, twists

3 Cross members buckled, bent, twists

4 Hitch/coupler damage

5. Axle, spring, spring hanger, wheel damage

6. Welds/connections cracks, breaks, damage

7 Damage to exposed gas, waterlınes, drain-lınes or supports

\section{B. FLOOR SYSTEMS}

1 Damage, separations, loosening of lags from chassis to floor

2 Buckled floor, damaged decking/floor coverings, opening of joints, loose for popped feathers

3. Damage to bottom board, patches, loose fasteners

\section{EXTERIOR/INTERIOR/MARRIAGE WALLS}

1. Interior wall panels - buckled, cracked, bowed, separations, fasteners popped or loose

2. Separation of walls at floor, ceiling, column supports, window and door openings

3. Exterior siding and trim - buckled, cracked, bowed, separations, fasteners popped or loose

4. Windows and doors - damaged, buckled, bowed, or parts missing

5. Windows and doors - operate properly

6. Damage to caulking and sealants

D. ROOF/CEILINGS

1. Roofing - buckled, cracked, bowed, splits, openings, loose or popped fasteners

2. Damage to roof penetrations - vents, roof jacks, skylights, caulking and sealants

3. Damage to eaves, overhangs, transitions

4. Ceilings - buckled, cracked, bowed, sagging, separations, loose or popped fasteners

\section{E. PLUMBING}

Damage to fixtures, piping, fittings, connections and supports

\section{E. MODIFIED COMPONENTS FOR TESTING}

Damaged?

Yes No

1. Axles and suspension

2 Wheels and tires 
Attachment 3, Continued

$$
10-16-18
$$

MHU Longevity Testing - Recurring Inspection, p.2

MHU

QDaseline

Upgraded
Mileage of Power Unit: $\quad 9 / 4 / 2$

Testing miles (multiple of 500):

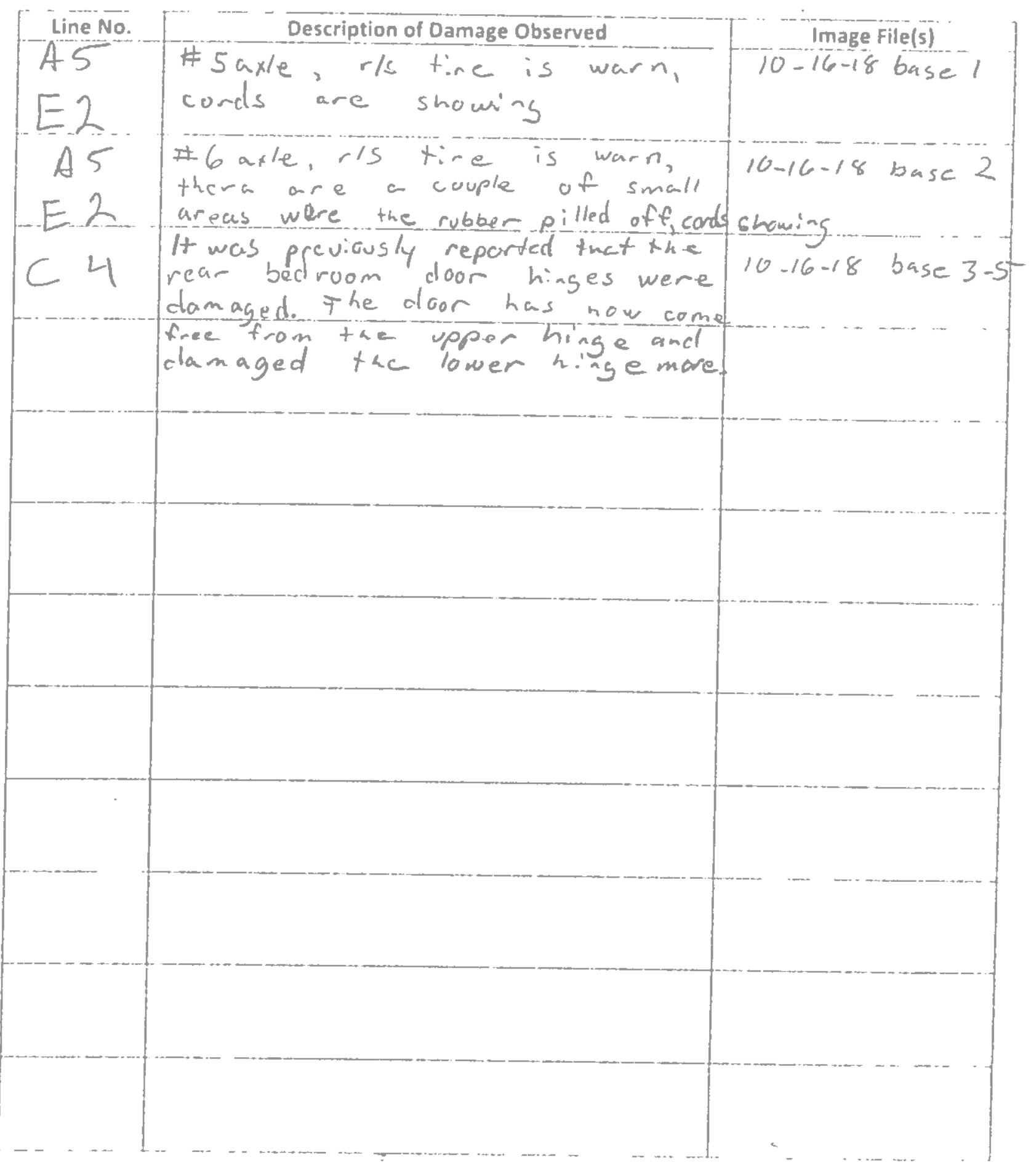




\section{Attachment 3: MHU Longevity Testing - Recurring Inspection}

MHU

Cr Baseline

Upgraded
Mileage of Power Unit: 92011

Miles into testing (multiple of 500 ):

\section{Damaged? \\ Yes \\ No}

A. CHASSIS

1 Main beams buckled, bent, twists

2 Outriggers buckled, bent, twists

3 Cross members buckled, bent, twists

4 Hitch/coupler damage

5. Axle, spring, spring hanger, wheel damage

6. Welds/connections cracks, breaks, damage

7. Damage to exposed gas, waterlines, drain-lines or supports

B. FLOOR SYSTEMS

1 Damage, separations, loosening of lags from chassis to floor

2 Buckled floor, damaged deckıng/floor coverings, openıng of joints, loose for popped feathers

3. Damage to bottom board, patches, loose fasteners

\section{EXTERIOR/INTERIOR/MARRIAGE WALLS}

1. Interior wall panels - buckled, cracked, bowed, separations, fasteners popped or loose

2. Separation of walls at floor, ceiling, column supports, window and door openings

3. Exterior siding and trim - buckled, cracked, bowed, separations, fasteners popped or loose

4. Windows and doors - damaged, buckled, bowed, or parts missing

5. Windows and doors - operate properly

6. Damage to caulking and sealants

\section{ROOF/CEILINGS}

1 Roofing buckled, cracked, bowed, splits, openıngs, loose or popped fasteners

2. Damage to roof penetrations - vents, roof jacks, skylights, caulking and sealants

3. Damage to eaves, overhangs, transitions

4. Ceilings - buckled, cracked, bowed, sagging, separations, loose or popped fasteners

\section{E. PLUMBING}

Damage to fixtures, pipıng, fittings, connections and supports

\section{E. MODIFIED COMPONENTS FOR TESTING}

1. Axles and suspension

2 Wheels and tires
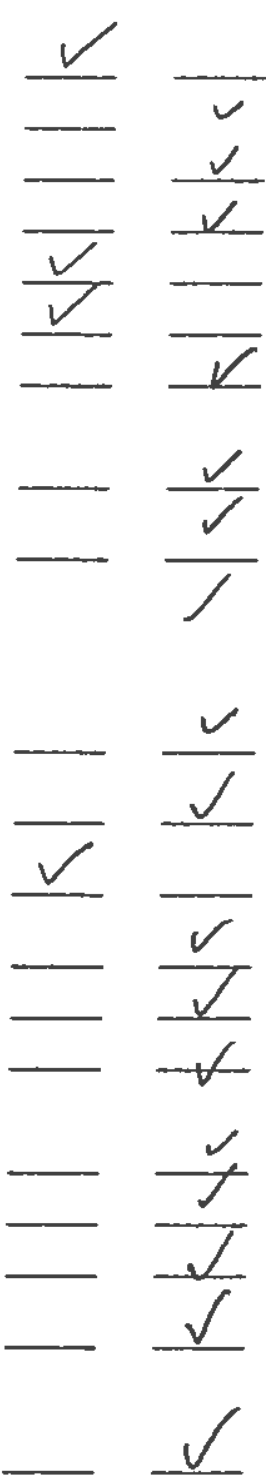
Attachment 3, Continued

$10-17-18$

MHU Longevity Testing - Recurring Inspection, p.2

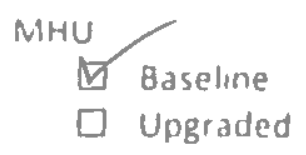

Mileage of Power Unit $\mathrm{cl} 2 \mathrm{OII}$

Testing mules (multiple of 500)

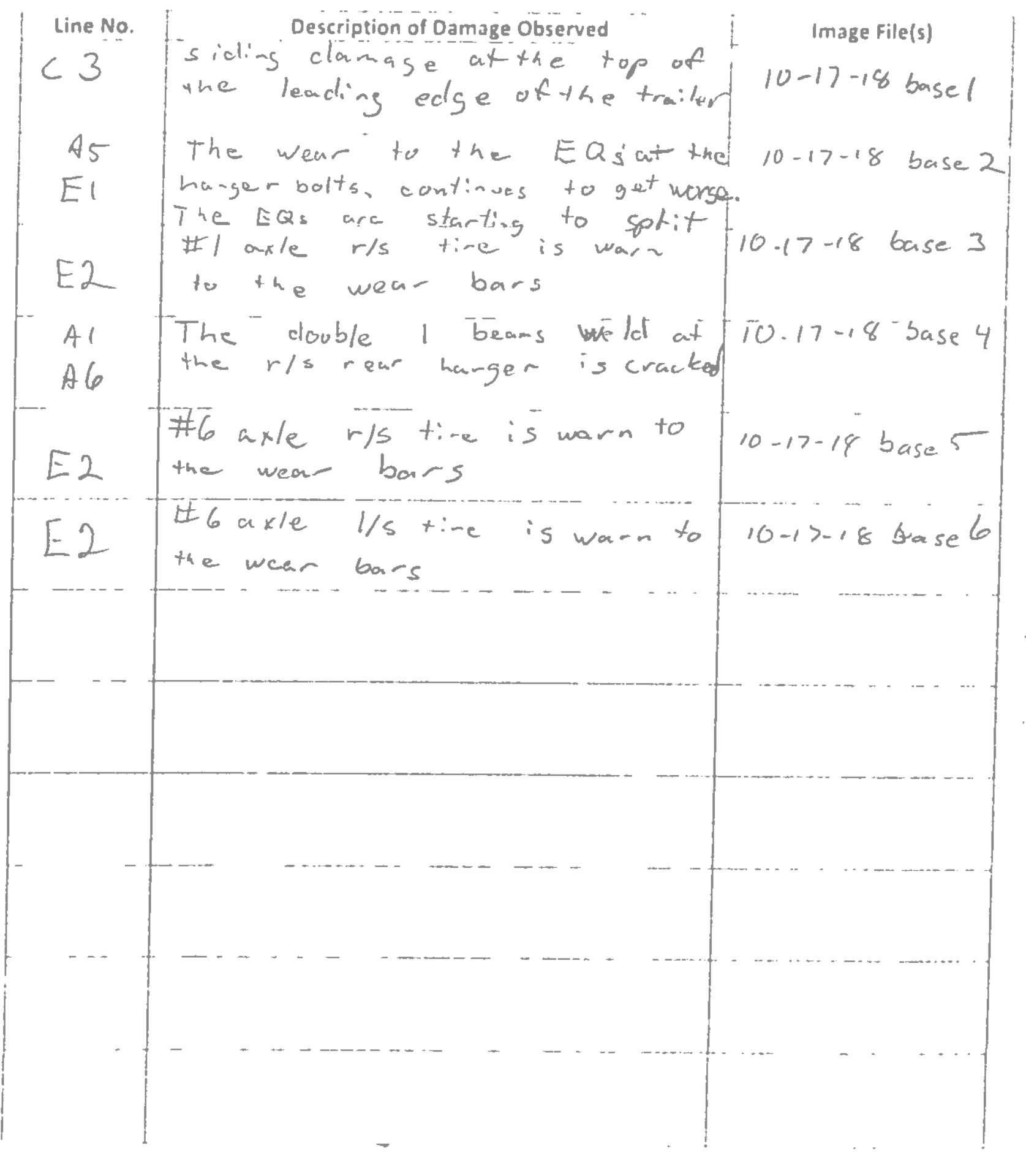




\section{Attachment 4: MHU Longevity Testing - Record of Damage}

Date: $\frac{7 / 6 / 18}{600}$

Time:

Tractor (if multiple used):

MHU

Baseline

$\square$ Upgraded

Type of damage:

Location of damage:

Corrective action

$\square$ Baseline

$\square$ Repairs as follows:

Image file(s): 
Attachment 4: MHU Longevity Testing - Record of Damage

Date: $7 / 17 / 18$

Mileage: $\quad 1100$

MHY

(4) Baseline

$\square$ Upgraded
Time:

Tractor (if multiple used):

Type of damage:

as

Location of damage:

Corrective action

$\square$ Baseline

口 Repairs as follows:

Image file(s): 


\section{Attachment 4: MHU Longevity Testing - Record of Damage}

Date: $\quad 8-1-18$

Mileage: $\quad 84665$
Time: $11: 00$

Tractor (if multiple used):

MHU

Baseline

$\square$ Upgraded

Type of damage: Siding cume loose

Location of damage: $\mathrm{r} / \mathrm{s}$ at forward win

Corrective action

$\square$ Baseline

$\square$ Repairs as follows:

Repairs as follows:
reinstalled siding instal wood
the top to hold in place

Image file(s):

B $\quad$ l


Attachment 4: MHU Longevity Testing - Record of Damage

Date: $9 / 15 / 18$

Time: Approx. 12:05 am

Mileage: $\quad$ 86,300 Approx. (3911 test miles) Tractor (if multiple used): $\quad$ LW28748

$\mathrm{MHU}$

$\square$ Baseline

$\square$ Upgraded

Type of damage: Deer strike - minimal damage

Location of damage: front bumper

Corrective action

$\square$ Baseline

$\square$ Repairs as follows:

None

Image file(s):

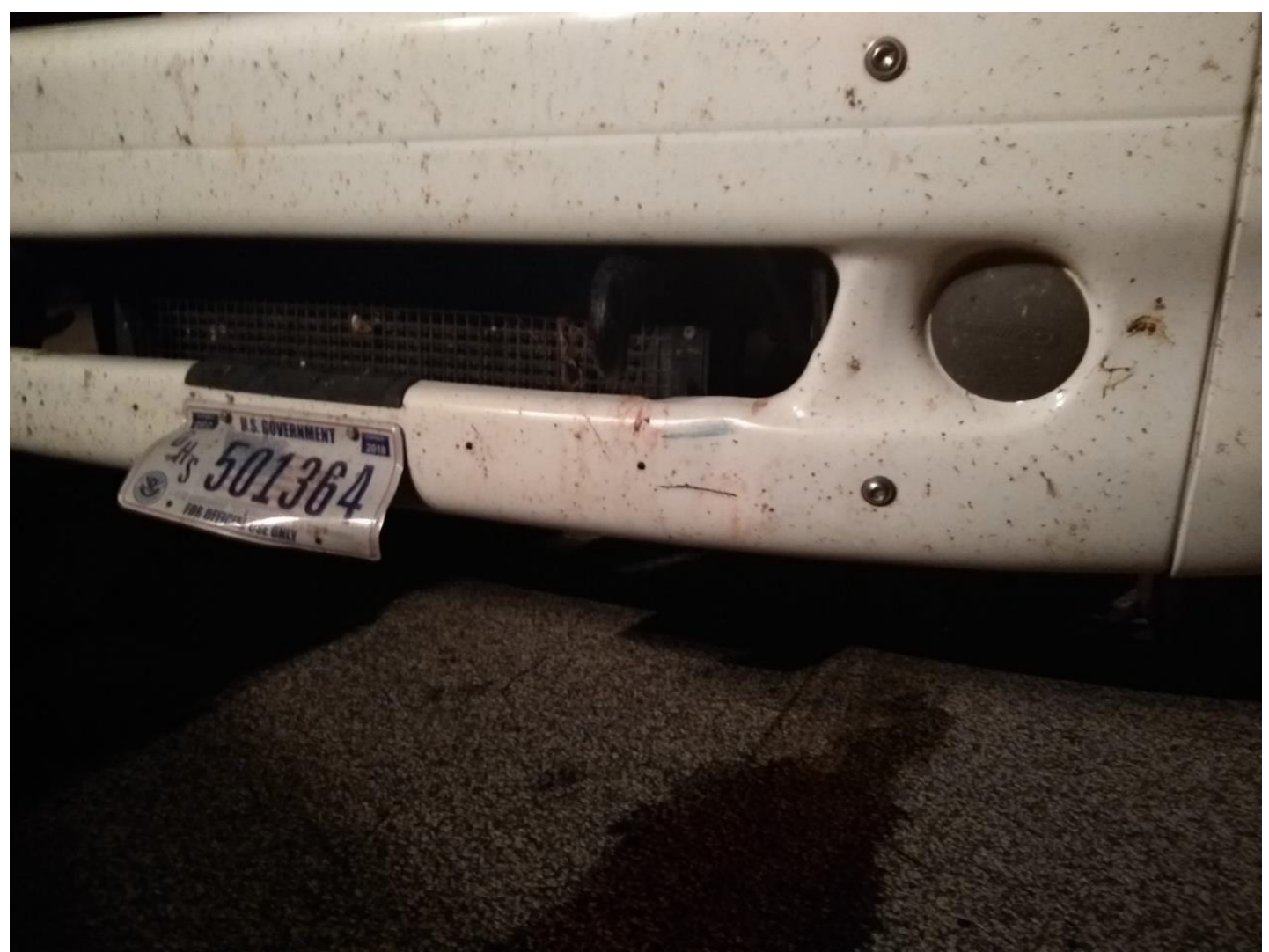

D-34 

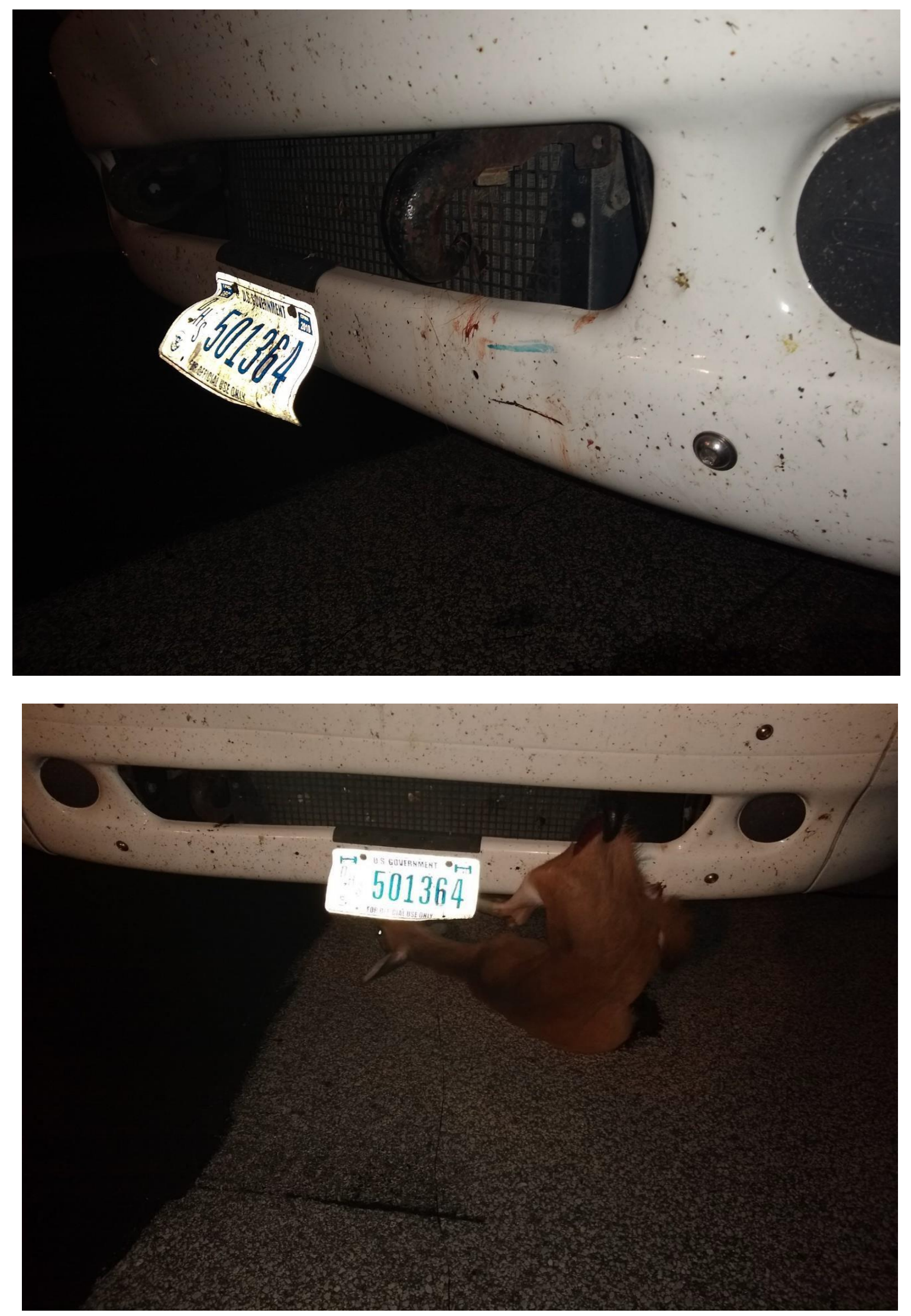

D-35 
Attachment 4: MHU Longevity Testing - Record of Damage

Date: $9 / 15 / 18$

Mileage: $\quad$ 86,637 (4248 test miles)
Time: Approx. $6 \mathrm{pm}$

Tractor (if multiple used): $\quad \underline{\text { LW28748 }}$

MHU

\section{$\square$ Baseline}

$\square$ Upgraded

Type of damage: Tire failure - blowout

Location of damage: Axle \#6 left side

Corrective action

$\square$ Baseline

$\square$ Repairs as follows:

Replaced tire

Image file(s):

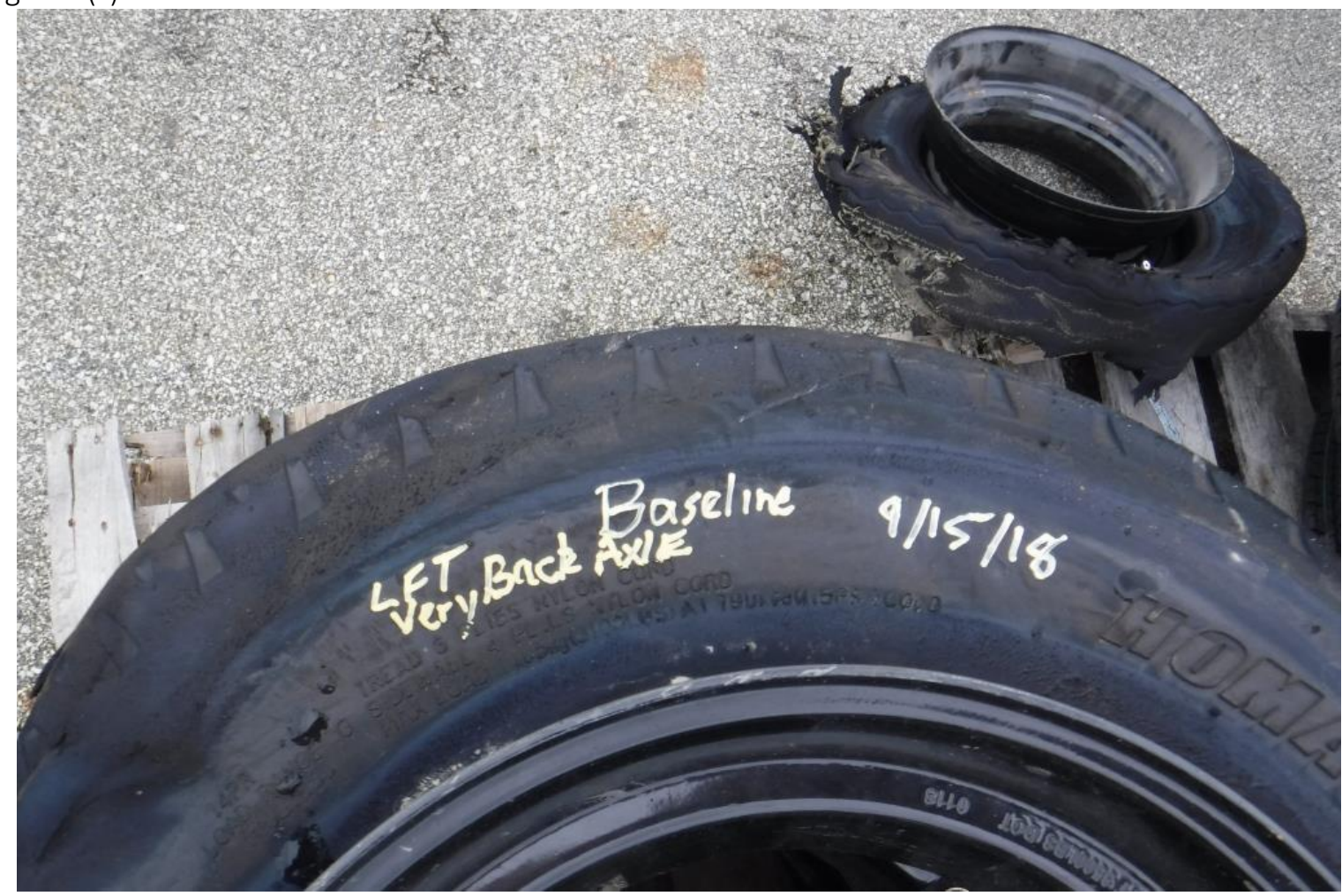

D-36 
Attachment 4: MHU Longevity Testing - Record of Damage

Date: $9 / 15 / 18$

Mileage: $\quad$ 86,701 (4248 test miles)
Time: Approx. 8 pm

Tractor (if multiple used): $\quad \underline{\text { LW28748 }}$

MHU

$\square$ Baseline

$\square$ Upgraded

Type of damage: Tire failure - blowout

Location of damage: Axle \#6 right side

Corrective action

$\square$ Baseline

$\square$ Repairs as follows:

Replaced tire

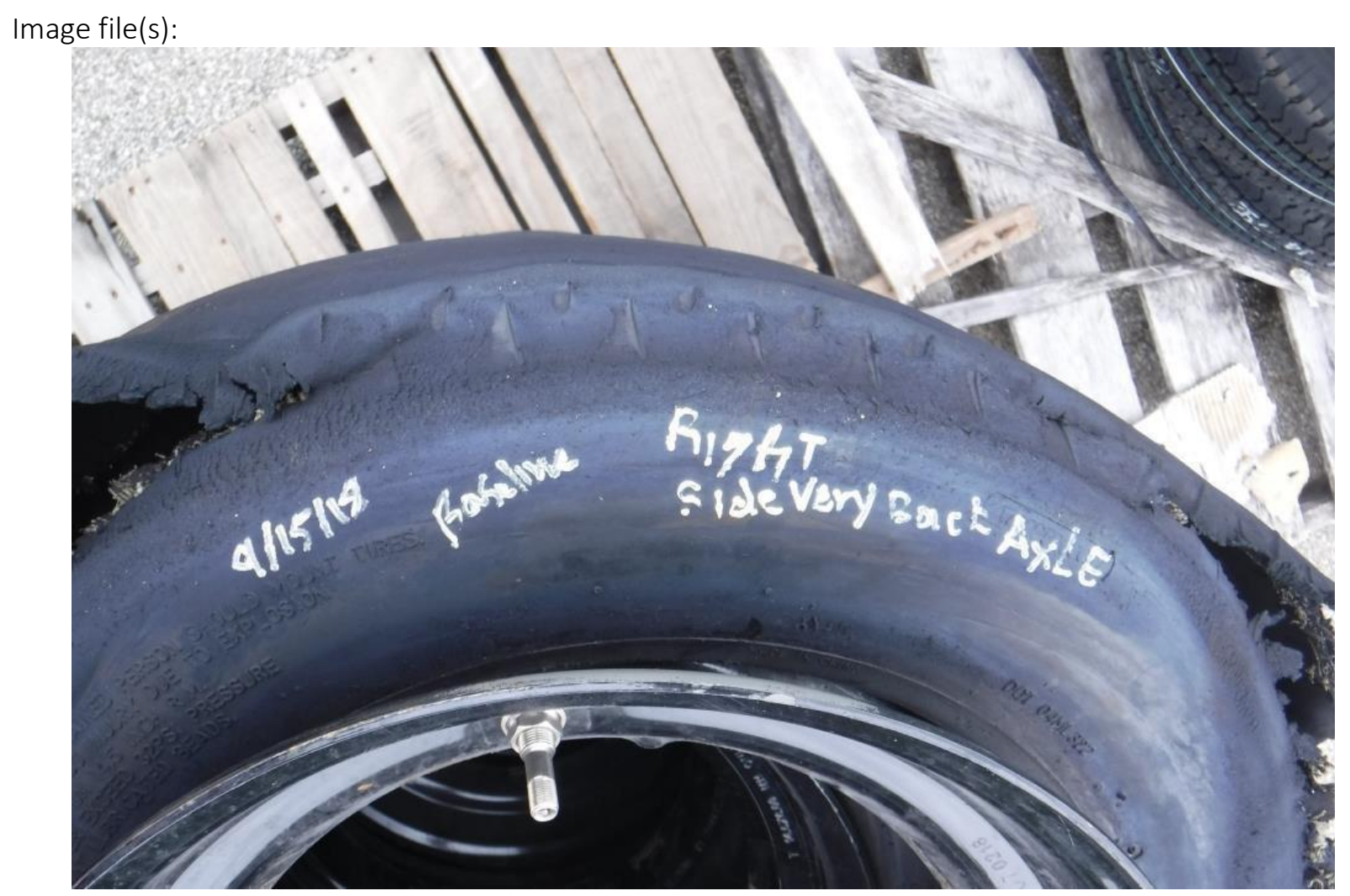


Attachment 4: MHU Longevity Testing - Record of Damage

Date: $\quad 9-17-18$

Time:

Mileage: $\quad 87218$

Tractor (if multiple used):

MHO

Baseline

Upgraded

Type of damage:

\# $4 / S+R / S$ tires bald, \#3 R/S leaking

Location of damage:

Corrective action

Baseline

Repairs as follows:

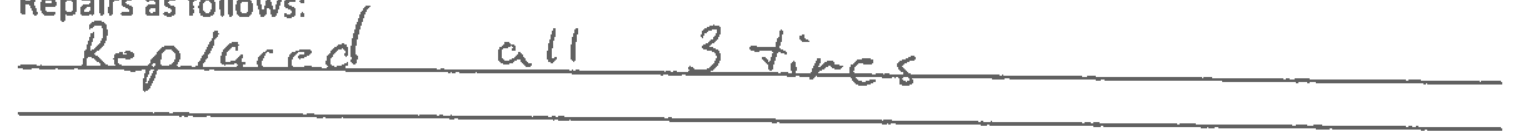

Image files):

pp

D-38 
Attachment 4: MHU Longevity Testing - Record of Damage

Date: $9 / 20 / 18$

Mileage:

$\underline{82,752 \text { (5000 test miles) }}$

MHU

$\square$ Baseline (with other tractor after swap) $\square$ Upgraded

Type of damage: Tire failure - blowout

Location of damage: Axle \#5 left side

Corrective action

$\square$ Baseline

$\square$ Repairs as follows:

Replaced tire
Time: Approx. 8 pm

Tractor (if multiple used): $\quad \underline{\text { LW28751 }}$

Image file(s):

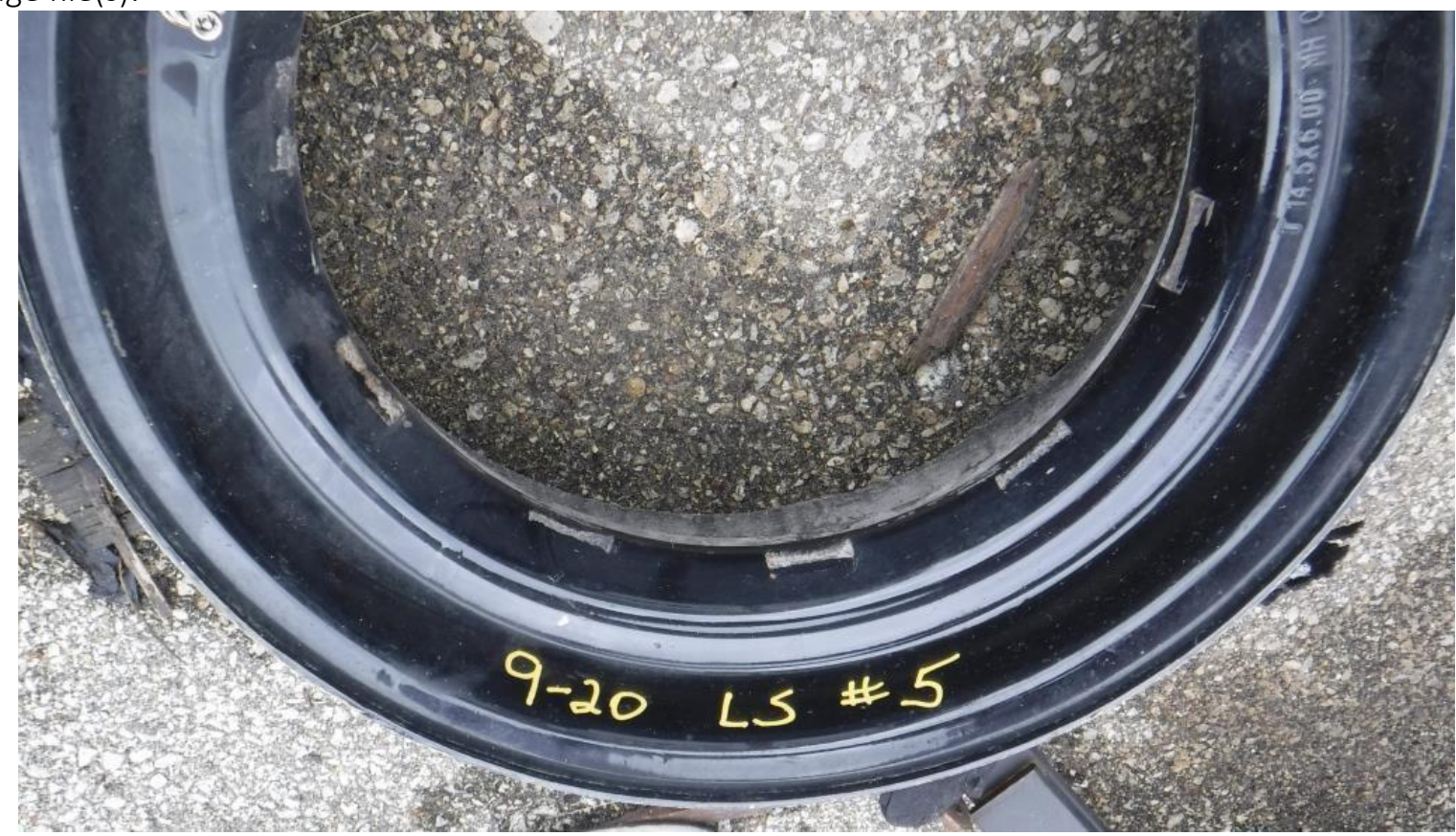


Attachment 4: MHU Longevity Testing - Record of Damage

Date: $9 / 20 / 18$

Mileage:

$\underline{82,752 \text { (5000 test miles) }}$

MHU

$\square$ Baseline (with other tractor after swap)

$\square$ Upgraded

Type of damage: Tire failure - Flat

Location of damage: Axle \#6 left side

Corrective action

$\square$ Baseline

$\square$ Repairs as follows:

Replaced tire
Time: Approx. 8 pm

Tractor (if multiple used): $\quad \underline{\text { LW28751 }}$

Image file(s):

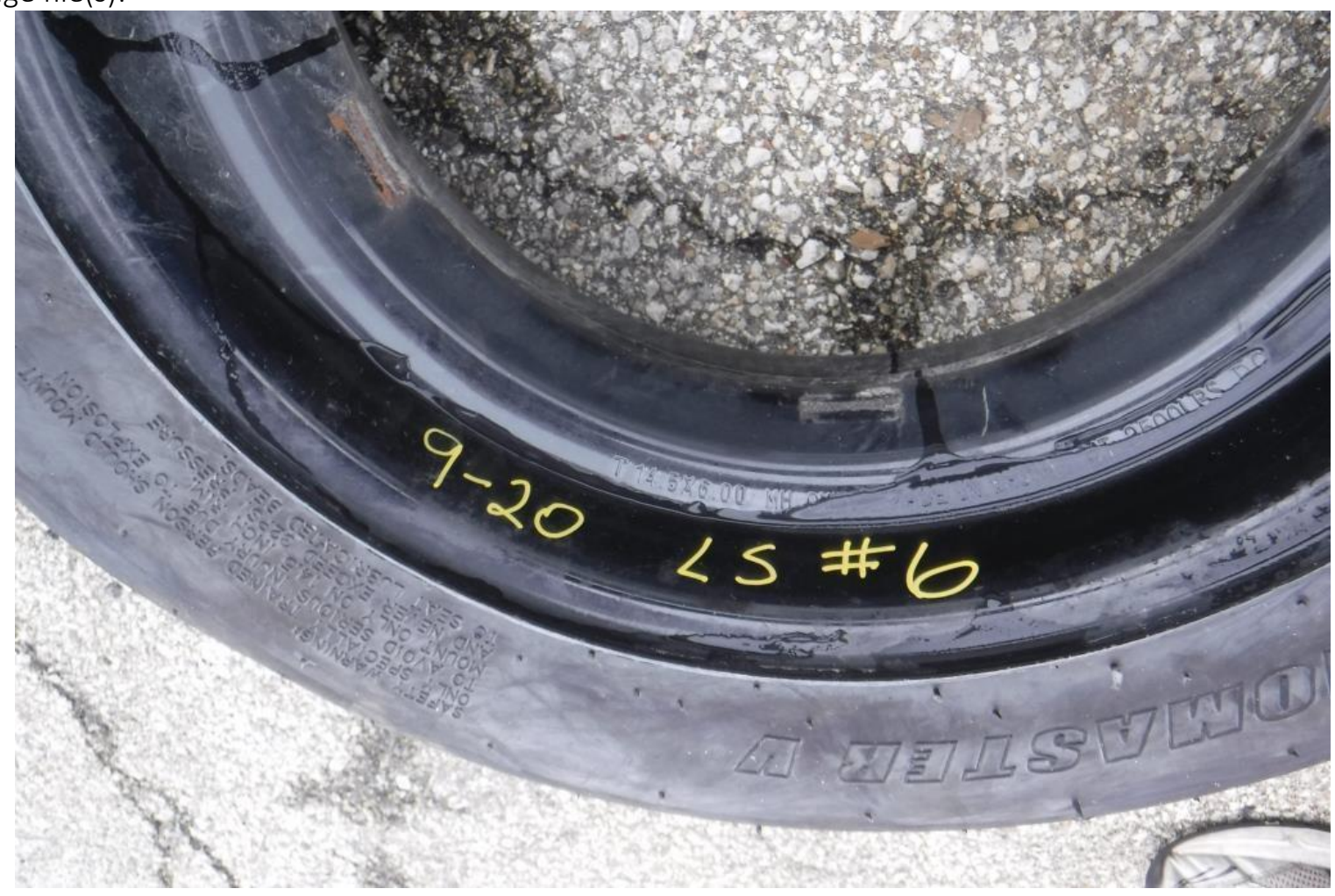


Attachment 4: MHU Longevity Testing - Record of Damage

Date: $9-21-18$

Mileage:
Time:

Tractor (if multiple used):

MHO

$\square$ Baseline

Upgraded

Type of damage:

Location of damage:

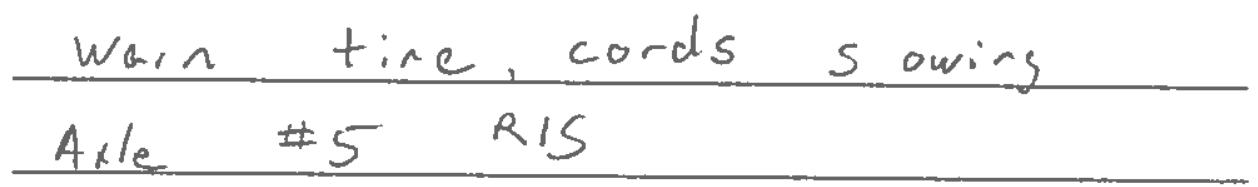

Corrective action

$\checkmark$ Baseline

$\square$ Repairs as follows:

Image files): $(9-21-18)$ base 1

D-41 
Attachment 4: MHU Longevity Testing - Record of Damage

Date: $\underline{9-26-18}$

Mileage: $\quad \underline{84331}$

$\mathrm{MHU}$

$\square$ Baseline

$\square$ Upgraded

Type of damage: $\quad$ Multiple sheets of siding have blown off the front of the unit.

Location of damage: Front exterior surface of MHU

Corrective action

$\square$ Baseline

$\square$ Repairs as follows: Installed wood shoring to support and retain remainder of siding.

Image file(s):

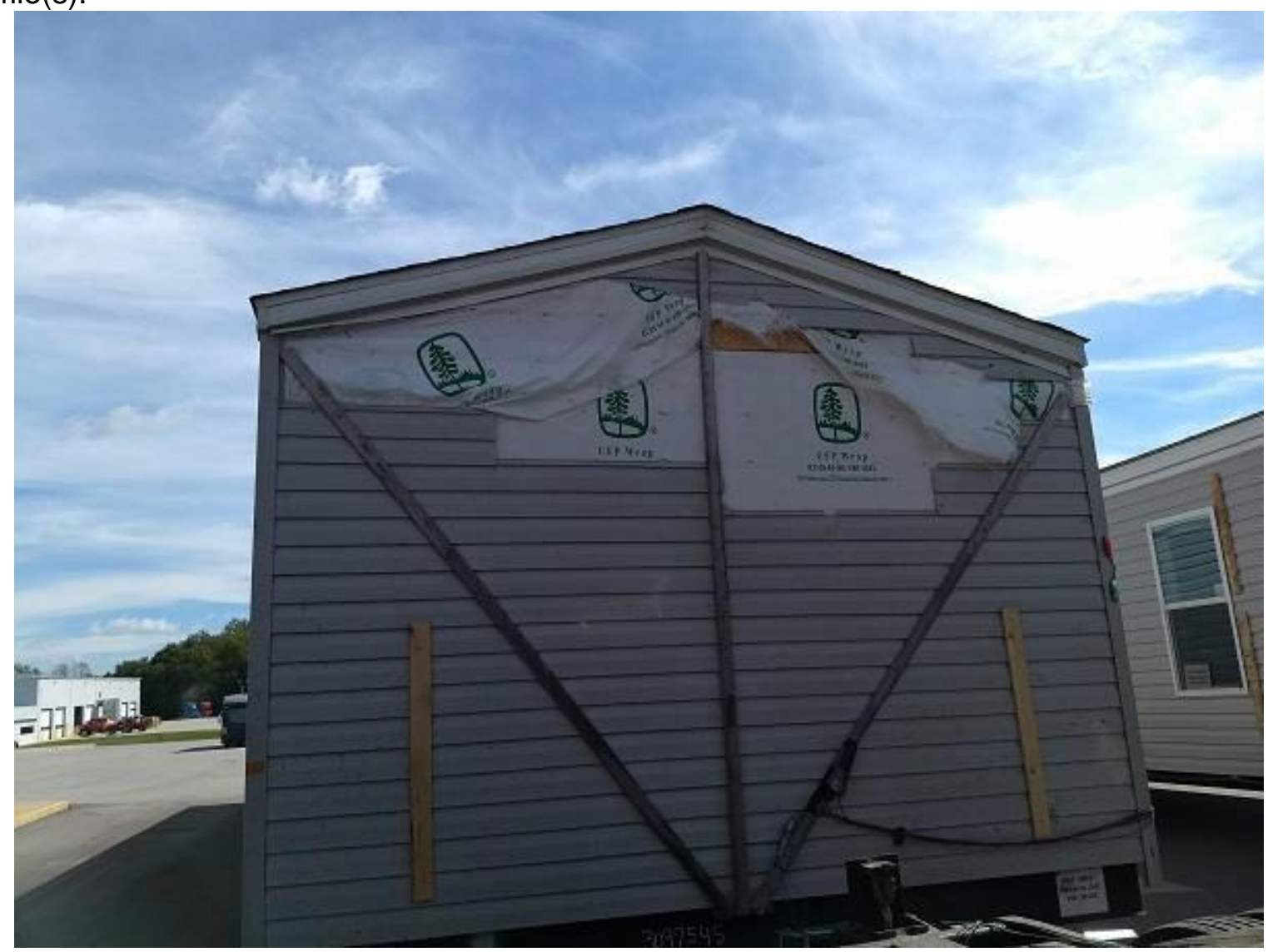

D-42 
Attachment 4: MHU Longevity Testing - Record of Damage

Date: $9-26-18$

Mileage: $\quad 84331$
Time:

Tractor (if multiple used):

MHO

Baseline

Upgraded

Type of damage: Bad tires

Location of damage: $\frac{\# 4 \mathrm{l} / \mathrm{s} \text { tread damage, } \# 5 \mathrm{l} / \mathrm{s} \text { flat, }}{\# 6 \mathrm{l} / \mathrm{s} \text { warn +cords showing }}$

Corrective action

$\checkmark$ Baseline

Repairs as follows:

Replaced all 3 tires

Image files):

D-43 


\section{Attachment 4: MHU Longevi y esting-Record of Damage}

Date $\frac{10-}{\text { Mileage }}$
MHU Baseline
$\square$ Upgraded

Time

Tractor (if multiple used):

$\begin{array}{ll}\text { Type of damage } & B d \text { tincs } \\ \text { Location of damage: } & \text { II } \# 1,2,3,5,6, r / 5 \# 1,2,4,6 .\end{array}$

Corrective action

[] Baseline

$\square$ Reparrs as follows $\frac{\text { ustalkd new tir, Torque logs o } 85 \mathrm{ft} .16 \mathrm{~s} .}{\text { Set pressuce te } 115 \text { ps, }}$

Image file(s):

$$
10-9-18 \text { base } 1,2,3,4,5,6,7,10,12
$$


a chment 4: MHU longevity Testing-Recor of Damage

Date $\frac{10-16-18}{91420}$
Mileage $\quad \therefore$
MHU
$\quad \square$ Baseline
$\square$ Upgraded

Time

Tractor (if multiple used):

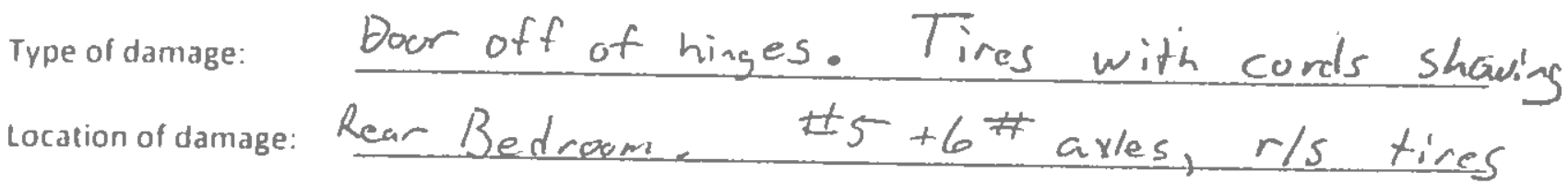

Corrective action

Baselıne

$\square$ Repairs as follows:

Removed door layed it ontop of remoued door
Replaced tines with new

Image file(s) $10-16-18$ base $1-5$ 
Attachment 4: MHU Longevity Testing - Record of Damage

Date: $\underline{10 / 16 / 18}$

Mileage: $\quad \underline{91125}$

$\mathrm{MHU}$

$\square$ Baseline

$\square$ Upgraded

Type of damage: Vehicle struck a deer on the oval track

Location of damage: Front bumper

Corrective action

$\square$ Baseline

$\square$ Repairs as follows:

None

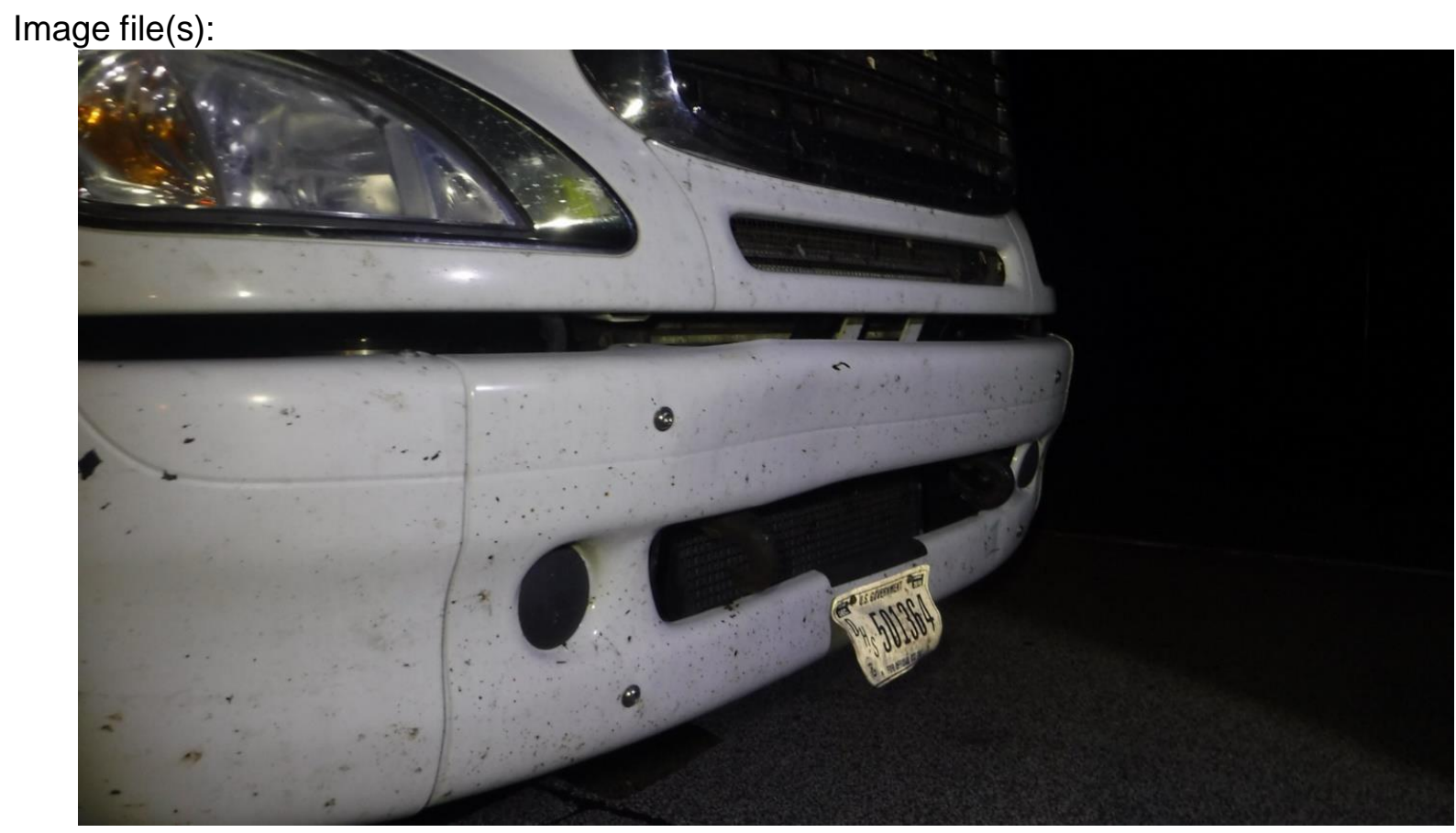



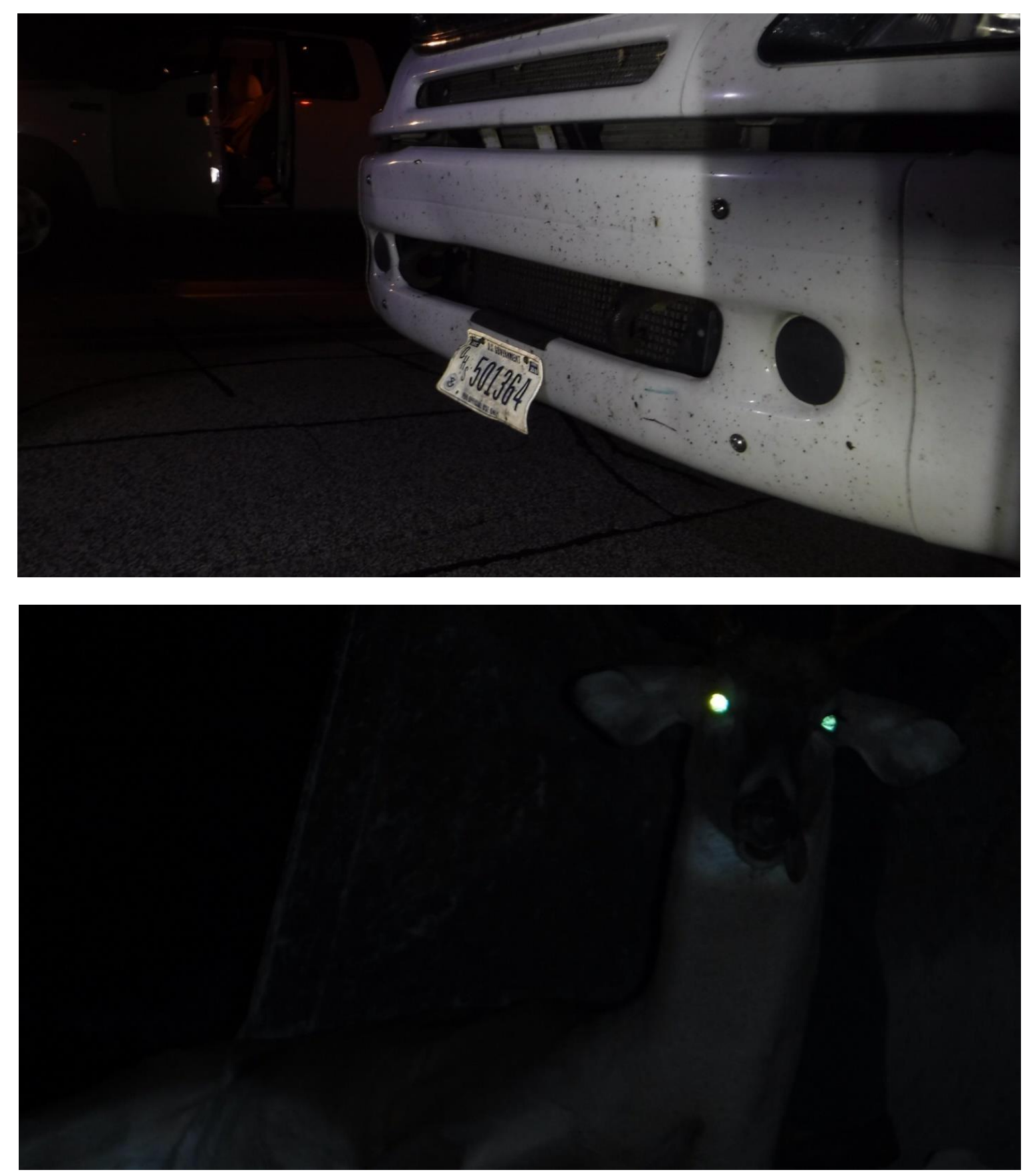

D-47 


\section{Incident Investigation Form}

Documenl Number: NCL-F:IIS000!

Revision. 1 Updated: 2-Oct-15

Ref: Safety Handbook

8.0: Incident Investigation

Incident Number: NCl.15-XXXX

Revision: $\Lambda$

W'rillen hy:

Reviented tipproved by: Safeng. Commintee

Page 1 OF 3

\section{Incident Details}

Date of Incident 10/66/8 Time 12:30 Ain Date Reported 10-16-18. Time 12:30. Ain

Location of incident north Twin of the Oval Truic

incident Type: Please select all that apply

$\square$ High Potential Incident $\square$ Low Potential Incident

$\square$ Near Miss (No injury)

$\square$ First Aid Injury

$\square$ Environmental

$\square$ Property Damage

ХAnimal (Complete through Incident Desc only)

$\square$ Recordable Injury

$\square$ Other

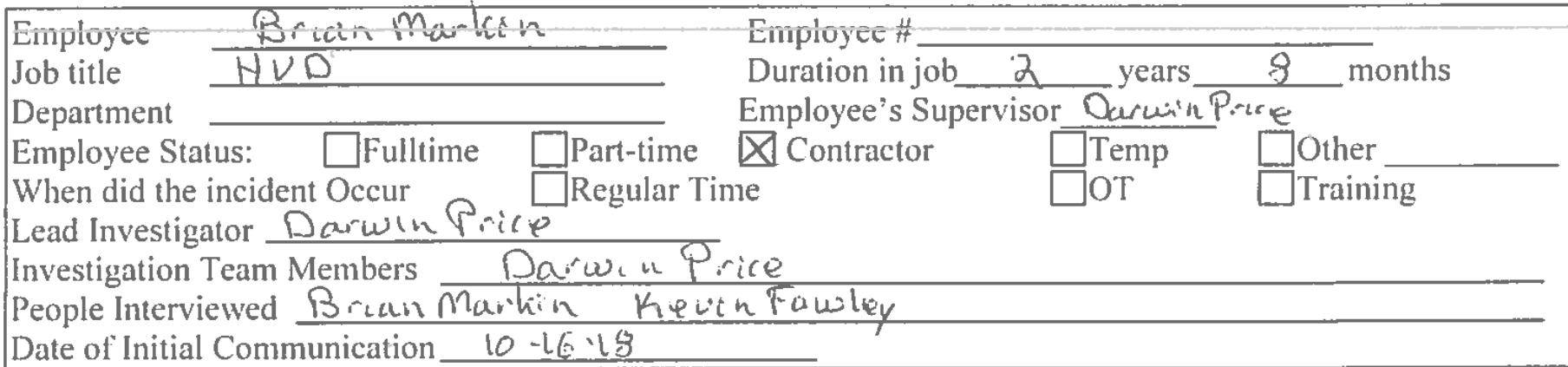

Incident Description/Facts (Who, What, When Where, Why, How?) (attach additional sheets if required) References: Procedure Step3, Training Materials A and B, Interview notes Section must be completed within 1 business day of incident Deer Juinped out in frout of Truck, Front Bumper damased 


\section{APPENDIX E. UPGRADE UNIT NPG INSPECTION REPORTS}





\section{APPENDIX E. UPGRADE UNIT NPG INSPECTION REPORTS}

This Appendix presents the Upgrade Unit inspections forms that were completed by the NPG test drivers at the end of each testing day during Part B, C1, C2, and D. Two different types of reports are included: 1) MHU Longevity Testing - Recurring Inspection, 2) MHU Longevity Testing - Record of Damage. The table below shows a summary of the results of the recurring inspections for each day of tasting. The numbers in the body of the table indicate the number of instances that the identified damage type was registered by the driver filling out the report. 
Table E- 1. Summary of Reported Damages during Part B, C1, C2 and D - Upgrade Unit.

\begin{tabular}{|c|c|c|c|c|c|c|c|c|c|c|c|c|c|c|c|}
\hline & \multicolumn{2}{|c|}{ Part B } & \multicolumn{2}{|c|}{$\begin{array}{c}\text { Part } \\
\text { C1 }\end{array}$} & \multicolumn{8}{|c|}{ Part C2 } & \multicolumn{3}{|c|}{ Part D } \\
\hline & 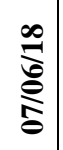 & $\underset{S}{\stackrel{\infty}{S}}$ & $\stackrel{\infty}{\stackrel{\infty}{\ominus}}$ & $\stackrel{\infty}{\stackrel{\infty}{\rho}}$ & $\frac{\infty}{\stackrel{\infty}{a}}$ & $\underset{\stackrel{\infty}{\ominus}}{\stackrel{\infty}{g}}$ & $\frac{\infty}{\stackrel{\infty}{\partial}}$ & $\frac{\infty}{\stackrel{\infty}{S}}$ & 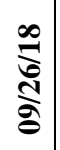 & $\underset{\stackrel{\infty}{S}}{\stackrel{\infty}{S}}$ & $\stackrel{\infty}{\stackrel{\infty}{\hat{~}}}$ & $\stackrel{\infty}{\stackrel{\infty}{S}}$ & 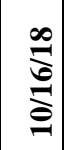 & $\stackrel{\infty}{\stackrel{\infty}{\Sigma}}$ & $\stackrel{\infty}{\stackrel{\infty}{ٍ}}$ \\
\hline CHASSIS & & & 2 & 0 & 0 & 1 & 0 & 0 & 0 & 1 & 1 & 4 & 1 & 6 & 2 \\
\hline Main beams - buckled, bent, twists & & & & & & & & & & & & 1 & & 3 & 1 \\
\hline Cross members - buckled, bent, twists & 2 & & & & & & & & & & & & & & \\
\hline Hitch/coupler damage & 1 & & & & & & & & & & & & & & \\
\hline Axle, spring, spring hanger, wheel damage & & & 2 & & & 1 & & & & 1 & 1 & 3 & 1 & 3 & 1 \\
\hline Welds/connections - cracks, breaks, damage & 1 & & & & & & & & & & & & & & \\
\hline \multicolumn{16}{|l|}{ Damage to exposed gas, waterlines, drain-lines or supports } \\
\hline FLOOR SYSTEMS & & & 0 & 0 & 0 & 0 & 0 & 0 & 0 & 0 & 0 & 0 & 0 & 0 & 0 \\
\hline Damage, separations, loosening of lags from chassis to floor & & 1 & & & & & & & & & & & & & \\
\hline \multicolumn{16}{|l|}{ Buckled floor, damaged decking/floor coverings, opening of joints, loose for popped feathers } \\
\hline \multicolumn{16}{|l|}{ Damage to bottom board, patches, loose fasteners } \\
\hline Interior wall panels - buckled, cracked, bowed, separations, fasteners popped or loose & 4 & & 2 & 1 & 1 & 2 & & & & 1 & & 1 & & & \\
\hline Separation of walls at floor, ceiling, column supports, window and door openings & & & & & 1 & 1 & & & & 1 & & & & & \\
\hline Exterior siding and trim - buckled, cracked, bowed, separations, fasteners popped or loose & 1 & & & 1 & 1 & 1 & & 2 & & & & & & 2 & 2 \\
\hline Windows and doors - damaged, buckled, bowed, or parts missing & 1 & & 1 & & 2 & & & & & & & & & & \\
\hline \multicolumn{16}{|l|}{ Windows and doors - operate properly } \\
\hline Damage to caulking and sealants & & & & & & 1 & & & & 1 & & 1 & & & \\
\hline ROOF/CEILINGS & & & 0 & 0 & 0 & 1 & 0 & 0 & 4 & 0 & 0 & 0 & 0 & 0 & 0 \\
\hline Roofing - buckled, cracked, bowed, splits, openings, loose or popped fasteners & & & & & & & & & 2 & & & & & & \\
\hline Damage to roof penetrations - vents, roof jacks, skylights, caulking and sealants & & & & & & & & & 2 & & & & & & \\
\hline \multicolumn{16}{|l|}{ Damage to eaves, overhangs, transitions } \\
\hline Ceilings - buckled, cracked, bowed, sagging, separations, loose or popped fasteners & & & & & & 1 & & & & & & & & & \\
\hline PLUMBING & & & 0 & 0 & 0 & 0 & 0 & 0 & 0 & 0 & 0 & 0 & 0 & 0 & 0 \\
\hline \multicolumn{16}{|l|}{ Damage to fixtures, piping, fittings, connections and supports } \\
\hline MODIFIED COMPONENTS FOR TESTING & & & 1 & 2 & 0 & 1 & 0 & 0 & 1 & 3 & 2 & 3 & 4 & 6 & 1 \\
\hline Axles and suspension & & & & & & 1 & & & & 1 & 1 & 3 & 1 & 3 & 1 \\
\hline Wheels and tires & 2 & 3 & 1 & 2 & & & & & 1 & 2 & 1 & & 3 & 3 & \\
\hline
\end{tabular}




\section{Attachment 3: MHU Longevity Testing - Recurring Inspection}

MHU

$\square$ Baseline
Mileage of Power Unit: 78418

Miles into testing (multiple of 500): 600

\section{A. CHASSIS}

1 Main beams buckled, bent, twists

2. Outriggers buckled, bent, twists

3. Cross members - buckled, bent, twists

4. Hitch/coupler damage

5 Axle, spring, spring hanger, wheel damage

6. Welds/connections - cracks, breaks, damage

7. Damage to exposed gas, waterlines, drain-lines or supports

\section{B. FLOOR SYSTEMS}

- amage, separations, oosening of lags from chassis to floor

2. Buckled floor, damaged deckıng/floor coverings, opening of joints oose for popped feathers

3. Damage to bottom board, patches, loose fasteners

\section{EXTERIOR/INTERIOR/MARRIAGE WALLS}

1. Interior wa pane s-buckled, crac e , owed, separations, as eners popped or loose

2. Separation of walls at floor, ceiling, column supports, window and door openings

3. Exterior siding and trim - buckled, cracked, bowed, separations, fasteners popped or loose

4. Windows and doors damaged buckled, bowed, or parts missıng

5. Windows and doors - operate properly

6. Damage to caulking and sealants

\section{ROOF/CEILINGS}

1. Roofing buckled, cracked bowed, splits, openings, loose or popped fasteners

2 Damage to roof penetratıons - vents, roof jacks, skylights caulking and sealants

3. Damage to eaves, overhangs, transitions

4. Ceilings buckled, cracked, bowed sagging separa ıns ose or popped fasteners

\section{E. PLUMBING}

Damage to fixtures, piping, fittıngs, connectıons and supports

\section{E. MODIFIED COMPONENTS FOR TESTING}

1 Ax es and suspension

2 Wheels and tires

Damaged?

Yes No
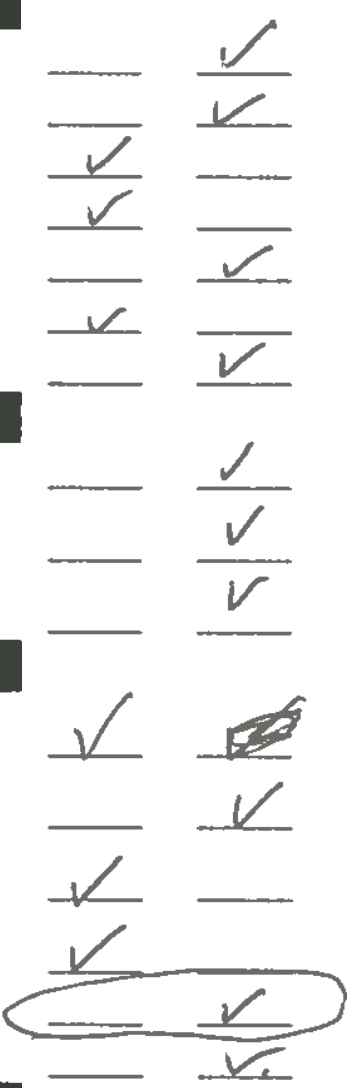
Attachment 3, Continued

MHU Longevity Testing - Recurring Inspection, p.2

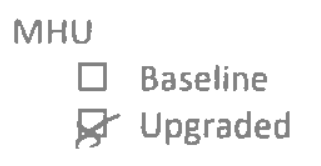

Mileage of Power Unit: $\geq 8418$

Upgraded

Testing miles (multiple of 500): 600

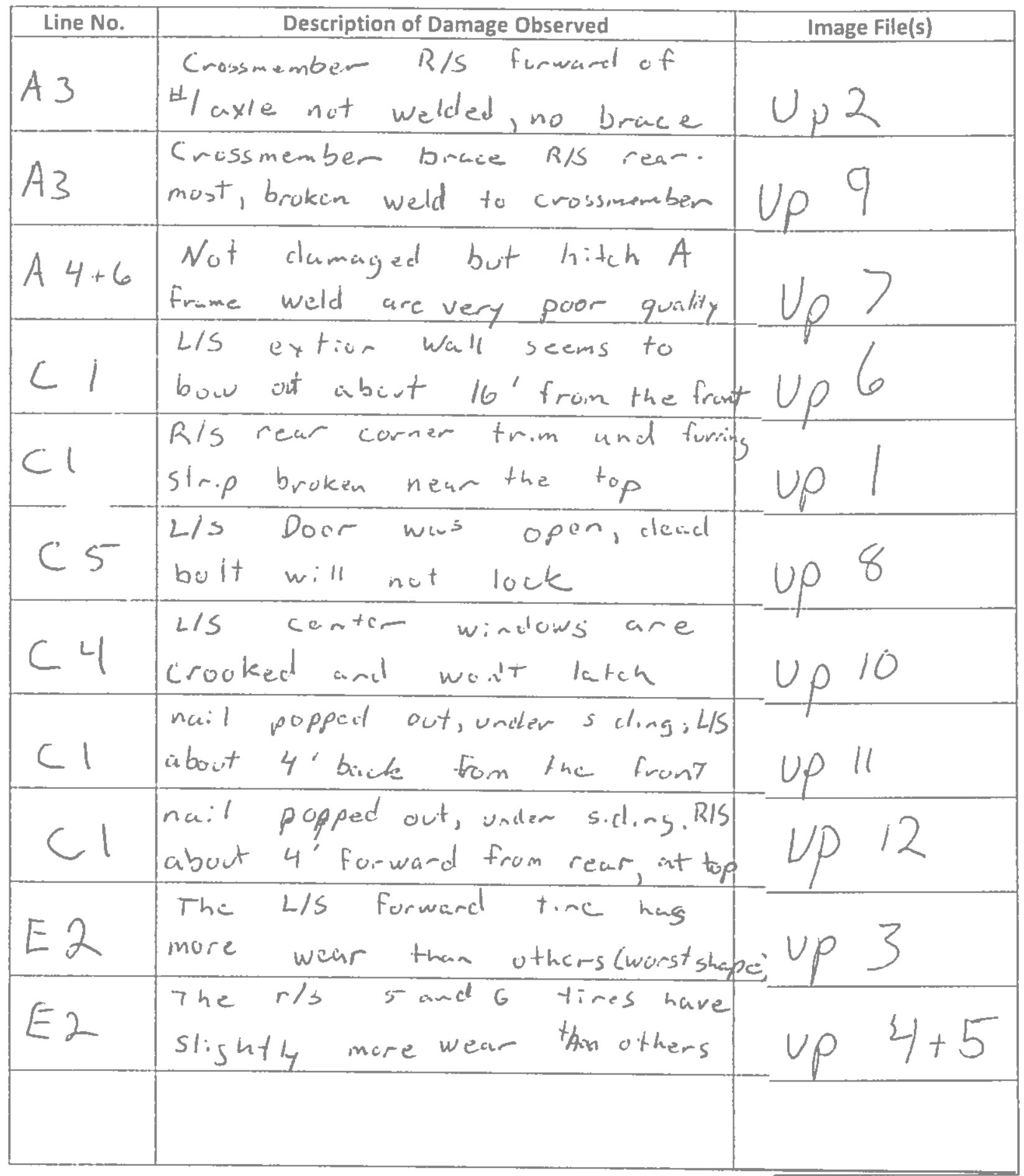

23

E-6 


\section{Attachment 3: MHU Longevity Testing - Recurring Inspection}

MHU

$\begin{array}{ll}\square & \text { Baseline } \\ \text { Upgraded }\end{array}$
Mileage of Power Unit: 78921

Miles into testing (multiple of 500): 1100

\section{A. CHASSIS}

Damaged?

1. Main beams - buckled, bent, twists

2. Outriggers - buckled, bent, twists

3. Cross members - buckled, bent, twists

4. Hitch/coupler damage

5. Axle, spring, spring hanger, wheel damage

6. Welds/connections - cracks, breaks, damage

7. Damage to exposed gas, waterlines, drain-lines or supports

\section{B. FLOOR SYSTEMS}

1. Damage, separations, loosening of lags from chassis to floor

2. Buckled floor, damaged decking/floor coverings, opening of joints, loose for popped feathers

3. Damage to bottom board, patches, loose fasteners

\section{EXTERIOR/INTERIOR/MARRIAGE WALLS}

1. Interior wall panels - buckled, cracked, bowed, separations, fasteners popped or loose

2. Separation of walls at floor, ceiling, column supports, window and door openings

3. Exterior siding and trim - buckled, cracked, bowed, separations, fasteners popped or loose

4. Windows and doors - damaged, buckled, bowed, or parts missing

5. Windows and doors - operate properly

6. Damage to caulking and sealants

\section{ROOF/CEILINGS}

1. Roofing - buckled, cracked, bowed, splits, openings, loose or popped fasteners

2. Damage to roof penetrations - vents, roof jacks, skylights, caulking and sealants

3. Damage to eaves, overhangs, transitions

4. Ceilings - buckled, cracked, bowed, sagging, separations, loose or popped fasteners

\section{E. PLUMBING}

Damage to fixtures, piping, fittings, connections and supports

\section{E. MODIFIED COMPONENTS FOR TESTING}

1. Axles and suspension

2. Wheels and tires

Yes

No
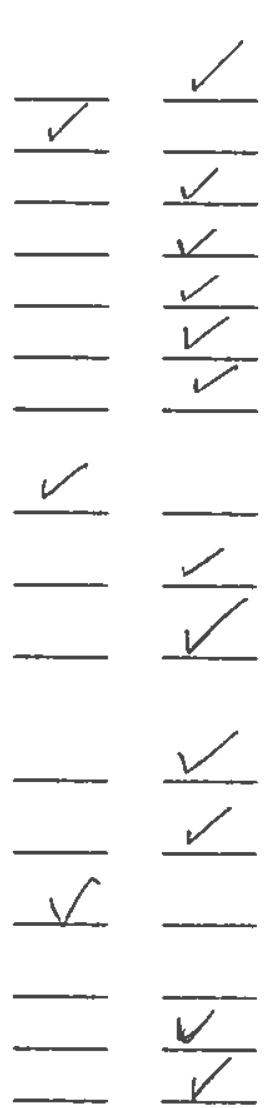

Existing

EY.st:an

Exisli:
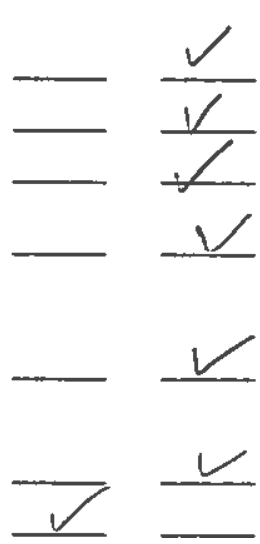
Attachment 3, Continued

MHU Longevity Testing - Recurring Inspection, p.2

MHO
$\square$ Baseline
$\square$ Upgraded

Mileage of Power Unit: 78921

Testing miles (multiple of 500): $1 / 00$

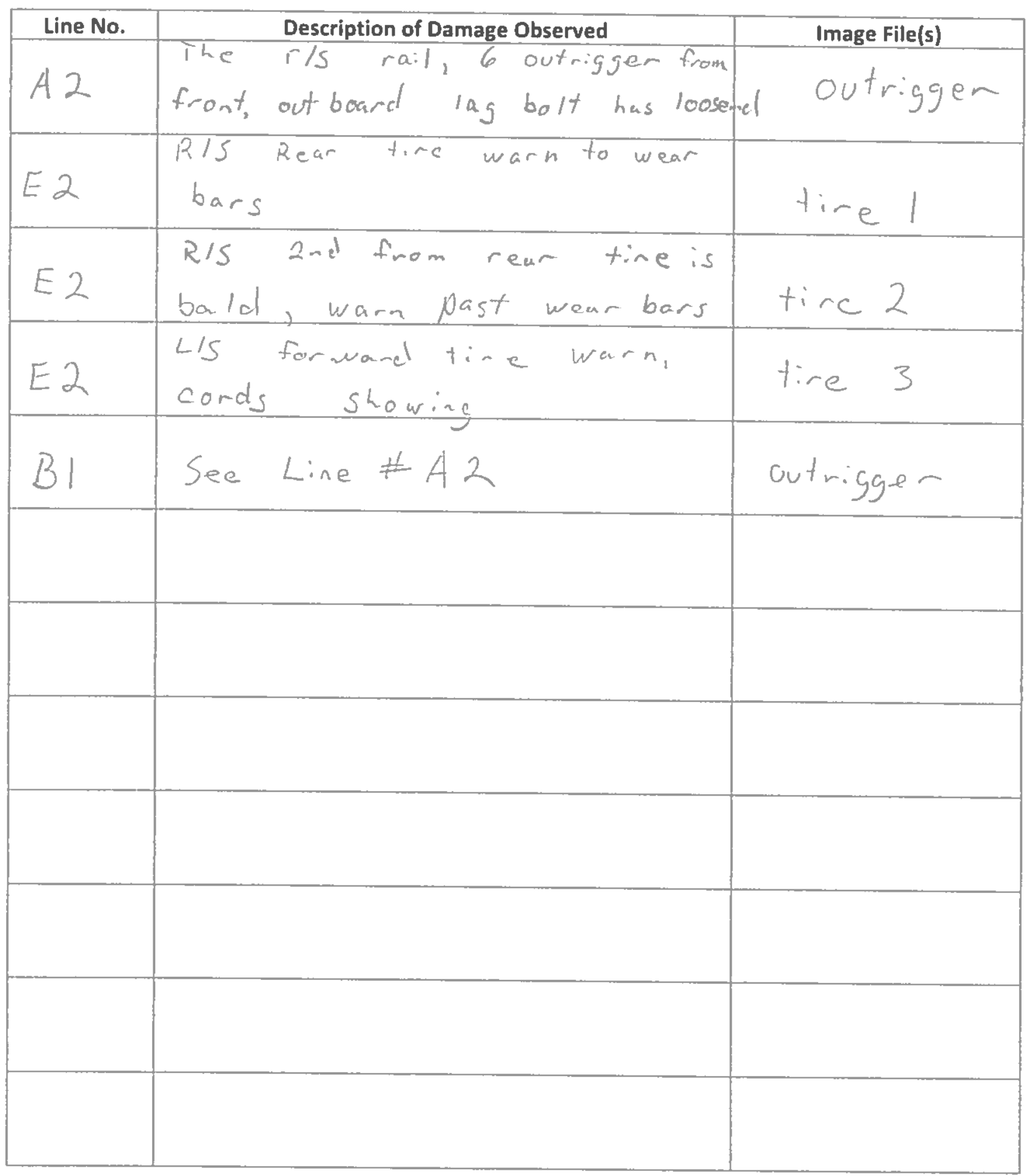

E-8

23 


\section{Attachment 3: MHU Longevity Testing Recurring Inspection}

MHU

Baseline

Upgraded
Mileage of Power Unit: 79489

Miles into testing (multiple of 500): 1677

Damaged?

Yes

No

A. CHASSIS

1. Main beams buckled, bent, twists

2 Outriggers - buckled, bent twists

3. Cross members - buckled, bent twists

4. Hitch/coupler damage

5 Axle, spring spring hanger, wheel damage

6. Welds/connections - cracks, breaks, damage

7. Damage to exposed gas, waterlınes, drain-lines or supports

B. FLOOR SYSTEMS

1. Damage, separations, loosening of lags from chassis to floor

2 Buckled floor, damaged deckıng/floor coverings, opening of joınts, loose for popped feathers

3 Damage to bottom board, patches, loose fasteners

C. EXTERIOR/INTERIOR/MARRIAGE WALLS

1. Interior wall panels - buckled, cracked, bowed, separations, fasteners popped or loose

2. Separation of walls at floor, ceiling, column supports, window and door openıngs

3 Exterior siding and trim buckled, cracked, bowed, separations fasteners popped or loose

4. Windows and doors - damaged, buckled, bowed, or parts missing

5. Windows and doors - operate properly

6. Damage to caulking and sealants

D. ROOF/CEILINGS

1. Roofing - buckled, cracked, bowed, splits, openings, loose or popped fasteners

2. Damage to roof penetrations - vents, roof jacks, skylights, caulking and sealants

3. Damage to eaves, overhangs, transitions

4. Ceilings - buckled, cracked, bowed, sagging, separations, loose or popped fasteners

E. PLUMBING

Damage to fixtures, piping, fittings, connections and supports

E. MODIFIED COMPONENTS FOR TESTING

1. Axles and suspension

2 Wheels and tires 
$7-30-18$

Attachment 3, Continued

MHU Longevity Testing - Recurring Inspection, p.2

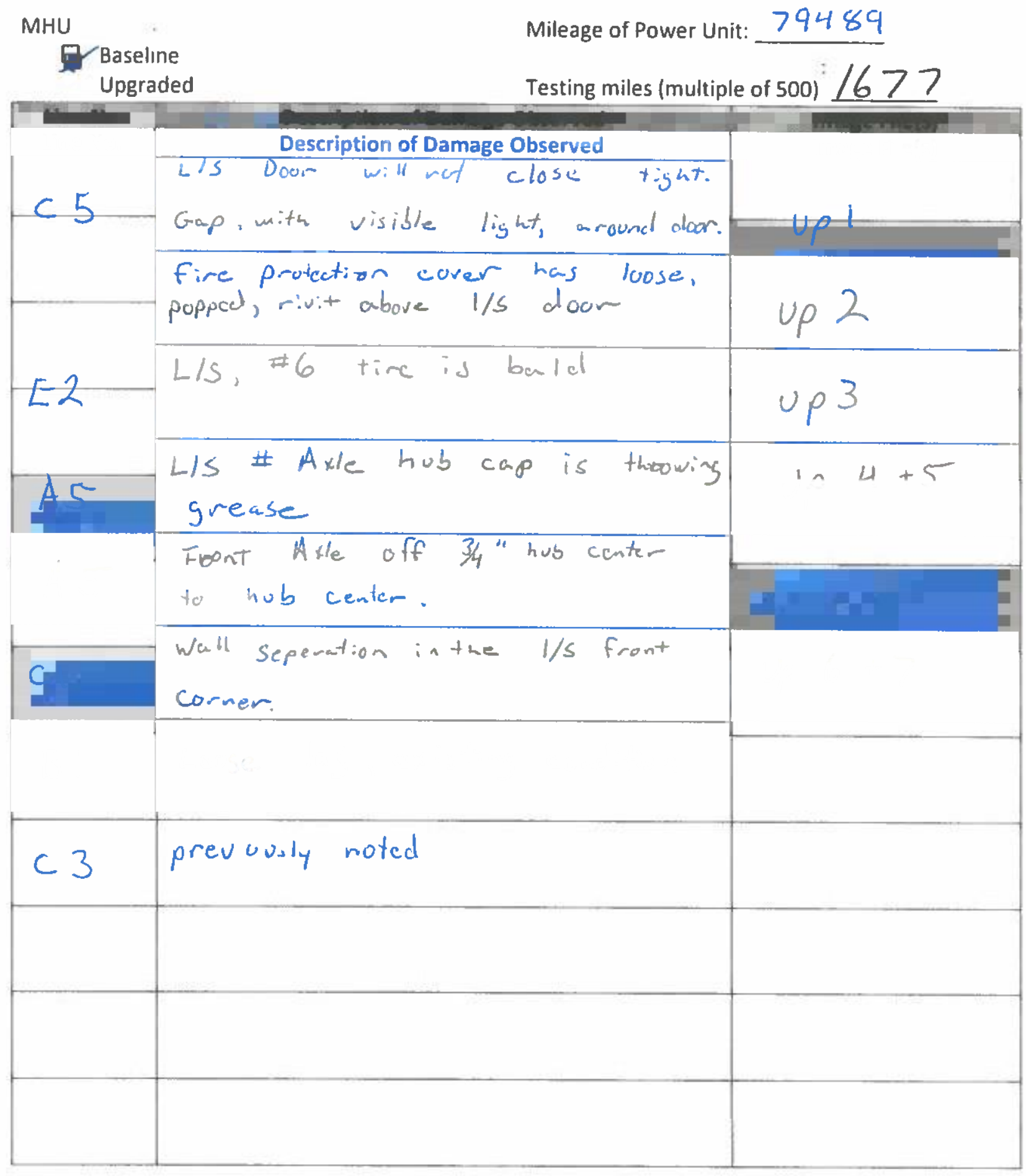




\section{Attachment 3: MHU Longevity Testing - Recurring Inspection}

MHU

$\square$ Baseline

Upgraded
Mileage of Power Unit: 80090

Miles into testing (multiple of 500):

\author{
2278
}

\section{A. CHASSIS}

1. Main beams - buckled, bent, twists

2 Outriggers - buckled, bent, twists

3. Cross members - buckled, bent, twists

4. Hitch/coupler damage

5. Axle, spring, spring hanger, wheel damage

6. Welds/connections - cracks, breaks, damage

7. Damage to exposed gas, waterlines, drain-lines or supports

\section{B. FLOOR SYSTEMS}

1. Damage, separations, loosening of lags from chassis to floor

2. Buckled floor, damaged decking/floor coverings, opening of joints, loose for popped feathers

3. Damage to bottom board, patches, loose fasteners

\section{EXTERIOR/INTERIOR/MARRIAGE WALLS}

1. Interior wall panels - buckled, cracked, bowed, separations, fasteners popped or loose

2. Separation of walls at floor, ceiling, column supports, window and door openings

3. Exterior siding and trim - buckled, cracked, bowed, separations, fasteners popped or loose

4. Windows and doors - damaged, buckled, bowed, or parts missing

5. Windows and doors - operate properly

6. Damage to caulking and sealants

D. ROOF/CEILINGS

1. Roofing - buckled, cracked, bowed, splits, openings, loose or popped fasteners

2. Damage to roof penetrations - vents, roof jacks, skylights, caulking and sealants

3. Damage to eaves, overhangs, transitions

4. Ceilings - buckled, cracked, bowed, sagging, separations, loose or popped fasteners

E. PLUMBING

Damage to fixtures, piping, fittings, connections and supports

E. MODIFIED COMPONENTS FOR TESTING

1. Axles and suspension

2. Wheels and tires

Damaged?

Yes No
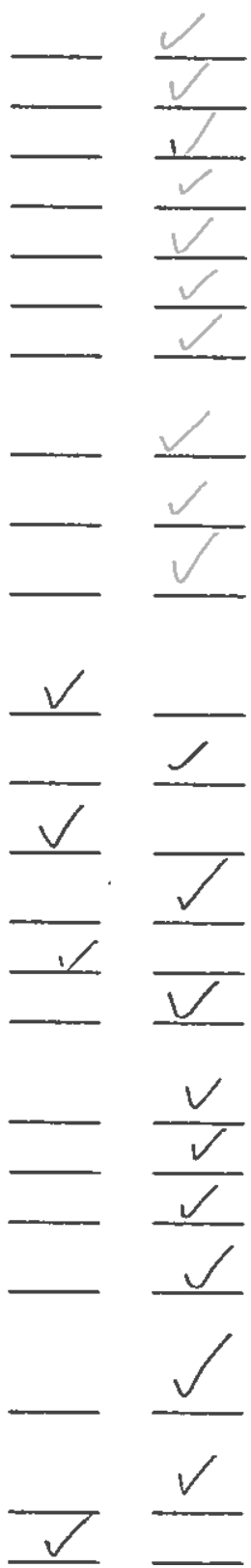
Attachment 3, Continued

MHU Longevity Testing - Recurring Inspection, p.2

MHU

$\square$ Baseline

Q Upgraded

Mileage of Power Unit: 80090

Testing miles (multiple of 500): 2278

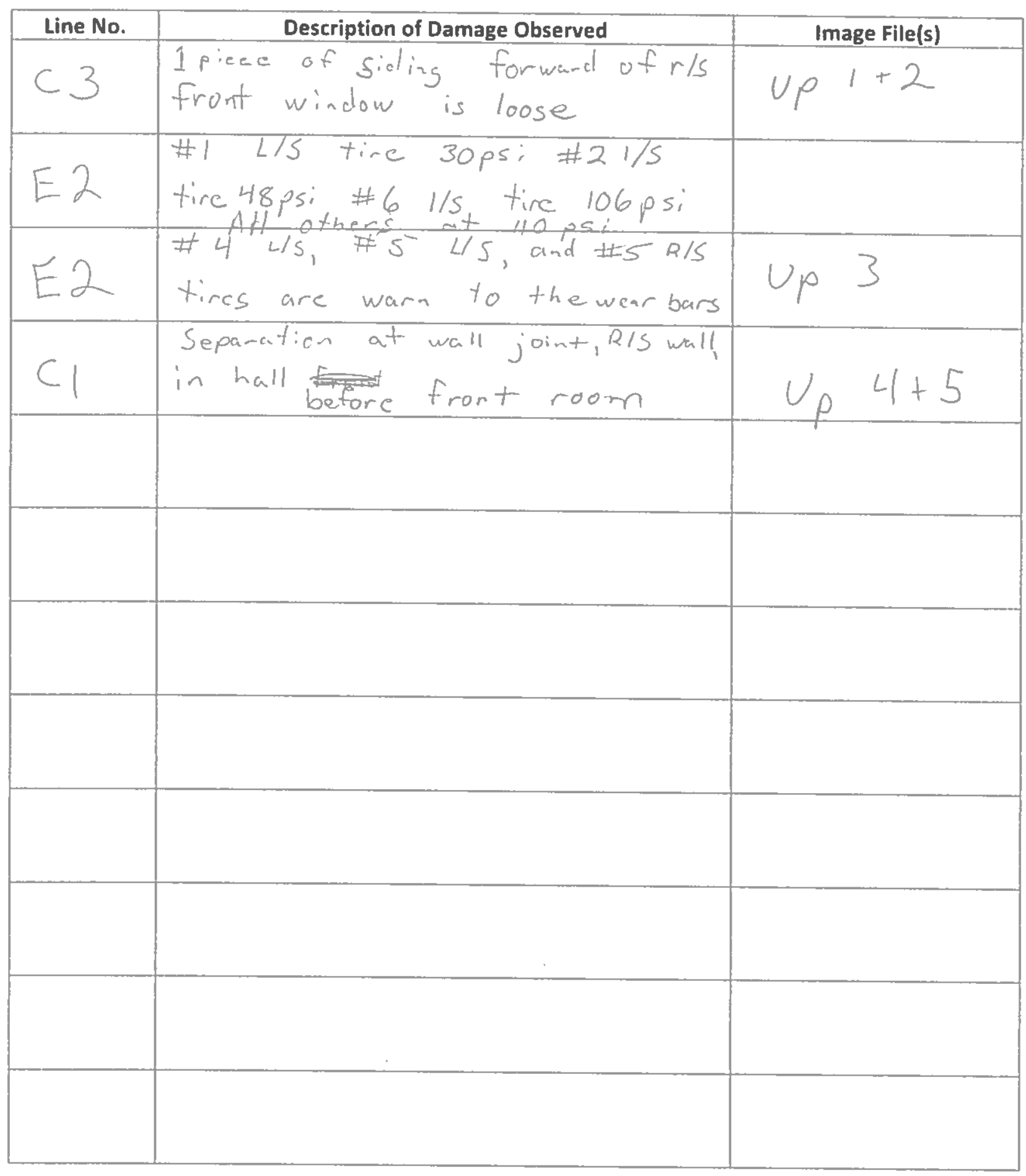




\section{Attachment 3: MHU Longevity Testing - Recurring Inspection}

MHU

$\square$ Baseline

X Upgraded
Mileage of Power Unit: $80>91$

Miles into testing (multiple of 500):

\section{A. CHASSIS}

Damaged?

1. Main beams - buckled, bent, twists

2. Outriggers - buckled, bent, twists

3. Cross members - buckled, bent, twists

4. Hitch/coupler damage

5. Axle, spring, spring hanger, wheel damage

6. Welds/connections - cracks, breaks, damage

7. Damage to exposed gas, waterlines, drain-lines or supports

B. FLOOR SYSTEMS

1. Damage, separations, loosening of lags from chassis to floor

2. Buckled floor, damaged decking/floor coverings, opening of joints, loose for popped feathers

3. Damage to bottom board, patches, loose fasteners

\section{EXTERIOR/INTERIOR/MARRIAGE WALLS}

1. Interior wall panels buckled, cracked, bowed, separations, fasteners popped or loose

2. Separation of walls at floor, ceiling, column supports, window and door openings

3. Exterıor siding and trım - buckled, cracked, bowed, separations, fasteners popped or loose

4. Windows and doors - damaged, buckled, bowed, or parts missing

5. Windows and doors operate properly

6. Damage to caulking and sealants

D. ROOF/CEILINGS

1. Roofing - buckled, cracked, bowed, splits, openings, loose or popped fasteners

2. Damage to roof penetrations vents, roof jacks, skylights, caulking and sealants

3. Damage to eaves, overhangs, transitions

4. Ceilıngs - buckled, cracked, bowed, sagging, separations, loose or popped fasteners

\section{E. PLUMBING}

Damage to fixtures, piping, fittings, connections and supports

\section{E. MODIFIED COMPONENTS FOR TESTING}

1 Axles and suspension

2 Wheels and tires

Yes

No
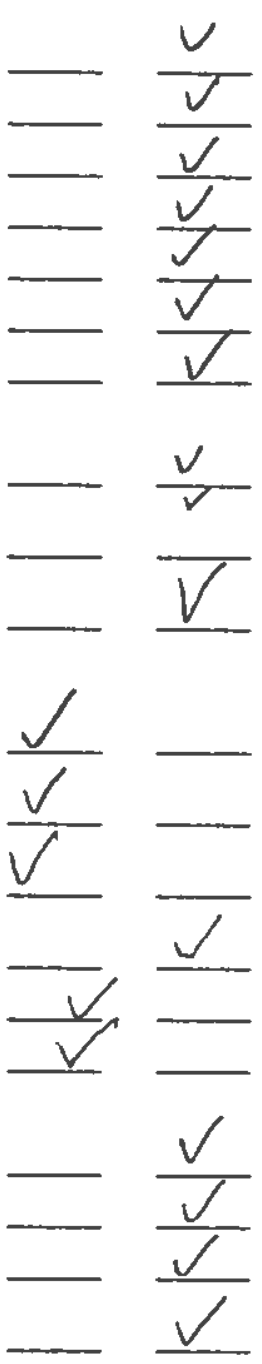

. 
Attachment 3, Continued

$9-13-18$

MHU Longevity Testing - Recurring Inspection, p.2

MHU

$\square$ Baseline

Upgraded
Mileage of Power Unit: 80791

Testing miles (multiple of 500):

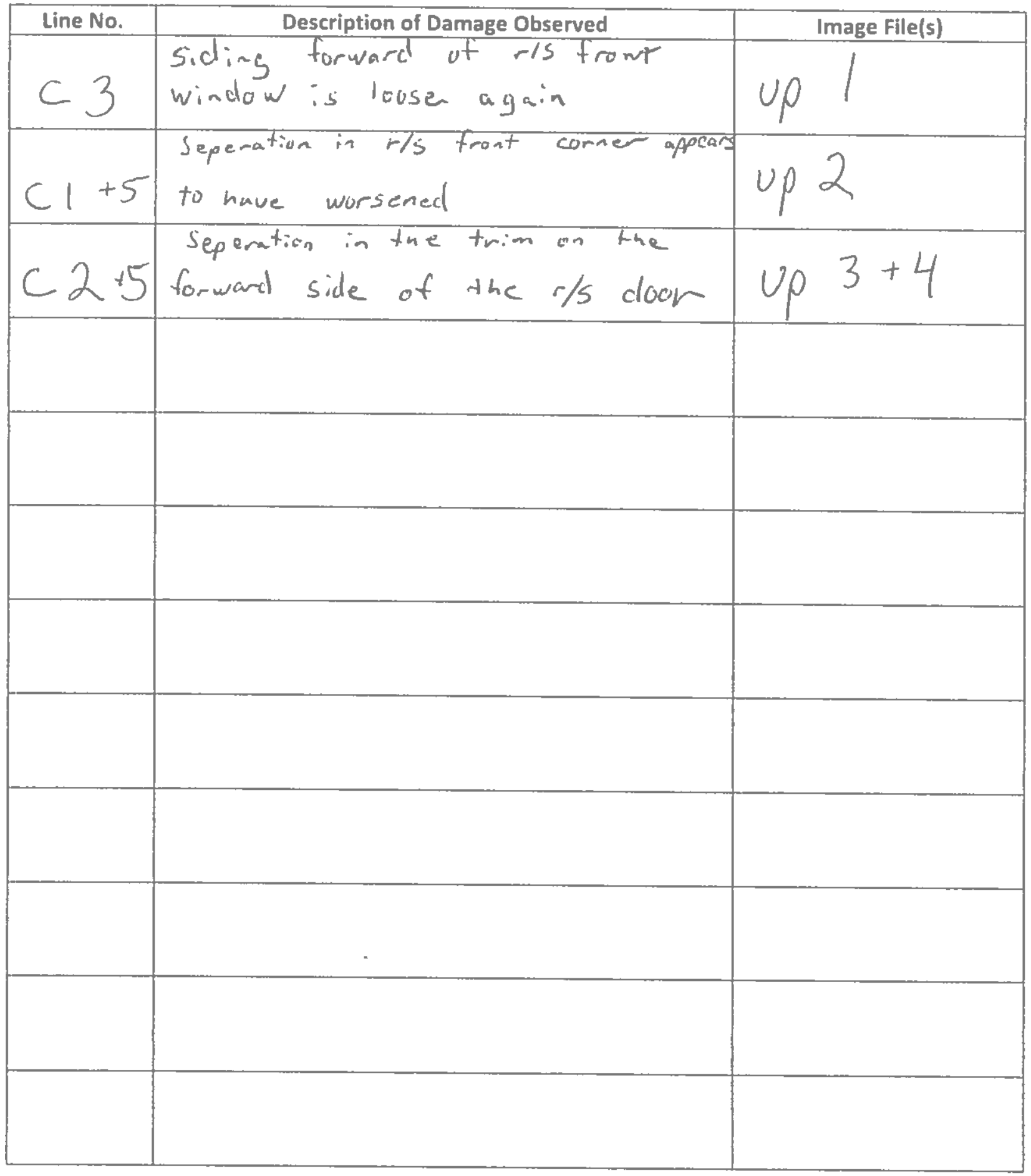




\section{Attachment 3: MHU Longevity Testing - Recurring Inspection}

MHU

$\square$ Baseline

অ Upgraded
Mileage of Power Unit: 814414

Miles into testing (multiple of 500):

\section{A. CHASSIS}

Damaged?

1. Main beams - buckled, bent, twists

2. Outriggers - buckled, bent, twists

3. Cross members - buckled, bent, twists

4. Hitch/coupler damage

5. Axle, spring, spring hanger, wheel damage

6. Welds/connections - cracks, breaks, damage

7. Damage to exposed gas, waterlines, drain-lines or supports

\section{B. FLOOR SYSTEMS}

1. Damage, separations, loosening of lags from chassis to floor

2. Buckled floor, damaged decking/floor coverings, opening of joints, loose for popped feathers

3. Damage to bottom board, patches, loose fasteners

C. EXTERIOR/INTERIOR/MARRIAGE WALLS

1. Interior wall panels - buckled, cracked, bowed, separations, fasteners popped or loose

2. Separation of walls at floor, ceiling, column supports, window and door openings

3. Exterior siding and trim - buckled, cracked, bowed, separations, fasteners popped or loose

4. Windows and doors - damaged, buckled, bowed, or parts missing

5. Windows and doors - operate properly

6. Damage to caulking and sealants

\section{ROOF/CEILINGS}

1. Roofing - buckled, cracked, bowed, splits, openings, loose or popped fasteners

2. Damage to roof penetrations - vents, roof jacks, skylights, caulking and sealants

3. Damage to eaves, overhangs, transitions

4. Ceilings - buckled, cracked, bowed, sagging, separations, loose or popped fasteners

E. PLUMBING

Damage to fixtures, piping, fittings, connections and supports

\section{E. MODIFIED COMPONENTS FOR TESTING}

1. Axles and suspension

2. Wheels and tires

Yes

No
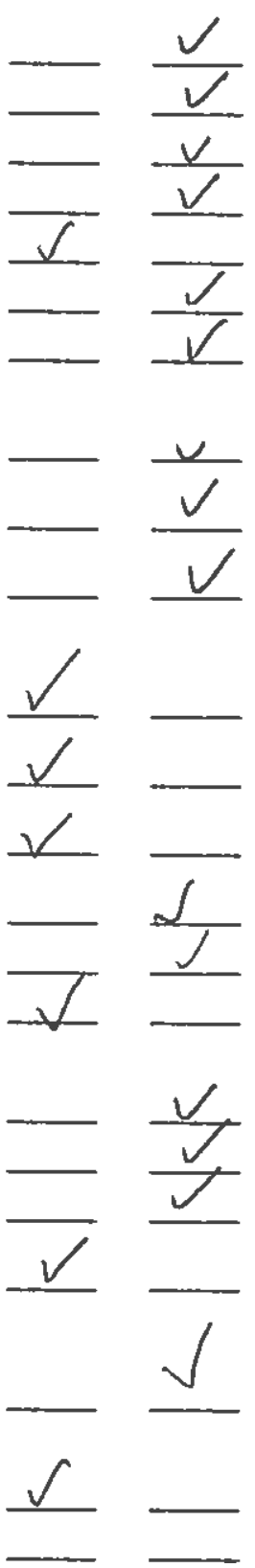
Attachment 3, Continued

$$
9-14-18
$$

MHU Longevity Testing - Recurring Inspection, p.2

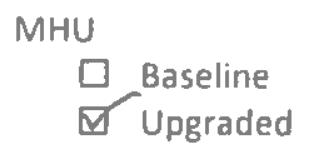

$$
\text { Mileage of Power Unit: } 8 / 414
$$

Testing miles (multiple of 500):

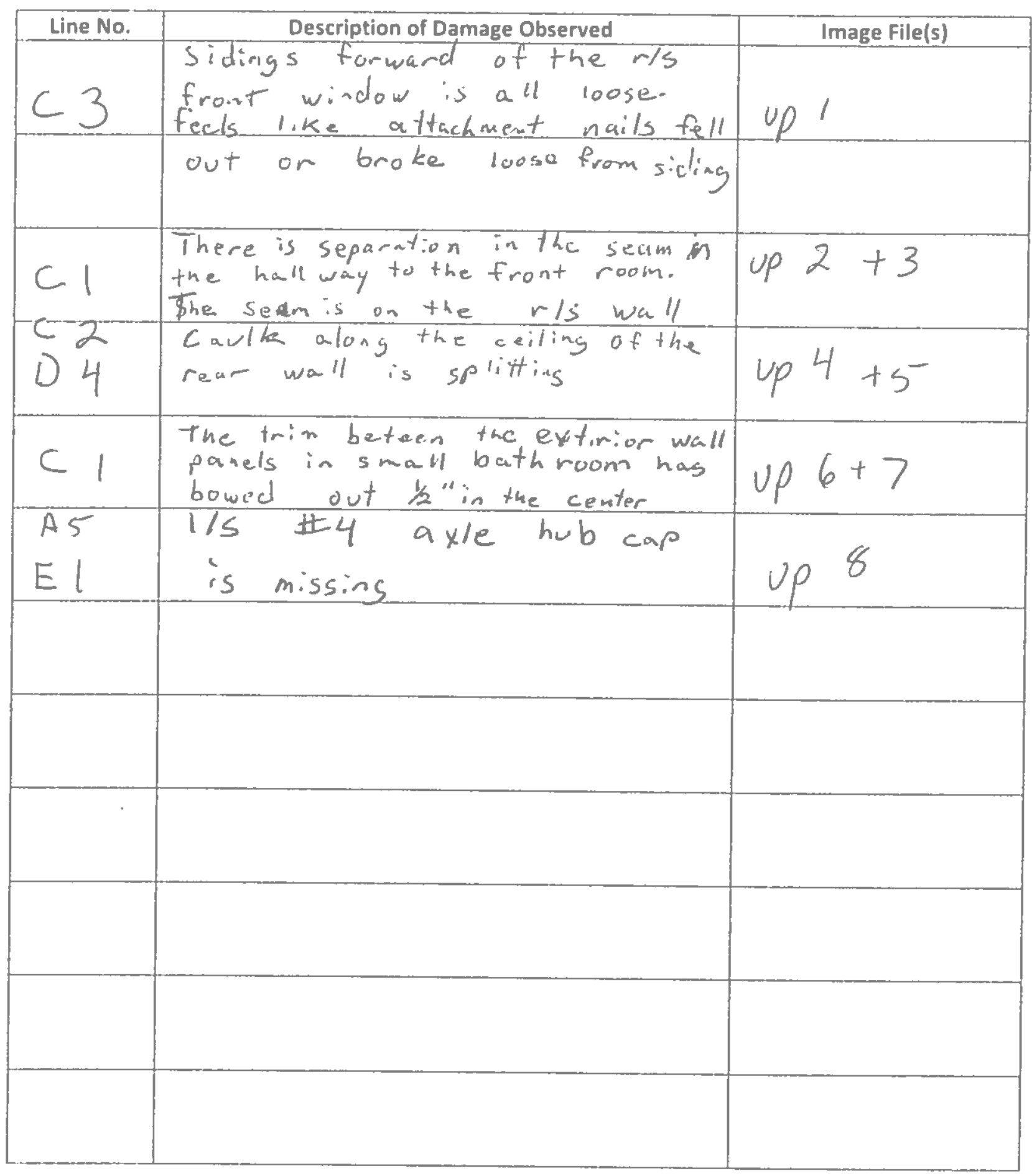

23

E-16 


\section{Attachment 3: MHU Longevity Testing - Recurring Inspection}

MHU

\author{
Baseline \\ Upgraded
}

Mileage o ower Unit: 81968

Miles into testing (multiple of 500)
Damaged?

Yes

No

A. CHASSIS

1. Main beams - buc ed, bent, twists

2. Outriggers - buckled, bent, twists

3. Cross members - buckled, bent, twists

4. Hitch/coupler damage

5. Axle, spring, spring hanger, wheel damage

6. Welds/connections cracks, breaks, damage

7 Damage to exposed gas, waterlınes, drain-lines or supports

B. FLOOR SYSTEMS

1 Damage, separations, loosening of ags from chassis to floor

2. Buckled floor damaged decking/floor coverings, openıng of joints, loose for popped feathers

3. Damage to bottom board, patches, loose fasteners

\section{EXTERIOR/INTERIOR/MARRIAGE WALLS}

1. Interior wall panels buckled, cracked, bowed, separations, fasteners poppe or loose

2. Separation of walls at floor, ceilıng, column supports, window and door openings

3. Exterior siding and trim buckled, cracked, bowed, separations, fasteners popped or loose

4. Windows and doors - damaged, buckled, bowed, or parts missing

5. Windows and doors - operate properly

6. Damage to caulking and sealants

D. ROOF/CEILINGS

1. Roofing - buckled, cracked, bowed, splits, openings, loose or popped fasteners

2. Damage to roof penetrations - vents, roof jacks, skylights, caulking and sealants

3. Damage to eaves, overhangs, transitions

4. Ceilings - buckled, cracked, bowed, sagging, separations, loose or popped fasteners

E. PLUMBING

Damage to fixtures, piping, fittings, connections and supports

E. MODIFIED COMPONENTS FOR TESTING

1 Axles and suspension

2. Wheels and tires

If "Yes" column is checked for any item, please take one or more pictures and detail on reverse.
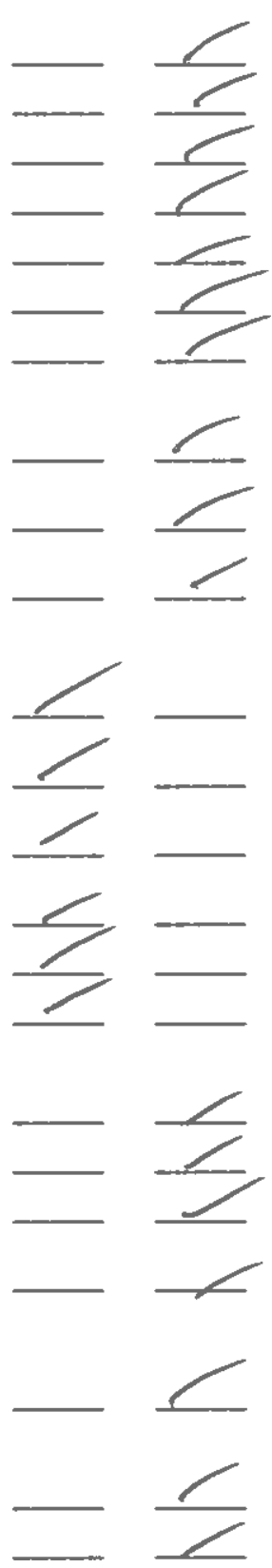


\section{Attachment 3: MHU Longevity Testing - Recurring Inspection}

MHU

$\square$ Baseline
$\square$ Upgraded
Mileage of Power Unit: $8785-6$

Miles into testing (multiple of 500 ):

\section{A. CHASSIS}

1. Main beams buckled, bent, twists

2 Outriggers buckled, bent, twists

3. Cross members - buckled, bent, twists

4. Hitch/coupler damage

5. Axle, spring, spring hanger, wheel damage

6 Welds/connections - cracks, breaks, damage

7. Damage to exposed gas, waterlines, drain-lines or supports

B. FLOOR SYSTEMS

1. Damage, separations, loosening of lags from chassis to floor

2. Buckled floor, damaged decking/floor coverings, opening of joınts, loose for popped feathers

3. Damage to bottom board, patches, loose fasteners

C. EXTERIOR/INTERIOR/MARRIAGE WALLS

1. Interior wall panels - buckled, cracked, bowed, separations, fasteners popped or loose

2. Separation of walls at floor, ceiling, column supports, window and door openings

3. Exterior siding and trim - buckled, cracked, bowed, separations, fasteners popped or loose

4. Windows and doors - damaged, buckled, bowed, or parts missing

5. Windows and doors - operate properly

6. Damage to caulking and sealants

D. ROOF/CEILINGS

1. Roofing - buckled, cracked, bowed, splits, openings, loose or popped fasteners

2 Damage to roof penetrations vents, roof jacks, skylights, caulking and sealants

3. Damage to eaves, overhangs, transitions

4 Ceilıngs buckled, cracked, bowed, sagging, separations, loose or popped fasteners

E. PLUMBING

Damage to fixtures, piping, fittings, connections and supports

E. MODIFIED COMPONENTS FOR TESTING

1 Axles and suspension

2 Wheels and tires

\section{Damaged?}

Yes

No
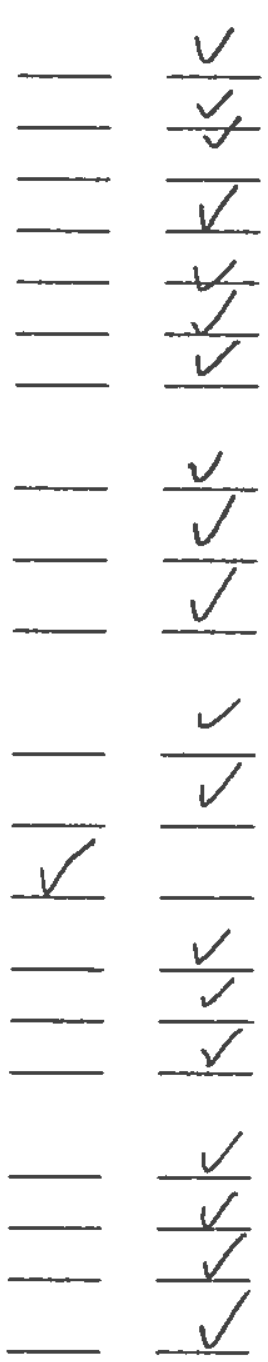
Attachment 3, Continued

MHU Longevity Testing - Recurring Inspection, p.2

$$
9-21-18
$$

MHU

[. Baseline

$\checkmark$ Upgraded
Mileage of Power Unit: 87856

Testing miles (multiple of 500):

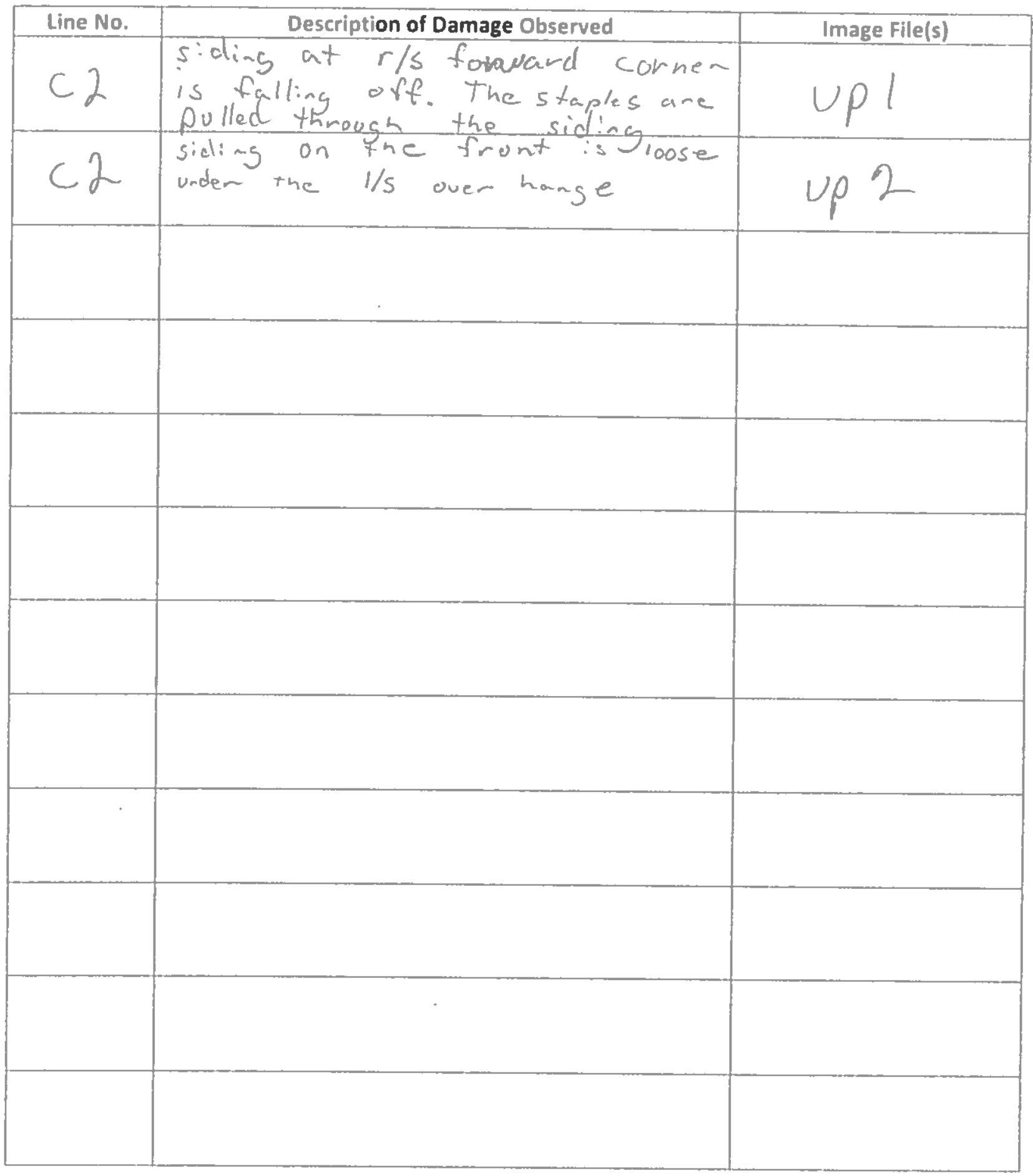

E-19 


\section{Attachment 3: MHU Longevity Testing - Recurring Inspection}

$$
9 \cdot 26-18
$$

MHU

$$
\square \text { Baseline }
$$

\section{Mileage of Power Unit: 88966}

Miles into testing (multiple of 500):

\section{A. CHASSIS}

1. Main beams buckled, bent, twists

2. Outriggers buckled, bent, twists

3. Cross members - buckled, bent, twists

4. Hitch/coupler damage

5. Axle, spring, spring hanger, wheel damage

6. Welds/connections - cracks, breaks, damage

7. Damage to exposed gas, waterlines, drain-lines or supports

B. FLOOR SYSTEMS

1. Damage, separations, loosening of lags from chassis to floor

2. Buckled floor, damaged decking/floor coverings, opening of joints, loose for popped feathers

3. Damage to bottom board, patches, loose fasteners

\section{EXTERIOR/INTERIOR/MARRIAGE WALLS}

1. Interior wall panels - buckled, cracked, bowed, separations, fasteners popped or loose

2. Separation of walls at floor, ceiling, column supports, window and door openings

3. Exterior siding and trim - buckled, cracked, bowed, separations, fasteners popped or loose

4. Windows and doors - damaged, buckled, bowed, or parts missing

5. Windows and doors - operate properly

6. Damage to caulking and sealants

D. ROOF/CEILINGS

1. Roofing - buckled, cracked, bowed, splits, openings, loose or popped fasteners

2. Damage to roof penetrations - vents, roof jacks, skylights, caulking and sealants

3. Damage to eaves, overhangs, transitions

4. Ceilings - buckled, cracked, bowed, sagging, separations, loose or popped fasteners

\section{E. PLUMBING}

Damage to fixtures, piping, fittings, connections and supports

\section{E. MODIFIED COMPONENTS FOR TESTING}

1. Axles and suspension

2. Wheels and tires

\section{Damaged?}

Yes

No
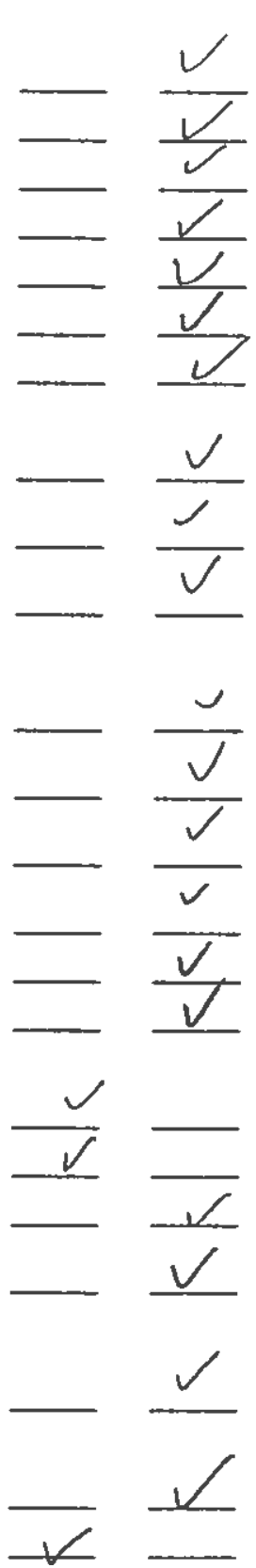
$\begin{array}{cc}\text { Attachment 3, Continued } & 9-26-18 \\ \text { MHU Longevity Testing - Recurring Inspection, p.2 } & 9\end{array}$

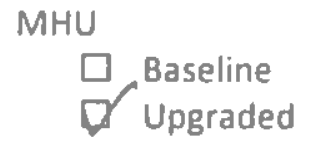

Mileage of Power Unit: 88966

Testing miles (multiple of 500):

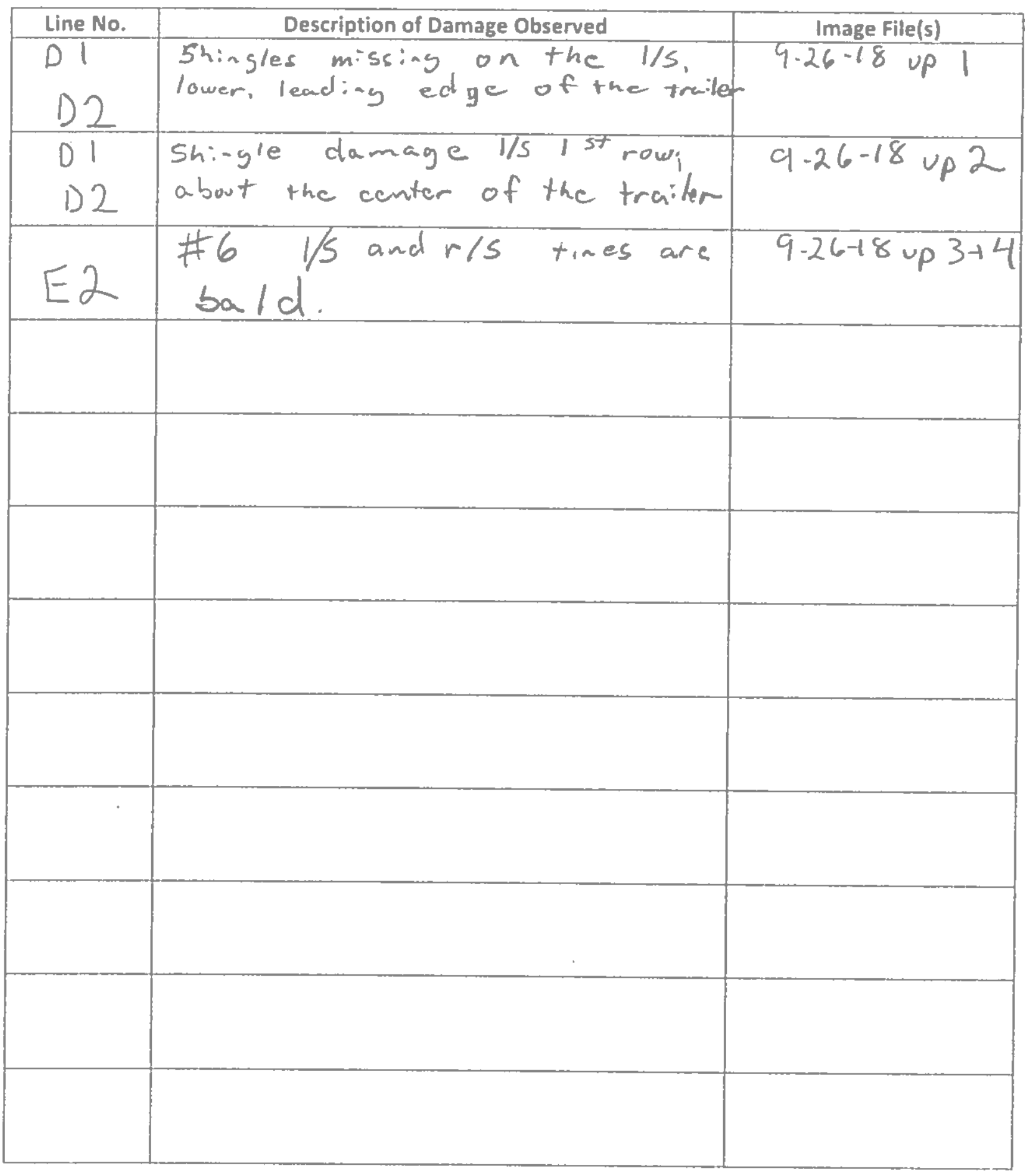

E-21

23 


\section{Attachment 3: MHU Longevity Testing - Recurring Inspection 9-27.18}

MHU

$\square$ Baseline

Upgraded
Mileage of Power Unit: $895-96$

Miles into testing (multiple of 500):

A. CHASSIS

1 Main beams buckled, bent, twists

2. Outriggers - buckled, bent, twists

3. Cross members - buckled, bent, twists

4. Hitch/coupler damage

5. Axle, spring, spring hanger, wheel damage

6. Welds/connections - cracks, breaks, damage

7. Damage to exposed gas, waterlines, drain-lines or supports

B. FLOOR SYSTEMS

1. Damage, separations, loosening of lags from chassis to floor

2. Buckled floor, damaged decking/floor coverings, openıng of joints, loose for popped feathers

3. Damage to bottom board, patches, loose fasteners

C. EXTERIOR/INTERIOR/MARRIAGE WALLS

1. Interior wall panels - buckled, cracked, bowed, separations, fasteners popped or loose

2. Separation of walls at floor, ceiling, column supports, window and door openings

3. Exterior siding and trim - buckled, cracked, bowed, separations, fasteners popped or loose

4. Windows and doors - damaged, buckled, bowed, or parts missing

5. Windows and doors - operate properly

6. Damage to caulking and sealants

D. ROOF/CEILINGS

1. Roofing - buckled, cracked, bowed, splits, openings, loose or popped fasteners

2. Damage to roof penetrations - vents, roof jacks, skylights, caulking and sealants

3. Damage to eaves, overhangs, transitions

4. Ceilings - buckled, cracked, bowed, sagging, separations, loose or popped fasteners

E. PLUMBING

Damage to fixtures, piping, fittings, connections and supports

E. MODIFIED COMPONENTS FOR TESTING

1. Axles and suspension

2 Wheels and tires

Damaged?

Yes

No
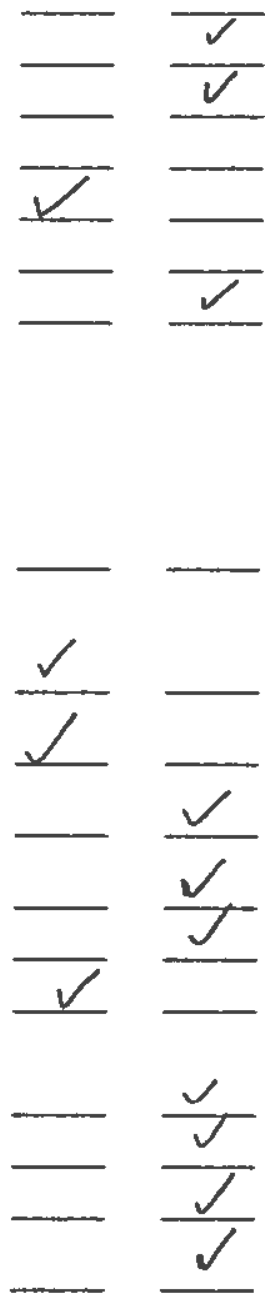
Attachment 3, Continued

MHU Longevity Testing - Recurring Inspection, p.2 9.27 .18

MHU

Baseline
Mileage of Power Unit: $895-96$

Testing miles (multiple of 500):

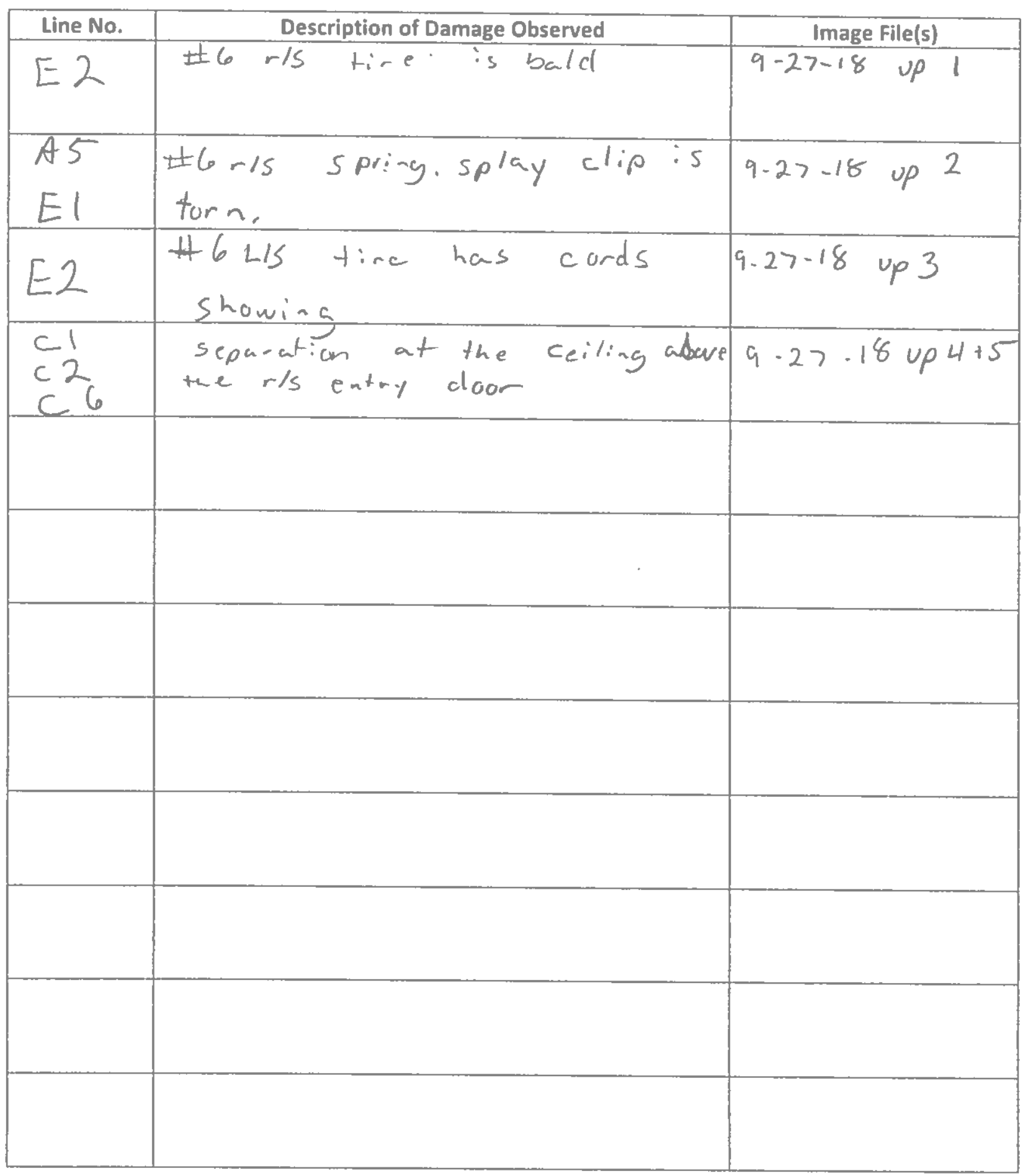




\section{Attachment 3: MHU Longevity Testing Recurring Inspection $10-9-18$}

MHU

$\square$ Baseline

$\checkmark$ Upgraded

\section{Mileage of Power Unit: 90242}

Miles into testing (multiple of 500):

\section{A. CHASSIS}

1 Main beams buckled, bent, twists

2 Outriggers buckled, bent, twists

3 Cross members buckled, bent, twists

4 Hitch/coupler damage

5 Axle, spring, spring hanger, wheel damage

6 Welds/connections cracks, breaks, damage

7 Damage to exposed gas, waterlınes, drain-lınes or supports

\section{B. FLOOR SYSTEMS}

1 Damage, separations, loosening of lags from chassis to floor

2 Buckled floor, damaged deckıng/floor coverıngs, openıng of joints, loose for popped feathers

3. Damage to bottom board, patches, loose fasteners

\section{EXTERIOR/INTERIOR/MARRIAGE WALLS}

1. Interior wall panels - buckled, cracked, bowed, separations, fasteners popped or loose

2. Separation of walls at floor, ceiling, column supports, window and door openings

3. Exterior siding and trim - buckled, cracked, bowed, separations, fasteners popped or loose

4 Windows and doors damaged, buckled, bowed, or parts missing

5. Windows and doors operate properly

6. Damage to caulking and sealants

D. ROOF/CEILINGS

1 Roofing buckled, cracked, bowed, splits, openings, loose or popped fasteners

2 Damage to roof penetrations vents, roof jacks, skylights, caulkıng and sealants

3 Damage to eaves, overhangs, transitions

4. Cellings - buckled, cracked, bowed, sagging, separations, loose or popped fasteners

\section{E. PLUMBing}

Damage to fixtures, pipıng, fittıngs, connections and supports

\section{E. MODIFIED COMPONENTS FOR TESTING}

1 Axles and suspension

2 Wheels and tures

Damaged?

Yes No
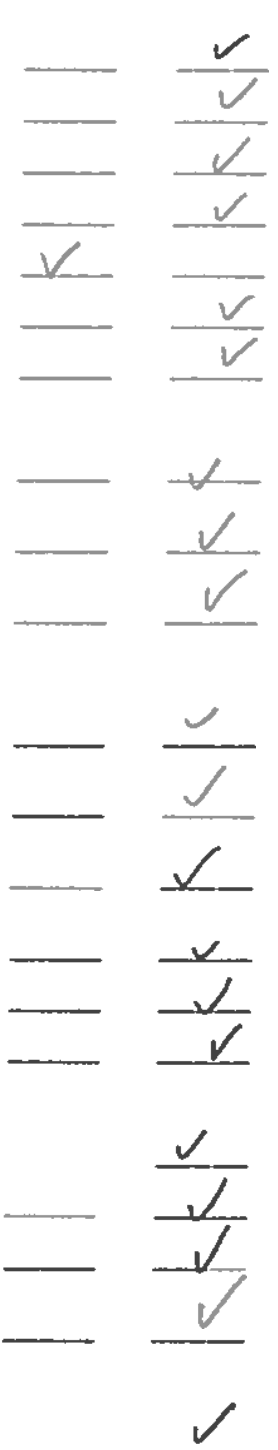
Attachment 3, Continued MHU Longevity Testing - Recurring Inspection, p.2 $10-9-18$

U

Baseline

U Upgraded
Mileage of Power Unit: 90242

Testing miles (multiple of 500):

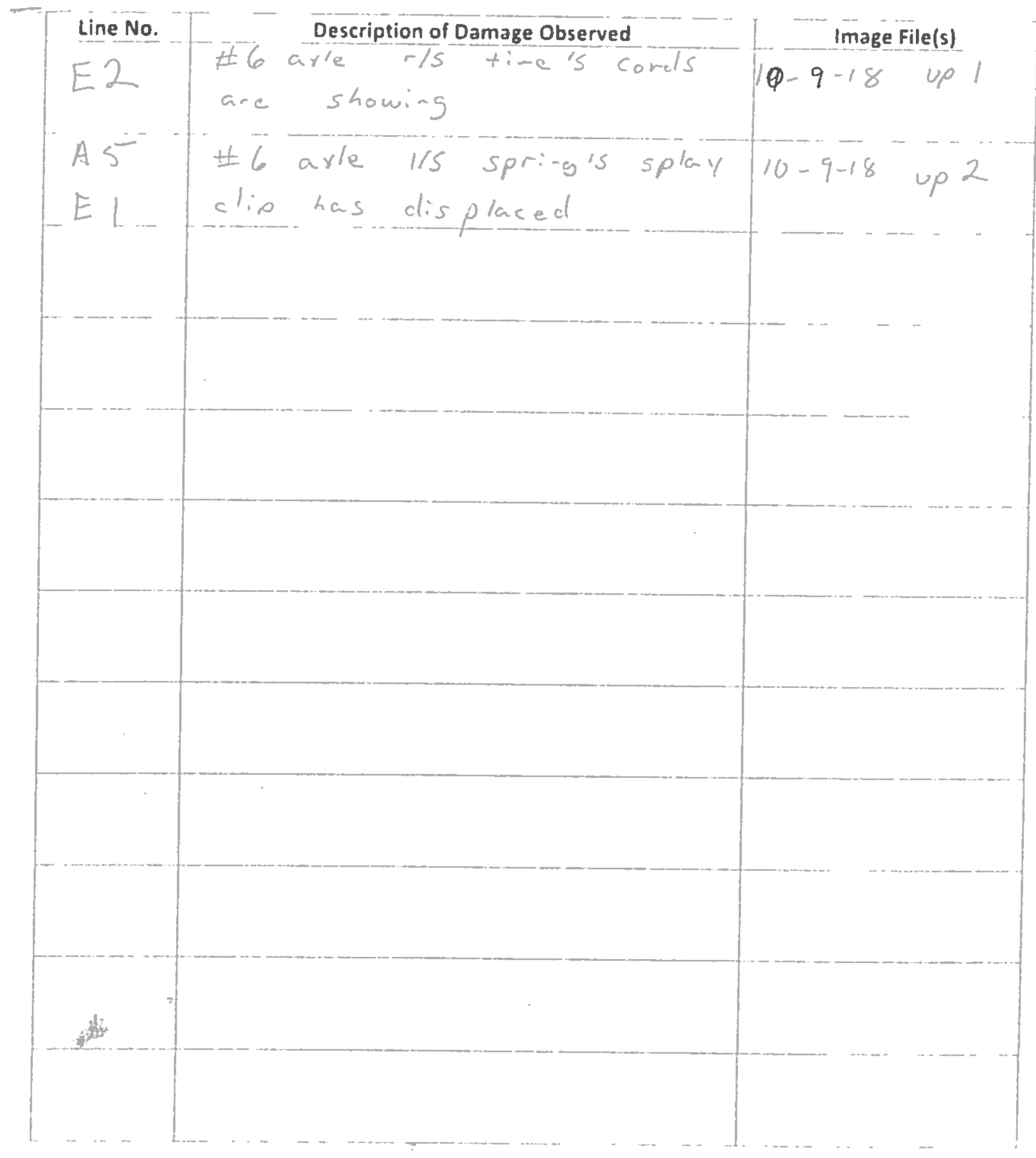




\section{Attuchment 3: MHU Longer ity Testing Recurring Inspection 10-10-18}

MHU

$\square$ Baselıne

ه Upgraded
Mileage of Power Unit: 90807

Miles into testing (inultiple of 500):

Damaged?

A. CHASSIS

Yes

No

1 Main beams buckled, bent, twists

2 Outriggers buckled, bent, twists

3 Cross members buckled, bent, twists

4 Hitch/coupler damage

5. Axle, spring, spring hanger, wheel damage

6 Welds/connections cracks, breaks, damage

7 Damage to exposed gas, waterlınes, drain-lines or supports

B. FLOOR SYSTEMS

1 Damage, separations, loosening of lags from chassis to floor

2 Buckled floor, damaged deckıng/floor coverıngs, opening of joints, loose for popped feathers

3. Damage to bottom board, patches, loose fasteners

C. EXTERIOR/INTERIOR/MARRIAGE WALLS

1. Interior wall panels - buckled, cracked, bowed, separations, fasteners popped or loose

2. Separation of walls at floor, ceiling, column supports, window and door openings

3. Exterior siding and trim - buckled, cracked, bowed, separations, fasteners popped or loose

4. Windows and doors - damaged, buckled, bowed, or parts missing

5. Windows and doors - operate properly

6. Damage to caulking and sealants

D. ROOF/CEILINGS

1. Roofing - buckled, cracked, bowed, splits, openings, loose or popped fasteners

2. Damage to roof penetrations - vents, roof jacks, skylights, caulking and sealants

3. Damage to eaves, overhangs, transitions

4. Ceilings - buckled, cracked, bowed, sagging, separations, loose or popped fasteners

\section{E. PLUMBING}

Damage to fixtures, piping, fittings, connections and supports

\section{E. MODIFIED COMPONENTS FOR TESTING}

1. Axles and suspension

2 Wheels and tires
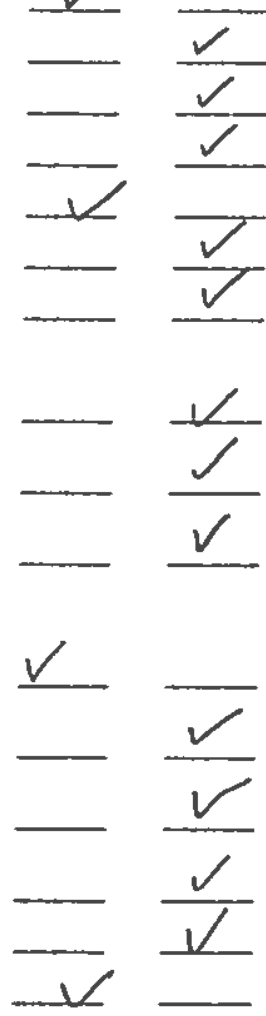
Attachment 3, Continued MHU Longevity Testing - Recurring Inspection, p.2

$$
10-10-18
$$

MHU

[.] Baseline

W Upgraded

Mileage of Power Unit: $9080 ?$

Testing miles (multiple of 500):

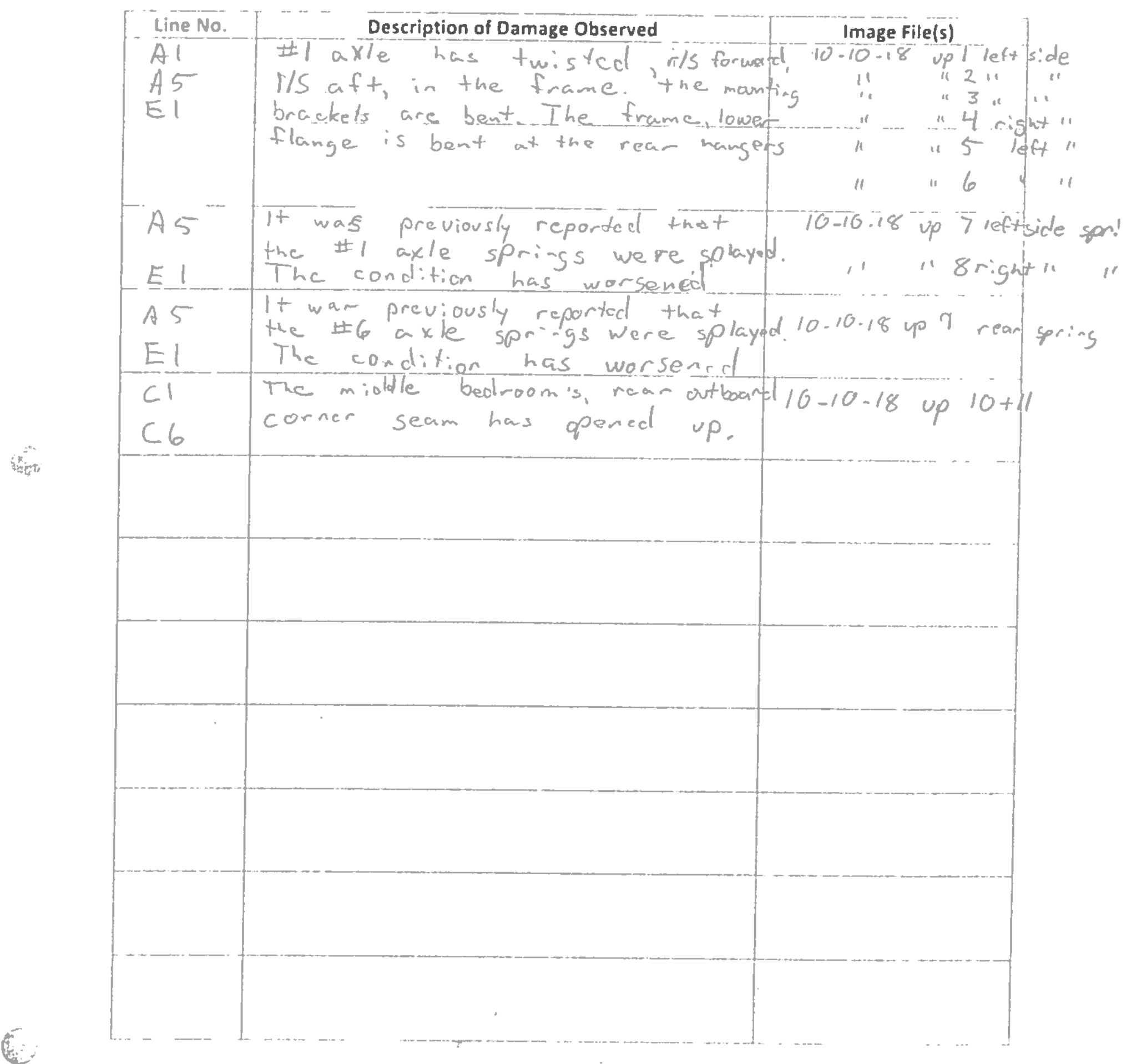




\section{Attachment 3: MHU Longevity Testing Recurring Inspection 10-16-18}

$\mathrm{MHU}$

$\square$ Baseline
$\square$ Upgraded
Mileage of Power Unit: $86>87$

Miles into testing (multiple of 500):

\section{A. CHASSIS}

1 Main beams buckled bent, twists

2 Outriggers buckled, bent, twists

3 Cross members buckled, bent, twists

4 Hitch/coupler damage

5. Axle, spring, spring hanger, wheel damage

6 Welds/connections cracks, breaks, damage

7 Damage to exposed gas, waterlınes, drain lines or supports

\section{B. FLOOR SYSTEMS}

1 Damage, separations, loosening of lags from chassis to floor

2 Buckled floor, damaged deckıng/floor coverıngs, openıng of joints, loose for popped feathers

3. Damage to bottom board, patches, loose fasteners

\section{EXTERIOR/INTERIOR/MARRIAGE WALLS}

1. Interior wall panels - buckled, cracked, bowed, separations, fasteners popped or loose

2 Separation of walls at floor, ceiling, column supports, window and door openings

3 Exterior siding and trim buckled, cracked, bowed, separatıons, fasteners popped or loose

4 Windows and doors damaged, buckled, bowed, or parts missing

5. Windows and doors - operate properly

6. Damage to caulking and sealants

\section{ROOF/CEILINGS}

1 Roofing buckled, cracked, bowed, splits, openings, loose or popped fasteners

2 Damage to roof penetrations vents, roof jacks, skylights, caulking and sealants

3 Damage to eaves, overhangs, transitions

4 Cellings buckled, cracked bowed, sagging, separatıons, loose or popped fasteners

\section{E. PLUMBING}

Damage to fixtures, pipıng, fittings, connections and supports

\section{E. MODIFIED COMPONENTS FOR TESTING}

1 Axles and suspension

2 Wheels and tires

\section{Damaged?}

Yes No
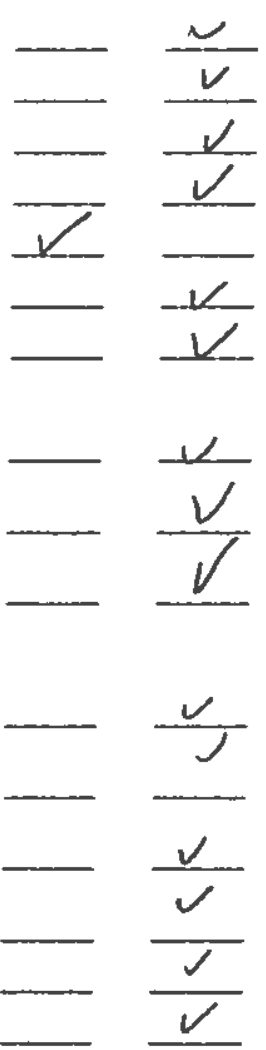

Wheels and tires 
Attachment 3, Continued

MHU Longevity Testing - Recurring Inspection, p.2 10-16-18

MHO
$\square$ Baseline
Upgraded

Mileage of Power Unit: 86787

Testing miles (multiple of 500):

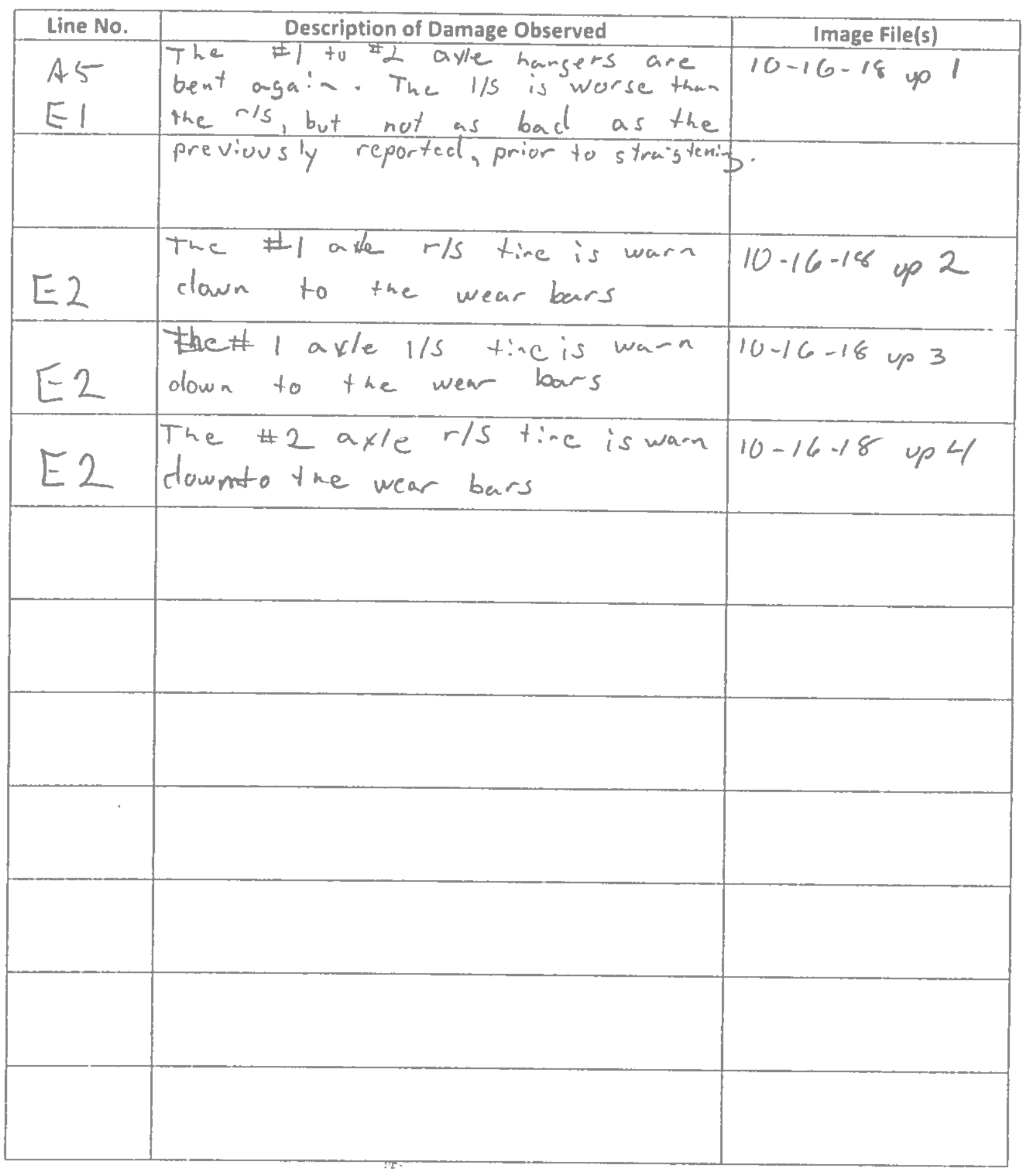

23

E-29 


\section{Attachment 3: MHU Longevity Testing Recurring Inspection}

MHU

Baselıne

$\checkmark$ Upgraded
Mileage of Power Unit: 87378

Miles into testing (multiple of 500):

\section{A. CHASSIS}

1 Main beams buckled, bent, twists

2 Outriggers buckled, bent, iwists

3 Cross members buckled, bent, twists

4 Hitch/coupler damage

5 Axle, spring, spring hanger, wheel damage

6 Welds/connections cracks, breaks, damage

7 Damage to exposed gas, waterlines, drain-lines or supports

B. FLOOR SYSTEMS

1 Damage, separations, loosening of lags from chassis to floor

2 Buckled floor, damaged deckıng/floor coverings, opening of joints, loose for popped feathers

3. Damage to bottom board, patches, loose fasteners

\section{EXTERIOR/INTERIOR/MARRIAGE WALLS}

1. Interior wall panels - buckled, cracked, bowed, separations, fasteners popped or loose

2. Separation of walls at floor, ceiling, column supports, window and door openings

3. Exterior siding and trim - buckled, cracked, bowed, separations, fasteners popped or loose

4. Windows and doors - damaged, buckled, bowed, or parts missing

5. Windows and doors - operate properly

6. Damage to caulking and sealants

\section{ROOF/CEILINGS}

1. Roofing - buckled, cracked, bowed, splits, openings, loose or popped fasteners

2. Damage to roof penetrations - vents, roof jacks, skylights, caulking and sealants

3. Damage to eaves, overhangs, transitions

4. Ceilings - buckled, cracked, bowed, sagging, separations, loose or popped fasteners

\section{E. PLUMBING}

Damage to fixtures, piping, fittings, connections and supports

\section{E. MODIFIED COMPONENTS FOR TESTING}

1. Axles and suspension

2 Wheels and tires 
Attachment 3, Continued

MHU Longevity Testing - Recurring Inspection, p.2

$10-17-18$

MHU

$\square$ Baseline
$\square$ Upgraded

Mileage of Power Unit $\quad 873 \geq 8$

Testing miles (multiple of 500)

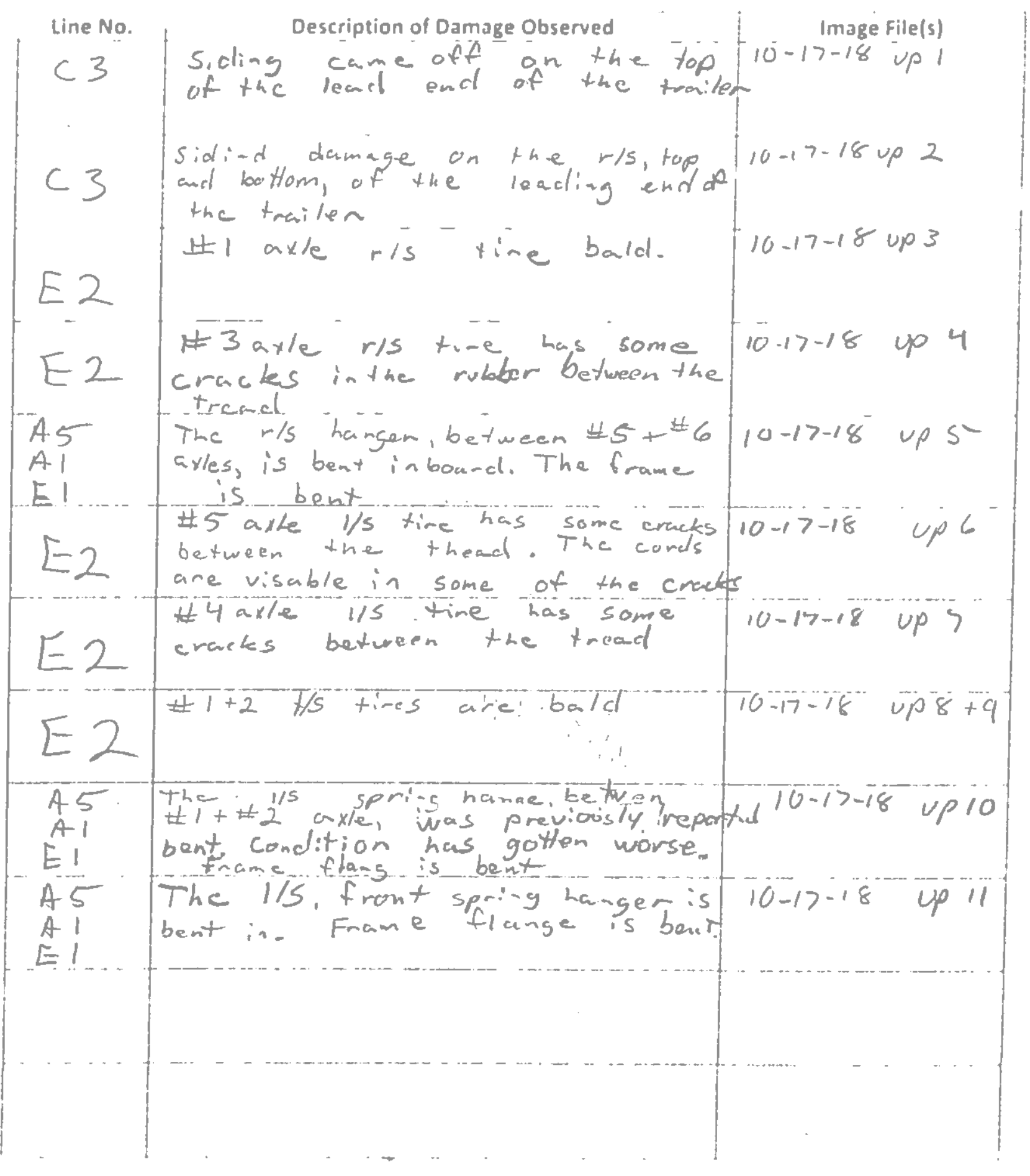




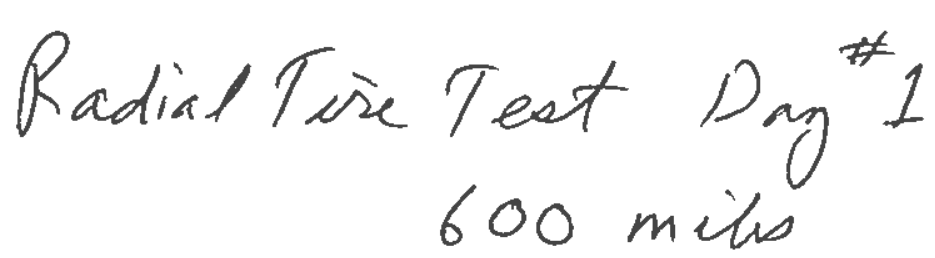

Attichment 3: MHU Longevity Testing-Recurring Inspection $10-23-18$

MHU

$\square$ Baseline

d Upgraded

Mileage of Power Unit: $\& \delta / / ?$

Miles into testing (multiple of 500):

1 Main beams buckled, bent, twists

2. Outriggers - buckled, bent, twists

3. Cross members - buckled, bent, twists

4. Hitch/coupler damage

5. Axle, spring, spring hanger, wheel damage

6. Welds/connections cracks, breaks, damage

7. Damage to exposed gas, waterlines, drain-lınes or supports

\section{B. FLOOR SYSTEMS}

1 Damage, separations, loosening of lags from chassis to floor

2 Buckled floor, damaged decking/floor coverings, openıng of joints, loose for popped feathers

3. Damage to bottom board, patches, loose fasteners

C. EXTERIOR/INTERIOR/MARRIAGE WALLS

1 Interior wall panels buckled, cracked, bowed, separations, fasteners popped or loose

2 Separation of walls at floor, celling, column supports, window and door openings

3. Exterior siding and trim buckled, cracked, bowed, separatıons, fasteners popped or loose

4 Windows and doors - damaged, buckled, bowed, or parts missing

5. Windows and doors - operate properly

6. Damage to caulking and sealants

D. ROOF/CEILINGS

1. Roofing buckled, cracked, bowed, splits, openings, loose or popped fasteners

2 Damage to roof penetrations vents, roof jacks, skylights caulking and sealants

3 Damage to eaves, overhangs, transitions

4 Ceilings buckled, cracked bowed, sagging, separations, loose or popped fasteners

\section{E. PLUMBING}

Damage to fixtures, piping, fittings, connections and supports

\section{E. MODIFIED COMPONENTS FOR TESTING}

1 Axles and suspension

2 Wheels and tires

\section{Damaged? \\ Yes No}
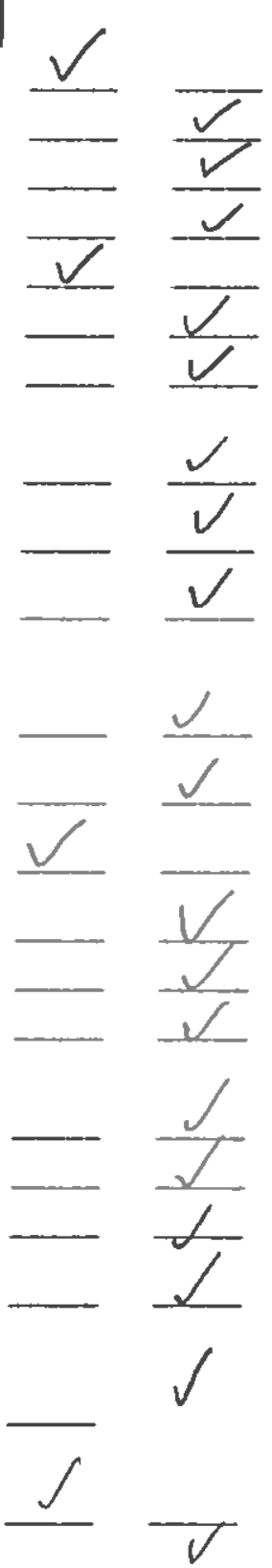
Attachment 3, Continued

MHU Longevity Testing - Recurring Inspection, p.2 $10-23-18$

MHU

[ Baseline
$\square$ Upgraded
Mileage of Power Unit: $\$ 81 / 2$

Testing miles (multiple of 500):

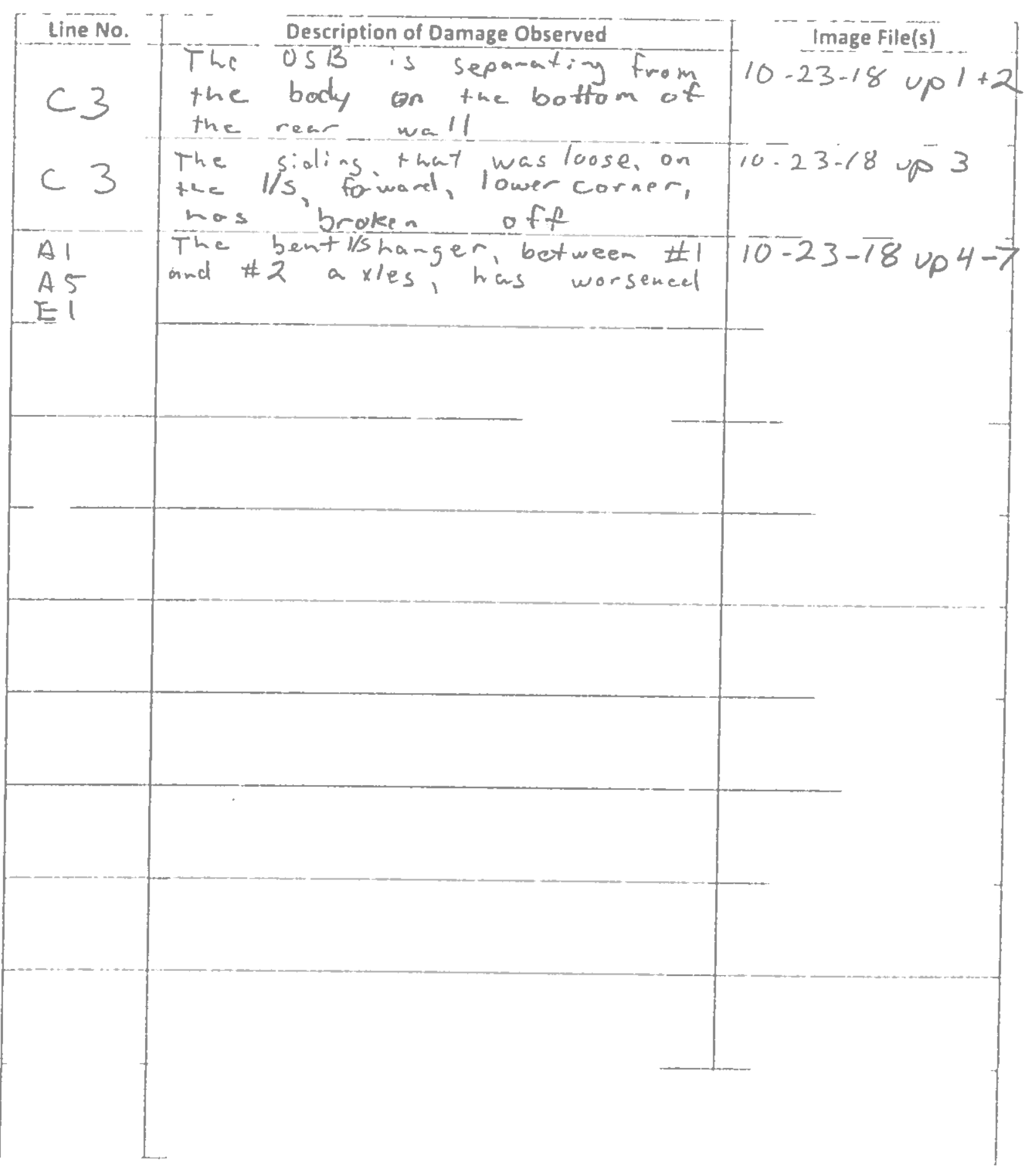




\section{Altachment 3: MHU Longevity Testing - Recurring Inspection $10-24-18$}

MHU

$\square$ Baselıne

U Upgraded
Mileage of Power Unit: $\quad 808021$

Miles into testing (multiple of 500):
Damaged?

Yes No

\section{A. CHASSIS}

1 Main beams buckled, bent, twists

2 Outriggers buckled, bent, twists

3 Cross members buckled, bent, twists

4 Hitch/coupler damage

5 Axle, spring, spring hanger, wheel damage

6 Welds/connections cracks, breaks, damage

7 Damage to exposed gas, waterlınes, drain-lines or supports

B. FLOOR SYSTEMS

1 Damage, separations, loosening of lags from chassis to floor

2 Buckled floor, damaged deckıng/floor coverings, openıng of joints, loose for popped feathers

3. Damage to bottom board, patches, loose fasteners

\section{EXTERIOR/INTERIOR/MARRIAGE WALLS}

1. Interior wall panels - buckled, cracked, bowed, separations, fasteners popped or loose

2 Separation of walls at floor, ceiling, column supports, window and door openings

3 Exterior siding and trim buckled, cracked, bowed, separatıons, fasteners popped or loose

4 Windows and doors damaged, buckled, bowed, or parts missing

5 Windows and doors - operate properly

6. Damage to caulking and sealants

D. ROOF/CEILINGS

1 Roofing buckled, cracked, bowed, splits, openings, loose or popped fasteners

2 Damage to roof penetrations vents, roof jacks, skylights, caulkıng and sealants

3 Damage to eaves, overhangs, transitions

4 Ceilings buckled, cracked, bowed, sagging, separatıons, loose or popped fasteners

\section{E. PLUMBING}

Damage to fixtures, pipıng, fittings, connections and supports

E. MODIFIED COMPONENTS FOR TESTING

1 Axles and suspension

2 Wheels and tires
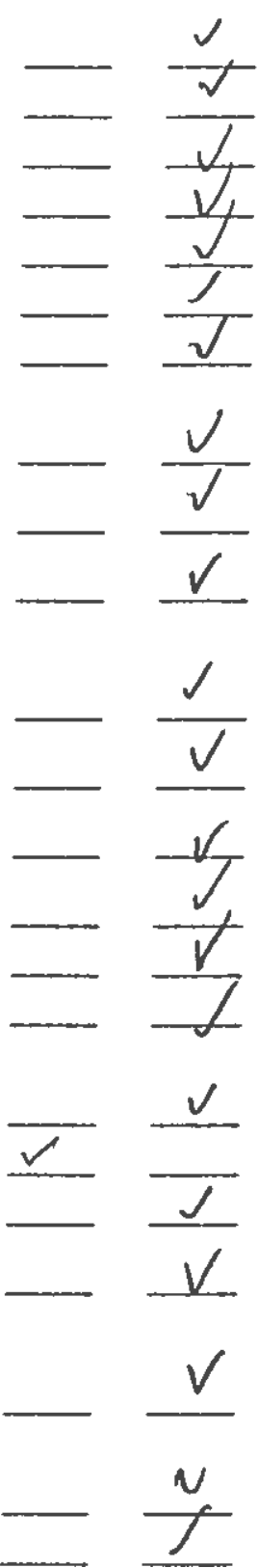
Attachment 3, Continued

$$
10-24-18
$$

MHU Longevity. Testing - Recurring Inspection, p.2

MHO

Baseline

Upgraded
Mileage of Power Uni 80801

Testing mites (multiple of 500)

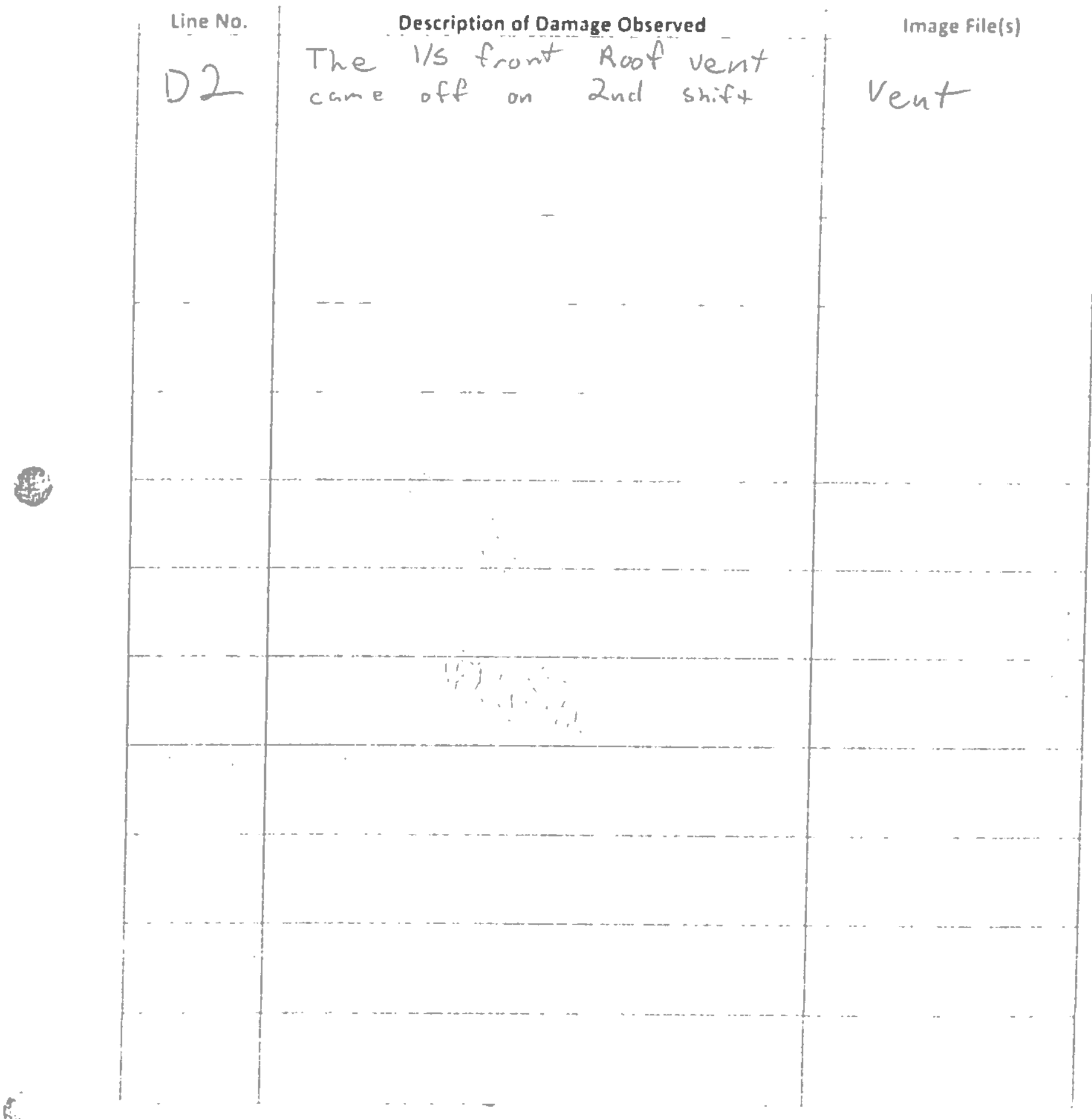

E-35

23 


\section{Attachment 3: MHU Longevity Testing - Recurring Inspection $\quad 11-5^{-} \cdot 18$}

MHU

$\square$ Baseline
Mileage of Power Unit: $\quad 89938$

Miles into testing (multiple of 500):

\section{Damaged?}

Yes No

A. CHASSIS

1 Main beams buckled, bent, twists

2 Outriggers buckled, bent, twists

3 Cross members - buckled, bent, twists

4. Hitch/coupler damage

5. Axle, spring, spring hanger, wheel damage

6. Welds/connections - cracks, breaks, damage

7. Damage to exposed gas, waterlines, drain-lines or supports

B. FLOOR SYSTEMS

1 Damage, separations, loosening of lags from chassis to floor

2. Buckled floor, damaged decking/floor coverings, opening of joints, loose for popped feathers

3. Damage to bottom board, patches, loose fasteners

\section{EXTERIOR/INTERIOR/MARRIAGE WALLS}

1. Interior wall panels - buckled, cracked, bowed, separations, fasteners popped or loose

2. Separation of walls at floor, ceiling, column supports, window and door openings

3. Exterior siding and trim - buckled, cracked, bowed, separations, fasteners popped or loose

4. Windows and doors - damaged, buckled, bowed, or parts missing

5. Windows and doors - operate properly

6. Damage to caulking and sealants

\section{ROOF/CEILINGS}

1. Roofing - buckled, cracked, bowed, splits, openings, loose or popped fasteners

2. Damage to roof penetrations - vents, roof jacks, skylights, caulking and sealants

3. Damage to eaves, overhangs, transitions

4. Ceilings - buckled, cracked, bowed, sagging, separations, loose or popped fasteners

\section{E. PLUMBING}

Damage to fixtures, piping, fittings, connections and supports

E. MODIFIED COMPONENTS FOR TESTING

1. Axles and suspension

2. Wheels and tires
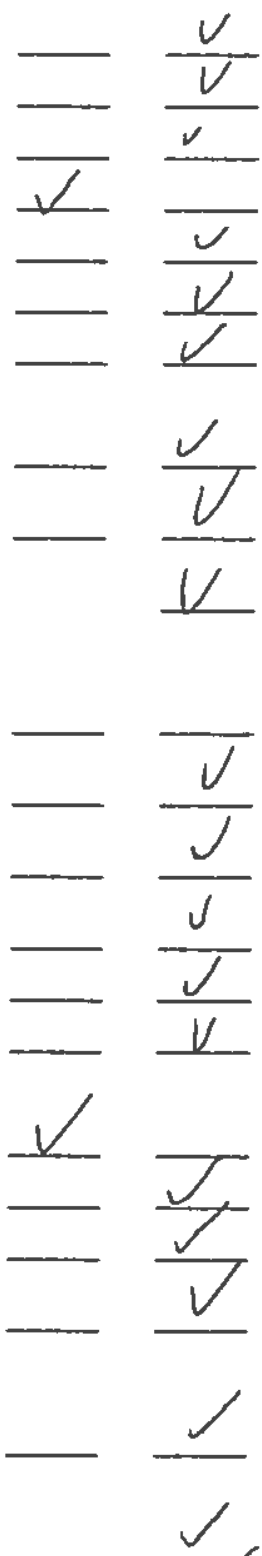
Attachment 3, Continued

MHU Longevity Testing - Recurring Inspection, p.2

$$
11-5-18
$$

MHU

$\square$ Baseline

Mileage of Power Unit: 89938

D) Upgraded

Testing miles (multiple of 500):

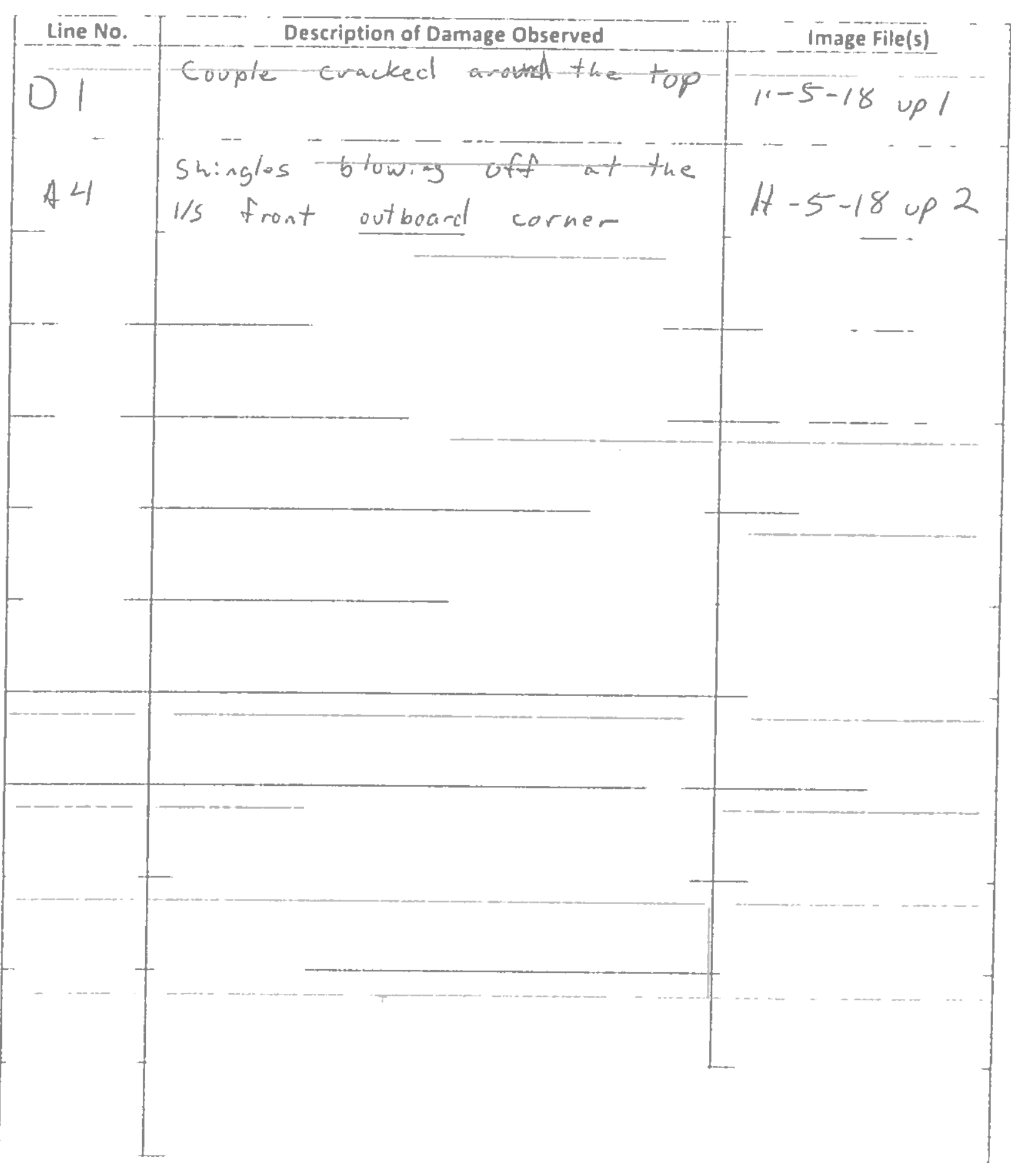


Attachment 4: MHU Longevity Testing - Record of Damage

Date: $7 / 4 / 18$

Mileage: $\quad \underline{78280(470 \text { test miles) }}$
Time: Approx. 2am

Tractor (if multipleused)： LW28751

$\mathrm{MHU}$

$\square$ Baseline

$\square$ Upgraded

Type of damage: Vehicle struck a deer on the oval track

Location of damage: Front bumper

Corrective action

$\square$ Baseline

$\square$ Repairs asfollows:

None

Image file(s):

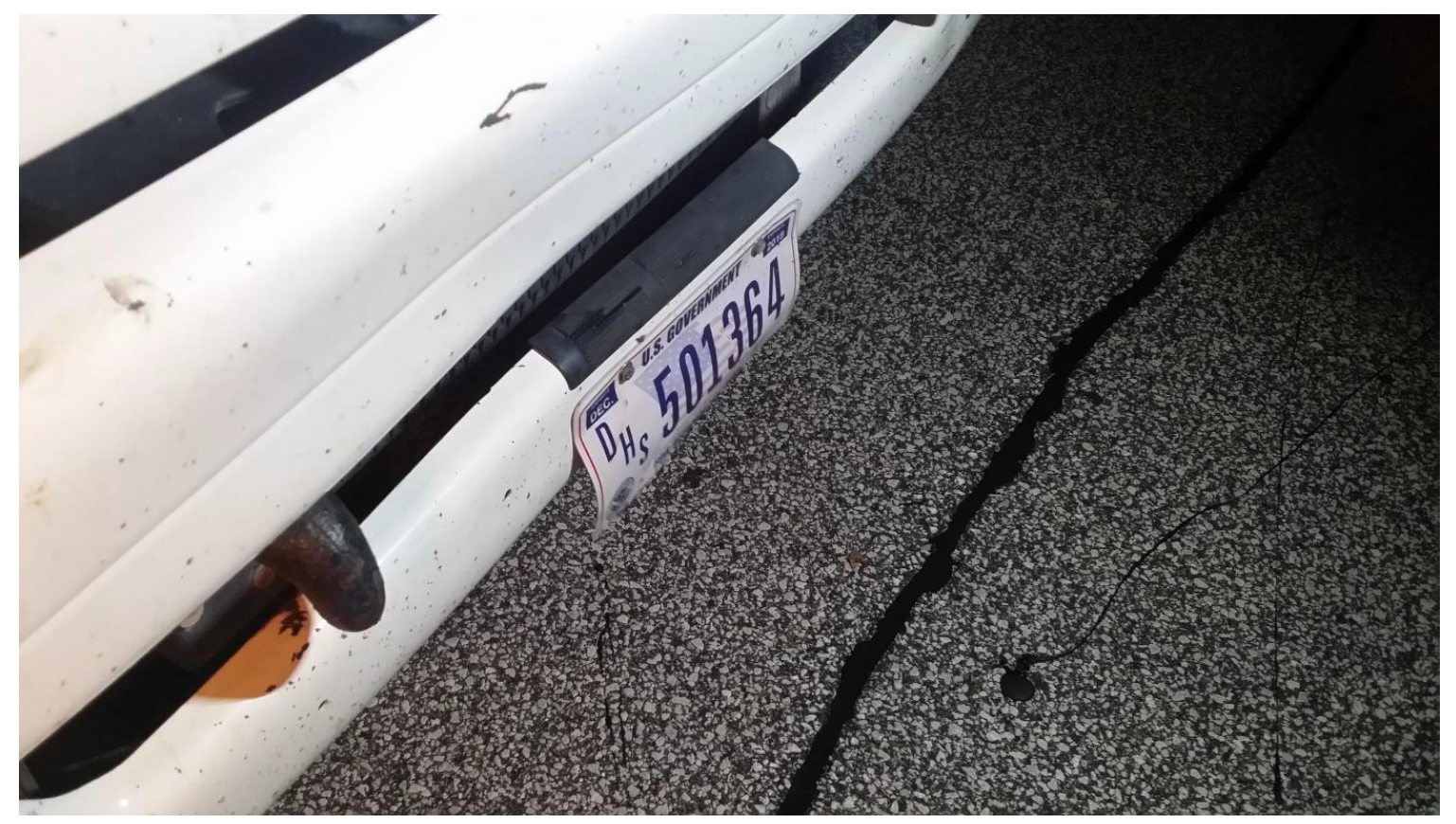



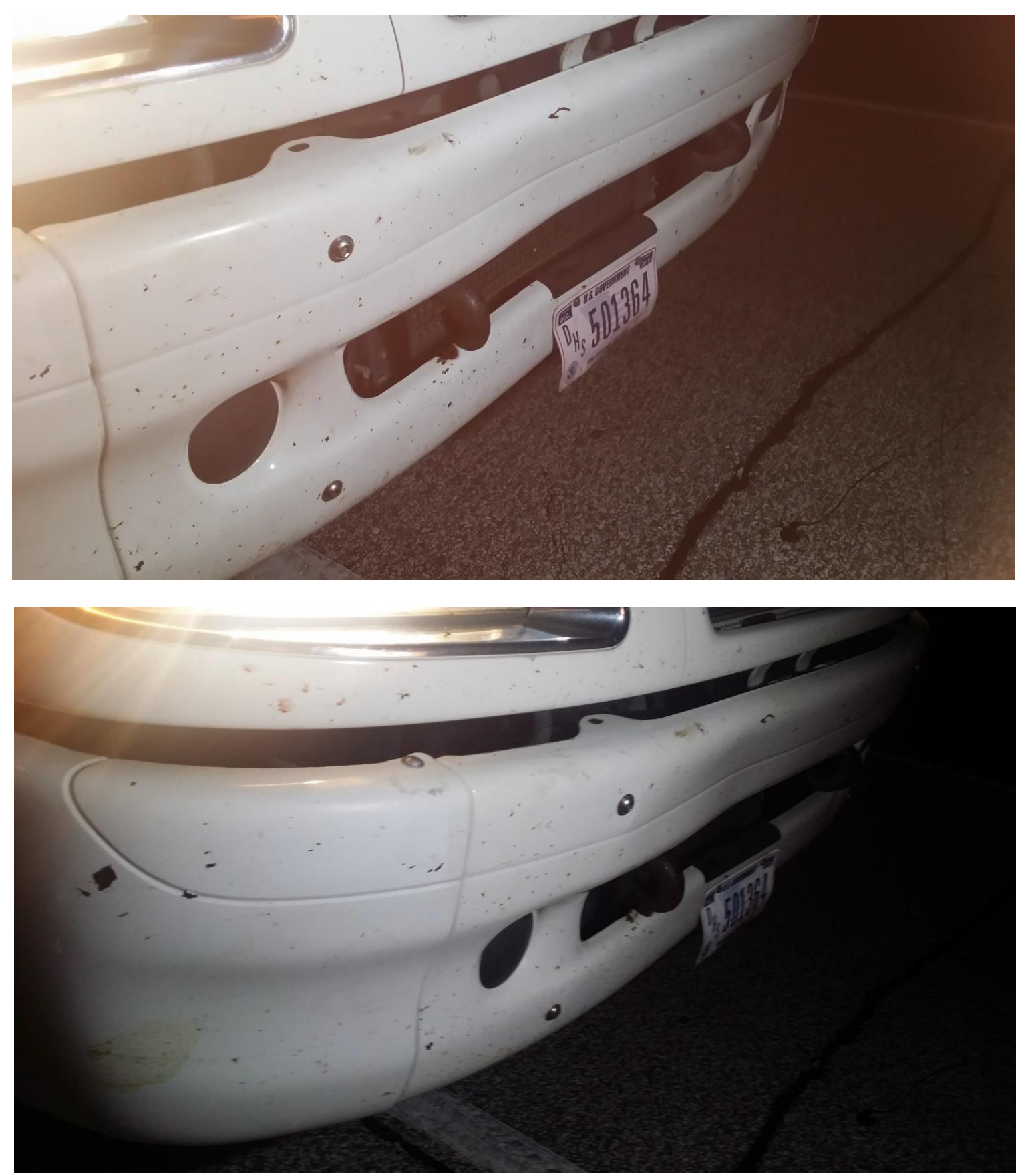
Attachment 4: MHU Longevity Testing - Record of Damage

Date: $\quad 7 \not 4 / 18$

Time: $\quad \underline{4: 35 \mathrm{am}}$

Mileage:

78381(571testmiles)

Tractor(ifmultipleused):

$\underline{L W 28751}$

\section{Component testmiles}

MHU

$\square$ Baseline

$\square$ Upgraded

Type of damage: Tire blowout

Location of damage: Axle \#4 - Right side tire

Corrective action

$\square$ Baseline

$\square$ Repairs as follows:

Replaced tire and wheel.

Image file(s):

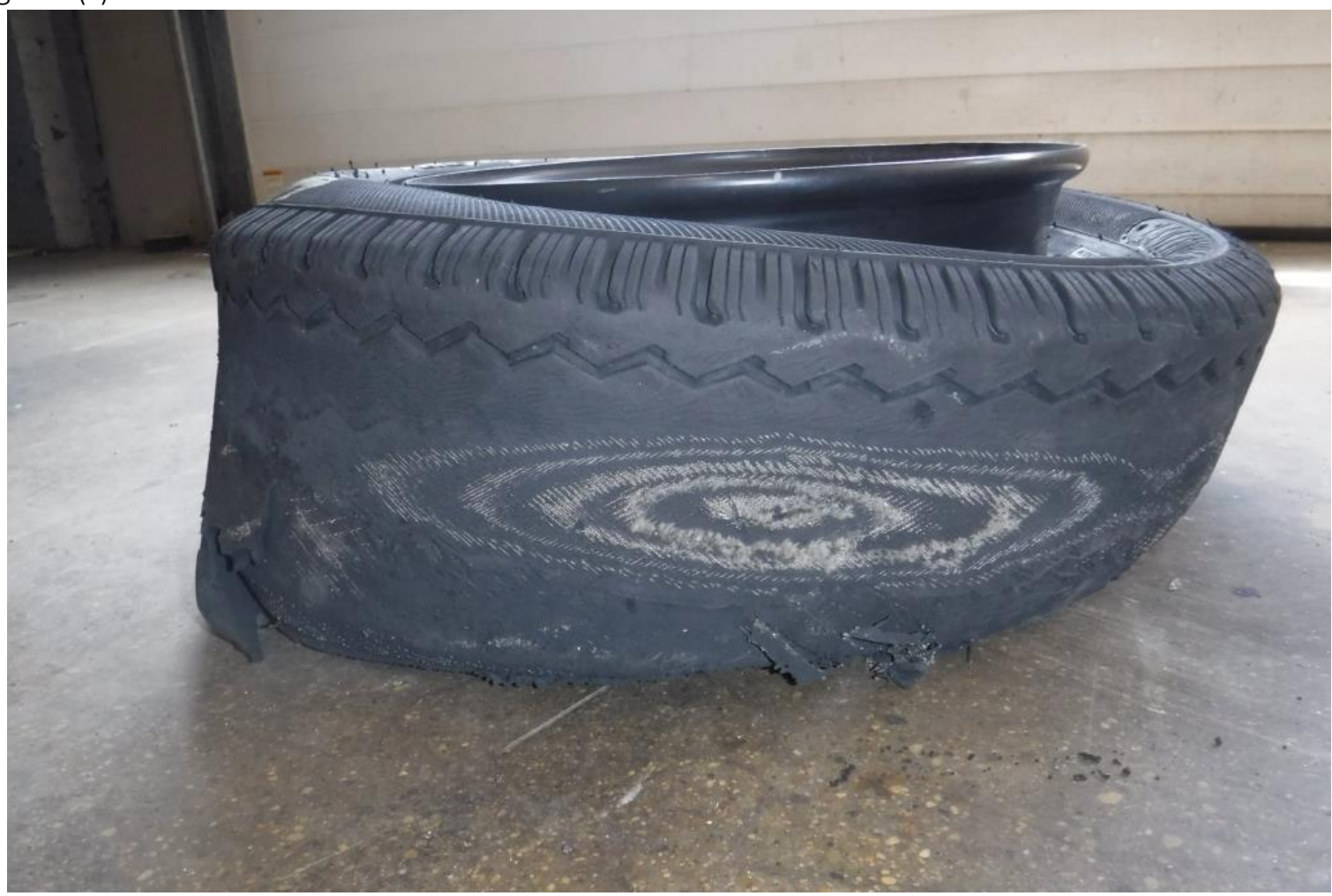



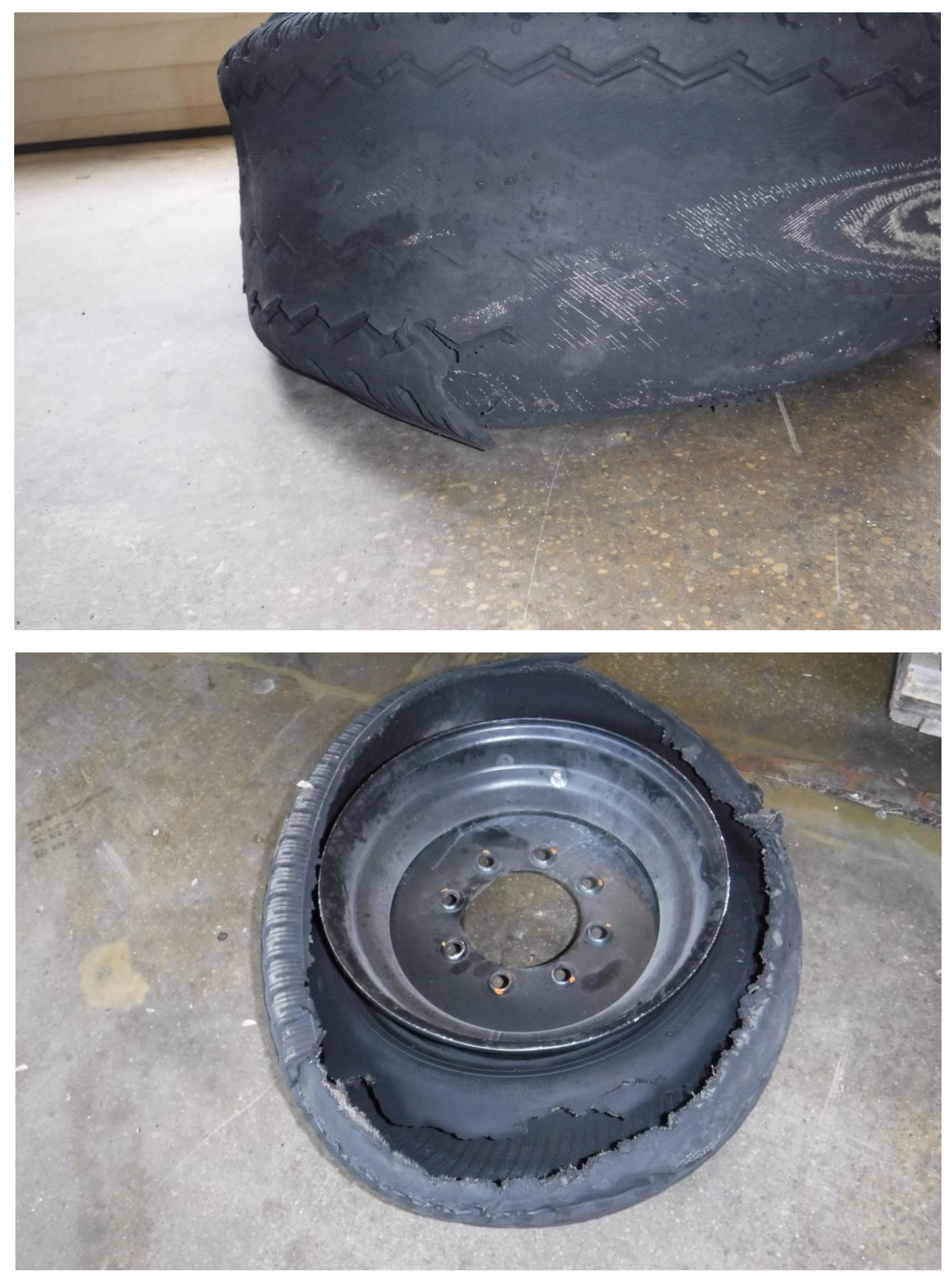

E-41 


\section{Attachment 4: MHU Longevity Testing - Record of Damage}

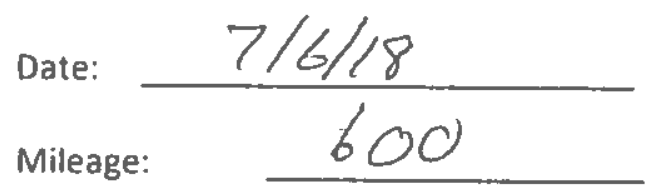

Time:

Tractor (if multiple used):

MHU

$\square$ Baseline

$\square$ Upgraded

Type of damage:

Location of damage:

Corrective action

$\square$ Baseline

$\square$ Repairs as follows:

Image file(s): 


\section{Attachment 4: MHU Longevity Testing - Record of Damage}

Date: $\quad 7 / 17 / 18$

Mileage:

1100

MHU

$\square$ Baseline

Up Upraded
Time:

Tractor (if multiple used):

Type of damage:

Location of damage:

Corrective action

$\square$ Baseline

$\square$ Repairs as follows:

Image file(s): 
Attachment 4: MHU Longevity Testing - Record of Damage

Date: $\quad 7 / 17 / 18$

Mileage:

78921(1100testmiles)

1100 Component testmiles
Time: $\quad$ 9:00 am

Tractor(ifmultipleused): $\quad$ LW28751

MHU

$\square$ Baseline

$\square$ Upgraded

Type of damage: Tire cords exposed. Imminent failure.

Location of damage: Axle \#1 - Left side tire

Corrective action

$\square$ Baseline

$\square$ Repairs asfollows:

Replaced tire and wheel.

Image file(s):

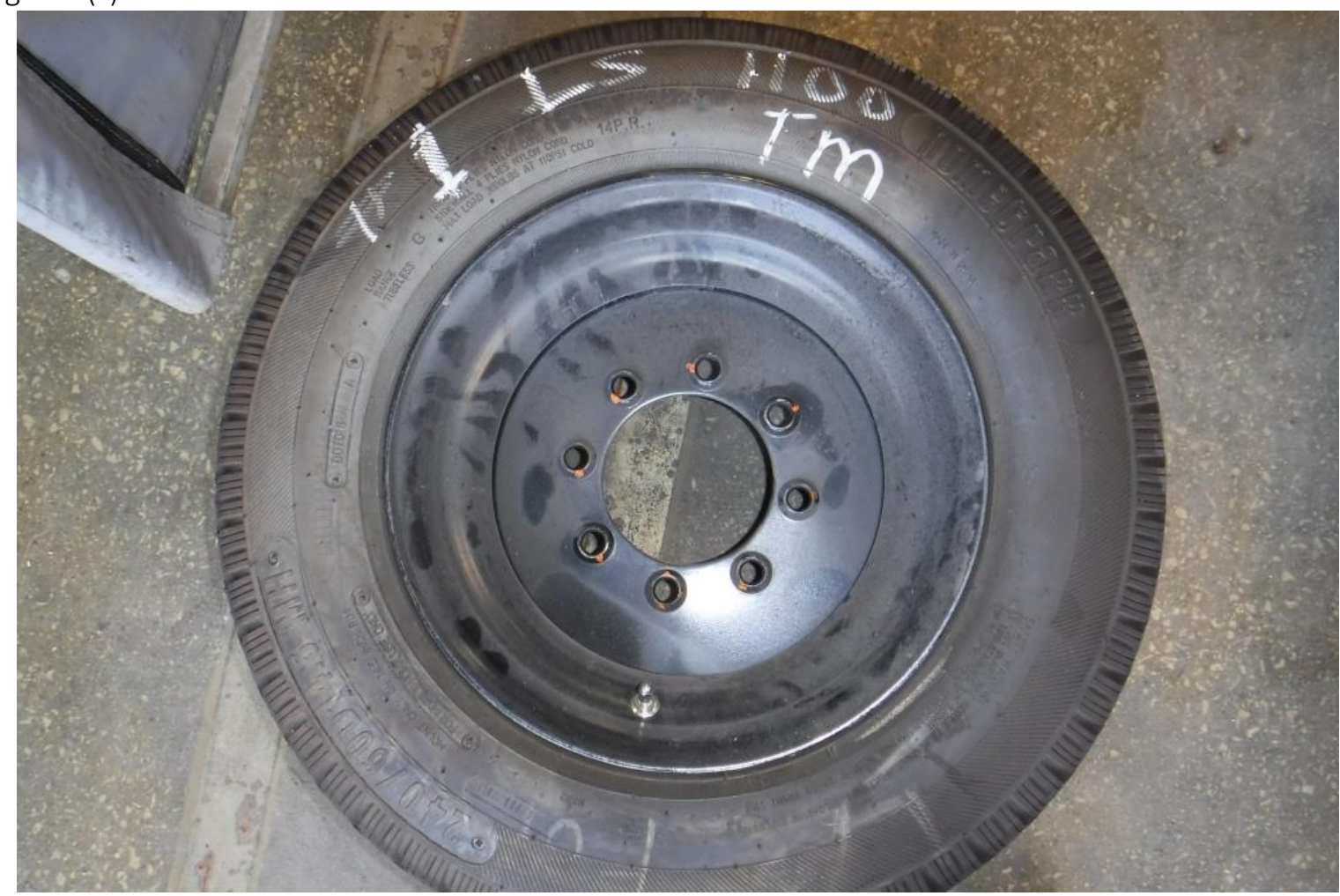




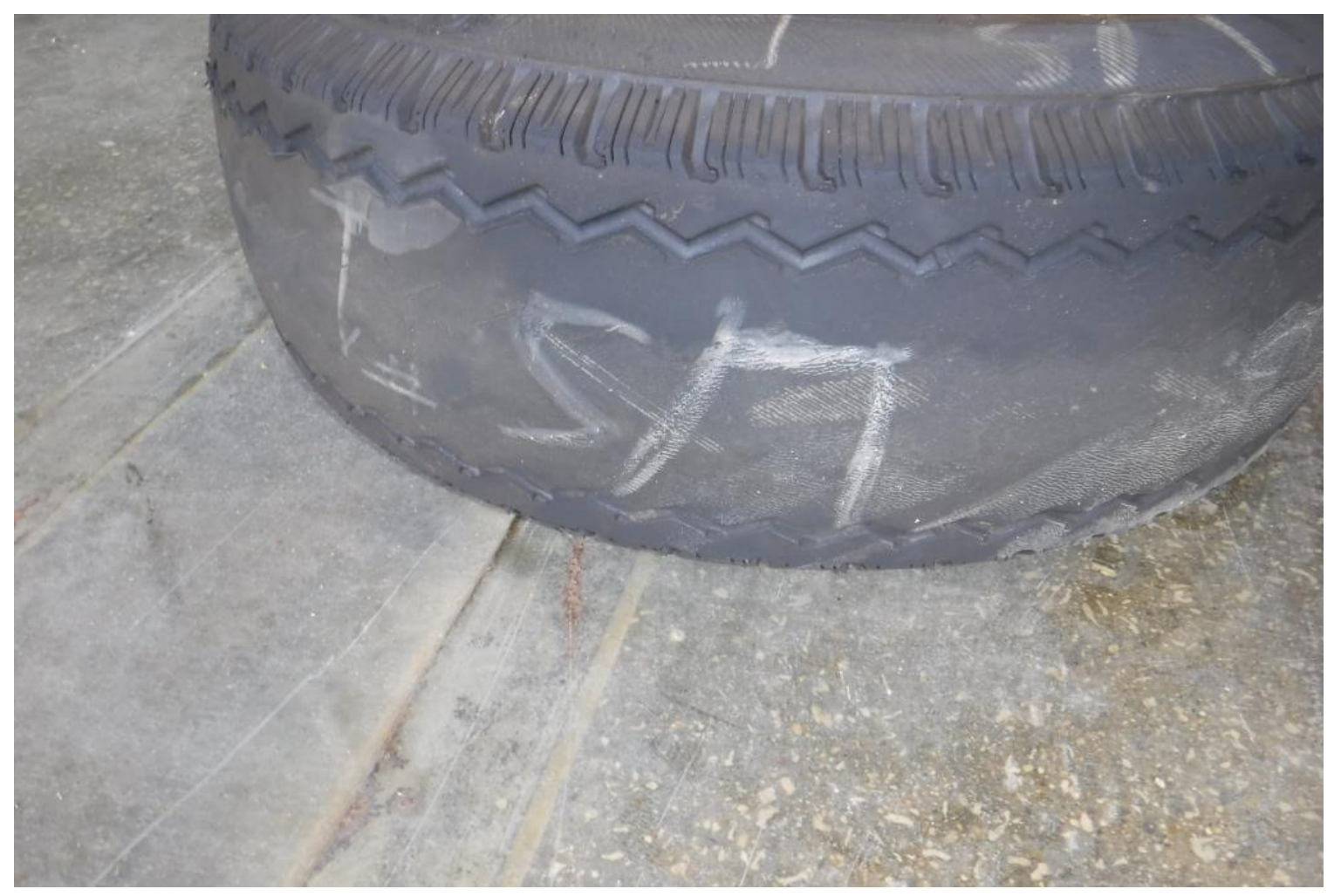

E-45 
Attachment 4: MHU Longevity Testing - Record of Damage

Date: $\quad \underline{7 / 27 / 18}$

Mileage: $\quad \underline{79161 \text { (1351 vehicle test miles) }}$ 1351 Component testmiles

MHU

$\square$ Baseline

$\square$ Upgraded

Type of damage: Tire blowout

Location of damage: Axle \#5 - Right side tire

Corrective action

$\square$ Baseline

$\square$ Repairs as follows:

Replaced tire and wheel.
Time: Approx. $10 \mathrm{pm}$

Tractor(ifmultipleused): $\quad$ LW28751 

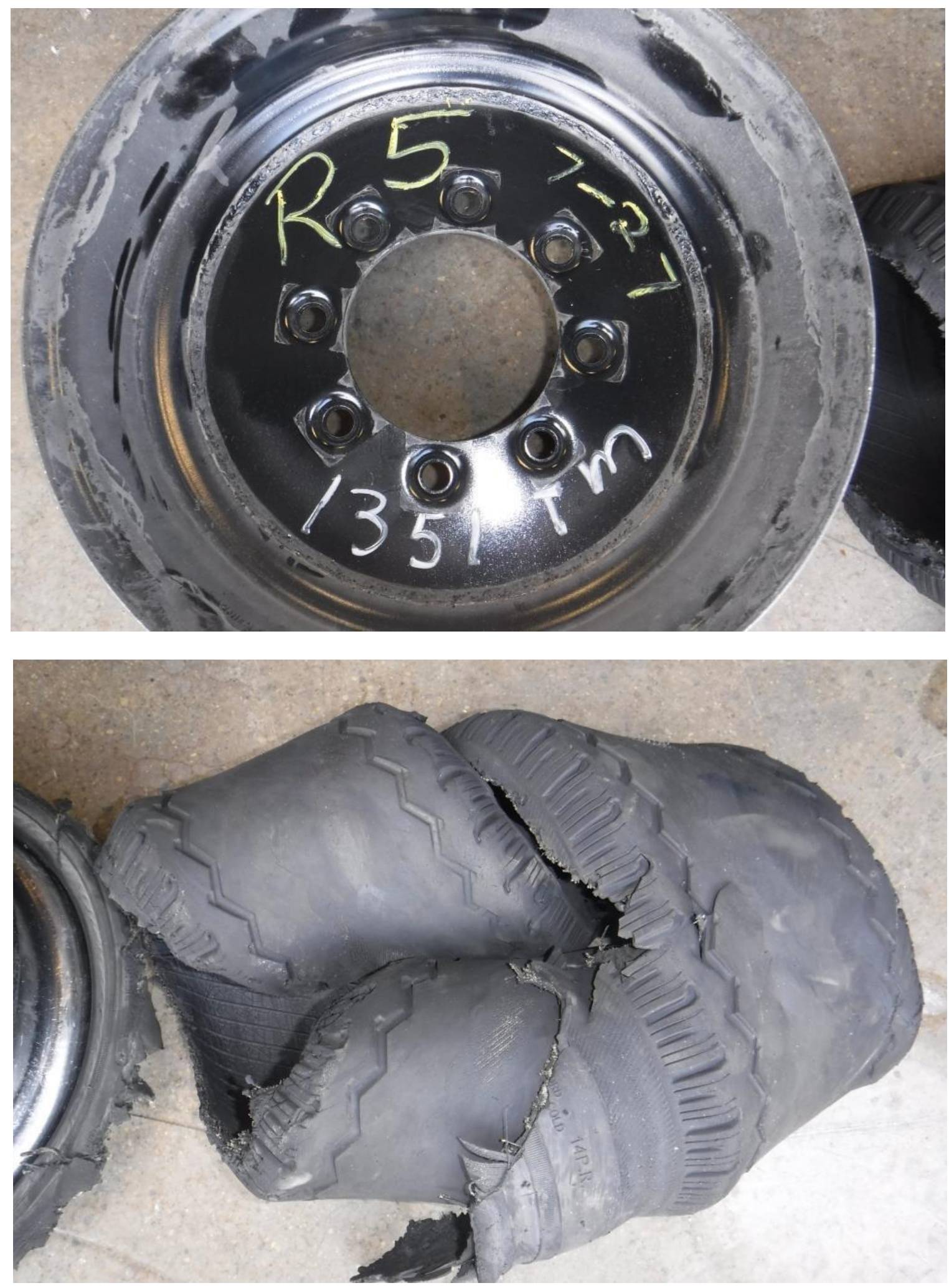
Attachment 4: MHU Longevity Testing - Record of Damage

Date: $\quad \underline{7 / 27 / 18}$

Mileage:

79182 (1372 vehicle test miles) 801 Component testmiles
Time: Approx. $11 \mathrm{pm}$

Tractor(ifmultipleused): $\quad$ LW28751

MHU

$\square$ Baseline

$\square$ Upgraded

Type of damage: Tire blowout

Location of damage: Axle \#4 - Right side tire

Corrective action

$\square$ Baseline

$\square$ Repairs as follows:

Replaced tire \& wheel.

Image file(s):

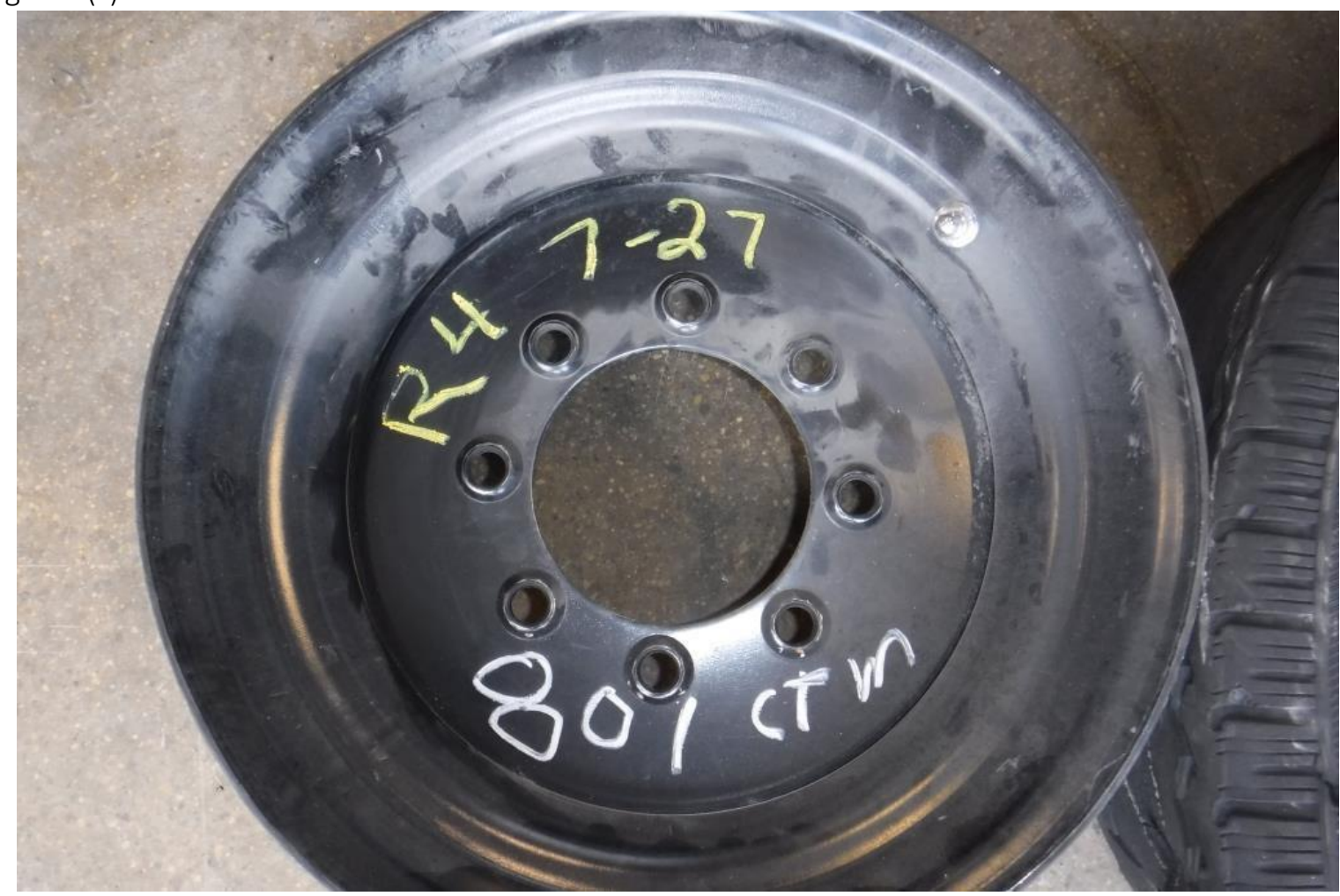



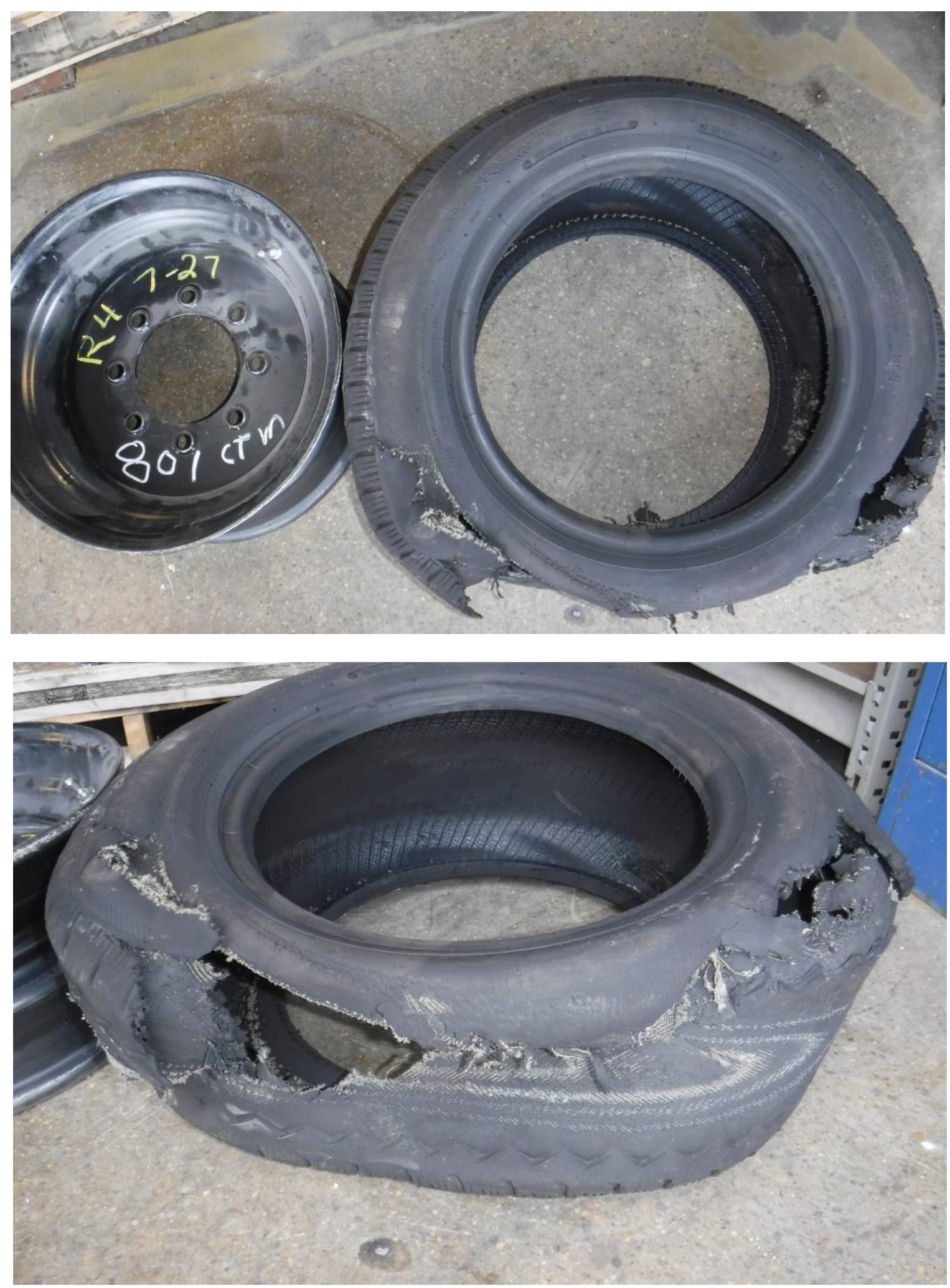
Attachment 4: MHU Longevity Testing - Record of Damage

Date: $\quad \underline{7 / 30 / 18}$

Mileage:

79287 (1477 vehicle test miles)

1477 Component testmiles

MHU

$\square$ Baseline

$\square$ Upgraded

Type of damage: Tire blowout

Location of damage: Axle \#6 - Right side tire

Corrective action

$\square$ Baseline

$\square$ Repairs as follows:

Replaced tire and wheel.

Image file(s):

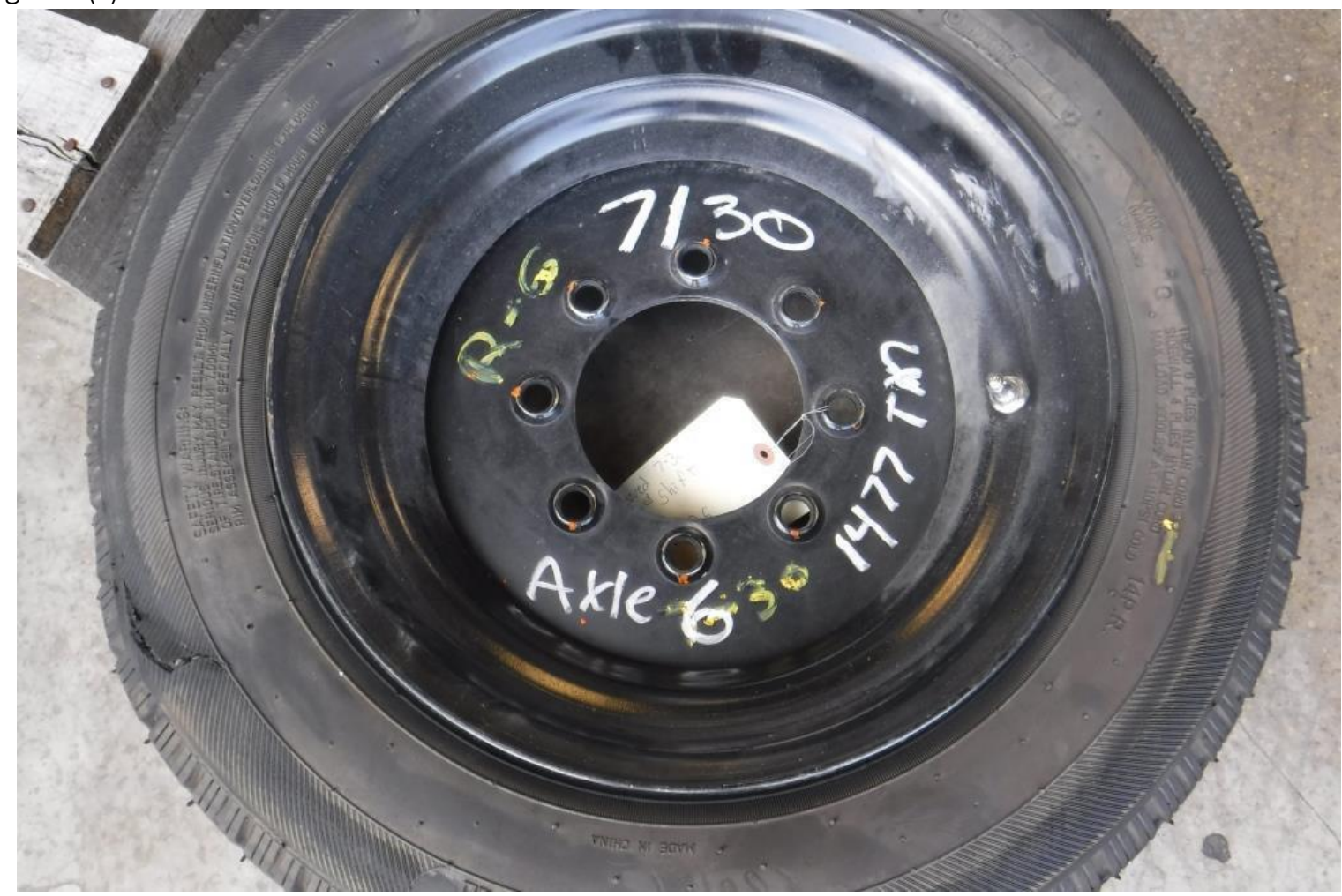

Time: Approx. 1:30 am

Tractor(ifmultipleused): $\quad$ LW28751 


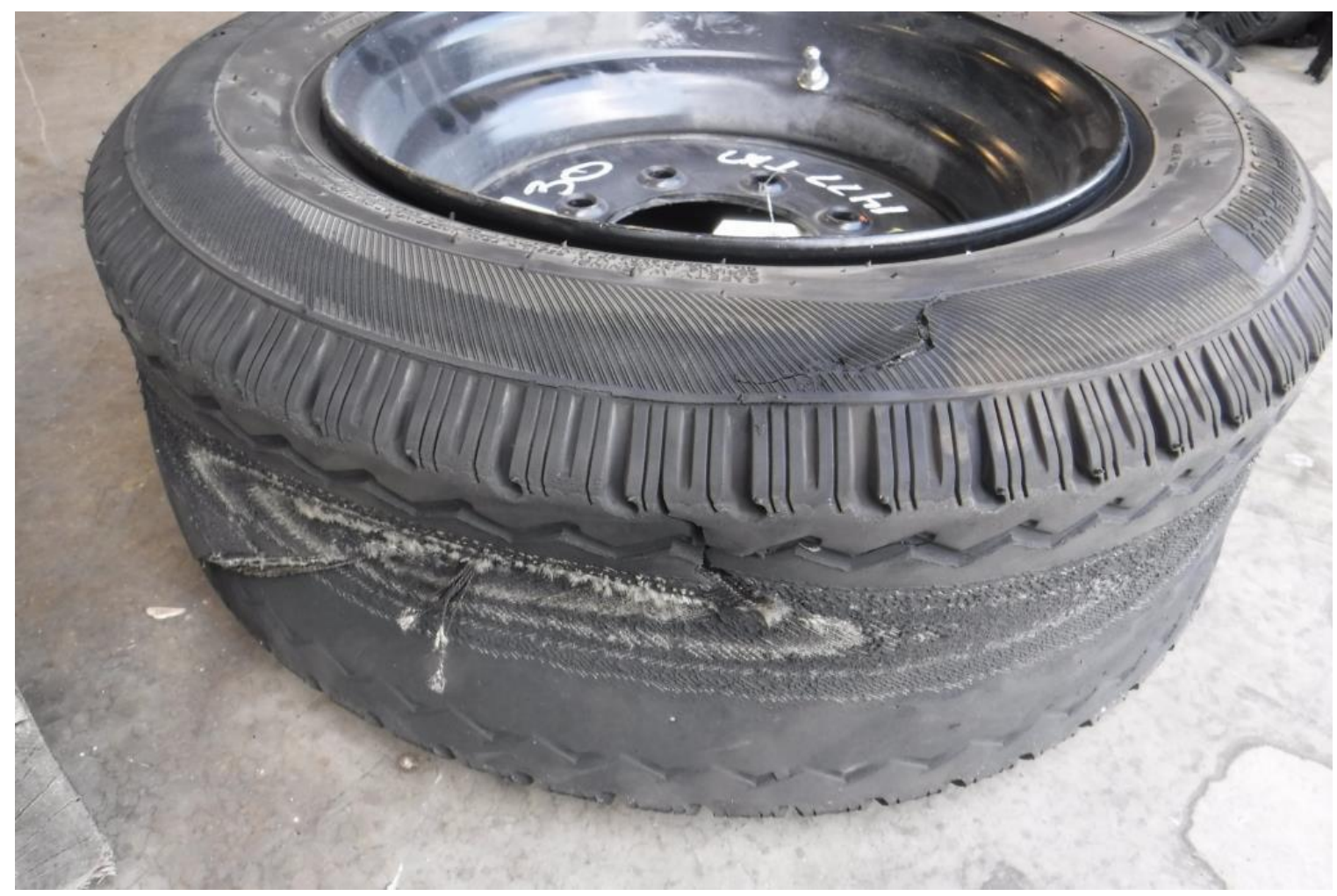

E-51 
Attachment 4: MHU Longevity Testing - Record of Damage

Date: $\underline{8 / 15 / 18}$

Mileage: $\quad \underline{80090 \text { (2278vehicle test miles) }}$ 2278 Component testmiles
Time: $\quad$ Approx. 4:30 pm

Tractor(ifmultipleused): $\quad$ LW28751

MHU

$\square$ Baseline

$\square$ Upgraded

Type of damage: Damage to shingles due to contact with garage door frame.

Location of damage: Curb side of vehicle, outer edge, approximately 20-feet from rear.

Corrective action

$\square$ Baseline

$\square$ Repairs as follows:

1. Contacted FEMA and IBTS regarding incident and repair options. $-8 / 16 / 18$

2. FEMAcontactedChampion HomesinTopeka, Indianato conduct repairs. $-8 / 23 / 18$

3. Navistar purchased materials for use in repairs. Materials approved by FEMAinspector.$\underline{8 / 27 / 18}$

4. Champion Homes contractor conducted repairs onsite at Navistar Proving Grounds.$8 / 27 / 18$.

5. FEMA inspector verbally approved repairs. $-8 / 27 / 18$.

Image file(s):
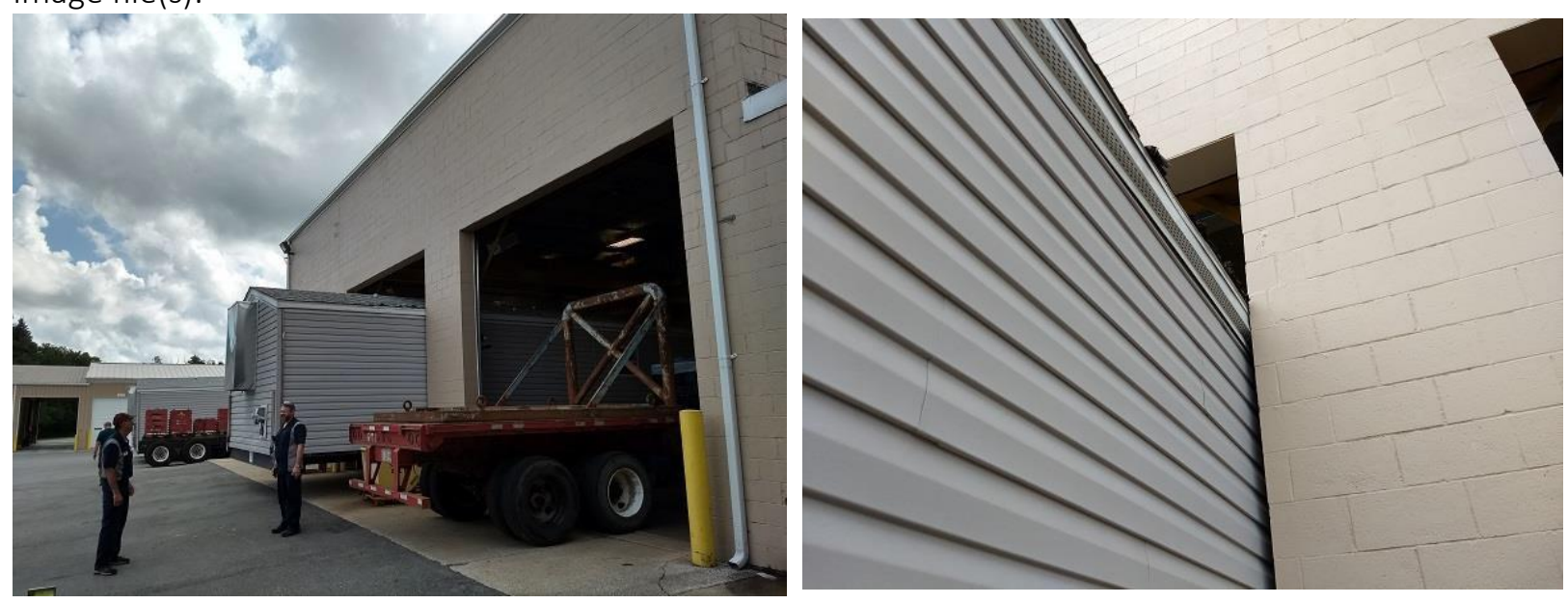

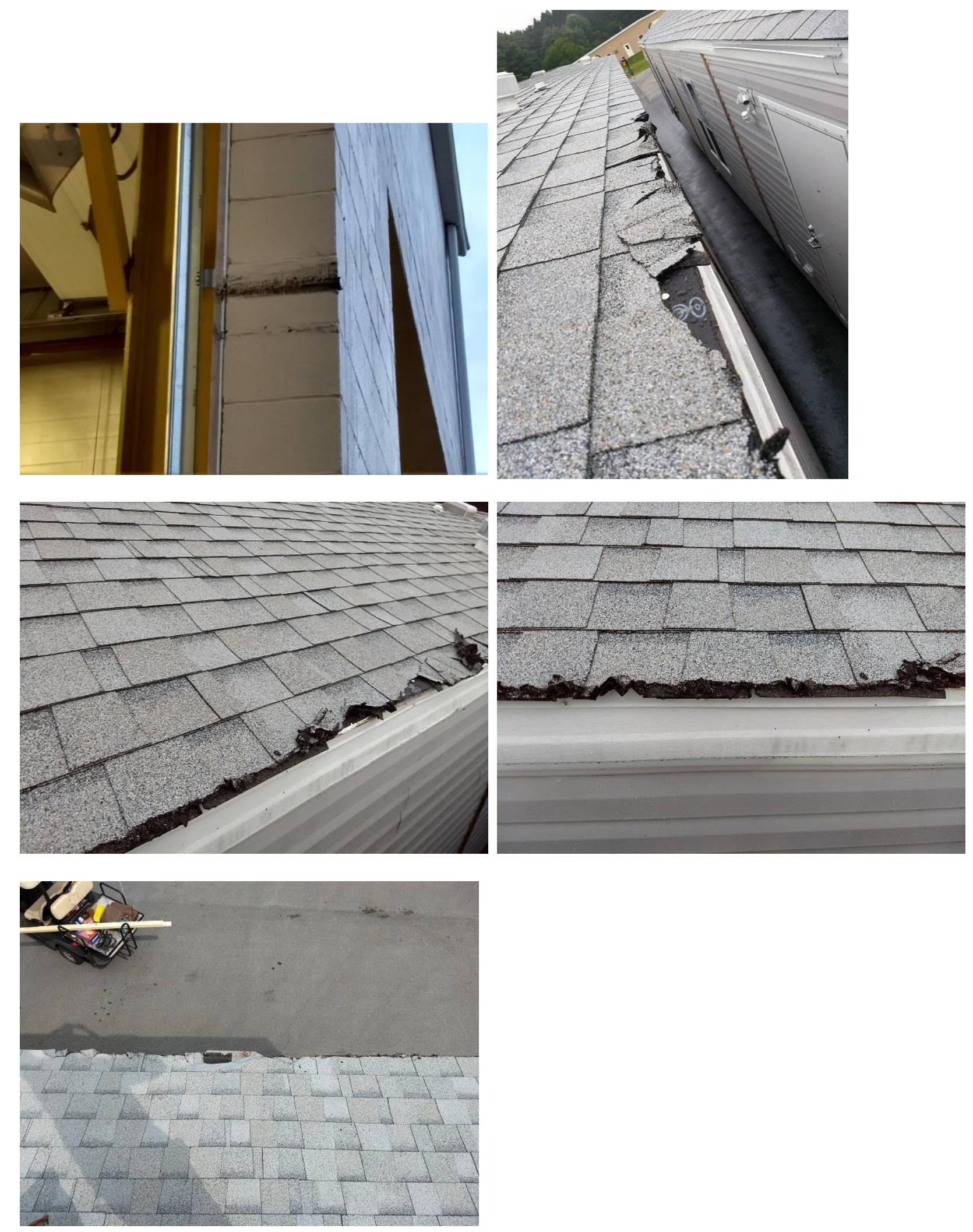
Post Repair Photos
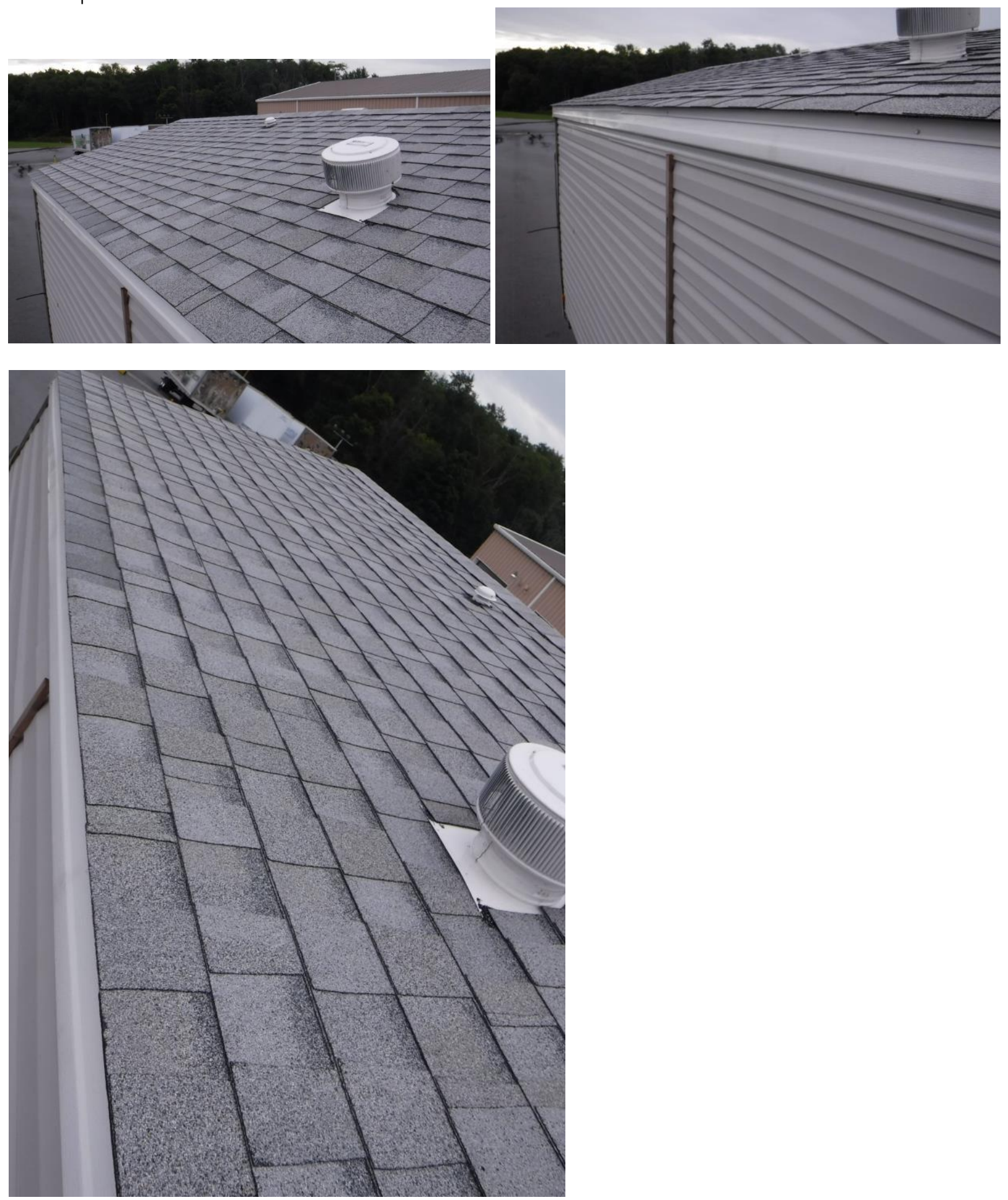

E-54 


\section{Attachment 4: MHU Longevity Testing - Record of Damage}

Date: $\underline{8 / 15 / 18}$

Mileage: $\quad \underline{80090 \text { (2278 vehicle test miles) }}$ 2278 Component testmiles
Time: Approx. 4:30 pm

Tractor(ifmultipleused): $\quad \underline{\text { LW28751 }}$

MHU

$\square$ Baseline

$\square$ Upgraded

Type of damage: Wind damage to shingles during testing.

Location of damage: Road side of vehicle, forward edge.

Corrective action

$\square$ Baseline

$\square$ Repairs as follows:

1. Contacted FEMA and IBTS regarding incident and repair options. $-8 / 16 / 18$

2. FEMAcontacted Champion Homes inTopeka, Indiana to conduct repairs. -8/23/18

3. Navistar purchased materials for use in repairs. Materials approved by FEMAinspector.$\underline{8 / 27 / 18}$

4. Champion Homes contractor conducted repairs onsite at NavistarProving Grounds.$8 / 27 / 18$.

5. FEMA inspector verbally approved repairs. $-8 / 27 / 18$.

Image file(s): 


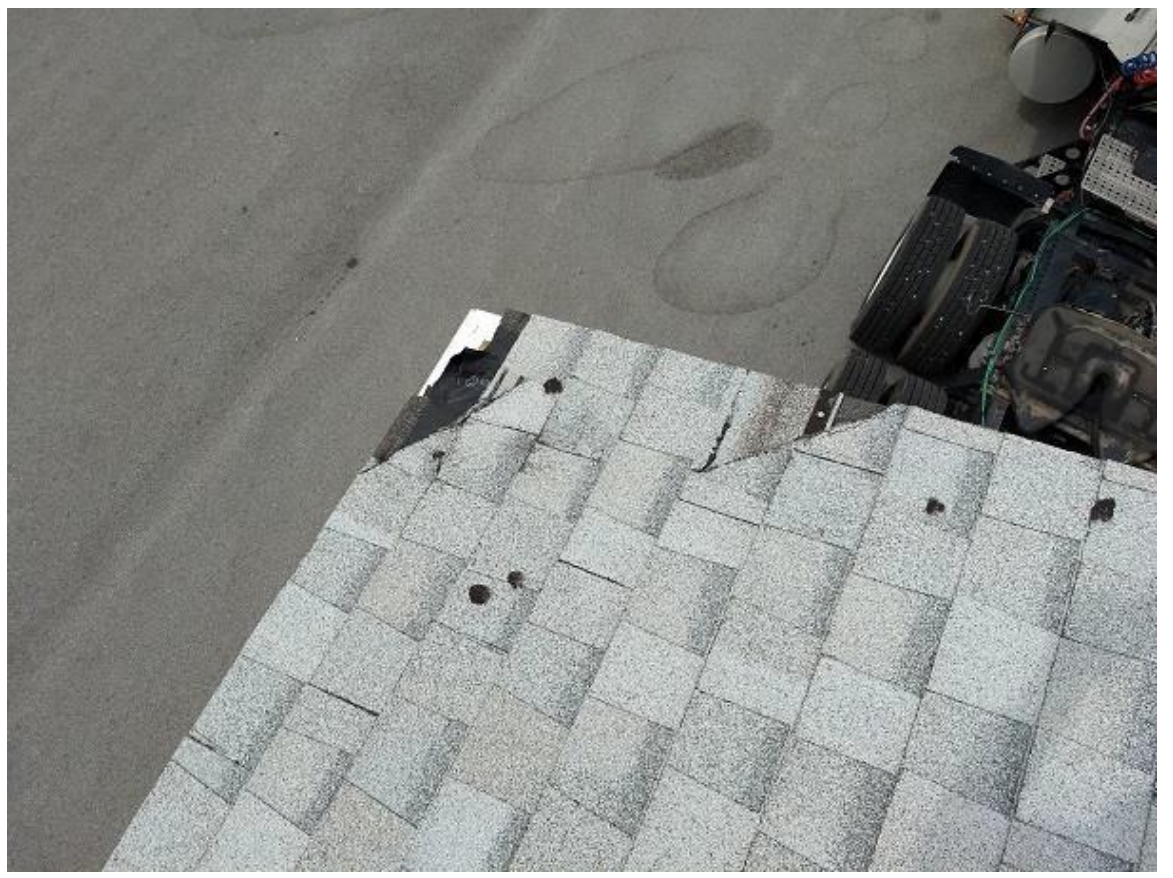

E-56 

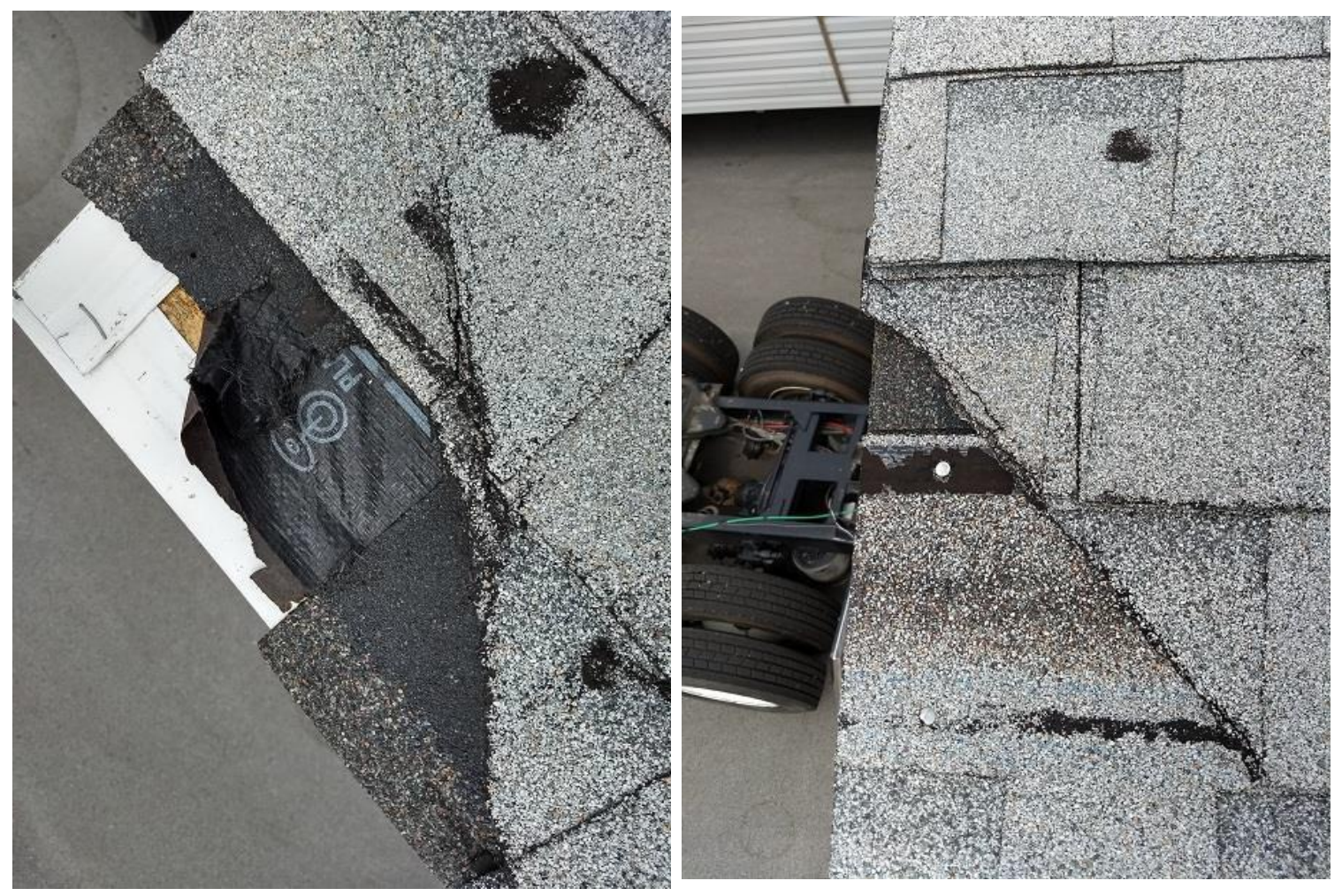

Post Repair Photos
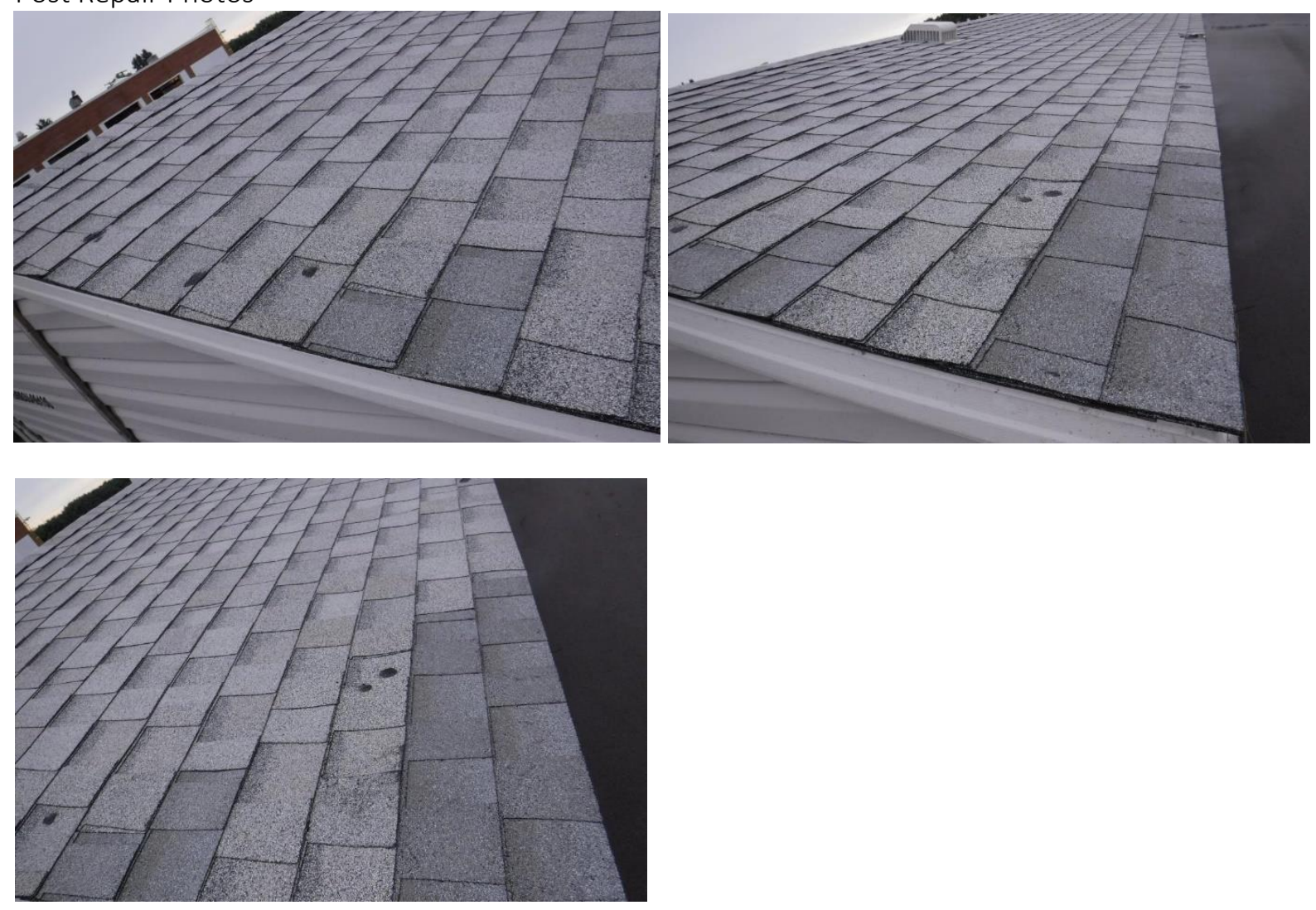
Attachment 4: MHU Longevity Testing - Record of Damage

Date: $9 / 12 / 18$

Mileage: $\quad \underline{80168 \text { (2358 test miles) }}$

MHU

$\square$ Baseline

$\square$ Upgraded

Type of damage: Tire failure - sidewall blowout

Location of damage: \#2 axle - left side

Corrective action

$\square$ Baseline

$\square$ Repairs as follows:

None
Time: Approx. $6 \mathrm{pm}$

Tractor (if multiple used): $\quad \underline{\text { LW28751 }}$

Image file(s):

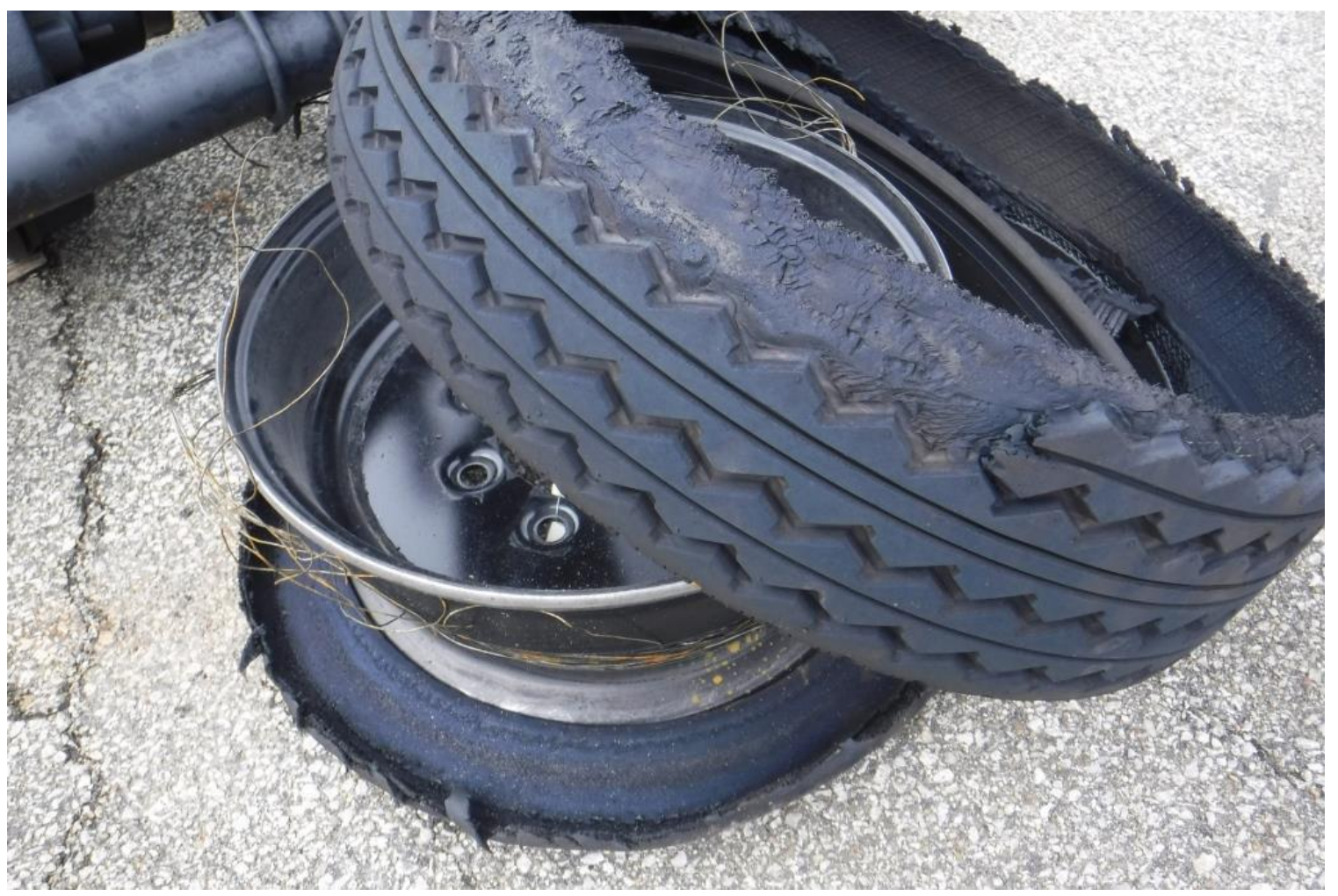




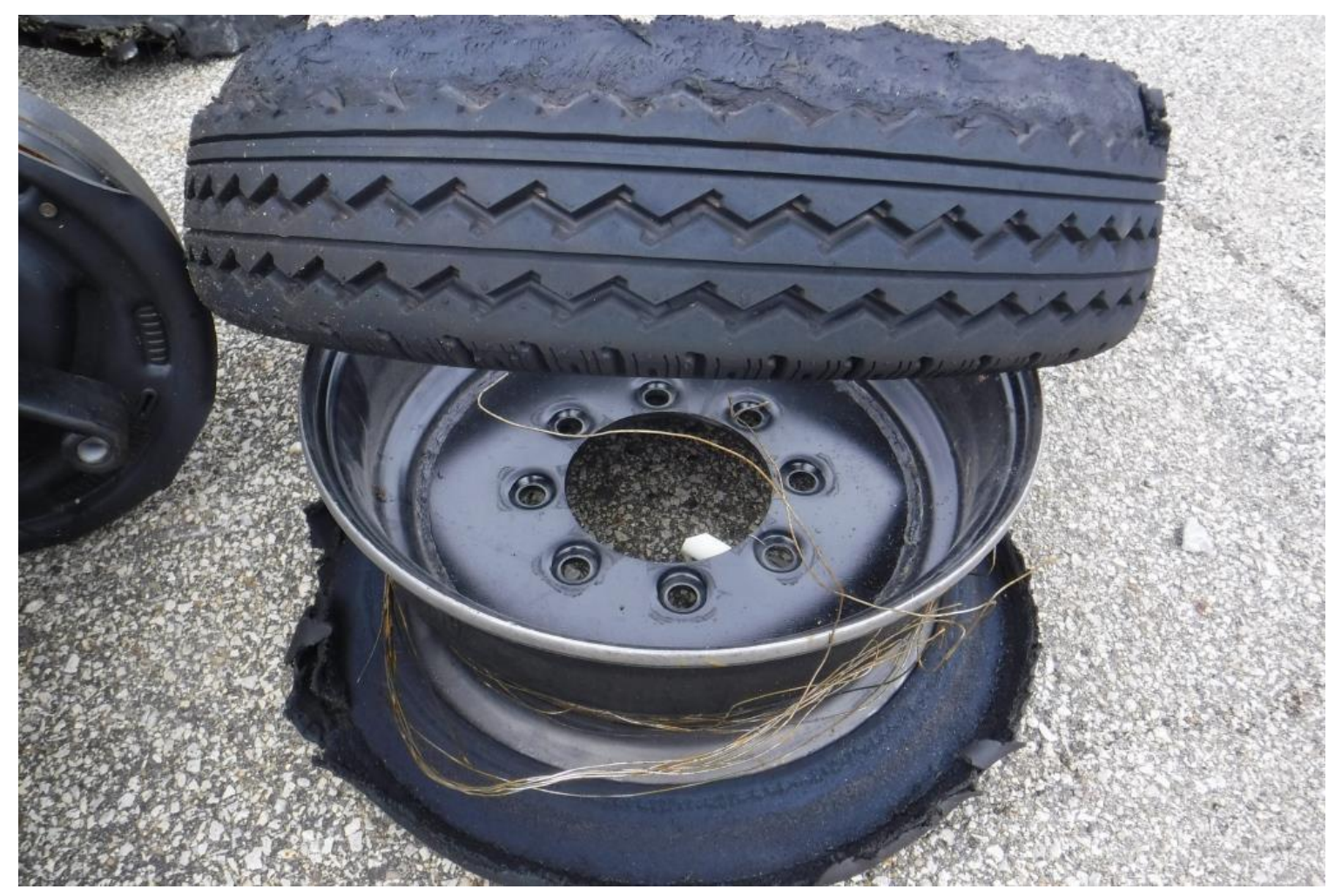

E-59 
Attachment 4: MHU Longevity Testing - Record of Damage

Date: $9-14-18$

Mileage: $\quad 814414$
Time: 11:00 AM

Tractor (if multiple used):

MHO

Baseline

Upgraded

Type of damage: $\frac{\text { Hub cap missing }}{\text { Location of damage: }}$

Corrective action

$\square$ Baseline

$\square$ Repairs as follows:

Installed new cap

Image files):

up 8

E-60 
Attachment 4: MHU Longevity Testing - Record of Damage

$\begin{array}{ll}\text { Date: } \frac{9-21-18}{87856} & \text { Time: } \\ \text { Mileage: } & 870 \text { Tractor (if multiple used): }\end{array}$

MHO

$\square$ Baseline

\ Upgraded

Type of damage: Side coming off

Location of damage: R/S forward edge

Corrective action

$\square$ Baseline

$\square$ Repairs as follows:

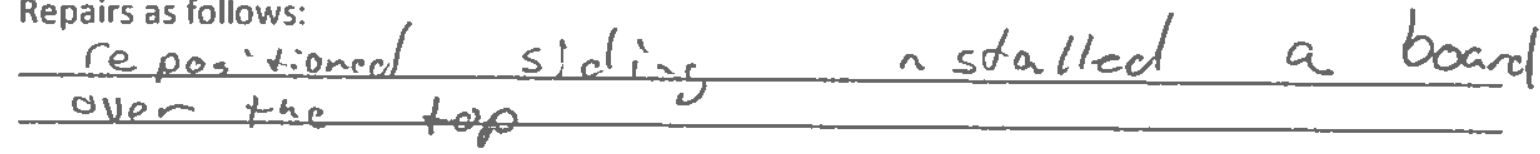

Image files): $(9-21-18) \quad$ pI

E-61 


\section{Attachment 4: MHU Longevity Testing - Record of Damage}

Date: $\quad 9-26-18$

Time:

Mileage: $\quad 88966 \quad$ Tractor (if multiple used):

MHU

D Baseline

Type of damage: Sh:agles $100 e$

Location of damage: L/S Forward lge

Corrective action

$\square$ Baseline

$\square$ Repairs as follows:

$\frac{\text { Nail down any loose shingles to prevent }}{\text { Further damage. The is rolled foof unden damaged section. }}$

Image file(s): $\quad 9-26-18$ up 


\section{Attachment 4: MHU Longevi y esting-Recore of Damage}

Date: $\frac{10-9-18}{90242} \quad$ Time $\quad$ Tractor (if multiple used):

MHU

$\square$ Baseline
$\square$ Upgraded

Type of damage: $\quad$ wan tirc

Location of damage: $\$ 6 \quad \mathrm{r} / \mathrm{s}$ tire

Corrective action

$\square$ Baseline

$\square$ Reparrs as follows:

replaced tire, torgued lugs to $120 \mathrm{ft}$.lbs. set
pressuec to $110 \mathrm{psi}$

Image file(s): $10-9-18$ up 
Attachment 4: MHU Longevity Testing - Record of Damage

Date: $\underline{10 / 17 / 18}$

Time: Approx. 4:30 am

Mileage:

$\underline{87245}$

Tractor(ifmultipleused):

$\underline{\text { LW28751 }}$

$\mathrm{MHU}$

$\square$ Baseline

$\square$ Upgraded

Type of damage: $\underline{\text { Vehicle struck a deer on the oval track }}$

Location of damage: Front of trailer

Corrective action

$\square$ Baseline

$\square$ Repairs as follows:

None

Image file(s):
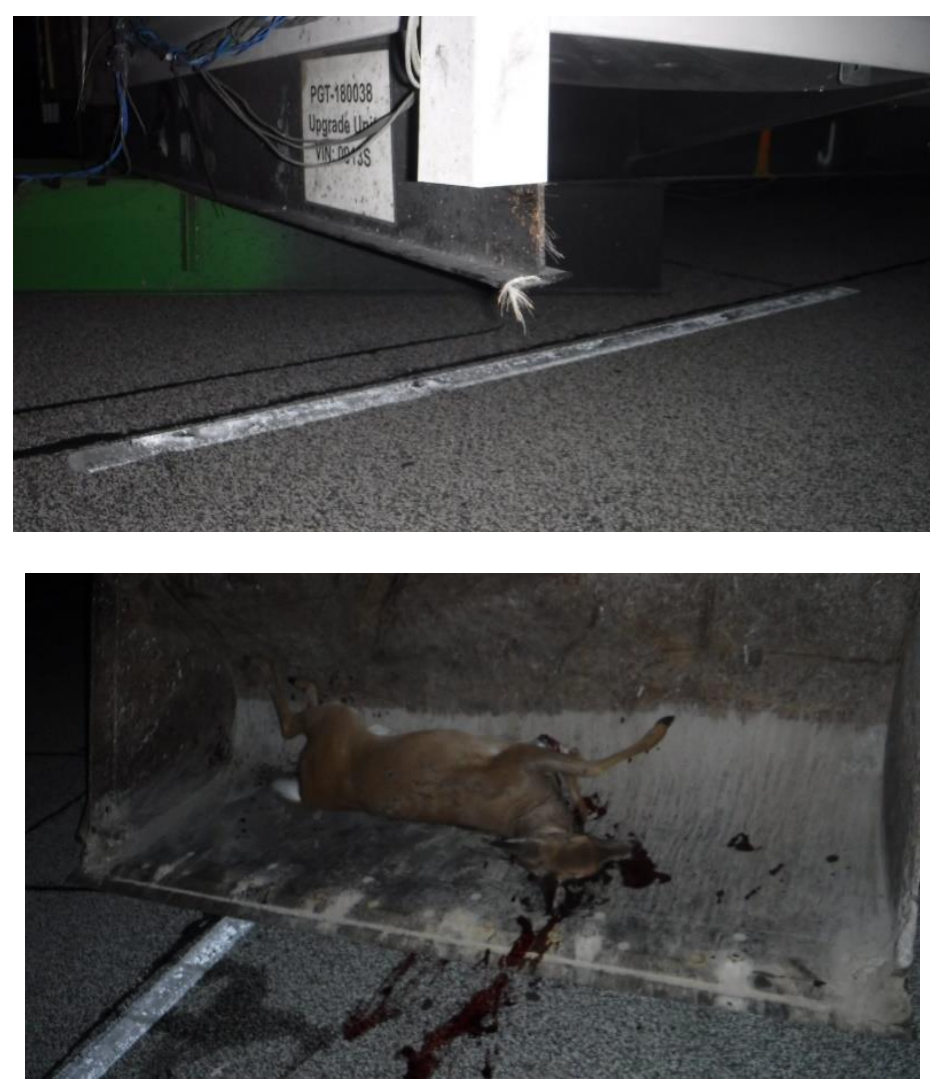

E-64 


\begin{tabular}{|c|c|c|}
\hline \multirow{3}{*}{\multicolumn{2}{|c|}{$\begin{aligned} \text { Nand } & \text { Incident Investigation Form }\end{aligned}$}} & $\begin{array}{l}\text { Document Number: NCl--1El1S0001 } \\
\text { Revision: 1 Updaled: 2-Oct-15 }\end{array}$ \\
\hline & & $\begin{array}{l}\text { Ref: Salety Handhook } \\
\text { 8.0: Incident Investigation }\end{array}$ \\
\hline & & Incident Number: NCLI5-XXXX \\
\hline "ritten by. & Revieuted/Alpproved hy: Safery Committee & Page 1 OF 3 \\
\hline
\end{tabular}

Incident Details
Date of Incident 10-17.18_Time 4:15 Am Date Reported 10-17.18 Time 4: 15 Am Location of incident North Curve of the Oval

\section{Incident Type: Please select all that apply \\ $\square$ High Potential Incident $\square$ Low Potential Incident \\ $\square$ Near Miss (No injury) $\square$ First Aid Injury \\ $\square$ Environmental \\ $\square$ First Aid Injury
$\square$ Property Damage}

区Animal (Complete through Incident Desc only)

$\square$ Recordable Injury

$\square$ Other

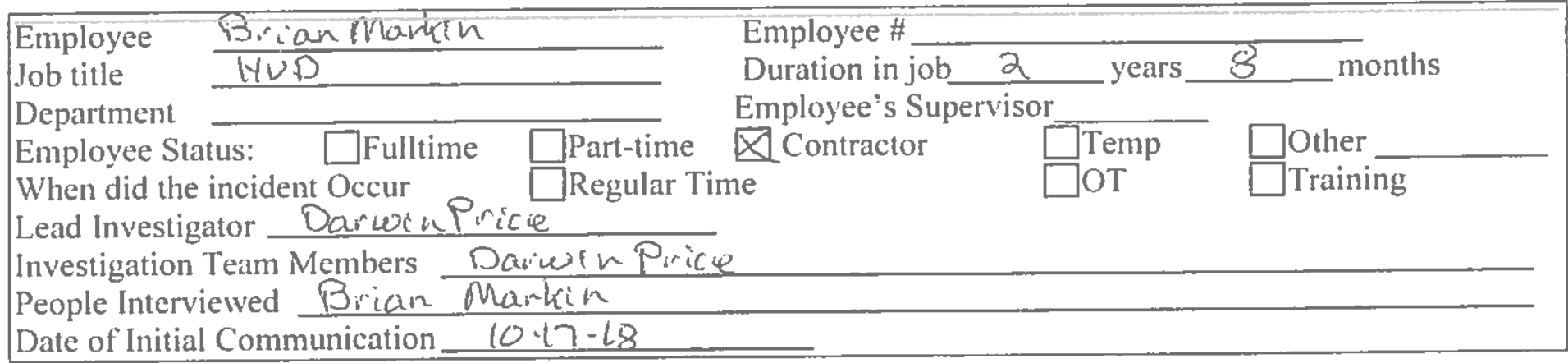

Incident Description/Facts (Who, What, When Where, Why, How?) (attach additional sheets if required) References: Procedure Step3, Training Maserials $A$ and $B$, interview notes Section must be completed within 1 business day of incident B.ean Markin hit a deer with the trailer while traveling on the north curve of the Oval trach. The dear came down from the top of track

\footnotetext{
List the Key Contributing Factors (These factors should relate it items already listed in the description / facts)

References: Procedure Step 4 and/or 5 Why Analysis

Section must be completed within 4 business days of incident
} 
Attachment 4: MHU Longevity Testing - Record of Damage

Date: $\quad 10 / 23 / 18$

Mileage:

$\underline{88440}$
Time: Approx. 11:15 pm

Tractor(ifmultipleused): $\quad \underline{\text { LW28751 }}$

$\mathrm{MHU}$

$\square$ Baseline

$\square$ Upgraded

Type of damage: Vehicle struck a deer on the oval track. Destroyed left side bumper facia.

Location of damage: Front of tractor

Corrective action

$\square$ Baseline

$\square$ Repairs asfollows:

None

Image file(s):
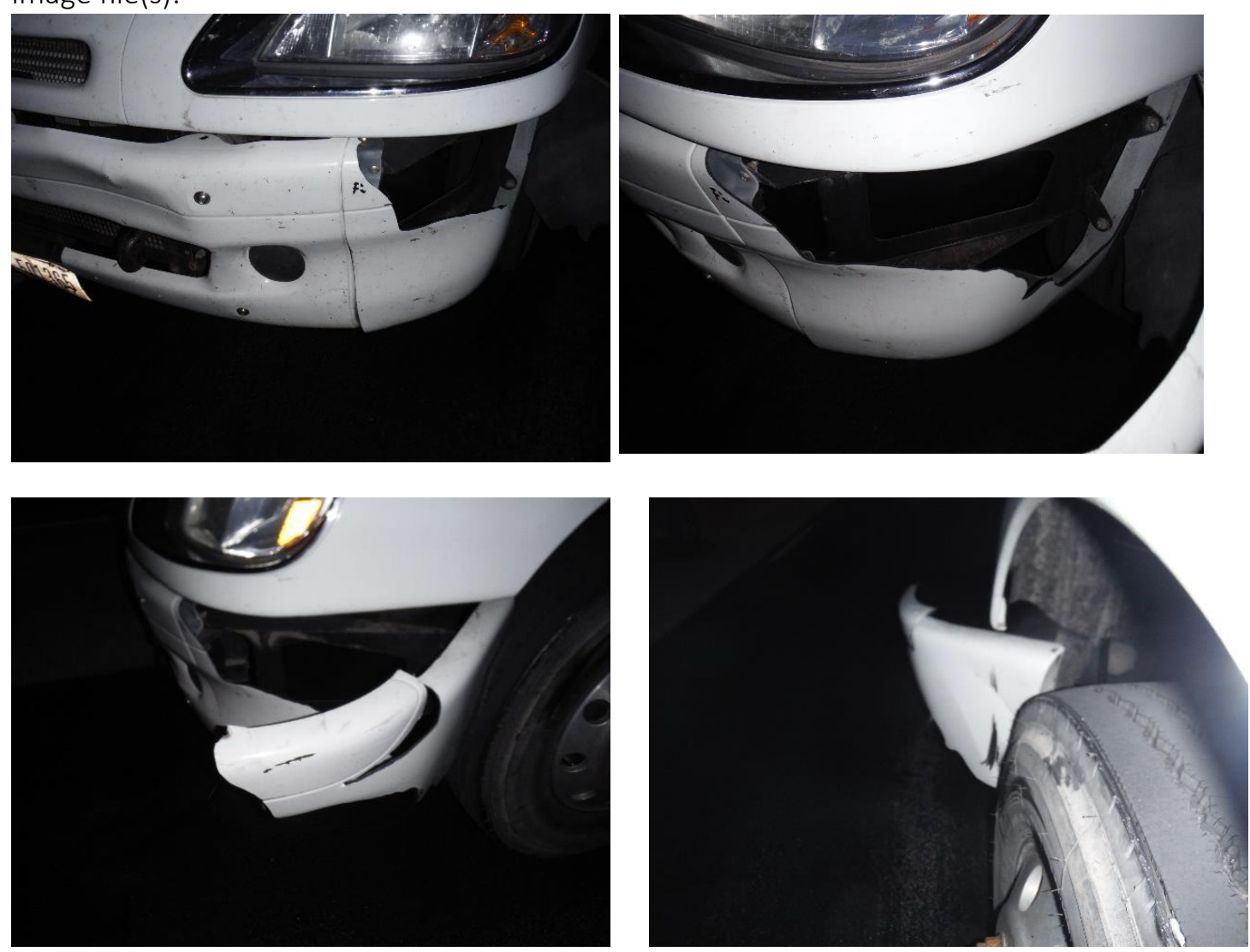


\begin{tabular}{|c|c|c|}
\hline \multirow{3}{*}{\multicolumn{2}{|c|}{ 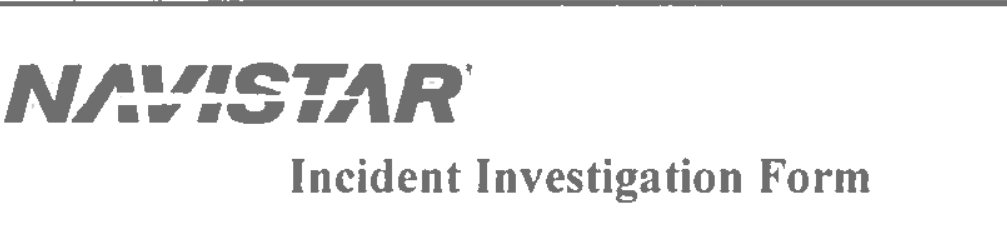 }} & $\begin{array}{l}\text { Documeral Number: NCl-1;IS0001 } \\
\text { Revision: I Upơaled: 2-Oct-15 }\end{array}$ \\
\hline & & $\begin{array}{l}\text { Ref: Safety Handhook } \\
\qquad 8.0 \text { : Incident Investigation }\end{array}$ \\
\hline & & Incident Number: NCl.15.XXXX \\
\hline Ifrulen by: & Reviented spprowed by: Safen Committee & Page 1 OF 4 \\
\hline
\end{tabular}

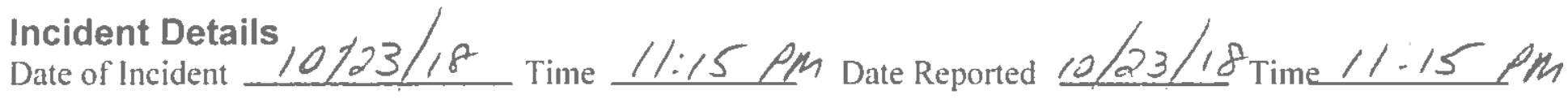
Location of incident 1.4 MILE MARKER OUAL TPACK

Incident Type: Please select all that apply

\begin{tabular}{|c|c|c|}
\hline High Potential Incident & $\square$ Low Potential Incident & AAnimal (Complete through Incident Desc onl \\
\hline r Miss (No injury) & $\square$ First Aid Injury & dable Injury \\
\hline ntal & ХProperty Damage & 1 \\
\hline
\end{tabular}

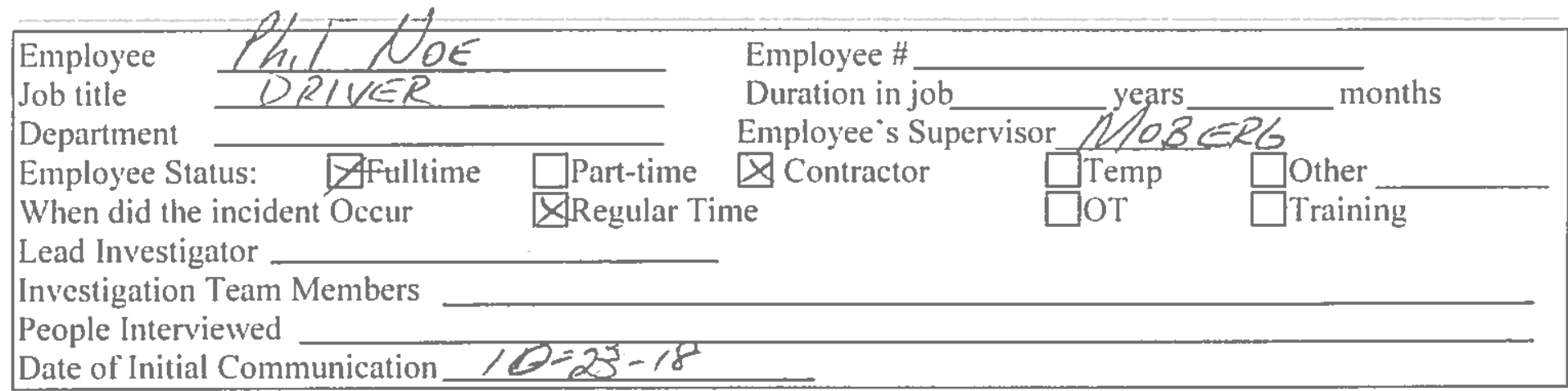

Incident Description/Facts (Who, What, When Where, Why, How?) (attach additional sheets if required) References: Procedure Step3, Training Materials $A$ and $B$, Interview notes Section must be completed within 1 business day of incident

End of shift tractor hit a deer on driver front and corner. Bent bumper in and ripped the plastic cover. No deer left on track. Removed the outer plastic cover on that corner and bent the inner structure back away from tire. See Deer Strike FEMA for pics.

List the Key Contributing Factors (These factors should relate it items already listed in the description / facts) 
Attachment 4: MHU Longevity Testing - Record of Damage

Date: $\quad 10 / 25 / 18$

Mileage:

89500

$\mathrm{MHU}$

$\square$ Baseline

$\square$ Upgraded

Type of damage: Vehicle struck a deer on the oval track.

Location of damage: Front of tractor

Corrective action

$\square$ Baseline

$\square$ Repairs as follows:

None

Image file(s):

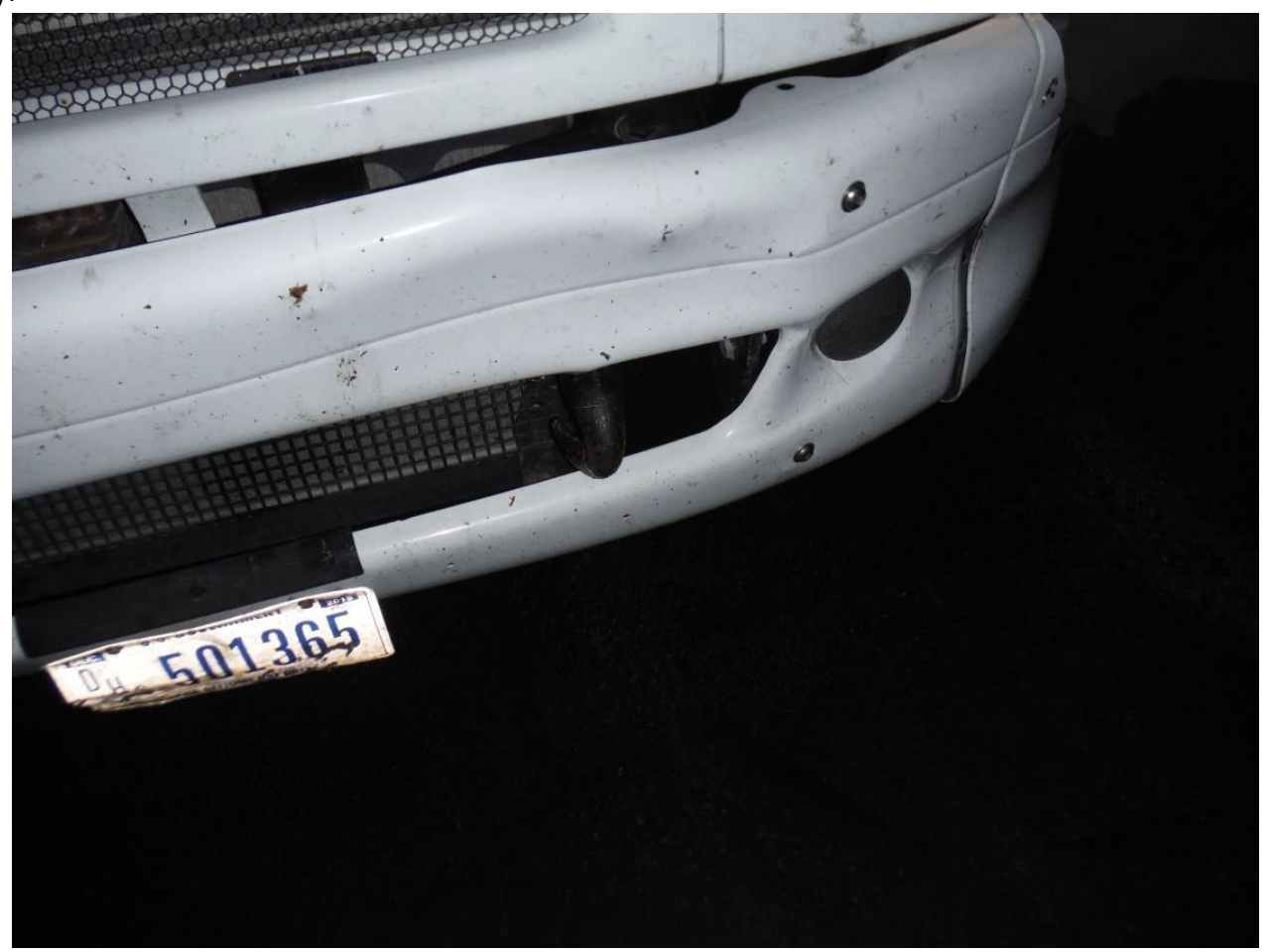

E-68 


\section{Incident Investigation Form}

Document Number: NCL.EHIS0001

Revision: I Undated: 2-Ocl-15

Ref: Safety: Ifandbook

8.0: Incident Investigation

Incident Number: NCL15-XXXX

Revision: $A$

I'rulen by'.

Reviewed dpproved by: Sufeny Commillee

Page 1 OF 3

Incident Details
Date of Incident $10 / 25 / 18$ Time 6:45 Date Reported 10/25/18 Time 6-45

Location of incident MLE MARKER 20 ON DUAL

Incident Type: Please select all that apply

$\square$ High Potential Incident $\square$ Low Potential Incident

$\square$ Near Miss (No injury) $\square$ First Aid Injury

Environmental

$\square$ Property Damage

XAnimal (Complete through Incident Desc only)

$\square$ Recordable Injury

Other

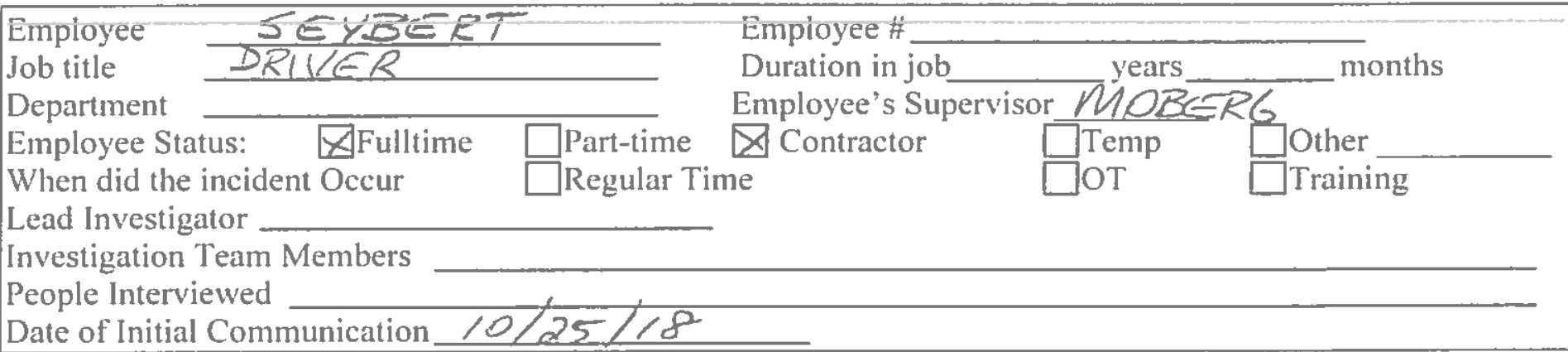

Incident Description/Facts (Who, What, When Where, Why, How?) (attach additional sheets if required) References: Procedure Step3, Training Materials $A$ and $B$, Interview notes Section must be completed within 1 business day of incident

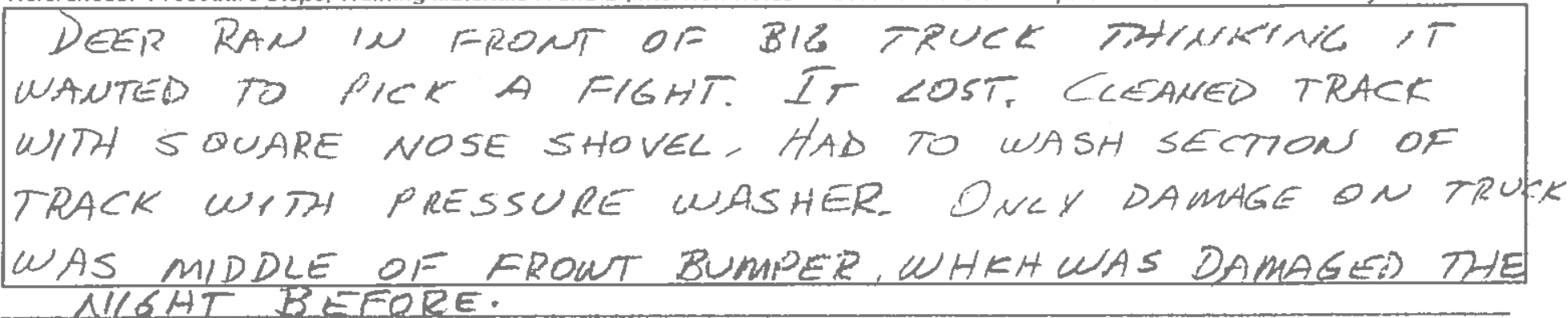

List the Key Contributing Factors (These factors should relate it items already listed in the description / facts) References: Procedure Step 4 and/or 5 Why Analysis

Section must be completed within 4 business days of incident 

APPENDIX F. BASELINE AND UPGRADE UNIT END-OF-TEST FEMA INSPECTION REPORT 



\section{APPENDIX F. BASELINE AND UPGRADE UNIT END-OF-TEST FEMA INSPECTION REPORT}

At the end of Part C2 testing, a qualified FEMA inspector provided a damage report for each one of the two MHU units. That report is included in this Appendix. Note: Unit serial \# LOHGA21733042AC refers to the Baseline Unit and Unit serial \# LOHGA21733043AC to the Upgrade Unit. 

Inspection and Repair Observation Report

Location: Navistar proving grounds 32104 IN-2, New Carlisle, IN 46552

Date: 10/12/2018 Inspector: Herb Warner

Summary: The repairs on two homes were monitored and each unit was inspected for serviceability. The below items were found to be deficient. Repairs were made to the exterior of the home on the siding and roof. There is interior and exterior damage that could be attributed to the prolonged amount of simulated road miles that the units have been subjected to. There does not appear to be any major structural damage as far as can be determined with all finishes still intact.

It is my determination that these units are capable of being placed into service if, and when, all repairs were to be made.

\section{Unit serial \# LOHGA21733042AC \\ Model \# FEMA-641414U \\ Date of Manufacture 12-5-2017 \\ HUD label \# GEO1543736}

Item 1: The vinyl siding on the hitch end wall, was damaged. The top $1 / 2$ of the siding was removed and new siding was installed. The siding on the home was double 5 " grey. The new siding that was installed was double 4" grey and the color does not match. The siding was properly installed.

Item 2: The shingles on the road side of the home were missing and or damaged, near the hitch end of the home. The damaged shingles were removed and 3 shingles were properly installed.

Item 3: One piece of vinyl siding was damaged curb side of the home at the top of the side wall.

Item 4: The vinyl siding has pulled loose from the fasteners at the front end of the home curb side and road side towards the hitch end.

Item 5: The vinyl siding is buckling, bowing and waving at the top of the side wall on the road side and the curb side of the home.

Item 6: On the curb side 4' from the front door towards the hitch the perimeter floor joist is gaped from the floor joist $1 / 2 "$.

Item 7: The first roof vent from the hitch end road side of the home is damaged.

Item 8: The front door curb side of the home, left side of the door, side wall to floor is gaped $1 / 8^{\prime \prime}$.

Item 9: All interior wall panels on all walls; exterior walls side walls interior walls, have some loose interior wall panels.

Item 10: The double windows on the road side of the home in the kitchen, are in a bind and will not open and close freely. The home was not level at the time of the inspection but this may still be an issue.

Item 11: The floor has a hump in it at the kitchen in the same location as the double windows. The home was not level at the time of the inspection but this may still be an issue.

Item 12: The shipping bracket for the refrigerator has a screw pulled from the wall.

Item 13: The rear bed room door hinges are damaged and the door will not open and close properly.

Item 14: The front bed room interior wall trim to celling is gaped $1 / 8^{\prime \prime}$.

Item 15: The front bed room road side wall trim to floor is gaped $1 / 8^{\prime \prime}$. 
Item 16: The frame on the home has some reverse camber near the front axle. The home was not level at the time of the inspection but this may still be an issue.

\section{Unit serial \# LOHGA21733043AC \\ Model \# FEMA-641414U \\ Date of Manufacture 12-5-2017 \\ HUD label \# GEO1543737}

Item 1: One piece of vinyl siding on the hitch end wall was damaged. A piece of siding from the other home was used, to replace the damaged siding on this home. The siding was properly removed and repaired.

Item 2: The shingles on the road side of the home were missing and or damaged, near the hitch end of the home. The damaged shingles were removed and 5 shingles were properly installed.

Item 3: The vinyl siding has pulled loose from the fasteners at the front end of the home curb side and road side towards the hitch end.

Item 4: The vinyl siding is buckling, bowing and waving at the top of the side wall on the road side and the off road side.

Item 5: On the curb side of the home the OSB is gaped from the perimeter floor joist at several locations.

Item 6: The bottom of the I-beam is bent, on the frame, on the road side of the home between the first and second axle.

Item 7: The vinyl siding, outside corner, on the curb side rear end of the home, is damaged at the top.

Item 8: All interior wall panels on all walls; exterior walls side walls interior walls, have some loose interior wall panels.

Item 9: The double windows on the road side of the home in the kitchen, are in a bind and will not open and close and cannot be locked. The home was not level at the time of the inspection but this may still be an issue.

Item 10: The floor has a hump in it at the kitchen in the same location as the double windows. The home was not level at the time of the inspection but this may still be an issue.

Item 11: The road side front end wall, to side wall trim is gaped $1 / 8$ ".

Item 12: The road side wall to floor trim is gaped $1 / 8^{\prime \prime}$.

Item 13: The frame on the home has some reverse camber near the front axle. The home was not level at the time of the inspection but this may still be an issue. 